\author{
UNIVERSIDADE DE SÃO PAULO \\ ESCOLA DE ENGENHARIA DE SÃO CARLOS \\ DEPARTAMENTO DE ENGENHARIA DE ESTRUTURAS
}

Danilo Mascarenhas Prado

Avaliação experimental de vigas de concreto armado reforçadas ao cisalhamento com laminados de CFRP por meio de análise estática e modal. 



\author{
UNIVERSIDADE DE SÃO PAULO \\ ESCOLA DE ENGENHARIA DE SÃO CARLOS \\ DEPARTAMENTO DE ENGENHARIA DE ESTRUTURAS
}

Danilo Mascarenhas Prado

\title{
Avaliação experimental de vigas de concreto armado reforçadas ao cisalhamento com laminados de CFRP por meio de análise estática e modal.
}

\author{
Tese apresentada ao Departamento de \\ Engenharia de Estruturas da Escola de \\ Engenharia de São Carlos, Universidade de São \\ Paulo, como parte dos quesitos necessários para \\ obtenção do título de Doutor em Engenharia \\ Civil (Estruturas).
}

Orientador: Prof. Dr. Vladimir Guilherme Haach

\section{Versão Corrigida}

A versão original encontra-se na Escola de Engenharia de São Carlos 
AUTORIZO A REPRODUÇÃO TOTAL OU PARCIAL QESTE TRABALHO, POR QUALQUER MEIO CONVENCIONAL OU ELETRONICO, PARA FINS DE ESTUDO E PESQUISA, DESDE QUE CITADA A FONTE.

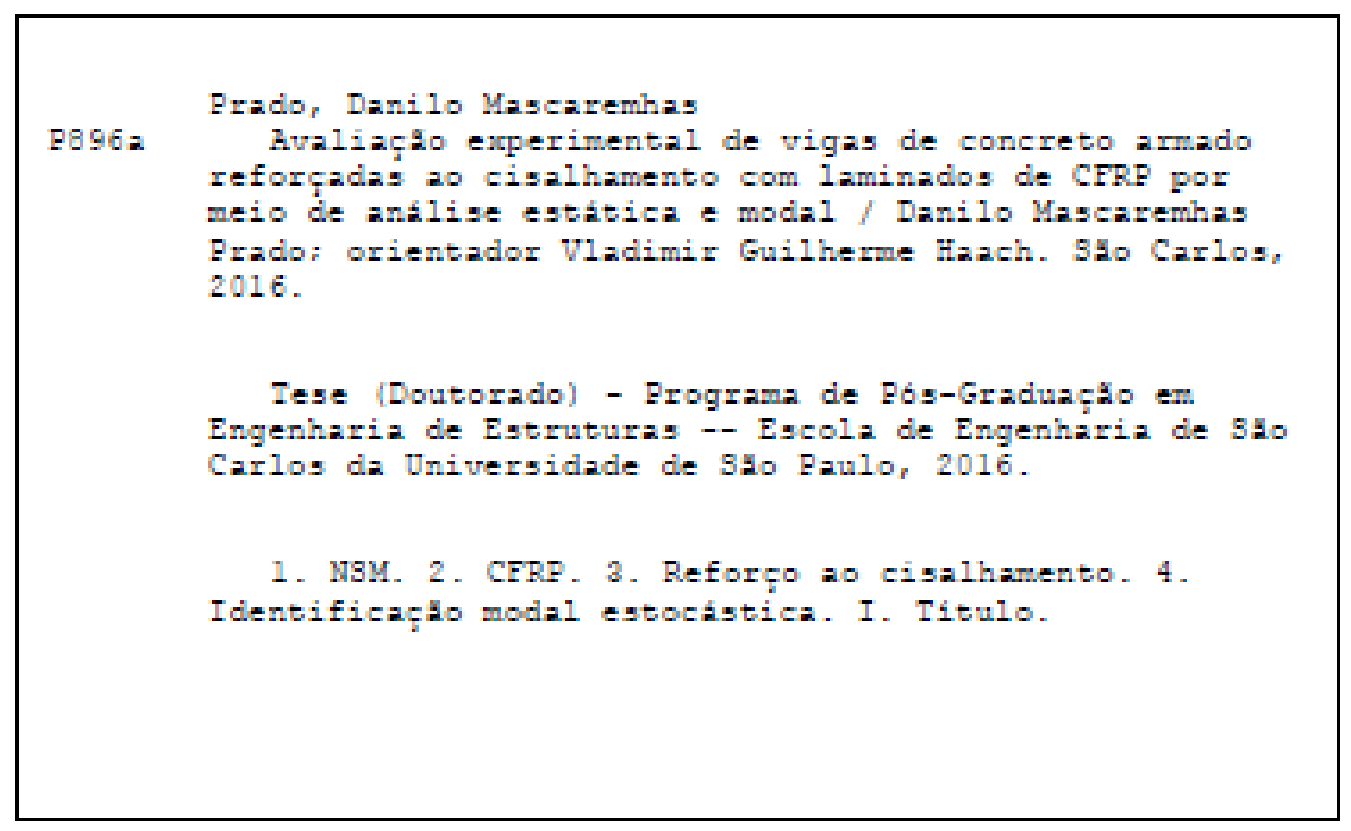




\section{FOLHA DE JULGAMENTO}

Cancidato: Engenheiro DANILO MASCARENHAS PRADO.

Titulo da tese: "Avaliaçăo experimental de vigas de concreto armado reforçadas ao cisalnamento com laminados de CFRP por meio de análise estática e modal".

Data da defeso: $30 / 06 / 2016$

Comissōo Julgadora:

Resultado:

Prof. Dr. Vladlmir Gullherme Haach

APROVADO

(Orientador)

(Escola de Engenharia de São Carlos/EESC)

Prot. Dr. Ricardo Carrazedo

APROVADO

[Escola de Engenharia de São Carlos/EESC)

Prot. Associodo Jonas de Carvalho

[Escola de Engenharia de SOo Carlos/EESC)

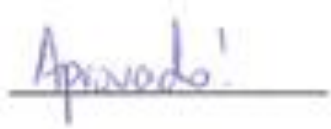

Prola. Dra. Gláucia Maria Dallré
(Universidade Federal da Integraçôo Latino-Americana/UNILA)

Prol. Dr. Walter Libardi

(Universidade Federal de Săo Carlos/UFSCar)

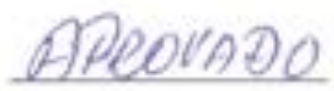

Coordenador do Programa de Pós-Graduação em Engenheira Civil (Engenharia de Estruturas):

Prof. Titular Humberto Breves Coda

Presidente da Comissåo de Pós-Graduaçõo:

Prof. Associado Paulo Sergio Lima Segantine 



\section{AGRADECIMENTOS}

Na minha conclusão de graduação agradeci a mim mesmo por ter sido a pessoa mais importante na obtenção daquele título. O que não deixa de ser verdade.

Nos agradecimentos do mestrado descrevi como é importante compreendermos o que nos atrapalha ou nos ajuda:

Quando não conseguimos realizar nosso objetivo tentamos colocar a culpa em alguém, mas no fundo sabemos que a culpa é inteiramente nossa, por não sabermos retirar as pedras e as pessoas erradas do caminho.

Quando conseguimos concluir com êxito nosso objetivo temos a obrigação de dividir nossa felicidade e agradecer àqueles que nos ajudaram. Sem a contribuição dessas pessoas, chegar até aqui seria impossível.

Ao longo desses desafios surgiram novas pessoas e houve aqueles que estiveram sempre presentes, os quais eu não poderia deixar de agradecer.

Agradeço principalmente à minha família, por toda educação e apoio que me transmitiram.

Meu pai Elias Júnior, que sempre foi um visionário com grandes ideais, um sonhador e executor de diversos feitos notáveis, obrigado!

Minha mãe Vera Lúcia, pela sua persistência em sempre ser uma professora para o mundo, e que nunca deixou de me ensinar.

Meu irmão Elias Neto, que até hoje mantem sua forma ímpar de pensar e que muito me faz refletir sobre qual o sentido da vida, o universo e tudo mais.

Minha irmã Danna, por me fazer ser menos linear e compreender os diferentes mundos, sendo eternamente jovens.

À Lorena Melo pela atenção, paciência e compreensão. Com quem Aprendi a conviver durante Todos esses anos e agora Iniciamos um novo Tempo para Amar.

A todos os meus amigos do Piauí que viveram junto comigo minhas angustias e me acolheram nos momentos de lazer, aqui faço em nome do amigo Helder Pontes.

Aos meus novos amigos, que com certeza chamarei um dia de velhos amigos, pois sem os momentos que convivemos as lembranças do Doutorado não seriam as mesmas. 
Aos amigos de departamento Arthur, Matheus e Ivan, que contribuíram efetivamente para o desenvolvimento desta tese, nas análises laboratoriais e teóricas.

Ao Prof. Dr. Vladimir Guilherme Haach, que nos anos de convivência muito me ensinou, contribuindo para meu crescimento científico e intelectual.

Ao Departamento de Engenharia de Estrutura, pela oportunidade de realização do curso do Doutorado.

Ao Instituto Federal de Educação, Ciência e Tecnologia do Maranhão (IFMA), por proporcionar afastamento para conclusão dos estudos e incentivar a qualificação docente.

À Sika S. A. pela doação dos laminados de CFRP e adesivo Epóxi que viabilizaram uma variabilidade de ensaios. 


\section{RESUMO}

PRADO, D. M. Avaliação experimental de vigas de concreto armado reforçadas ao cisalhamento com laminados de CFRP por meio de análise estática e modal. 2016. 189 p. Tese (Doutorado em Engenharia Civil (Estruturas)) - Escola de Engenharia de São Carlos, Universidade de São Paulo, São Carlos, 2016.

O uso de Carbon Fiber Reinforced Polymer (CFRP) como reforço em estruturas de concreto armado tem evoluído com o avanço das técnicas e com a melhora das fibras, principalmente com um novo método: o Near Surface Mounted (NSM), em que os laminados de fibra são inseridos no cobrimento do concreto. Uma análise da eficiência dos sistemas de reforço ao cisalhamento em vigas de concreto armado foi realizada por meio de ensaios experimentais. As vigas foram reforçadas nas configurações íntegra e com carregamento prévio de $40 \%$ e $70 \%$ da força máxima. O programa experimental compreende ensaios de flexão em prismas e vigas de concreto armado além de ensaios não destrutivos de análise de vibrações para a determinação das frequências naturais e dos modos de vibração. A análise modal foi realizada com uso de um método de identificação modal estocástica, em que na sua formulação não é usada força de excitação. Nestas, foram analisadas as variações nas frequências naturais e dos modos de vibração, utilizando MAC, COMAC, DCM e ID. Como resultados, todas as vigas com sistemas de reforço obtiveram acréscimos na capacidade de carga, alterando suas formas de ruptura de cisalhamento para destacamento da camada de concreto adjacente aos laminados de CFRP e para ruptura por esmagamento do concreto à flexão, independente da ocorrência de carregamento prévio. $\mathrm{Na}$ análise modal foi possível identificar a presença e local do dano nas vigas na maioria dos métodos utilizados, mas a identificação do sistema de reforço não foi significativa.

Palavras-chave: NSM. CFRP. Reforço ao cisalhamento. Identificação modal estocástica. 

PRADO, D. M. Experimental evaluation of reinforced concrete beams shear-strengthened with CFRP laminates through static and modal analysis. 2016. 189 f. thesis (Dr. Sc. in Civil Engineering (Structures)) - School of Engineering of São Carlos, University of São Paulo, São Carlos, 2016.

The use of Carbon Fiber Reinforced Polymer (CFRP) in concrete structures has enhanced with the advancement of techniques and the improvement of fiber, especially with the usage of the new method: the Near Surface Mounted (NSM) when the fiber laminates are inserted to cover thickness the concrete. An analysis of the efficiency of these shear reinforcements in reinforced concrete beams was performed by destructive and non-destructive experimental tests. The beams were reinforced intact and preloading of $40 \%$ and $70 \%$ of maximum load. The experimental program includes flexural tests on reinforced concrete beams as well as non-destructive testing to determine the natural frequencies and vibration modes. The modal analysis was done use of method stochastic modal identification, which in its formulation is not used excitation force. The variations were analyzed in the natural frequencies and vibration modes, using MAC, COMAC, DCM and ID. In the results are obtained increase in load capacity in all beams with reinforcement systems, regardless of the occurrence of preloading, changed the form of shear break for rupture due detachment off cover concrete adjacent to the laminate and crushing of concrete in flexion. In modal analysis, it was possible to identify the presence and local damage in the beams on most of methods used, but the identification of reinforcements systems was not significant

Keywords: NSM. CFRP. Reinforced shear. Stochastic modal identification. 



\section{SUMÁRIO}

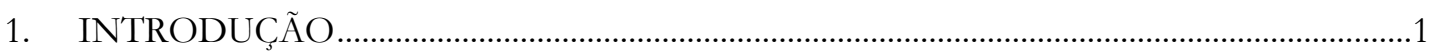

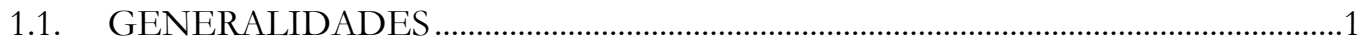

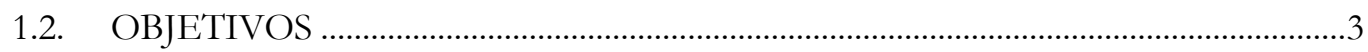

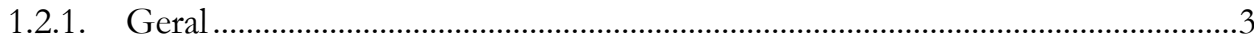

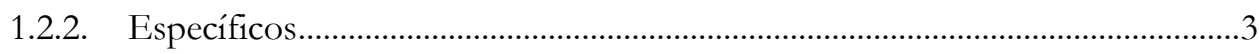

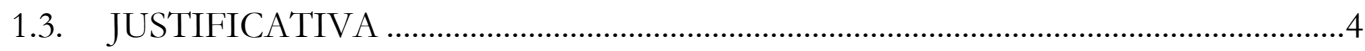

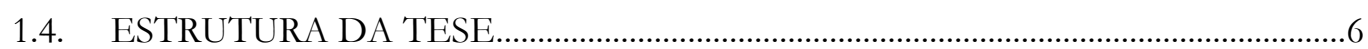

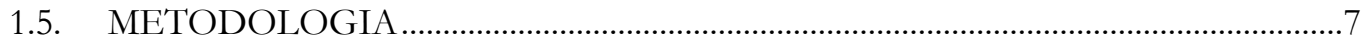

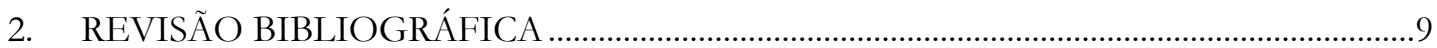

2.1. REFORÇO EM VIGAS COM CFRP ……………...............................................

2.1.1. Reforço com Técnica EBR.................................................................................

2.1.2. Reforço com Técnica NSM ............................................................................... 13

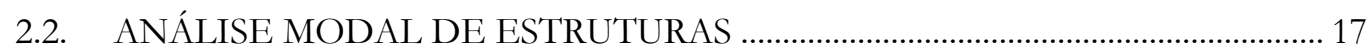

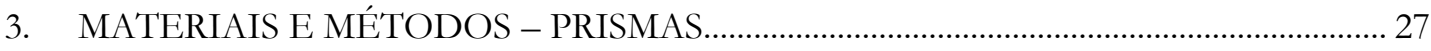

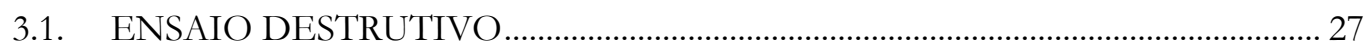

3.1.1. Preparo dos Prismas ……………………………………………………..... 29

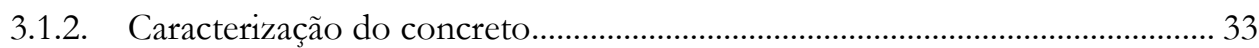

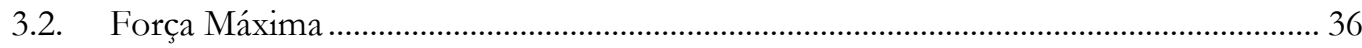

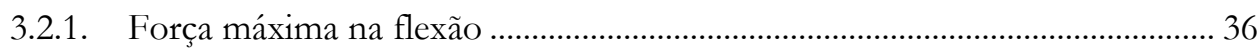

3.2.2. Força máxima no cisalhamento …………………………………………..... 37

3.2.3. Força máxima no cisalhamento com reforço .................................................. 38

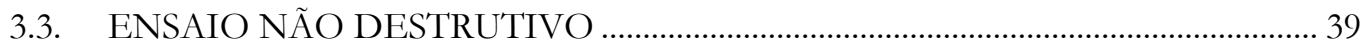

3.4. MODELAGEM COMPUTACIONAL DOS PRISMAS .............................................. 43

4. APRESENTAÇÃO E ANÁLISE DE RESULTADOS - PRISMAS ……………………….... 47

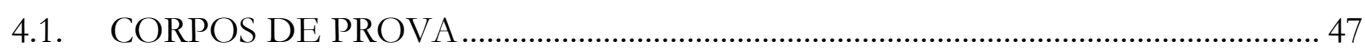

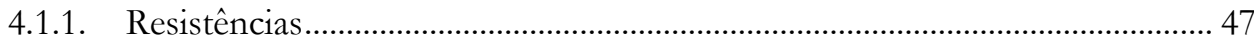

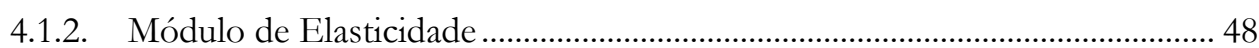

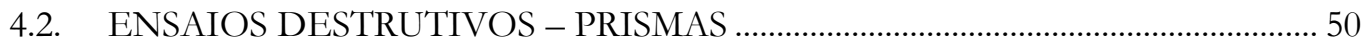

4.2.1. Forças máximas ............................................................................................. 50

4.2.2. Forma de ruptura dos prismas ..................................................................... 53

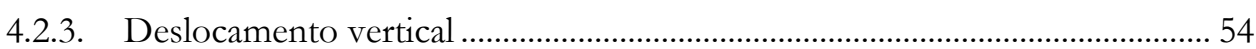

4.2.4. Deformação no aço............................................................................................ 58

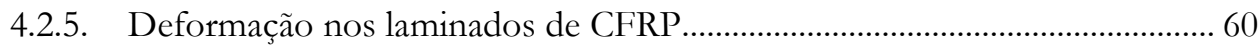

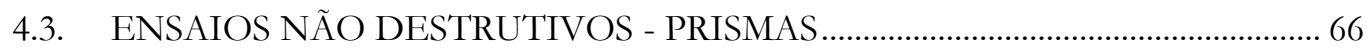

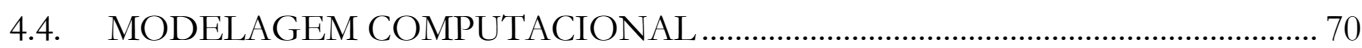

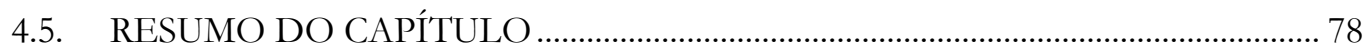

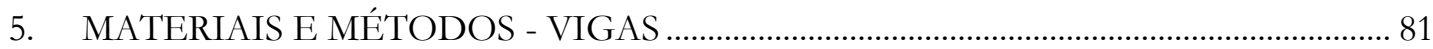

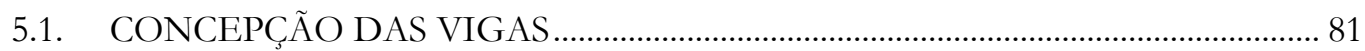

5.2. MOLDAGEM E CONCRETAGEM DOS MODELOS …........................................ 84

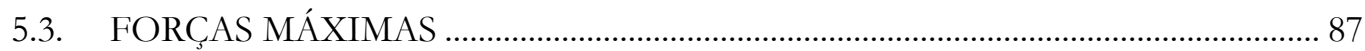


5.3.1. Força máxima para a flexão $\left(F_{\text {máx }}\right)$...................................................................

5.3.2. Força máxima no cisalhamento $\left(\mathrm{F}_{\mathrm{Wmáx}}\right)$.............................................................89

5.3.3. Força máxima no cisalhamento com reforço $\left(\mathrm{F}_{\mathrm{WR}}\right)$..........................................89

5.4. ENSAIO DESTRUTIVO_.....................................................................................91

5.5. ENSAIO DINÂMICO NÃO DESTRUTIVO …………………………………......92

6. APRESENTAÇÃO E ANÁLISE DE RESULTADOS DAS VIGAS - ENSAIOS

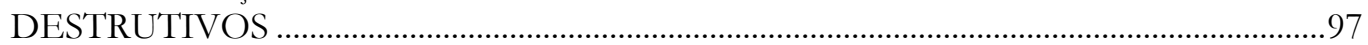

6.1. FISSURAÇÃO E FORMA DE RUPTURA …………………………………….......97

6.2. MATERIAIS COMPONENTES DAS VIGAS ………………………………......... 104

6.2.1. Corpos de Prova.............................................................................................. 104

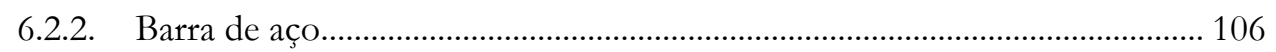

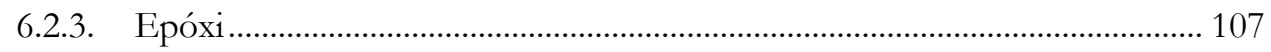

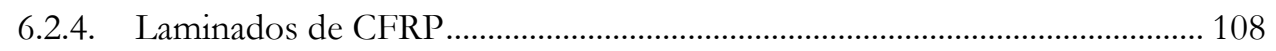

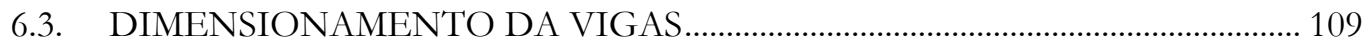

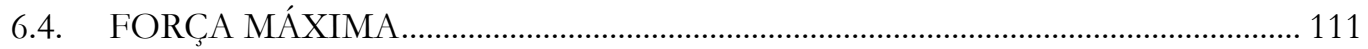

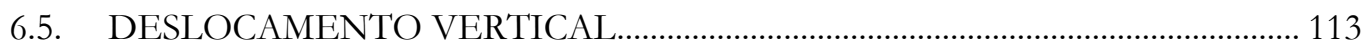

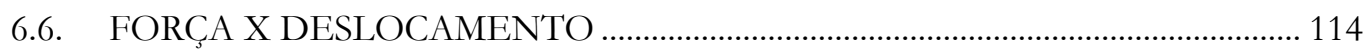

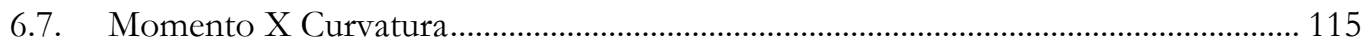

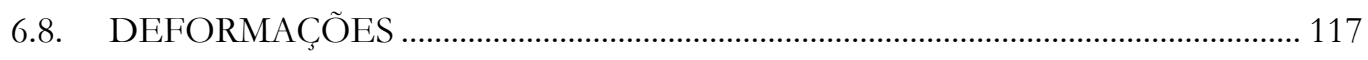

6.8.1. Deformações nas armaduras longitudinais ..................................................... 117

6.8.2. Deformações nas armaduras transversais e laminados de CFRP ................. 120

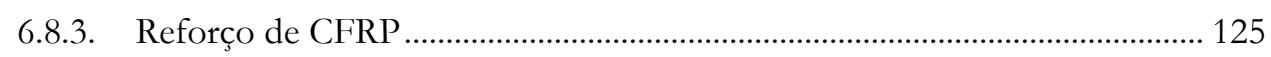

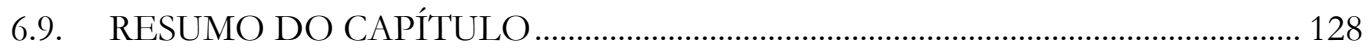

7. APRESENTAÇÃO E ANÁLISE DE RESULTADOS DAS VIGAS - ENSAIOS NÃO

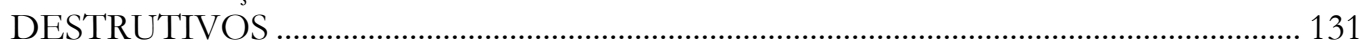

7.1. VARIAÇÃO DAS FREQUÊNCIAS NATURAIS E ANSPD ................................ 131

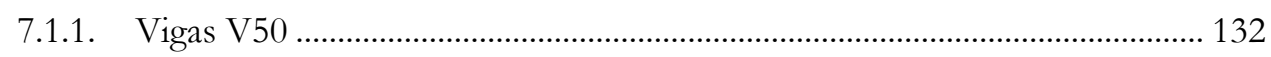

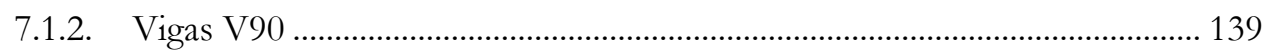

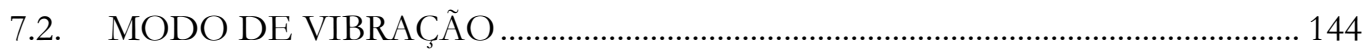

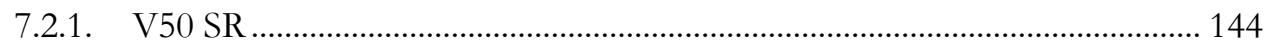

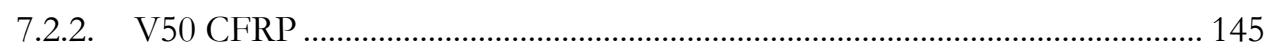

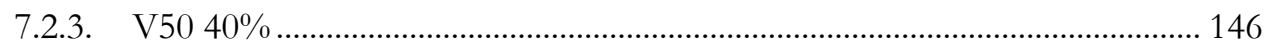

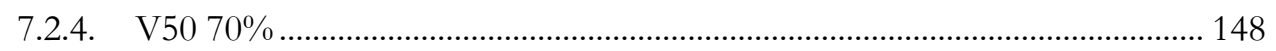

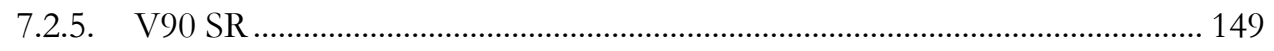

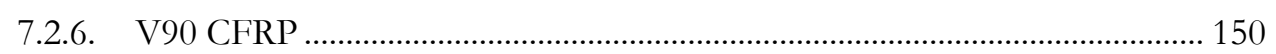

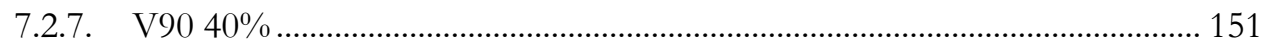

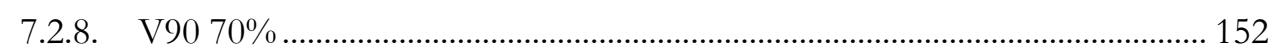

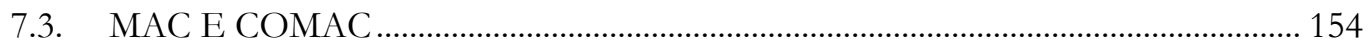

7.3.1. Estudo da quantidade de modo de vibração ……………………………….... 154

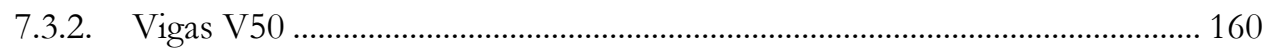

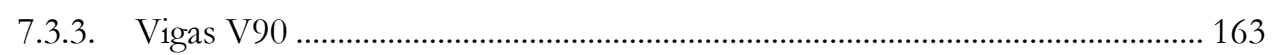

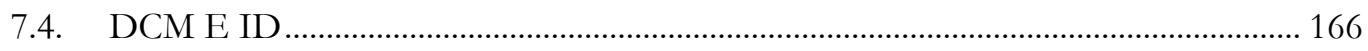

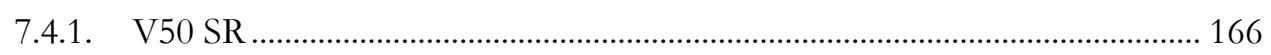




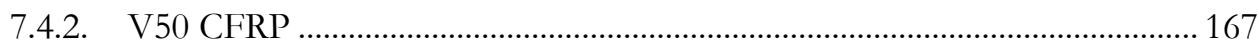

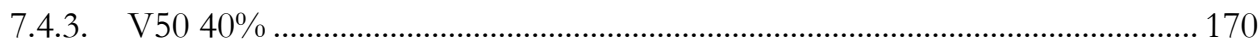

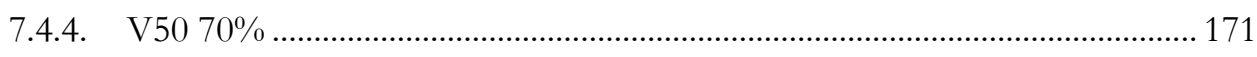

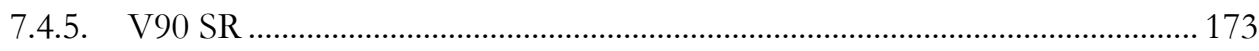

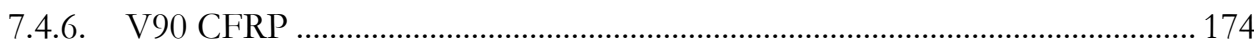

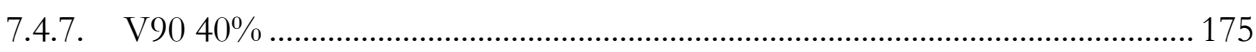

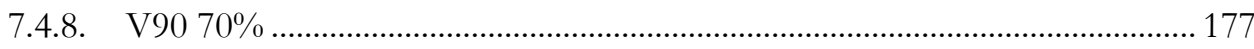

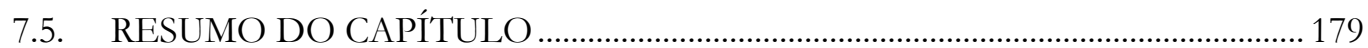

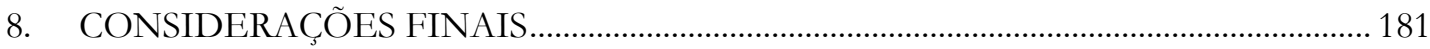

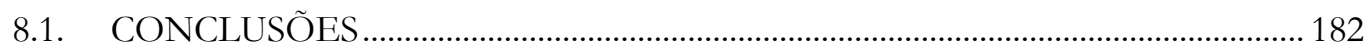

8.2. SUGESTÕES PARA TRABALHOS FUTUROS ………………………………...... 184

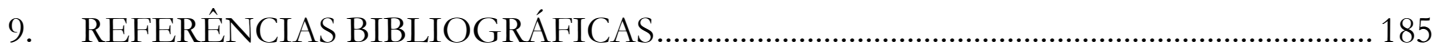

Apêndice A - Memoria de Cálculo............................................................................................... 191

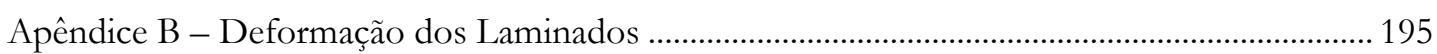

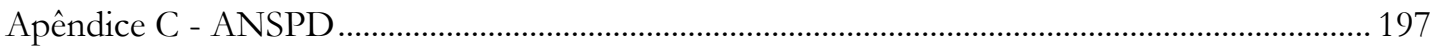

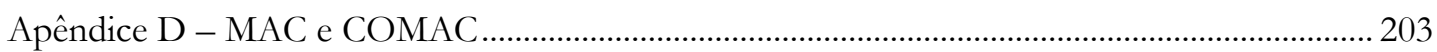

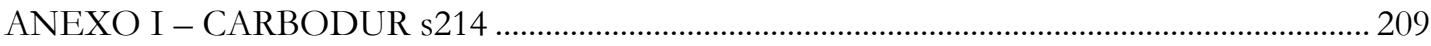

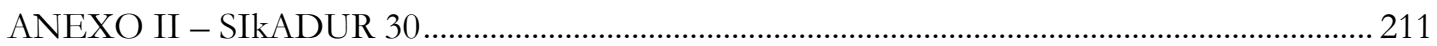





\section{LISTA DE FIGURAS}

Figura 2.1 - Diagrama esquemático do equilibrio da seção transversal reforçada por Beber (2013) ........... 10

Figura 2.2 - Fluxograma de cálculo de vigas reforçadas por Beber (2013).................................................... 11

Figura 2.3 - Interface gráfica do programa de dimensionamento de reforços com CFRP da Sika.............. 12

Figura 2.4 - Ensaios de Khalifa (1999) com reforço em mantas de CFRP ....................................................... 14

Figura 2.5 - Ensaios de Khalifa et al (2000) com reforço em NSM............................................................... 14

Figura 2.6 - Ensaios de Dias (2008) com reforço em NSM com diferentes ângulos ..................................... 15

Figura 2.7 - Principio de funcionamento do Sonelastic ${ }^{\circledR}$ fonte: ATCP (2014) …………………………….... 20

Figura 2.8 - Espectros íntegro e rompido de Diógenes (2013) ……………………………………………...... 21

Figura 2.9 - $3^{\circ}$ modo de vibração flexional da viga de Diógenes (2013) ........................................................... 21

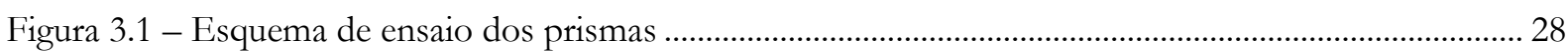

Figura 3.2 - Instrumentação e armadura dos Prismas ...................................................................................... 29

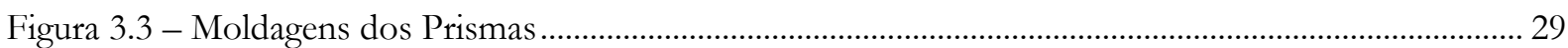

Figura 3.4 - Propriedades do laminado de CFRP. Fonte: Sika (2009) ............................................................. 30

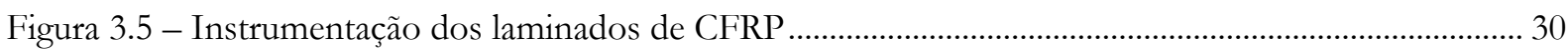

Figura 3.6 - Recomendações para dimensão de ranhuras usando a técnica NSM. Fonte: Dias (2008) ....... 31

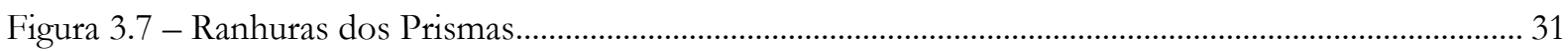

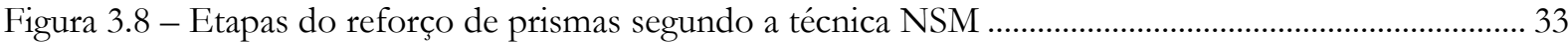

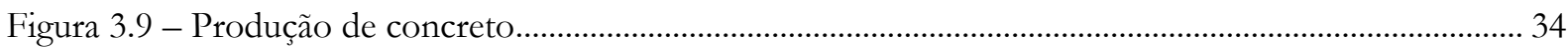

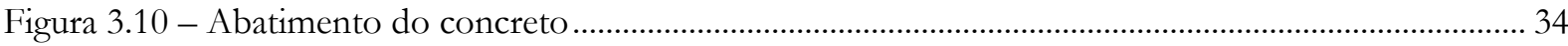

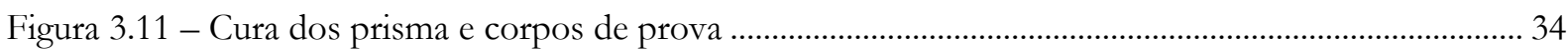

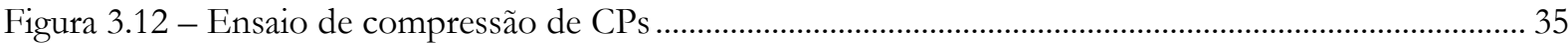

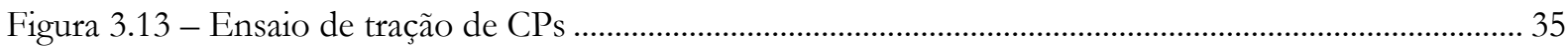

Figura 3.14 - Módulo de elasticidade longitudinal com Sonelastic ${ }^{\circledR}$ e Interface gráfica do programa (Fonte:

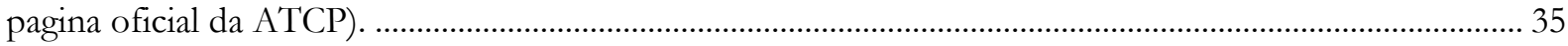

Figura 3.15 - Pórtico para suspender os prismas e apoio em elásticos ............................................................. 40

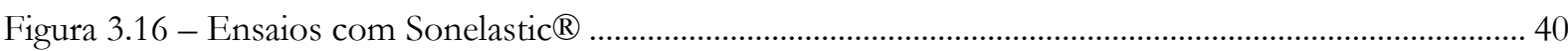

Figura 3.17 - Interface gráfica do programa Signal Calc ACE …………………………………................ 41

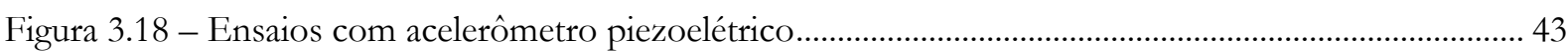

Figura 3.19 - Modelagem em elementos tridimensionais para simular a análise modal ................................. 45

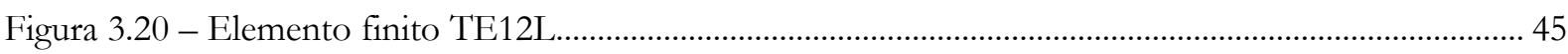

Figura 4.1 - Fissuras no Prisma P40 SR ................................................................................................. 54

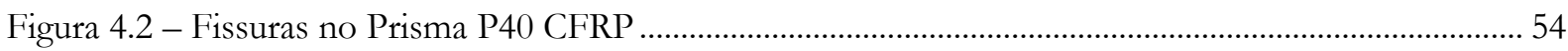

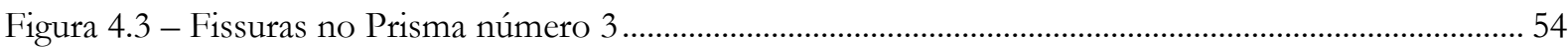

Figura 4.4 - Localização dos laminados inseridos nos prismas .......................................................................... 60

Figura 4.5 - Modos de vibração dos prismas C40 CFRP …………………………………………………...... 72

Figura 4.6 - Modelo computacional com ranhuras e reforços ........................................................................... 74

Figura 4.7 - Modos de vibração dos primas P60 CFRP ................................................................................ 75

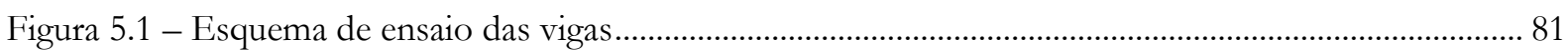

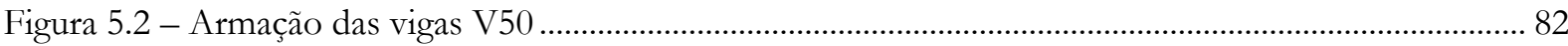


Figura 5.3 - Armação das vigas V90

Figura 5.4 - Esquema e imagem da instrumentação de extensômetros nas vigas .........................................83

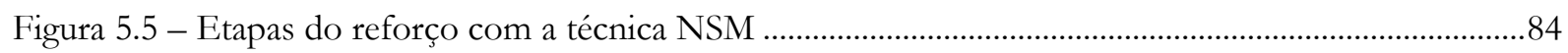

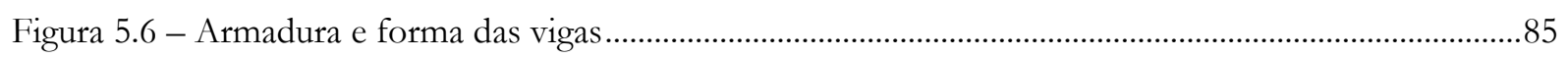

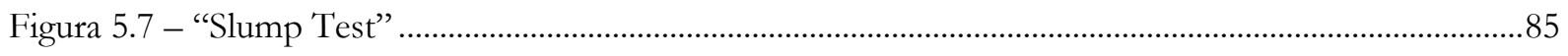

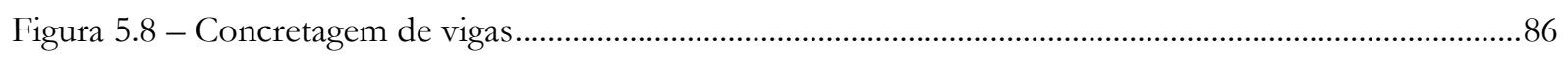

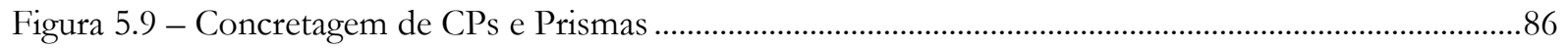

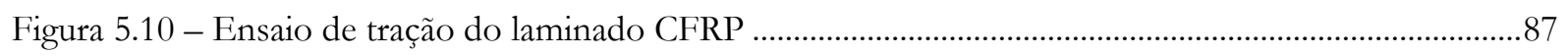

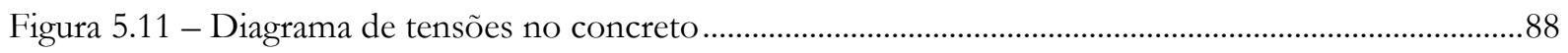

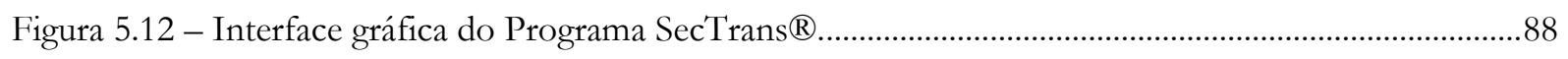

Figura 5.13 - Posicionamento dos laminados de CFRP na viga (dimensões em $\mathrm{cm}$ ) ..................................90

Figura 5.14 - Esquema de ensaio e detalhe do atuador ..................................................................................91

Figura 5.15 - Esquema de ensaio com detalhe do atuador hidráulico ..........................................................92

Figura 5.16 - Interface gráfica software LabVIEW SignalExpress..............................................................93

Figura 5.17 - Posicionamento dos acelerômetros .........................................................................................94

Figura 5.18 - Posicionamento dos acelerômetros e suporte metálicos ........................................................94

Figura 5.19 - Resultados do programa desenvolvido no Matlab ${ }^{\circledR}$..............................................................95

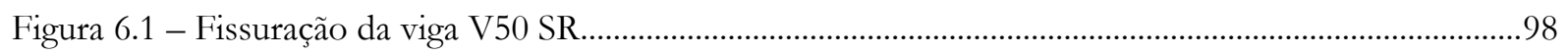

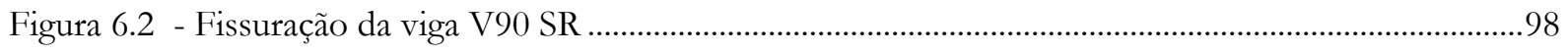

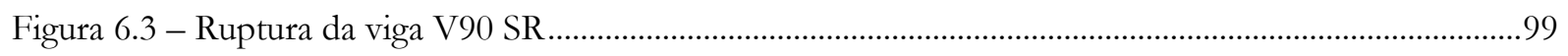

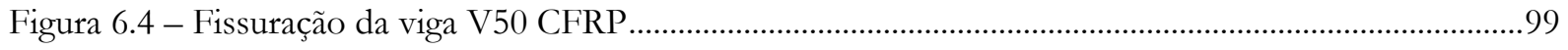

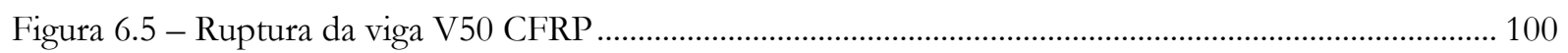

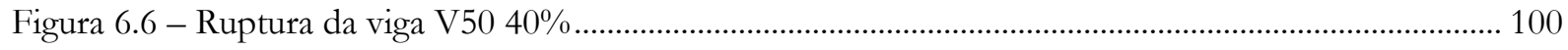

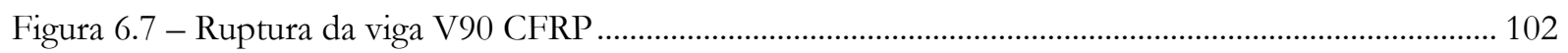

Figura 6.8 - Diagrama Momento x Curvatura - V90 …............................................................................ 102

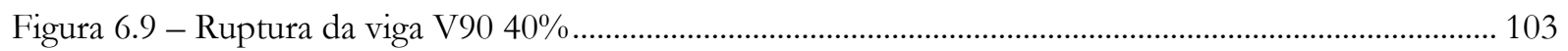

Figura 6.10 - Ensaio de tração do laminado CFRP .................................................................................... 108

Figura 6.11 - Posicionamento dos estribos e laminados de CFRP ............................................................ 121

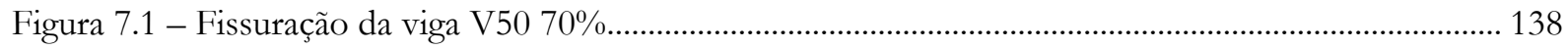

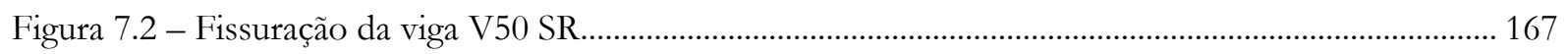

Figura 7.3 - Fissuração da viga V50 CFRP......................................................................................... 170 


\section{LISTA DE TABELAS}

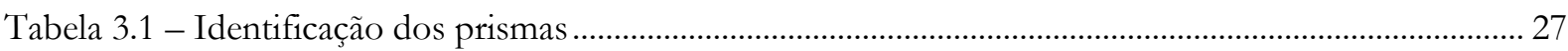

Tabela 3.2 - Informações sobre o ensaio dinâmico com acelerômetro ………………………………………. 42

Tabela 4.1 - Resistências à compressão e à tração dos corpos de prova C40 ……………………………….... 48

Tabela 4.2 - Resistências à compressão e à tração dos corpos de prova C60 …………………………………... 48

Tabela 4.3 - Módulo de elasticidade dos corpos de prova C40......................................................................... 49

Tabela 4.4 - Módulo de elasticidade dos corpos de prova C60 ……………………………………………..... 49

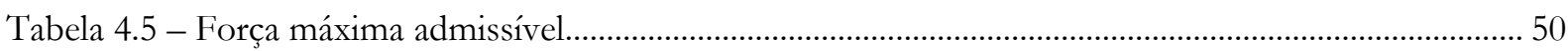

Tabela 4.6 - Forças máxima de ensaio dos prismas ........................................................................................ 51

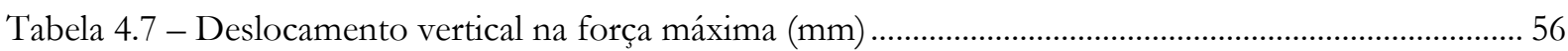

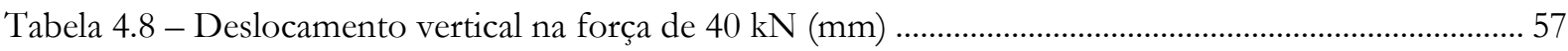

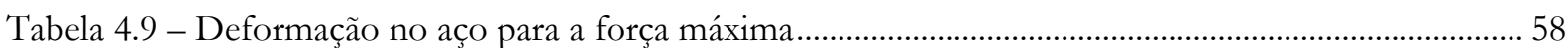

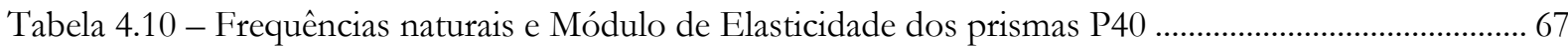

Tabela 4.11 - Médias das Frequências naturais e Módulo de Elasticidade dos prismas P40......................... 67

Tabela 4.12 - Frequências naturais e Módulo de Elasticidade dos prismas P60 .............................................. 69

Tabela 4.13 - Médias das Frequências naturais e Módulo de Elasticidade dos prismas P60.......................... 69

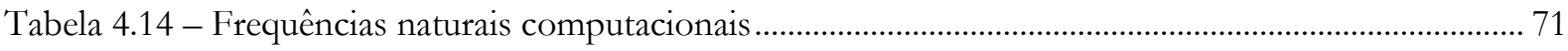

Tabela 4.15 - Frequências naturais experimentais e computacionais - P40.................................................... 73

Tabela 4.16 - Frequências naturais experimentais e computacionais - P60 ..................................................... 73

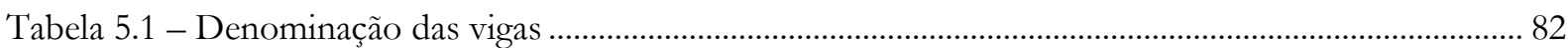

Tabela 6.1 - Resistências e Módulo de elasticidade dos CPs C50 …………………………………….......... 105

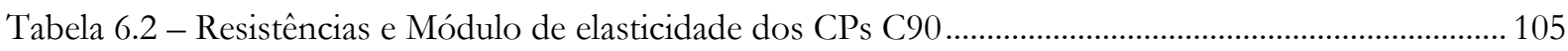

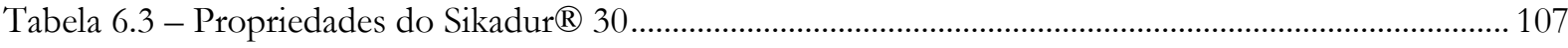

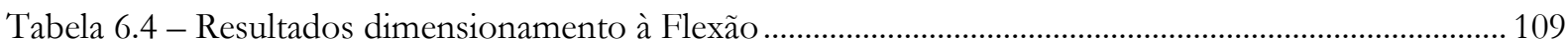

Tabela 6.5 - Resultados do dimensionamento ao Cisalhamento ...................................................................... 109

Tabela 6.6 - Resultados do dimensionamento ao Cisalhamento com reforço de CFRP .............................. 110

Tabela 6.7 - Forças máximas calculadas para a flexão, cisalhamento e cisalhamento com reforço ............ 110

Tabela 6.8 - Deslocamentos verticais no ponto de aplicação da força $(\mathrm{mm})$................................................ 113

Tabela 6.9 - Deformação nas armaduras positivas e negativas das vigas ....................................................... 118

Tabela 6.10 - Deformação nas armaduras transversais das vigas na força máxima ........................................ 121

Tabela 6.11 - Deformação no Laminados de CFRP ................................................................................ 125

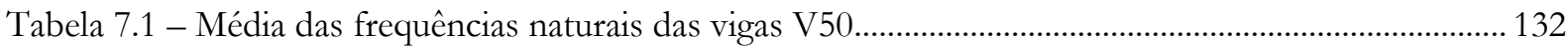

Tabela 7.2 - Frequências naturais das vigas V50 40\% e V50 70\% após Dano ............................................... 133

Tabela 7.3 - Frequências naturais das vigas V50 CFRP, V50 40\% e V50 70\% após Ranhuras................... 133

Tabela 7.4 - Frequências naturais das vigas V50 CFRP, V50 40\% e V50 70\% após Reforço...................... 134

Tabela 7.5 - Frequências naturais das vigas V50 após Ruptura.................................................................... 135

Tabela 7.6 - Média das frequências naturais das vigas V90......................................................................... 139

Tabela 7.7 - Frequências naturais das vigas V90 40\% e V90 70\% após Dano .............................................. 140

Tabela 7.8 - Frequências naturais das vigas V90 CFRP, V90 40\% e V90 70\% após Ranhuras................... 140

Tabela 7.9 - Frequências naturais das vigas V90 CFRP, V90 40\% e V90 70\% após Reforço ..................... 141

Tabela 7.10 - Frequências naturais das vigas V90 após Ruptura .................................................................. 141 
Tabela 7.11 - Resumo da identificação de Dano, Ranhura, Reforço e Ruptura........... 


\section{LISTA DE GRÁFICOS}

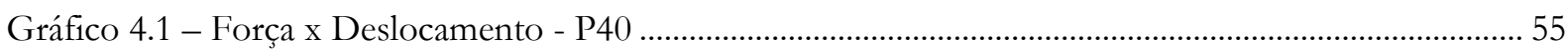

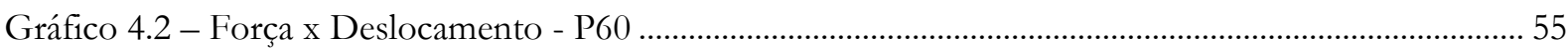

Gráfico 4.3 - Força x Deformação no aço dos Prismas C40......................................................................... 59

Gráfico 4.4 - Força x Deformação no aço dos Prismas C60 ......................................................................... 59

Gráfico 4.5 - Força x Deformação nos laminados - Prisma P5 - P40 CFRP................................................... 61

Gráfico 4.6 - Força x Deformação nos laminados - Prisma P9 - P40 CFRP................................................... 61

Gráfico 4.7 - Força x Deformação nos laminados - Prisma P11 - P40 40\% ……………………………...... 62

Gráfico 4.8 - Força x Deformação nos laminados - Prisma - P40 40\% …………………………………...... 63

Gráfico 4.9 - Força x Deformação nos laminados - Prisma P3 - P40 70\% ……………………………….... 63

Gráfico 4.10 - Força x Deformação nos laminados - Prisma P18 - P60 CFRP .............................................. 64

Gráfico 4.11 - Força x Deformação nos laminados - Prisma P23 - P60 40\% ……………………………..... 65

Gráfico 4.12 - Resposta em frequência de ensaio Flexional do Prisma 10 ………………………………..... 76

Gráfico 4.13 - Resposta em frequência de ensaio Torcional do Prisma 10 ………......................................... 77

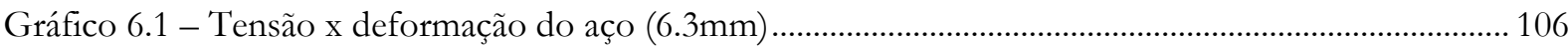

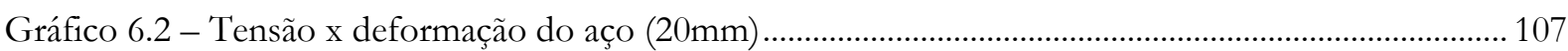

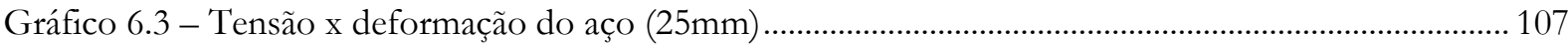

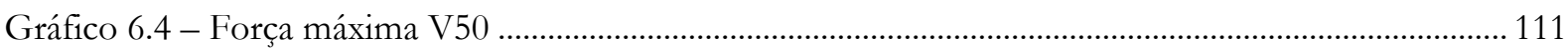

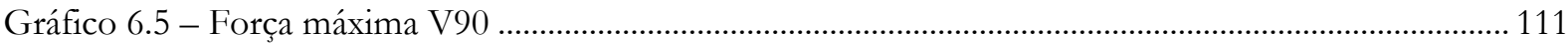

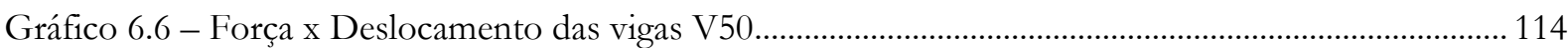

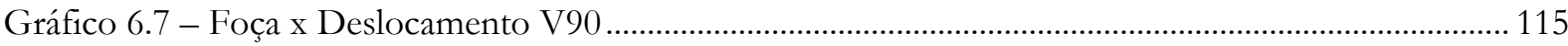

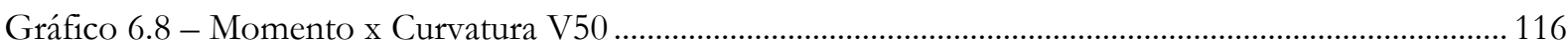

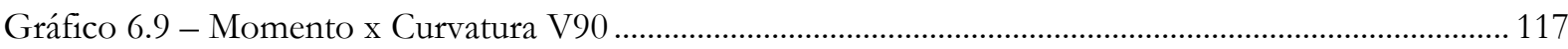

Gráfico 6.10 - Força x Deformação Armadura longitudinal - V50 …………………………………......... 119

Gráfico 6.11 - Força x Deformação Armadura Positiva - V90 …………………………………………….... 120

Gráfico 6.12 - Força x Deformação na armadura transversal - V50 SR....................................................... 122

Gráfico 6.13 - Força x Deformação na armadura transversal - V50 CFRP .................................................... 122

Gráfico 6.14 - Força x Deformação na armadura transversal - V50 estribo 5 .............................................. 123

Gráfico 6.15 - Força x Deformação na armadura transversal - V90 SR......................................................... 123

Gráfico 6.16 - Força x Deformação na armadura transversal - V90 estribo 3 .............................................. 124

Gráfico 6.17 - Força x Deformação nos Laminados - V50 CFRP ................................................................ 126

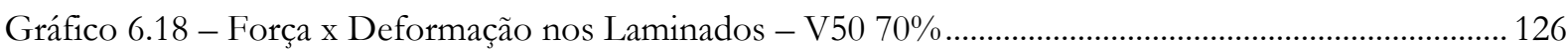

Gráfico 6.19 - Força x Deformação nos Laminados - V90 CFRP ................................................................ 127

Gráfico 6.20 - Força x Deformação nos Laminados - V90 70\% ………………………………………..... 128

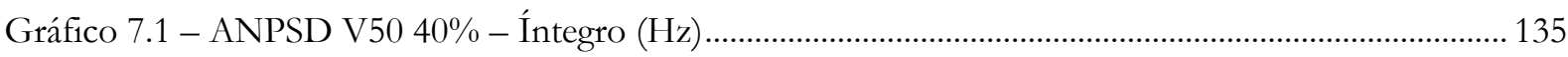

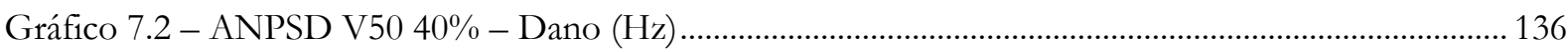

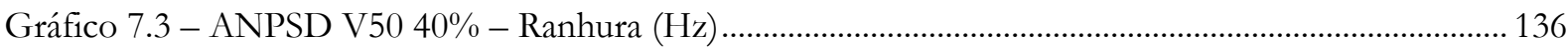

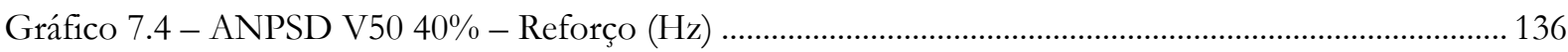

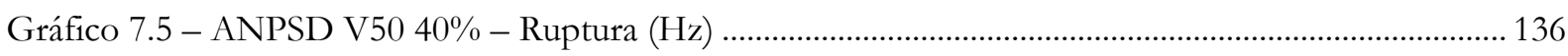

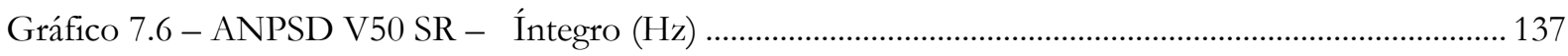

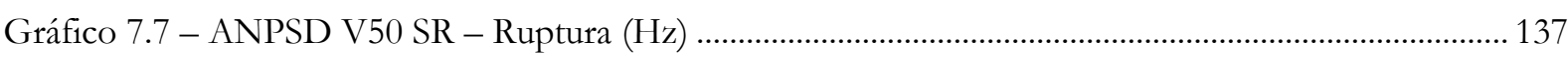




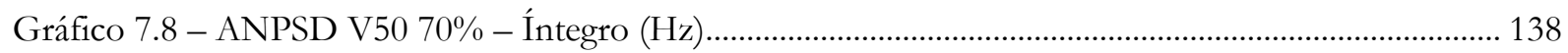

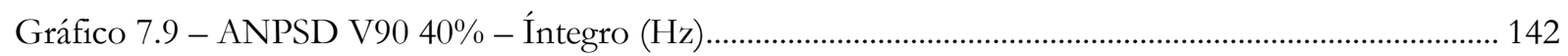

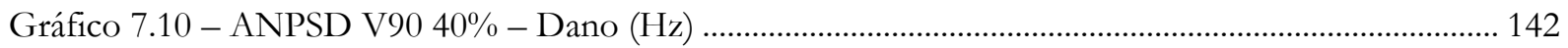

Gráfico 7.11 - ANPSD V90 40\% - Ranhura (Hz) …………………………………………………...... 142

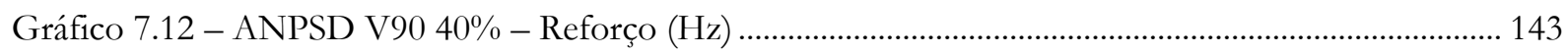

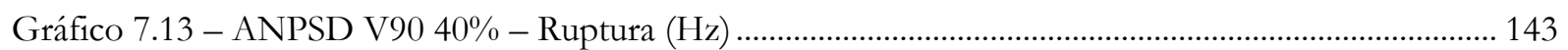

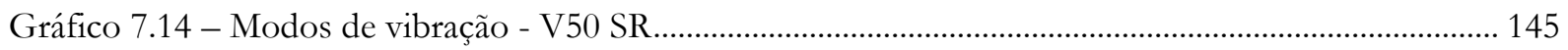

Gráfico 7.15 - Modos de vibração - V50 CFRP .................................................................................................. 146

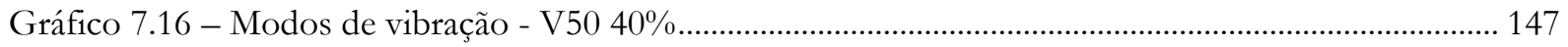

Gráfico 7.17 - Modos de vibração - V50 70\%................................................................................................ 148

Gráfico 7.18 - Modos de vibração - V90 SR............................................................................................ 149

Gráfico 7.19 - Modos de vibração - V90 CFRP ........................................................................................ 150

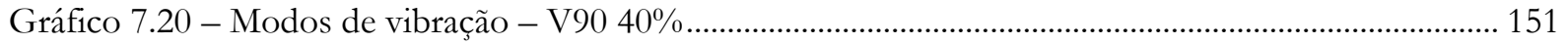

Gráfico 7.21 - Modos de vibração - V90 70\%.......................................................................................... 153

Gráfico 7.22 - Estudo do MAC usando entre 3 e 5 modos de vibração - Dano ........................................... 155

Gráfico 7.23 - Estudo do COMAC usando entre $3^{\circ}$ e $5^{\circ}$ modos de vibração - Dano................................ 156

Gráfico 7.24 - Estudo do MAC usando entre $3^{\circ}$ e $5^{\circ}$ modos de vibração -Ranhura .................................... 156

Gráfico 7.25 - Estudo do COMAC usando entre $3^{\circ}$ e $5^{\circ}$ modos de vibração - Ranhura............................ 157

Gráfico 7.26 - Estudo do MAC usando entre $3^{\circ}$ e $5^{\circ}$ modo de vibração - Reforço ....................................... 158

Gráfico 7.27 - Estudo do COMAC usando entre $3^{\circ}$ e $5^{\circ}$ modos de vibração - Reforço ............................ 158

Gráfico 7.28 - Estudo do MAC usando entre $3^{\circ}$ e $5^{\circ}$ modo de vibração - Ruptura ...................................... 159

Gráfico 7.29 - Estudo do COMAC usando entre $3^{\circ}$ e $5^{\circ}$ modos de vibração - Ruptura ............................. 159

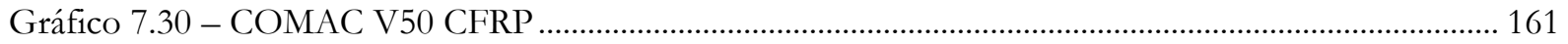

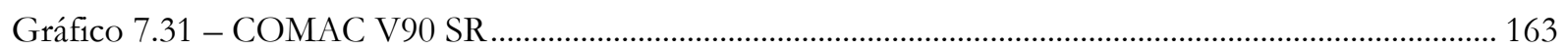

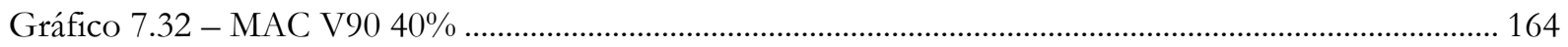

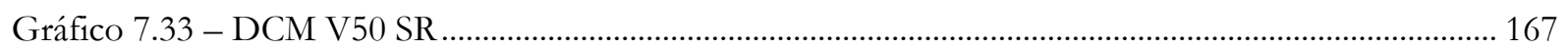

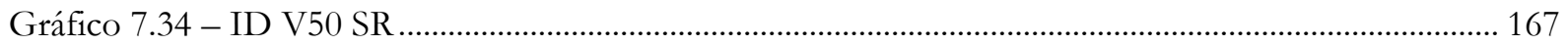

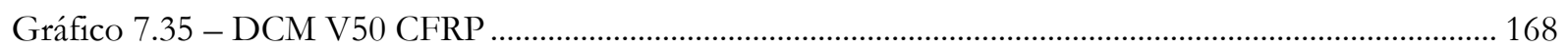

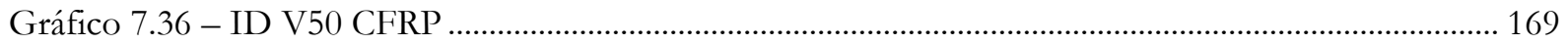

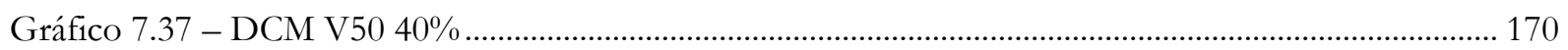

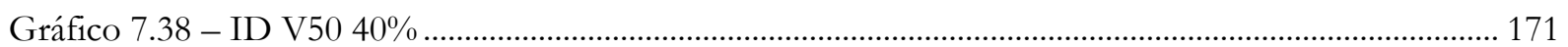

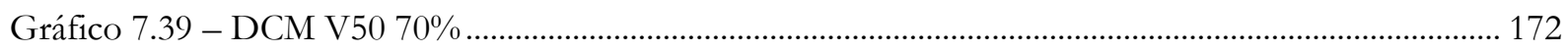

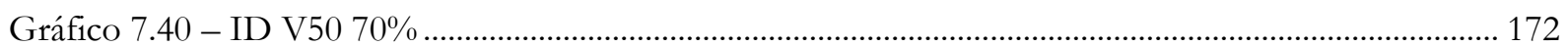

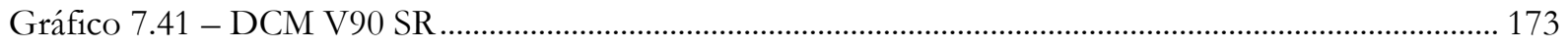

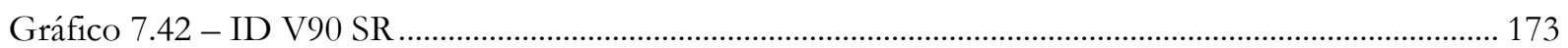

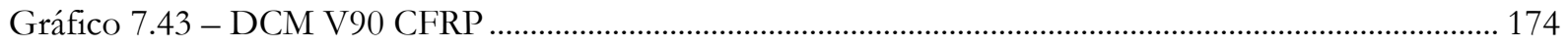

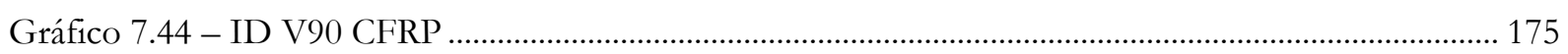

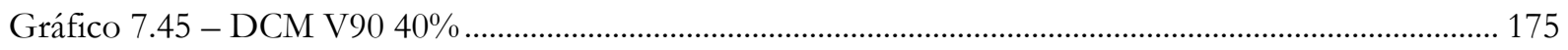

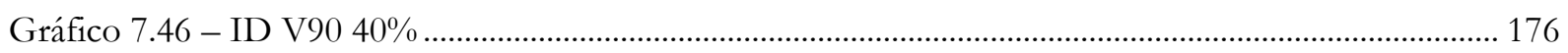

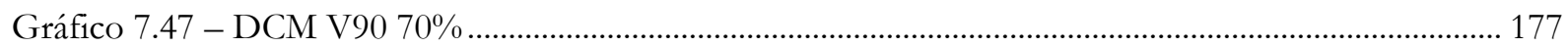

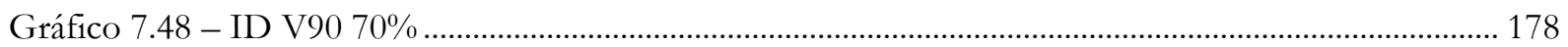

Gráfico 0.1 - Força x Deformação nos Laminados - V50 CFRP ………………………………………..... 195

Gráfico 0.2 - Força x Deformação nos Laminados - V50 40\% …………………………………............ 195 
Gráfico 0.3 - Força x Deformação nos Laminados - V50 70\% …………………………………………..... 196

Gráfico 0.4 - Força x Deformação nos Laminados - V90 CFRP ................................................................ 196

Gráfico 0.5 - Força x Deformação nos Laminados - V90 CFRP .................................................................. 196

Gráfico 0.6 - Força x Deformação nos Laminados - V90 70\% …………………………………………....... 196

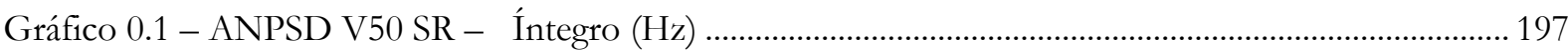

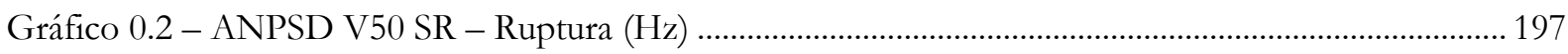

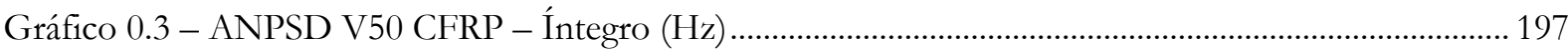

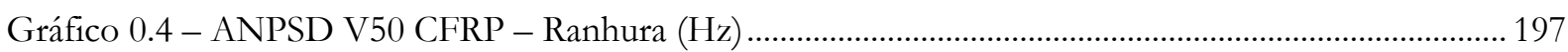

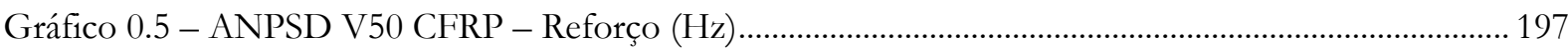

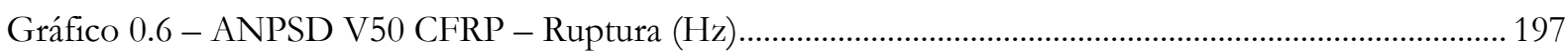

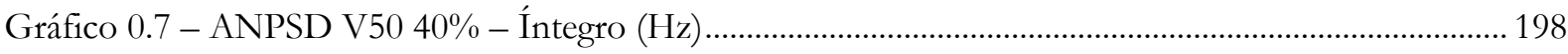

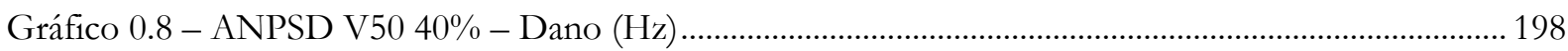

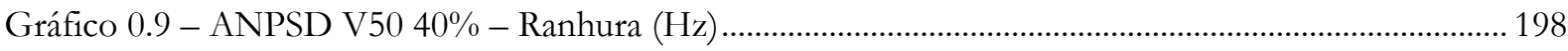

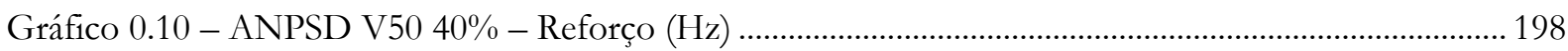

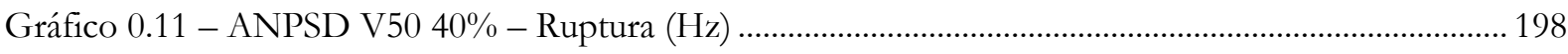

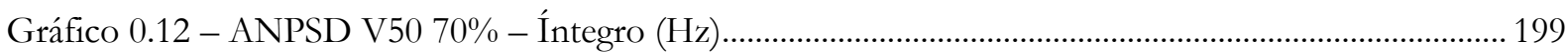

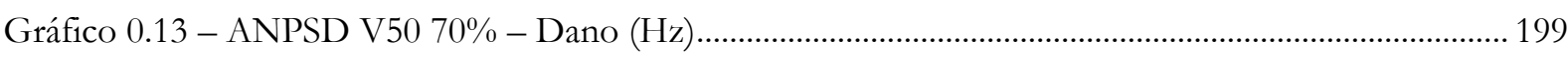

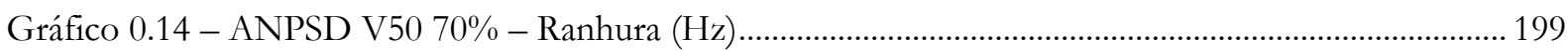

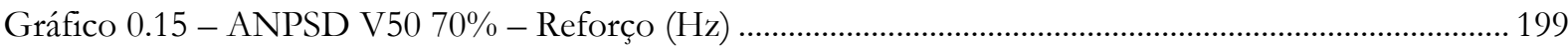

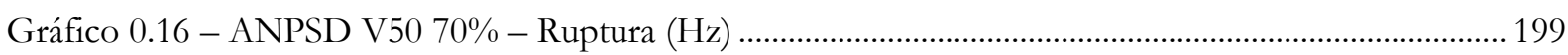

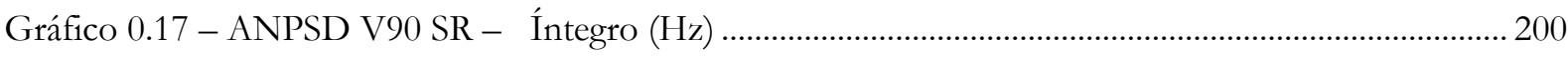

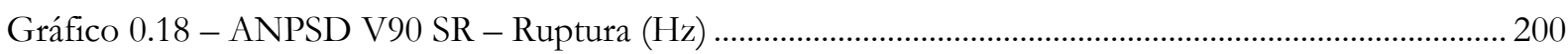

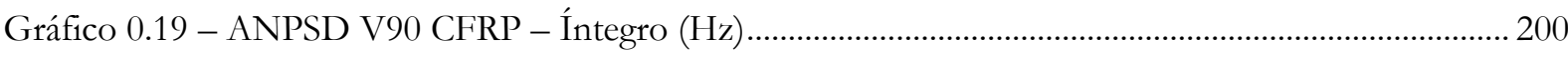

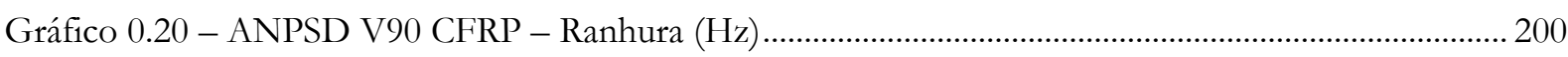

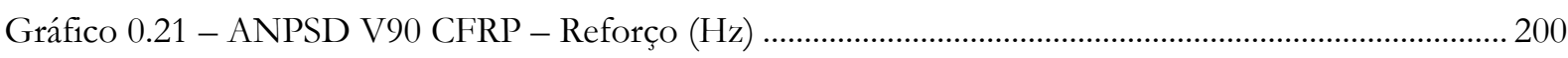

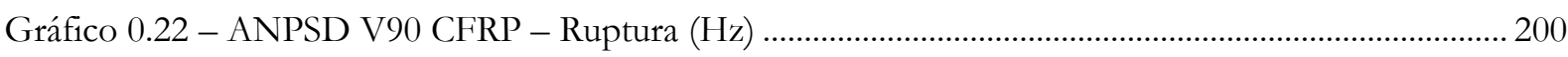

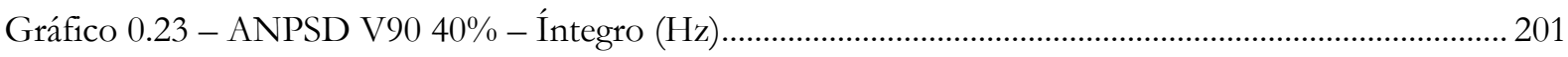

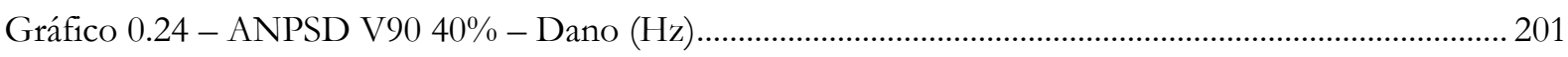

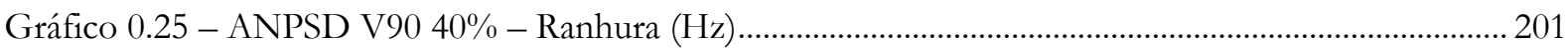

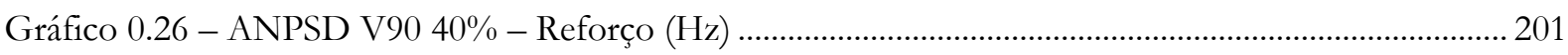

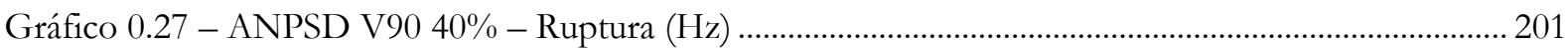

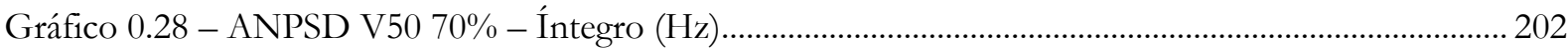

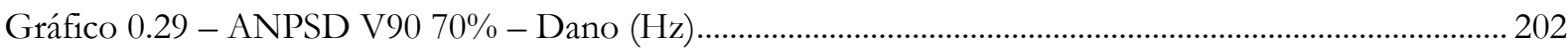

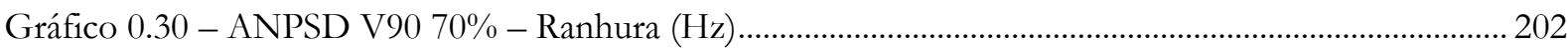

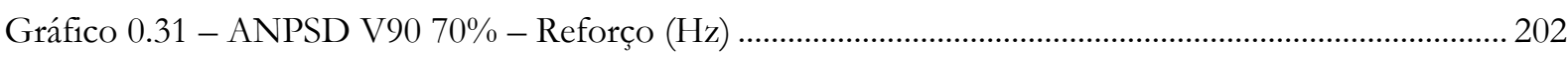

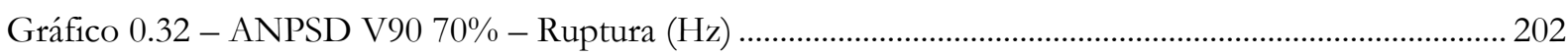

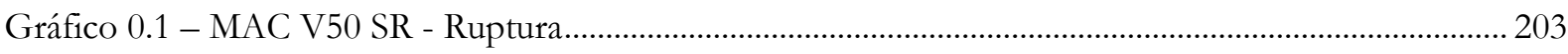

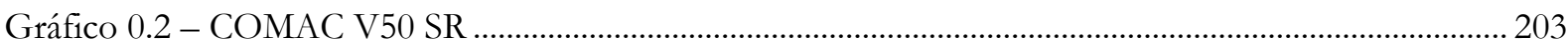

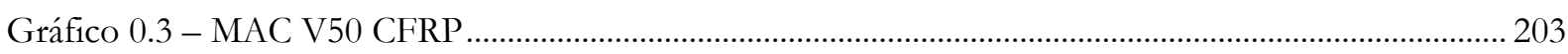

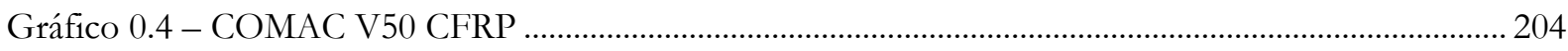

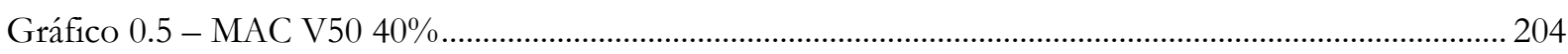

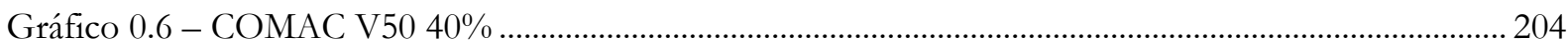

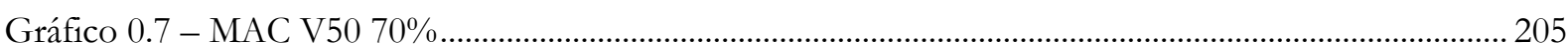




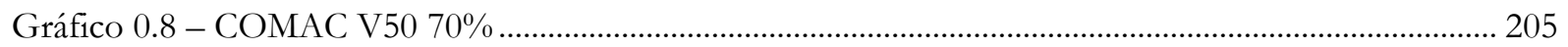

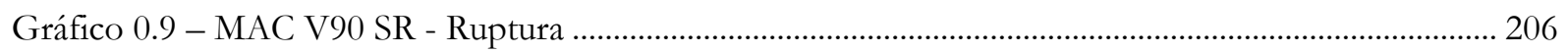

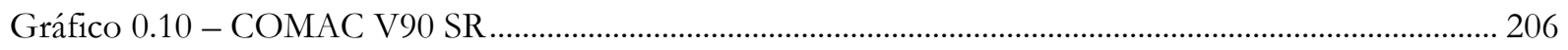

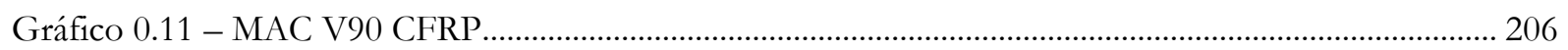

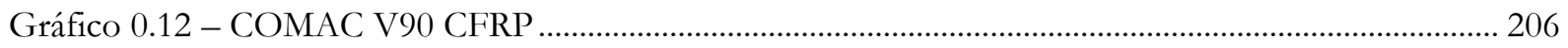

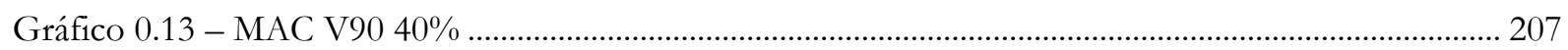

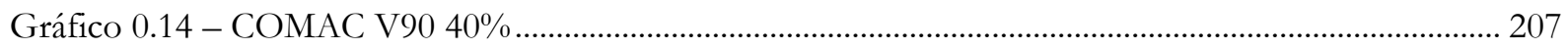

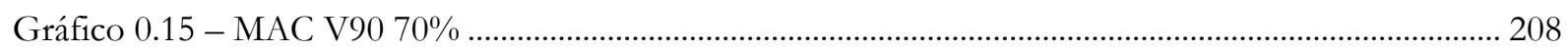

Gráfico 0.16 - COMAC V90 70\% ……………………………………………………………………...... 208 


\section{INTRODUÇÃO}

\subsection{GENERALIDADES}

A construção civil atualmente vem se desenvolvendo na recuperação e reforço de estruturas de concreto armado. Este aumento na quantidade do uso e do estudo de reforços ocorre, na maioria dos casos, pelo uso inadequado das construções, por erros de projeto ou construção, por deterioração devido ao uso e por alterações na finalidade de uso.

Os processos de recuperação mais comuns nas construções civis são: injeção de cimento ou resina epóxi em fissuras, reforço de elementos estruturais com a utilização de perfis metálicos laminados ou com concreto armado, utilização de concreto projetado, adição de cabos de protensão externos e o tradicional reforço mediante colagem de laminados de aço com resina epóxi (BEBER; FILHO; CAMPAGNOLO, 2000).

O uso de materiais de elevado desempenho para a recuperação de estruturas proporcionou o desenvolvimento de novas técnicas de reforço. Um dos materiais mais utilizados como reforço de estruturas de concreto é o Carbon Fiber Reinforced Polymer (CFRP), traduzido como Polímeros Reforçado com Fibras de Carbono (PRFC), utilizado principalmente por apresentar elevada resistência mecânica e facilidade de aplicação junto ao concreto danificado. O seu uso ocorre, em geral, por meio da técnica Externally Bonded Reinforcement (EBR), principalmente em grandes obras como pontes e viadutos, em que mantas são coladas na superfície de vigas e lajes ou para confinamento de pilares.

Dentre os modos de aplicação do CFRP existe uma técnica denominada Near Surface Mounted (NSM), essa técnica diferencia-se do uso tradicional do CFRP, pois nela laminados ou barras de CFRP são inseridos no concreto, preferencialmente na região de cobrimento.

O NSM é uma tecnologia promissora para melhorar a resistência dos esforços à flexão, como para sistemas de reforço ao cisalhamento. A principal vantagem dos laminados de CFRP aplicados segundo a técnica NSM comparados com os colados externamente segundo a técnica EBR é uma melhor ancoragem do sistema de reforço no concreto.

$\mathrm{Na}$ busca de novas técnicas e tecnologias para a recuperação de estruturas de concreto armado observa-se a necessidade de identificação da situação das estruturas antes do reforço. A localização das falhas estruturais nem sempre são facilmente observadas, necessitando muitas vezes de coletas de material, inspeções visuais, ensaios de prova de força ou ensaios não destrutivos. 
Dentre as técnicas utilizadas para a identificação de dano em estruturas de concreto a análise modal vem ganhando destaque na comunidade cientifica pois ocorre de maneira não destrutiva e com baixo custo de implantação. Em geral esta técnica permite observar experimentalmente as frequências naturais de vibração das estruturas. Alterações nessas frequências naturais indicam uma mudança de comportamento da estrutura, em geral, causados por falhas estruturais.

O estudo das frequências naturais das estruturas de concreto permite uma maior compreensão de como a estrutura se comporta, em que uma variação nos modos de vibração pode ser utilizada para identificar a presença e a magnitude do dano. Existem diversos métodos de ensaios para a obtenção das frequências naturais em estruturas, a maioria destes são baseados em som com o uso de um analisador de sinais dinâmico e em aceleração com o uso de acelerômetros piezoelétricos.

Uma análise periódica das frequências naturais pode ser utilizada para monitorar a condição do dano em estruturas, pois, uma vez conhecidas as frequências naturais dos elementos no seu estágio inicial, o seu monitoramento permite identificar a variação dessas frequências.

O dano em estruturas de concreto armado resulta na diminuição da rigidez do elemento e essa variação pode ser medida indiretamente em uma diminuição das frequências naturais e pelos modos de vibração. Este efeito ocorre devido à microfissuração do concreto, que reduz o seu módulo de elasticidade e afeta diretamente a rigidez da estrutura.

As técnicas de ensaio e análise desenvolvidas no âmbito da identificação modal clássica, em que a análise modal experimental tem controle e medição das forças de excitação, podem ser aplicadas em estruturas de engenharia civil, utilizando-se para tal vibradores servo-hidráulicos, de massas excêntricas ou sistemas de aplicação de impulsos. Segundo Rodrigues (2004), as dimensões da maioria das estruturas de engenharia civil, as suas características dinâmicas e o tipo de utilização, na maioria das situações não são possíveis utilizar essas técnicas de uma forma econômica. $\mathrm{O}$ pesquisador destaca que devido as grandes dimensões das estruturas de engenharia civil, suas frequências naturais de vibração podem ter valores bastante baixos e os equipamentos de excitação necessários para o ensaio são de grandes dimensões, sendo caros e tendo uma utilização também dispendiosa. Indica ainda para o uso da identificação modal clássica tornando-se necessário a interrupção de uso do funcionamento das edificações, o que nem sempre é possível.

Para que a identificação modal de estruturas de engenharia civil seja feita de uma forma econômica, é conveniente que seja efetuada através de métodos de ensaios e análises em que apenas se mede a resposta das estruturas às ações decorrentes da sua própria utilização. Neste tipo de 
ensaios de identificação modal, que podem ser designados por ensaios de medição de vibrações ambiente, as forças de excitação correspondentes às ações ambientais não são controladas nem medidas, a este método denomina-se identificação modal estocástica (RODRIGUES, 2004).

Nem sempre observar as pequenas fissuras no concreto em ensaios experimentais ocorre facilmente, desta forma o estudo por meio de uma análise computacional com programas de elementos finitos permite observar de forma precisa as tensões e deformações da estrutura, observando como as fissuras se propagam durante o carregamento. Nesta tese também foram utilizadas técnicas de modelagem computacional com análise modal para identificação do comportamento do sistema de reforço ao cisalhamento em vigas de concreto armado reforçadas com laminados de CFRP aplicados segundo a técnica NSM.

\subsection{OBJETIVOS}

\subsubsection{Geral}

Esta pesquisa tem como objetivo principal estudar a eficiência da incorporação de laminados de fibra de carbono como reforço ao cisalhamento em vigas de concreto armado, identificando a capacidade dos ensaios não destrutivos em detectar as alterações nas frequências naturais ocorridas devido ao dano e ao reforço.

\subsubsection{Específicos}

Analisar a influência do sistema de reforço com laminados de CFRP em relação ao aumento da força de máxima e deformação de vigas, bem como seu efeito na tensão dos estribos e na alteração da forma de ruptura;

Identificar a influência do carregamento prévio no resultado final da força máxima, do deslocamento vertical e da deformação nas armaduras e nos laminados de CFRP;

Por meio de análise modal, identificar as alterações nas frequências naturais e modos de vibração de vigas devido a presença de carregamento prévio, de ranhuras necessária para incorporação dos laminados, do sistema de reforço e após a ruptura;

Analisar a eficiência dos métodos de identificação de dano por ensaios não destrutivos, utilizando análise modal para obter a posição e a magnitude do dano, além de identificar a presença do sistema de reforço com laminados de CFRP. 


\subsection{JUSTIFICATIVA}

A recuperação estrutural abrange edificações abaladas por sinistros de qualquer natureza ou por falhas no planejamento, projeto, execução ou por emprego de materiais, componentes de baixa qualidade e alteração de finalidade da edificação. Segundo Beber, Filho e Campagnolo (2000), a discussão a respeito da manutenção e durabilidade das estruturas é assunto de vital importância. O Reino Unido, por exemplo, consome cerca de 4\% de seu PNB com o reparo e a manutenção de estruturas.

O estudo da aplicação de sistemas de reforço em estruturas civis conta hoje com o CFRP, um material de elevado desempenho e de grande utilização mundial, tanto que, já existem normas em diversos países para o uso adequado desse material. A American Composites Manufacturers Association, em seu site, lista as principais normas já desenvolvidas sobre o assunto, sendo que algumas já sofreram atualizações. (ACMANT 2013)

EUA

- ACI 440.1R-01 2001, Guide for the Design and Construction of Concrete Reinforced with FRP Bars, Committee 440, American Concrete Institute, Farmington Hills, MI. (May 2001), www.aci-int.org

- ACI 440R 1996, State-of-the-Art Report on Fiber Reinforced Plastic Reinforcement for Concrete Structures, Committee 440, American Concrete Institute, Farmington Hills, MI. (February 1996), 67 pp.

Canada

- CAN/CSA-S806-02, Design and Construction of Building Components with Fibre-Reinforced Polymers, Canadian Standards Association, Toronto, Ontario, Canada (May 2002), 187 pp.

- CAN/CSA-S6-00, Canadian Highway Bridge Design Code, Canadian Standards Association, Toronto, Ontario, Canada (December 2000), 734pp.

- ISIS Canada, Design Manual No. 3, Reinforcing Concrete Structures with Fiber Reinforced Polymers, Canadian Network of Centers of Excellence on Intelligent Sensing for Innovative Structures, ISIS Canada Corporation, Winnipeg, Manitoba, Canada (Spring 2001), 158 pp, www.isiscanada.com

Japão

- Japan Society of Civil Engineers (JSCE), Recommendation for Design and Construction of Concrete Structures Using Continuous Fiber Reinforced 
Materials, Concrete Engineering Series 23, ed. by A. Machida, Research Committee on Continuous Fiber Reinforcing Materials, Tokyo, Japan, (1997), 325 pp.

\section{Europa}

- Fib Task Group 9.3, FRP Reinforcement for Concrete Structures, Federation Internationale du Beton, (1999).

- Report \# STF 22 a 98741, Eurocrete Modifications to NS3473 When Using FRP Reinforcement, Norway (1998).

Diversas Normas citadas no site da ACMANT (2013) já sofreram atualizações, demonstrando a efetiva utilização do CFRP para reforço em estruturas de concreto. Como por exemplo as normas: ACI 440.1R (2015), CAN/CSA-S806-12 (2012), Fib bulletin 14 (2001), Fib bulletin 40 (2015).

No Brasil não existem normas para a utilização de reforço de CFRP em concreto, sendo essencial o desenvolvimento de mais pesquisas sobre o tema. Atualmente existe uma comissão de estudos, a ABNT/CEE-193, visando a elaboração de uma norma brasileira com uso de materiais não convencionais para reforço de estruturas de concreto.

Dentre as técnicas de reforço o Near Surface Mounted (NSM) utiliza o CFRP e é tema de pesquisas mais aprofundadas na comunidade científica. Dentre estas, no Brasil encontra-se a Universidade de São Paulo (USP), especificamente a Escola de Engenharia de São Carlos (EESC), que já desenvolve pesquisas com a técnica NSM em vigas para reforço à flexão (ARQUEZ 2010 e FONSECA 2007). Com o propósito de continuar o estudo do uso de CFRP com a técnica NSM na EESC optou-se pelo estudo específico do reforço ao cisalhamento.

O estudo de técnicas de recuperação de estruturas de concreto armado necessita de uma correta identificação do local e magnitude do dano. Nessa linha de estudo, a análise modal de estruturas tem iniciado pesquisas experimentais na EESC, objetivando principalmente a identificação de dano com ensaios não destrutivos. Atualmente estudos experimentais com análise modal experimental foram desenvolvidos por Almeida (2010), Diógenes (2013), Juliani (2014) e Amancio (2016).

A continuidade das pesquisas dentro do departamento permite desenvolver os métodos de ensaios e de análise de resultados, uma vez que as dificuldades encontradas podem ser diretamente analisadas com os pesquisadores da área, facilitando assim sua compreensão e reduzindo a ocorrência dos mesmos erros. 
Desta forma, esta tese foi desenvolvida com o intuito de contribuir para a comunidade científica nos estudos de reforço ao cisalhamento com laminados de CFRP aplicados segundo a técnica NSM e no desenvolvimento de técnicas de identificação de dano por analise modal utilizando ensaios não destrutivos.

\subsection{ESTRUTURA DA TESE}

Esta tese de doutorado foi elaborada em capítulos, separados em:

- Introdução, com as Generalidades para ambientar o leitor sobre os principais temas contemplados pelo estudo; Objetivos para destacar o foco das análises; Justificativa definindo a motivação deste estudo e Metodologia para definir a execução de cada etapa do estudo;

- Revisão Bibliográfica, discorrendo sobre as normas, métodos e técnicas utilizadas no Brasil e no mundo sobre o uso de reforço com CFRP e sobre as técnicas de análise modal com ensaios dinâmicos não destrutivos;

- Materiais e Métodos de Prismas de concreto (ensaio piloto) reforçados com CFRP, discriminando as técnicas e normas utilizadas para a elaboração dos ensaios;

- Apresentação e Análise de Resultados de Prismas (ensaio piloto), para os ensaios destrutivos, não destrutivos e para a modelagem computacional com programa de elementos finitos;

- Materiais e Métodos de Vigas de concreto (ensaio principal) reforçados com CFRP, discriminando as técnicas e normas utilizadas para a elaboração dos ensaios;

- Apresentação e Análise de Resultados de Vigas (ensaio principal) de concreto armado com reforços de CFRP, para os ensaios experimentais destrutivos e não destrutivos;

- Conclusões das principais análises observadas nos ensaios piloto e principal;

- Sugestões para trabalhos futuros, destacando opções para melhorias nos trabalhos futuros com sistemas de reforço ao cisalhamento e na identificação de dano por análise modal experimental;

- Referências Bibliográficas, apresentando os trabalhos e normas utilizadas em auxílio a elaboração da presente Tese. 


\subsection{METODOLOGIA}

O desenvolvimento da tese iniciou com um estudo bibliográfico sobre os temas pertinentes ao trabalho por meio de artigos, livros, teses e normas técnicas, sendo destacado como referências os estudos com maior proximidade com os trabalhos efetuados ou para o embasamento dos temas estudados.

No ensaio piloto utilizou-se prismas de concreto armado, para seu estudo foram moldados vinte e quatro (24) prismas para ensaios de flexão. Neste estudo utilizou-se como variáveis: duas resistências de concreto; prismas com e sem reforços de CFRP; prismas íntegros e com carregamentos prévios de $40 \%$ e $70 \%$ da força máxima.

Para os ensaios piloto foram ainda realizados ensaios dinâmicos, com o intuito principal de caracterizar as frequências naturais de vibração e a rigidez das vigas. Estes foram realizados nas três configurações das vigas: quando íntegra, com carregamento prévio e após a ruptura. Nestes ensaios foram utilizados dois conjuntos de equipamentos para a determinação das frequências naturais, sendo eles: Um sistema com acelerômetros piezoelétricos uniaxial, martelo de impacto, condicionadores e amplificadores de sinal; Um analisador de sinais dinâmico para ensaio de

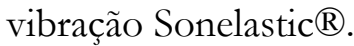

Com o intuito de auxiliar a compreensão da análise modal dos prismas, foi realizada uma modelagem computacional com simulações em prismas de concreto com o auxílio do programa DIANA®, utilizando as mesmas dimensões definidas para o ensaio piloto. Com a modelagem computacional buscou-se verificar frequências naturais e os modos de vibração dos prismas.

Após a análise de resultados do ensaio piloto com prismas de concreto, verificou-se a necessidade de produzir vigas, e assim minimizar as interferências oriundas do tamanho das estruturas em relação ao reforço evidente no ensaio piloto.

No estudo das vigas foram mantidas as mesmas variáveis dos prismas, sendo moldado oito (8) exemplares, sendo quatro (4) para cada resistência do concreto, com uma viga sem reforço e três com reforço de CFRP.

As vigas foram dimensionadas para ocorrer ruptura por cisalhamento, sendo o lado mais solicitado reforçado com laminados de CFRP com a técnica NSM. Para isso foi ensaiado a flexão com força excêntrica, visando obter uma maior tensão de cisalhamento no lado reforçado. Neste ensaio foi medido em cada passo de força os deslocamentos verticais das vigas e as deformações nas armaduras e laminados de CFRP. 
Para os ensaios não destrutivos das vigas foi realizado uma técnica mais elaborada que a utilizada nos ensaios piloto, permitindo captar além das frequências naturais, os modos de vibração. Com esta técnica foi possível utilizar os métodos matemáticos com o intuito de identificação de dano, sendo eles o MAC, COMAC, DCM e ID e desta maneira analisar além da variação da rigidez, a localização e a magnitude dos danos ocorridos nas vigas.

As conclusões do estudo foram elaboradas individualmente para os prismas, vigas e ensaios não destrutivos, ponderando a relação entre os efeitos observados nos ensaios destrutivos com os resultados das análises modais dos ensaios não destrutivos. 


\section{REVISÃO BIBLIOGRÁFICA}

Uma revisão bibliográfica foi desenvolvida com a finalidade de compreender todas as etapas necessárias para o estudo de reforço ao cisalhamento em vigas com CFRP e análise modal de estruturas. Esta teve como foco o estudo de normas, apostilas, artigos e teses atuais sobre os assuntos e foi realizada de maneira continua até o fim do doutorado.

Para uma melhor compreensão dos estudos relacionados sobre esta pesquisa a revisão bibliográfica foi dividida em duas (2) linhas de estudo essenciais utilizadas nesta tese, sendo elas: reforço em vigas com CFRP; análise modal de estruturas.

\subsection{REFORÇO EM VIGAS COM CFRP}

O estudo das ciências dos materiais tem evoluído na criação de novos materiais específicos para a engenharia, onde na última década tem havido grande procura por materiais muito resistentes, duráveis, pouco deformáveis e capazes de absorver e dissipar energia, sem ocorrência de ruptura frágil e sem patamar de escoamento. (JUVANDES 2002)

Beber (2013) explica em seu trabalho as diferenças entre os principais materiais utilizados para sistemas de reforço em estruturas de concreto, verificando que as formas de componentes mais usadas dos reforços são fibras, partículas, lâminas, flocos, fillers e matrizes. Dentre todos os tipos de compósitos, os Fiber Reinforced Polimer (FRP), têm atraído a atenção de muitos pesquisadores envolvidos com aplicações na engenharia estrutural. A resistência e a rigidez dos compósitos de FRP dependem, basicamente, do tipo de fibra, da matriz polimérica e da interface entre estas duas. Construir fibras envolve alinhar as moléculas do material, resultando em alta resistência à tração. As principais fibras utilizadas comercialmente em aplicações na engenharia civil, incluindo também os concretos reforçados com fibras, são as de vidro, carbono e aramida.

\subsubsection{Reforço com Técnica EBR}

Diversos trabalhos apresentam formulações e resultados com os benefícios de sistemas de reforço com a técnica EBR, a sua compreensão é fundamental para a comparação com a técnica de reforço com NSM. Assim são apresentados alguns estudos mostrando quão evoluídos encontrase o conhecimento das técnicas EBS de reforço com CFRP.

Algumas normas internacionais já apresentam instruções para o correto uso de CFRP como reforço em estruturas de concreto. Em 2001 o Comité Euro International du Béton (CEB) 
publicou boletim com diretrizes de projeto para o uso de reforço de CFRP, de acordo com o formato do projeto do código modelo CEB-FIP e Eurocode2, o Fib bulletin 14 (2001).

O American Concrete Institute, em 2001, publicou artigo como um guia para o projeto e construção de concreto estrutural reforçado com barras de CFRP, o ACI 440. Este vem sendo atualizado com a última versão em 2008, com o ACI 440.2R (2008). A norma americana descreve um breve histórico de uso de CFRP, as suas propriedades físicas e mecânicas, métodos de aplicação e metodologia de cálculo para o uso de CFRP como reforço de estruturas de concreto. O reforço previsto no ACI permite a sua utilização em vigas à flexão e ao cisalhamento. Entretanto para o uso da técnica NSM, prevê apenas a flexão. No artigo são descritos exemplos de cálculo de:

$\checkmark$ Reforço à flexão de viga de concreto armado com laminados colados de CFRP;

$\checkmark$ Reforço à flexão de viga de concreto armado com a técnica NSM;

$\checkmark$ Reforço à flexão de uma viga de concreto protendido com laminados CFRP;

$\checkmark$ Reforço ao cisalhamento de viga T;

$\checkmark$ Reforço ao cisalhamento de pilar;

$\checkmark$ Reforço de pilar de concreto não circular para aumento de forças axiais e de flexão.

Beber (2013) em sua pesquisa, sugere uma formulação para o dimensionamento de viga com reforço com CFRP à flexão, considerando, segundo a norma ABNT NBR 6118:2007, uma análise do estado limite último, pela combinação do equilíbrio de tensões, compatibilidade de deformações e leis constitutivas dos materiais na ruptura. Devendo para o dimensionamento proposto os procedimentos de cálculos necessários por meio de métodos interativos, seguindo o fluxograma apresentado na Figura 2.2. Ressalta ainda que para devida comparação com os ensaios experimentais o efeito Rush e os coeficientes de segurança devem ser desconsiderados. A Figura 2.1 mostra as distribuições de tensões e deformações, de uma seção reforçada como determinado pelo pesquisador.

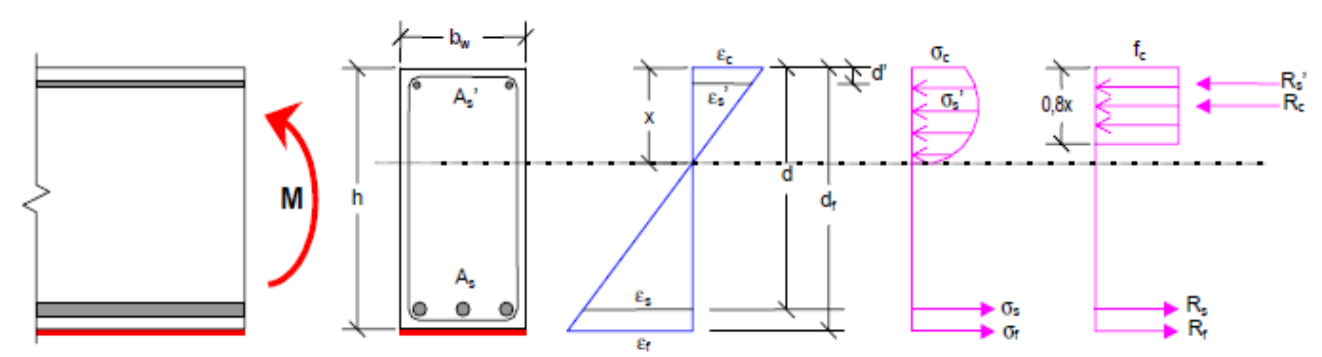

Figura 2.1 - Diagrama esquemático do equilíbrio da seção transversal reforçada por Beber (2013) 


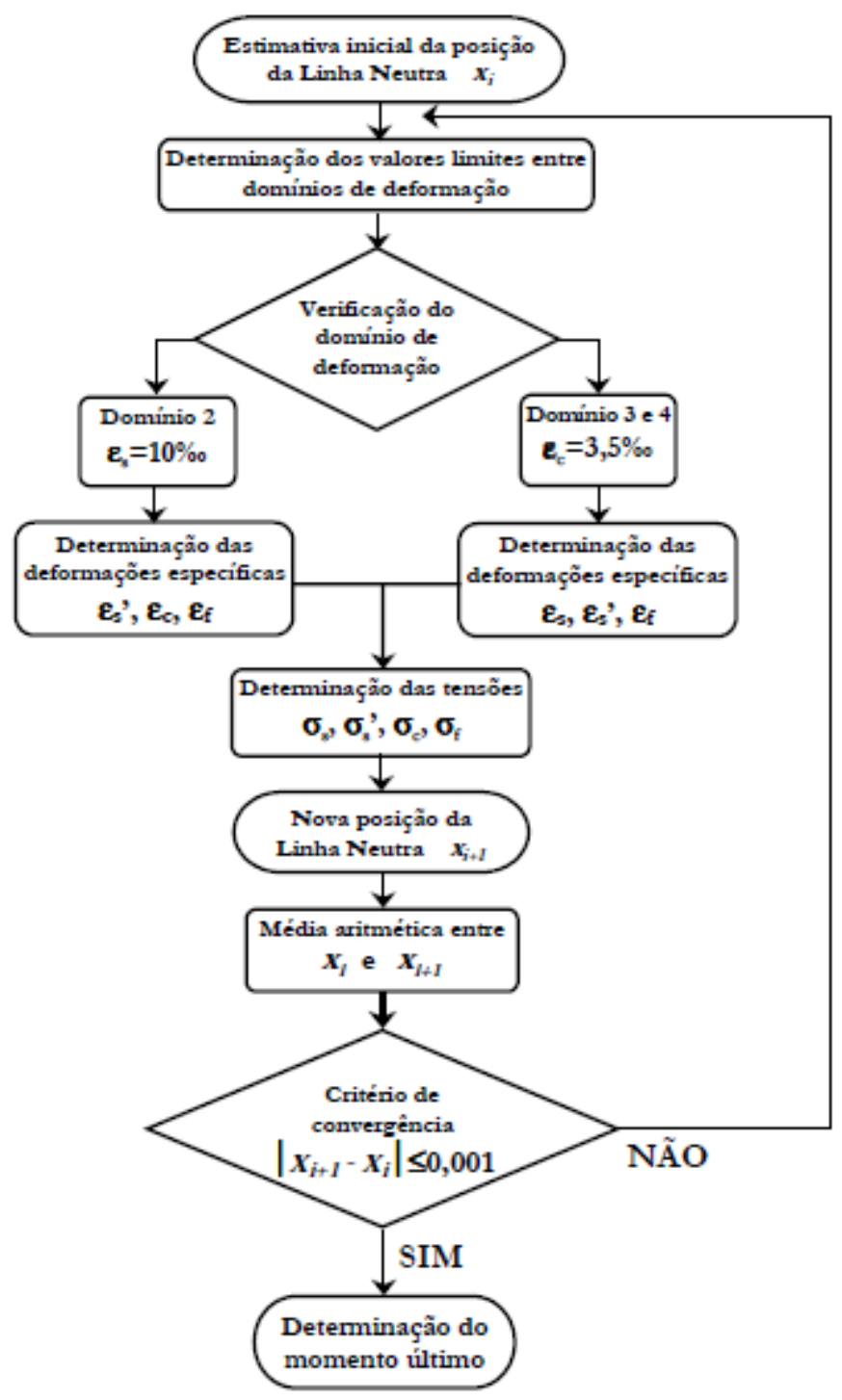

Figura 2.2 - Fluxograma de cálculo de vigas reforçadas por Beber (2013)

Infelizmente, segundo Beber (2013) o uso de sistemas de reforço com CFRP é feito na sua maioria com material importado, aumentando o custo e tempo de execução. Atualmente já são vendidas no Brasil reforços em forma de laminados, dentre as empresas observou-se que a empresa Sika S.A. possui laminados de polímero reforçado com fibras de carbono para reforço de estruturas de concreto, madeira e alvenaria.

A empresa Sika S.A. desenvolveu ainda um programa de dimensionamento de sistemas de reforço de CFRP para vigas e pilares de concreto, utilizando como formulação o Fib bulletin 14 (2001), podendo verificar a quantidade de reforço a ser utilizada na flexão, cisalhamento de vigas e no confinamento de pilares. O desenvolvimento de programas para a utilização de reforços de CFRP mostra o avanço desenvolvido a nível internacional. 
O programa desenvolvido contempla somente o reforço com aplicação convencional, com a colagem dos laminados e mantas de CFRP, não sendo adequado para a técnica NSM utilizada nesta tese. A Figura 2.3 apresenta a interface gráfica do programa para as hipóteses de reforça à flexão e ao cisalhamento.

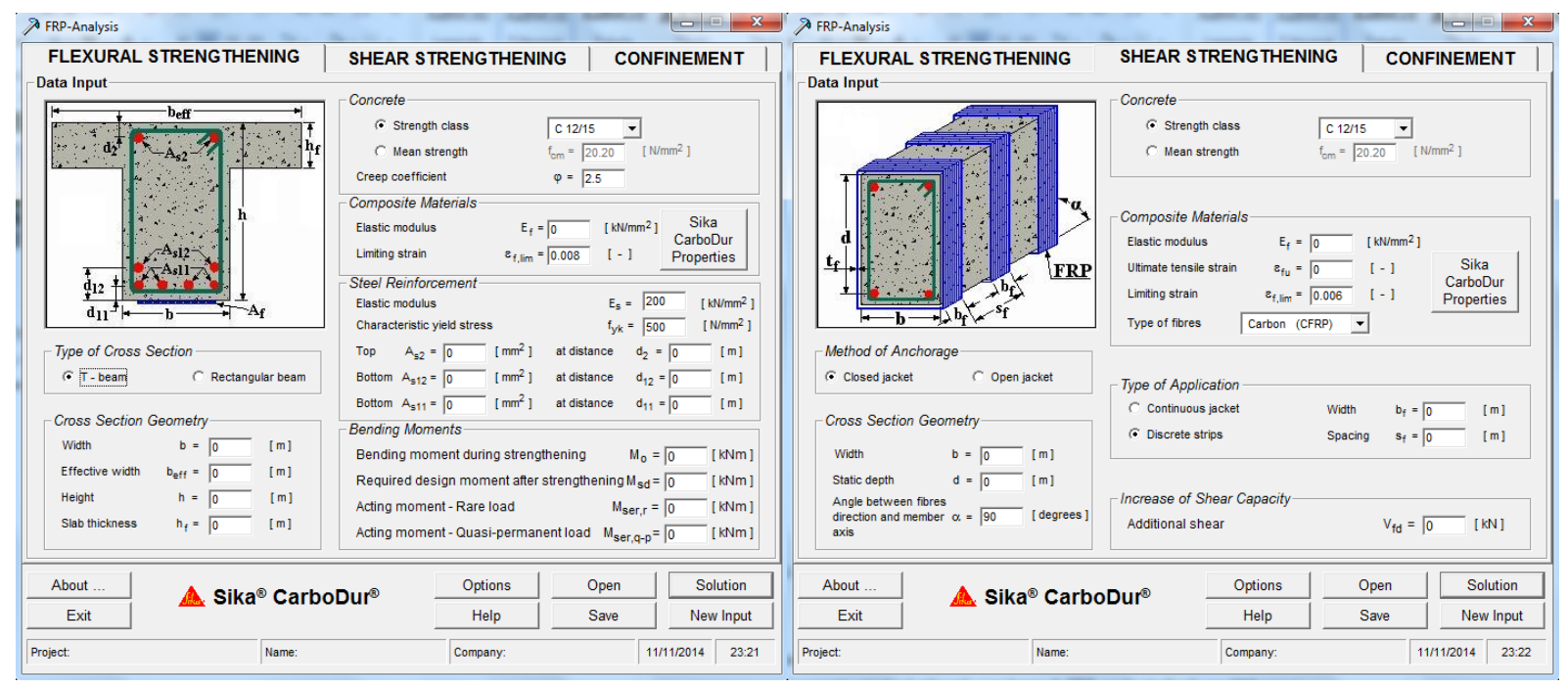

Figura 2.3 - Interface gráfica do programa de dimensionamento de reforços com CFRP da Sika

Jayaprakash et al. (2008) realizou estudos experimentais em vigas retangulares reforçadas ao cisalhamento com aplicação de CFRP, com a técnica EBR, estudando o carregamento prévio e, tendo obtido resultados diversificados, com acréscimos da capacidade de carga última entre 11 e $139 \%$. Os pesquisadores observaram que o espaçamento entre as faixas de reforço possui grande influência em vigas que sofreram carregamento prévio e afirmam que o uso de CFRP com fibras em duas direções é mais eficiente, pois a técnica reduz a quantidade de material e o custo total do reparo.

Khalifa (1999) desenvolveu estudos com sistemas de reforço de CFRP ao cisalhamento com mantas coladas em vigas de concreto em várias configurações, alternando orientação das fibras, posicionando de forma intercalada e contínua, reforçando apenas as laterais ou toda a seção transversal. Utilizou para isso vigas com seção transversal retangular e "T", observando que o sistema de reforço apresentou eficiência em viga independentemente da seção transversal, aumentando a força de ruptura das vigas (Figura 2.4). O pesquisador concluiu que o benefício do sistema de reforço está diretamente relacionado com a sua ancoragem, em que a ruptura ocorre sem que o reforço de CFRP obtenha sua tensão máxima devido à concentração de tensão e ao destacamento da superfície do concreto.

Estudos mais específicos com o intuito de melhorar a deficiência da ancoragem no uso de sistemas de reforço com a técnica EBR foram realizados por Khalifa el al. (2000). Estes, 
realizaram ensaios experimentais em vigas de concreto armado de seção "T" reforçadas com CFRP, pesquisando as influências da rugosidade da superfície do concreto antes do reforço ao cisalhamento com mantas de CFRP. Concluíram que os métodos usuais de preparo da superfície com mantas coladas apresentam resultados satisfatórios independente dos diferentes graus de rugosidade da superfície do concreto, afirmando ainda ser mais importante o uso de mantas com maiores módulos de elasticidade que a rugosidade da superfície do concreto.

Alguns pesquisadores brasileiros já desenvolvem estudos no uso de CFRP como sistema de reforço juntamente a simulação computacional em programas de elementos finitos. Gamino (2007), ensaiou vigas de concreto com mantas coladas como reforço ao cisalhamento e comparou seus resultados experimentais com vários métodos de cálculo de vigas reforçadas com CFRP disponíveis na literatura. O pesquisador realizou ainda modelagem computacional nos programas DIANA $®$, FEMOOP $®$ e QUEBRA2D $®$, obtendo resultados similares entre os programas e com o ensaio experimental.

Gamino (2007), realizou em seu trabalho ensaios experimentais em vigas com seções retangulares e "T" com sistema de reforço de mantas de CFRP à flexão e ao cisalhamento, onde praticamente todas as vigas ensaiadas possuíam mecanismos de colapso por destacamento da camada de reforço de fibra de carbono. Concluiu que algumas das respostas encontradas no DIANA® indicavam um modelo numérico mais rígido que o modelo físico, sobretudo devido aos modelos de aderência (aço/concreto e CFRP/concreto) disponível no programa, causando um enrijecimento da estrutura, principalmente para forças de serviço.

\subsubsection{Reforço com Técnica NSM}

O estudo de reforço em estruturas de concreto com o uso de CFRP atualmente já é desenvolvido por pesquisadores e empresas especializadas em recuperação de estruturas. Para este trabalho realizou-se uma revisão dos estudos realizados em vigas quando utilizado o sistema de reforço com a técnica NSM.

Diversos pesquisadores, tais como Fortes et al. (2003) realizaram estudos comparativos entre formas de reforço com CFRP em vigas de concreto à flexão, com mantas de CFRP coladas na superfície (EBR), com laminados colados na superfície ou com laminados inseridos no concreto (NSM). Os pesquisadores apontam que o uso da técnica NSM é mais eficiente que as demais, apresentando maior capacidade de acréscimo de força nas estruturas. Destacam que a eficácia do 
sistema de reforço diminui com o aumento da taxa de armadura convencional e com a redução do número de laminados inseridos.

No mesmo artigo de Khalifa el al. (2000), foi estudado um método em que barras de CFRP são inseridas no cobrimento do concreto (NSM), como uma alternativa para melhorar a ancoragem. Como conclusão, a técnica apresentou bons resultados, com o aumento na capacidade de resistências das vigas, mas com a ruptura ainda permanecendo no + /destacamento do epóxi de ligação do CFRP com o concreto (Figura 2.5).

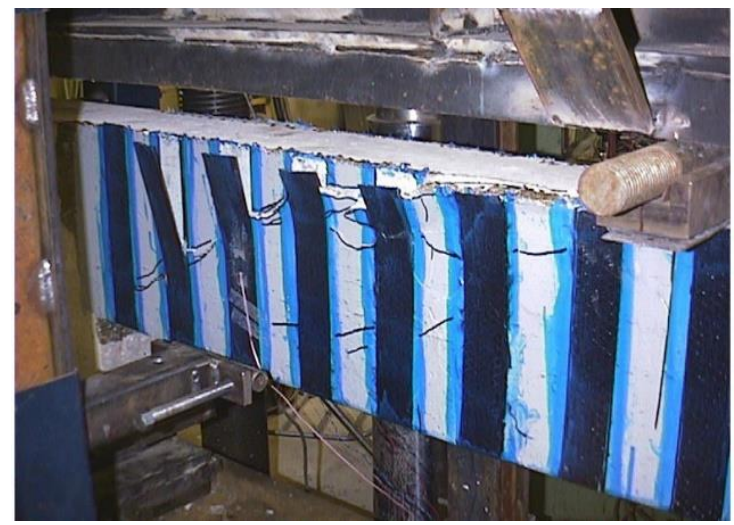

Figura 2.4 - Ensaios de Khalifa (1999) com reforço em mantas de CFRP

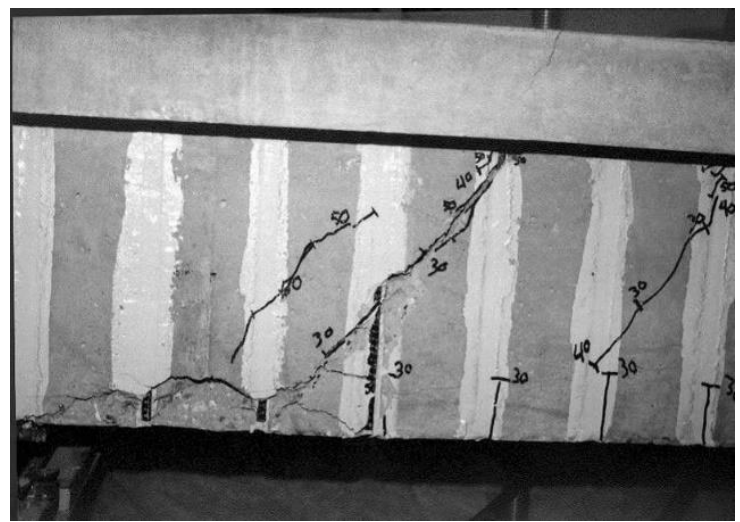

Figura 2.5 - Ensaios de Khalifa et al (2000) com reforço em NSM

De Lorenzis e Nanni (2001) apresentam o artigo, fazendo uma revisão dos trabalhos recentes e explicando a comunidade científica a técnica NSM com barras de CFRP. Utilizando os resultados experimentais de uma série de vigas de seção " $T$ " e apresentando formulação para previsão da parcela resistente do reforço. Para o cálculo destaca duas hipóteses; com o descolamento da ligação entre o reforço e o concreto e com a ruptura das barras de CFRP.

A mesma pesquisadora, em 2006, apresenta uma revisão das pesquisas desenvolvidas com o uso da técnica NSM. O artigo fornece uma revisão crítica das pesquisas existentes nessa área, identificando as lacunas de conhecimento e descrevendo as direções para futuras pesquisas (DE LORENZIS; TENG, 2006).

Em Portugal, a aplicação da técnica NSM com laminados de CFRP no reforço de estruturas de concreto vem sendo estudada no Departamento de Engenharia da Universidade do Minho no âmbito do reforço à flexão de pilares, vigas e lajes. Dias (2008), pesquisador de grande relevância na área de sistema de reforço com CFRP, afirma que o reforço à flexão e o confinamento de pilares com compósitos de CFRP apresentam, atualmente, um estado de conhecimento confortavelmente aprofundado, fato que não acontece em relação ao uso de reforço ao cisalhamento com CFRP. 
A técnica NSM consiste em inserir barras ou laminados de CFRP no cobrimento do concreto, servindo como uma segunda armadura para este concreto. Este método segundo Dias (2008) apresenta diversas vantagens em relação à técnica usual de colagem externa de CFRP (NSM). Entre elas estão:

$\checkmark$ Melhor aderência das fibras com o concreto, pois possui mais que o dobro de área de contato;

$\checkmark$ Melhor aproveitamento da resistência das fibras, pois na técnica convencional ocorre com maior frequência o descolamento das mantas e laminados de CFRP colados externamente;

$\checkmark$ Maior proteção das fibras, que ficam inseridas no concreto e não na face;

$\checkmark$ Facilidade e rapidez de aplicação.

Dias (2008), estudou exaustivamente vigas “T”' de concreto com reforço de CFRP em NSM e em manta (EBR), variando a resistência do concreto, a taxa de armadura ao cisalhamento, a taxa de reforço, a orientação do reforço e a aplicação de carregamento prévio.

Obteve resultados positivos para todos os sistemas de reforço utilizados, com aumento da força máxima, tendo como melhores resultados a técnica NSM do que quando utilizado mantas coladas (EBR), recomendando a orientação inclinada das barras, tanto em 45 graus como 60 graus em relação a vertical. Fez também um estudo detalhado das formas de ruptura e uma formulação numérica para avaliação do desempenho do reforço com CFRP (Figura 2.6).
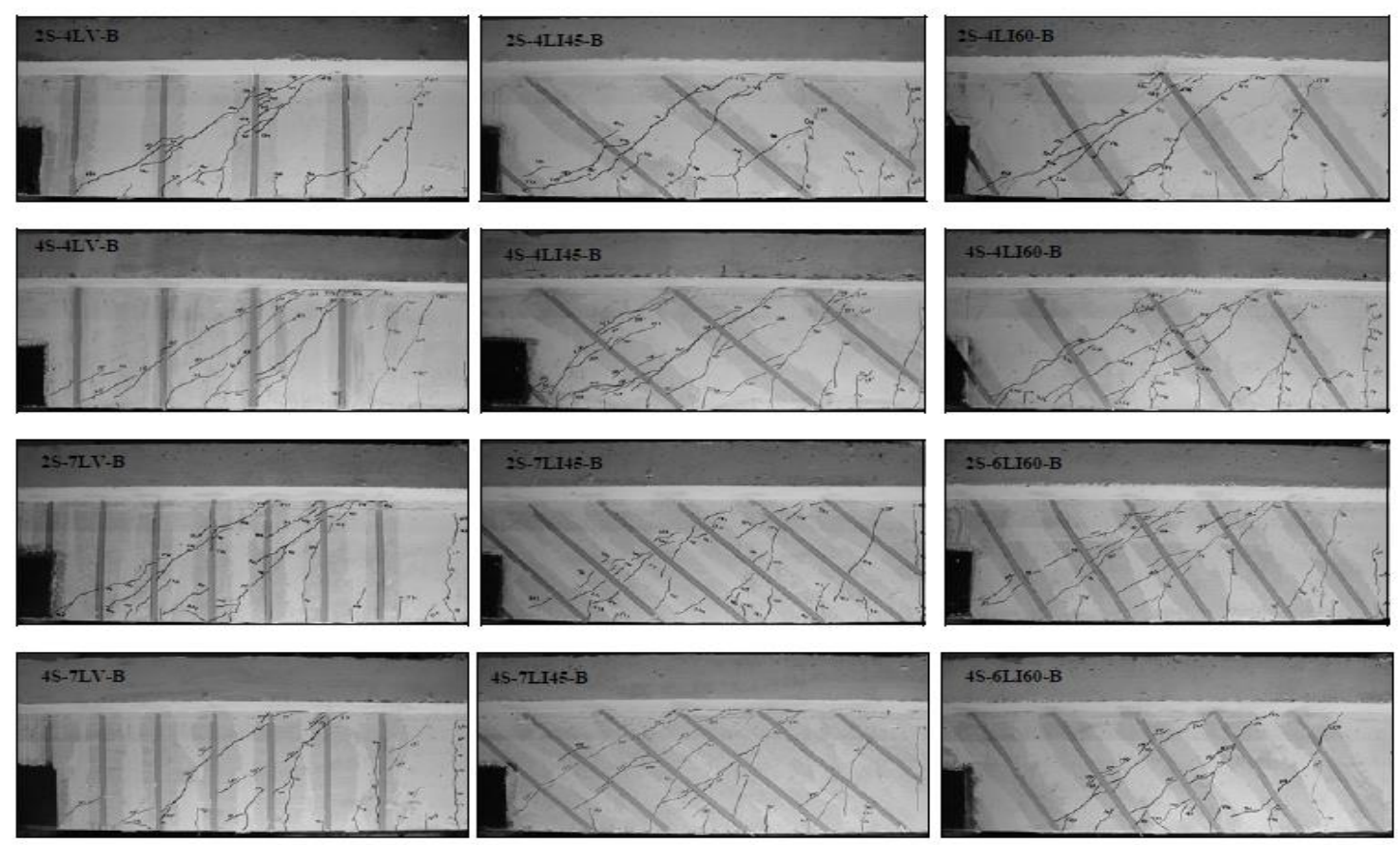

Figura 2.6 - Ensaios de Dias (2008) com reforço em NSM com diferentes ângulos 
Outras pesquisas na Universidade do Minho com sistemas de reforço utilizando a técnica NSM vem sendo desenvolvidas em lajes. Nestas, destacam-se os trabalhos de Bonaldo (2008) e em seguida Dalfré e Barros (2012) que realizam ensaios experimentais com reforço em lajes contínuas utilizando a técnica NSM. Estes trabalhos foram desenvolvidos com o objetivo de ampliar a capacidade de carga por meio de reforço à flexão posicionados nas regiões de momento positivos e negativos. A técnica mostrou-se eficiente também para elementos esbeltos, como lajes, ampliando suas capacidades de força e deformação.

Em nível mundial, o uso de CFRP vem evoluindo, passando de pesquisa, para aplicações práticas, desde a recuperação de pontes e viadutos a construção de elementos estruturais exclusivamente de CFRP. Correia (2012), apresenta pontes e obras utilizadas em Portugal, construídas de elementos em estruturas mistas com concreto e CFRP ou ainda em estruturas 100\% feitas de compósitos de GFRP.

No Brasil, poucas pesquisas com a técnica NSM vem sendo desenvolvidas. Menon e Padaratz (2006), realizaram estudos com a técnica NSM em reforço ao cisalhamento de vigas de concreto, variando unicamente a forma de inserção do laminado entre espessura e largura. Concluíram que a técnica de reforço NSM apresenta melhor eficiência quando os laminados são inseridos na sua espessura, ocorrendo assim uma maior aderência com o concreto.

Arquez (2010), estudou o reforço em vigas de concreto com o uso do NSM, de uma forma diferenciada, utilizando uma técnica que consiste em retirar parte do concreto fissurado e substitui-lo por um concreto de alta resistência e com adição de fibras metálicas. A pesquisadora conclui, que o uso das duas técnicas em conjunto é bastante eficiente, pois além de elevar a capacidade de carga e a rigidez das vigas, a sua forma de ruptura se torna mais dúctil, fato incomum em sistemas de reforço de vigas. Em sua dissertação destacam-se ensaios de aderência de laminados de CFRP ao concreto coladas com resina epóxi, uma vez que no ensaio de arranchamento ela é o material mais frágil.

Alguns pesquisadores já desenvolve o uso de sistema de reforço juntamente com a protensão do concreto. Um exemplo é a pesquisa de Garcezi et al. (2012), com o objetivo de utilizar o reforço de CFRP com um melhor aproveitamento, investigaram a eficiência do seu uso com protensão. Os pesquisadores destacam que mesmo com a protensão em diversos estudos com análise de ensaios experimentais, frequentemente ocorrem rupturas prematuras nas estruturas reforçadas, sem o esgotamento da capacidade resistente do CFRP.

Atualmente, não existem normas especificas para a uso de sistemas de reforço ao cisalhamento pela técnica NSM, sendo as normas Europeia Fib bulletin 14 (2001) específicas 
apenas para reforço em vigas com técnica EBR e a norma Norte Americana ACI 440.2R (2008) considera o sistema de reforço pela técnica NSM apenas para a flexão. Alguns pesquisadores como, De Lorenzis e Nannin (2011), Dias (2008) elaboraram formulações para a determinação da parcela resistente do sistema de reforço ao cisalhamento utilizando a técnica NSM.

As formulações estudadas não são baseadas nas normas internacionais já apresentadas, tendo como principal analise a deformação efetiva do laminado $\left(\varepsilon_{\mathrm{fe}}\right)$. Segundo Dias (2008), a inclinação do sistema de reforço ao cisalhamento influencia na deformação especifica e deve ser calculada segundo a Equação 2.1 para a inclinação 45 graus, pela Equação 2.2 para laminados com a inclinação 60 graus e pela Equação 2.3 para laminados com a inclinação 90graus. Em suas formulações o pesquisador considera que vigas sob sistema de reforço apresentam menores níveis de mobilização da armadura transversal quando comparado com vigas sem sistema de reforço.

$$
\begin{aligned}
& \varepsilon_{f e}=0,1685 \cdot\left[\frac{\left(E_{f} \cdot \rho_{f}\right)+\left(E_{s} \cdot \rho_{s w}\right)}{\left(f_{c m}^{2 / 3}\right)}\right]^{-1,117} \\
& \varepsilon_{f e}=0,153 \cdot\left[\frac{\left(E_{f} \cdot \rho_{f}\right)+\left(E_{s} \cdot \rho_{s w}\right)}{\left(f_{c m}^{2 / 3}\right)}\right]^{-1,102} \\
& \varepsilon_{f e}=0,5162\left[\frac{\left(E_{f} \cdot \rho_{f}\right)+\left(E_{s} \cdot \rho_{s w}\right)}{\left(f_{c m}^{2 / 3}\right)}\right]^{-0,675}
\end{aligned}
$$

Onde:

$\mathrm{E}_{\mathrm{f}}=$ Módulo de elasticidade do Laminado de CFRP em GPa

$\mathrm{E}_{\mathrm{s}}=$ Módulo de elasticidade do aço de CFRP em GPa

$\mathrm{f}_{\mathrm{cm}}=$ Resistência média à compressão do concreto em $\mathrm{MPa}$

$\rho_{\mathrm{f}}=$ Taxa de reforço ao cisalhamento do CFRP

$\rho_{\mathrm{s}}=$ Taxa de armadura transversal

\subsection{ANÁLISE MODAL DE ESTRUTURAS}

Os estudos do comportamento de estruturas através de ensaios não destrutivos estão se tornando mais frequentes e permitem avaliar principalmente as frequências naturais, os modos de vibração, o amortecimento e a rigidez das estruturas.

Salawu e Williams (1993), fizeram uma análise crítica sobre o uso da análise dinâmica em estruturas de concreto em larga escala. Seu estudo mostra que o uso da análise dinâmica é bastante empregada há muitos anos e destaca alguns motivos para realizar estas análises, entre eles:

$\checkmark$ Medições dinâmicas sobre uma estrutura em larga escala servem para aumentar a base de dados sobre o comportamento dinâmico de estruturas similares; 
$\checkmark$ Determinar a integridade de uma estrutura após a ocorrência de uma sobreforça;

$\checkmark$ Validar modelos teóricos de estruturas;

$\checkmark$ Avaliar a integridade de uma estrutura, quando os níveis de força mais elevados estão previstos;

$\checkmark$ Monitoramento da condição geral de uma estrutura, por meio de medição habitual da sua resposta dinâmica.

Nepomuceno (1999), fez uma revisão sobre os principais métodos de ensaios não destrutivos. Neste trabalho é destacado o ultrassom por não causar danos na superfície do concreto. A técnica deste ensaio fundamenta-se basicamente na medição do tempo de percurso que uma onda ultrassônica atravessa o concreto numa determinada extensão conhecida. $\mathrm{O}$ resultado final é expresso em termos de velocidade de propagação dos ultrassons em $\mathrm{km} / \mathrm{s}$, calculado a partir da razão entre o comprimento e o tempo gasto no percurso. Por este método o Módulo de elasticidade medido por ensaio dinâmico pode ser calculado conforme a Equação 2.4.

$$
E_{d}=\rho \cdot V^{2} \cdot \frac{\left(1+v_{d}\right) \cdot\left(1-2 \cdot v_{d}\right)}{1-v_{d}}
$$

Onde:

$\mathrm{E}_{\mathrm{d}}=$ Módulo de elasticidade medido por ensaio dinâmico $\left[\mathrm{MN} / \mathrm{m}^{2}\right]$;

$v_{\mathrm{d}}=$ Coeficiente dinâmico de Poisson;

$\rho=$ Densidade, $\mathrm{em}\left[\mathrm{kg} / \mathrm{m}^{3}\right]$;

$\mathrm{V}=$ Velocidade dos ultrassons, em $[\mathrm{km} / \mathrm{s}]$.

Existem diversos tipos de ensaios não destrutivos específicos para o estudo da resistência do concreto. Raramente mede-se diretamente a propriedade de interesse, mas sim propriedades a elas relacionadas como as frequências naturais, tempo e velocidade. A confiabilidade dos ensaios não destrutivos depende fortemente da correlação entre a propriedade de interesse e a propriedade realmente medida.

O estudo de ensaios não destrutivos na USP de São Carlos, na área de engenharia de estruturas civis, já iniciou com alguns trabalhos. O estudo de Almeida (2005) utilizou ensaios dinâmicos em corpos de prova e vigas de concreto medindo a rigidez dos elementos em estado íntegro e danificado. Concluindo que em função do aumento da fissuração macroscópica, em diferentes estágios de solicitação o módulo de elasticidade de vigas com grande fissuração reduz em média 63,3\% em relação à viga no estado íntegro.

A mesma pesquisadora durante sua tese (ALMEIDA, 2010) desenvolveu um método para a identificação da Rigidez em elementos de ligação em escala reduzida, utilizando ensaios dinâmicos 
com acelerômetros piezoelétricos. Em sua pesquisa utilizou diversos métodos de ensaio para obter os seus resultados, sendo eles:

$\checkmark$ Vibração livre, com medição da entrada de dados (impacto) e de saída (aceleração), tendo obtido as frequências naturais e os amortecimentos dos modelos;

$\checkmark$ Vibração forçada, com os elementos engastados aplicou sinal aleatório com excitador, obtendo a aceleração e a primeira frequência natural;

$\checkmark$ Vibração forçada para a determinação da força dinâmica, aplicando com excitador a primeira frequência natural e captando a força no sinal de saída;

$\checkmark$ Vibração forçada para a determinação da rigidez da ligação, utilizando dois acelerômetros e excitador aplicando sinal senoidal.

A pesquisadora obteve boa relação das rigidezes entre os ensaios físicos e dinâmicos, além de observar as variações nas frequências naturais e nos amortecimentos ocorridos após a ruptura das estruturas. Almeida (2010) atenta na época para a falta de um programa computacional específico para análise modal experimental no Laboratório de Estruturas da EESC, principalmente quanto à quantidade de canais do sistema de aquisição de dados dinâmicos. Atualmente o referido Laboratório possuí um software LabVIEW SignalExpress ${ }^{\circledR}$ com sistema de aquisição de dados e capacidade de nove (9) canais de aquisição, ampliando sua capacidade de pesquisas com ensaios dinâmicos.

Diógenes et al. (2011) investigaram a relação entre o modulo de elasticidade estático e dinâmico de corpos de prova e prismas de concreto. Para isso utilizaram um equipamento para a caracterização não destrutiva dos módulos de elasticidade de materiais a partir das frequências naturais de vibração, obtidas por um programa que utiliza a técnica de excitação por impulso, o Sonelastic ${ }^{\circledR}$. A Figura 2.7 apresenta o princípio de funcionamento deste equipamento. 


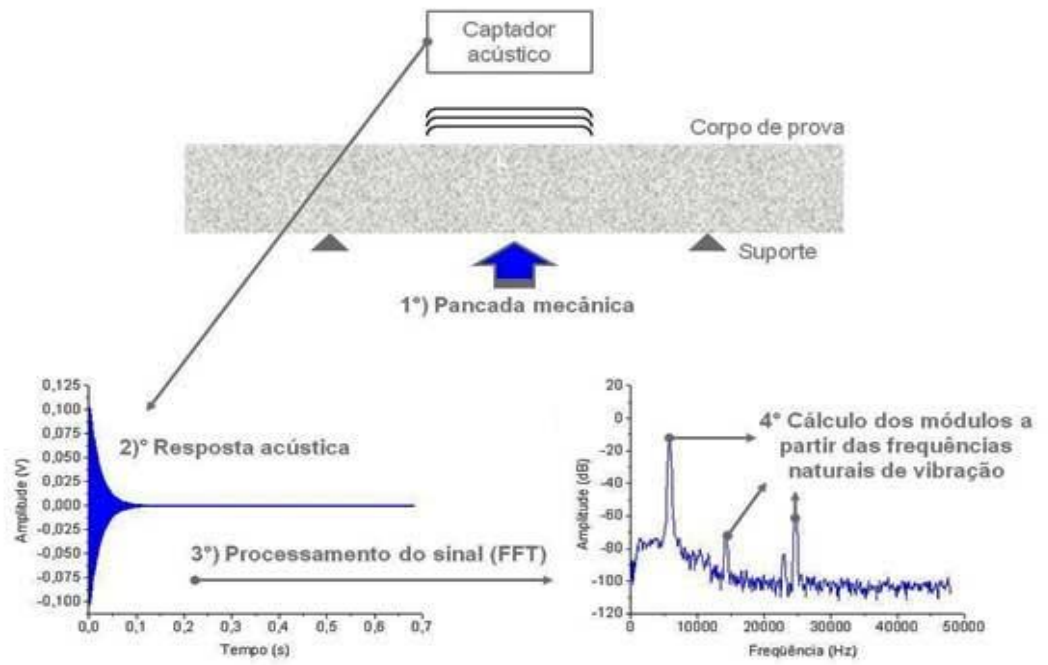

Figura 2.7 - Princípio de funcionamento do Sonelastic ${ }^{\circledR}$ fonte: ATCP (2014)

Para geometrias simples existe uma relação matemática entre as frequências naturais de vibração com as dimensões e a massa do corpo de prova, parâmetros que podem ser facilmente medidos com um paquímetro e uma balança. Conhecendo-se as dimensões, a massa e as frequências naturais de vibração, o cálculo do módulo de elasticidade é imediato, em que o programa realiza automaticamente conforme a formulação da norma ASTM C215 (2008) descrita no capitulo Materiais e Métodos. Podendo ainda ser calculado o amortecimento nesse sistema de aquisição a partir do decremento logarítmico da amplitude de vibração, a partir da taxa de atenuação do sinal.

Os pesquisadores destacam a facilidade de uso do equipamento, em que a resposta acústica do corpo de prova é capturada empregando um captador acústico (microfone), ao invés da utilização de um acelerômetro fixado ao corpo de prova, como ocorre na maioria dos sistemas de aquisição convencionais para ensaios não destrutivos. Por não demandar de fixação de sensores, o emprego do captador acústico facilita ainda mais a montagem do aparato de ensaio. Outro aspecto importante desse sistema, consiste em não demandar hardwares adicionais, pelo fato de serem utilizadas as placas de áudio já disponíveis nos computadores atuais.

Com os resultados obtidos por Diógenes et al. (2011), foi obtida uma relação entre os módulos de elasticidade medidos no ensaio dinâmico e estático, sendo em média de 1,204 para corpo de prova cilíndricos e de 1,265 para prismas de concreto.

Diógenes (2013) utilizou acelerômetros piezoelétricos para determinar as frequências naturais e os modos de vibração num estudo experimental de estruturas mistas com ligações por aderência aço-concreto. Em seu estudo, Diógenes destaca a dificuldade de se determinar as frequências naturais corretas para as vigas devido a quantidade demasiada de frequências naturais 
até $200 \mathrm{~Hz}$. Como solução, o pesquisador utilizou a terceira frequência natural à flexão para a análise do comportamento vibracional. A Figura 2.8 apresenta as frequências naturais de uma de suas vigas nas configurações íntegra e após a ruptura, enquanto que a Figura 2.9 mostra o modelo computacional desenvolvido pelo pesquisador no terceiro modo de vibração das vigas.
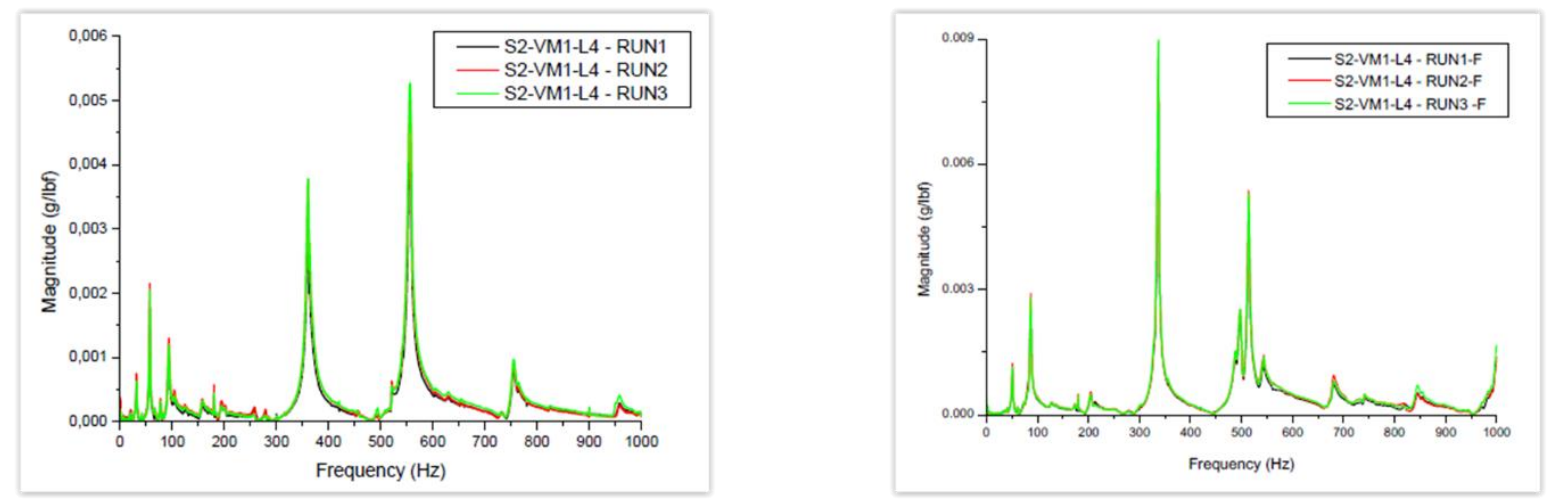

Figura 2.8 - Espectros íntegro e rompido de Diógenes (2013)

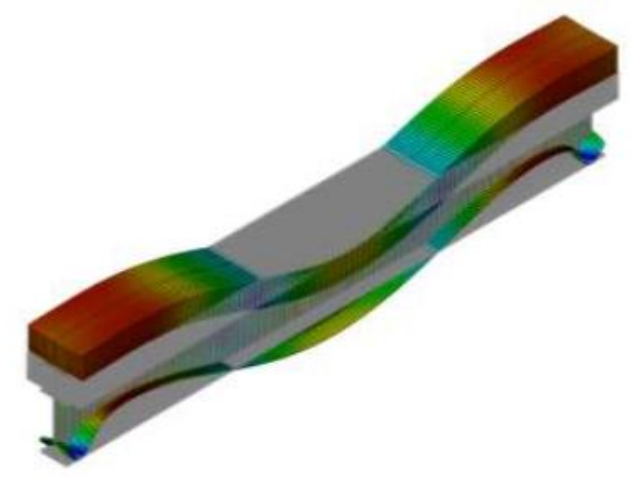

Figura 2.9 - $3^{\circ}$ modo de vibração flexional da viga de Diógenes (2013)

A maioria das técnicas de identificação modal é elaborada com a realização de ensaios com forças controladas aplicadas a análise modal experimental com controle e medição das forças de excitação, esta análise é denominada de identificação modal clássica (RODRIGUES, 2004). Em estruturas com grandes dimensões, como as estruturas de engenharia civil, também é possível aplicar análises de identificação modal clássica. Os equipamentos utilizados para excitação das forças controladas em estruturas civis são de grandes dimensões, o que acarreta em um grande custo de execução nesse tipo de ensaio. Outro problema na utilização desses equipamentos é a necessidade de interrupção de funcionamento, causando muitos transtornos aos usuários, como interrupção de fluxo em pontes ou a evacuação de um edifício.

Segundo Juliani (2014), para o método de identificação modal estocástica, a entrada no sistema não é medida e deve ser considerada uma hipótese em que as forças são idealizáveis por 
um processo estocástico gaussiano de tipo ruído branco, de densidade espectral constante, com média nula.

Diversos estudos como o de Felber (1993), apresentam a dedução da equação da auto densidade espectral cruzada, conforme a Equação 2.5, onde $G_{\mathrm{ij}}(\mathrm{w})$ é o quadrado da magnitude dos valores complexos de aceleração $\ddot{X}_{j}(w)$ e seu complexo conjugado $\ddot{X}_{i^{*}}(w)$, onde i e j são graus de liberdade.

É possível estimar os modos de vibração pela transmissibilidade fornecida pela relação entre, a parte real da auto densidade espectral cruzada e pela auto densidade espectral da posição de referência. Conforme a Equação 2.6.

$$
\begin{aligned}
& G_{i j}(w)=\ddot{X}_{i}^{*}(w) \cdot \ddot{X}_{j}(w) \\
& T R(w)=\frac{\operatorname{real}\left(G_{i j}(w)\right)}{G_{i j}^{1}(w)}
\end{aligned}
$$

Juliani (2014), destaca em seu estudo, métodos de identificação de dano analisando os dados dos vetores modais obtidos no modo de vibração. Os quatro métodos utilizados pelo pesquisador foram adotados nesta pesquisa, sendo eles: Modal Assurance Criterion (MAC) e Coordinate Modal Assurance Criterion (COMAC), Diferença de Curvatura Modal (DCM) e Índice de Dano (ID). Estes métodos são aqui descritos e equalizados conforme explicado pelo pesquisador.

O MAC, desenvolvido por Allemang e Brown (1982), fornece uma medida de consistência entre estimativas de vetores modais, permitindo que vetores modais experimentais das situações íntegra e nas demais sejam comparados entre si. Com o resultado, coeficiente 1 indica que não houve alteração nos vetores modais e o coeficiente 0 indica que os vetores modais comparados são ortogonais entre si, indicando que não existe relação entre os vetores modais.

Para a determinação do coeficiente MAC é utilizada a equação 2.7:

$$
\operatorname{MAC}_{(i j)}=\frac{\mid\left\{\phi_{i}^{a}\right\}^{T} \cdot\left(\phi_{j}^{e}\right\}^{e}}{\left(\left\{\phi_{i}^{a}\right\}^{T} \cdot\left\{\phi_{i}^{a}\right\}\right) \cdot\left(\left\{\phi_{j}^{e}\right\}^{T} \cdot\left\{\phi_{j}^{e}\right\}\right)}
$$

Onde:

$\left\{\phi_{i}^{a}\right\}=$ vetor modal íntegro referente ao modo de vibração i 
$\left\{\phi_{j}^{e}\right\}=$ vetor modal danificado referente ao modo de vibração j

O coeficiente COMAC (LIEVEN; EWINS, 1988), correlaciona dois vetores modais para cada modo de vibração considerado, realizando um somatório entre essas correlações em cada local de controle das acelerações. Funciona como uma extensão do coeficiente MAC, identificando quais locais de medição contribuem para um baixo valor do MAC. Assumem valores entre 0 e 1.

Para a definição do COMAC é utilizada a Equação 2.8

$$
\operatorname{COMAC}_{(j)}=\frac{\left(\sum_{i=1}^{n}\left\{\phi_{i}^{a}\right\}_{j} \cdot\left\{\phi_{i}^{e}\right\}_{j}\right)^{2}}{\left(\sum_{i=1}^{n}\left\{\phi_{i}^{a}\right\}_{j} \cdot\left\{\phi_{i}^{a}\right\}_{j}\right)\left(\sum_{i=1}^{n}\left\{\phi_{i}^{e}\right\}_{j} \cdot\left\{\phi_{i}^{e}\right\}_{j}\right)}
$$

Onde:

$\left\{\phi_{i}^{a}\right\}=$ vetor modal íntegro referente ao modo de vibração i

$\left\{\phi_{i}^{e}\right\}=$ vetor modal danificado referente ao modo de vibração i

Outra técnica para a identificação de dano utilizada foi a Diferença de Curvatura Modal (DCM), método proposto por Pandey, Biswas e Samman (1991). Nesta técnica realiza-se um somatório das diferenças entre as segundas derivadas dos modos de vibração em cada posição de medição. De acordo com Farrar e Worden (2013), a vantagem da curvatura é que o processo derivativo tem o efeito de amplificar uma eventual descontinuidade no modo de vibração ocorrido por um dano.

Em vigas que modos de vibração são obtidos por pontos de medição nos ensaios dinâmicos, espaçados a distâncias constante ao longo de seu comprimento. A curvatura nos pontos de medição pode ser calculada pela equação 2.9 , sendo que o primeiro e último pondo de medição são calculados pela 2.10 e 2.11 respectivamente, utilizando-se a aproximação das diferenças centrais.

$$
\begin{aligned}
& \phi_{i}^{\prime \prime}=\frac{\phi_{i+1}-2 \cdot \phi_{i}+\phi_{i-1}}{h^{2}} \\
& \phi_{1}^{\prime \prime}=\frac{\phi_{1}-2 \cdot \phi_{2}+\phi_{3}}{h^{2}} \\
& \phi_{i u}^{\prime \prime}=\frac{\phi_{i u-2}-2 \cdot \phi_{i u-1}+\phi_{i u}}{h^{2}}
\end{aligned}
$$

Assim, a localização do dano é obtida pela média das diferenças de curvatura entre as curvaturas íntegra e danificada, conforme equação 2.12 


$$
D C M=\frac{1}{N} \cdot \sum_{n=1}^{N}\left|\phi_{i}^{e^{\prime \prime}}-\phi_{i}^{a^{\prime \prime}}\right|
$$

Onde:

$\mathrm{i}=$ ponto de medição

$\phi=$ modo de vibração

$\mathrm{h}=$ distância entre os pontos de medição

$\mathrm{a}=$ configuração íntegra

$\mathrm{b}=$ configuração danificada

Uma técnica baseada nas curvaturas dos modos de vibração e na energia de deformação modal, o Índice de Dano (ID), desenvolvida por Stubbs, Kim e Farrar (1995), também é utilizado para a identificação de dano. Quando um dano ocorre, a distribuição de energia de deformação originalmente armazenada em uma estrutura será alterada de uma maneira mais pronunciada nas regiões danificadas, alterando a capacidade de absorver energia dessas regiões. Nas equações do ID faz-se a diferença entre os índices de cada posição com média dos somatórios dos índices de dano, divididos pelo seu desvio padrão. Os valores maiores que a média destacam o local em que a energia sofreu maior alteração e, consequentemente, onde ocorreu o dano.

Quando considerados vários modos de vibração no cálculo, a soma dos índices de dano de cada modo individual pode ser realizada para computar um ID global, conforme apresenta a Equação 2.13. Os valores de $\beta_{i j}$ são assumidos como uma amostra de população de variáveis aleatórias normalmente distribuídas, com valor normalizado conforme a Equação 2.14

$$
\begin{aligned}
& \beta_{i j}=\frac{\left(\left\{\phi_{d}^{\prime \prime}\right\}_{i j}^{2}+\sum_{1}^{i_{\max }}\left\{\phi_{d}^{\prime \prime}\right\}_{i j}^{2}\right) \cdot \sum_{1}^{i_{\max }}\left\{\phi^{\prime \prime}\right\}_{i j}^{2}}{\left(\left\{\phi^{\prime \prime}\right\}_{i j}^{2}+\sum_{1}^{i_{\max }}\left\{\phi^{\prime \prime}\right\}_{i j}^{2}\right) \cdot \sum_{1}^{i_{\max }}\left\{\phi_{d}^{\prime \prime}\right\}_{i j}^{2}} \\
& Z_{j}=\frac{\beta_{j}-\overline{\beta_{j}}}{\sigma_{j}}
\end{aligned}
$$

Onde:

$\mathrm{i}_{\max }=$ última posição de medida

$\beta_{\mathrm{j}}=$ média dos valores de índice de dano entre todos os pontos em um mesmo modo

$\sigma_{j}=$ desvio padrão dos valores de índice de dano entre todos os pontos em um mesmo modo de vibração.

Pesquisas de identificação modal com ênfase teóricas vem sendo desenvolvidas na EESC, a mais recente foi desenvolvida por Gómez (2015). O Pesquisador desenvolveu diferentes técnicas de identificação modal para estruturas sob excitações baseadas na função de transmissibilidade. $O$ 
trabalho faz também uma revisão nos métodos de domínio na frequência para análise modal operacional.

A interação entre estudos teóricos e experimentais no mesmo departamento auxiliam no desenvolvimento das pesquisas. Nas análises modais realizadas nesta tese os conceitos estudados por Gómez (2015) e Juliani (2014) foram utilizados, permitindo uma troca de conhecimento e a continuidade das pesquisas. 


\section{MATERIAIS E MÉTODOS - PRISMAS}

O estudo dos ensaios experimentais com sistema de reforço de CFRP foi iniciado com prismas de concreto armado. Neste buscou-se identificar as alterações em estruturas de concreto devido a aplicação do sistema de reforço e do carregamento prévio. O ensaio piloto com prismas foi fundamental para compreender a técnica de reforço e a identificação modal por ensaios não destrutivos.

Neste capítulo serão descritos os materiais e métodos utilizados na confecção e ensaios dos prismas de concreto, as equações teóricas utilizadas para a definição das forças máximas, os equipamentos e fórmulas utilizados na análise modal, bem como os critérios utilizados na modelagem computacional.

\subsection{ENSAIO DESTRUTIVO}

Para este ensaio foram utilizados prismas de concreto armado com dimensões de $15 \mathrm{~cm} x$ $15 \mathrm{~cm} \times 75 \mathrm{~cm}$. Foram moldados vinte e quatro (24) prismas, sendo doze (12) com resistência à compressão de $40 \mathrm{MPa}$ e doze (12) com resistência à compressão de $60 \mathrm{MPa}$. Três prismas de cada resistência foram ensaiados sem reforços ao cisalhamento a fim de se identificar suas forças máximas e sua forma de ruptura, estes foram denominados de P40 SR e P60 SR.

Os outros dezoito (18) modelos foram ensaiados com reforço ao cisalhamento, sendo seis (6) sem carregamento inicial, denominados de P40 CFRP e P60 CFRP, seis (6) com carregamento prévio de 40\% da força máxima, denominados de P40 40\% e P60 40\% e seis (6) com carregamento prévio de 70\% da força máxima, denominados de P40 70\% e P60 70\%. A Tabela 3.1 identifica os prismas conforme a utilização de reforços e de carregamento prévio.

Tabela 3.1 - Identificação dos prismas

\begin{tabular}{|c|c|c|c|c|c|}
\hline Prismas C40 & Tipo & Configuração & Prismas C60 & Tipo & Configuração \\
\hline 1 & P40 SR & Sem Reforço & 13 & P60 SR & Sem Reforço \\
\hline 2 & P40 SR & Sem Reforço & 14 & P60 SR & Sem Reforço \\
\hline 3 & P40 70\% & Carregamento Prévio & 15 & P60 70\% & Carregamento Prévio \\
\hline 4 & P40 40\% & Carregamento Prévio & 16 & P60 40\% & Carregamento Prévio \\
\hline 5 & P40 CFRP & Reforço & 17 & P60 CFRP & Reforço \\
\hline 6 & P40 40\% & Carregamento Prévio & 18 & P60 CFRP & Reforço \\
\hline 7 & V40 SR & Sem Reforço & 19 & P60 SR & Sem Reforço \\
\hline 8 & P40 70\% & Carregamento Prévio & 20 & P60 40\% & Carregamento Prévio \\
\hline 9 & P40 CFRP & Reforço & 21 & P60 70\% & Carregamento Prévio \\
\hline 10 & P40 70\% & Carregamento Prévio & 22 & P60 70\% & Carregamento Prévio \\
\hline 11 & P40 40\% & Carregamento Prévio & 23 & P60 40\% & Carregamento Prévio \\
\hline 12 & P40 CFRP & Reforço & 24 & P60 CFRP & Reforço \\
\hline
\end{tabular}


Primeiramente o ensaio foi realizado nos prismas sem reforços (P40 SR e P60 SR) para determinar a força máxima dos modelos sem o sistema de reforço de CFRP. Após o resultado destes prismas pôde-se determinar as forças equivalentes a 40\% e 70\% da força máxima a serem aplicados nos prismas com carregamento prévio.

Os reforços de CFRP foram inseridos no cobrimento do concreto com um ângulo de 45 graus, nos dois lados dos prismas, interceptando as principais fissuras de cisalhamento. Diversos pesquisadores como Khalifa el al. (2000) e Dias (2008) indicam uma melhor eficiência dos sistemas de reforço quando utilizados com inclinação, principalmente pelo fato dos esforços serem interceptados por uma maior quantidade de laminados de CFRP nesta configuração.

Com o intuito de evitar qualquer interferência na resistência dos materiais componentes dos prismas, os ensaios destrutivos dos prismas com sistema de reforço foram realizados 30 dias após a inserção dos laminados de CFRP.

O ensaio piloto consiste no esquema em flexão típico de três pontos realizado na prensa Instron, modelo $300 \mathrm{HVL}$, com capacidade para $1.500 \mathrm{kN}$ e altura útil de ensaio de $1.500 \mathrm{~mm}$. Nesta máquina é possível realizar ensaios estáticos com controle de deslocamento do pistão, o que permite a captação de dados experimentais após a força máxima. Os ensaios foram finalizados após a redução em aproximadamente $20 \%$ da força máxima.

Nos apoios, foram utilizados roletes metálicos permitindo a rotação dos prismas durante o ensaio. O ensaio foi realizado com vão de $70 \mathrm{~cm}$ e com carregamento centralizado.

Para a captação dos dados dos prismas foram utilizados cinco (5) extensômetros da marca Kyowa com sensibilidade para deformação de 2,1 $\pm 1 \%$, sendo um (1) na armadura longitudinal central e quatro (4) nos laminados de CFRP. Foram utilizados ainda três (3) transdutores de deslocamento resistivos, com curso de 10 e $25 \mathrm{~mm}$ para medir o deslocamento no centro do vão e a deformação do concreto nas partes tracionadas e comprimidas em uma das laterais dos prismas, como mostra a Figura 3.1.
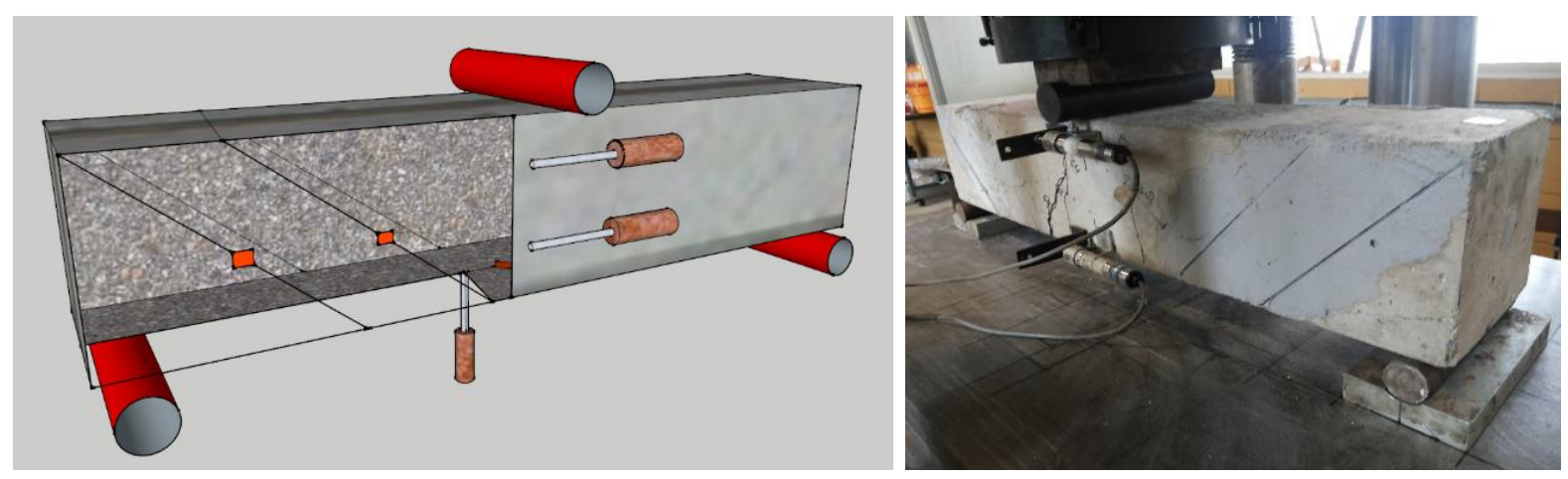

Figura 3.1 - Esquema de ensaio dos prismas 


\subsubsection{Preparo dos Prismas}

Como o objetivo do estudo não é o reforço à flexão, e sim ao cisalhamento, somente armaduras positivas foram utilizadas com cobrimento de $2,5 \mathrm{~cm}$ da face inferior, pois as pequenas dimensões do prisma $(15 \mathrm{~cm}$ x $15 \mathrm{~cm}$ x $75 \mathrm{~cm})$ impossibilitaram a utilização de armadura transversal, tendo somente o concreto e o reforço de CFRP contribuição na resistência ao cisalhamento.

A armadura longitudinal utilizada foi a mesma para todos os prismas, independentemente da resistência dos concreto, sendo de três (3) barras de $10 \mathrm{~mm}$ de CA50 para todos os 24 prismas. A barra central de todos os prismas foi instrumentada com extensômetros da marca Kyowa com sensibilidade para deformação de 2,1 $\pm 1 \%$ para medir sua deformação durante os ensaios (Figura $3.2)$.
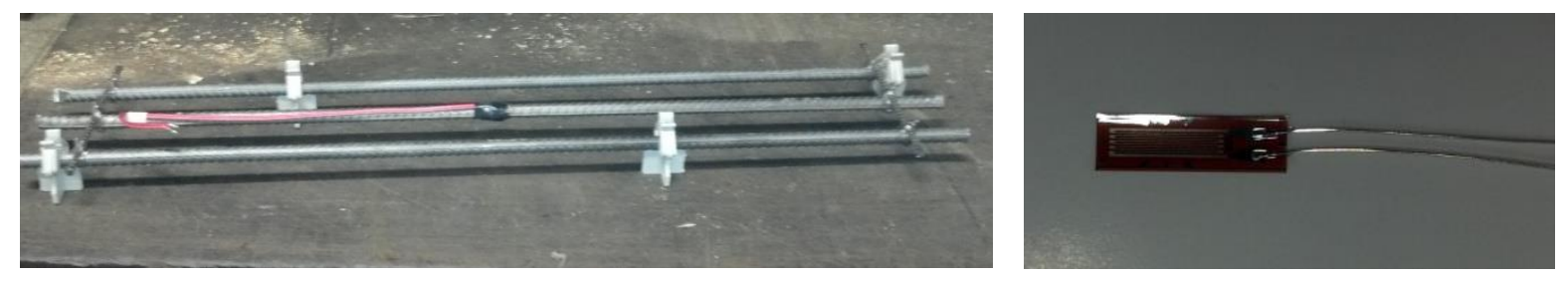

Figura 3.2 - Instrumentação e armadura dos Prismas

Os prismas foram concretados em quatro betonadas e em dois dias, com o mesmo concreto confeccionado na produção dos corpos de prova. Devido ao tamanho pequeno dos elementos no seu adensamento foi utilizado um vibrador de mesa, evitando vibrações nas armaduras (Figura 3.3).
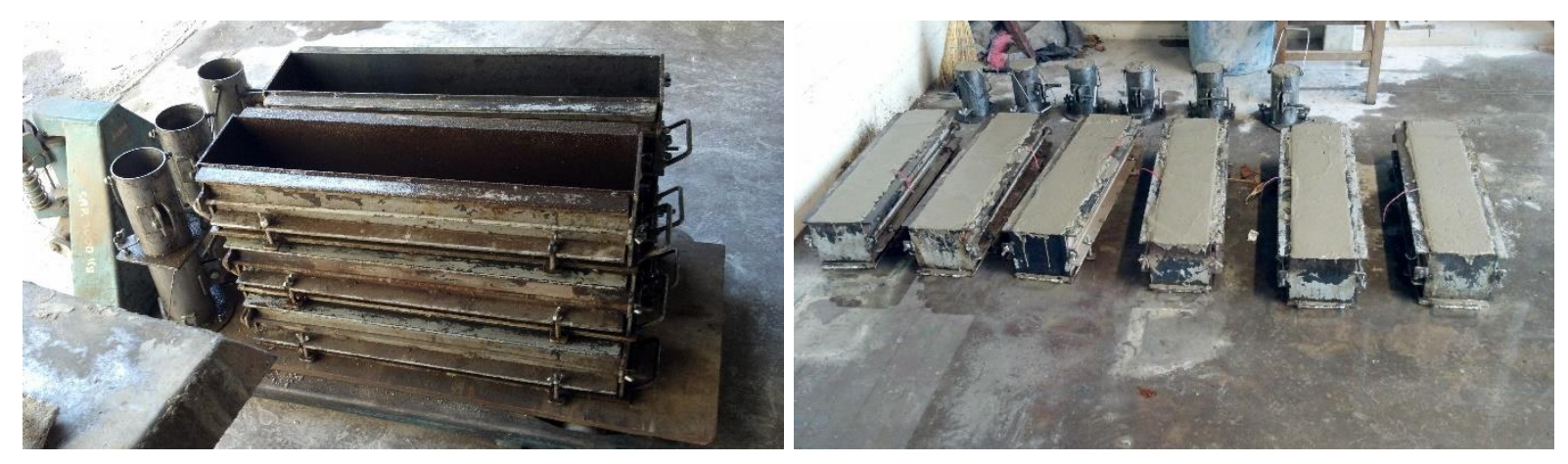

Figura 3.3 - Moldagens dos Prismas

Os laminados de CFRP utilizados nesta pesquisa foram doados pela Sika que possui diversas opções de dimensões do material, dentre eles foi selecionado o Sika ${ }^{\circledR}$ CarboDur ${ }^{\circledR}$ Plates S214, com todas as propriedades descritas no Anexo I. Segundo o fabricante, estes produzidos com lâminas pultrudadas de polímero reforçado com fibras de carbono para reforço de estruturas de concreto, madeira e alvenaria. Todos os laminados de CFRP utilizados no presente trabalho foram fornecidos em rolos e tinham seção transversal de $20 \mathrm{~mm}$ de largura por 1,4mm de espessura. 
A Figura 3.4 apresenta as propriedades dos laminados de CFRP fornecidos pela ficha do produto da Sika (2009).

\begin{tabular}{|c|c|c|c|c|}
\hline & & \multicolumn{3}{|c|}{ Sika ${ }^{\otimes}$ CarboDur } \\
\hline \multicolumn{2}{|r|}{ (valores em MPa) } & $S$ & $\mathrm{M}$ & $\mathrm{H}$ \\
\hline \multirow{4}{*}{$\begin{array}{l}\frac{0}{\bar{z}} \\
\text { 을 }\end{array}$} & Valor Médio & 165.000 & 210.000 & 300.000 \\
\hline & Valor Mínimo & $>160.000$ & $>200.000$ & 290.000 \\
\hline & 5\% Valor de Ruptura & 162.000 & 210.000 & \\
\hline & 95\% Valor de Ruptura & 180.000 & 230.000 & \\
\hline \multirow{4}{*}{ 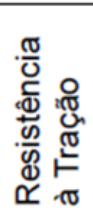 } & Valor Médio & 3.100 & 3.200 & 1.500 \\
\hline & Valor Mínimo & $>2.800$ & $>2.900$ & $>1.350$ \\
\hline & $5 \%$ Valor de Ruptura & 3.000 & 3.000 & \\
\hline & 95\% Valor de Ruptura & 3.600 & 3.900 & \\
\hline \multicolumn{2}{|c|}{ Deformação na Ruptura* (mín.) } & $>1,7 \%$ & $>1,35 \%$ & $>0,45 \%$ \\
\hline
\end{tabular}

Figura 3.4 - Propriedades do laminado de CFRP. Fonte: Sika (2009)

Os prismas foram reforçados com oito (8) laminados de CFRP, sendo que, metade destes foram instrumentados com extensômetro (Strain Gages) da marca Kyowa com sensibilidade para deformação de 2,1 \pm 1\% para medição de deformação durante os ensaios (Figura 3.5).
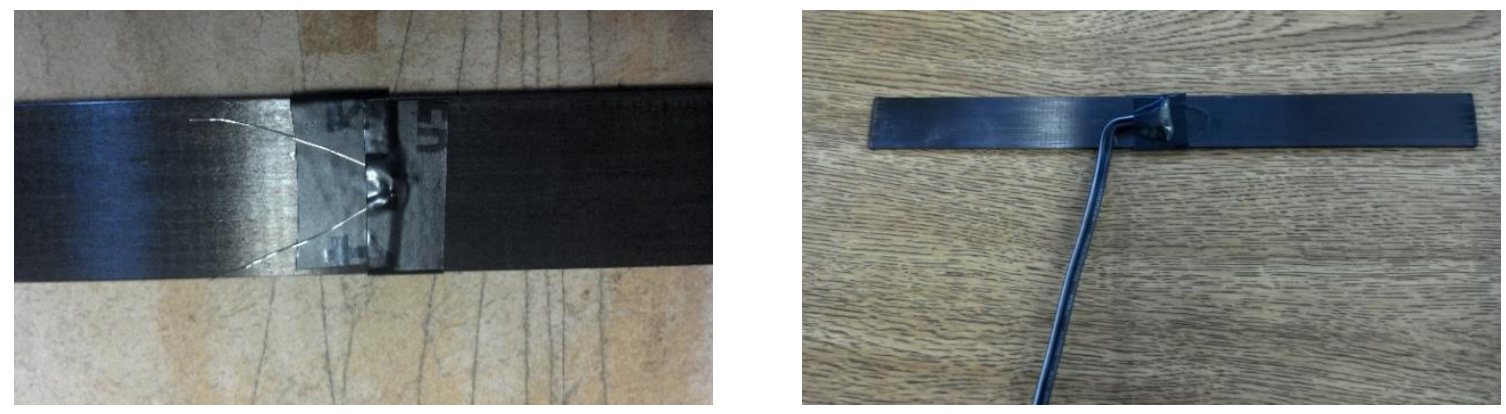

Figura 3.5 - Instrumentação dos laminados de CFRP

O adesivo epóxi utilizado também foi doado pela Sika, sendo escolhido pela melhor interação entre o adesivo e o reforço da mesma marca. Conforme o fabricante, o Sikadur ${ }^{\circledR} 30$ é um adesivo estrutural à base de resina epóxi e agregados especiais, tixotrópico, bicomponente e de pega normal, com todas as propriedades descritas no Anexo II. (SIKA 2010)

Para o reforço ao cisalhamento na técnica NSM são realizadas inserções dos laminados de CFRP no concreto e para a sua aplicação é necessária a abertura de ranhuras nos locais de aplicação do reforço. Nesta pesquisa foram idealizadas ranhuras de 4,2 $\mathrm{mm}$ de espessura e $25 \mathrm{~mm}$ de profundidade para garantir uma melhor aderência entre os laminados de CFRP e o concreto, como sugere Dias (2008) pelas equações apresentadas na Figura 3.6. 


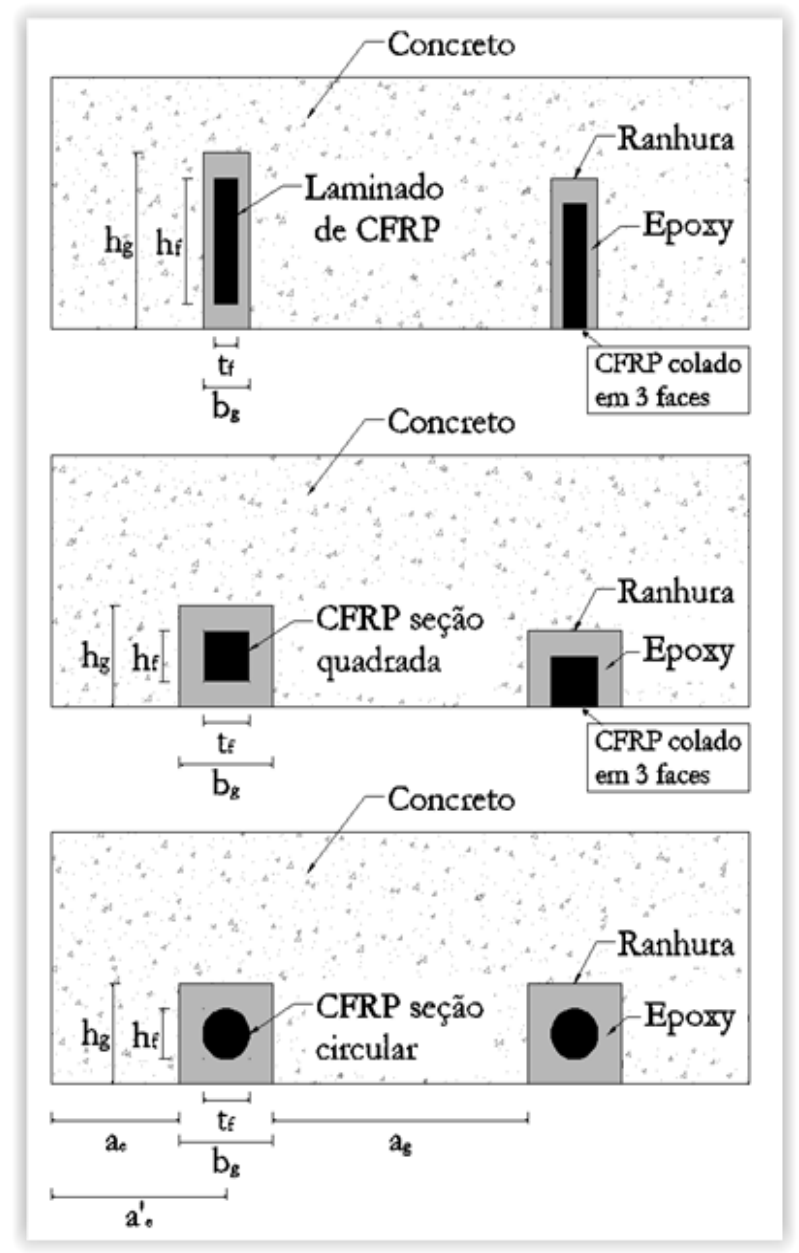

Legenda:

$b_{g}$ - largura da ranhura

$\mathrm{h}_{\mathrm{g}}$ - profundidade da ranhura

$t_{f}$ - espessura do CFRP

$\mathrm{h}_{\mathrm{f}}-$ largura do CFRP

$\mathrm{d}_{\mathrm{b}}$ - diâmetro da barra de CFRP

$a_{g}-$ distância entre ranhuras adjacentes

$a_{e}$ - distância da ranhura à face da viga

$\mathrm{a}^{\prime}{ }_{\mathrm{e}}$ - distância do reforço a face da viga

Recomendações para as dimensões das

Ranhuras:

- caso de barras circulares e seção quadrada

De Lorenzis (2002)

$\mathrm{K}=\mathrm{b}_{\mathrm{g}} / \mathrm{d}_{\mathrm{b}}=1,5$ barras lisas

$\mathrm{K}=2,0$ barras nervuradas

Parretti e Nanni (2001)

$\mathrm{b}_{\mathrm{g}}=1,5 \mathrm{~d}_{\mathrm{b}}$

$\mathrm{h}_{\mathrm{g}}=1,5 \mathrm{~d}_{\mathrm{g}}$

- caso com laminados

Blaschko (2003)

$\mathrm{b}_{\mathrm{g}}=\mathrm{t}_{\mathrm{f}}+3$

$\mathrm{h}_{\mathrm{g}}=\mathrm{h}_{\mathrm{f}}+3$

Parretti e Nanni (2001)

$\mathrm{b}_{\mathrm{g}}=3 . \mathrm{t}_{\mathrm{f}}$

$\mathrm{h}_{\mathrm{g}}=1,5 \cdot \mathrm{h}_{\mathrm{f}}$

Figura 3.6 - Recomendações para dimensão de ranhuras usando a técnica NSM. Fonte: Dias (2008)

Para a abertura das ranhuras foi necessário o seu deslocamento para uma marmoraria, pois as maquinas serra mármore usuais de mercado e disponíveis no laboratório possuem uma espessura de corte muito fina, menores que três milímetros. Mesmo com esse cuidado as ranhuras realizadas não obtiveram a precisão desejada, sendo necessário aumentar a espessura das ranhuras em que os laminados possuíam instrumentação, como pode ser observado na Figura 3.7.

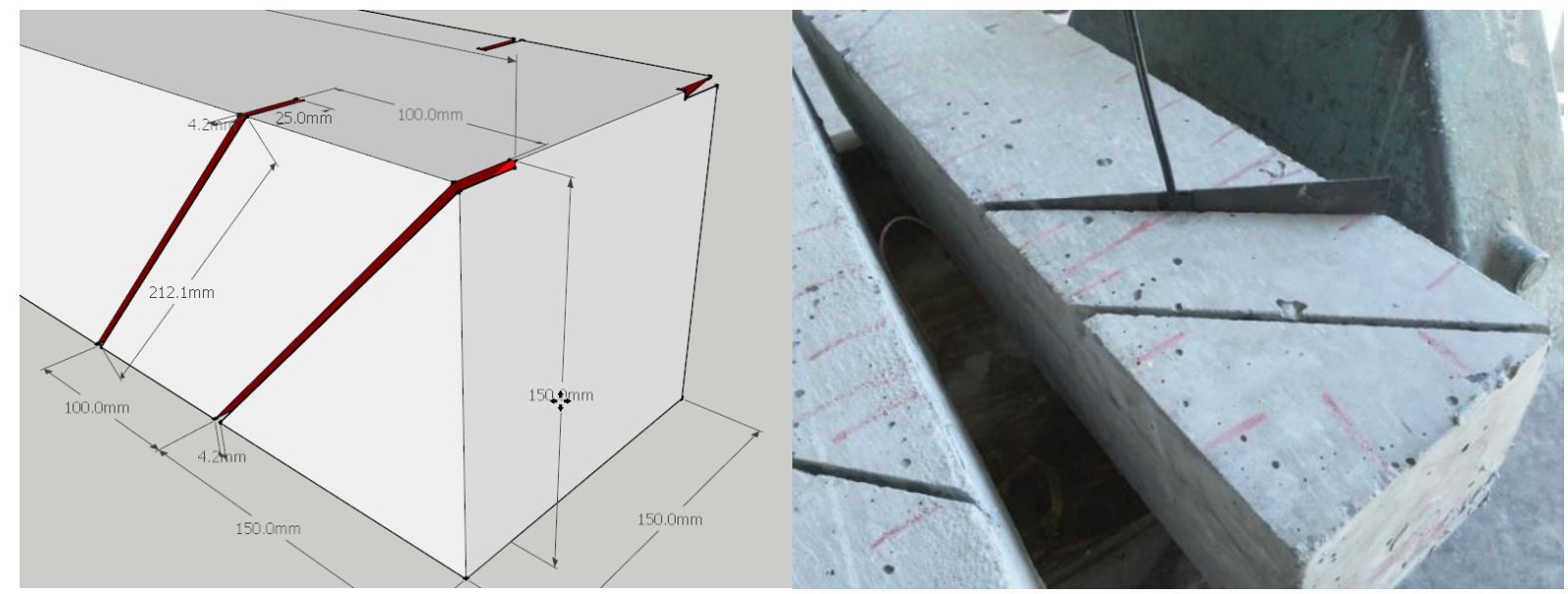

Figura 3.7 - Ranhuras dos Prismas 
Nas técnicas de sistema de reforço por aplicação de laminado no cobrimento do concreto (NSM) seguiu-se os procedimentos já devidamente documentados por Dias (2008). A Figura 3.8 ilustra os procedimentos adotados na técnica NSM, em que envolvem essencialmente quatro tarefas:

a) Abertura das ranhuras:

$\checkmark$ Corte das ranhuras no concreto, com dimensões maiores que o laminado, para a correta aderência;

$\checkmark$ Verificar as armaduras existentes, para que não sejam danificadas;

$\checkmark$ Concreto deve apresentar-se seco e isento de poeira ou grossuras.

b) Preparo dos materiais constituintes:

$\checkmark$ Cortes dos laminados com o comprimento desejado;

$\checkmark$ Limpeza e instrumentação dos laminados;

$\checkmark$ Preparação do adesivo epóxi.

c) Inserção dos laminados de CFRP

$\checkmark$ Preenchimento da ranhura com adesivo epóxi;

$\checkmark$ Aplicação do adesivo no laminado de CFRP;

$\checkmark$ Inserção do laminado na ranhura e remoção do excesso de epóxi.

d) Controle de qualidade em todas as fases anteriores e após o endurecimento do adesivo.

$\checkmark$ Nos materiais utilizados;

$\checkmark$ Nas condições de aplicação dos laminados;

$\checkmark$ Observância na existência de vazios durante a aplicação. 


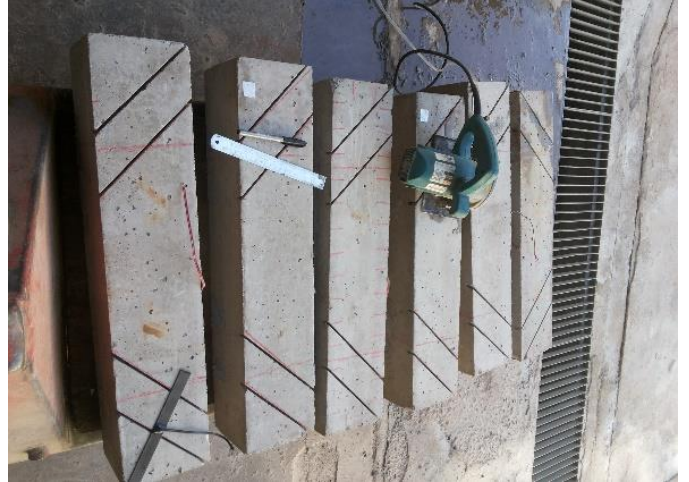

(a) abertura das ranhuras

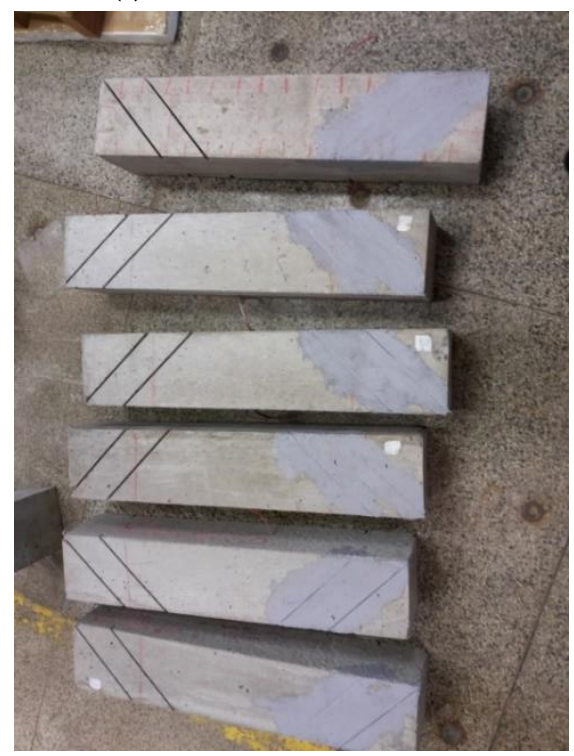

(c) inserção dos laminados

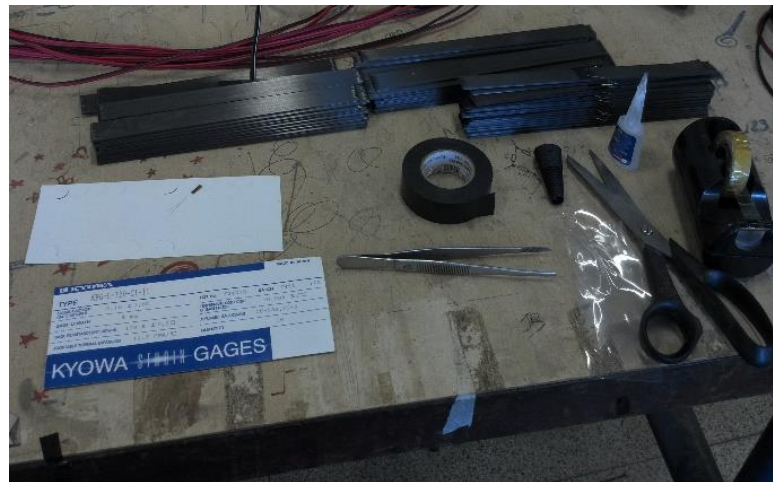

(b) praparo dos materiais componentes

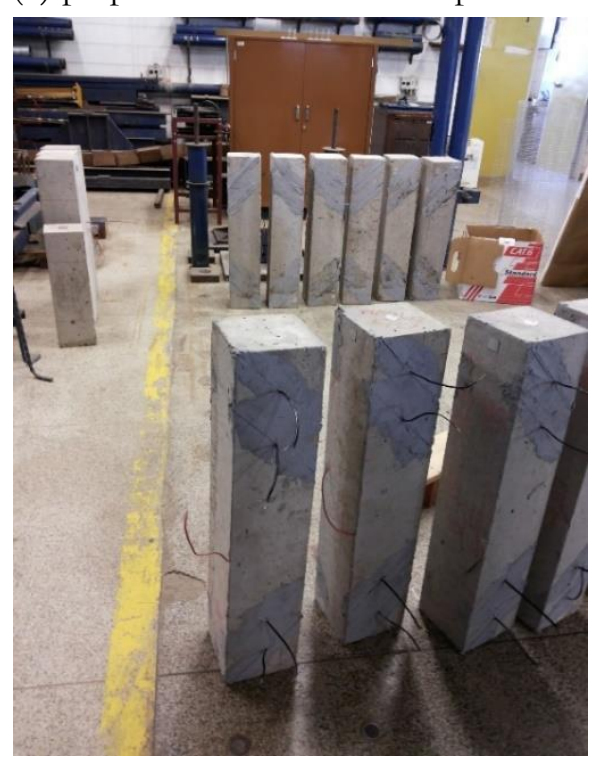

(d) controle de qualidade

Figura 3.8 - Etapas do reforço de prismas segundo a técnica NSM

\subsubsection{Caracterização do concreto}

Para a produção do concreto foram selecionadas duas resistências à compressão, uma de $40 \mathrm{MPa}$ com o objetivo de estudar o comportamento do reforço em estruturas de concreto usuais e outra de $60 \mathrm{MPa}$ permitindo verificar as diferenças para um concreto de alta resistência.

Na confecção do concreto foi utilizado Cimento Portland de alta resistência inicial (CPV - ARI) da marca Holcim, com agregado graúdo de diâmetro máximo de 9,5 mm e agregado miúdo com módulo de finura de 2,75. A umidade dos agregados foi devidamente medida em ensaio com estufas e corrigida durante a dosagem dos concretos. A Figura 3.9 apresenta o aspecto visual da produção de concreto em betoneira enquanto que a Figura 3.10 destaca o ensaio de abatimento do tronco de cone conforme a norma ABNT NBR NM 67:1998. 


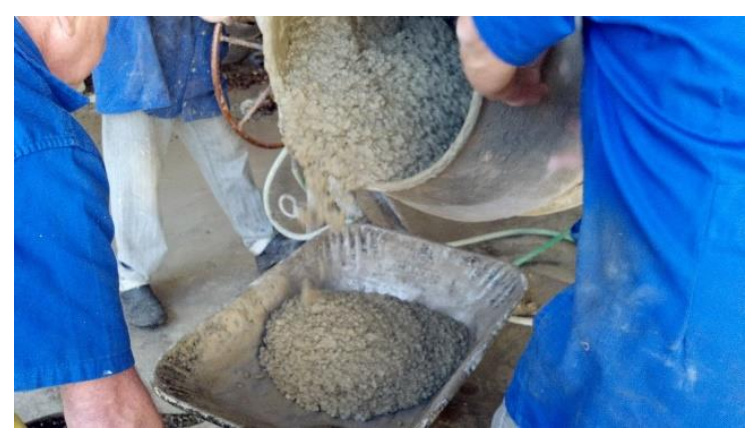

Figura 3.9 - Produção de concreto

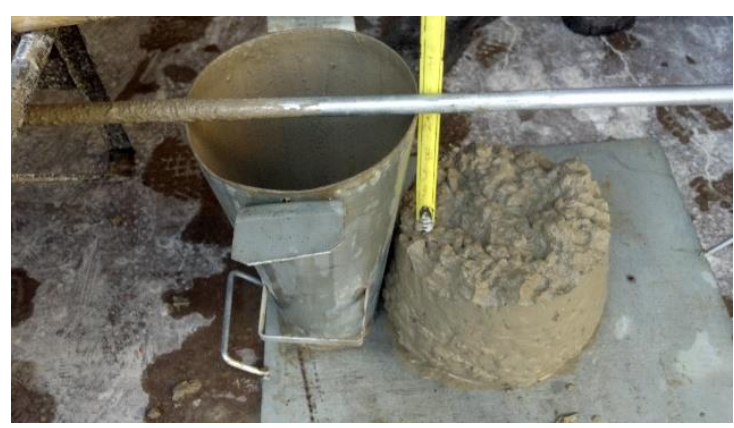

Figura 3.10 - Abatimento do concreto

Para a produção dos prismas e corpos de prova foram necessárias duas betonadas por tipo de concreto utilizado. Estas foram ainda feitas em dias diferentes, devido a limitação da quantidade de formas de prismas no laboratório.

Na primeira moldagem das vigas de concreto utilizou-se um traço dosado em peso de 1 : $2,42: 3,68: 0,72$, obtendo textura e trabalhabilidade desejadas, com abatimento de $14 \mathrm{~cm}$ para a primeira betonada e de $16 \mathrm{~cm}$ para a segunda betonada. A segunda moldagem de concreto foi executada com traço em peso de $1: 1,32: 2,48: 0,47$, em que também obtiveram a trabalhabilidade esperadas, com abatimento de $13 \mathrm{~cm}$ para a primeira betonada e de $14 \mathrm{~cm}$ para a segunda betonada

Para cada tipo de concreto foram moldados doze (12) corpos de prova cilíndricos com seção de $10 \mathrm{~cm}$ diâmetro e $20 \mathrm{~cm}$ de comprimento. Antes dos ensaios todos os corpos de prova foram retificados e armazenados em local seco durante 2 dias.

Os corpos de prova foram levados à cura na câmara úmida e lá permaneceram por 65 dias em média, nestes corpos de prova foram realizados ensaios para a obtenção da resistência à compressão, resistência à tração e módulo de elasticidade por ensaios dinâmicos. (Figura 3.11)
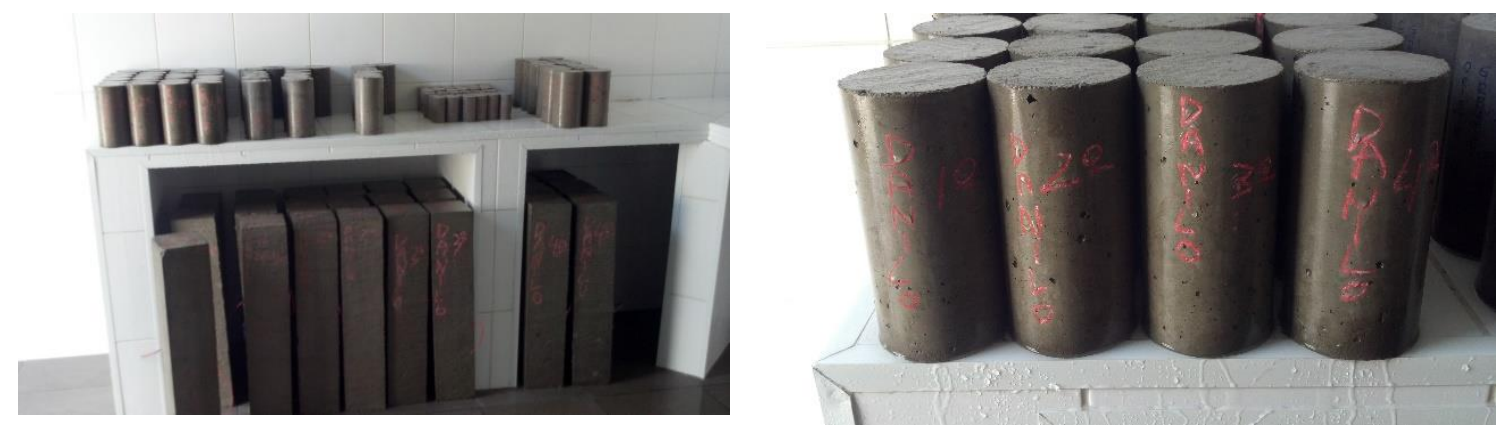

Figura 3.11 - Cura dos prisma e corpos de prova

Para cada tipo de concreto foram ensaiados seis (6) corpos de prova à compressão e seis (6) à tração. Os ensaios de resistência a compressão (Figura 3.12) e tração do concreto foram realizados em uma prensa com capacidade para $150 \mathrm{kN}$, da marca ELE, com sistema de automação da velocidade de carregamento em função do ensaio realizado e para o ensaio de tração foi utilizado 
um dispositivo para ensaio por compressão diametral (Figura 3.13). Para determinação das resistências à compressão e à tração foram seguidas as normas ABNT NBR 5739:2007 e NBR 7222:2011, respectivamente.

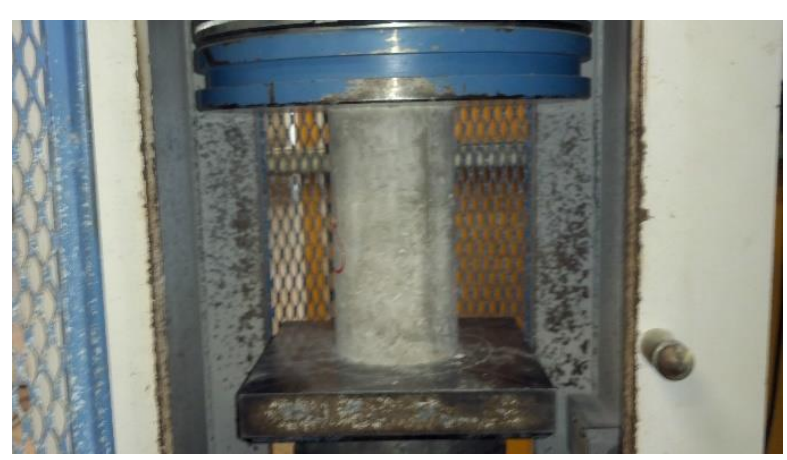

Figura 3.12 - Ensaio de compressão de CPs

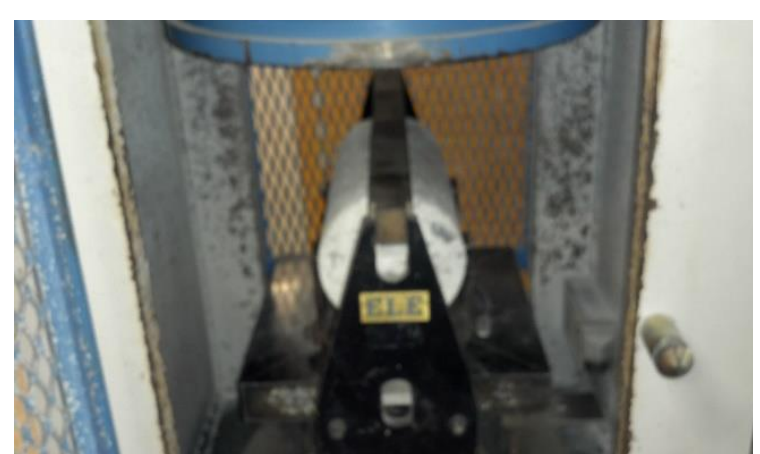

Figura 3.13 - Ensaio de tração de CPs

$\mathrm{Na}$ determinação do módulo de elasticidade dos corpos de prova foram realizados ensaios não destrutivos utilizando o programa Sonelastic ${ }^{\circledR}$ em todos os 24 corpos de prova. O ensaio consiste em aplicar um leve golpe nos corpos de prova para produzir vibração, que é captada por um microfone de alta precisão acoplado ao aparelho. Com os dados iniciais deve-se inserir no equipamento as dimensões e peso dos elementos e como resultado são calculados as frequências naturais e o módulo de elasticidade (Figura 3.14).

Nesta tese todos os ensaios de módulo de elasticidade foram realizados de forma não destrutiva com o programa Sonelastic ${ }^{\circledR}$ ou com acelerômetros piezoeléctricos.
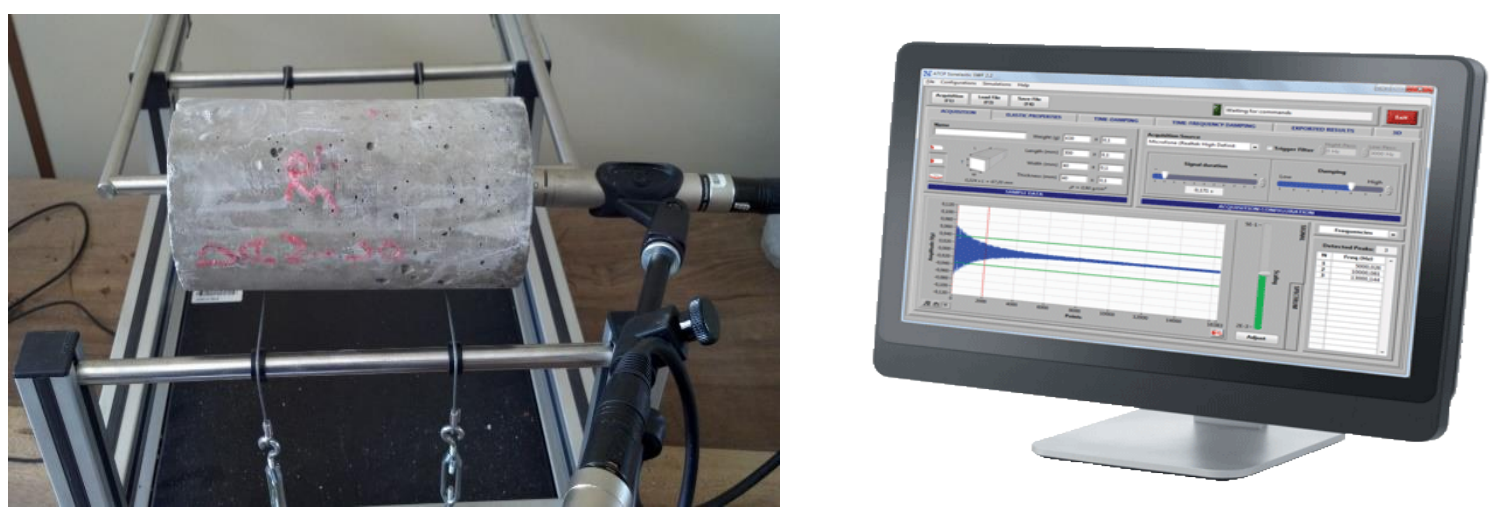

Figura 3.14 - Módulo de elasticidade longitudinal com Sonelastic ${ }^{\circledR}$ e Interface gráfica do programa (Fonte: pagina oficial da ATCP).

Para os corpos de prova cilíndricos foram utilizadas a Equação 3.1 no cálculo do módulo de elasticidade flexional ( $\left.\mathrm{E}_{\text {flex }}\right)$ e a Equação 3.3 para o módulo de elasticidade longitudinal ( $\left.\mathrm{E}_{\text {long }}\right)$.

$$
\begin{aligned}
& \mathrm{E}_{\text {flex }}=\mathrm{C} \cdot \mathrm{M} \eta^{2} \\
& \mathrm{C}=\frac{1,6067 \cdot \mathrm{L}^{3} \cdot T}{d^{4}}
\end{aligned}
$$




$$
\begin{aligned}
& \mathrm{E}_{\text {long }}=\mathrm{D} \cdot \mathrm{M} \cdot\left(\eta^{\prime}\right)^{2} \\
& \mathrm{D}=\frac{5,093 \cdot \mathrm{L}}{d^{2}}
\end{aligned}
$$

Onde:

$\mathrm{M}=$ Massa, em $\mathrm{kg}$

$\eta=$ Frequência flexional, em $\mathrm{Hz}$

$\mathrm{L}=$ Comprimento, em $\mathrm{m}$

$\mathrm{d}=$ Diâmetro, em m,

$\mathrm{T}=$ correção do fator que depende do raio de giração, $\mathrm{K}$ (o raio de giração do cilindro é d/4), dividindo K/L, e com o coeficiente de Poisson (adotado 0,2) obtém-se o valor de

T com o auxílio de uma tabela da norma citada.

\subsection{FORÇA MÁXIMA}

As forças máximas foram consideradas para três hipóteses de ruptura: na flexão, no cisalhamento e no cisalhamento com reforço.

\subsubsection{Força máxima na flexão}

Foram calculados segundo a norma ABNT NBR 6118:2014 para a resistência à ruptura a flexão e ao cisalhamento. Para os cálculos da resistência à flexão e ao cisalhamento os prismas foram dimensionados com o objetivo de obter a força máxima suportada sem reforço, com força aplicada no centro do vão. A norma ABNT NBR 6118:2014 faz distinção de coeficientes da resistência do concreto de alta resistência, com fck $>50 \mathrm{MPa}$. As forças máximas a serem suportadas foram calculadas pelo equilíbrio das forças e momentos utilizando as equações a seguir:

$$
F_{d}=\frac{4 \cdot M_{R d 1}}{l}
$$

$M_{R d 1}=\alpha_{c} \cdot f_{c d} \cdot \lambda \cdot x \cdot b_{w} \cdot\left(d-\frac{\lambda \cdot x}{2}\right)$

$$
M_{R d 1}=A_{s} \cdot f_{y d} \cdot\left(d-\frac{\lambda \cdot x}{2}\right)
$$

Para concreto de $40 \mathrm{MPa}$

Para concreto de $60 \mathrm{MPa}$

$\lambda=0,8$ até fck de $50 \mathrm{MPa}$

$\lambda=0,8-[(f c k-50) / 40]$ quando

fck $>50 \mathrm{MPa}$, nesse caso $\lambda=0,775$

$\alpha_{c}=0,85$ até fck de $50 \mathrm{MPa}$

$\alpha_{c}=0,85 .[1.0-(f c k-50) / 200]$ quando

fck $>50 \mathrm{MPa}$, nesse caso $\alpha_{c}=0,8075$

Onde: 
$\mathrm{F}_{\mathrm{d}}=$ Força máxima admissível para a flexão

$\mathrm{M}_{\mathrm{Rd} 1}=$ Momento máximo admissível

$1=$ Comprimento do prisma

$\mathrm{b}_{\mathrm{w}}=$ Largura do prisma

$\mathrm{d}=$ Altura útil do prisma

$\mathrm{A}_{\mathrm{s}}=$ Área de aço da armadura longitudinal

$\mathrm{f}_{\mathrm{cd}}=$ Resistencia à compressão do concreto

$\mathrm{f}_{\mathrm{yd}}=$ Resistencia à tração de escoamento do aço

$\mathrm{x}=$ Profundidade efetiva da linha neutra

$\lambda=$ Relação entre a profundidade do diagrama retangular de compressão equivalente e a profundidade efetiva da linha neutra

$\alpha_{c}=$ Parâmetro de redução da resistência do concreto na compressão

\subsubsection{Força máxima no cisalhamento}

Para o dimensionamento por força cortante optou-se pelo Método de Cálculo I descrito na norma brasileira, que admite diagonais de compressão inclinadas de $\theta=45$ graus em relação ao eixo longitudinal do elemento estrutural e considera a parcela complementar $V_{c}$ com valor constante, independentemente de $\mathrm{V}_{\mathrm{Sd}}$. Como os prismas não possuem armadura transversal o valor de $\mathrm{V}_{\mathrm{sw}}$ é nulo. Para o seu cálculo foram utilizadas as formulas a seguir:

$$
\begin{gathered}
F_{W}=2 \cdot V_{R d 3} \\
V_{R d 2}=0,27 \cdot \alpha_{V 2} \cdot f_{c d} \cdot b_{w} \cdot d \\
V_{c}=0,6 \cdot f_{c t d} \cdot b_{w} \cdot d \\
V_{S W}=0,9 \cdot \frac{A_{S W}}{s} \cdot d \cdot f_{y} \\
V_{R d 3}=V_{c}+V_{s w}
\end{gathered}
$$

Onde:

$\mathrm{F}_{\mathrm{W}}=$ Força máxima admissível ao cisalhamento

$\mathrm{V}_{\mathrm{Rd} 2}=$ Força cortante resistente de cálculo, relativa à ruína das diagonais comprimidas de concreto

$\mathrm{V}_{\mathrm{Rd} 3}=$ Força cortante resistente de cálculo, relativa à ruína por tração diagonal

$\mathrm{V}_{\mathrm{sw}}=$ Parcela de força cortante resistida pela armadura transversal

$\alpha_{V 2}=$ Coeficiente relacionado com a resistência do concreto $\alpha_{V 2}=1-f c k / 250$

$\mathrm{f}_{\mathrm{ctd}}=$ Resistência a tração de cálculo do concreto no limite de formação de fissuras

$\mathrm{f}_{\mathrm{cd}}=$ Resistência à compressão de cálculo do concreto

$\mathrm{b}_{\mathrm{w}}=$ Largura do prisma

$\mathrm{d}=$ Altura útil da viga

$\mathrm{V}_{\mathrm{c}}=$ parcela de força cortante do concreto resistida por mecanismos complementares ao modelo em treliça 


\subsubsection{Força máxima no cisalhamento com reforço}

Para o cálculo da parcela resistente do sistema de reforço de CFRP ao cisalhamento pela técnica NSM não existem normas específicas, sendo as normas Europeia Fib bulletin 14 (2001) específicas apenas para reforço em vigas com técnica EBR e a norma Norte Americana ACI 440.2R (2008) considera o sistema de reforço pela técnica NSM apenas para a flexão. Alguns pesquisadores com o De Lorenzis e Nannin (2011), Dias (2008) elaboraram formulações para a determinação da parcela resistente do sistema de reforço ao cisalhamento utilizando a técnica NSM.

Devido à falta de norma específica para o dimensionamento do acréscimo de força oriundo do sistema de reforço ao cisalhamento com a técnica NSM, neste trabalho foi utilizado as equações desenvolvidas por Dias (2008), que apresenta um método de cálculo que considera o reforço de CFRP de maneira análoga a armação com barras de aço internas, calculado no estado limite ultimo para o cisalhamento.

$\mathrm{O}$ cálculo da resistência ao cisalhamento assimilado pelo reforço $\left(\mathrm{V}_{\mathrm{fd}}\right)$ é somada às parcelas resistentes do concreto e aço para Equação 3.14, neste caso, apenas ao concreto, pois os prismas não possuem estribos. A contribuição do reforço é calculado pela Equação 3.15 considera a orientação do reforço em relação ao eixo longitudinal da viga ( $\left.\theta_{\mathrm{f}}\right)$ igual a 45 graus e a orientação das fissuras de cisalhamento $(\alpha)$ admitidas em 45 graus.

$$
\begin{gathered}
F_{W R}=2 \cdot V_{W R} \\
V_{W R}=V_{c}+V_{s w}+V_{f} \\
V_{f}=h_{w} \cdot \frac{A_{f_{v}}}{s_{f}} \varepsilon_{f e} \cdot E_{f} \cdot\left(\cot \alpha+\cot \theta_{f}\right) \cdot \operatorname{sen} \theta_{f}
\end{gathered}
$$

A deformação especifica do reforço $\left(\boldsymbol{\varepsilon}_{\mathrm{fe}}\right)$ é o fator determinante da equação, podendo ele ocorrer pelo destacamento do reforço ou pela ruptura do reforço, calculada pela Equação 3.16. Sendo necessário ainda a determinação da taxa de reforço segundo a Equação 3.17.

$$
\begin{gathered}
\varepsilon_{f e}=0,1685 .\left[\frac{\left(E_{f} \cdot \rho_{f}\right)+\left(E_{s} \cdot \rho_{s w}\right)}{\left(f_{c m}^{2 / 3}\right)}\right]^{-1,117} \\
\rho_{f}=\left(\frac{2 \cdot A_{f_{v}}}{b_{w} \cdot s_{f}}\right)
\end{gathered}
$$

Onde:

$\mathrm{E}_{\mathrm{f}}=$ Módulo de elasticidade do Laminado de CFRP em GPa 
$\mathrm{E}_{\mathrm{s}}=$ Módulo de elasticidade do aço de CFRP em GPa

$\mathrm{f}_{\mathrm{cm}}=$ Resistência média à compressão do concreto em $\mathrm{MPa}$

$\mathrm{A}_{\mathrm{fv}}=$ Área da seção transversal do reforço de CFRP

$\mathrm{s}_{\mathrm{f}}=$ Espaçamento dos Laminados

$\rho_{\mathrm{f}}=$ Taxa de reforço ao cisalhamento do CFRP

$\rho_{\mathrm{s}}=$ Taxa de armadura transversal

$\mathrm{F}_{\mathrm{WR}}=$ Força máxima admissível para o cisalhamento com reforço de CFRP

$\mathrm{V}_{\mathrm{WR}}=$ Força cortante resistente de cálculo para o cisalhamento com reforço de CFRP

$\mathrm{h}_{\mathrm{w}}=$ Altura útil vertical do reforço

\subsection{ENSAIO NÃO DESTRUTIVO}

Os ensaios não destrutivos foram realizados por duas técnicas, uma imediatamente após a outra, sendo uma por um analisador de sinais dinâmicos para ensaio de vibração (Sonelastic®) e a outra por martelo de impacto e acelerômetros piezoelétricos. Devido aos ensaios serem realizados no mesmo instante, as dúvidas ocasionadas pela leitura das frequências em um dos ensaios foram minimizadas, pois eram conferidas imediatamente pelo segundo método.

Os ensaios dinâmicos foram realizados com o intuito principal de caracterizar as frequências naturais de vibração e a rigidez dos prismas. Estes foram realizados nos prismas em várias etapas: íntegro, com carregamento prévio, reforçado com CFRP e após a ruptura.

Os apoios foram idealizados conforme a norma ASTM C215 (2008), que determina apoios à distância da face ao centro de 0,224 do comprimento dos prismas, esta configuração visa obter a primeira frequência flexional com a menor interferência dos apoios. A mesma norma foi utilizada para determinar os módulos de elasticidade dos ensaios. Para este ensaio utilizou-se um pórtico metálico e elásticos com gancho que permitiram apoiar os prismas com baixa interferência nas frequências naturais (Figura 3.15). 

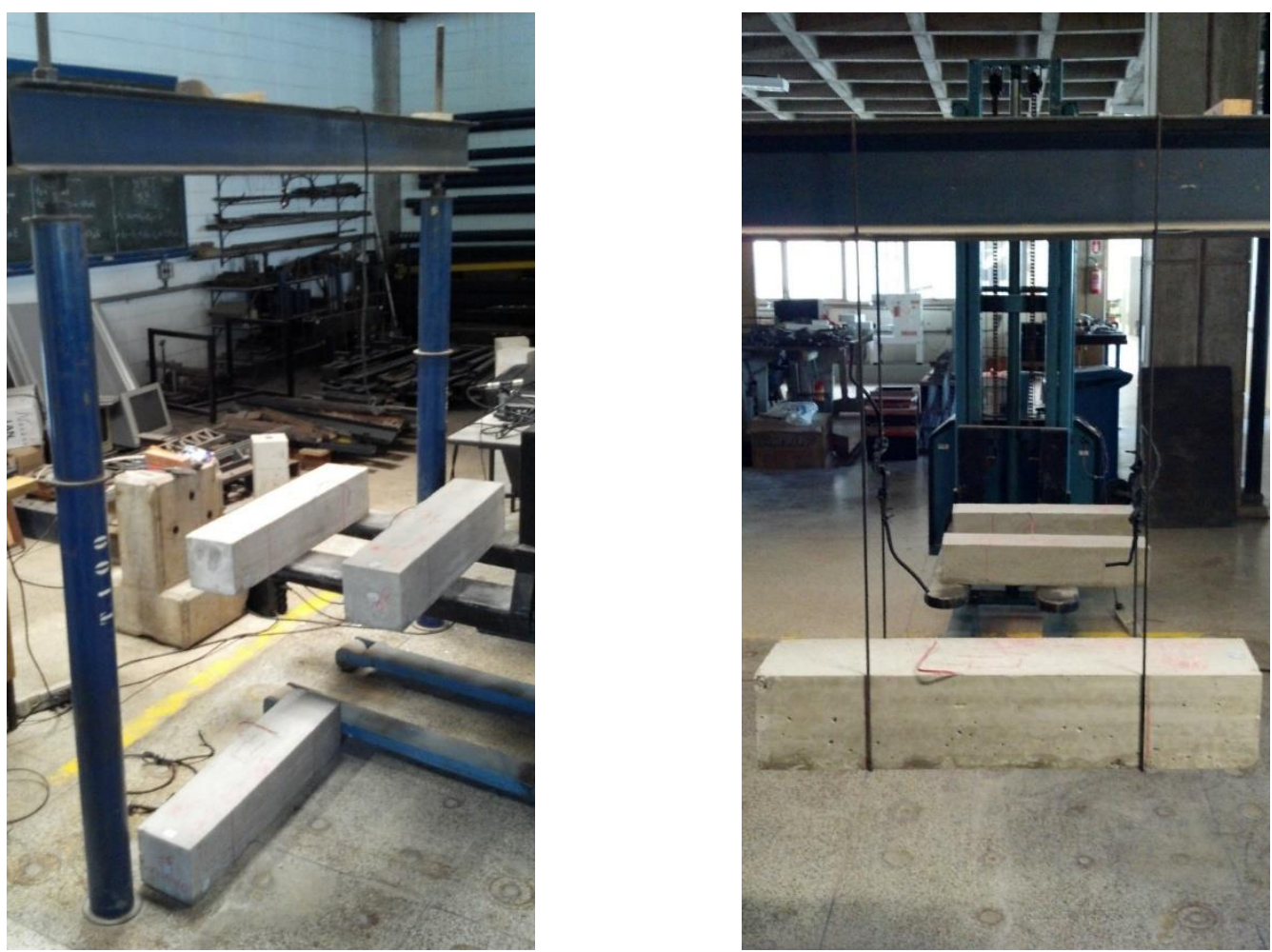

Figura 3.15 - Pórtico para suspender os prismas e apoio em elásticos

Um ensaio com analisador de sinais dinâmico, utilizando o programa Sonelastic ${ }^{\circledR}$, foi realizado com uma haste de ponta metálica para impacto nos prismas e um microfone para a captação dos resultados. Foram realizadas duas medições, uma solicitando as frequências torcionais e flexionais e a outra solicitando as frequências longitudinais (Figura 3.16).
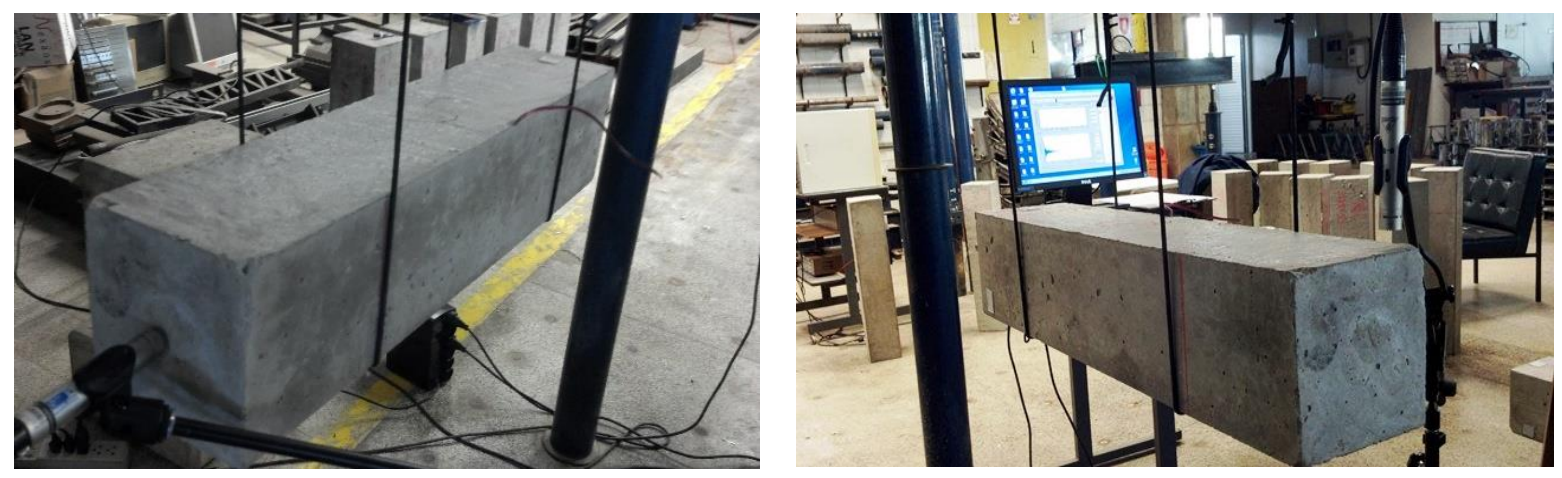

Figura 3.16 - Ensaios com Sonelastic ${ }^{\circledR}$

O ensaio com martelo de impacto e acelerômetro piezoeléctrico utilizou o programa Signal Calc ACE, que tem capacidade de fornecer uma extensa saída de dados. Para o ensaio dos prismas, optou-se por visualizar os dados de entrada da magnitude da força aplicada, fornecida pelo martelo de impacto (S1,1), o Power Spetrum da saída no acelerômetro piezoelétricos $(\mathrm{S} 2,2)$, a coerência desses resultados em uma média de dez impactos $(\mathrm{C} 1,2)$ e a função resposta em frequência $(\mathrm{H} 1,2)$. A visualização destes parâmetros durante o ensaio permitiu minimizar os erros, 
pois o uso da média reduziu os erros de imprecisão e a coerência auxiliou na interpretação das variações entre cada impacto ao longo das frequências (Figura 3.17).

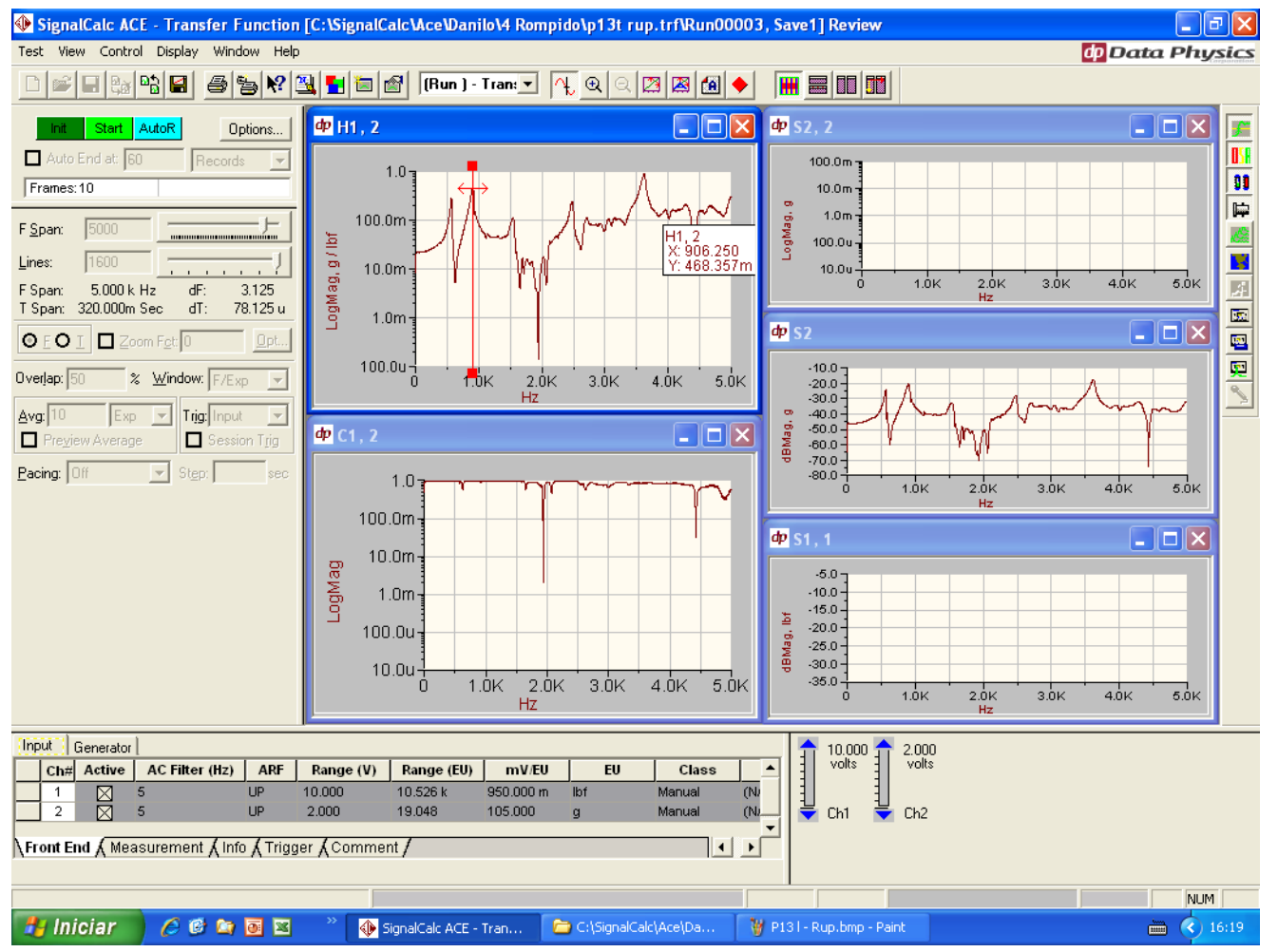

Figura 3.17 - Interface gráfica do programa Signal Calc ACE

Este ensaio foi utilizado com o objetivo principal de obter as primeiras frequências naturais flexionais, longitudinais e torcionais. As frequências naturais permitem calcular o módulo de elasticidade dos prismas, utilizando a norma ASTM C215 (2008), esta norma fornece formulação para o cálculo do módulo de elasticidade flexional $\left(\mathrm{E}_{\text {flex }}\right)$ e módulo de elasticidade longitudinal $\left(\mathrm{E}_{\text {long }}\right)$.

Para o cálculo dos módulos de elasticidade medidos flexionalmente $\left(\mathrm{E}_{\mathrm{flex}}\right)$ e longitudinalmente ( $\mathrm{E}_{\text {long }}$ ) foram utilizadas a Equação 3.18 e Equação 3.20 respectivamente, obtidas conforme a norma ASTM C215 (2008).

$$
\begin{gathered}
\mathrm{E}_{\text {flex }}=\mathrm{C} \cdot \mathrm{M} \cdot \eta^{2} \\
\mathrm{C}=0,9464 \cdot \frac{\left(\mathrm{L}^{3} \cdot T\right)}{b \cdot t} \\
\mathrm{E}_{\text {long }}=\mathrm{D} \cdot \mathrm{M} \cdot\left(\eta^{\prime}\right)^{2} \\
\mathrm{D}=\frac{4 \cdot \mathrm{L}}{\mathrm{b} \cdot \mathrm{t}}
\end{gathered}
$$


Onde:

$\mathrm{M}=$ Massa, em $\mathrm{kg}$

$\eta=$ Frequência flexional, em $\mathrm{Hz}$

$\eta^{\prime}=$ Frequência longitudinal, em $\mathrm{Hz}$

$\mathrm{t}, \mathrm{b}=$ Dimensões da seção transversal para prismas, em $\mathrm{m}$

$\mathrm{L}=$ Comprimento, em $\mathrm{m}$

$\mathrm{T}=$ correção do fator que depende do raio de giração, $\mathrm{K}$ (o raio de giração do prisma é

t/3,464), dividindo K/L, e com o coeficiente de Poisson (adotado 0,2) obtém-se o valor de $\mathrm{T}$ com o auxílio de uma tabela da norma citada.

A instrumentação, parâmetros do sistema de aquisição e métodos de análise utilizados no ensaios não destrutivos com acelerômetro piezoelétrico e martelo de impacto do ensaio piloto são apresentados na Tabela 3.2

Tabela 3.2 - Informações sobre o ensaio dinâmico com acelerômetro

\begin{tabular}{l|l}
\hline \multicolumn{1}{l}{ Instrumentação } & $\begin{array}{l}\text { Descrição } \\
\text { Foram coladas pequenas chapas metálicas }(2 \mathrm{~cm} \times 2 \mathrm{~cm}) \text { para fixação do } \\
\text { acelerometro, em 3 posições dos prismas. }\end{array}$ \\
\hline $\begin{array}{l}\text { Sistema de aquisição de } \\
\text { dados }\end{array}$ & $\begin{array}{l}\text { SignalCalc ACE da Data Physics Corporation com placa PCMCIA e } \\
\text { computador portátil. }\end{array}$ \\
\hline Parâmetros do sistema & $\begin{array}{l}\text { Janela hanning para tratamento dos dados; faixa de amostragem até } 5000 \\
\text { Hz; resolução em frequência dF }=3,125 \mathrm{~Hz} \text {; overlap }=50 \% \text { e resposta } \\
\text { obtida com a média de } 10 \text { ensaios. }\end{array}$ \\
\hline $\begin{array}{l}\text { Acelerômetro } \\
\text { piezoelétrico }\end{array}$ & $\begin{array}{l}\text { Marca IEPE modelo 3055B2100mV } / \mathrm{g}, \text { com escala de frequência de } 1 \text { a } \\
10.000 \mathrm{~Hz}\end{array}$ \\
\hline
\end{tabular}

Neste ensaio foram realizadas três (3) medições, uma solicitando as frequências flexionais realizando impacto na vertical em uma extremidade do prisma e captando os dados na outra extremidade; outro posicionamento para solicitar as frequências longitudinais, posicionando o acelerômetro no topo do prisma e solicitando na outra extremidade; e por último, solicitando as frequências torcionais com acelerômetro e martelo posicionados na lateral do prisma conforme a Figura 3.18. 


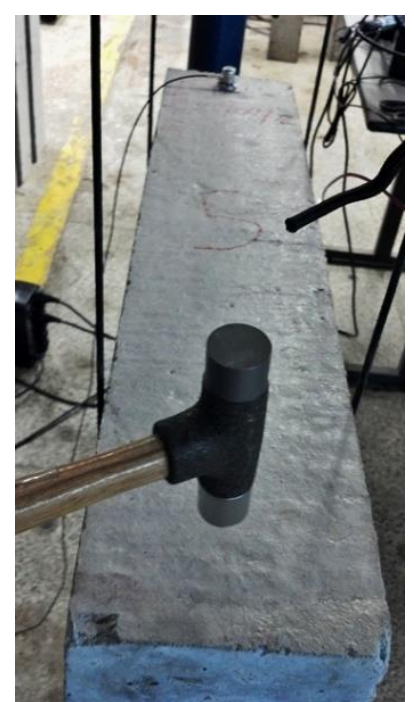

(a) Flexional

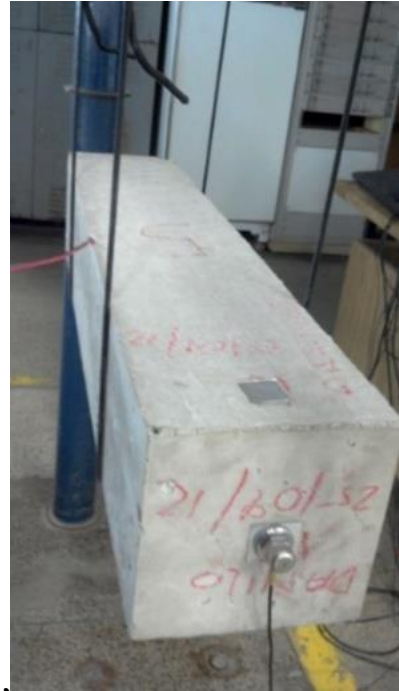

(b) Longitudinal

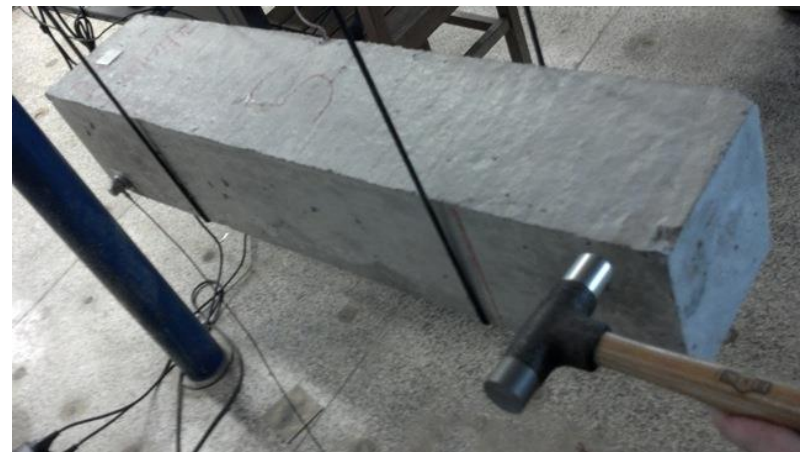

(c) Torcional

Figura 3.18 - Ensaios com acelerômetro piezoelétrico

\subsection{MODELAGEM COMPUTACIONAL DOS PRISMAS}

A modelagem computacional foi desenvolvida no programa DIANA® com auxílio do pré e pós processador FX, este programa foi selecionado por utilizar elementos finitos, permitindo que problemas não convencionais de engenharia sejam resolvidos através de modelagem avançada com comportamento complexo de material não linear e tensões induzidas a partir de condições de forças extremas.

Foi realizada uma análise modal dos prismas para a comparação das frequências naturais obtidas por simulação computacional como as obtidas nos ensaios não destrutivos. O modelo foi executado em três dimensões e com pequenas dimensões dos elementos finitos, permitindo assim obter um valor mais coerente das frequências naturais. A simulação com elementos tridimensionais permitiu obter os modos de vibração e frequências naturais torcionais dos prismas.

Para evitar qualquer influência dos elementos nos resultados, estes foram divididos em elementos finitos piramidais sólidos (TE12L) que permitiram modelar com maior precisão as pequenas dimensões das ranhuras. 
Os dados utilizados na modelagem computacional para a análise modal foram:

Para os prismas de concreto C40:

$\checkmark$ Módulo de elasticidade de $35.000 \mathrm{~N} / \mathrm{mm}^{2}$

$\checkmark$ Densidade de $2,55 \times 10^{-3} \mathrm{~g} / \mathrm{mm}^{3}$;

$\checkmark$ Coeficiente de Poisson de 0,2.

Para os prismas de concreto C60:

$\checkmark$ Módulo de elasticidade de $40.000 \mathrm{~N} / \mathrm{mm}^{2}$;

$\checkmark$ Densidade de $2,55 \times 10^{-3} \mathrm{~g} / \mathrm{mm}^{3}$;

$\checkmark$ Coeficiente de Poisson de 0,2;

Para o Aço:

$\checkmark$ Módulo de elasticidade de $210.000 \mathrm{~N} / \mathrm{mm}^{2}$;

$\checkmark$ Densidade de $7,85 \times 10^{-3} \mathrm{~g} / \mathrm{mm}^{3}$;

$\checkmark$ Coeficiente de Poisson de 0,3.

$\checkmark$ Área de Aço de $240 \mathrm{~mm}^{2}$

Para o CFRP:

$\checkmark$ Módulo de elasticidade de $165.000 \mathrm{~N} / \mathrm{mm}^{2}$;

$\checkmark$ Densidade de $1,5 \times 10^{-3} \mathrm{~g} / \mathrm{mm}^{3}$;

$\checkmark$ Coeficiente de Poisson de 0.3;

$\checkmark$ Área da seção transversal de cada laminado de $28 \mathrm{~mm}^{2}$.

Para o Epóxi:

$\checkmark$ Módulo de elasticidade de $10.000 \mathrm{~N} / \mathrm{mm}^{2}$;

$\checkmark$ Densidade de $1,65 \times 10^{-9} \mathrm{~g} / \mathrm{mm}^{3}$;

$\checkmark$ Coeficiente de Poisson de 0,2.

$\mathrm{Na}$ definição do comportamento dos materiais dentro do programa DIANA®, algumas aproximações foram realizadas para os prismas, onde os laminados de CFRP e as barras de aço foram incorporadas ao substrato (concreto ou epóxi) utilizando opção reinforcement, desta forma ocorre uma perfeita ligação com substrato, além de não contribuir para o peso do elemento.

Como já mencionado, nos ensaios dos prismas foram feitos oito (8) ranhuras no concreto a inserção dos laminados de CFRP, estas ranhuras possuíam pequenas dimensões $(4,2 \mathrm{~mm} \times$ $25 \mathrm{~mm}$ ). Com o objetivo de investigar a influência dessas ranhuras no concreto na modelagem computacional a malha de elementos finitos teve que ser dividida com dimensões mínimas de 4 $\mathrm{mm}$, ocasionando ranhuras de $4 \mathrm{~mm} \times 24 \mathrm{~mm}$. Assim os prismas foram divididos em 223.358 (duzentos e vinte e três mil e trezentos e cinquenta e oito) elementos, valor aparentemente elevado, 
mas que não causou grandes custos computacionais para a análise modal. A Figura 3.19 apresenta o modelo dividido em elementos finitos.
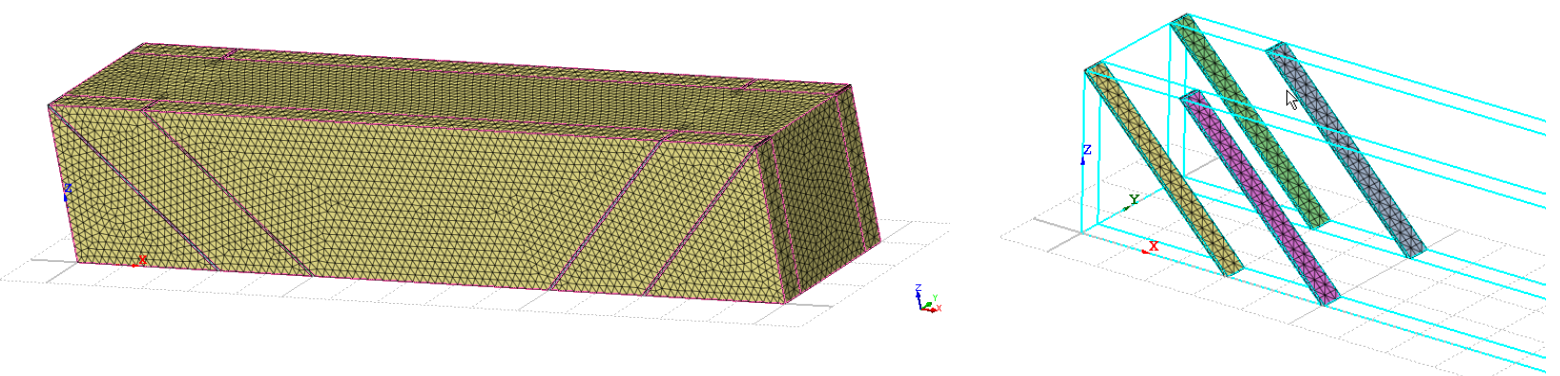

Figura 3.19 - Modelagem em elementos tridimensionais para simular a análise modal

O elemento finito utilizado TE12L (Figura 3.20) é descrito pelo próprio manual do programa DIANA (2012) com quatro nós, três lados isoparamétrico em formato piramidal sólido. Utiliza interpolação linear e a integração numérica. Os polinômios com translação $\mathrm{u}_{\mathrm{xyz}}$ tem formulação matemática expressa pela Equação 3.22. Normalmente esses polinômios produzem uma tensão constante e distribuição de tensões sobre o volume do elemento.

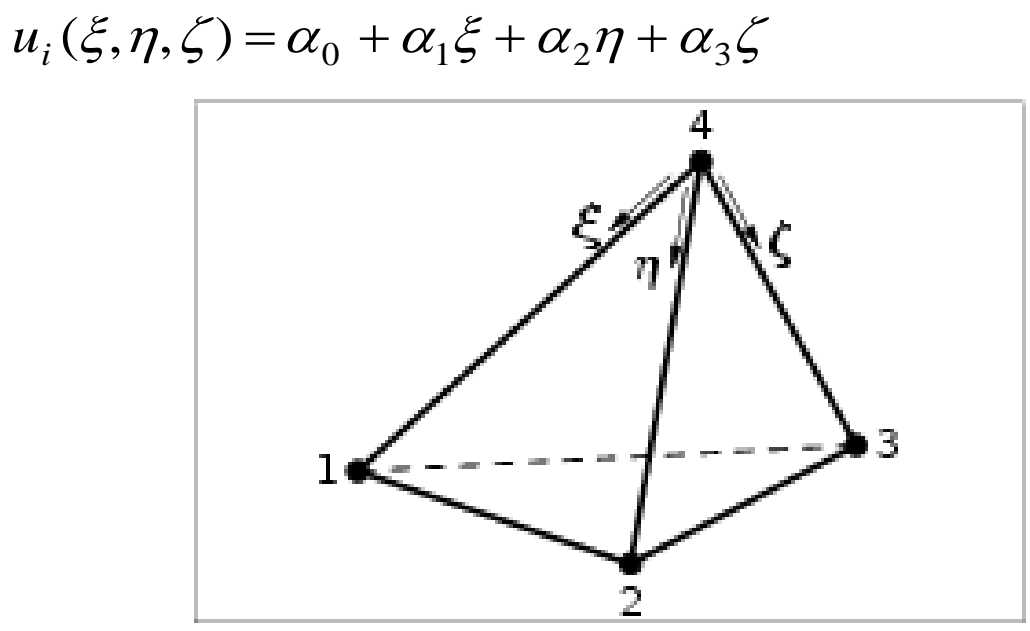

Figura 3.20 - Elemento finito TE12L

Alguns parâmetros utilizados para o concreto foram calibrados de maneira que o ensaio computacional fosse o mais próximo do experimental, algumas considerações devem ser explicadas aqui:

$\checkmark$ O módulo de elasticidade medido por ensaios dinâmicos é maior que o estático. Para a sua adequação aos valores obtidos em ensaios dinâmicos foram aqui reduzidos com um coeficiente de 1,3 considerando os estudos de Diógenes et al (2011);

$\checkmark \mathrm{Na}$ discriminação da resistência a tração do concreto foram utilizadas as menores resistências obtidas nos corpos de prova. 


\section{APRESENTAÇÃO E ANÁLISE DE RESULTADOS - PRISMAS}

Os ensaios piloto experimentais foram divididos em ensaios destrutivos e não destrutivos, realizados com prismas de concreto reforçados ao cisalhamento com laminados de CFRP pela técnica NSM e por análise modal das frequências naturais dos prismas.

Primeiramente foram analisados os resultados das resistências e módulos de elasticidade dos corpos de prova de concreto, utilizados para caracterização dos materiais dos Prismas. Para os demais componentes como o aço, o adesivo epóxi e o laminado de CFRP foram considerados as propriedades fornecidas pelo fabricante nas análises de resultados dos ensaios piloto, sendo os mesmos devidamente caracterizados e ensaiados somente no ensaio principal.

Nos ensaios destrutivos foram analisadas as forças máximas, a forma de ruptura, os deslocamentos verticais e as deformações nas armaduras longitudinal e nos laminados de CFRP. Nos ensaios não destrutivos analisou-se a variação dos módulos de elasticidade, determinadas pelas frequências naturais dos prismas.

\subsection{CORPOS DE PROVA}

\subsubsection{Resistências}

Como já mencionado, os ensaios de resistência a compressão e tração do concreto foram executados conforme as normas ABNT NBR 5739:2007 e NBR 7222:2011 respectivamente. A primeira moldagem de concreto obteve resistência à compressão média aos $43,75 \mathrm{MPa}$, sendo assim denominado de C40, e obteve resistência média à tração de 3,38MPa. Para a segunda moldagem de concreto, a resistência à compressão média foi de 62,28MPa, sendo assim denominado de C60, apresentando uma resistência média à tração foi de 4,11MPa.

A Tabela 4.1 e Tabela 4.2 apresentam as idades de ensaio e as resistências à tração e a compressão dos corpos de prova dos concretos C40 e C60 respectivamente. 
Tabela 4.1 - Resistências à compressão e à tração dos corpos de prova C40

\begin{tabular}{c|c|c|c|c}
\hline $\mathbf{C P s}$ & $\begin{array}{c}\text { Peso } \\
\mathbf{( g )}\end{array}$ & $\begin{array}{c}\text { Idade } \\
\text { (dias) }\end{array}$ & $\begin{array}{c}\text { Tensão de } \\
\text { compressão } \mathbf{( M P a )}\end{array}$ & $\begin{array}{c}\text { Tensão de } \\
\text { tração } \mathbf{( M P a )}\end{array}$ \\
\hline $\mathbf{1}$ & 3819,3 & 71 & 46,25 & \\
\hline $\mathbf{2}$ & 3824,1 & 71 & 46,82 & \\
\hline $\mathbf{3}$ & 3792,0 & 71 & 43,01 & \\
\hline $\mathbf{4}$ & 3802,5 & 71 & & 4,08 \\
\hline $\mathbf{5}$ & 3762,5 & 71 & & 3,011 \\
\hline $\mathbf{6}$ & 3831,8 & 71 & & 2,725 \\
\hline $\mathbf{7}$ & 3860,3 & 69 & 42,99 & \\
\hline $\mathbf{8}$ & 3808,8 & 69 & 42,51 & \\
\hline $\mathbf{9}$ & 3832,6 & 69 & 41,12 & \\
\hline $\mathbf{1 0}$ & 3824,6 & 69 & & 2,989 \\
\hline $\mathbf{1 1}$ & 3807,7 & 69 & & 3,421 \\
\hline $\mathbf{1 2}$ & 3810,0 & 69 & & 4,039 \\
\hline & & Média & $\mathbf{4 3 , 7 8}$ & $\mathbf{3}, \mathbf{3 8}$ \\
\hline & & CV & $5,7 \%$ & $17,0 \%$ \\
\hline
\end{tabular}

Tabela 4.2 - Resistências à compressão e à tração dos corpos de prova C60

\begin{tabular}{c|c|c|c|c}
\hline $\mathbf{C P s}$ & $\begin{array}{c}\text { Peso } \\
\mathbf{( g )}\end{array}$ & $\begin{array}{c}\text { Idade } \\
\text { (dias) }\end{array}$ & $\begin{array}{c}\text { Tensão de } \\
\text { compressão (MPa) }\end{array}$ & $\begin{array}{c}\text { Tensão de } \\
\text { tração (MPa) }\end{array}$ \\
\hline $\mathbf{1 3}$ & 3841,5 & 64 & 64,14 & \\
\hline $\mathbf{1 4}$ & 3835,2 & 64 & 64,86 & \\
\hline $\mathbf{1 5}$ & 3802,8 & 64 & 60,11 & 4,141 \\
\hline $\mathbf{1 6}$ & 3841,0 & 64 & & 4,086 \\
\hline $\mathbf{1 7}$ & 3806,6 & 64 & & 5,046 \\
\hline $\mathbf{1 8}$ & 3831,1 & 64 & & \\
\hline $\mathbf{1 9}$ & 3841,3 & 62 & 65,12 & \\
\hline $\mathbf{2 0}$ & 3860,1 & 62 & 62,07 & \\
\hline $\mathbf{2 1}$ & 3895,3 & 62 & 57,36 & 3,363 \\
\hline $\mathbf{2 2}$ & 3813,9 & 62 & & 4,115 \\
\hline $\mathbf{2 3}$ & 3879,0 & 62 & & 3,898 \\
\hline $\mathbf{2 4}$ & 3821,4 & 62 & & $\mathbf{4 , 1 1}$ \\
\hline & & Média & $\mathbf{6 2 , 2 8}$ & $13,2 \%$ \\
\hline & & CV & $5,2 \%$ & \\
\hline
\end{tabular}

\subsubsection{Módulo de Elasticidade}

Os módulos de elasticidade apresentados neste trabalho foram obtidos por ensaios dinâmicos na mesma data dos ensaios de resistências e para o seu cálculo foram utilizadas as equações da norma ASTM C215 (2008), descritas no capitulo materiais e métodos. No seu cálculo é considerada apenas a primeira frequência natural, peso e dimensões dos elementos, podendo ser utilizados tanto para os resultados com acelerômetros piezoelétricos como no programa Sonelatic ${ }^{\circledR}$. Os resultados dos módulos de elasticidades calculados são apresentados na Tabela 4.3 e na Tabela 4.4. 
Tabela 4.3 - Módulo de elasticidade dos corpos de prova C40

\begin{tabular}{c|c|c|c|c}
\hline CPs & $\begin{array}{c}\text { Frequência } \\
\text { Flexional (Hz) }\end{array}$ & $\begin{array}{c}\text { Frequência } \\
\text { Longitudinal (Hz) }\end{array}$ & $\begin{array}{c}\mathbf{E}_{\text {flex }} \\
\mathbf{( G P a )}\end{array}$ & $\begin{array}{c}\mathbf{E}_{\text {long }} \\
\mathbf{( G P a )}\end{array}$ \\
\hline \multicolumn{5}{|c|}{ Copos de prova com C40 } \\
\hline $\mathbf{1}$ & 6030 & 9731 & 38,38 & 36,84 \\
\hline $\mathbf{2}$ & 5950 & 9682 & 37,41 & 36,51 \\
\hline $\mathbf{3}$ & 5946 & 9722 & 37,05 & 36,51 \\
\hline $\mathbf{4}$ & 5946 & 9736 & 37,15 & 36,72 \\
\hline $\mathbf{5}$ & 5970 & 9785 & 37,06 & 36,69 \\
\hline $\mathbf{6}$ & 5943 & 9720 & 37,40 & 36,88 \\
\hline $\mathbf{7}$ & 6266 & 10040 & 41,89 & 39,64 \\
\hline $\mathbf{8}$ & 6313 & 10090 & 41,95 & 39,50 \\
\hline $\mathbf{9}$ & 6395 & 10137 & 43,31 & 40,12 \\
\hline $\mathbf{1 0}$ & 6366 & 10174 & 42,83 & 40,32 \\
\hline $\mathbf{1 1}$ & 6251 & 10092 & 41,12 & 39,50 \\
\hline $\mathbf{1 2}$ & 6248 & 10101 & 41,10 & 39,60 \\
\hline & & Média & $\mathbf{3 9 , 7 2}$ & $\mathbf{3 8 , 2 4}$ \\
\hline & & CV & $6,3 \%$ & $4,3 \%$ \\
\hline
\end{tabular}

Tabela 4.4 - Módulo de elasticidade dos corpos de prova C60

\begin{tabular}{|c|c|c|c|c|}
\hline CPs & $\begin{array}{c}\text { Frequência } \\
\text { Flexional (Hz) }\end{array}$ & $\begin{array}{c}\text { Frequência } \\
\text { Longitudinal (Hz) }\end{array}$ & $\begin{array}{c}\mathbf{E}_{\text {flex }} \\
(\mathbf{G P a})\end{array}$ & $\begin{array}{c}\mathbf{E}_{\text {long }} \\
\mathbf{( G P a})\end{array}$ \\
\hline \multicolumn{5}{|c}{ Copos de prova com C60 } \\
\hline $\mathbf{1 3}$ & 6610 & 10533 & 46,38 & 43,42 \\
\hline $\mathbf{1 4}$ & 6679 & 10630 & 47,28 & 44,14 \\
\hline $\mathbf{1 5}$ & 6656 & 10645 & 46,56 & 43,89 \\
\hline $\mathbf{1 6}$ & 6689 & 10583 & 47,49 & 43,82 \\
\hline $\mathbf{1 7}$ & 6621 & 10566 & 46,12 & 43,29 \\
\hline $\mathbf{1 8}$ & 6640 & 10580 & 46,68 & 43,68 \\
\hline $\mathbf{1 9}$ & 6493 & 10541 & 44,75 & 43,48 \\
\hline $\mathbf{2 0}$ & 6636 & 10701 & 46,98 & 45,02 \\
\hline $\mathbf{2 1}$ & 6504 & 10514 & 45,54 & 43,86 \\
\hline $\mathbf{2 2}$ & 6475 & 10476 & 44,19 & 42,63 \\
\hline $\mathbf{2 3}$ & 6580 & 10650 & 46,41 & 44,81 \\
\hline $\mathbf{2 4}$ & 6455 & 10466 & 44,00 & 42,64 \\
\hline & & Média & 46,03 & 43,72 \\
\hline & & CV & $2,5 \%$ & $1,7 \%$ \\
\hline
\end{tabular}

Os corpos de prova obtiveram para o $\mathrm{C} 40$ valores médios do modulo de elasticidade com os ensaios flexionais de 39,62GPa e com os ensaios longitudinais de 38,24GPa. O coeficiente de variação dos módulos no concreto C40 foi de 6,5\%, este valor foi elevado pelas concretagens em dois dias diferentes, observados na mudança dos resultados nos corpos de prova de número 1 a 6 para os de número 7 a 12 . 
O C60 apresentou menor variação nos resultados, com CV de até 2,5\% e módulos de elasticidade maiores que os dos corpos de prova $\mathrm{C} 40$, tanto medidos nos ensaios flexionais como nos ensaios longitudinais.

\subsection{ENSAIOS DESTRUTIVOS - PRISMAS}

Os prismas sem o sistema de reforço foram dimensionados com seção superarmada, no domínio 4 , onde o aço terá alongamento menor que $\varepsilon_{\mathrm{yd}}$ e o concreto com encurtamento máximo. A opção por dimensionar os prismas em superarmados foi adotada para garantir que uma maior capacidade de carga na flexão e assim a ruptura ocorresse no cisalhamento.

\subsubsection{Forças máximas}

As forças máximas foram calculadas teoricamente conforme descrito no capítulo matérias e métodos dos prismas, nas hipóteses de ruptura por flexão, cisalhamento e cisalhamento com reforço de CFRP. Os valores da força máxima admissíveis são apresentados na Tabela 4.5

Tabela 4.5 - Força máxima admissível

\begin{tabular}{c|c|c}
\hline Dimensionamento & C40 & C60 \\
\hline Flexão & $255 \mathrm{kN}$ & $292 \mathrm{kN}$ \\
\hline Cisalhamento & $54 \mathrm{kN}$ & $76,3 \mathrm{kN}$ \\
\hline Cisalhamento com Reforço & $129,1 \mathrm{kN}$ & $152,7 \mathrm{kN}$ \\
\hline
\end{tabular}

Os dimensionamentos das forças máximas admissíveis para os prismas mostram que os valores obtidos para o cisalhamento são bem inferiores aos obtidos na ruptura por flexão, determinando assim o modo de ruptura dos prismas por cisalhamento. O mesmo efeito permanece nos prismas com reforço de CFRP, onde os valores calculados teoricamente são inferiores aos da flexão.

Os resultados das forças de ruptura experimentais dos prismas são apresentados na Tabela 4.6. Nesta são apresentadas também as relações entre os resultados com a média dos prismas sem reforço (SR) e dos prismas com reforço (CFRP). 
Tabela 4.6 - Forças máxima de ensaio dos prismas

\begin{tabular}{|c|c|c|c|}
\hline \multicolumn{2}{|l|}{ P40 } & \multicolumn{2}{|c|}{ P60 } \\
\hline \multicolumn{2}{|l|}{ P40 SR } & \multicolumn{2}{|c|}{ P60 SR } \\
\hline P1 & $58,46 \mathrm{kN}$ & P13 & $61,44 \mathrm{kN}$ \\
\hline P2 & $47,43 \mathrm{kN}$ & P14 & $49,54 \mathrm{kN}$ \\
\hline P7 & $62,90 \mathrm{kN}$ & P19 & $60,98 \mathrm{kN}$ \\
\hline Média & $56,27 \mathrm{kN}$ & Média & $57,32 \mathrm{kN}$ \\
\hline $\mathrm{CV}$ & $14,2 \%$ & $\mathrm{CV}$ & $11,8 \%$ \\
\hline \multicolumn{2}{|l|}{ P40 CFRP } & \multicolumn{2}{|c|}{ P60 CFRP } \\
\hline P5 & $70,83 \mathrm{kN}$ & P17 & $86,89 \mathrm{kN}$ \\
\hline P9 & $69,54 \mathrm{kN}$ & P18 & $84,47 \mathrm{kN}$ \\
\hline P12 & $63,50 \mathrm{kN}$ & P24 & $79,89 \mathrm{kN}$ \\
\hline Média & $67,96 \mathrm{kN}$ & Média & $83,75 \mathrm{kN}$ \\
\hline $\mathrm{CV}$ & $5,8 \%$ & $\mathrm{CV}$ & $4,2 \%$ \\
\hline Relação com o SR & $+20,8 \%$ & & $+46,1 \%$ \\
\hline \multicolumn{2}{|l|}{ P40 40\% } & \multicolumn{2}{|c|}{ P60 40\% } \\
\hline P4 & $70,60 \mathrm{kN}$ & P16 & $74,81 \mathrm{kN}$ \\
\hline P6 & $54,94 \mathrm{kN}$ & P20 & $77,05 \mathrm{kN}$ \\
\hline P11 & $77,46 \mathrm{kN}$ & P23 & $73,76 \mathrm{kN}$ \\
\hline Média & $67,67 \mathrm{kN}$ & Média & $75,20 \mathrm{kN}$ \\
\hline CV & $17,1 \%$ & CV & $2,2 \%$ \\
\hline Relação com o SR & $+20,3 \%$ & & $+31,2 \%$ \\
\hline Relação com o CFRP & $-0,4 \%$ & & $-10,2 \%$ \\
\hline \multicolumn{2}{|l|}{ P40 70\% } & \multicolumn{2}{|c|}{ P60 70\% } \\
\hline P3 & $76,50 \mathrm{kN}$ & P15 & $78,10 \mathrm{kN}$ \\
\hline P8 & $72,70 \mathrm{kN}$ & P21 & $77,10 \mathrm{kN}$ \\
\hline P10 & $62,90 \mathrm{kN}$ & P22 & $82,50 \mathrm{kN}$ \\
\hline Média & $70,70 \mathrm{kN}$ & Média & $79,23 \mathrm{kN}$ \\
\hline $\mathrm{CV}$ & $9,9 \%$ & $\mathrm{CV}$ & $3,6 \%$ \\
\hline Relação com o SR & $+25,7 \%$ & & $+38,2 \%$ \\
\hline Relação com o CFRP & $+4,0 \%$ & & $-5,4 \%$ \\
\hline
\end{tabular}

Os prismas com P40 SR obtiveram uma força máxima média de $56,27 \mathrm{kN}$, sendo este valor 4,2\% maior que o previsto em cálculo teórico. Quando reforçados os prismas P40 CFRP obtiveram força máxima média 20,8\% maiores que os prismas P40 SR, demonstrando a capacidade do reforço de CFRP no reforço ao cisalhamento. As forças máximas das vigas reforçadas com CFRP foram bem inferiores aos valores teóricos, pois a ruptura manteve-se no cisalhamento do concreto e não no reforço de CFRP. As pequenas dimensões dos prismas não permitiram a utilização do acréscimo de força do reforço por completo.

Os prismas com carregamento prévio P40 40\%, apresentaram um aumento de 20,3\% em relação aos prismas P40 SR e apenas 0,4\% menores que os prismas P40 CFRP. Valores médios que poderiam ser maiores caso o prisma 6 não tivesse um comportamento e resistência muito 
diferente dos demais, causando um coeficiente de variação de 17,1\%. Constatando que o carregamento prévio de $40 \%$ para os prismas P40 não influenciou na capacidade.

Ao utilizar prismas com maior carregamento prévio P40 70\%, a força máxima média aumentou em 25,7\% em relação aos prismas P40 SR são 4\% maiores que os prismas P40 CFRP. Observou-se novamente que as forças máximas de todos os prismas reforçados estão muito próximos, não sendo influenciada pelo carregamento prévio.

Ao estudar os prismas com concreto mais resistente (C60) ocorreu um aumento muito baixo na força máxima, com valores médios para o P60 SR de 57,32 kN. Seus valores quando comparados com os previstos em cálculo apresentaram uma redução, sendo $24,9 \%$ diferente do ocorrido nos prismas P40.

A força de ruptura dos prismas P40 SR foi apenas 1,9\% menor que os prismas P60 SR, fato que não deveria ter ocorrido, pois estes ao romper por cisalhamento dependem diretamente da resistência do concreto, uma vez que nestes elementos não existem armaduras de transversais. Com um aumento da resistência à tração do concreto de 3,38MPa para 4,11MPa esperava-se uma maior diferença entre a capacidade de carga dos prismas, pois nos cálculos teóricos das forças máximas indicava um aumento de 29,5\%.

Quando prismas com P60 foram reforçados com CFRP a força máxima média foi de $83,75 \mathrm{kN}$, aumentando em $47,5 \%$ a capacidade de carga. Demostrando uma capacidade de reforço maior que a dos prismas com C40.

Já quando os prismas com P60 reforçados com CFRP sofreram carregamento prévio P60 $40 \%$, apresentaram aumentado da força máxima em 32,4\% em relação aos prismas P60 SR e redução em 10,2\% em relação prismas P60 CFRP.

Ao utilizar prismas P60 70\% obteve-se uma força máxima 39,5\% maior em relação aos prismas P60 SR e 5,4\% menor que os prismas P60 CFRP. Observou-se novamente que mesmo com carregamento prévio de 70\% da força máxima, os resultados dos prismas P60 CFRP e P60 $70 \%$ são similares. Os prismas fabricados com C60 reduziram um pouco a capacidade de carga desses elementos, diferentemente do ocorrido nos prismas com C40.

Constatou-se que o carregamento prévio pouco influenciou na força máxima dos prismas, ocorrendo maiores alterações nos prismas P60 40\%, desta forma podemos afirmar que a capacidade de incremento de força oriunda do reforço sofreram poucas influências do dano das fissurações pré-existentes no concreto. 
Quase todos os modelos reforçados com laminados de fibra de carbono apresentaram capacidade de carga maior que a média dos prismas sem reforço. A exceção ocorreu no prisma P6, que apresentou problemas durante o ensaio, sendo verificado que um dos lados do prisma foi mais solicitado. A grande diferença deste prisma poderia ter ocorrido devido a uma falha na concretagem, mas esta hipótese foi descartada pois o mesmo não apresentou alterações nos ensaios dinâmicos e de módulo de elasticidade.

\subsubsection{Forma de ruptura dos prismas}

Todos os modelos ensaiados apresentaram ruptura por cisalhamento do concreto, ao comparar as fissuras os prismas sem reforços com os reforçados com CFRP observa-se que o ângulo das fissuras de ruptura apresentou alterações, deixando de se deslocar em direção ao apoio e passando para a região próxima ao reforço de CFRP. A capacidade de alterar a inclinação das fissuras de cisalhamento indica a influência do reforço.

Os prismas sem reforços apresentaram em sua maioria pequenas fissuras de flexão e grandes fissuras de cisalhamento, partindo do ponto de aplicação da força até próximo aos apoios, normalmente com maior intensidade de um lado do prisma.

Devido ao carregamento ser efetuado por controle de deslocamento, foi possível observar como o prisma sem reforços se comporta após a ruptura, que ao ocorrer, reduz bruscamente a força aplicada com o aumento das fissuras e transferência dos esforços para o aço. A Figura 4.1 apresenta a formação típica das fissuras para todos os prismas sem reforços.

Os prismas reforçados também apresentaram ruptura por cisalhamento, tendo como principal diferença o ângulo das fissuras, que ao invés de se deslocarem do ponto de aplicação da força até os apoios, foram até o fim do reforço de CFRP (Figura 4.2). Acredita-se que caso fossem acrescentados mais uma camada de laminados posicionados até a parte central dos prismas os resultados seriam melhores e a forma de ruptura poderia mudar ocorrendo uma maior influência do sistema de reforço. 


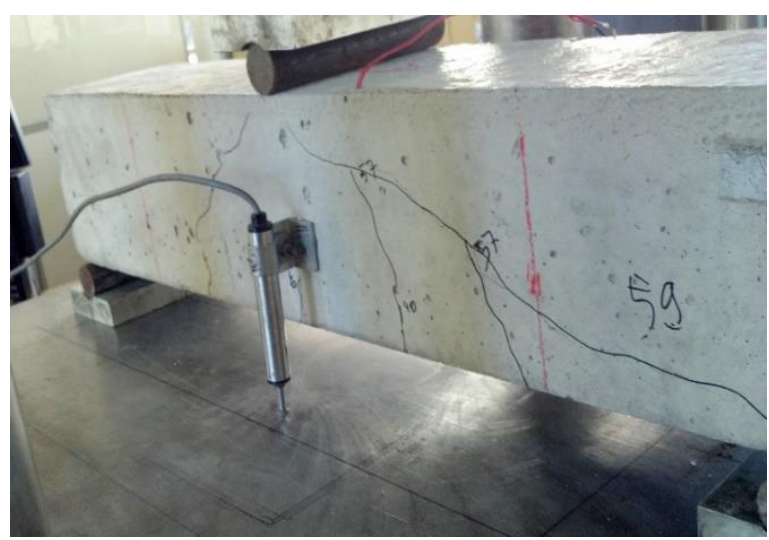

Figura 4.1 - Fissuras no Prisma P40 SR

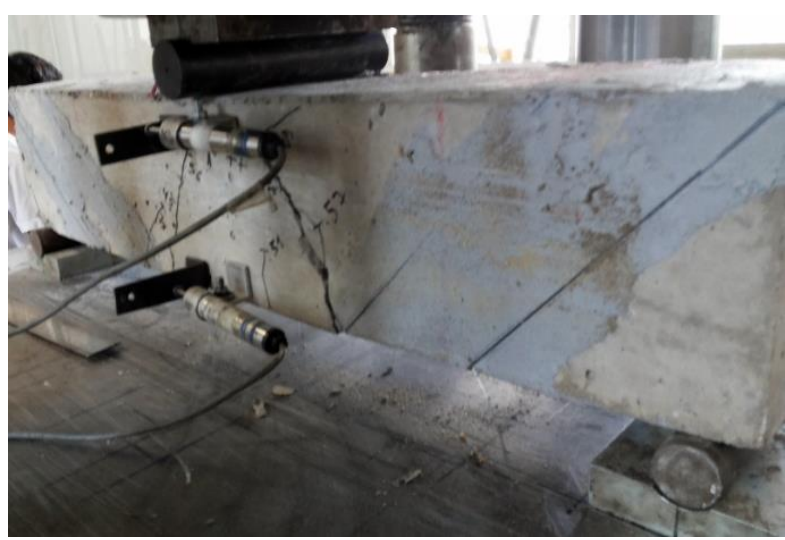

Figura 4.2 - Fissuras no Prisma P40 CFRP

O carregamento prévio dos prismas não influenciou na forma de ruptura para nenhuma das classes de concreto, apresentando inicialmente pequenas fissuras de flexão e cisalhamento da parte central do prisma e com fissuras de ruptura do ponto de aplicação da força até fim do reforço de CFRP.

Com o objetivo de entender melhor o comportamento pós pico, o prisma P3 foi solicitado até sua ruptura completa, com a fissura separando toda a seção transversal. As fissuras de um dos lados do prisma tiveram aberturas maiores que $1 \mathrm{~cm}$ e houve o destacamento do concreto de cobrimento na face inferior do prisma. A Figura 4.3 mostra as fissuras ocorridas no prisma P3, com destaque para a parte inferior do prisma, que mostra como as fissuras após passarem pela espessura dos laminados de CFRP, concentram-se na linha central do prisma, região mais fraca por não apresentar os reforços.
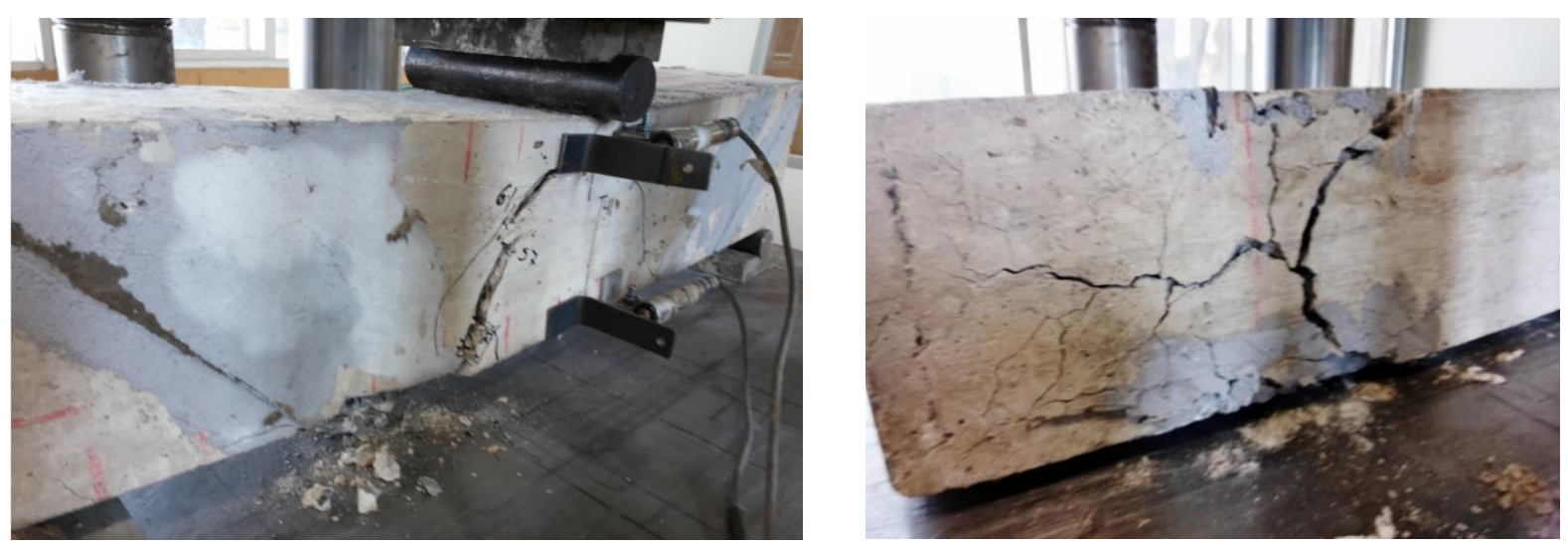

Figura 4.3 - Fissuras no Prisma número 3

\subsubsection{Deslocamento vertical}

No deslocamento vertical os resultados dos prismas sem reforços foram comparados com os reforçados em duas etapas de carregamento. A primeira na força máxima, para demonstrar o maior deslocamento dos prismas em função da maior força máxima. Em seguida seus valores serão 
comparados na força de $50 \mathrm{kN}$ demostrando a capacidade do reforço de reduzir os deslocamentos verticais.

$\mathrm{Na}$ força máxima, os prismas P40 CFRP apresentaram deslocamentos verticais no meio do vão maior que os prismas P40 SR (P1, P2, P7), excluindo o prisma P6 que apresentou problemas de ensaio. O Gráfico 4.1 apresenta os diagramas força x deslocamento da média dos resultados dos prismas $\mathrm{P} 40$

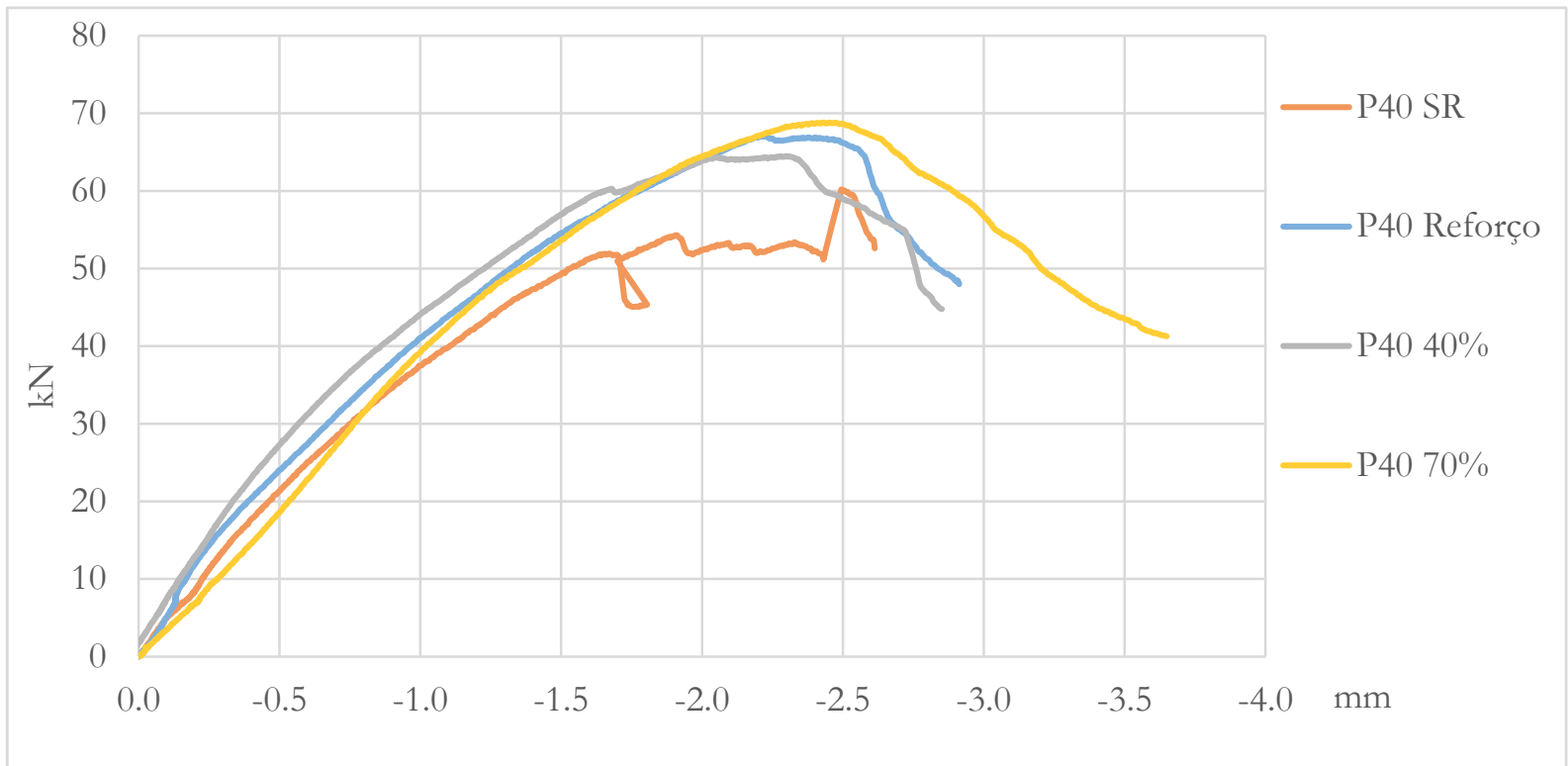

Gráfico 4.1 - Força x Deslocamento - P40

O mesmo efeito foi observado nos prismas com um concreto mais resistente. Nestes os prismas P60 com sistema de reforço apresentaram deslocamento vertical no meio do vão maiores que os sem reforço (P60 SR) como pode-se observar no Gráfico 4.2.

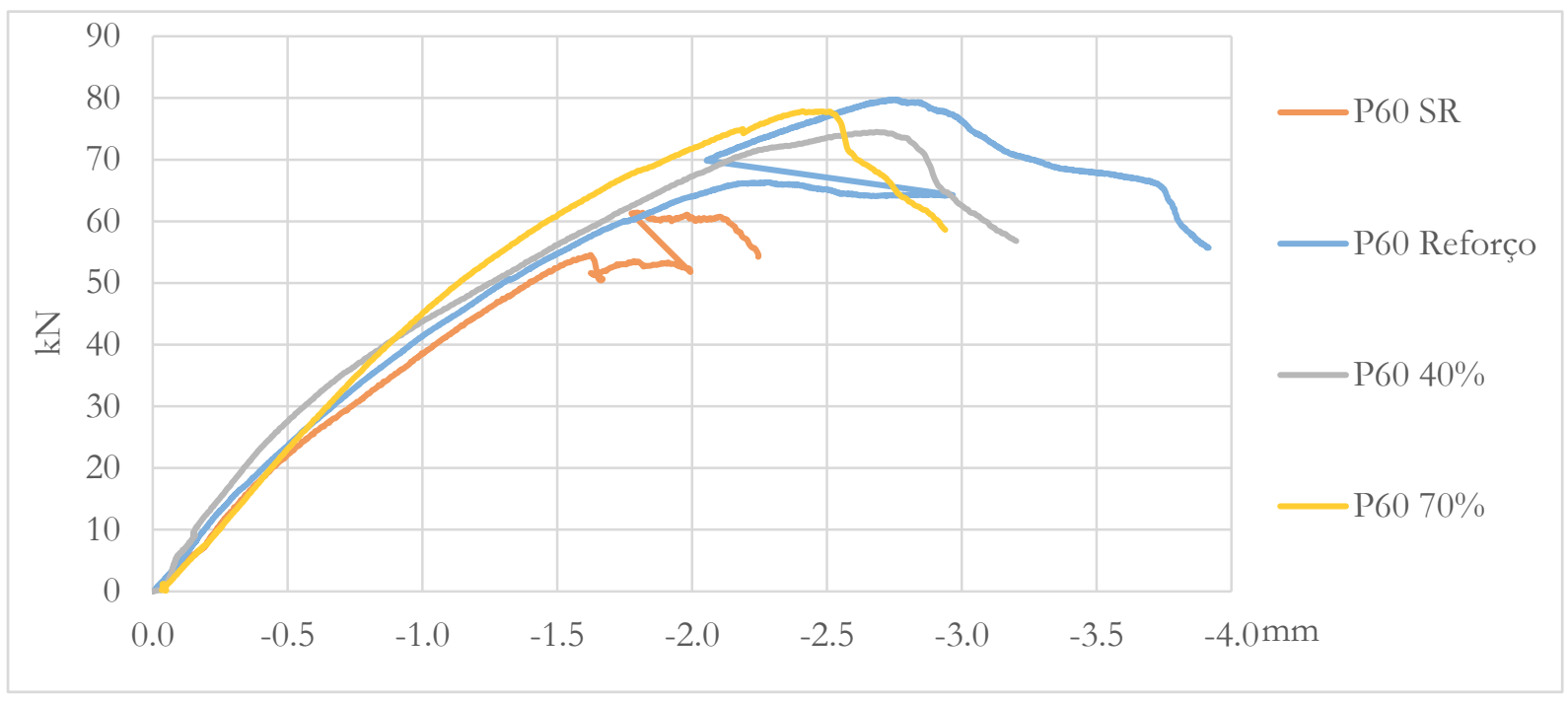

Gráfico 4.2 - Força x Deslocamento - P60 
Os efeitos do carregamento prévio da mudança de comportamento do deslocamento central dos prismas somente foram observados para os prismas P60, onde ao serem carregados previamente ocorre uma pequena redução nos deslocamentos verticais. Os resultados são apresentados na Tabela 4.7.

Tabela 4.7 - Deslocamento vertical na força máxima (mm)

\begin{tabular}{|c|c|c|c|}
\hline \multicolumn{2}{|l|}{ P40 } & \multicolumn{2}{|c|}{ P60 } \\
\hline \multicolumn{2}{|l|}{ P40 SR } & \multicolumn{2}{|c|}{ P60 SR } \\
\hline P1 & $-1,79$ & P13 & $-1,80$ \\
\hline P2 & $-1,83$ & P14 & $-1,74$ \\
\hline P7 & $-2,12$ & P19 & $-1,65$ \\
\hline Média & $-1,80$ & Média & $-1,73$ \\
\hline $\mathrm{CV}$ & $9,4 \%$ & $\mathrm{CV}$ & $4,3 \%$ \\
\hline \multicolumn{2}{|l|}{ P40 CFRP } & \multicolumn{2}{|c|}{ P60 CFRP } \\
\hline P5 & $-2,48$ & P17 & $-3,38$ \\
\hline P9 & $-2,24$ & P18 & $-3,43$ \\
\hline P12 & $-2,20$ & P24 & $-2,84$ \\
\hline Média & $-2,31$ & Média & $-3,22$ \\
\hline $\mathrm{CV}$ & $6,7 \%$ & $\mathrm{CV}$ & $10,2 \%$ \\
\hline Relação com o SR & $+20,4 \%$ & & $+86,2 \%$ \\
\hline \multicolumn{2}{|l|}{ P40 40\% } & \multicolumn{2}{|c|}{ P60 40\% } \\
\hline P4 & $-2,33$ & P16 & $-2,09$ \\
\hline P6 & $-1,36$ & P20 & $-3,08$ \\
\hline P11 & $-2,67$ & P23 & $-2,87$ \\
\hline Média & $-2,12$ & Média & $-2,68$ \\
\hline $\mathrm{CV}$ & $32,0 \%$ & $\mathrm{CV}$ & $19,4 \%$ \\
\hline Relação com o SR & $+10,7 \%$ & & $+55,2 \%$ \\
\hline Relação com o CFRP & $-8,0 \%$ & & $-16,7 \%$ \\
\hline \multicolumn{2}{|l|}{ P40 70\% } & \multicolumn{2}{|c|}{ P60 70\% } \\
\hline P3 & $-2,71$ & P15 & $-2,57$ \\
\hline P8 & $-2,38$ & $\mathbf{P} 21$ & $-2,67$ \\
\hline P10 & $-2,37$ & P22 & $-2,49$ \\
\hline Média & $-2,49$ & Média & $-2,58$ \\
\hline CV & $7,8 \%$ & $\mathrm{CV}$ & $3,6 \%$ \\
\hline Relação com o SR & $+30,0 \%$ & & $+49,1 \%$ \\
\hline Relação com o CFRP & $+8,0 \%$ & & $-20,0 \%$ \\
\hline
\end{tabular}

Observou-se que ocorre um deslocamento vertical maior dos elementos reforçados em relação aos sem reforço. Assim como na força máxima, os deslocamentos verticais dos prismas P60 apresentaram um maior aumento após reforçadas. Essa maior deformação nos prismas ocorre principalmente por que as forças máximas dos prismas reforçados também foram maiores.

No prisma P40, o carregamento prévio de $40 \%$ reduziu o deslocamento vertical para a força máxima, enquanto que o carregamento prévio de $70 \%$ aumentou o deslocamento. Constatou- 
se que o carregamento prévio não interferiu no deslocamento vertical destes prismas, onde novamente os maiores e menores deslocamentos dependeram somente das forças máximas dos prismas. Para os prismas P60 houve a mesma constatação do prisma P40.

Quando se compara os deslocamentos verticais na mesma força, utilizando como referência uma força de $40 \mathrm{kN}$, comum a todos os prismas, é possível observar a eficiência dos sistemas de reforço de CFRP em reduzir os deslocamentos dos prismas (Tabela 4.8).

\begin{tabular}{|c|c|c|c|}
\hline \multicolumn{2}{|l|}{ P40 } & \multicolumn{2}{|c|}{ P60 } \\
\hline \multicolumn{2}{|l|}{ P40 SR } & \multicolumn{2}{|c|}{ P60 SR } \\
\hline P1 & $-0,94$ & P13 & $-0,96$ \\
\hline P2 & $-1,28$ & P14 & $-1,28$ \\
\hline P7 & $-0,96$ & P19 & $-0,94$ \\
\hline Média & $-1,06$ & Média & $-1,06$ \\
\hline $\mathrm{CV}$ & $18,1 \%$ & $\mathrm{CV}$ & $17,8 \%$ \\
\hline \multicolumn{2}{|l|}{ P40 CFRP } & \multicolumn{2}{|c|}{ P60 CFRP } \\
\hline P5 & $-1,03$ & P17 & $-0,92$ \\
\hline P9 & $-0,90$ & P18 & $-0,92$ \\
\hline P12 & $-0,99$ & P24 & $-0,90$ \\
\hline Média & $-0,98$ & Média & $-0,91$ \\
\hline $\mathrm{CV}$ & $6,7 \%$ & $\mathrm{CV}$ & $0,8 \%$ \\
\hline Relação com o SR & $-7,6 \%$ & & $-14,0 \%$ \\
\hline \multicolumn{2}{|l|}{ P40 40\% } & \multicolumn{2}{|c|}{ P60 40\% } \\
\hline P4 & $-0,93$ & P16 & $-0,55$ \\
\hline P6 & $-0,72$ & P20 & $-1,09$ \\
\hline P11 & $-0,93$ & P23 & $-0,90$ \\
\hline Média & $-0,86$ & Média & $-0,84$ \\
\hline $\mathrm{CV}$ & $14,5 \%$ & CV & $32,5 \%$ \\
\hline Relação com o SR & $-18,7 \%$ & & $-20,5 \%$ \\
\hline Relação com o CFRP & $-12,0 \%$ & & $-7,6 \%$ \\
\hline \multicolumn{2}{|l|}{ P40 70\% } & \multicolumn{2}{|c|}{ P60 70\% } \\
\hline P3 & $-0,94$ & P15 & $-0,82$ \\
\hline P8 & $-0,94$ & P21 & $-1,04$ \\
\hline P10 & $-1,21$ & P22 & $-0,76$ \\
\hline Média & $-1,03$ & Média & $-0,87$ \\
\hline $\mathrm{CV}$ & $15,2 \%$ & $\mathrm{CV}$ & $17,0 \%$ \\
\hline Relação com o SR & $-2,8 \%$ & & $-17,6 \%$ \\
\hline Relação com o CFRP & $5,2 \%$ & & $-4,3 \%$ \\
\hline
\end{tabular}

Observou-se que os deslocamentos verticais médios na força de $40 \mathrm{kN}$ são menores para todos os prismas reforçados com CFRP, para os dois tipos de concreto, C40 e C60. Este efeito demonstra a capacidade do reforço de reduzir as deformações em elementos estruturais. 
Independente da intensidade dos carregamentos prévios, os deslocamentos medidos na força de $40 \mathrm{kN}$ apresentaram a mesma ordem de grandeza, ocorrendo prismas com maiores e menores valores dos de referencia (P40 CFRP e P60 CFRP). Constatando-se que o carregamento prévio dos prismas não alterou o deslocamento vertical.

\subsubsection{Deformação no aço}

Assim como no deslocamento vertical, em média todos os prismas reforçados tiveram maiores deformações do aço nas forças máximas. Isto ocorreu devido ao acréscimo de capacidade de carga dos prismas reforçados, que solicitou mais da armadura longitudinal. Tabela 4.9

Tabela 4.9 - Deformação no aço para a força máxima

\begin{tabular}{|c|c|c|c|}
\hline \multicolumn{2}{|l|}{ P40 } & \multicolumn{2}{|c|}{ P60 } \\
\hline \multicolumn{2}{|l|}{ P40 SR } & \multicolumn{2}{|c|}{ P60 SR } \\
\hline P1 & $2,006 \%$ & P13 & $1,860 \%$ \\
\hline P2 & $1,585 \%$ & P14 & $1,632 \%$ \\
\hline P7 & $1,914 \%$ & P19 & $2,075 \%$ \\
\hline Média & $1,835 \%$ & Média & $1,856 \%$ \\
\hline $\mathbf{C V}$ & $12,1 \%$ & $\mathrm{CV}$ & $11,9 \%$ \\
\hline \multicolumn{2}{|l|}{ P40 CFRP } & \multicolumn{2}{|c|}{ P60 CFRP } \\
\hline P5 & $2,236 \%$ & P17 & $2,641 \%$ \\
\hline P9 & $2,017 \%$ & P18 & $2,441 \%$ \\
\hline P12 & $2,077 \%$ & P24 & $2,378 \%$ \\
\hline Média & $2,110 \%$ & Média & $2,486 \%$ \\
\hline $\mathbf{C V}$ & $5,4 \%$ & $\mathrm{CV}$ & $5,5 \%$ \\
\hline Relação com o SR & $15,0 \%$ & & $34,0 \%$ \\
\hline \multicolumn{2}{|l|}{ P40 40\% } & \multicolumn{2}{|c|}{ P60 40\% } \\
\hline P4 & $2,144 \% 0$ & P16 & $2,222 \%$ \\
\hline P6 & $1,490 \%$ & P20 & $1,976 \%$ \\
\hline P11 & $2,093 \%$ & P23 & $2,131 \%$ \\
\hline Média & $1,909 \%$ & Média & $2,110 \%$ \\
\hline CV & $19,1 \%$ & $\mathrm{CV}$ & $5,9 \%$ \\
\hline Relação com o SR & $4,0 \%$ & & $13,7 \%$ \\
\hline Relação com o CFRP & $-9,5 \%$ & & $-15,2 \%$ \\
\hline \multicolumn{2}{|l|}{ P40 70\% } & \multicolumn{2}{|c|}{ P60 70\% } \\
\hline P3 & $1,974 \%$ & P15 & $2,191 \%$ \\
\hline P8 & $2,087 \%$ & P21 & $2,219 \%$ \\
\hline P10 & $1,792 \%$ & P22 & $2,079 \%$ \\
\hline Média & $1,951 \%$ & Média & $2,163 \%$ \\
\hline CV & $7,6 \%$ & $\mathrm{CV}$ & $3,4 \%$ \\
\hline Relação com o SR & $6,3 \%$ & & $16,6 \%$ \\
\hline Relação com o CFRP & $-7,5 \%$ & & $-13,0 \%$ \\
\hline
\end{tabular}

Os prismas sem reforço tiveram, em média, deformações no aço de 1,835 \% para o P40

SR e de 1,856 \% para o P60 SR. As deformações aumentaram com o reforço de CFRP, elevando 
em 15\% para P40 e em 34\% para o P60. O aumento na deformação do aço nos prismas P60 CFRP foram maiores que nos dos prismas P40 CFRP devido ao acréscimo na capacidade de carga também serem maiores.

Os demais prismas reforçados, em que ocorreu carregamento prévio, tanto o com $40 \%$ quanto o com $70 \%$, tiveram redução de deformação no aço quando comparados com os prismas reforçados sem carregamento prévio para os dois tipos de concreto. Ocorrendo uma redução maior nos prismas com carregamento prévio de 40\%. Essa redução da deformação no aço ocorreu devido aos concretos com carregamento prévio também possuírem menor capacidade de carga que os reforçados (P40 CFRP e P60 CFRP) (Gráfico 4.3 e Gráfico 4.4).

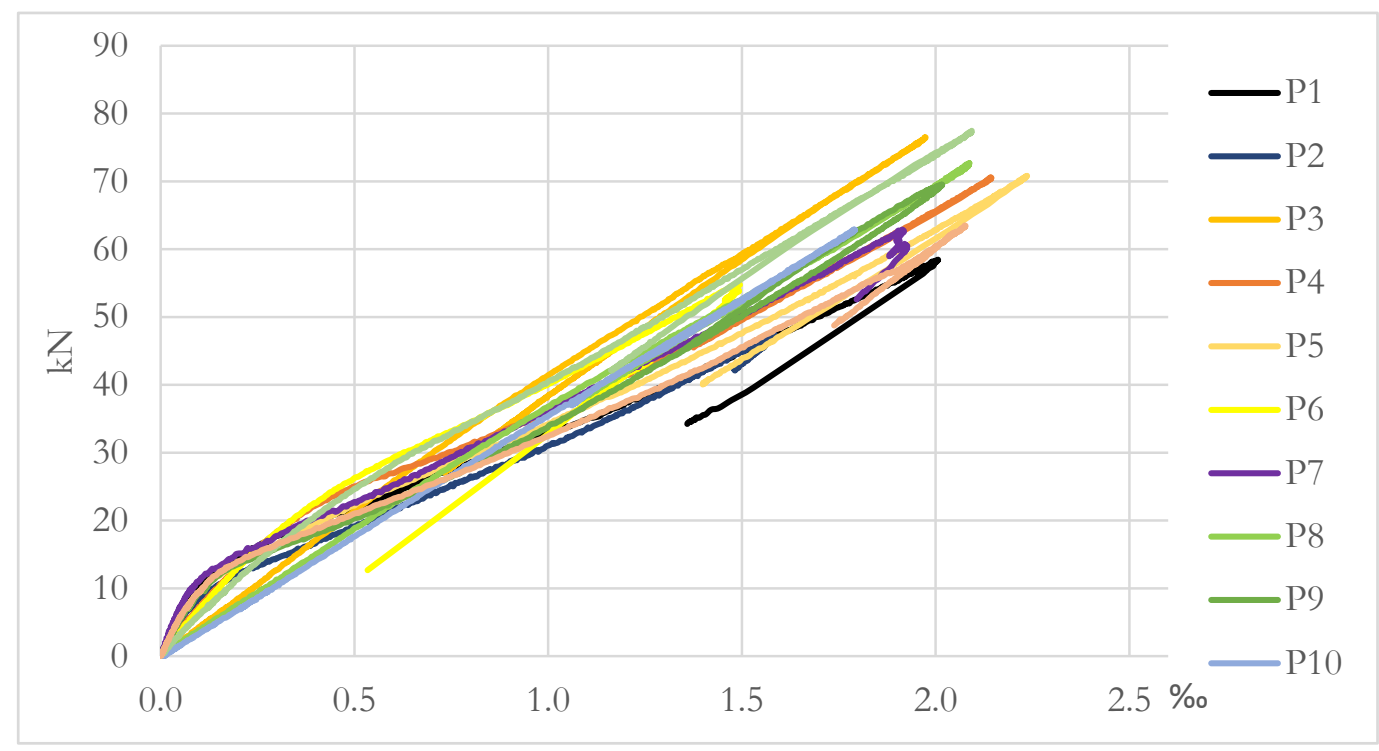

Gráfico 4.3 - Força x Deformação no aço dos Prismas C40

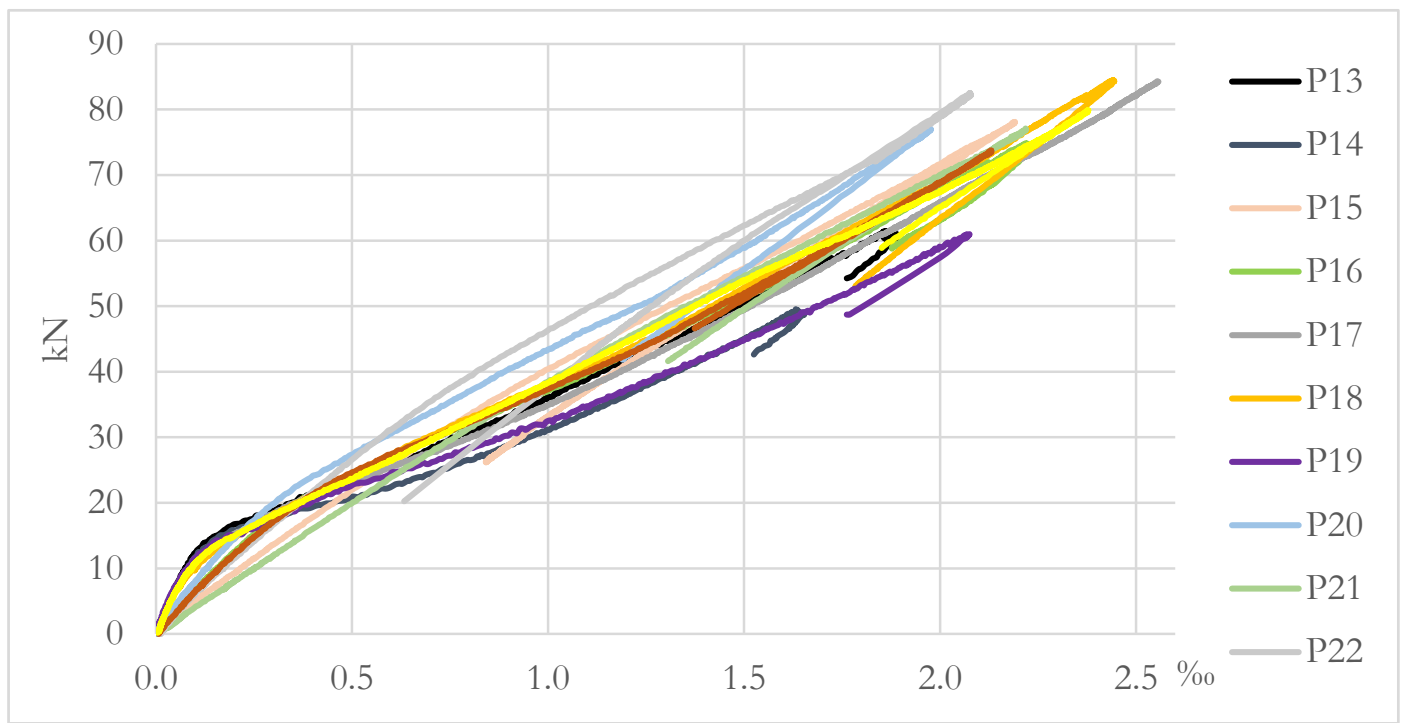

Gráfico 4.4 - Força x Deformação no aço dos Prismas C60 
Assim como observado na análise de resultados dos deslocamentos verticais, ao verificarmos a deformação do aço em uma mesma força, por exemplo $40 \mathrm{kN}$, observou-se um comportamento semelhante entre as curvas de todos os laminados com reforço de CFRP, independentemente da ocorrência de carregamento prévio.

A curvas dos prismas sem reforço (P1, P2, P7 e P13, P14, P19) apresentaram com o início das fissuras, em $14 \mathrm{kN}$, um aumento na deformação da armadura longitudinal, demostrando que a mesma é mais solicitada quando os prismas não possuem reforço.

\subsubsection{Deformação nos laminados de CFRP}

Para a análise de resultados da deformação dos laminados, estes foram denominados como laminados 1 e 2, para os que estão posicionadas ao lado esquerdo do prisma, enquanto que os laminados 3 e 4 estão posicionadas ao lado direito do prisma, como representado na Figura 4.4.

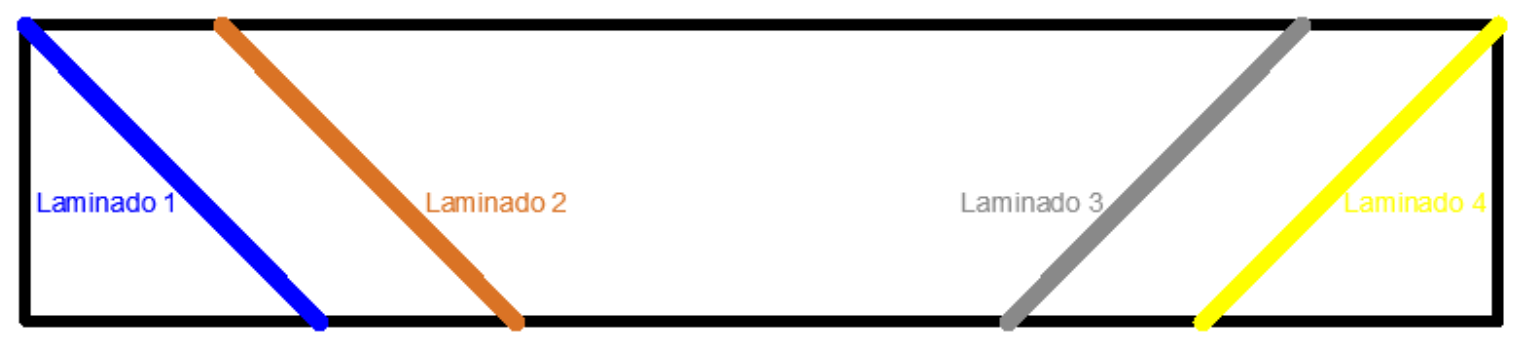

Figura 4.4 - Localização dos laminados inseridos nos prismas

\subsubsection{Prisma P40}

A análise das deformações dos laminados ocorrerá por meio de comparação entre os prismas de mesma categoria e nas alterações oriundas do carregamento prévio. Somente foram apresentados neste capítulo alguns gráficos destas deformações, sendo os demais apresentados no Apêndice B.

Os prismas reforçados C40 CFRP (P5, P9 e P12) apresentam curvas força x deformação com diferenças entre os modelos ensaiados, em que os prismas P5 e P12 apresentam uma deformação mais acentuada em um dos lados, enquanto que no prisma P9 os dois lados atuam com intensidade próximas.

No prisma P5 as deformações iniciam nos laminados 1 e 2, posicionados do lado esquerdo, ocorrendo deformações desde o início do carregamento, já os laminados do lado direito só iniciaram a deformar após uma força de $20 \mathrm{kN}$ (laminado 3) e $30 \mathrm{kN}$ (laminado 4). Na força máxima os laminados 3 e 4 possuíram deformações menores que os laminados 1 e 2, mas após a 
ruptura, as deformações do lado direito (laminados 3 e 4) aumentaram muito e as do lado esquerdo reduziram, caracterizando a ruptura no lado direito do prisma. (Gráfico 4.5)

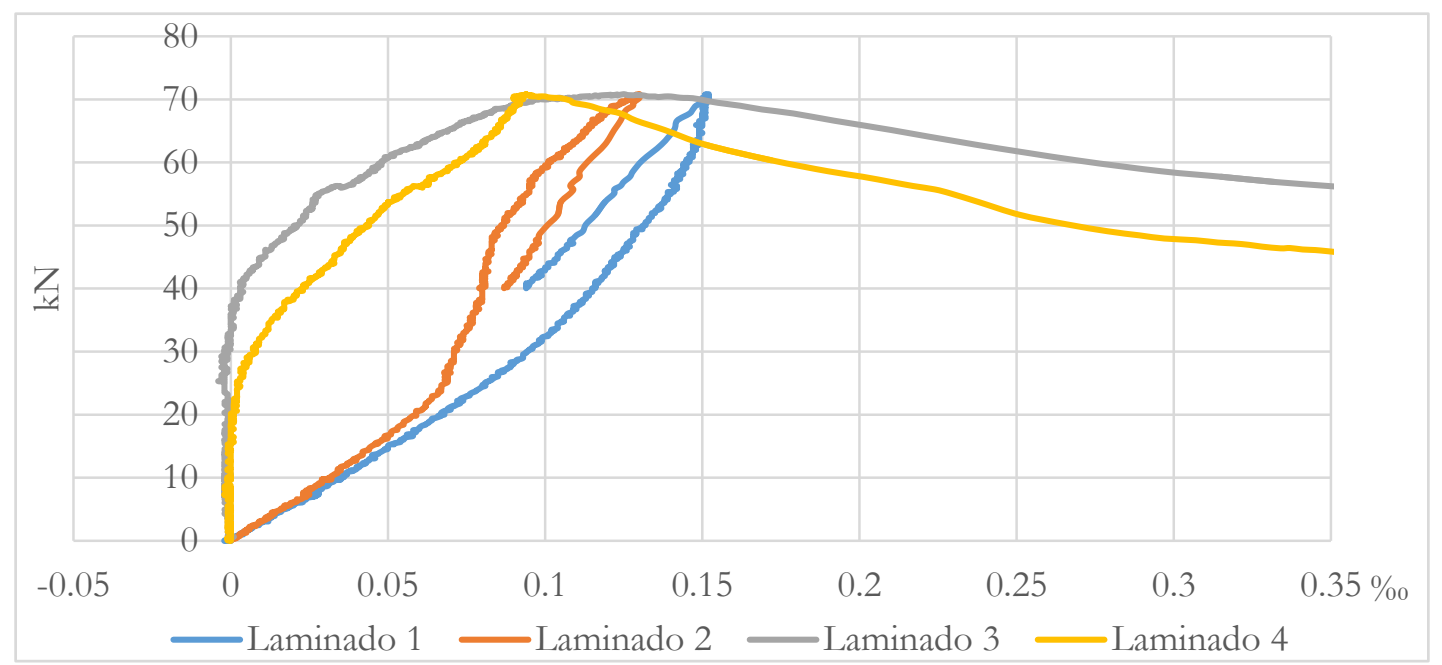

Gráfico 4.5 - Força x Deformação nos laminados - Prisma P5 - P40 CFRP

No prisma P9 ocorreu uma melhor simetria nas deformações dos reforços, tendo todos os laminados apresentado deformações desde o início do carregamento, com maiores deformações dos laminados do lado esquerdo. A ruptura ocorreu no lado esquerdo onde os laminados de CFRP foram mais solicitados. (Gráfico 4.6)

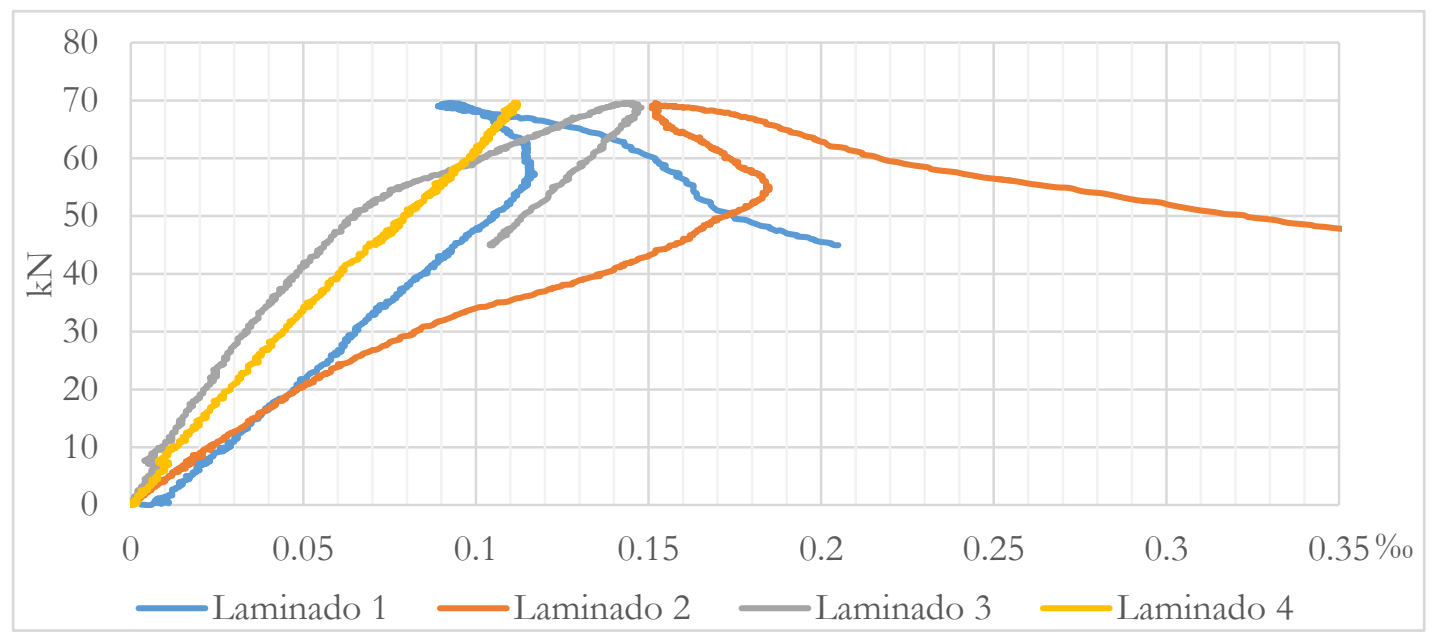

Gráfico 4.6 - Força x Deformação nos laminados - Prisma P9 - P40 CFRP

O prisma P12 apresentou a menor força máxima entre os P40 CFRP, ocorrendo deformação dos laminados em apenas um lado do prisma e com ruptura ocorrendo no lado em que os laminados não foram solicitados.

Numa comparação entre os resultados dos prismas P40 CFRP (P5, P9 e P12), observouse que a deformação no laminado tanto podem iniciar juntamente ao carregamento dos dois lados 
do prisma, como podem iniciar somente em um dos lados. Após a ruptura, os laminados do lado que ocorre a fissura principal aumentam suas deformações.

Nos prismas P5 e P9 que os laminados internos (2 e 3) apresentaram maiores deformações que os externos ( 1 e 4), demonstrando que a força cortante absorvida pelos laminados foi maior na parte central do prisma.

Nos prismas em que os laminados de CFRP auxiliaram no reforço dos dois lados (P5 e P9), observou-se que a deformação dos laminados mais solicitados foram menores, próxima de 0,15\% na força máxima, enquanto que no prisma P12 a deformação máxima foi de 0,26\%. Esta solicitação diferenciada dos laminados de CFRP do prisma P12 refletiu em uma força máxima de $63,5 \mathrm{kN}$, inferior aos prismas P5 e do prisma P9.

Dentre os prismas com carregamento prévio de 40\%, os prismas P4 e P11 tiveram comportamento similares aos prismas P5 e P9. Nestes, os 4 laminados deformaram desde o início do carregamento. Após a ruptura o lado com os laminados menos solicitados aumentou a deformação. (Gráfico 4.7)

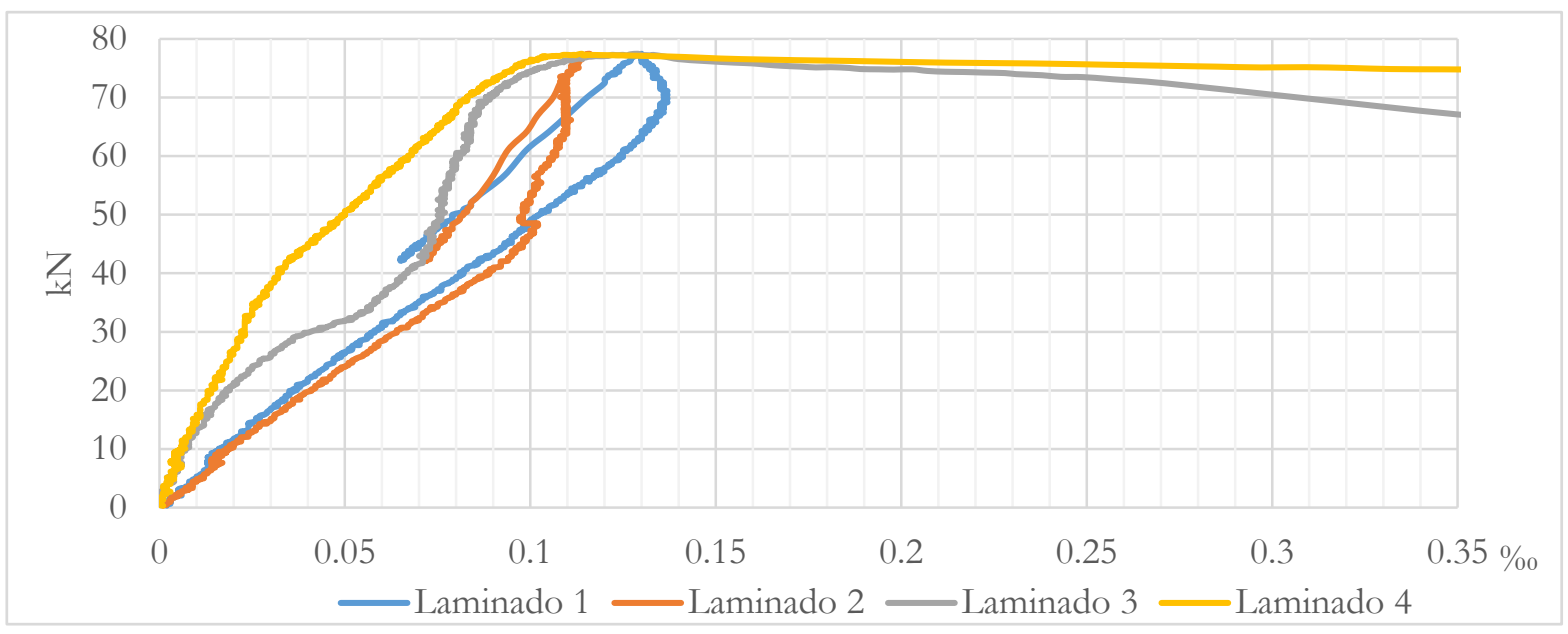

Gráfico 4.7 - Força x Deformação nos laminados - Prisma P11 - P40 40\%

O prisma P6 apresentou resultados diferentes de todos os demais prismas, tendo uma força máxima inferior aos prismas desta série. A deformação dos laminados de CFRP e ruptura do prisma ocorreu apenas do seu lado direto, com resultados anormais de deformação negativa, de compressão, no laminado 2. Este prisma com reforço de CFRP foi o único com força máxima abaixo dos prismas não reforçados. A falha deste prisma pode ter sido causado nas diversas etapas do ensaio, como na inserção e colagem dos laminados, no transporte do prisma ou até em excentricidades de carregamento acidentais durante o ensaio (Gráfico 4.8). 


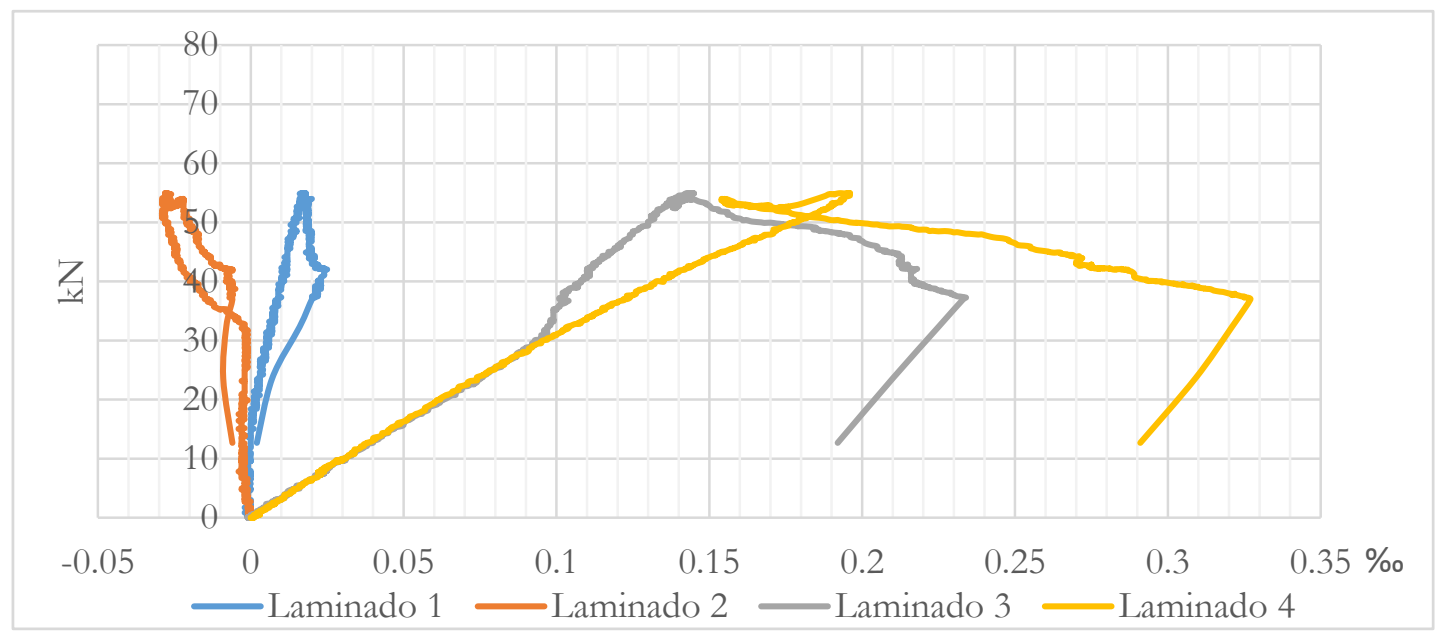

Gráfico 4.8 - Força x Deformação nos laminados - Prisma - P40 40\%

Ao aumentar o carregamento prévio para 70\%, os prismas não alteraram as solicitações nos reforços. Dentre eles, o prisma P3 apresentou melhor homogeneidade na deformação dos laminados, sendo os dois lados do prisma solicitados desde o início do carregamento e as rupturas ocorrendo do lado menos solicitado. Novamente identificou-se que o prisma com deformações dos laminados mais homogêneos apresentou maior capacidade de carga (Gráfico 4.9).

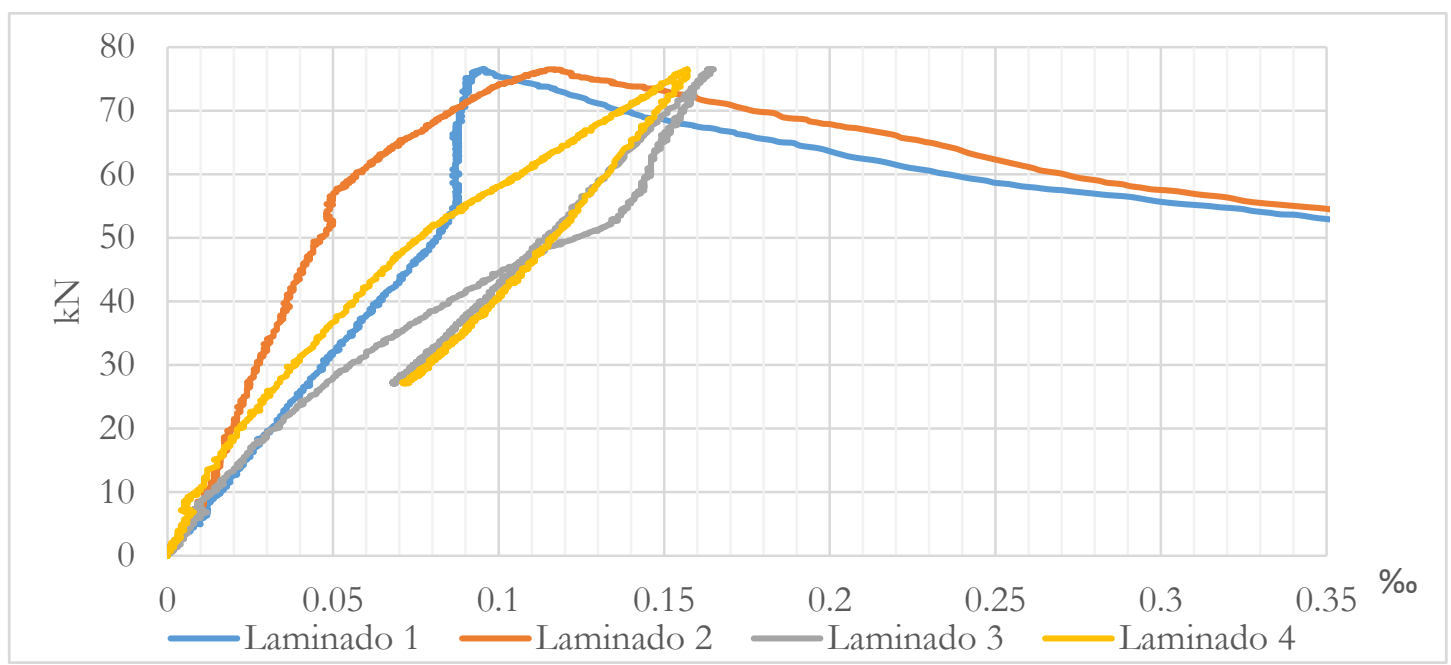

Gráfico 4.9 - Força x Deformação nos laminados - Prisma P3 - P40 70\%

Nos prismas C40 70\%, os três modelos tiveram comportamento similares, com os 4 laminados deformando desde o início do carregamento. No lado com os laminados menos solicitados ocorreu a ruptura.

Os valores das deformações nos prismas com carregamento prévio não diferem dos prismas P40 CFRP, tendo em média deformações de 0,16\% nos laminados de maior solicitação de 0,10\%, nos laminados menos solicitados quando as deformações são homogêneas. Em todas as series estudadas um dos prismas apresentou deformações maiores em um dos lados. Quando 
este efeito foi observado, os valores máximos das deformações aumentaram para valores próximos a $0,26 \%$. Observou-se que estes prismas apresentaram dentro das suas series as piores forças máximas.

\subsubsection{Prismas $\mathbf{P} 60$}

Nos prismas P60 CFRP (P17, P18 e P24) verificou-se deformações dos laminados maiores que as ocorridas nos prismas P40 CFRP e mais homogêneas. Os prismas P60 CFRP sofreram solicitações nos laminados mais uniformes, permitindo uma melhor distribuição das tensões no prisma.

No prisma P18 os laminados apresentam altas deformações com valores máximos próximos a 0,50\% para os laminados 1, 2 e 3. Todos os prismas P60 CFRP apresentaram um excelente desempenho no aumento da capacidade de carga dos prismas, onde as altas deformações nos laminados de CFRP demonstram que o reforço foi melhor utilizado absolvendo melhor as tensões solicitantes (Gráfico 4.10).

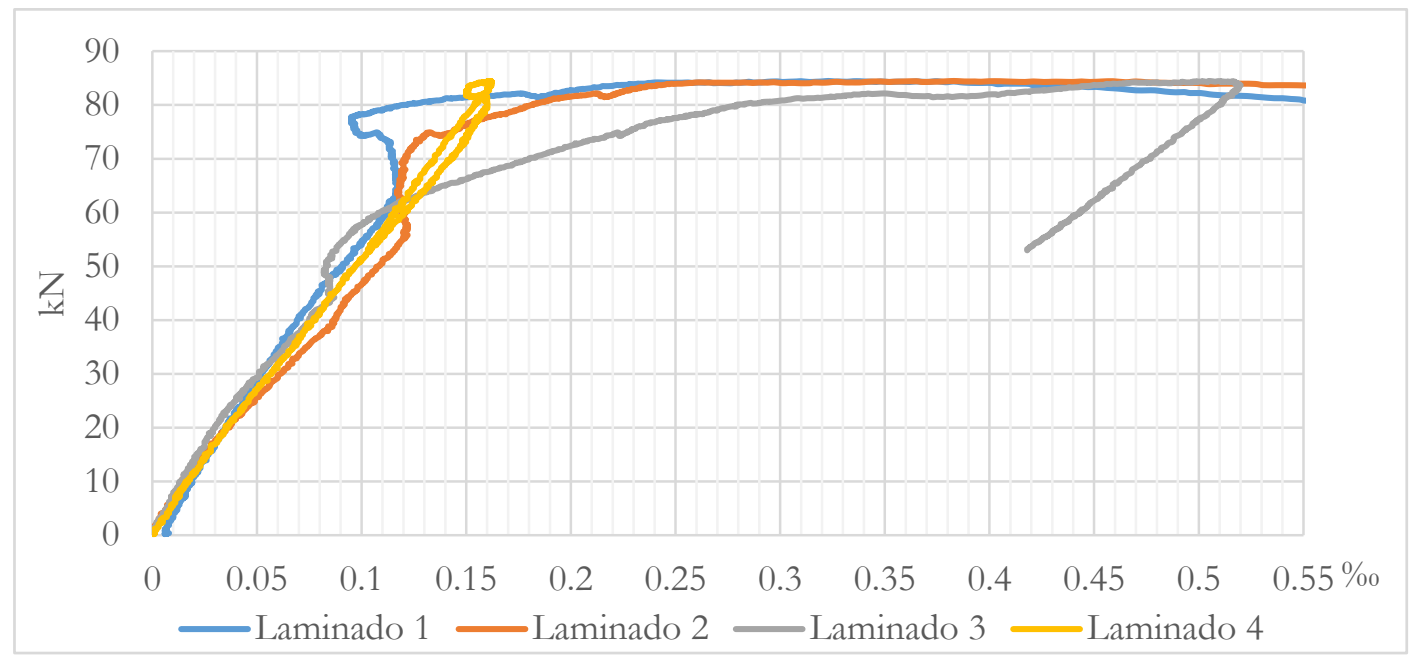

Gráfico 4.10 - Força x Deformação nos laminados - Prisma P18 - P60 CFRP

Dos prismas P60 40\% o P23 apresentou deformações diferenciadas, onde no lado esquerdo não apresentou deformações nos laminados até a força de $40 \mathrm{kN}$, enquanto que do lado direito já haviam deformações elevadas. A ruptura deste prisma ocorreu no lado direito, o mais solicitado. (Gráfico 4.13) 


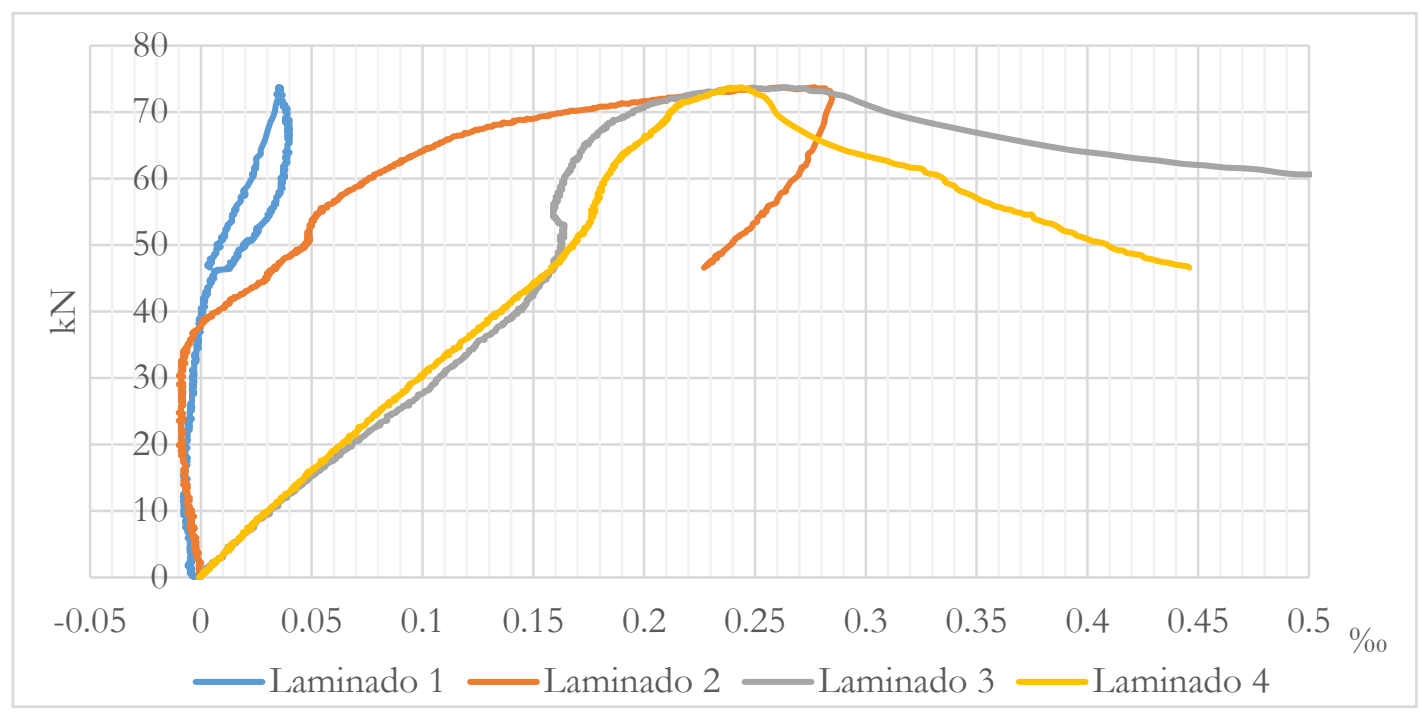

Gráfico 4.11 - Força x Deformação nos laminados - Prisma P23 - P60 40\%

Novamente identificou-se um prisma que teve um lado mais solicitado que o outro. Em todos os casos que isso ocorreu a força máxima foi menor que a dos demais prismas da mesma série. O mesmo efeito pode ser identificado nos prismas P6, P10, P12, P15 e P23.

O aumento do carregamento prévio para 70\% não alterou o comportamento do reforço de CFRP, permanecendo com todos os laminados deformando desde o início do carregamento e com os laminados internos mais solicitados que os laminados externos.

Pôde-se constatar, que quando utilizou um concreto com maior resistência, os laminados de CFRP apresentaram maiores deformações, sendo assim mais solicitados e permitindo um maior acréscimo na capacidade de carga dos prismas.

Nos prismas P60, o carregamento prévio reduziu as deformações nos laminados de CFRP indicando que o concreto fissurado apresenta alguma influência na capacidade de reforço. Apesar da redução das deformações nos laminados de CFRP ter ocorrido também pelas menores forças de ruptura dos prismas com carregamento prévio.

Os prismas P60 tiveram resultados mais semelhantes entre si que os P40. Na maioria os laminados sofreram deformações desde o início do carregamento, nos dois lados dos prismas.

Em nenhum caso houve ruptura ou destacamento dos laminados de CFRP demonstrando que mesmo com seção transversal pequena $\left(28 \mathrm{~mm}^{2}\right)$ a tensão nas fibras de carbono foi baixa em relação a sua capacidade de resistência. De Lorenzis e Teng (2007) afirmam que o destacamento das barras de CFRP pode ocorrer quando se possui baixo valor da relação entre a área da superfície colada e a área da seção transversal da barra e laminados de CFRP. 


\subsection{ENSAIOS NÃO DESTRUTIVOS - PRISMAS}

Como já descrito no capítulo materiais e métodos, os ensaios dinâmicos foram realizados com o intuito principal de caracterizar as frequências naturais e a rigidez das vigas de maneira a tentar identificar a eficiência do reforço por meio da avaliação da rigidez. Estes foram realizados nas três configurações de fissuras das vigas, quando íntegra, com carregamento prévio e após a ruptura.

Para os ensaios dinâmicos foram utilizados dois métodos de análise do módulo de elasticidade do material, os acelerômetros piezoelétricos uniaxiais, com martelo de impacto, condicionadores e amplificadores e o analisador de sinais dinâmico para ensaio de vibração Sonelastic ${ }^{\circledR}$.

No estudo entre os métodos utilizados observou-se que o programa Sonelastic $\mathbb{R}$ apresentou resultados praticamente iguais aos obtidos do acelerômetro piezoeléctrico, sendo desnecessária sua explanação neste trabalho. Assim, somente os resultados do ensaio com acelerômetro piezoelétrico foram apresentados.

O ensaio com acelerômetro piezoelétrico foi utilizado com o objetivo principal de obter as primeiras frequências naturais flexionais, longitudinais e torcionais. É importante ressaltar que as formulas utilizadas para os prismas foram desenvolvidas para elementos isotrópicos e neste estudo foram utilizadas para elementos fissurados de concreto com barras de aço e laminados de CFRP inseridos. Sendo assim, estes não são os módulos de elasticidade reais dos prismas, mas servem para a comparação entre as configurações de carregamento estudadas (Íntegro, Dano, Reforçado e Rompido).

A Tabela 4.10 apresenta os resultados das frequências naturais dos prismas P40 obtidas na flexional, longitudinal e torcional. O cálculo dos módulos de elasticidade foi realizado conforme descrito no capítulo materiais e métodos. A Tabela 4.11 apresenta as médias dos módulos de elasticidade e sua relação entre as configurações dos prismas íntegros, com dano e após o reforço. 
Tabela 4.10 - Frequências naturais e Módulo de Elasticidade dos prismas P40

\begin{tabular}{|cc|ccc|cc|}
\hline \multirow{2}{*}{} & \multirow{2}{*}{ Prismas } & \multicolumn{5}{|c|}{ P40 } \\
\cline { 3 - 7 } & $\begin{array}{c}\text { Flexional } \\
(\mathrm{Hz})\end{array}$ & $\begin{array}{c}\text { Longitudinal } \\
(\mathrm{Hz})\end{array}$ & $\begin{array}{c}\text { Torcional } \\
(\mathrm{Hz})\end{array}$ & $\begin{array}{c}\mathrm{E}_{\text {flex }} \\
(\mathrm{GPa})\end{array}$ & $\begin{array}{c}\mathrm{E}_{\text {long }} \\
(\mathrm{GPa})\end{array}$ \\
\hline 1 & Íntegro & 878,1 & 2553 & 1441 & 32,18 & 36,50 \\
1 & Após a ruptura & 698,8 & 1913 & 993,7 & 20,38 & 20,49 \\
\hline 2 & Íntegro & 875 & 2563 & 1447 & 31,95 & 36,79 \\
\hline 2 & Após a ruptura & 740,6 & 2078 & 1172 & 22,89 & 24,18 \\
\hline 3 & Íntegro & 893,7 & 2566 & 1459 & 33,33 & 36,87 \\
3 & Dano 70\% & 818,7 & 2366 & 1397 & 27,97 & 31,35 \\
3 & Reforçado & 615,6 & 1869 & 1184 & 15,82 & 19,56 \\
\hline 4 & Íntegro & 925 & 2587 & 1466 & 35,71 & 37,48 \\
4 & Dano 40\% & 856,2 & 2472 & 1447 & 30,60 & 34,22 \\
4 & Reforçado & 796,8 & 2322 & 1394 & 26,50 & 30,19 \\
\hline 5 & Íntegro & 903 & 2619 & 1497 & 34,03 & 38,41 \\
\hline 5 & Reforçado & 846,8 & 2453 & 1425 & 29,93 & 33,70 \\
\hline 6 & Íntegro & 928,1 & 2625 & 1503 & 35,95 & 38,59 \\
6 & Dano 40\% & 878,1 & 2506 & 1466 & 32,18 & 35,17 \\
\hline 6 & Reforçado & 809 & 2347 & 1409 & 27,32 & 30,85 \\
\hline 7 & Íntegro & 928,1 & 2638 & 1525 & 35,95 & 38,97 \\
\hline 7 & Após a ruptura & 328,1 & 1669 & 1006 & 4,49 & 15,60 \\
\hline 8 & Íntegro & 937,5 & 2656 & 1538 & 36,68 & 39,50 \\
8 & Dano 70\% & 825 & 2366 & 1431 & 28,41 & 31,35 \\
8 & Reforçado & 696 & 2025 & 1300 & 20,22 & 22,96 \\
\hline 9 & Integro & 909,3 & 2550 & 1466 & 34,51 & 36,41 \\
\hline 9 & Reforçado & 853 & 2391 & 1406 & 30,37 & 32,01 \\
\hline 10 & Íntegro & 915,6 & 2572 & 1472 & 34,99 & 37,05 \\
10 & Dano 70\% & 803,1 & 2275 & 1338 & 26,92 & 28,98 \\
\hline 10 & Reforçado & 643,7 & 1850 & 1122 & 17,29 & 19,17 \\
\hline 11 & Íntegro & 909,3 & 2597 & 1494 & 34,51 & 37,77 \\
11 & Dano 40\% & 850 & 2434 & 1453 & 30,15 & 33,18 \\
11 & Reforçado & 750 & 2203 & 1366 & 23,48 & 27,18 \\
\hline 12 & Íntegro & 937,5 & 2616 & 1500 & 36,68 & 38,32 \\
12 & Reforçado & 862 & 2444 & 1438 & 31,01 & 33,45 \\
\hline
\end{tabular}

Tabela 4.11 - Médias das Frequências naturais e Módulo de Elasticidade dos prismas P40

\begin{tabular}{|c|c|c|c|c|c|c|}
\hline Situação dos Prismas & CV & Relação & Média & CV & Relação & Média \\
\hline Íntegro & $4,6 \%$ & - & 34,71 & $2,7 \%$ & - & 37,72 \\
Após reforço & $1,7 \%$ & $-6,5 \%$ & 32,44 & $2,6 \%$ & $-8,1 \%$ & 34,68 \\
Após a ruptura & $62,7 \%$ & $-54,1 \%$ & 15,92 & $21,4 \%$ & $-46,7 \%$ & 20,09 \\
\hline Com Dano40\% & $3,4 \%$ & $-10,7 \%$ & 30,98 & $2,9 \%$ & $-9,4 \%$ & 34,19 \\
Com Dano 40\% após reforço & $7,8 \%$ & $-25,8 \%$ & 25,76 & $6,7 \%$ & $-22,0 \%$ & 29,41 \\
\hline Com Dano 70\% & $2,8 \%$ & $-20,0 \%$ & 27,77 & $4,5 \%$ & $-19,0 \%$ & 30,56 \\
\hline Com Dano 70\% após reforço & $12,6 \%$ & $-48,8 \%$ & 17,78 & $10,2 \%$ & $-45,5 \%$ & 20,56 \\
\hline
\end{tabular}


Nos prismas Íntegros P40 a média do módulo de elasticidade obtido pelo primeiro modo de vibração medido na flexional $\left(\mathrm{E}_{\text {flex }}\right.$ ) foi de $34,71 \mathrm{GPa}$, com um coeficiente de variação de 4,6\% e o módulo de elasticidade calculado pelo primeiro modo de vibração medido na longitudinal ( $\left.\mathrm{E}_{\text {long }}\right)$ de $37,72 \mathrm{GPa}$ com um coeficiente de variação de $2,7 \%$.

Após o reforço com os laminados de fibra de carbono os módulos de elasticidade medidos no sentido flexional e longitudinal reduziram em 6,5\% e 8,1\%, respectivamente, dando uma falsa impressão de que o reforço piorou a rigidez dos prismas, pois apresentaram módulos de elasticidade equivalentes menores.

Acredita-se que o processo de inserção dos laminados ou o manuseio dos prismas possam ter causado algum dano aos prismas, pois para inserir os laminados no concreto foi necessária a abertura de ranhuras com espessura suficiente para introduzir o CFRP. Neste processo parte do concreto foi retirado e substituído por massa Epóxi e laminados de CFRP, ambos com módulo de elasticidade inferiores aos do concreto.

Quando os prismas sofreram carregamento prévio de 40\% da força máxima, os módulos de elasticidade reduziram. Essa redução indica a capacidade de identificação de dano pela análise da variação dos módulos de elasticidade ou diretamente pela variação das frequências naturais.

Após a aplicação do sistema de reforço dos prismas P40 40\% previa-se um aumento das frequências naturais e consequentemente um aumento dos módulos de elasticidade. Mas após o reforço o módulo de elasticidade medido na flexional reduziu em $25,8 \%$, indicando o contrário do esperado, grande redução na rigidez dos prismas.

O mesmo efeito de identificação do dano ocorreu nos prismas P40 70\%. Nestes o Módulo de elasticidade medido na flexional reduziram em $20 \%$ após o dano, indicando a capacidade de identificação deste dano. Por ser uma variação maior que a ocorrida nos prismas P40\%, indica uma capacidade de identificar a magnitude do dano pela avaliação das variações das frequências naturais.

Nos prismas com carregamento prévio, após o reforço de CFRP, as frequências naturais reduziram mais, indicando uma piora na rigidez desses prismas. Mesmo assim, o desempenho estrutural foi satisfatório, pois como já apresentado, a capacidade de carga dos prismas com carregamento prévio foi maior que a dos prismas P40 SR.

Ao analisar os prismas com resistência do concreto maior, o P60, verificou-se que o reforço com CFRP reduziu o módulo de elasticidade dos prismas em porcentagens próximas ao ocorrido com os prismas P40. O reforço com CFRP nos prismas com Dano também apresentaram reduções nos módulos de elasticidade (Tabela 4.12 e Tabela 4.15). 
Tabela 4.12 - Frequências naturais e Módulo de Elasticidade dos prismas P60

\begin{tabular}{|cc|ccc|c|c|}
\hline \multirow{2}{*}{} & Prismas & \multicolumn{5}{|c|}{ P60 } \\
\cline { 3 - 7 } & $\begin{array}{c}\text { Flexional } \\
(\mathrm{Hz})\end{array}$ & $\begin{array}{c}\text { Longitudinal } \\
(\mathrm{Hz})\end{array}$ & $\begin{array}{c}\text { Torcional } \\
(\mathrm{Hz})\end{array}$ & $\begin{array}{c}\mathrm{E}_{\text {flex }} \\
(\mathrm{GPa})\end{array}$ & $\begin{array}{c}\mathrm{E}_{\text {long }} \\
(\mathrm{GPa})\end{array}$ \\
\hline 13 & Íntegro & 956,2 & 2684 & 1547 & 38,16 & 40,34 \\
13 & Após a ruptura & 378,1 & 1828 & 906,2 & 5,97 & 18,71 \\
\hline 14 & Íntegro & 984,3 & 2703 & 1550 & 40,44 & 40,91 \\
14 & Após a ruptura & 434,3 & 1478 & 828,1 & 7,87 & 12,23 \\
\hline 15 & Íntegro & 993,7 & 2716 & 1556 & 41,21 & 41,31 \\
15 & Dano 70\% & 887,5 & 2450 & 1475 & 32,87 & 33,61 \\
15 & Reforçado & 793 & 2133 & 1388 & 26,25 & 25,48 \\
\hline 16 & Íntegro & 996,8 & 2725 & 1572 & 41,47 & 41,58 \\
16 & Dano 40\% & 940 & 2644 & 1550 & 36,88 & 39,15 \\
16 & Reforçado & 875 & 2441 & 1488 & 31,95 & 33,37 \\
\hline 17 & Íntegro & 950 & 2684 & 1544 & 37,67 & 40,34 \\
17 & Reforçado & 909 & 2547 & 1506 & 34,49 & 36,33 \\
\hline 18 & Íntegro & 968,7 & 2725 & 1569 & 39,16 & 41,58 \\
18 & Reforçado & 918 & 2569 & 1509 & 35,17 & 36,96 \\
\hline 19 & Íntegro & 968,7 & 2725 & 1566 & 39,16 & 41,58 \\
19 & Após a ruptura & 387,5 & 1984 & 1063 & 6,27 & 22,04 \\
\hline 20 & Íntegro & 984,3 & 2728 & 1566 & 40,44 & 41,68 \\
20 & Dano 40\% & 925 & 2459 & 1531 & 35,71 & 33,86 \\
\hline 20 & Reforçado & 846,8 & 2419 & 1469 & 29,93 & 32,77 \\
\hline 21 & Íntegro & 959,3 & 2728 & 1556 & 38,41 & 41,68 \\
21 & Dano 70\% & 862,5 & 2459 & 1475 & 31,05 & 33,86 \\
21 & Reforçado & 730 & 2106 & 1372 & 22,24 & 24,84 \\
\hline 22 & Íntegro & 990,6 & 2747 & 1578 & 40,96 & 42,26 \\
22 & Dano 70\% & 884,3 & 2503 & 1497 & 32,64 & 35,08 \\
22 & Reforçado & 796,8 & 2275 & 1438 & 26,50 & 28,98 \\
\hline 23 & Íntegro & 959,3 & 2719 & 1556 & 38,41 & 41,40 \\
23 & Dano 40\% & 909,3 & 2600 & 1525 & 34,51 & 37,86 \\
23 & Reforçado & 828,1 & 2419 & 1456 & 28,62 & 32,77 \\
\hline 24 & Íntegro & 990,6 & 2738 & 1575 & 40,96 & 41,98 \\
24 & Reforçado & 921 & 2563 & 1513 & 35,40 & 36,79 \\
\hline
\end{tabular}

Tabela 4.13 - Médias das Frequências naturais e Módulo de Elasticidade dos prismas P60

\begin{tabular}{|c|c|c|c|c|c|c|}
\hline Situação dos Prismas & CV & Relação & Média & CV & Relação & Média \\
\hline Íntegro & $3,4 \%$ & - & 39,70 & $1,4 \%$ & - & 41,39 \\
Após reforço & $1,4 \%$ & $-12 \%$ & 35,02 & $0,9 \%$ & $-11 \%$ & 36,69 \\
Após a ruptura & $15,3 \%$ & $-83 \%$ & 6,70 & $28,2 \%$ & $-57 \%$ & 17,66 \\
\hline Com Dano 40\% & $3,3 \%$ & $-10 \%$ & 35,70 & $7,5 \%$ & $-11 \%$ & 36,96 \\
Com Dano 40\% após reforço & $5,6 \%$ & $-24 \%$ & 30,17 & $1,0 \%$ & $-20 \%$ & 32,97 \\
\hline Com Dano 70\% & $3,1 \%$ & $-19 \%$ & 32,19 & $2,3 \%$ & $-17 \%$ & 34,19 \\
\hline Com Dano 70\% após reforço & $9,6 \%$ & $-37 \%$ & 24,99 & $8,4 \%$ & $-36 \%$ & 26,43 \\
\hline
\end{tabular}


Nos prismas P60 SR, a média do $\mathrm{E}_{\text {flex }}$ foi de 39,70GPa, com um coeficiente de variação de 3,4\% e o módulo de elasticidade medido na longitudinal ( $\mathrm{E}_{\text {long }}$ ) de 41,39 GPa com um coeficiente de variação de 1,4\%. Após o reforço os módulos de elasticidade medidos reduziram em uma proporção maior que o ocorrido no C40.

As reduções devido ao reforço nos prismas com C60 foram muito próximas as ocorridas nos prismas P40 para os dois níveis de carregamento prévio estudado. Com redução de 10\% para o P60 40\% e de 19\% para o P60 70\%. Novamente identificou-se uma maior redução dos módulos de elasticidade quando ocorrem maiores carregamentos prévios, indicando a capacidade do método em medir a magnitude do dano.

Após a inserção do reforço de CFRP os módulos de elasticidade reduziram mais ainda, igualmente ao ocorrido nos prismas P40, com redução de 24\% para P60 40\% no $\mathrm{E}_{\text {flex }}$ e de 37\%, para o P60 70\%.

Os efeitos da fissuração e do reforço no módulo de elasticidade longitudinal foram semelhantes ao flexional para todos os prismas estudados, o que nos permite concluir que tanto o estudo das frequências naturais medidas na longitudinal como as medidas na flexional permitem avaliar com a mesma eficiência os prismas de concreto reforçados com CFRP.

Os resultados apresentados para o módulo de elasticidade demonstram que o dano pode ser identificado por ensaios pela análise modal, podendo ainda ser medido sua intensidade.

O ensaio não destrutivo deve ser estudado com cuidado, pois o reforço com CFRP permitiu uma melhora na capacidade de carga e deformação nos prismas em todos os elementos. Demonstrando a eficácia do reforço de CFRP mesmo após fissuração do concreto de $70 \%$ da força máxima, mas apresentaram uma grande redução no módulo de elasticidade. Para investigar este efeito uma modelagem computacional foi desenvolvida com análise modal dos prismas.

\subsection{MODELAGEM COMPUTACIONAL}

Os prismas foram modelados no programa DIANA® com o objetivo de reproduzir o comportamento obtido nos ensaios experimentais. Para sua produção utilizou-se inicialmente as propriedades dos materiais obtidas em ensaio ou fornecidas pelo fabricante e para a sua seleção procurou-se ao máximo reproduzir as frequências naturais.

A modelagem computacional foi realizada com elementos tridimensionais para realizar uma análise modal, simulando a frequências naturais e os modos de vibração dos prismas. 
As frequências naturais obtidas no programa DIANA® foram realizadas nos prismas sem reforço e com reforço de CFRP. A modelagem computacional nos prismas sem reforços apresentou pequena diferença entre os resultados com e sem reforços. Nelas obteve-se na primeira frequência uma variação diferença máxima de $4 \mathrm{~Hz}$, enquanto que nas frequências maiores ocorram variações de até $29 \mathrm{~Hz}$. Os valores obtidos das frequências naturais computacionais são apresentados na Tabela 4.14 e comparadas com os seus valores experimentais.

Tabela 4.14 - Frequências naturais computacionais

\begin{tabular}{c|c|c|c|c|c|c|c|}
\hline \multicolumn{1}{c}{$(\boldsymbol{H} \boldsymbol{z})$} & Ordem & P40 SR & P40 CFRP & \multicolumn{1}{c}{ Variação } & P60 SR & P60 CFRP & Variação \\
\hline \multirow{3}{*}{ Flexionais } & $1^{\mathrm{a}}$ & 942 & 942 & 0 & 1003 & 1002 & +1 \\
\cline { 2 - 8 } & $2^{\mathrm{a}}$ & 2206 & 2201 & +5 & 2350 & 2343 & +7 \\
\cline { 2 - 8 } & $3^{\mathrm{a}}$ & 3674 & 3665 & +9 & 3916 & 3903 & +13 \\
\hline \multirow{3}{*}{ Torcionais } & $1^{\mathrm{a}}$ & 1474 & 1478 & -4 & 1576 & 1579 & +3 \\
\cline { 2 - 8 } & $2^{\mathrm{a}}$ & 2950 & 2952 & -2 & 3153 & 3150 & +3 \\
\cline { 2 - 8 } & $3^{\mathrm{a}}$ & 4424 & 4429 & -5 & 4730 & 4727 & -3 \\
\hline \multirow{3}{*}{ Longitudinais } & $1^{\mathrm{a}}$ & 2541 & 2539 & +2 & 2707 & 2703 & +4 \\
\cline { 2 - 8 } & $2^{\mathrm{a}}$ & 5043 & 5023 & +20 & 5376 & 5347 & +29 \\
\hline
\end{tabular}

A Figura 4.5 apresenta os modos de vibração dos prismas P40 CFRP para cada frequência citada, sendo ( $a, b, c)$ para flexionais, $(d, e, f)$ para torcionais e $(g, h)$ para as longitudinais. Para estas figuras não foram inseridas escalas de cores, por apresentarem valores muito pequenos. Nas figuras ocorre uma escala crescente de deslocamentos, sendo a cor azul como sem deslocamentos, a verde com pequenos valores, amarela com deslocamentos maiores e vermelha com grandes deslocamentos. 


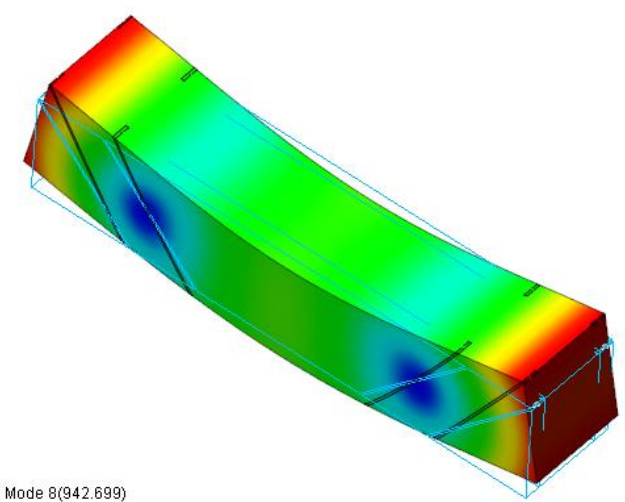

(a) $1^{\circ}$ modo flexional

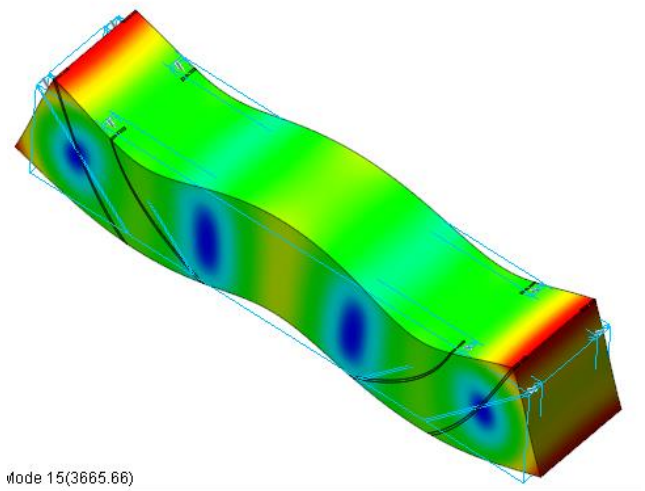

(c) $3^{\circ}$ modo flexional

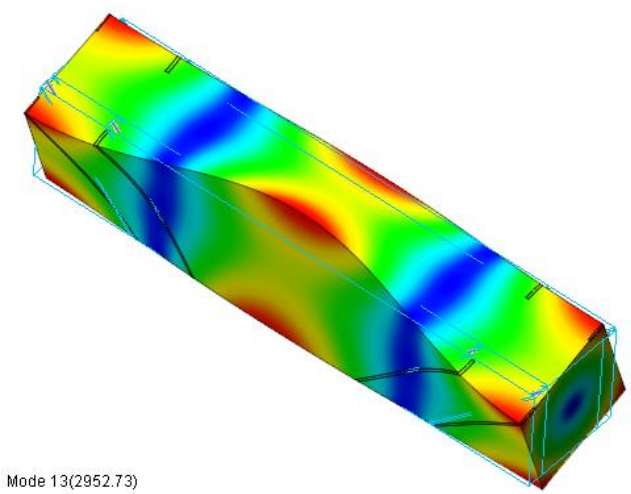

(e) $2^{\circ}$ modo torcional

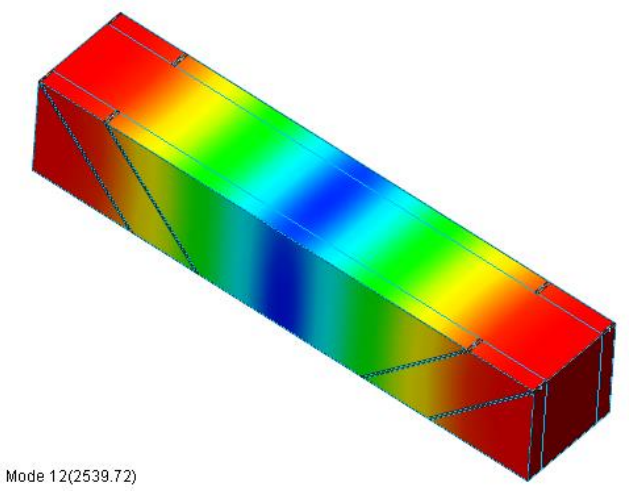

(g) $1^{\circ}$ modo longitudinal

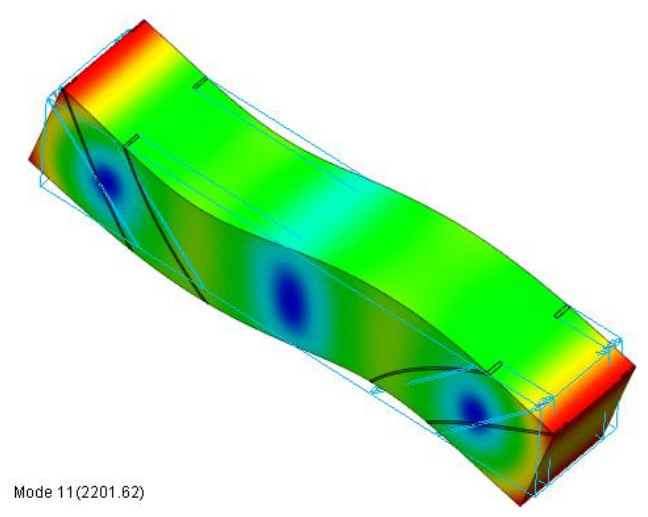

(b) $2^{\circ}$ modo flexional

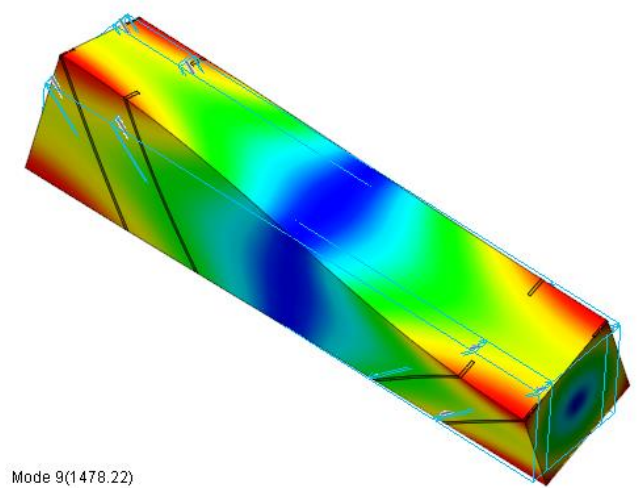

(d) $1^{\circ}$ modo torcional

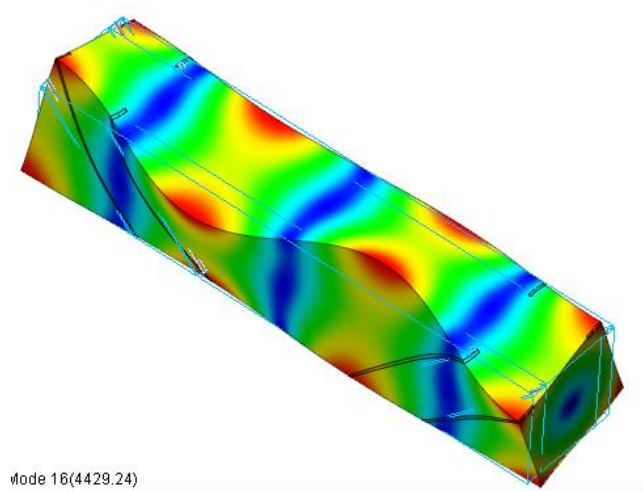

(f) $3^{\circ}$ modo torcional

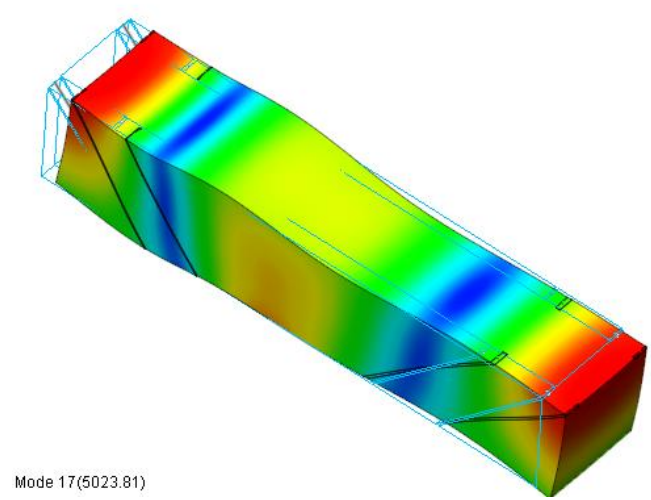

(h) $2^{\circ}$ modo longitudinal

Figura 4.5 - Modos de vibração dos prismas C40 CFRP 
$\mathrm{Na}$ comparação das frequências naturais dos ensaios experimentais com os modelados no programa DIANA® observou-se boas relações para os prismas íntegros, tanto para os P40 SR como para o P60 SR. Já as frequências naturais experimentais dos prismas reforçados com CFRP apresentaram uma elevada redução na frequência natural. Na simulação computacional também ocorreram reduções em algumas frequências naturais, mas com menor intensidade que o ocorrido nos ensaios experimentais.

A Tabela 4.15 e Tabela 4.16 apresentam os resultados das frequências naturais experimentais comparadas com as computacionais dos prismas P40 e P60 com e sem reforços de CFRP. Para esta comparação alguns prismas foram selecionados, sendo para os prismas P40 o Prisma 10 e para os prismas P60 o Prisma 16.

Tabela 4.15 - Frequências naturais experimentais e computacionais - P40

\begin{tabular}{|c|c|c|c|c|c|c|c|}
\hline$(\mathrm{Hz})$ & Ordem & $\begin{array}{c}\text { P40 SR } \\
\text { Ensaio } \\
\text { (Prisma 10) }\end{array}$ & $\begin{array}{l}\text { P40 SR } \\
\text { Comp. }\end{array}$ & Variação & $\begin{array}{c}\text { P40 CFRP } \\
\text { Ensaio } \\
\text { (Prisma 10) }\end{array}$ & $\begin{array}{l}\text { P40 CFRP } \\
\text { Comp. }\end{array}$ & Variação \\
\hline \multirow{3}{*}{ Flex } & $1^{a}$ & 915 & 942 & $2,95 \%$ & 644 & 942 & $46,27 \%$ \\
\hline & $2^{\mathrm{a}}$ & 2153 & 2206 & $2,46 \%$ & 1769 & 2201 & $24,42 \%$ \\
\hline & $3^{a}$ & 3650 & 3674 & $0,66 \%$ & 3372 & 3665 & $8,69 \%$ \\
\hline \multirow{3}{*}{ Tor } & $1^{a}$ & 1472 & 1474 & $0,14 \%$ & 1122 & 1478 & $31,73 \%$ \\
\hline & $2^{\mathrm{a}}$ & 2956 & 2950 & $-0,2 \%$ & 2456 & 2952 & $20,19 \%$ \\
\hline & $3^{a}$ & 4469 & 4424 & $-1,01 \%$ & 4134 & 4429 & $7,18 \%$ \\
\hline \multirow{2}{*}{ Long } & $1^{a}$ & 2572 & 2541 & $-1,21 \%$ & 1850 & 2539 & $37,24 \%$ \\
\hline & $2^{\mathrm{a}}$ & - & 5043 & - & 4637 & 5023 & - \\
\hline
\end{tabular}

Tabela 4.16 - Frequências naturais experimentais e computacionais - P60

\begin{tabular}{|c|c|c|c|c|c|c|c|}
\hline$(\mathrm{Hz})$ & Ordem & $\begin{array}{c}\text { P60 SR } \\
\text { Ensaio } \\
\text { (Prisma 16) }\end{array}$ & $\begin{array}{l}\text { P60 SR } \\
\text { Comp. }\end{array}$ & Variação & $\begin{array}{c}60 \text { CFRP } \\
\text { Ensaio } \\
\text { (Prisma 16) }\end{array}$ & $\begin{array}{l}\text { P60 CFRP } \\
\text { Comp. }\end{array}$ & Variação \\
\hline \multirow{3}{*}{ Flex } & $1^{a}$ & 997 & 1003 & $0,6 \%$ & 875 & 1002 & $14,51 \%$ \\
\hline & $2^{a}$ & 2315 & 2350 & $1,51 \%$ & 2134 & 2343 & $9,79 \%$ \\
\hline & $3^{a}$ & 3897 & 3916 & $0,49 \%$ & 3562 & 3903 & $9,57 \%$ \\
\hline \multirow{3}{*}{ Tor } & $1^{a}$ & 1572 & 1576 & $0,25 \%$ & 1488 & 1579 & $6,11 \%$ \\
\hline & $2^{a}$ & 3128 & 3153 & $0,8 \%$ & 2978 & 3150 & $5,77 \%$ \\
\hline & $3^{a}$ & 4703 & 4730 & $0,27 \%$ & 4506 & 4727 & $4,9 \%$ \\
\hline \multirow{2}{*}{ Long } & $1^{a}$ & 2725 & 2707 & $0,66 \%$ & 2441 & 2703 & $10,73 \%$ \\
\hline & $2^{a}$ & - & 5376 & - & - & 5347 & - \\
\hline
\end{tabular}

Para os prismas P40 SR as diferenças entre os ensaios experimentais e a modelagem computacional foram pequenos, ocorrendo a maior variação na primeira frequência natural flexional. Não sendo possível verificar a diferença da segunda frequência natural na longitudinal, pois nos ensaios experimentais só foram medidas frequências até $5000 \mathrm{~Hz}$. 
Nos prismas P40 CFRP observou-se uma grande diferença entre os resultados experimentais e computacionais. Essa diferença ocorreu devido as frequências naturais experimentais dos prismas apresentarem grande redução ao serem inseridos os laminados de CFRP.

Nos prismas P60 SR obteve-se na modelagem computacional frequências naturais ainda mais próximas dos ensaios experimentais, com maior variação na segunda frequência natural medida na flexional, de $1,51 \%$.

Comparando as frequências naturais dos elementos sem reforços obtidas experimentalmente com a modelagem computacional, observou-se resultados muito próximos, menores que a variação média entre os prismas ensaiados, isso permite afirmar que os prismas modelados computacionalmente sem sistema de reforço conseguiram representar com boa correlação com os elementos reais.

Na comparação entre as frequências naturais dos ensaios experimentais e da modelagem computacional dos prismas P60 CFP observou-se grandes variações. Assim como ocorrido nos prismas P40 CFRP, as frequências naturais experimentais não puderam ser corretamente representadas pela simulação computacional.

Em busca de respostas para esta variação foram simulados computacionalmente prismas com ranhuras, com seção de $4 \mathrm{~mm}$ x $24 \mathrm{~mm}$, dimensões próximas à usadas para inserir os laminados de CFRP. (Figura 4.6)
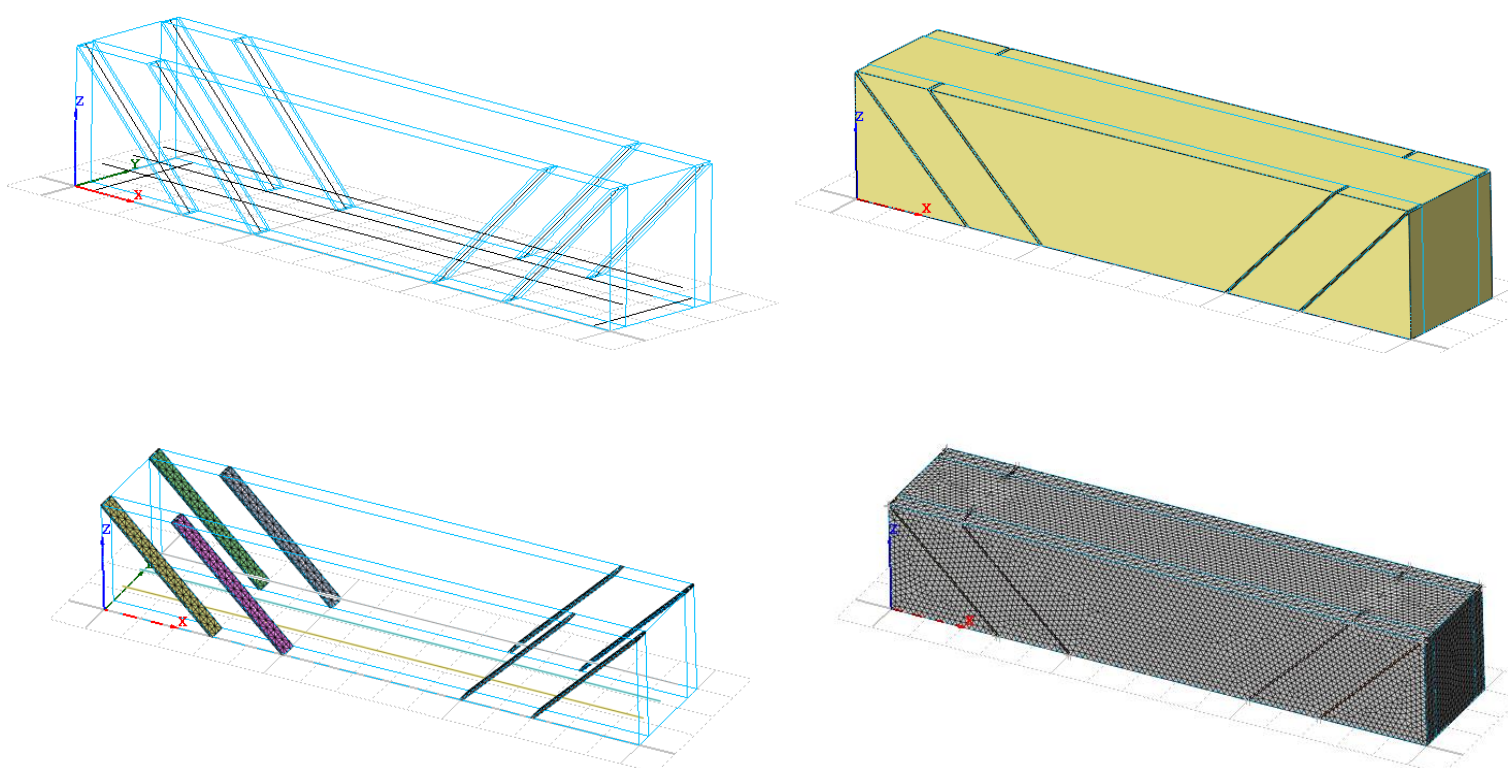

Figura 4.6 - Modelo computacional com ranhuras e reforços 
As ranhuras na modelagem computacional reduziram as frequências naturais, mas em uma proporção bem inferiores ao ocorrido nos ensaios experimentais, com valores médios de 3\%. Ao simular as vigas com o reforço de CFRP e com epóxi na região das ranhuras as frequências naturais retornaram para valores próximos aos dos prismas íntegros. Conclui-se que não foi possível identificar por meio de modelagem computacional numericamente o motivo da redução das frequências naturais, ocasionadas pela abertura de ranhuras necessárias para inserir o reforço com laminados de CFRP utilizando a técnica NSM.

O programa DIANA® permite ainda observar os modos de vibração dos elementos componentes da estrutura separadamente, podendo assim observar os modos de vibração das armaduras longitudinais e dos laminados de CFRP inseridos nos prismas. A Figura 4.7 apresenta os modos de vibração dos prismas P60 CFRP e dos seus reforços para a primeira frequência natural, sendo (a, b) para flexional, (c, d) para torcional e (e, f) para longitudinal.

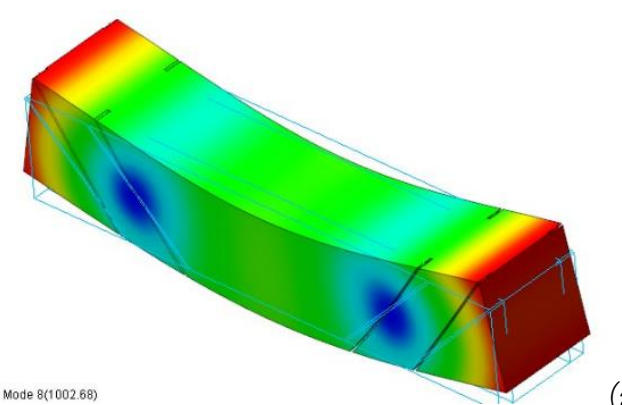

(a)

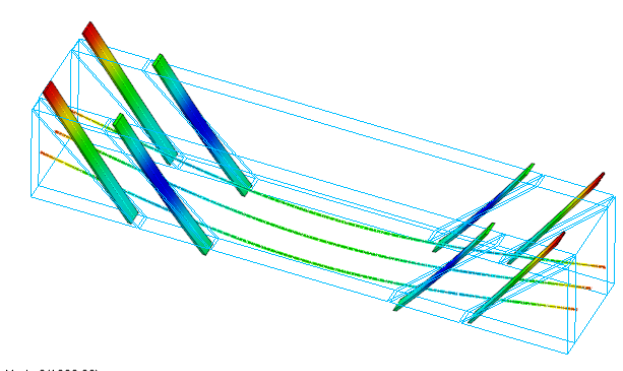

Mode 8(1002.6

Mode 8(1002.68)

(b)

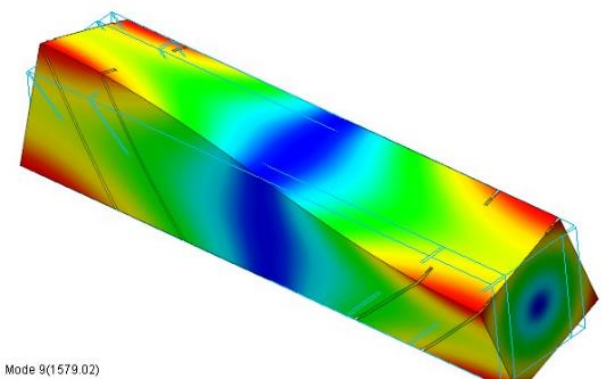

(c)

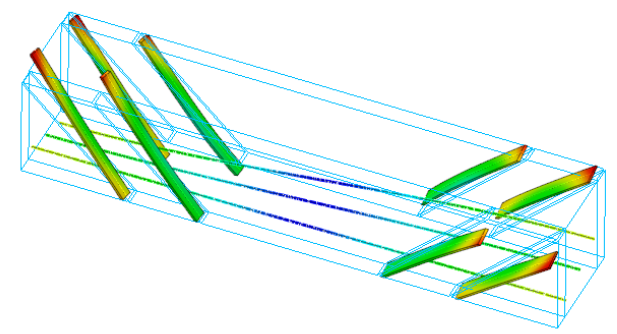

Mode $9(1579.02$

(d)
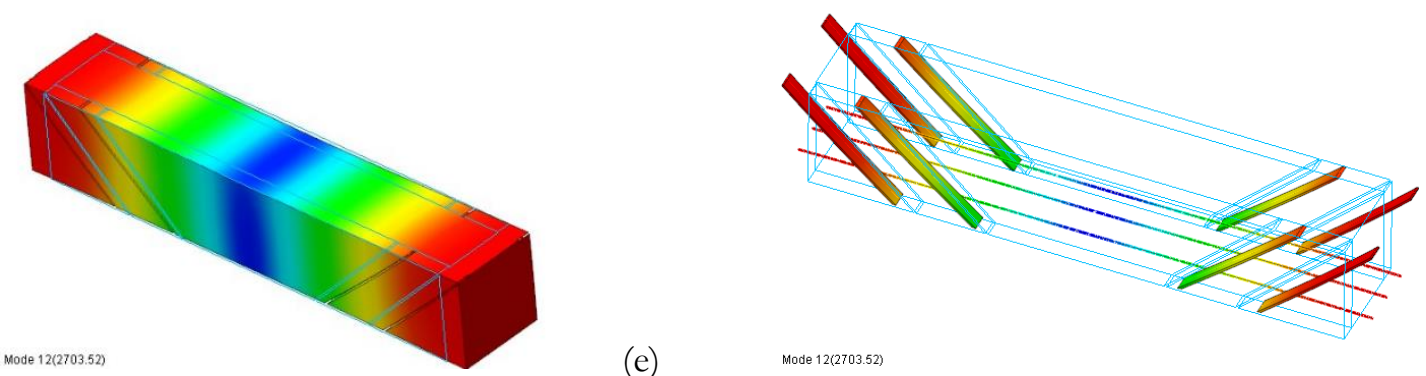

(e) Mode 122703052)

(f)

Figura 4.7 - Modos de vibração dos primas P60 CFRP

O Gráfico 4.12 e Gráfico 4.13 apresentam as curvas resposta em frequência do Prisma 10 para os ensaios com acelerômetro piezoelétricos de flexão e torção, com suas indicações de amplitude e fase, além dos valores das frequências obtidos na modelagem computacional, 
denominados de FM1, FM2 e FM3 para as frequências naturais flexionais e de TM1, TM2 e TM3 para as frequências naturais torcionais.
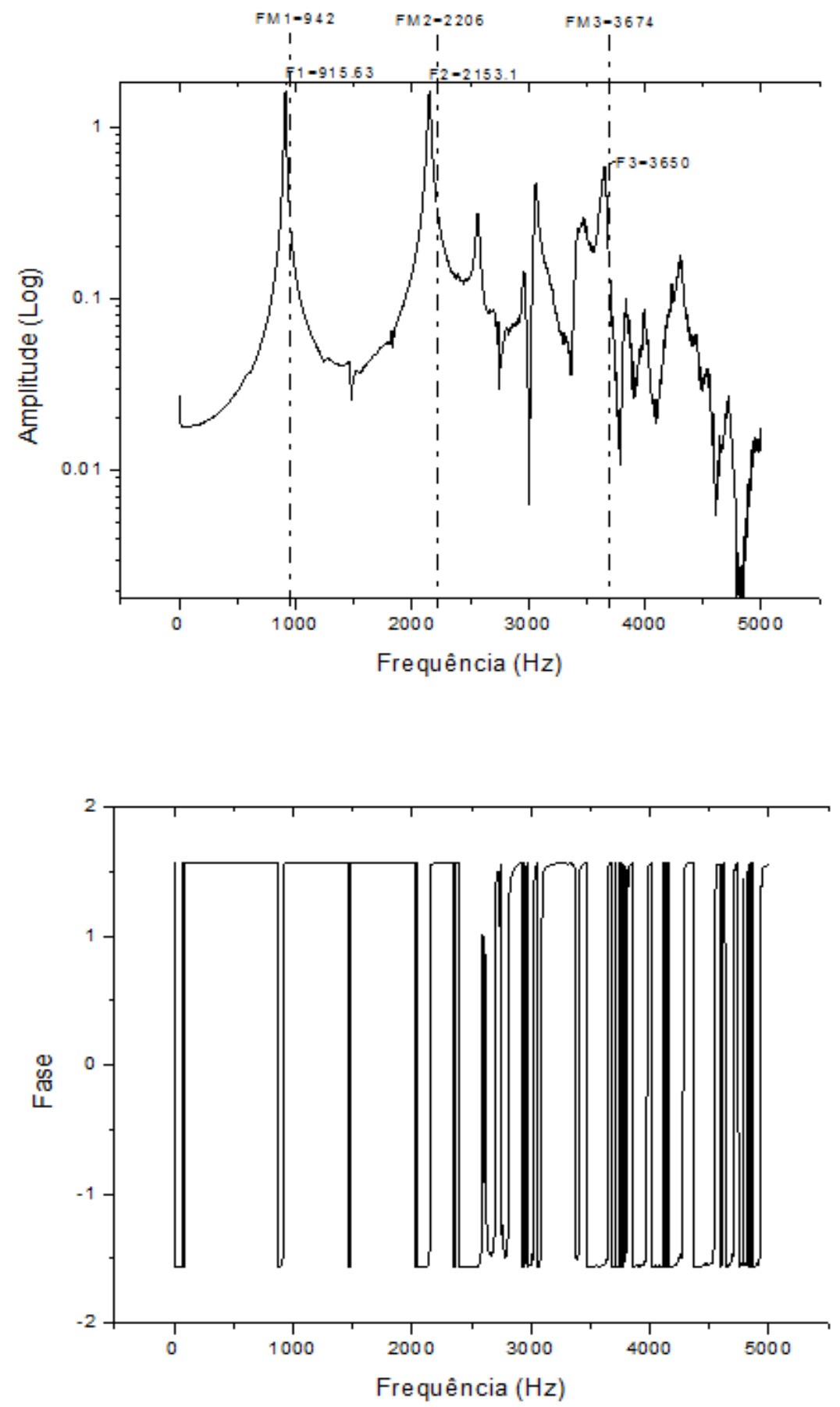

Gráfico 4.12 - Resposta em frequência de ensaio Flexional do Prisma 10 

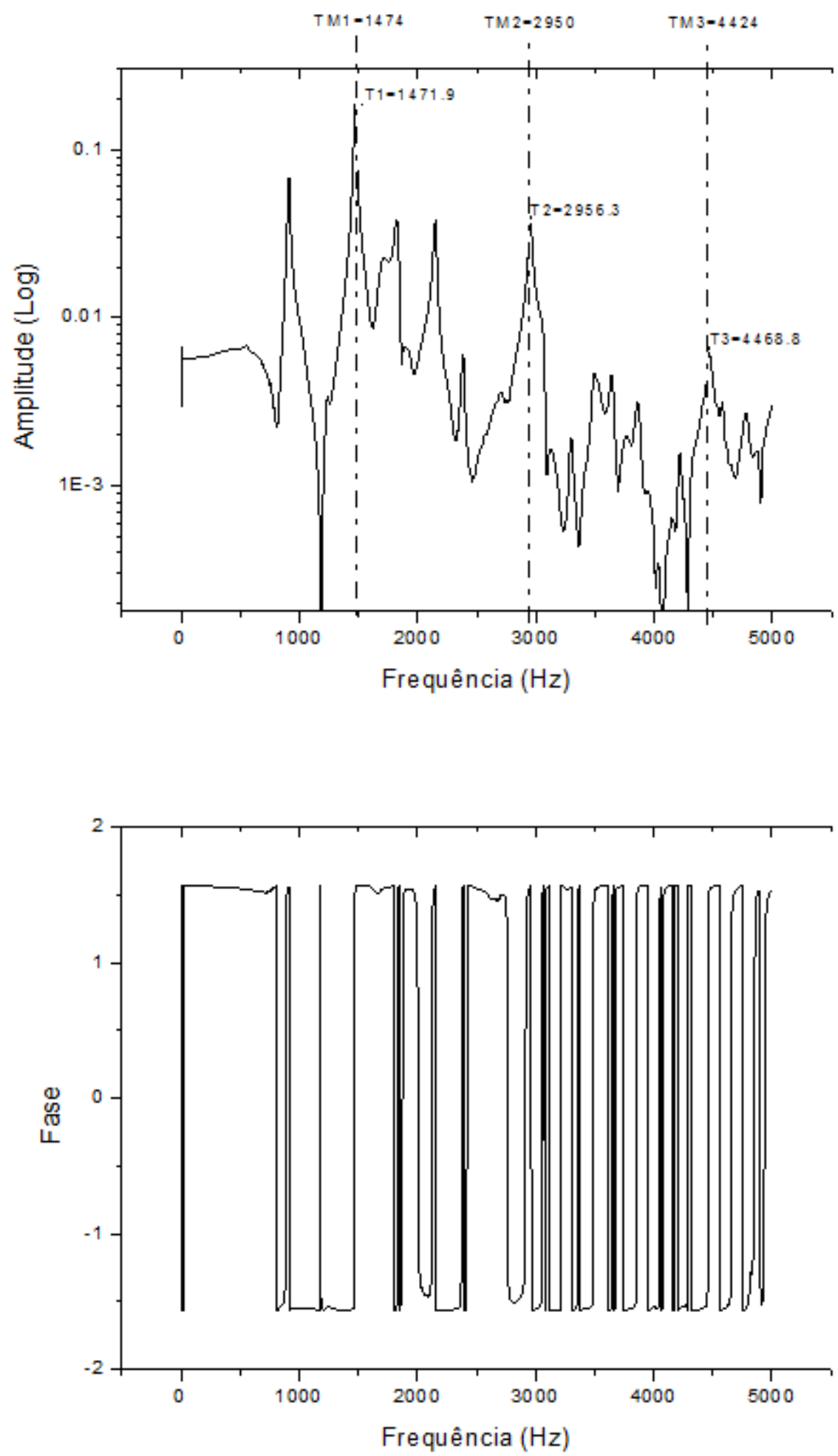

Gráfico 4.13 - Resposta em frequência de ensaio Torcional do Prisma 10 


\subsection{RESUMO DO CAPÍTULO}

O estudo piloto realizado nos permitiu concluir que a incorporação de laminados Polímeros de fibra de carbono (CFRP) aumentou efetivamente a resistência dos prismas ensaiados, ocorrendo aumento médio da capacidade força de 20,7\% para os prismas P40 e de 46,1\% para os prismas P60. Esse aumento na capacidade de carga refletiu em aumento no deslocamento vertical no centro do vão.

O estudo do carregamento prévio mostrou que o reforço tem eficiência mesmo quando aplicada uma força próxima a ruptura (70\% da força máxima), ocorrendo ainda no pior caso, o P60 $40 \%$ um aumento na capacidade de carga de 31,2\% em relação ao prisma P60 SR e com redução média de 10,2\% em relação ao prisma reforçado.

Observou-se que a eficiência do sistema de reforço em relação ao cálculo teórico foi insatisfatória. Sendo o ensaio influenciado pelo posicionamento dos laminados e pelas pequenas dimensões dos prismas, não permitindo sua utilização de forma eficiente.

A forma de ruptura também indicou uma subutilização dos sistemas de reforço de CFRP, pois em todos os modelos ocorreu ruptura por cisalhamento do concreto, não ocorrendo as hipóteses de dimensionamento do reforço, como o destacamento ou a ruptura do laminado.

A análise modal com ensaios não destrutivos, tanto com o Sonelastic ${ }^{\circledR}$ quanto com os acelerômetros piezoelétricos, permitiram observar as diferenças dos módulos de elasticidade para os diferentes tipos de concreto (C40 e C60). Quando inserido um dano controlado de 40\% e 70\% da força máxima os dois métodos permitiram observar uma redução na frequência natural dos prismas e consequentemente uma redução dos módulos de elasticidade.

Ao inserir os laminados no concreto com a técnica NSM foram realizadas ranhuras nos prismas e em seguida preenchidos com os laminados de CFRP e o adesivo epóxi. Ao contrário do que se esperava as frequências naturais dos prismas com sistemas de reforço, reduziu em todos os modelos de maneira não uniforme impossibilitando uma previsão do efeito do reforço com laminados de CFRP pelos ensaios não destrutivo. Acredita-se que esta redução possa ter ocorrido pela abertura das ranhuras juntamente com o manuseio inadequado dos prismas devido ao peso dos prismas ser próximo a $43 \mathrm{~kg}$.

$\mathrm{Na}$ modelagem computacional as frequências naturais dos prismas com sistemas de reforço apresentaram valores praticamente iguais aos dos prismas íntegros diferenciando-se do ocorrido no ensaio físico. Foi realizada uma modelagem computacional dos prismas com ranhuras 
a fim de identificar as reduções apresentadas nos ensaios experimentais, esta não apresentou resposta para este efeito.

A análise das frequências naturais por meio de modelagem computacional apresentou excelentes resultados para os prismas íntegros P40 SR e P60 SR, suas frequências quando comparadas aos ensaios não destrutivos apresentam uma variação máxima de 3\%, valor menor que a variação entre os elementos de mesmo tipo. 


\section{MATERIAIS E MÉTODOS - VIGAS}

No estudo piloto realizado em prismas de concreto sem estribos e de pequenas dimensões surgiu a necessidade de realizar estudos experimentais que permitissem mitigar os problemas elencados no capítulo anterior, possibilitando uma maior compreensão das alterações estruturais obtidas pelo reforço ao cisalhamento em vigas de concreto armado. Com esse propósito foi realizado um estudo em vigas retangulares de concreto armado com pequenas dimensões, confeccionadas em laboratório e reforçadas ao cisalhamento com laminados de CFRP usando técnica NSM. As principais variáveis deste experimento foram as diferentes resistências do concreto e os efeitos pré-fissuração do concreto antes do reforço com CFRP

\subsection{CONCEPÇÃO DAS VIGAS}

Para a realização do estudo experimental de vigas de concreto armado foram confeccionadas 8 (oito) vigas, sendo 4 (quatro) para cada classe de concreto, com seção transversal de $16 \mathrm{~cm}$ x $30 \mathrm{~cm}$ e comprimento de $220 \mathrm{~cm}$, projetadas para ensaio de 3 pontos com carregamento excêntrico e reforço ao cisalhamento apenas no lado mais solicitado ao cisalhamento, conforme Figura 5.1.

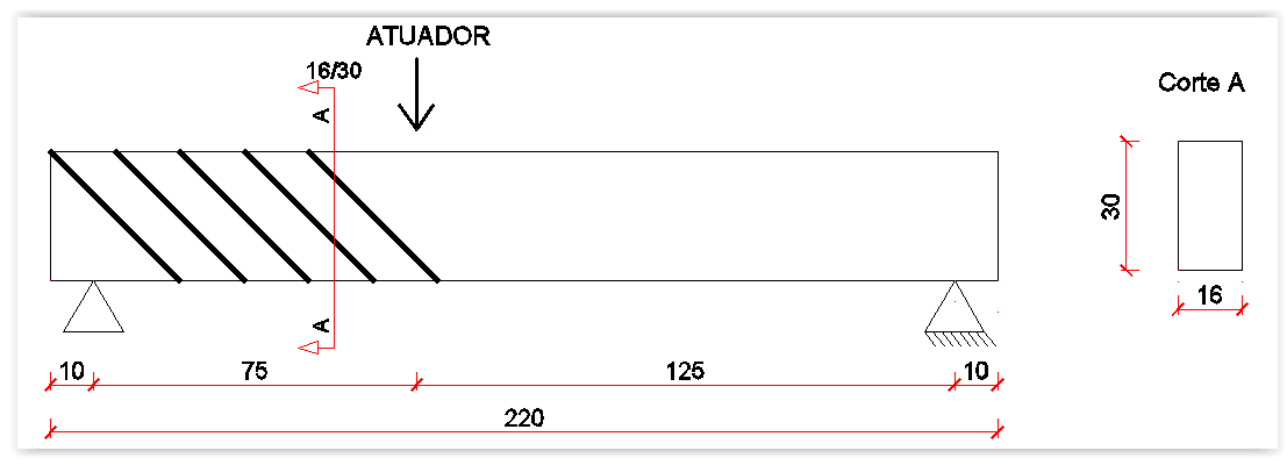

Figura 5.1 - Esquema de ensaio das vigas

A relação entre o vão de cisalhamento e a altura útil da seção transversal (relação a/d) foi mantida para todos os ensaios em 3,0, uma vez que a força foi aplicada a uma distância de $75 \mathrm{~cm}$ do apoio, com um vão total de $200 \mathrm{~cm}$ e as vigas possuíam altura útil (d) de $25 \mathrm{~cm}$. A inclinação dos laminados de CFRP também foi constante para todas as vigas, com 45 graus, não sendo avaliada uma variação entre os ângulos de inserção do reforço. Uma vez que diversos pesquisadores como Dias (2008) e Jayaprakash et al. (2008) afirmam que a orientação dos laminados inclinados a 45 graus possuem melhor desempenho que a solução de laminados posicionados a 90 graus. 
Com o intuito de estudar a capacidade de reforço em diferentes resistências do concreto, 4 (quatro) vigas foram confeccionadas com 52MPa e 4 (quatro) com 90MPa, sendo 1 sem reforço, 1 reforçada com a viga íntegra, 2 reforçadas após carregamento (40\% e 70\% da força máxima da viga sem reforço). Para facilitar a classificação das vigas, estas foram denominadas conforme sua classe de concreto, quanto ao uso de reforço e ao percentual de dano, conforme a Tabela 5.1.

Tabela 5.1 - Denominação das vigas

\begin{tabular}{|c|c|c|c|}
\hline ID & Descrição & ID & Descrição \\
\hline V50 SR & $52 \mathrm{MPa}$ sem reforço de CFRP & V90 SR & $90 \mathrm{MPa}$ sem reforço de CFRP \\
\hline V50 CFRP & $52 \mathrm{MPa}$ reforçadas íntegra; & V90 CFRP & $90 \mathrm{MPa}$ reforçadas íntegra; \\
\hline V50 40\% & $\begin{array}{l}52 \mathrm{MPa} \text { reforçadas após } \\
\text { carregamento de } 40 \% \text { da força } \\
\text { máxima da V50 SR; }\end{array}$ & V90 40\% & $\begin{array}{l}90 \mathrm{MPa} \text { reforçadas após } \\
\text { carregamento de } 40 \% \text { da força } \\
\text { máxima da V90 SR; }\end{array}$ \\
\hline V50 70\% & $\begin{array}{l}52 \mathrm{MPa} \text { reforçadas após } \\
\text { carregamento de } 70 \% \text { da força } \\
\text { máxima da V50 SR; }\end{array}$ & V90 70\% & $\begin{array}{l}90 \mathrm{MPa} \text { reforçadas após } \\
\text { carregamento de } 70 \% \text { da força } \\
\text { máxima da V90 SR; }\end{array}$ \\
\hline
\end{tabular}

Objetivando o colapso por cisalhamento, um dimensionamento para cada classe de concreto foi realizado considerando estruturas superamadas à flexão e com baixa taxa de armaduras de cisalhamento no trecho da viga reforçada. Esta configuração foi dimensionada para permitir uma completa utilização do sistema de reforço com a permanência da ruptura por cisalhamento.

Todas as vigas possuíam uma elevada taxa de armadura longitudinal (5,68\%) com 3 barras de $25 \mathrm{~mm}$, mais 2 barras de $20 \mathrm{~mm}$ em segunda camada de armação positiva, com 2 barras de $20 \mathrm{~mm}$ de armação negativa. Para as armaduras transversais houve uma diferenciação no diâmetro das barras no trecho mais solicitado, onde as vigas V50 utilizaram barras de 6,3mm enquanto que as vigas V90 barras de $8 \mathrm{~mm}$, ambas com espaçamentos de $15 \mathrm{~cm}$. Na região de menor esforço todas as vigas utilizaram 19 estribos de $8 \mathrm{~mm}$ a cada $7 \mathrm{~cm}$ (Figura 5.2 e Figura 5.3).

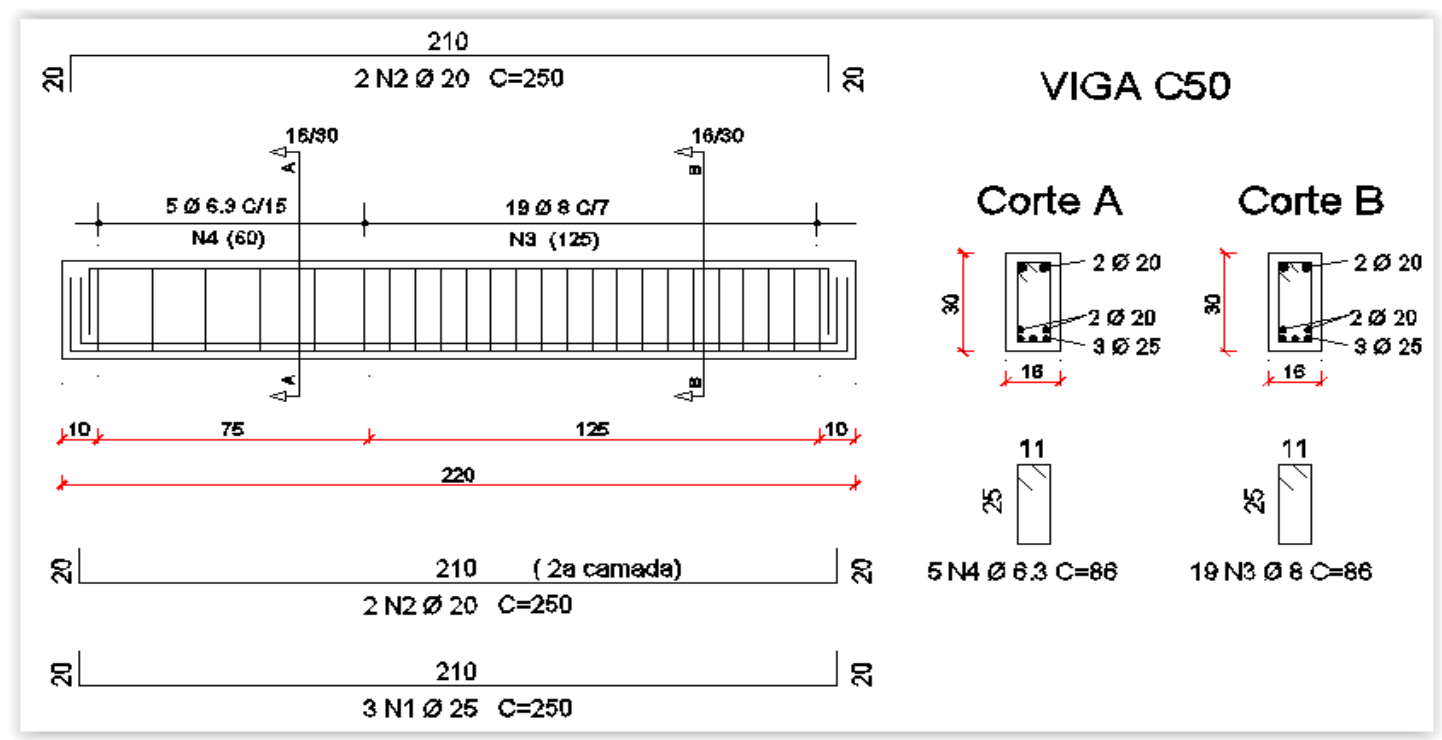

Figura 5.2 - Armação das vigas V50 


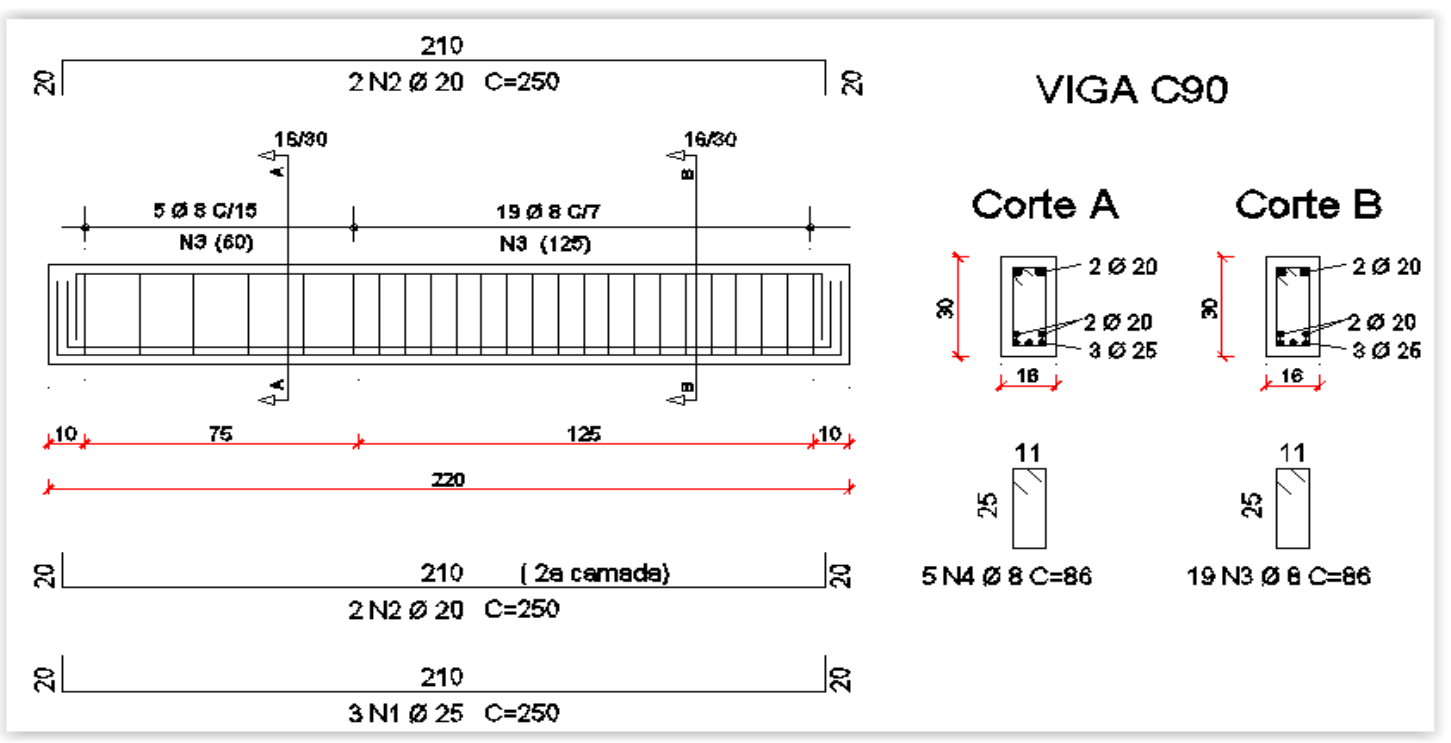

Figura 5.3 - Armação das vigas V90

As vigas foram instrumentadas para medir sua deformação durante os ensaios com extensômetro de deformação (Strain Gages) da marca Kyowa com sensibilidade para deformação de $2,1 \pm 1 \%$. Estes foram utilizados uma armadura longitudinal positiva e negativa, nos estribos do trecho mais solicitado ao cisalhamento e nos laminados de CFRP. A Figura 5.4 apresenta o esquema e imagem da instrumentação dos extensômetros nas vigas.
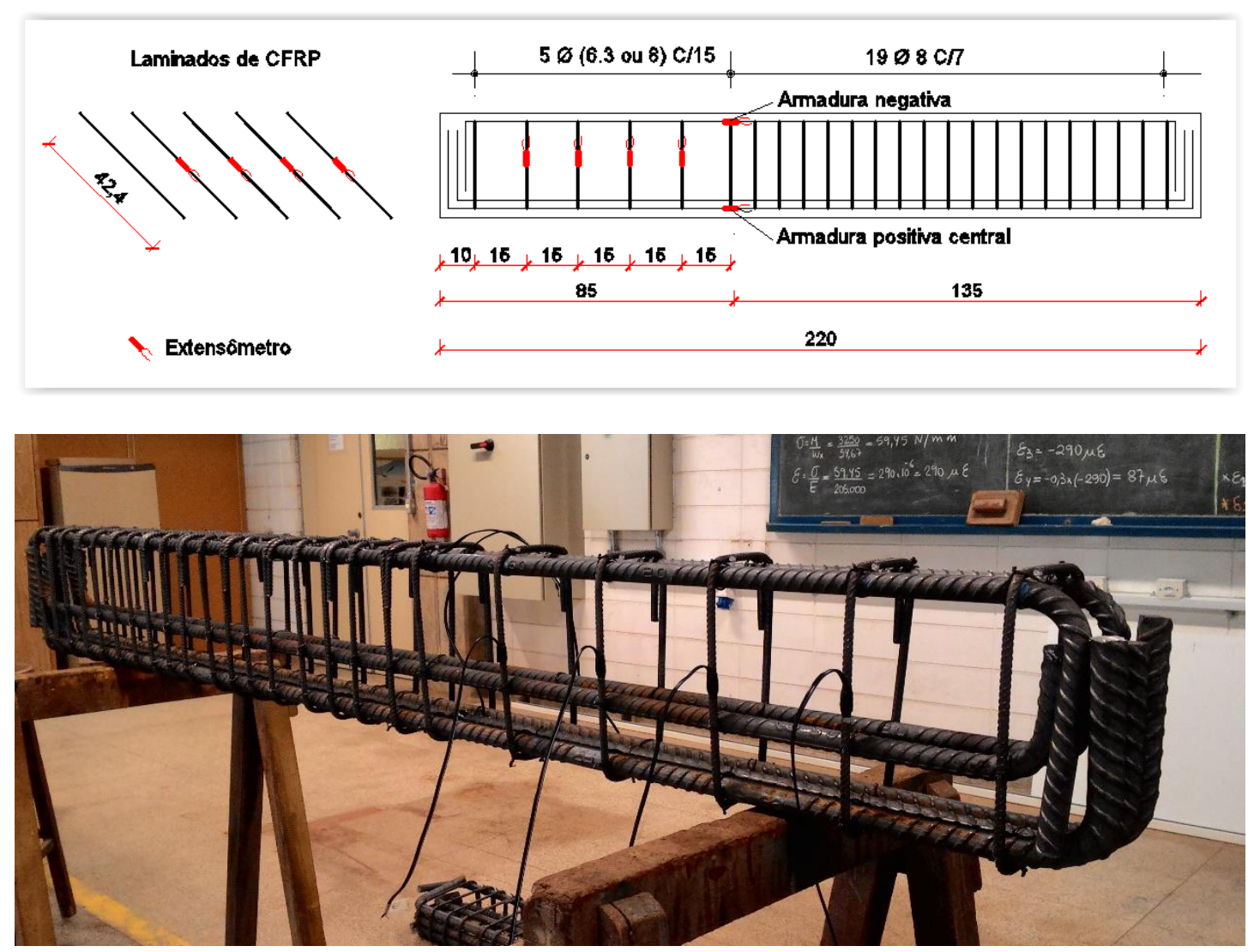

Figura 5.4 - Esquema e imagem da instrumentação de extensômetros nas vigas 
Para a inserção dos laminados levando em conta o reforço ao cisalhamento pela técnica NSM, foi necessário a abertura de ranhuras nos locais de aplicação do reforço. Nesta pesquisa foram idealizadas ranhuras de $4,2 \mathrm{~mm}$ de espessura e $25 \mathrm{~mm}$ de profundidade para garantir uma melhor aderência entre os laminados de CFRP e o concreto como sugerem De Lorenzis e Teng, (2007), já devidamente explicadas nesta tese. A abertura das ranhuras foi realizada com maquina serra mármore usuais de mercado, pois o transporte para marmorarias poderia causar danos nas vigas.

As vigas foram reforçadas com 10 (dez) laminados de CFRP inseridos no cobrimento do concreto, sendo 5 (cinco) em cada lado, a um ângulo de 45 graus e com comprimentos de $42,4 \mathrm{~cm}$. No presente trabalho todos os laminados de CFRP utilizados foram fornecidas em um rolo e tinha seção transversal de $20 \mathrm{~mm}$ de largura por $1.4 \mathrm{~mm}$ de espessura, com módulo de elasticidade fornecido pelo fabricante de $165 \mathrm{kN} / \mathrm{mm}^{2}$.

Para a aplicação do reforço no concreto seguiram-se os procedimentos já devidamente documentados por Dias (2008). A Figura 5.5 ilustra alguns dos procedimentos realizados para a aplicação da técnica de reforço por colagem de laminados em ranhuras (NSM).

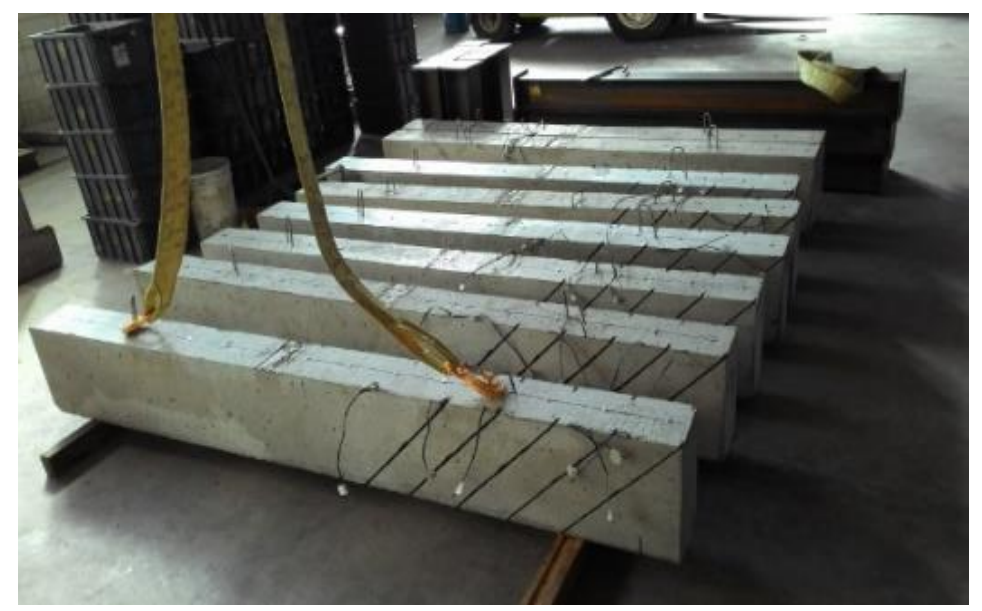

(a) Abertura das ranhuras

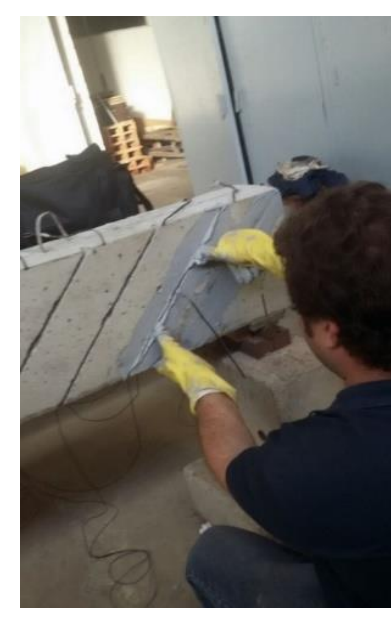

(b) aplicação do reforço

Figura 5.5 - Etapas do reforço com a técnica NSM

\subsection{MOLDAGEM E CONCRETAGEM DOS MODELOS}

Nos ensaios experimentais algumas alterações ocorreram na produção do concreto, pois pretendia-se utilizar duas classes de concretos na fabricação das vigas com propriedades semelhantes aos concretos utilizados na fabricação dos prismas. $O$ concreto foi alterado principalmente devido à elevada taxa de armadura longitudinal e transversal da viga, bem como suas dimensões reduzidas, fazendo-se necessário uma redefinição dos traços de concreto para a obtenção de uma maior trabalhabilidade. 
Os traços de concreto foram dimensionados por tabelas, utilizando o Método INT e com o objetivo de produzir concreto utilizando agregados graúdos de pequenas dimensões (pedrisco), com alta trabalhabilidade e resistências à compressão de $40 \mathrm{MPa}$ e $60 \mathrm{MPa}$. A trabalhabilidade e a capacidade de preenchimento das pequenas dimensões ocasionadas pela elevada taxa de armadura foram obtidas, mas a resistências à compressão dos concreto foram maior que a esperada, com $52 \mathrm{MPa}$ e $90 \mathrm{MPa}$.

A Figura 5.6 apresenta a armadura das vigas inseridas na forma, com pequeno espaço para a passagem do concreto e a Figura 5.7 mostra o ensaio de trabalhabilidade "Slump Test", realizado conforme a ABNT NBR NM 67:1998.

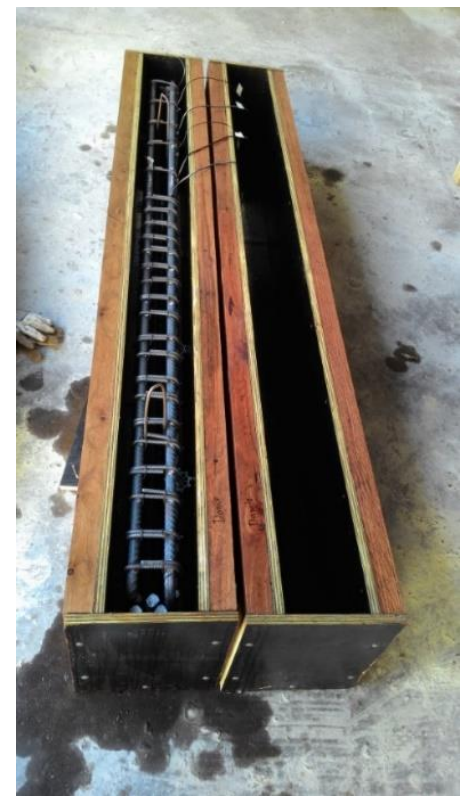

Figura 5.6 - Armadura e forma das vigas

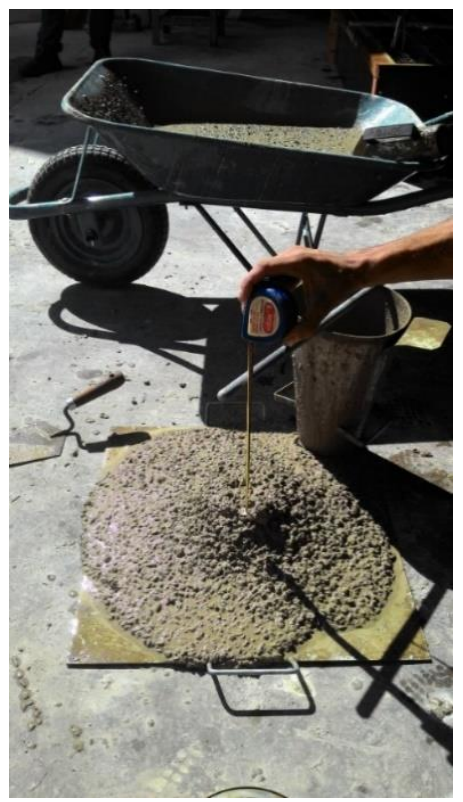

Figura 5.7 - "Slump Test"

No primeiro traço utilizou-se uma dosagem em massa de $1: 2,68: 2,67: 0,57$, obtendo textura e trabalhabilidade elevada conforme planejado, com abatimento de $25 \mathrm{~cm}$ para a primeira betonada e de $26 \mathrm{~cm}$ para a segunda betonada. O segundo tipo de concreto foi executado com traço de $1: 1,72: 1,73: 0,40$, em que também obtiveram a trabalhabilidade esperadas, com abatimento de $23 \mathrm{~cm}$ para as duas betonadas.

Para cada traço de concreto dimensionado foram produzidos 500 (quinhentos) litros de concreto, com capacidade de concretar 4 (vigas) vigas com $16 \mathrm{~cm}$ x $30 \mathrm{~cm}$ x $220 \mathrm{~cm}, 12$ (doze) corpos de prova de $10 \mathrm{~cm}$ x $20 \mathrm{~cm}$ e 2 (dois) prismas de $15 \mathrm{~cm}$ x $15 \mathrm{~cm}$ x $50 \mathrm{~cm}$. Devido a capacidade de produção da betoneira utilizada no laboratório de 300 litros, cada tipo de concreto foi produzido em duas betonadas. Com o objetivo de reduzir as possíveis variações causadas na produção do 
concreto em betonadas distintas, produziu-se pelo turno da manhã no mesmo dia todas as vigas com 52MPa e na semana seguinte da mesma forma as vigas com 90MPa (Figura 5.8 e Figura 5.9).

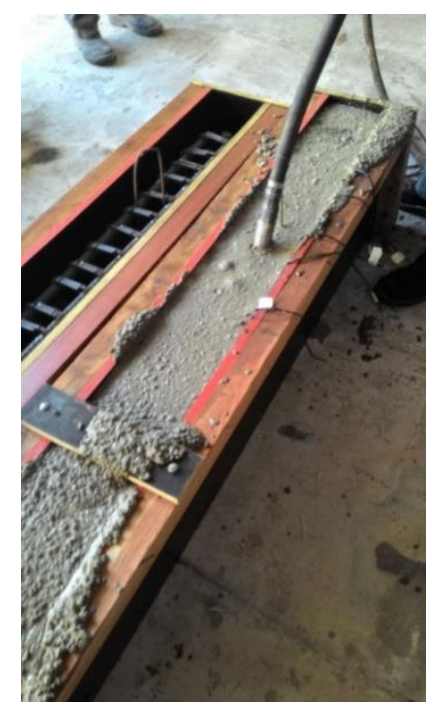

Figura 5.8 - Concretagem de vigas

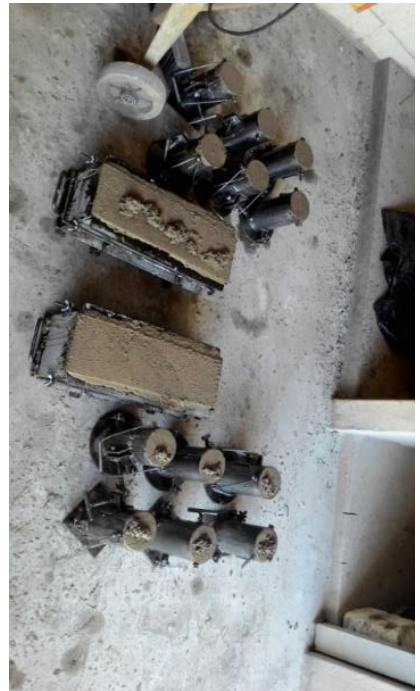

Figura 5.9 - Concretagem de CPs e Prismas

Os ensaios de resistência dos corpos de prova foram realizados na prensa hidráulica elétrica para ensaios de compressão, da marca ELE, com sistema de automação da velocidade de carregamento em função do ensaio realizado. Foram utilizados para cada traço de concreto 6 (seis) corpos de prova para o ensaio a compressão e 6 (seis) para o ensaio a tração.

O ensaio do módulo de elasticidade foi realizado utilizando-se o software Sonelastic ${ }^{\circledR}$ de forma não destrutiva. Para a realização destes ensaios foram usados os mesmos 12 corpos de prova $(10 \mathrm{~cm} \times 20 \mathrm{~cm})$ necessários para a definição das resistências à tração e compressão. Os materiais e métodos dos ensaios de resistência à compressão e à tração, assim como os de módulo de elasticidade já foram devidamente descritos no capítulo materiais e métodos dos prismas.

Para a definição das propriedades do aço foi realizado ensaio de tração nas barras de 6.3, 20mm e 25mm, conforme a norma ABNT NBR ISO 6892:2015. Realizado na prensa Instron, modelo $300 \mathrm{HVL}$, com capacidade para $1.500 \mathrm{kN}$, com acoplamento de garras e controle de deslocamento do pistão.

Foram realizados ainda ensaios de tração e modulo de elasticidade nos laminados de CFRP. Estes foram realizados na prensa hidráulicas EMIC DL 10000 com o auxílio de um extensômetro. Para o ensaio dos corpos de prova de laminado de CFRP foi seguida a norma ASTM D3039M (2000), adotando as dimensões sugeridas com e sem a colagem de abas (Figura 5.10). 

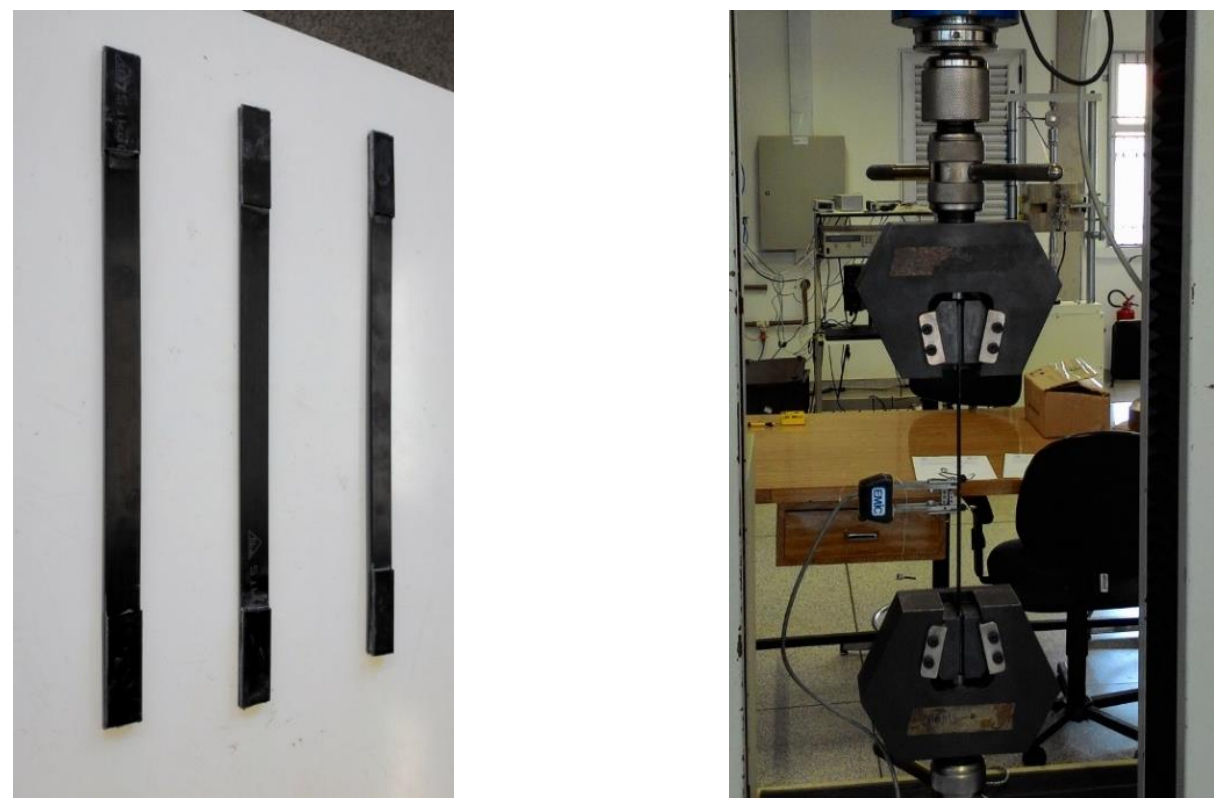

Figura 5.10 - Ensaio de tração do laminado CFRP

\subsection{FORÇAS MÁXIMAS}

As vigas sem reforços V50 SR e V90 SR foram calculadas segundo a norma ABNT NBR 6118:2014 para a determinação das forças máximas na flexão e no cisalhamento. Para o dimensionamento foram considerados os resultados das resistências à compressão e à tração e do módulo de elasticidade dos materiais componentes obtidos nos ensaios de laboratório.

No dimensionamento das vigas com reforço ao cisalhamento foram consideradas o acréscimo na capacidade de carga conforme as formulações desenvolvidas por Dias (2008) já apresentadas nos capitulo materiais e métodos dos prismas.

\subsubsection{Força máxima para a flexão $\left(\mathrm{F}_{\text {máx }}\right)$}

Como o objetivo desta pesquisa é avaliar o desempenho do reforço ao cisalhamento, optou-se por fabricar vigas com elevada taxa de armação longitudinal (5,68\%), utilizando armadura dupla, isso permitiu aumentar a capacidade de resistência à flexão. A armadura longitudinal foi mantida para todas as vigas, independente da classe de concreto e da ocorrência posterior de reforço, com 3 barras de $25 \mathrm{~mm}\left(\mathrm{~A}_{\mathrm{s} 1}\right)$ mais 2 barras de $20 \mathrm{~mm}\left(\mathrm{~A}_{\mathrm{s} 2}\right)$ de armadura tracionada, além de 2 barras de $20 \mathrm{~mm}$ de armadura comprimida $\left(\mathrm{A}_{\mathrm{s}^{\prime}}\right)$.

$\mathrm{Na}$ configuração do diagrama de tensões na viga, foram consideradas após a fissuração, forças na parte comprimida Fs' para o aço e Fc para o concreto. Na parte tracionada foram consideradas as duas camadas de aço separadamente, com $F_{S 1}$ para as três barras de $25 \mathrm{~mm}$ e $\mathrm{F}_{\mathrm{S} 2}$ para as duas barras de $20 \mathrm{~mm}$, com as devidas distâncias entre as forças apresentadas na Figura 5.11. 


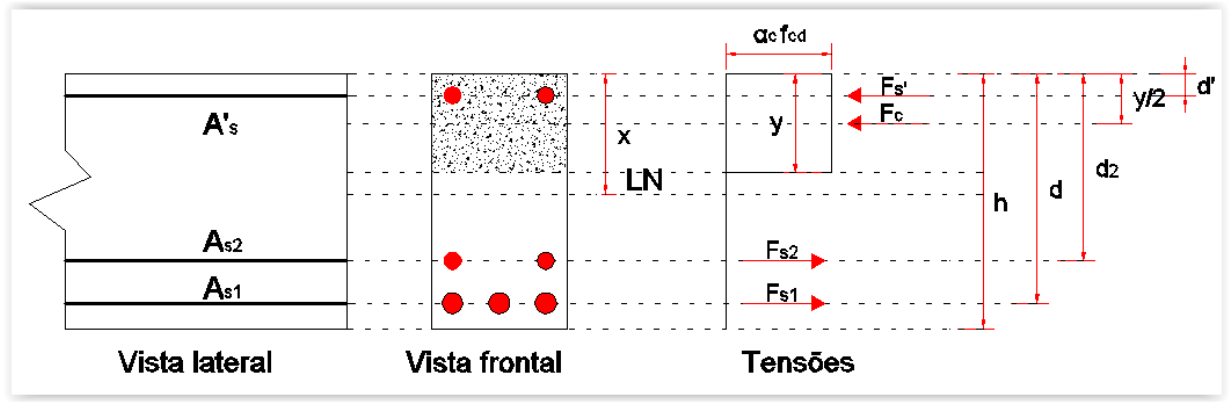

Figura 5.11 - Diagrama de tensões no concreto

O dimensionamento a flexão foi executado com auxílio do programa SecTrans® versão 10 criado pelo Professor Dr. Vladimir G. Haach orientador desta pesquisa. O programa permite além da obtenção do momento máximo suportado para a flexão, o posicionamento da linha neutra, a curvatura, tensão e deformação para qualquer etapa de carregamento. O programa utiliza para cálculo a norma ABNT NBR 6118:2014. A Figura 5.12 mostra o Interface gráfica do programa SecTrans ${ }^{\circledR}$.
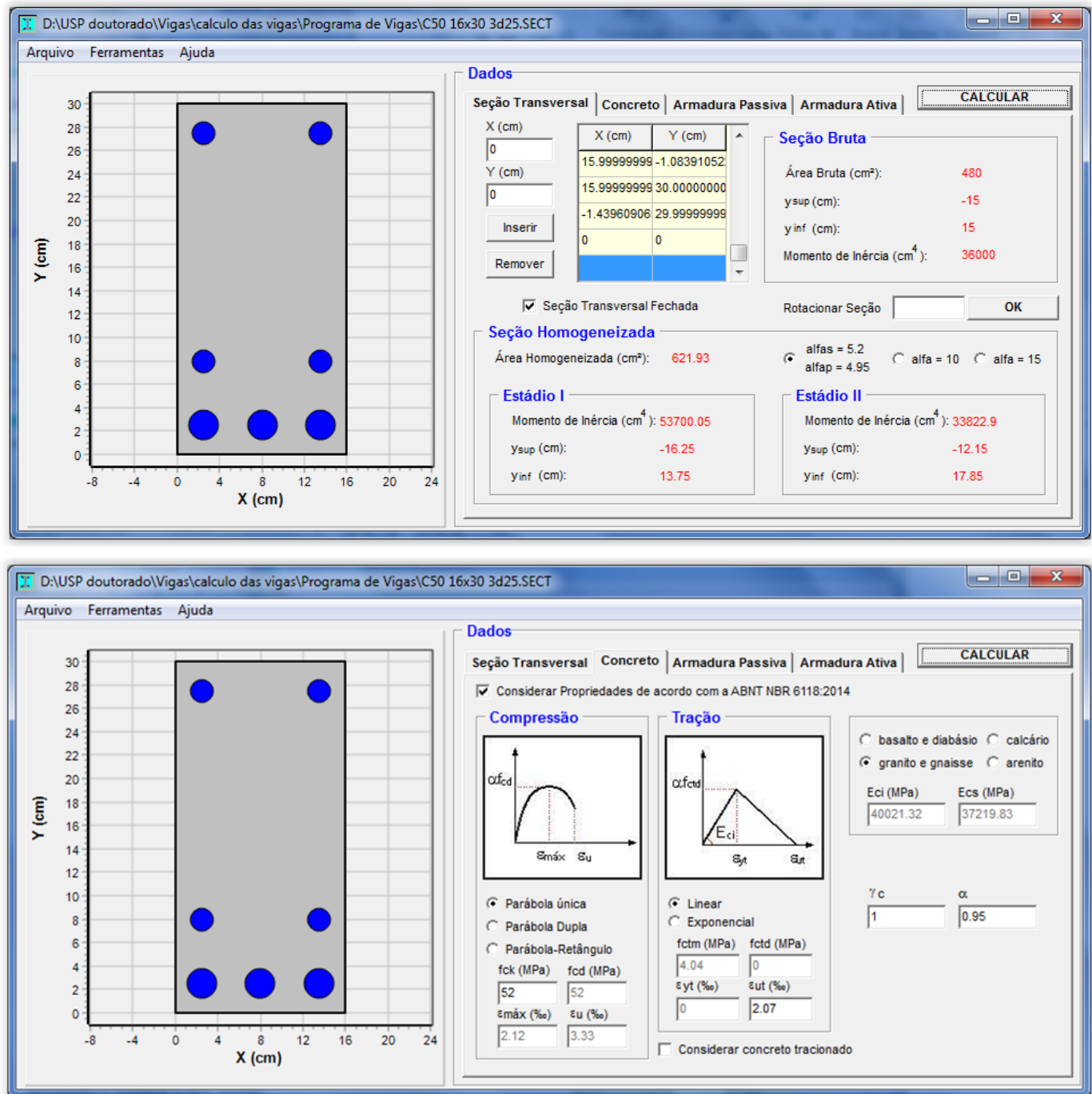

Figura 5.12 - Interface gráfica do Programa SecTrans ${ }^{\circledR}$. 
Para a determinação da força máxima suportada pela viga na flexão foi utilizada a Equação 5.1 considerando o equilíbrio de esforços na viga. A Tabela 6.4 apresenta os resultados das inércias íntegras, fissuradas e dos momentos fletores máximos obtidos segundo o programa SecTrans ${ }^{\circledR}$, bem como os resultados das forças máximas admitidas no dimensionamento à flexão das vigas V50 e V90.

$$
F_{\text {máx }}=\frac{M_{\text {máx }} \cdot l}{a . b}
$$

Onde:

$\mathrm{F}_{\text {máx }}=$ Força máxima admissível para a flexão

$\mathrm{M}_{\text {máx }}=$ Momento máximo admissível

$1=$ Comprimento da viga $(200 \mathrm{~cm})$

$\mathrm{a}=$ Menor lado da viga $(75 \mathrm{~cm})$

$\mathrm{b}=$ Maior lado da viga $(125 \mathrm{~cm})$

\subsubsection{Força máxima no cisalhamento $\left(\mathrm{F}_{\mathrm{Wmáx}}\right)$}

Para o dimensionamento da força máxima no cisalhamento, optou-se pelo método de cálculo I descrito na norma ABNT NBR 6118:2014, o qual admite diagonais de compressão inclinadas $\operatorname{com} \theta=45$ graus em relação ao eixo longitudinal do elemento estrutural e admite ainda que a parcela complementar do concreto $\left(V_{c}\right)$ tenha valor constante, independentemente da força cortante solicitante de cálculo $\left(\mathrm{V}_{\mathrm{Sd}}\right)$. Igualmente ao utilizado no dimensionamento dos prismas, mas com a presença da parcela resistente da armadura transversal $\left(V_{\text {sw }}\right)$.

Para a determinação da força máxima suportada pelas vigas $\left(\mathrm{F}_{\mathrm{Wmáx}}\right)$ foi utilizada a Equação 5.2 considerando o equilíbrio de esforços na viga.

$$
F_{\text {Wmáx }}=\frac{V_{S D} \cdot l}{b}
$$

\subsubsection{Força máxima no cisalhamento com reforço $\left(\mathrm{F}_{\mathrm{WR}}\right)$}

No reforço de todas as vigas foram utilizados os laminados de CFRP com seção transversal de $1,4 \mathrm{~mm} \times 20 \mathrm{~mm}$, inseridos apenas no lado mais solicitado da viga, em ambas as faces, espaçados a cada $15 \mathrm{~cm}$ e inclinados a 45 graus. Esta configuração permitiu que todos os laminados de CFRP estivessem posicionados interseccionando dois estribos de aço. Desta maneira toda a seção reforçada possui a mesma capacidade de carga (Figura 5.13). 


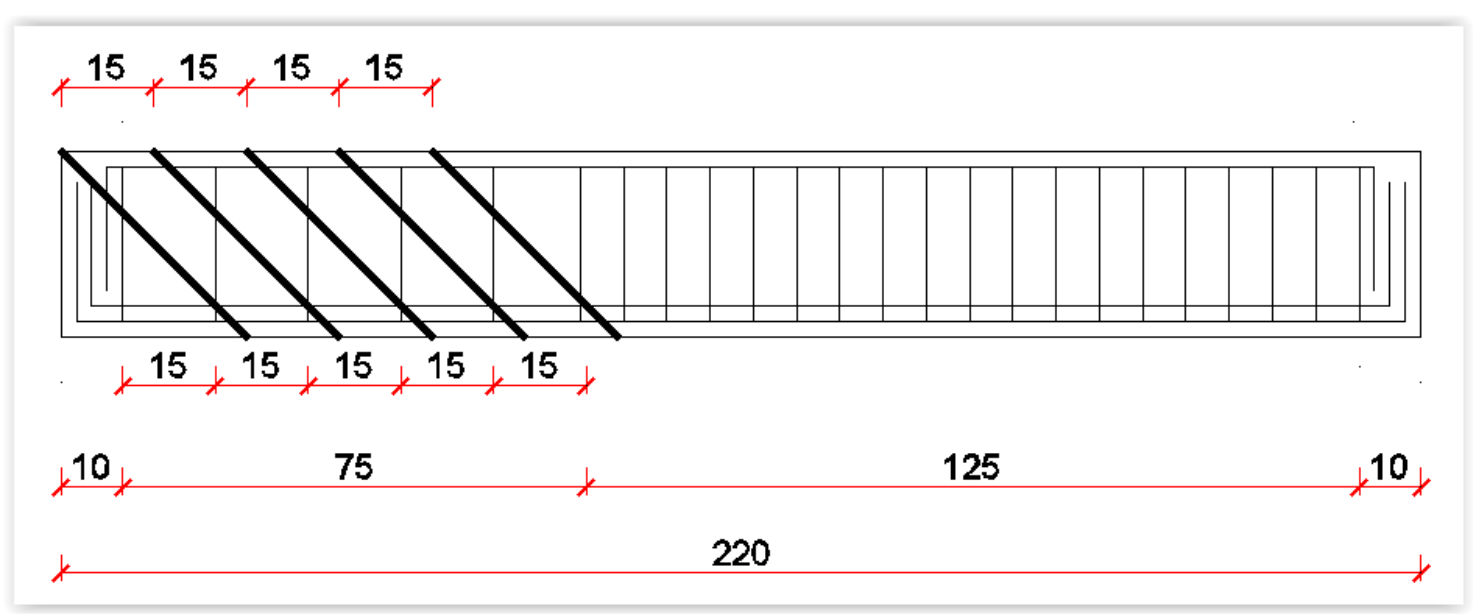

Figura 5.13 - Posicionamento dos laminados de CFRP na viga (dimensões em $\mathrm{cm}$ )

Gamino (2007) apresenta em seus estudos oito métodos de cálculo para a determinação da contribuição do reforço de CFRP na capacidade de carga de vigas, essa variabilidade de métodos ocorre devido as diferentes formas de ruptura da viga, com modelos que levam em consideração a capacidade resistente ao cortante, modelos que consideram as regiões de concreto existentes entre duas fissuras de flexão e os modelos de resistência da interface.

Devido à falta de norma brasileira especifica para sistemas de reforço com CFRP, ocorreram dificuldades para determinar a contribuição do reforço de CFRP, não observando estudos no Brasil de dimensionamento com CFRP usando a técnica NSM. Nesta pesquisa para a determinação da contribuição do reforço na capacidade de carga das vigas foi utilizado a formulação desenvolvidas por Dias (2008).

A deformação especifica do reforço $\left(\boldsymbol{E}_{\mathrm{fe}}\right)$ é a principal diferença entre os métodos de cálculo nos estudos apresentados por Gamino (2007), onde até a norma Europeia o Fib bulletin 14 (2001), destaca que a sua definição é extremamente difícil, tendo sua formulação baseada em rigorosas análises. As principais observações referem-se a orientação das fibras serem diferentes do sentido do carregamento e ao fato de no estado limite último ser sempre esperado um certo grau de destacamento na interface concreto-CFRP, que causam esforço excessivo no CFRP.

Para o cálculo da resistência ao cisalhamento da seção, a parcela assimilada pelo reforço $\left(V_{f}\right)$ é somada às parcelas resistentes do concreto e aço. Sua formulação foi descrita no capítulo materiais de métodos dos prismas. Na contribuição do reforço é calculado pela Equação 3.15 que considera a orientação do reforço em relação ao eixo longitudinal da viga $\left(\theta_{\mathrm{f}}\right)$ e a orientação das fissuras de cisalhamento $(\alpha)$ admitidas em 45 graus. 


\subsection{ENSAIO DESTRUTIVO}

O ensaio destrutivo consiste no esquema de três pontos com carregamento descentralizado a uma distância de $75 \mathrm{~cm}$ do apoio do lado mais solicitado da viga, sendo esta biapoiada a $10 \mathrm{~cm}$ da face da viga e com $220 \mathrm{~cm}$ de comprimento, conforme já apresentado.

Para a realização do ensaio foi necessária a montagem de pórtico de reação com atuador servo-hidráulico, controlados por computador, com capacidade para $500 \mathrm{kN}$ e curso de $150 \mathrm{~mm}$ da marca MTS. Nesta máquina é possível realizar ensaios estáticos deslocamento do pistão, causando uma ruptura menos brusca dos elementos ensaiados, o que permite observar as deformações após a força máxima.

Para a medição dos dados no ensaio das vigas foram utilizados 9 (nove) extensômetros nas vigas como já ilustrado na Figura 5.4, além de três (3) transdutores para medir o deslocamento, sendo um no ponto de aplicação da força e dois nos apoios das vigas para subtrair os deslocamentos ocorridos devido a acomodação nos apoios. A Figura 5.14 mostra o esquema de ensaio com detalhe do atuador utilizado.
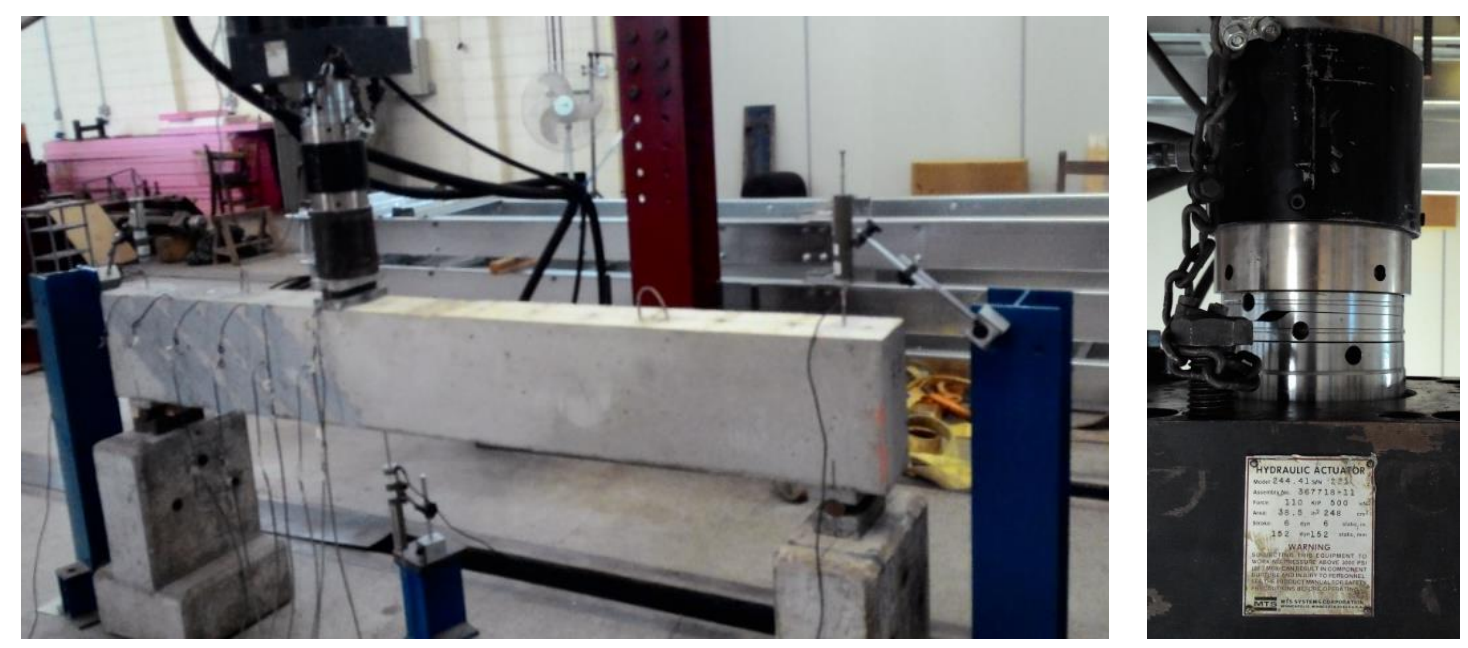

Figura 5.14 - Esquema de ensaio e detalhe do atuador

Durante o ensaio das vigas sem reforço pode-se observar que as primeiras fissuras visíveis nas vigas ocorreram com $37 \%$ da força máxima e o aumento das fissuras de cisalhamento ocorreram com $65 \%$ da força máxima. Desta forma, os valores preestabelecidos de fissuração de 40 e 70\% mostraram-se adequados para o estudo, pois permitiram observar o reforço em estruturas após a primeira fissuração e com fissuras de cisalhamento.

O ensaio primeiramente foi realizado nas vigas sem reforço (V50 SR e V90 SR) até a ruptura, permitindo assim determinar a capacidade de carga das vigas. O carregamento prévio para a pré-fissuração das vigas foi realizado com o mesmo esquema de ensaio de ruptura. 
Devido à proximidade do limite de força do atuador de $500 \mathrm{kN}$ na viga sem reforço C90 SR, ocasionados pela elevada resistência dos concretos utilizados para a confecção das vigas, (50 e $90 \mathrm{MPa}$ ) valores acima do esperado (40 e $60 \mathrm{MPa}$ ). As vigas reforçadas com concreto de $90 \mathrm{MPa}$ (C90 CFRP, C90 40\% e C90 70\%) tiveram que ser ensaiadas em um outro pórtico e com outro atuador de força mais uma célula de força, diferentemente do atuador utilizado nas vigas com C50. O atuador hidráulico utilizado, com capacidade de carga de $1000 \mathrm{kN}$, não possui controle de deslocamento, ocasionando em rupturas mais bruscas, piorando a captação de dados após a ruptura (Figura 5.15).
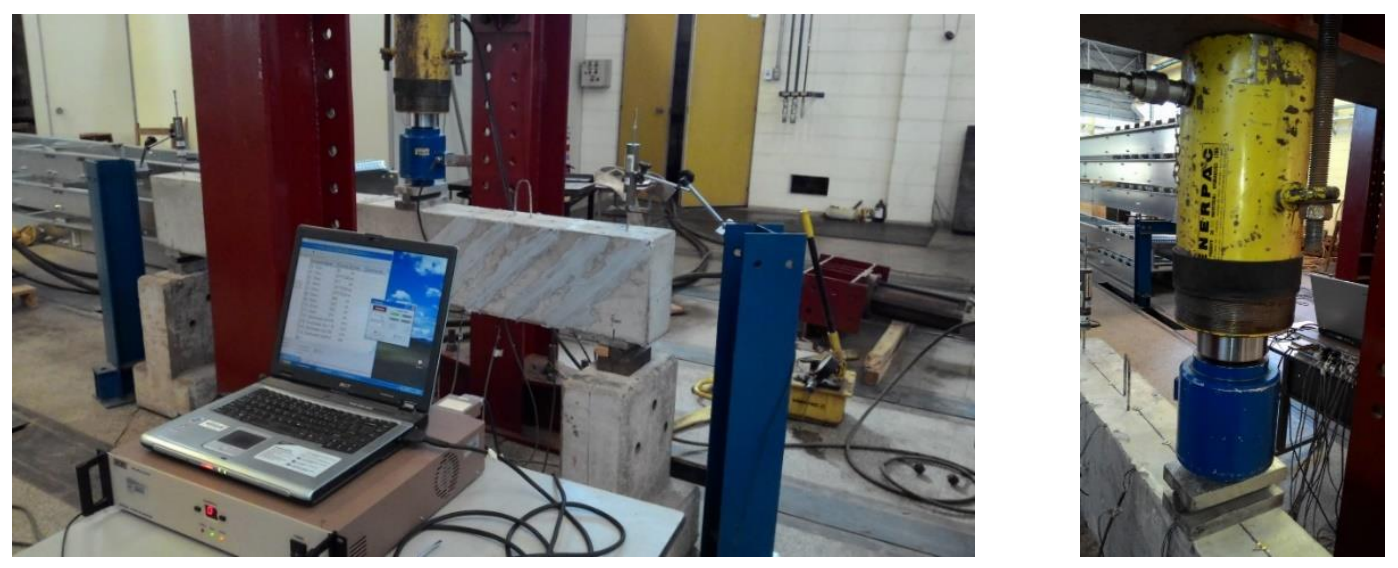

Figura 5.15 - Esquema de ensaio com detalhe do atuador hidráulico

\subsection{ENSAIO DINÂMICO NÃO DESTRUTTIVO}

A análise dinâmica foi realizada utilizando métodos de identificação modal estocásticos. Estas metodologias de identificação modal diferenciam-se da forma clássica, principalmente por não utilizar medições da força de excitação. A identificação modal estocástica permite uma estrapolação dos ensaios realizados nas vigas para estruturas reais em operação, uma vez que o método possibilita realizar ensaios em estruturas civis usando somente as forças operacionais (vento, trafego, pedestres, entre outras). Isto gera, que os ensaios sejam menos onerosos e não precisem da interrupção do uso normal da estrutura.

Segundo Carrillo e Laier (2006), a ideia básica da detecção de dano considera que os parâmetros modais (frequências, formas modais e amortecimento modal), são funções das propriedades físicas da estrutura (massa, amortecimento e rigidez), e, portanto, qualquer mudança destas propriedades causará mudança nos parâmetros modais. Este fato permite a detecção de dano a partir da resposta dinâmica da estrutura.

As vigas foram ensaiadas em várias etapas de configuração de dano, com a pretensão de identificar as alterações nas frequências naturais à flexão das vigas e o comportamento dos modos de vibração. As 5 (cinco) etapas de danificação denominadas: Íntegra, Dano, Ranhura, Reforço e 
Ruptura. Logicamente as vigas que não possuem reforço não foram analisadas as configurações de Ranhura e Reforçada.

O equipamento utilizado para os ensaios dinâmicos consistiu em oito acelerômetros piezoelétricos da marca Bruel \& Kjaer, 2 modelos 8344, com sensibilidade de $2500 \mathrm{mV} / \mathrm{g}$ e faixa de frequência 0,2 a $3000 \mathrm{~Hz}$ e 6 modelos 4533-B-2 com sensibilidade de $490 \mathrm{mV} / \mathrm{g}$ dentro da faixa de frequência de 0,3 a $12800 \mathrm{~Hz}$. O sistema de aquisição de dados da marca National Instrument, modelo NI 9232, com software LabVIEW SignalExpress ${ }^{\circledR}$ foi utilizado para a administração do armazenamento, análise e visualização dos dados registrados dos instrumentos de aquisição

O sistema de aquisição permitiu obter dados no domínio do tempo, fazendo automaticamente a transformação destes dados para o domínio da frequência. Durante os ensaios o programa permite a visualização dos dados no domínio do tempo e da frequência, facilitado uma análise visual da qualidade dos ensaios para uma seleção de resultados com menores interferências.

A Figura 5.16 apresenta a interface gráfica do programa em duas configurações: potência $\mathrm{x}$ frequência em escala linear e potência $\mathrm{x}$ frequência em escala exponencial.
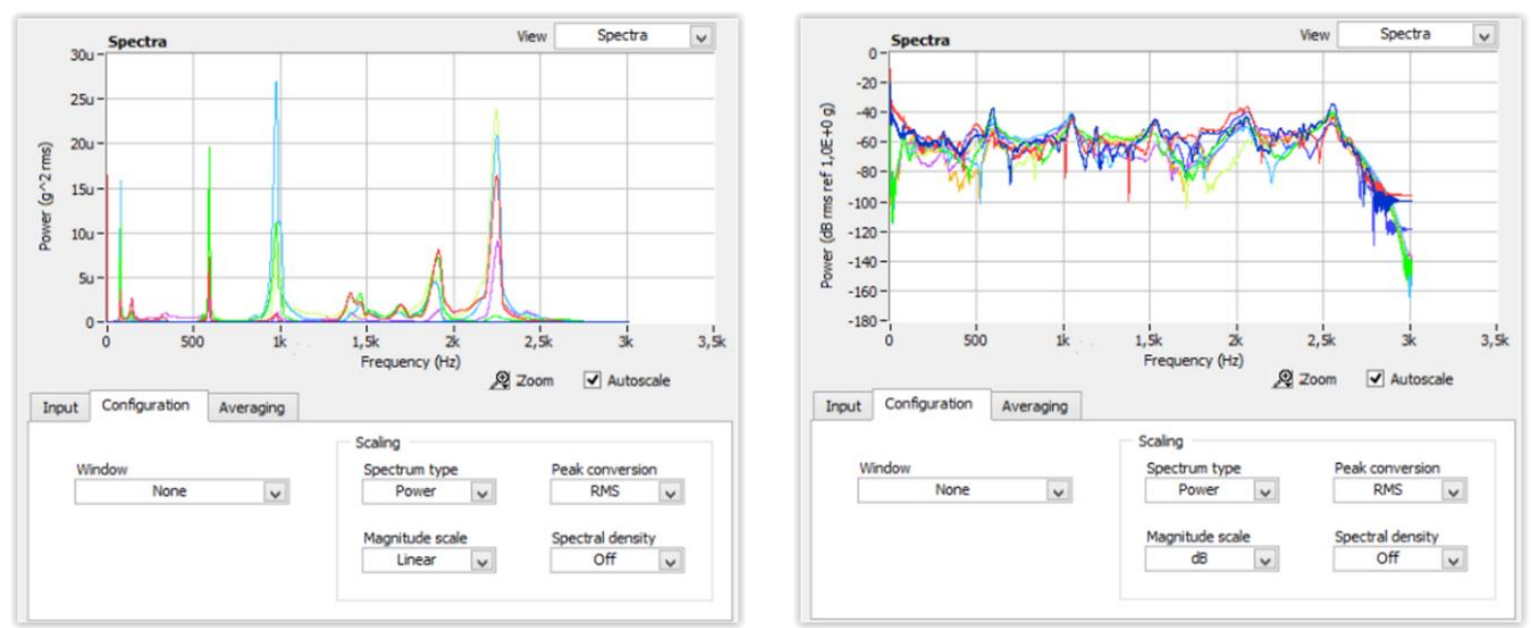

Figura 5.16 - Interface gráfica software LabVIEW SignalExpress

A medição das frequências naturais é feita com o uso de acelerômetros piezoelétricos com o programa já apresentado, mas para a determinação dos modos de vibração é necessário a medição da vibração ao longo da viga, com vários acelerômetros simultaneamente.

Para a determinação dos modos de vibração é necessário a medição de acelerações ao longo da viga com a colocação simultânea de vários acelerômetros. Assim, quando a quantidade de pontos de coleta é superior ao número de acelerômetros, faz-se necessário a utilização de um ponto de referência fixo. $\mathrm{O}$ acelerômetro escolhido como referência permanece em uma posição, enquanto que os demais acelerômetros são posicionados nos demais pontos. 
Os acelerômetros foram posicionados com espaçamentos equidistastes, a cada $15 \mathrm{~cm}$ como disposto na Figura 5.17, esta configuração necessitou da utilização de 15 posições e teve que ser dividida em duas series de ensaios com 8 acelerômetros cada, sendo utilizado na posição "a" o acelerômetro de referência.

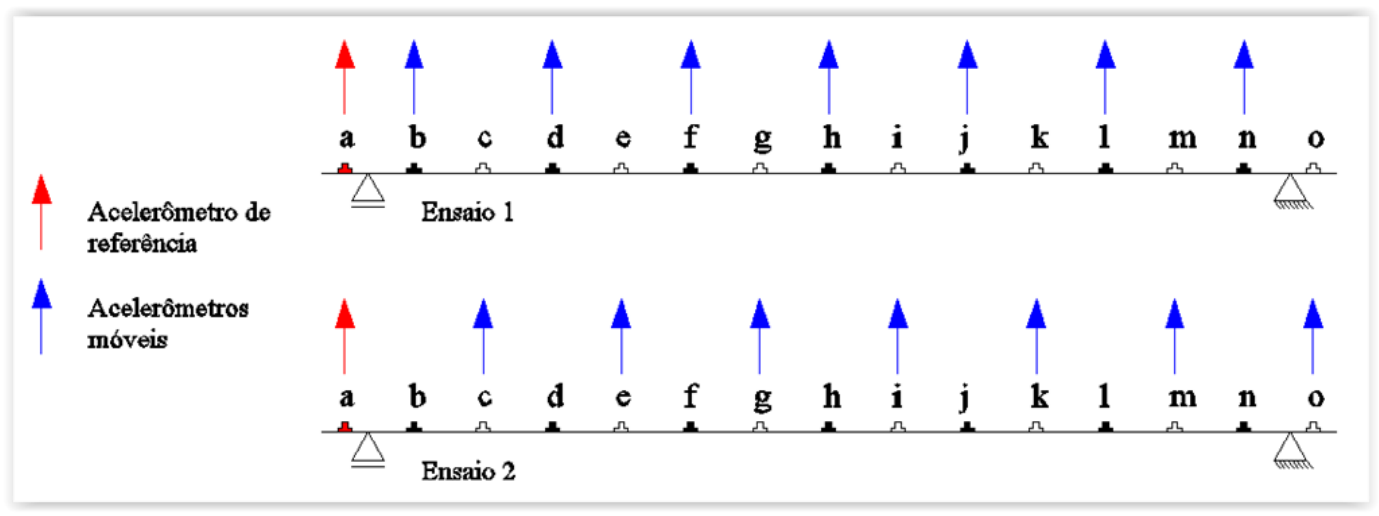

Figura 5.17 - Posicionamento dos acelerômetros

Devido aos ensaios não destrutivos terem sido realizados em várias etapas de dano das vigas, foram fabricados suportes metálicos com parafusos permitindo um acoplamento mais rápido dos acelerômetros. Isso permitiu uma ligação com menor interferência que a realizada de forma usual, com cera de abelha. A Figura 5.18 mostra o posicionamento dos acelerômetros em uma série de ensaios, com detalhe do suporte metálico colado.
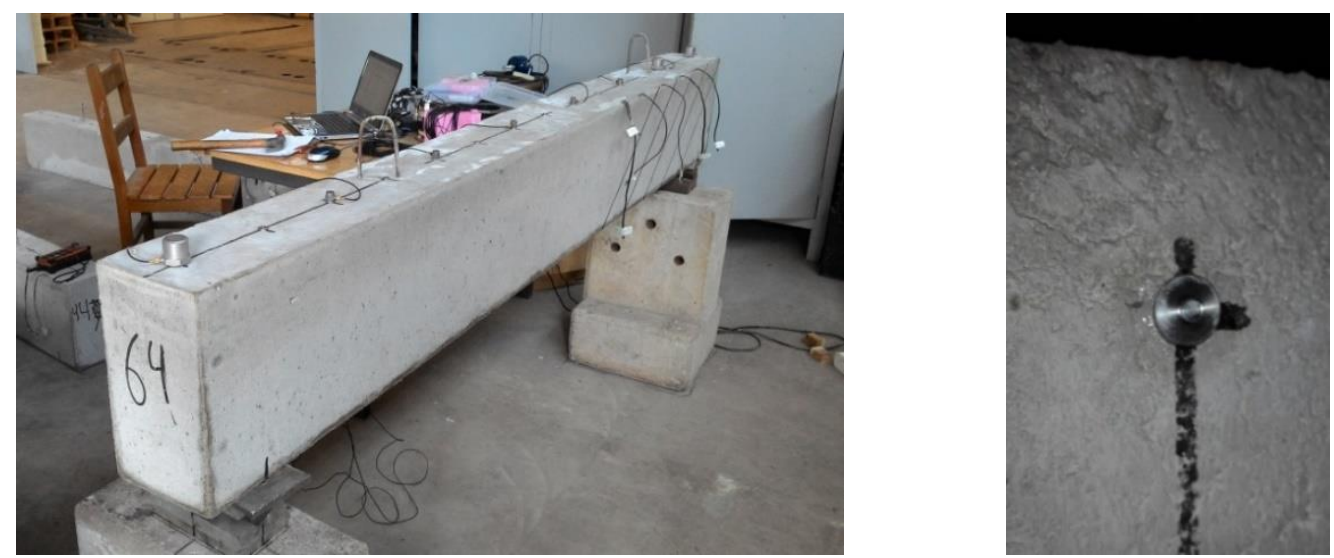

Figura 5.18 - Posicionamento dos acelerômetros e suporte metálicos

Para a excitação da viga nos ensaios não destrutivos foi utilizado um martelo metálico convencional, realizando impactos na vertical de maneira aleatória entre os pontos de coleta de dados dos acelerômetros.

Para a análise dos dados foi utilizado o método identificação modal chamado como Average Normalized Power Spectral Densities (ANPSDs). A estimação das frequências do sistema é baseada na construção de uma média normalizada dos autos espectros dos diferentes registros de sinais (FELBER 1993). Nesse método as deformadas modais são avaliadas a partir do uso das 
funções de transmissibilidade entre os vários pontos de medições da estrutura com respeito ao ponto de referência. Nesse sentido foi necessário o desenvolvimento de um programa computacional no software Matlab® que unisse as duas series de ensaios com acelerômetros, permitindo ainda obter a média normalizada dos auto-espectros e os modos de vibração.

O programa foi desenvolvido no Matlab ${ }^{\circledR}$ utilizando as técnicas de análise modal por Gómez (2015) e em parceria com autor, que é estudante de Pós Doutorado em Estruturas na USP de São Carlos. O desenvolvimento do programa foi baseado no seu conhecimento amplo em análise modal de estruturas utilizando o método ANPSDs.

Como resultado do programa desenvolvido é possível obter uma função resposta em frequência dos dados de aceleração e visualizar os modos de vibração para cada frequência natural, como mostrado na Figura 5.19. A comparação destas frequências naturais e dos modos de vibração nos vários estágios de dano da viga foram utilizados para analisar o local e magnitude do dano.

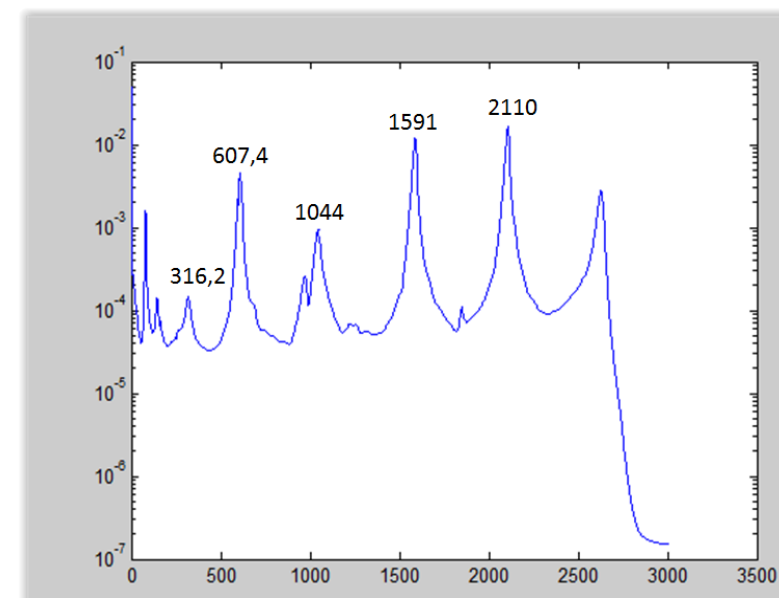

(a) Função resposta em frequência

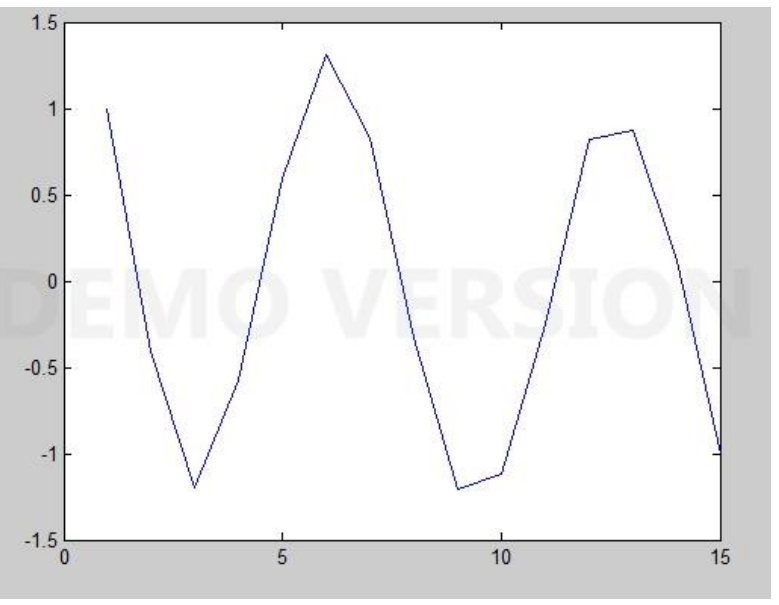

(b) $4^{\circ}$ modo de vibração

Figura 5.19 - Resultados do programa desenvolvido no Matlab ${ }^{\circledR}$

Para a devida análise dos resultados, além das alterações nas frequências naturais, foram utilizados métodos de identificação de dano, analisando os dados dos vetores modais obtidos no modo de vibração. Os métodos utilizados seguiram as recomendações de Juliani (2014), já descritas na revisão bibliográfica. Assim, foram utilizados os métodos de identificação de dano: Modal Assurance Criterion (MAC) e Coordinate Modal Assurance Criterion (COMAC), Diferença de Curvatura Modal (DCM) e Índice de Dano (ID). 


\section{APRESENTAÇÃO E ANÁLISE DE RESULTADOS DAS VIGAS - ENSAIOS DESTRUTIVOS}

Neste capítulo são apresentados resultados dos ensaios experimentais destrutivos e realizados nas vigas de concreto. São também analisados os principais resultados destes estudos, verificando os benefícios do sistema de reforço de CFRP empregado com a técnica NSM.

Nesse item serão apresentados os resultados experimentais das vigas divididos nas análises da força máxima, diagramas força x deslocamento, momento x curvatura, força x deformação nas armaduras longitudinais, transversais e nos laminados de CFRP.

É importante frisar que as vigas reforçadas com CFRP são vigas distintas das de referência, e que apesar de possuírem concreto de mesma resistência e configuração de armação, nos resultados dos ensaios experimentais ocorrem pequenas diferenças nas forças, deslocamentos e deformações dos materiais componentes dessas vigas. Nas comparações a seguir, os resultados das vigas reforçadas com e sem carregamento prévio de 40\% e 70\% foram comparadas diretamente com as vigas de referência.

Como critério para o encerramento do ensaio definiu-se que após observada a redução da força do atuador, permaneceu o carregamento até uma redução de $10 \%$ da força máxima identificada. Este critério permitiu observar o comportamento da viga após a ruptura e definir a força máxima como ruptura da viga.

\subsection{FISSURAÇÃO E FORMA DE RUPTURA}

Durante os ensaios destrutivos foram observadas a formação de fissuras nas vigas, verificando principalmente se ocorriam no lado em que foi aplicado o sistema de reforço, sua interação com os estribos e reforço de CFRP e seu ângulo em relação a seção das vigas.

As vigas sem reforço apresentaram fissuração com maior visibilidade, uma vez que ao aplicar o reforço de CFRP as vigas ficam sujas com adesivo epóxi dificultando a observação das fissuras. Posteriormente aos ensaios verificou-se ser adequado a preparação das vigas com fitas, reduzindo a sujeira do epóxi na viga.

A Figura 6.1 mostra a fissuração ocorrida na viga V50 SR. Nela pode-se observar a formação de duas fissuras principais, a primeira partindo do ponto de aplicação da força em um ângulo médio de 30 graus e a segunda surgindo a uma distância de $17 \mathrm{~cm}$ do ponto de aplicação da força com inclinação média de 35 graus até o apoio da viga. A ruptura da viga ocorreu aos $307 \mathrm{kN}$ com o aumento das duas fissuras, sem apresentar fissuras no lado menos solicitado da viga. 


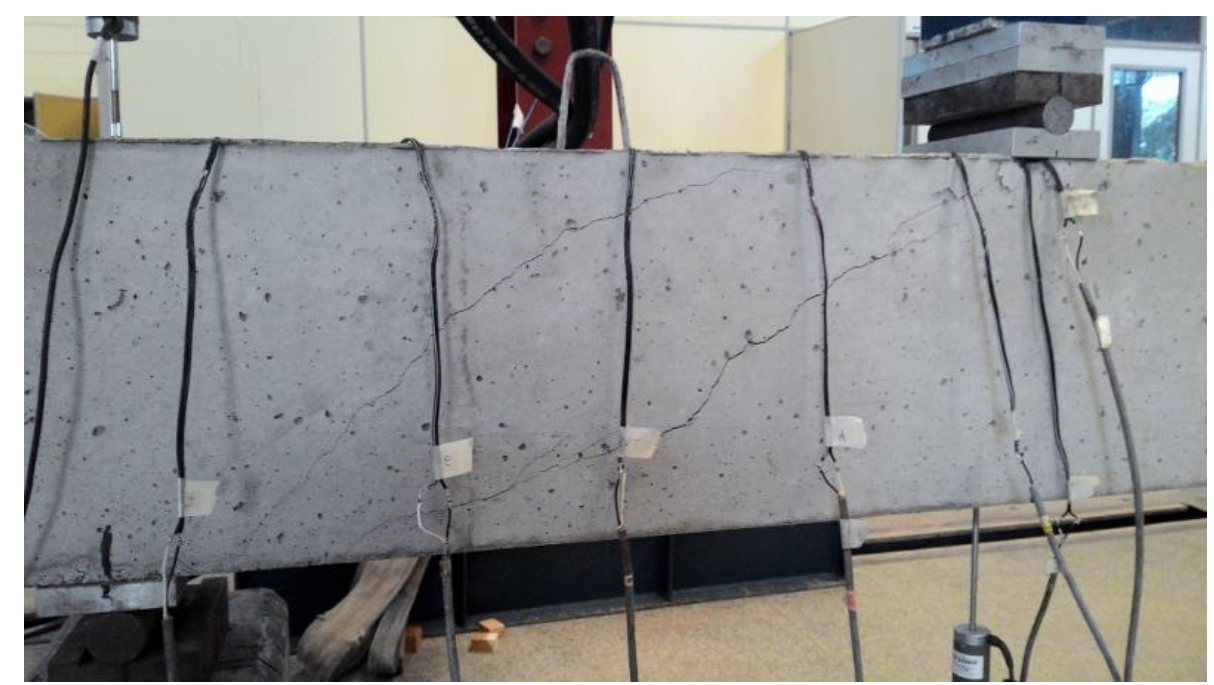

Figura 6.1 - Fissuração da viga V50 SR

A viga V90 SR apresentou uma fissuração homogênea, com 4 fissuras principais, distanciadas em $15 \mathrm{~cm}$, formando internamente na viga uma treliça de concreto armado. Com o incremento da força as fissuras foram aumentando na proximidade dos estribos 3 e 4 (Figura 6.2).

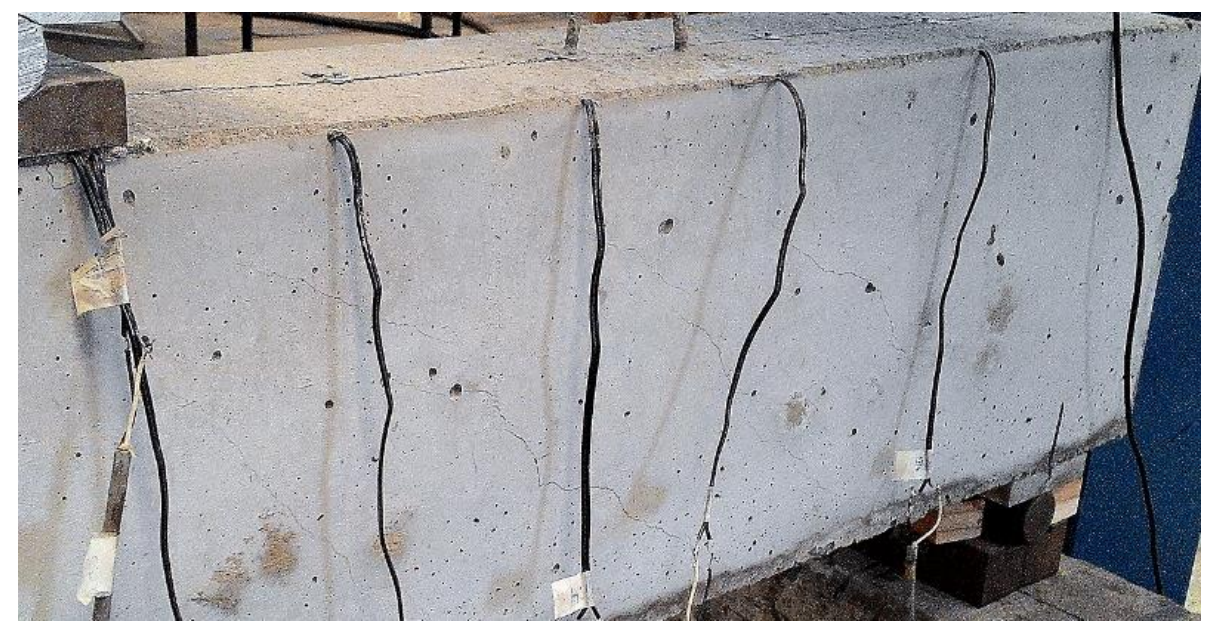

Figura 6.2 - Fissuração da viga V90 SR

A viga V90 SR apresentou ainda pequenas fissuras de flexão na região abaixo do ponto de aplicação da força, mas com pequena abertura, e não apresentou fissuras de cisalhamento no lado menos solicitado da viga.

A ruptura da viga V90 SR ocorreu bruscamente com uma nova fissura diagonal entre o ponto de aplicação da força e o apoio da viga. A ruptura ocorreu juntamente com o escoamento dos estribos 3 e 4. (Figura 6.3) 


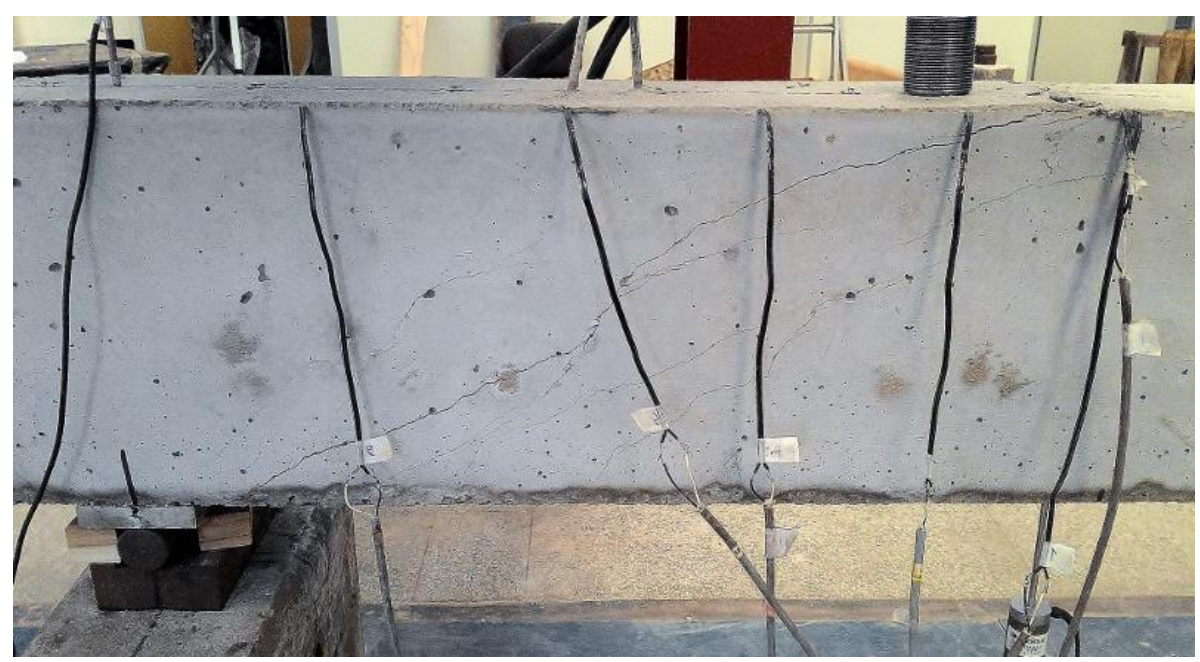

Figura 6.3 - Ruptura da viga V90 SR

A viga reforçada V50 CFRP apresentou uma nova configuração de fissuração, onde as fissuras iniciavam-se na extremidade inferior dos laminados com inclinação entre 45 graus e 60 graus. Com o acréscimo de força iniciaram fissuras do ponto de aplicação da força até o laminado 5, onde observou-se que as fissuras não ultrapassavam o reforço. (Figura 6.4)

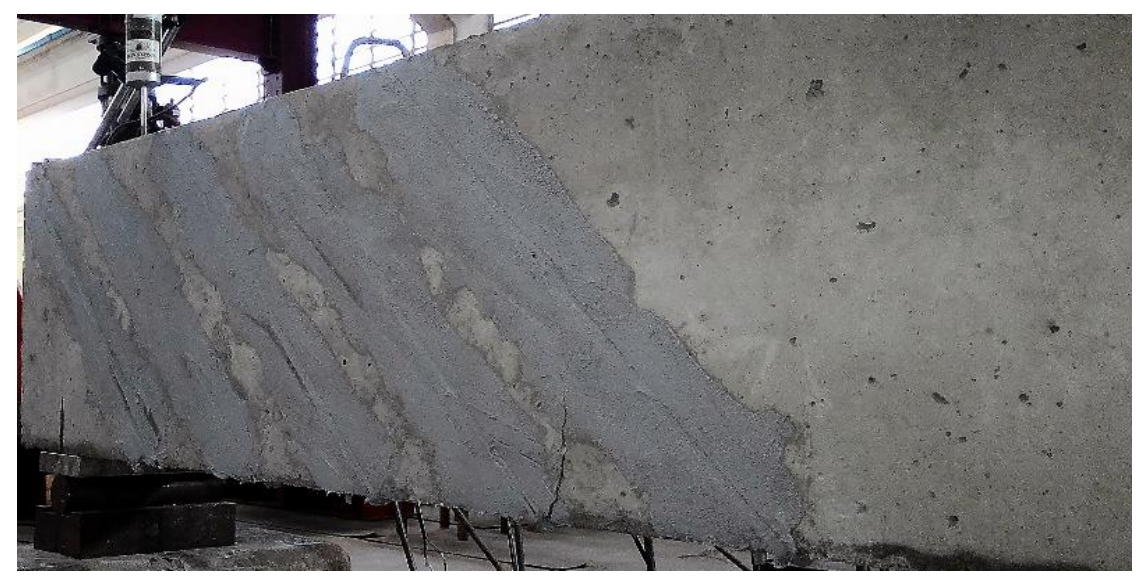

Figura 6.4 - Fissuração da viga V50 CFRP

Em forças elevadas, fissuras surgiram no sentido longitudinal da viga, na parte inferior e superior da viga unindo as fissuras posicionadas nas extremidades dos laminados. A ruptura da viga V50 CFRP ocorreu pelo destacamento do cobrimento de concreto, separando a camada de concreto com reforço do núcleo da viga, efeito denominado de fish bones na técnica NSM (Figura 6.5). 


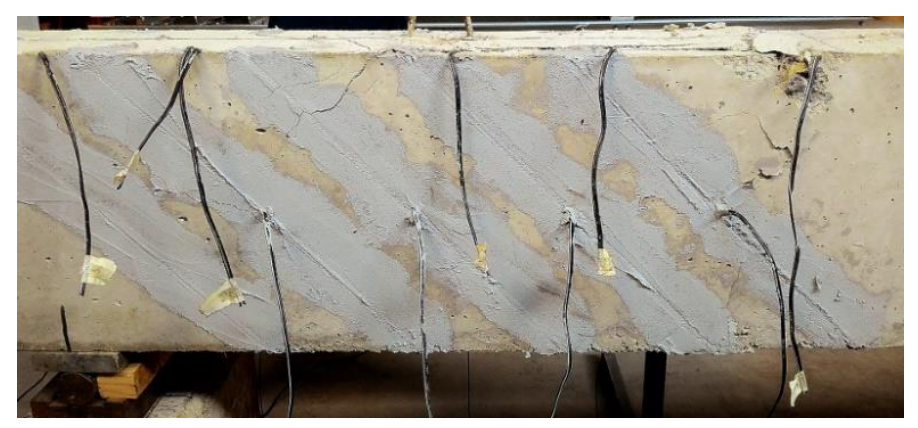

(a) lateral

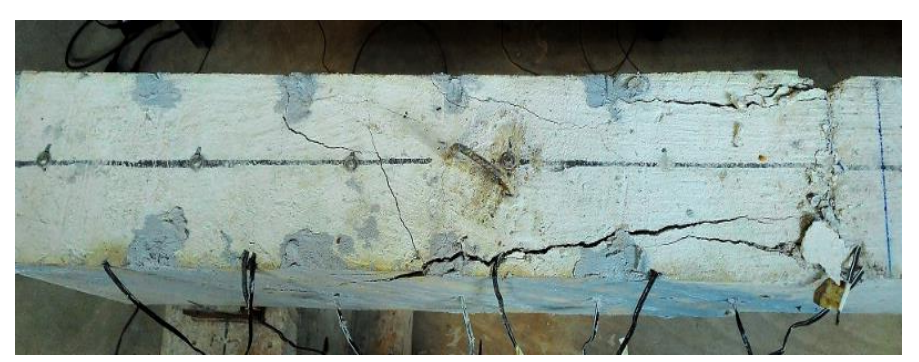

(b) superior

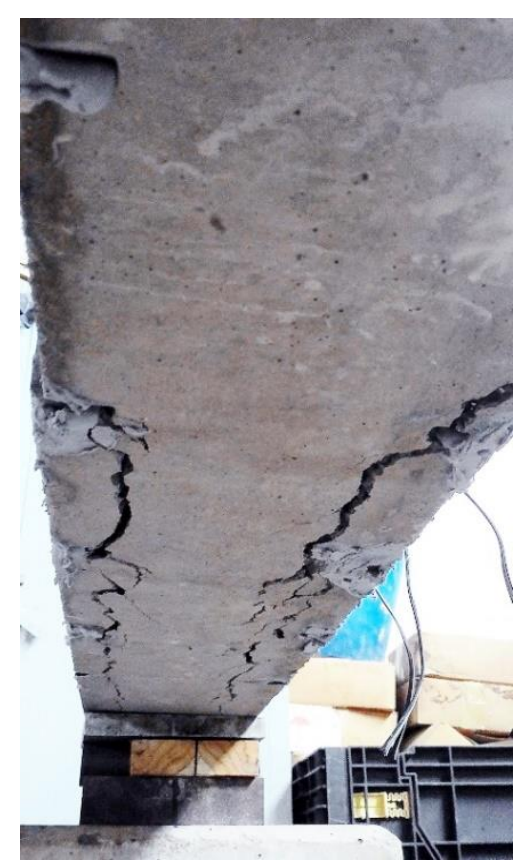

(c) inferior

Figura 6.5 - Ruptura da viga V50 CFRP

A viga com carregamento prévio V50 40\% apresentou uma fissuração no sentido longitudinal com formato similar à viga V50 CFRP, mas com menor intensidade, ocorrendo sua ruptura pelo destacamento do cobrimento de concreto em apenas um lado da viga, como pode ser observado na Figura 6.6. Este efeito pode ter ocorrido tanto por uma força excêntrica no ensaio, como pelo efeito do carregamento prévio. A forma de ruptura pode ter reduzido a capacidade de carga desta viga, sendo essa entre as vigas V50 com reforço a de menor resistência.

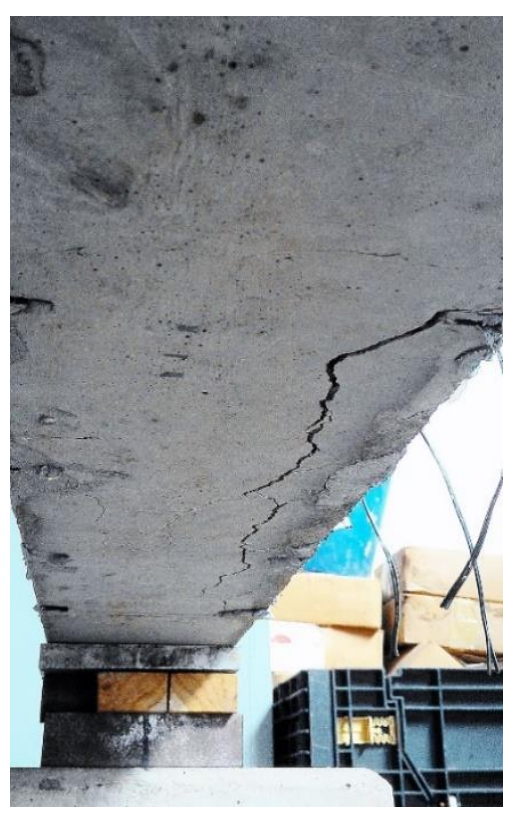

Figura 6.6 - Ruptura da viga V50 40\% 
A viga com carregamento prévio V50 70\% apresentou uma fissuração com formato similar ao da viga V50 CFRP, tendo início da fissuração nos estremos do reforço, mas com uma inclinação maior, com ângulos até de 90 graus.

A ruptura da viga V50 70\% ocorreu pelo destacamento do cobrimento de concreto separando-a do núcleo da viga igualmente ao ocorrido na viga V50 CFRP, ocorrendo ainda esmagamento de parte comprimida do concreto e a ruina da seção transversal na região do Laminado 5 logo após a ruptura.

Nas vigas V90, a força máxima calculada ao cisalhamento com reforço ficou próxima a força máxima de ruptura à flexão, de $582,8 \mathrm{kN}$. Essa proximidade inesperada ocorreu devido ao aumento da resistência a compressão com o concreto, que inicialmente foi projetado para $60 \mathrm{MPa}$ e atingiu valores médios maiores que $90 \mathrm{MPa}$. Devido a essa proximidade entre as forças máximas, a ruptura dessas vigas poderia ocorrer tanto por cisalhamento quanto por flexão.

$\mathrm{Na}$ viga reforçada íntegra V90 CFRP as fissuras de cisalhamento ocorrem na extremidade dos laminados com ângulos de 90 graus, mas com baixa intensidade, tendo como principal diferença das vigas V50 a formação de fissuras de flexão. Durante o carregamento ocorreram fissuras e destacamento do concreto comprimido.

A ruptura na viga V90 CFRP ocorreu por esforços de flexão, especificamente por esmagamento do concreto na parte comprimida da viga, esse efeito pôde ser verificado na Figura 6.7, em que as fissuras de flexão aparecem com grande comprimento. Observou-se ainda pela vista superior, que não ocorreram fissuras no sentido longitudinal da viga e pela vista inferior, que não ocorreram destacamento das camadas de cobrimento na região dos laminados de CFRP. 


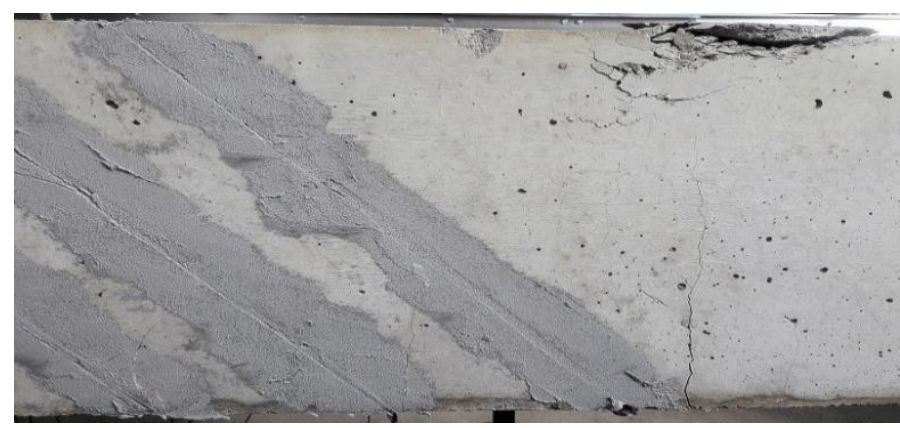

(a) lateral

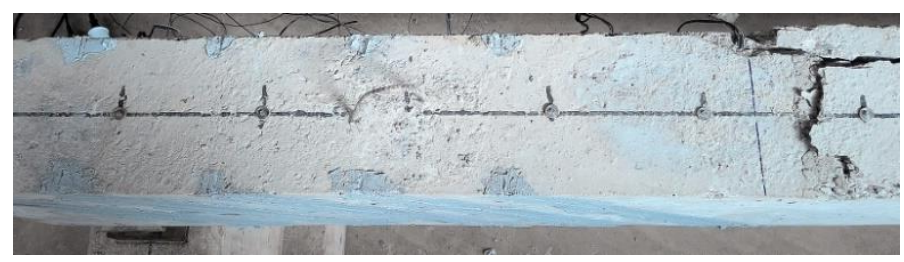

(b) superior

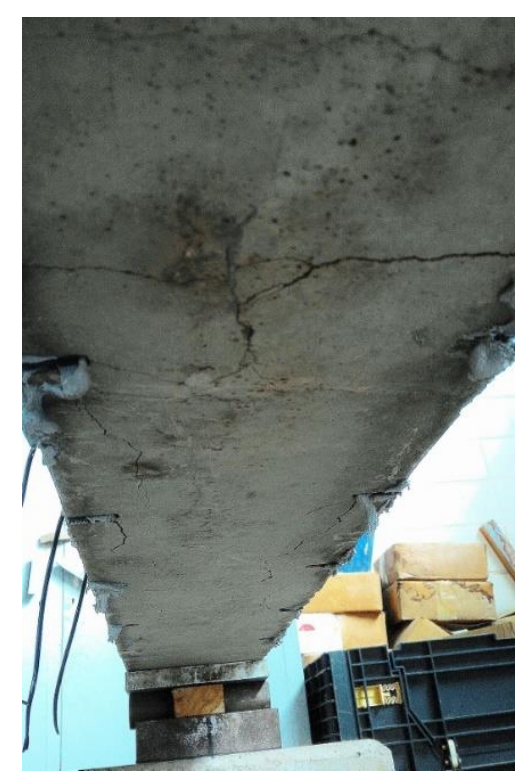

(c) inferior

Figura 6.7 - Ruptura da viga V90 CFRP

No intuito de observar a alteração na forma de ruptura das vigas V90 CFRP, foram analisados os cálculos teóricos realizados com o programa SecTrans ${ }^{\circledR}$. Com o resultado do programa foi possível observar as deformações nas seções da viga para cada etapa de força por meio do gráfico momento x curvatura. A Figura 6.8 apresenta o resultado extraído de referido programa para a força máxima.

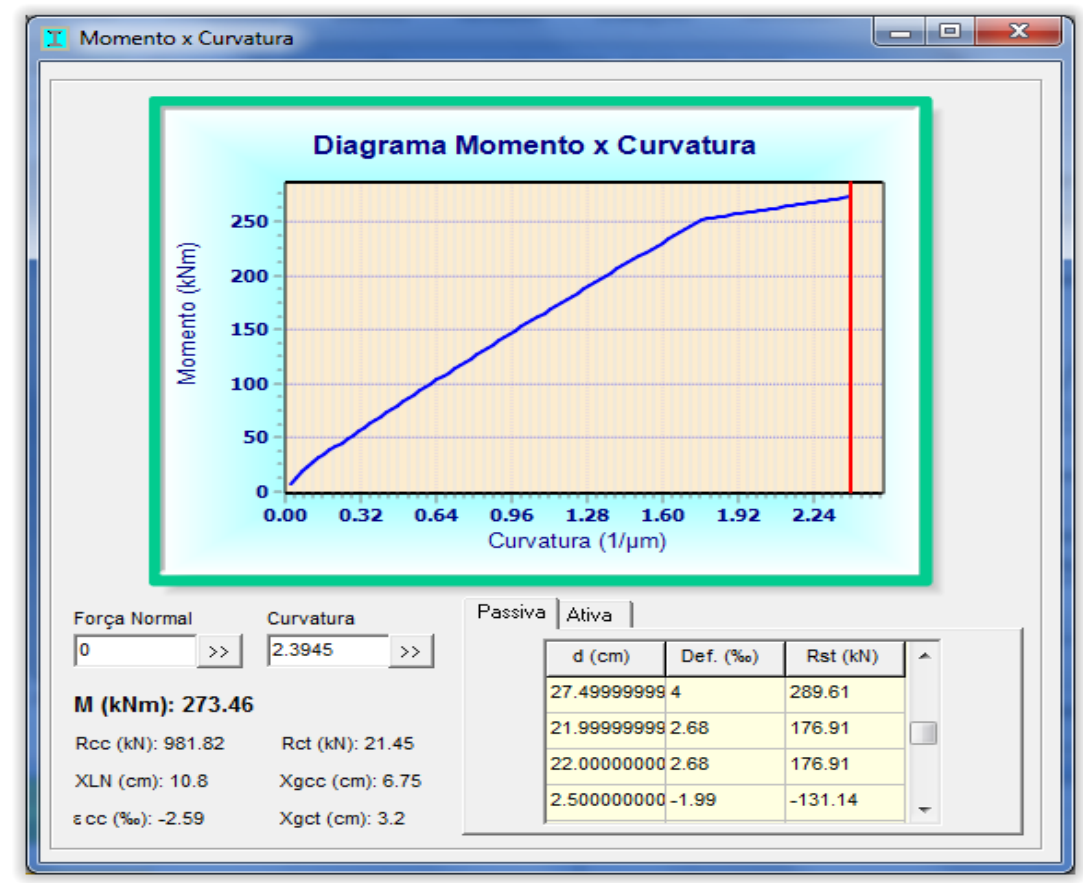

Figura 6.8 - Diagrama Momento x Curvatura - V90

No estudo teórico pode-se identificar a deformação das barras de aço com 4\%o na primeira camada, 2,68\% na segunda camada e -1,99\%o na armadura de compressão. O concreto 
por sua vez apresentou uma deformação de -2,59\%o sendo o concreto em questão de $90 \mathrm{MPa}$ com um limite de deformação de $-2,6 \%$. Concluiu-se que, quando a ruptura das vigas V90 com reforço CFRP ocorrer por flexão, esta ocorrerá por esmagamento do concreto comprimido.

As vigas com carregamento prévio apresentaram fissurações similares à viga V90 CFRP, com fissuras de cisalhamento iniciando nos extremos dos laminados de CFRP a 90 graus e fissuras de flexão, sem apresentar grandes fissuras de destacamento da camada de cobrimento do concreto na região dos laminados.

A ruptura da viga com carregamento prévio V90 40\% apresentou a mesma forma de ruptura da viga V90 CFRP com esmagamento do concreto por flexão. Observou-se ainda maior intensidade nas fissuras de destacamento da camada de concreto com reforço nas faces inferiores e superiores das vigas V90 40\%, indicando uma maior proximidade da viga em romper ao cisalhamento que a viga V90 CFRP. (Figura 6.9)

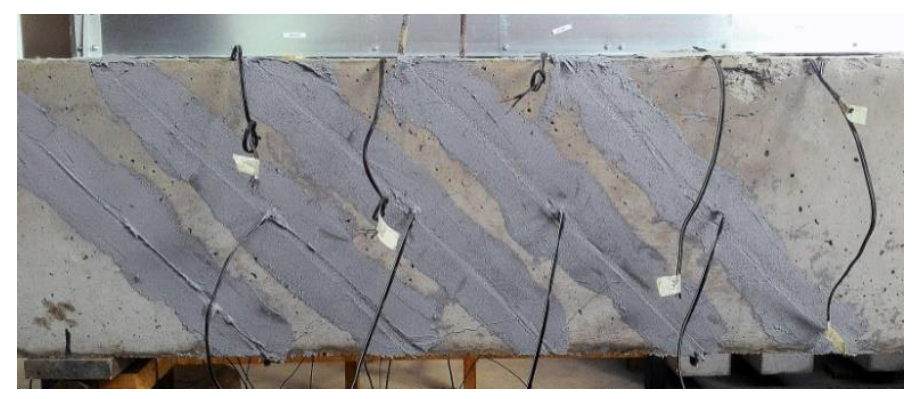

(a) lateral

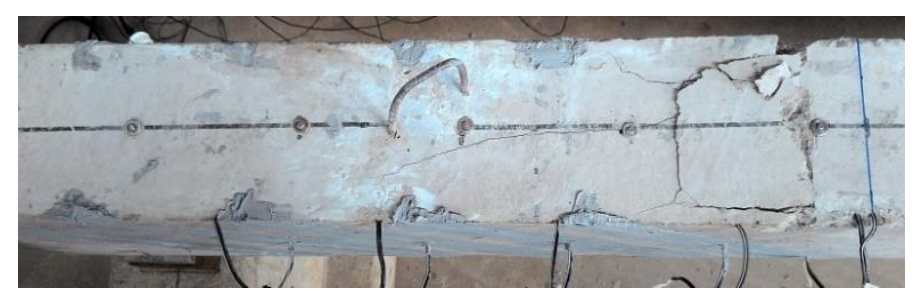

(b) superior

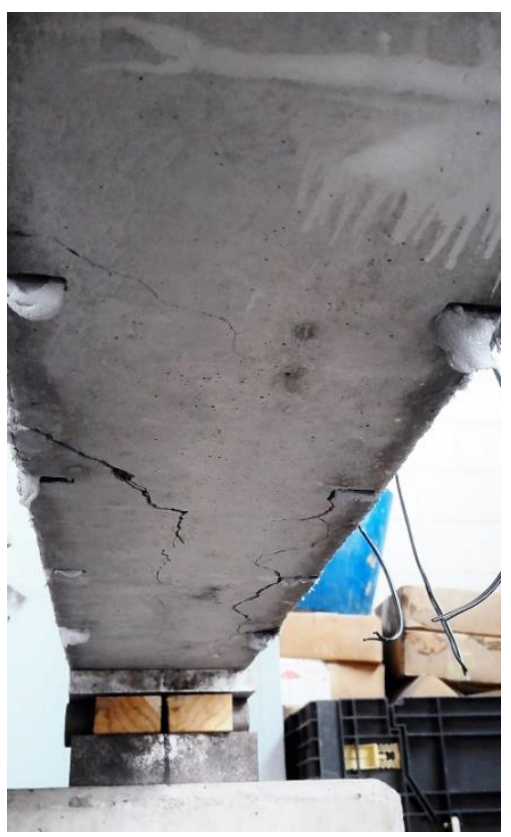

(c) inferior

Figura 6.9 - Ruptura da viga V90 40\%

Na viga V90 70\% ocorreu a maior força máxima, mas nela ocorreu a menor incidência de fissuras por cisalhamento, como pequenas fissuras de destacamento dos laminados (fish bones), separando parte da camada de cobrimento de concreto na região dos laminados de CFRP. Sua ruptura ocorreu na flexão pelo esmagamento do concreto, ocorrendo uma fissura de flexão na parte tracionada da viga na seção de aplicação da força. Igual ao ocorrido na viga V90 CFRP.

As vigas sem reforço (V50 SR e V90 SR) durante o início do ensaio apresentaram fissuras típicas de cisalhamento, partindo do ponto de aplicação da força, com inclinações entre 30 e 45 
graus. Nas vigas com os sistemas de reforço de CFRP as fissuras não ultrapassam os laminados, ocorrendo uma maior concentração de fissuras na extremidade inferior dos laminados, com inclinações predominantemente de 60 graus para as vigas V50 e de 90 graus para as vigas V90.

$\mathrm{Na}$ ruptura, as vigas sem reforço apresentaram fissuras indo desde o ponto de aplicação da força até o apoio mais próximo, com poucas fissuras de flexão. Na ruptura das vigas com reforço ocorreram maiores fissurações na parte inferior da viga, concentrando tanto as fissuras de flexão como as fissuras de cisalhamento.

$\mathrm{Na}$ ruptura das vigas com reforço de CFRP as formas de rupturas foram alteradas. Ocorrendo nas vigas V50 destacamento da camada de cobrimento do concreto onde estão inseridos os laminados de CFRP, enquanto que na viga V90 ocorreu esmagamento do concreto comprimido devido aos esforços oriundos da flexão.

Observou-se que o carregamento prévio não alterou a forma de ruptura das vigas, permanecendo nas vigas V50 por destacamento do cobrimento de concreto na região dos sistemas de reforço de CFRP e nas vigas V90 por flexão por esmagamento do concreto na flexão.

\subsection{MATERIAIS COMPONENTES DAS VIGAS}

\subsubsection{Corpos de Prova}

Com os corpos de prova foi possível obter a resistência à compressão e a resistência à tração por compressão diametral conforme descrito no capítulo materiais e métodos, além do módulo de elasticidade por ensaio dinâmico utilizando o aparelho Sonelastic ${ }^{\circledR}$.

Os resultados das resistências à tração e compressão, primeiras frequências naturais à flexão e módulo de elasticidade dos corpos de prova são apresentados na Tabela 6.1 e Tabela 6.2 para CPs C50 e C90 respectivamente. 
Tabela 6.1 - Resistências e Módulo de elasticidade dos CPs C50

\begin{tabular}{c|c|c|c|c|c|c}
\hline CPs & Peso (g) & $\begin{array}{c}\text { Idade } \\
\text { (dias) }\end{array}$ & $\begin{array}{c}\text { Tensão de } \\
\text { compressão } \\
\mathbf{( M P a}\end{array}$ & $\begin{array}{c}\text { Tensão } \\
\text { de tração } \\
\mathbf{( M P a )}\end{array}$ & $\begin{array}{c}\text { Frequência } \\
\text { Flexional } \\
\mathbf{( H z )}\end{array}$ & $\begin{array}{c}\text { E } \\
\text { Flexional } \\
\mathbf{( G P a )}\end{array}$ \\
\hline $\mathbf{1}$ & \multicolumn{5}{|c|}{ Copos de prova com C50 } \\
\hline $\mathbf{1}$ & 3715,7 & 41 & 52,03 & & 6342 & 38,56 \\
\hline $\mathbf{2}$ & 3642,8 & 41 & 46,98 & & 6397 & 38,46 \\
\hline $\mathbf{3}$ & 3678,3 & 41 & 48,36 & & 6440 & 39,37 \\
\hline $\mathbf{4}$ & 3662,5 & 41 & & 3,75 & 6415 & 38,89 \\
\hline $\mathbf{5}$ & 3692,2 & 41 & & 2,27 & 6399 & 39,02 \\
\hline $\mathbf{6}$ & 3668,9 & 41 & & 2,97 & 6407 & 38,86 \\
\hline $\mathbf{7}$ & 3707,6 & 41 & 53,36 & & 6351 & 38,59 \\
\hline $\mathbf{8}$ & 3714,2 & 41 & 57,4 & & 6425 & 39,56 \\
\hline $\mathbf{9}$ & 3712,3 & 41 & 54,57 & & 6320 & 38,26 \\
\hline $\mathbf{1 0}$ & 3706,4 & 41 & & 3,38 & 6409 & 39,28 \\
\hline $\mathbf{1 1}$ & 3702,8 & 41 & & 3,98 & 6459 & 39,86 \\
\hline $\mathbf{1 2}$ & 3689,5 & 41 & & 3,39 & 6466 & 39,80 \\
\hline Média & $\mathbf{3 6 9 1 , 1}$ & & $\mathbf{5 2 , 1 2}$ & $\mathbf{3 , 2 9}$ & $\mathbf{6 4 0 3}$ & $\mathbf{3 9 , 0 4}$ \\
\hline $\mathbf{C V}$ & $0,6 \%$ & & $7,4 \%$ & $18,5 \%$ & $0,7 \%$ & $1,4 \%$ \\
\hline
\end{tabular}

Tabela 6.2 - Resistências e Módulo de elasticidade dos CPs C90

\begin{tabular}{c|c|c|c|c|c|c}
\hline CPs & Peso (g) & $\begin{array}{c}\text { Idade } \\
\text { (dias) }\end{array}$ & $\begin{array}{c}\text { Tensão de } \\
\text { compressão } \\
\mathbf{( M P a )}\end{array}$ & $\begin{array}{c}\text { Tensão } \\
\text { de tração } \\
\mathbf{( M P a )}\end{array}$ & $\begin{array}{c}\text { Frequência } \\
\text { Flexional } \\
\mathbf{( H z )}\end{array}$ & $\begin{array}{c}\mathbf{E} \\
\text { Flexional } \\
\mathbf{( G P a )}\end{array}$ \\
\hline $\mathbf{7 3}$ & 3826,1 & 30 & 90,7 & & 6730 & 44,72 \\
\hline $\mathbf{1 4}$ & 3816,6 & 30 & 92,2 & & 6773 & 45,17 \\
\hline $\mathbf{1 5}$ & 3799,5 & 30 & 86,8 & & 6706 & 44,09 \\
\hline $\mathbf{1 6}$ & 3811,3 & 30 & & 3,74 & 6711 & 44,28 \\
\hline $\mathbf{1 7}$ & 3819,4 & 30 & & 4,58 & 6741 & 44,79 \\
\hline $\mathbf{1 8}$ & 3810,9 & 30 & & 4,44 & 6826 & 45,81 \\
\hline $\mathbf{1 9}$ & 3850,9 & 30 & 60,7 & & 6725 & 44,93 \\
\hline $\mathbf{2 0}$ & 3856,5 & 30 & 89,1 & & 6735 & 45,14 \\
\hline $\mathbf{2 1}$ & 3889,2 & 30 & 94,3 & & 6755 & 45,79 \\
\hline $\mathbf{2 2}$ & 3849,8 & 30 & & 5,01 & 6833 & 46,38 \\
\hline $\mathbf{2 3}$ & 3824 & 30 & & 4,05 & 6813 & 45,80 \\
\hline $\mathbf{2 4}$ & 3803,9 & 30 & & 5,79 & 6843 & 45,96 \\
\hline Média & $\mathbf{3 8 2 9 , 8}$ & & $\mathbf{9 0 , 6 2}$ & $\mathbf{4 , 6 0}$ & $\mathbf{6 7 6 6}$ & $4 \mathbf{4 5 , 2 4}$ \\
\hline $\mathbf{C V}$ & $0,7 \%$ & & $3,2 \%$ & $15,8 \%$ & $0,7 \%$ & $1,6 \%$ \\
\hline
\end{tabular}

Os concretos apresentaram resistência à compressão média diferentes das previstas nas dosagens originalmente idealizadas de $40 \mathrm{MPa}$ e $60 \mathrm{MPa}$, ocorrendo um grande acréscimo para $52,12 \mathrm{MPa}$ e $90,62 \mathrm{MPa}$, respectivamente. Desta forma, as vigas compostas com esses concretos foram denominadas de V50 e V90. O dimensionamento das vigas foi alterado, utilizando as devidas 
resistências dos concretos, que influenciaram nas forças máximas suportadas pelas vigas à flexão e ao cisalhamento antes e após o reforço com CFRP.

Para o cálculo da resistência média à compressão dos corpos de prova $\mathrm{C} 90$, o corpo de prova número 19 foi desconsiderado pois durante o ensaio apresentou ruptura diferenciada e consequente o valor de tensão muito inferior aos demais corpos de prova estudados.

As resistências à tração apresentaram grande dispersão para os dois concretos, com desvio padrão de 18,5\% para o C50 e de 15,8\% para o C90, apresentando valores médios de 3,29MPa e 4,60MPa respectivamente.

Os módulos de elasticidade foram obtidos em ensaios dinâmicos por meio das frequências naturais flexionais dos corpos de provas. Estes apresentaram baixas dispersões de resultados nas duas classes de resistência, com valores médios de 39,04GPa para o concreto C50 e 45,24GPa para o concreto C90 e com desvio padrão de 1,4\% para o C50 e de 1,6\% para o C90

\subsubsection{Barra de aço}

O aço utilizado foi fornecido cortado e dobrado, reduzindo assim o trabalho em laboratório. Foram coletadas para a caracterização do aço amostras das barras de $6.3 \mathrm{~mm}, 20 \mathrm{~mm}$ e 25mm, ensaiadas à tração conforme a norma ABNT NBR ISO 6892:2015. O Gráfico 6.1 ao Gráfico 6.3 apresentam os diagramas tensão x deformação obtida no ensaio de tração.

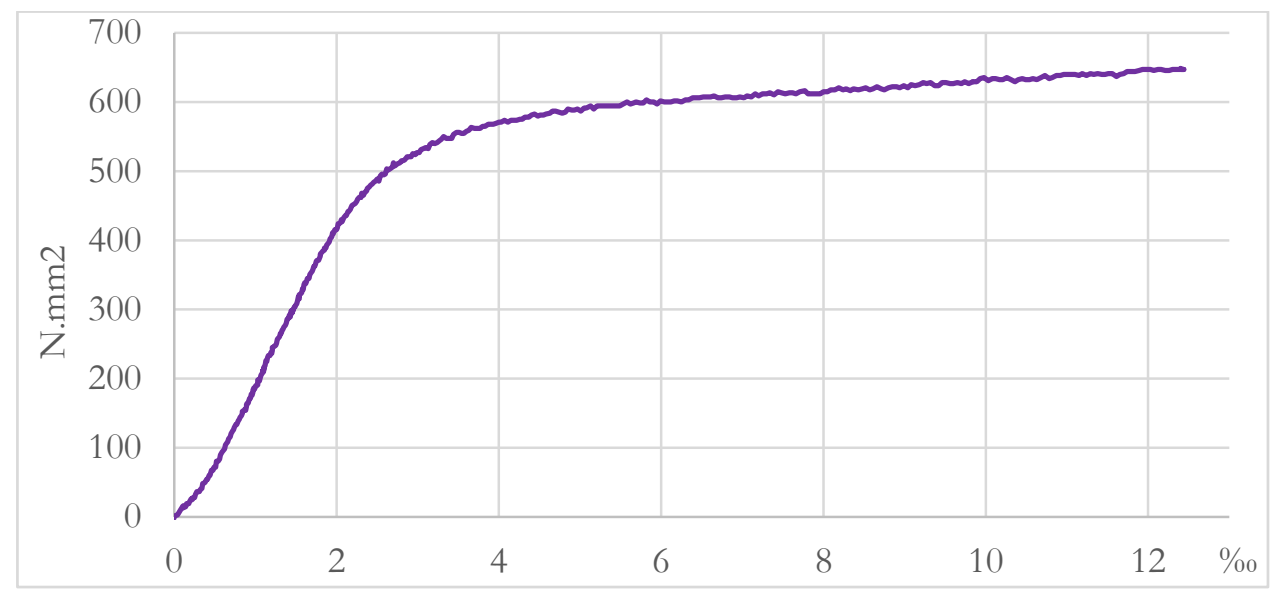

Gráfico 6.1 - Tensão x deformação do aço (6.3mm) 

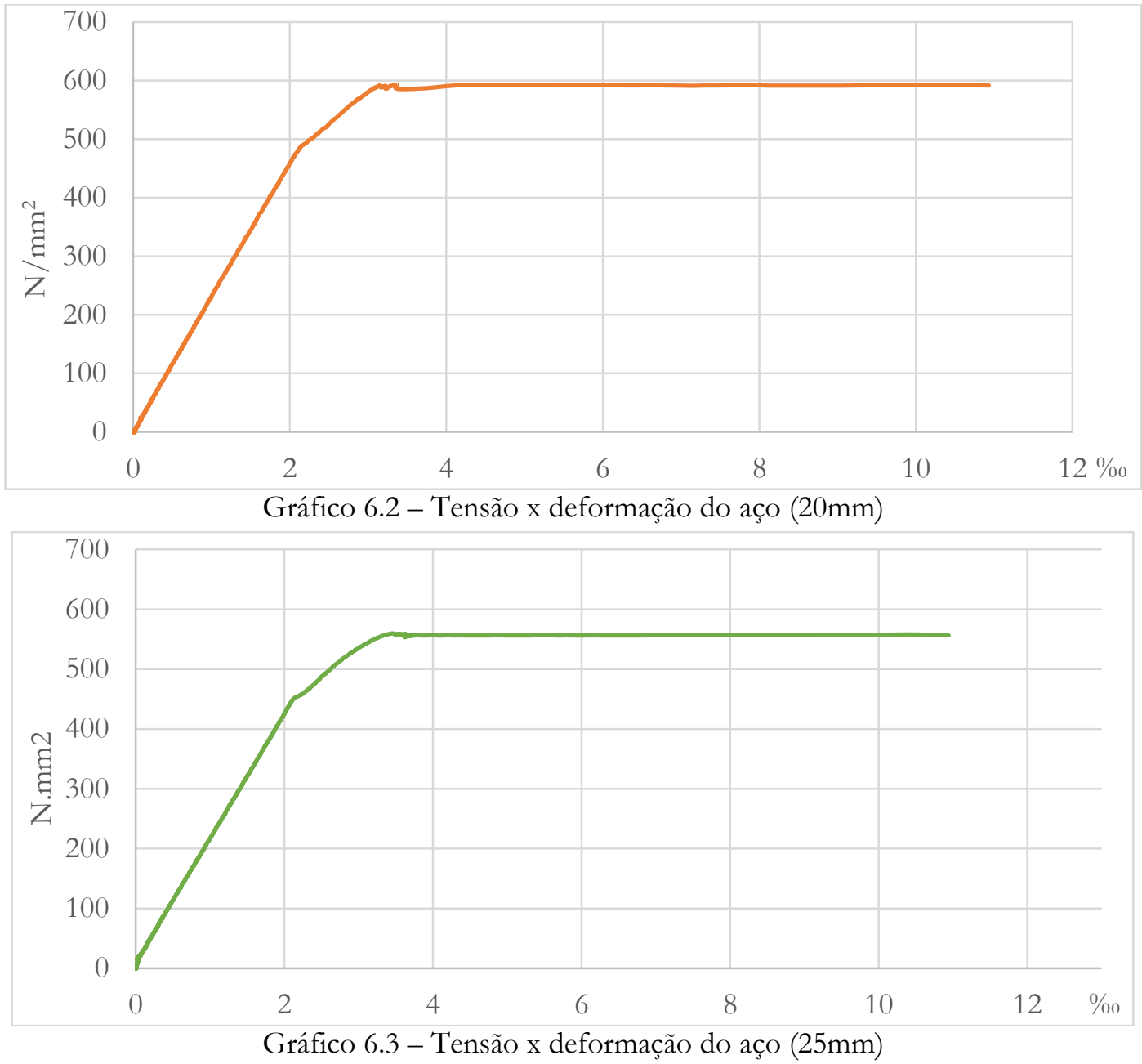

A barra de $6.3 \mathrm{~mm}$ não apresentou patamar característico de escoamento, com tensão de ruptura de $647 \mathrm{~N} / \mathrm{mm}^{2}$. A amostra da barra de $20 \mathrm{~mm}$ foi ensaiada a tração para a definição das propriedades do aço, obtendo tensão de escoamento de $590 \mathrm{~N} / \mathrm{mm}^{2}$, enquanto que a barra de $25 \mathrm{~mm}$ obteve tensão de escoamento de $547 \mathrm{~N} / \mathrm{mm}^{2}$.

\subsubsection{Epóxi}

O Adesivo epóxi utilizado foi o Sikadur ${ }^{\circledR} 30$ e para sua caraterização foram moldados dois corpos de prova cilíndricos de $5 \mathrm{~cm} \times 10 \mathrm{~cm}$ e ensaiados à compressão para a avaliação da resistência à compressão e com o Sonelastic ${ }^{\circledR}$ para a definição do módulo de elasticidade. A Tabela 6.3 apresenta a média dos resultados das propriedades do adesivo epóxi utilizado para reforçar as vigas, bem como os dados fornecidos pelo fabricante.

Tabela 6.3 - Propriedades do Sikadur ${ }^{\circledR} 30$

\begin{tabular}{|c|c|c|c|c|}
\hline & Unidades & Ensaio & Fabricante & Relação \\
\hline Módulo de Elasticidade & $\mathrm{GPa}$ & 14,4 & 9,60 & 1,50 \\
\hline Densidade & $\mathrm{Kg} / \mathrm{dm}^{3}$ & 1,82 & 1,65 & 1,10 \\
\hline Resistencia à compressão & $\mathrm{MPa}$ & 81,97 & 70 a 95 & - \\
\hline
\end{tabular}


A densidade média obtida nos ensaios experimentais foi maior que o valor fornecido pelo fabricante. O módulo de elasticidade apresentou uma maior diferença na comparação dos resultados de ensaio e o fornecido pelo fabricante, isso correu devido aos valores obtidos experimentalmente terem sido realizados por ensaios dinâmicos, diferentemente dos apresentados pelo fabricante, que foram estáticos.

\subsubsection{Laminados de CFRP}

Com os ensaios dos CFRP, não foi possível obter suas propriedades, sendo realizadas duas tentativas para a obtenção da resistência à tração dos laminados. Para isso foram produzidos primeiramente corpos de prova com a colagem de abas e posteriormente sem a colagem das abas. O laboratório do departamento de estruturas não possuía a prensa adequada ao ensaio, sendo o mesmo realizado em outro campus da USP.

Ambos os ensaios apresentaram problemas na execução, primeiramente com o escorregamento da cola entre os laminados e posteriormente com o esmagamento do laminado, que consequentemente desfiou os fios que o compõe. (Figura 6.10)
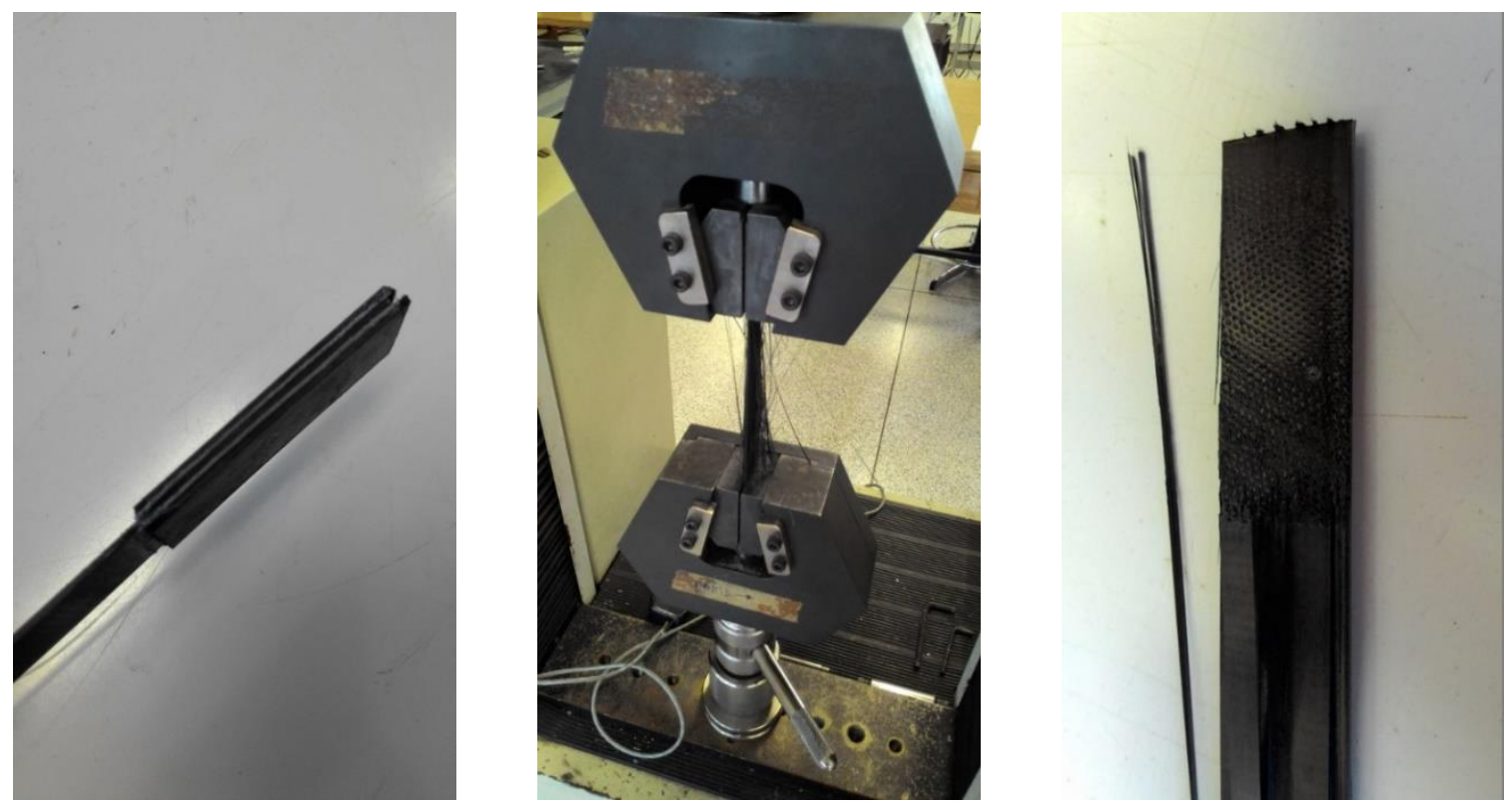

Figura 6.10 - Ensaio de tração do laminado CFRP

Em virtude da não obtenção da resistência à tração dos laminados de CFRP pelos ensaios, nesta tese foram utilizados os dados fornecidos pelo fabricante: módulo de elasticidade de $165 \mathrm{GPa}$, limite de deformação na ruptura de 1,7\% e resistência à tração de $3100 \mathrm{MPa}$.

Os laminados de CFRP são materiais de elevado desempenho e de baixa variabilidade em suas propriedades. Em nenhuma das vigas estudas ocorreu ruptura dos laminados de CFRP, nem 
a sua deformação máxima, sendo assim não foram realizadas novas tentativas de caracterizar este material componente.

\subsection{DIMENSIONAMENTO DA VIGAS}

Para o dimensionamento foram considerados os resultados das resistências à compressão e à tração e do módulo de elasticidade dos materiais componentes obtidos nos ensaios de laboratório.

Para cada classe de concreto em estudo foram definidas três forças máximas para a ruptura das vigas, sendo uma para a flexão $\left(\mathrm{F}_{\text {máx }}\right)$, uma para a força cortante $\left(\mathrm{F}_{\text {Wmáx }}\right)$ e uma para a força cortante com reforço de CFRP ( $\left.F_{W R}\right)$.

Com a finalidade de comparação dos resultados do dimensionamento com os dos ensaios experimentais, em todos os resultados aqui apresentados os coeficientes de segurança foram desconsiderados.

A Tabela 6.4 apresenta os resultados obtido no dimensionamento à flexão das vigas V50 e V90. Definindo a força máxima teórica para que ocorra ruptura nas vigas por flexão.

Tabela 6.4 - Resultados dimensionamento à Flexão

\begin{tabular}{c|c|c|c|c}
\hline & Nomes & Unidades & V50 & V90 \\
\hline $\mathbf{I}_{\mathbf{c}}$ & Inercia Íntegra & $\mathrm{cm}^{4}$ & 36000 & 36000 \\
\hline $\mathbf{I}_{\text {II }}$ & Inercia fissurada & $\mathrm{cm}^{4}$ & 33823 & 27735 \\
\hline $\mathbf{M}_{\text {máx }}$ & Momento Máximo & $\mathrm{kN} . \mathrm{cm}$ & 25208 & 27319 \\
\hline $\mathbf{F}_{\text {máx }}$ & Força máxima à flexão & $\mathrm{kN}$ & 537,8 & 582,8 \\
\hline
\end{tabular}

No dimensionamento ao cisalhamento foram obtidas para cada classe de concreto duas forças máximas. A primeira relativa a ruina pela diagonal comprimida do concreto $\left(\mathrm{F}_{\mathrm{WVR} 22}\right)$ e a segunda relativa à tração diagonal do concreto $\left(F_{W \text { máx }}\right)$. Os resultados obtidos no dimensionamento da flexão das vigas são apresentados na Tabela 6.5.

Tabela 6.5 - Resultados do dimensionamento ao Cisalhamento

\begin{tabular}{|c|c|c|c|c|}
\hline & Nomes & Unidades & V50 & V90 \\
\hline VRd2 & $\begin{array}{l}\text { Força de compressão diagonal } \\
\text { do concreto }\end{array}$ & $\mathrm{kN}$ & 480,4 & 671,8 \\
\hline $\mathrm{F}_{\mathrm{WVRd} 2}$ & $\begin{array}{l}\text { Força máxima ao cisalhamento } \\
\text { pela diagonal comprimida }\end{array}$ & $\mathrm{kN}$ & 768,0 & 1074,9 \\
\hline Vc & $\begin{array}{l}\text { Tração diagonal - parcela do } \\
\text { concreto }\end{array}$ & $\mathrm{kN}$ & 108,3 & 131,7 \\
\hline Asw & Área de aço transversal & $\mathrm{cm}^{2}$ & 4,13 & 6,73 \\
\hline Vsw & Tração diagonal - parcela do aço & $\mathrm{kN}$ & 59,3 & 96,5 \\
\hline VRd3 & $\begin{array}{l}\text { Força de tração diagonal do } \\
\text { concreto }\end{array}$ & $\mathrm{kN}$ & 167,6 & 228,3 \\
\hline$F_{W \text { máx }}$ & Força máxima ao cisalhamento & $\mathrm{kN}$ & 268,1 & 365,2 \\
\hline
\end{tabular}


A vigas foram dimensionadas propositalmente com excesso de armadura longitudinal e baixa armadura transversal, obtendo devido a isso $\mathrm{F}_{\mathrm{Wmáx}}$ bem inferiores aos $\mathrm{F}_{\text {máx }}$. Esta configuração objetivou analisar o reforço ao cisalhamento com menor interferência do efeito da flexão

Ao dimensionar uma elevada capacidade de carga na flexão e uma baixa capacidade de carga ao cisalhamento permite-se realizar sistemas de reforço ao cisalhamento que elevam a capacidade de carga da viga até a força máxima ao cisalhamento com reforço ( $\left.F_{W R}\right)$. Para sua obtenção a parcela da força cortante resistida pelo reforço $\left(\mathrm{V}_{\mathrm{fd}}\right)$ é somada à força cortante previamente calculada no dimensionamento a flexão.

Tabela 6.6 - Resultados do dimensionamento ao Cisalhamento com reforço de CFRP

\begin{tabular}{|c|c|c|c|c|}
\hline & Nomes & Unidades & V50 & V90 \\
\hline$\varepsilon_{\mathrm{f}, \mathrm{e}}$ & Deformação especifica do CFRP & $\%$ & 3,5 & 6,0 \\
\hline $\mathbf{V}_{\mathrm{fd}}$ & Tração diagonal - parcela do CFRP & $\mathrm{cm}^{2}$ & 90,8 & 96,3 \\
\hline $\mathbf{V}_{\text {sd }}$ & $\begin{array}{l}\text { Força cortante solicitante de } \\
\text { calculo }\end{array}$ & $\mathrm{kN}$ & 258,4 & 324,5 \\
\hline $\mathrm{F}_{\mathrm{WR}}$ & $\begin{array}{c}\text { Força máxima ao cisalhamento } \\
\text { com Reforço de CFRP }\end{array}$ & $\mathrm{kN}$ & 413,5 & 519,3 \\
\hline
\end{tabular}

Os resultados das forças máximas calculadas para a flexão, cisalhamento e cisalhamento com reforço das vigas são apresentados na Tabela 6.7.

Tabela 6.7 - Forças máximas calculadas para a flexão, cisalhamento e cisalhamento com reforço

\begin{tabular}{|c|c|c|c|c|}
\hline & Nomes & Unidades & V50 & V90 \\
\hline$F_{\text {máx }}$ & Força máxima à flexão & $\mathrm{kN}$ & 537,8 & 582,8 \\
\hline $\mathrm{F}_{\mathrm{Wmáx}}$ & Força máxima ao cisalhamento & $\mathrm{kN}$ & 268,1 & 365,2 \\
\hline F $_{\text {WVRd2 }}$ & $\begin{array}{c}\text { Força máxima ao cisalhamento pela } \\
\text { diagonal comprimida }\end{array}$ & $\mathrm{kN}$ & 768,0 & 1074,9 \\
\hline $\mathrm{F}_{\mathrm{WR}}$ & $\begin{array}{l}\text { Força máxima ao cisalhamento } \\
\text { com Reforço de CFRP }\end{array}$ & $\mathrm{kN}$ & 413,5 & 519,3 \\
\hline
\end{tabular}

Os valores das forças máximas para que ocorra ruptura por cisalhamento $\left(\mathrm{F}_{\mathrm{Wmáx}}\right)$ nas vigas são bem inferiores às forças máximas à flexão ( $\mathrm{F}_{\text {máx }}$. Esta diferença permitiu que nas vigas sem o reforço de CFRP ocorressem ruptura ao cisalhamento, como esperado nesta pesquisa.

A proximidade entre os valores das forças máximas à flexão $\left(F_{\text {Wmáx }}\right)$ e ao cisalhamento com reforço $\left(\mathrm{F}_{\mathrm{WR}}\right)$ nas vigas V90 tornou possível as duas formas de ruptura. Esta pequena diferença não era a desejada nesta pesquisa, pois permitiu a ruptura pela flexão, e consequentemente sem utilizar toda a capacidade do reforço de CFRP.

O valor elevado da $\mathrm{F}_{\mathrm{WR}}$ ocorreu devido ao aumento indesejado da resistência do concreto. Este aumento além de alterar as formas de ruptura das vigas, impossibilitou o uso de atuadores com controle de deslocamento, uma vez que a capacidade máxima deste tipo de atuador disponível no laboratório da EESC é de 500 kN. 


\subsection{FORÇA MÁXIMA}

As forças de ruptura das vigas V50 e V90 são apresentadas pelo Gráfico 6.4 e o Gráfico 6.5 respectivamente, considerando como referência as vigas sem reforço de CFRP e explicitando o acréscimo de força ocorrido devido ao reforço em cada uma das vigas.
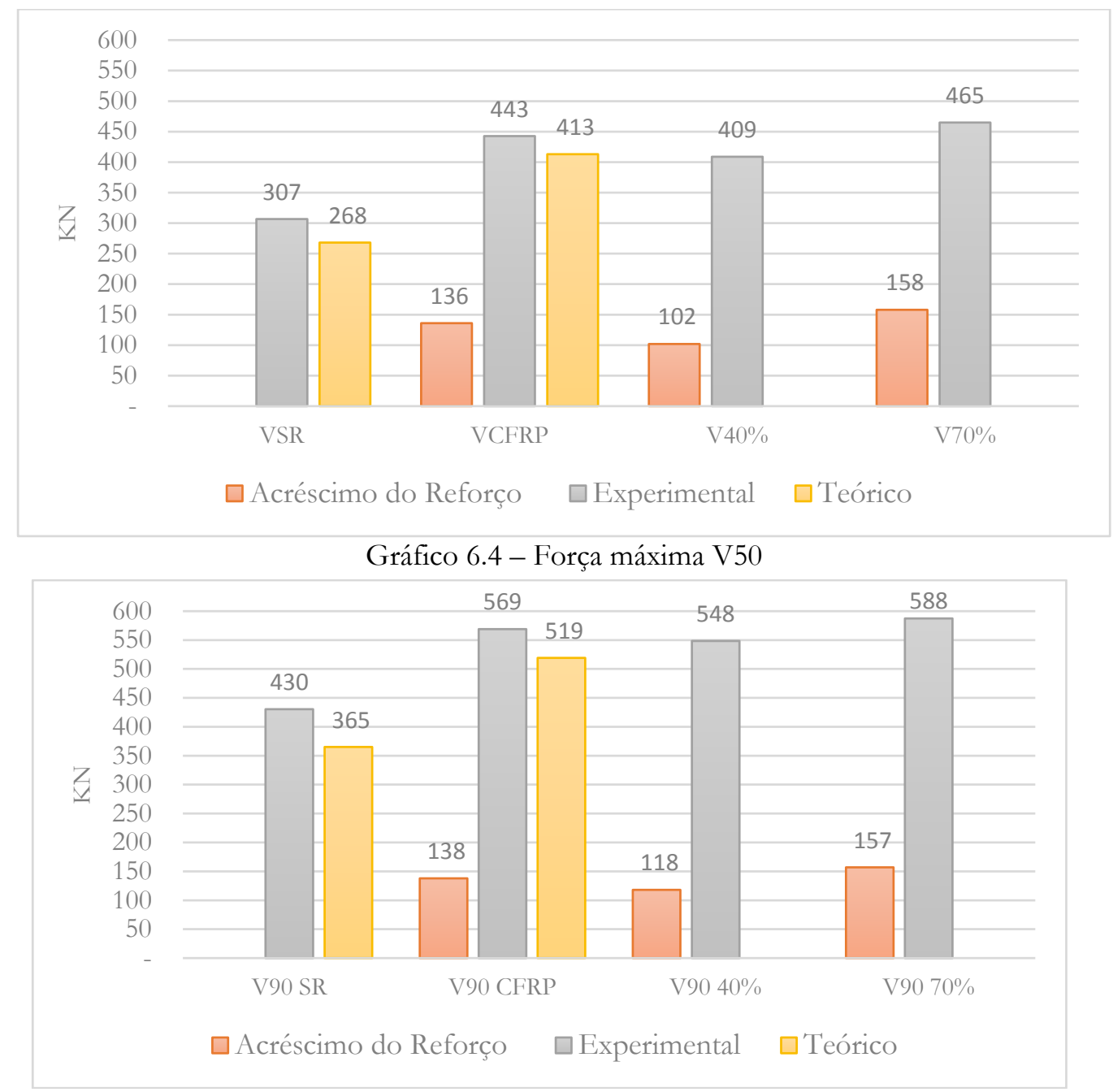

Gráfico 6.5 - Força máxima V90

As forças de ruptura das vigas sem reforços foram maiores que as previstas nos cálculos teóricos de $268 \mathrm{kN}$ para a V50 e de $365 \mathrm{kN}$ para a V90. Nos ensaios a V50 SR obteve uma força máxima de $307 \mathrm{kN}, 14,5 \%$ maior que o calculado, enquanto que a V90 SR obteve uma força máxima de $430 \mathrm{kN}$, um acréscimo de 17,8\% em relação ao calculado.

Nas vigas, todos os modelos reforçados com laminados de fibra de carbono apresentaram capacidade de carga maior que as vigas sem reforço, ocorrendo um acréscimo na capacidade de carga de $136 \mathrm{kN}(44,3 \%)$ na viga V50 CFRP e um acréscimo de $138 \mathrm{kN}(32,3 \%)$ para a V90 CFRP.

A melhoria na capacidade de carga também ocorreu para as vigas reforçadas com carregamento prévio de 40\% e 70\%, ampliando a capacidade de carga em $102 \mathrm{kN}(33,2 \%)$ na viga 
V50 40\%, e ampliando em 158kN (51,4\%) na V50 70\%. O mesmo comportamento ocorreu paras as vigas com C90, onde a força máxima em relação a viga sem reforço aumentou em $118 \mathrm{kN}(27,4 \%)$ na viga V90 40\%, e ampliando em $157 \mathrm{kN}$ (36,7\%) para a viga V90 70\%.

As vigas reforçadas após carregamento prévio de $40 \%$ da força máxima apresentaram capacidade de acréscimo de força inferior as vigas reforçadas íntegras, indicando que a melhoria do reforço é menor em vigas com concreto com pequenas fissurações. No sentido oposto a esta afirmação as vigas reforçadas após carregamento prévio de $70 \%$ da força máxima apresentaram aumento da força máxima em relação as vigas reforçadas íntegras.

Observou-se que a diferença entre os valores de força na ruptura entre as vigas reforçadas com e sem carregamento prévio foram pequenos tanto paras as vigas V50 como para as vigas V90. Constatou-se que o carregamento prévio não influenciou na capacidade de carga das vigas, sendo as diferenças apresentadas apenas variações ocasionais de resultados laboratoriais.

O acréscimo de força oriundo dos sistemas de reforço de CFRP demonstrou a eficiência da técnica NSM em elevar a força máxima em vigas, tendo em todas acréscimos acima de $102 \mathrm{kN}$. Apresentando em média acréscimo na capacidade de carga de 43\% para as vigas V50 e de 32,1\% para as vigas $\mathrm{V} 90$.

Os valores teóricos da força máxima no cisalhamento com reforço de CFRP apresentaram boa relação com os resultados experimentais das vigas com reforço. Para a viga V50 o valor teórico calculado foi de $413 \mathrm{kN}$ e para a V90 de $519 \mathrm{kN}$. A viga V50 CFRP obteve experimentalmente força máxima de $443 \mathrm{kN}$, um acréscimo de apenas 7,2\%, enquanto que a V90 CFRP obteve experimentalmente força máxima de $569 \mathrm{kN}$, acréscimo de $10,9 \%$ em relação ao valor teórico calculado.

Nas vigas com carregamento prévio foram considerados os mesmos valores teóricos da força máxima ao cisalhamento com reforço de CFRP, pois considerou-se que o carregamento prévio não alterou a capacidade de carga das vigas.

Assim como não foram alteradas as formas de ruptura. As vigas com carregamento prévio de $40 \%$ apresentaram força máxima menores que as vigas reforçadas íntegra, enquanto que as vigas com $70 \%$ de carregamento prévio apresentaram força máxima maiores. Constatando-se que as diferenças na força máxima não foram ocasionadas pelo carregamento prévio e sim pela variação natural de resultados de ensaios experimentais. 


\subsection{DESLOCAMENTO VERTICAL}

O deslocamento vertical das vigas foi medido no ponto de aplicação da força, sendo para sua análise subtraído dos deslocamentos ocorridos devido a acomodação nos apoios. Ocorreu em todas as vigas com reforço um aumento das deformações verticais na força máxima.

Para análise da alteração no deslocamento vertical ocorrido devido ao reforço e por carregamento prévio, seus valores foram medidos também na força de $200 \mathrm{kN}$ reduzindo a influência das deformações plásticas nos materiais.

A Tabela 6.8 apresenta os deslocamentos verticais (f) no ponto de aplicação da força, ocorridos na força máxima das vigas. Nela podemos observar que o acréscimo de deslocamento ocorreu devido ao acréscimo de capacidade de carga das vigas com reforço de CFRP. Nesta tabela são apresentados ainda os deslocamentos verticais na força de $200 \mathrm{kN}$.

Tabela 6.8 - Deslocamentos verticais no ponto de aplicação da força (mm)

\begin{tabular}{c|c|c|c|c|c|c}
\hline Vigas & $\begin{array}{c}\text { Força } \\
(\mathbf{k N})\end{array}$ & $\begin{array}{c}\text { Variação } \\
\text { de força }\end{array}$ & $\mathbf{f}(\mathbf{m m})$ & $\boldsymbol{\Delta} \mathbf{f}$ & $\begin{array}{c}\mathbf{f ~ e m ~ 2 0 0 ~ k N ~} \\
\mathbf{( m m})\end{array}$ & $\boldsymbol{\Delta} \mathbf{f}$ \\
\hline V50 SR & 307 & & 7,5 & & 3,58 & \\
\hline V50 CFRP & 443 & $44 \%$ & 10,7 & $43 \%$ & 3,19 & $-12,5 \%$ \\
\hline V50 40\% & 409 & $33 \%$ & 9,6 & $29 \%$ & 3,21 & $-11,5 \%$ \\
\hline V50 70\% & 465 & $52 \%$ & 10,8 & $45 \%$ & 3,18 & $-12,6 \%$ \\
\hline \hline V90 SR & 430 & & 9,4 & & 3,51 & \\
\hline V90 CFRP & 569 & $32 \%$ & 11,3 & $21 \%$ & 2,68 & $-31,1 \%$ \\
\hline V90 40\% & 548 & $27 \%$ & 10,8 & $15 \%$ & 2,71 & $-29,6 \%$ \\
\hline V90 70\% & 588 & $37 \%$ & 11,9 & $27 \%$ & 2,96 & $-18,7 \%$ \\
\hline
\end{tabular}

Com o reforço, a viga V50 CFRP apresentou deslocamento de $10,7 \mathrm{~mm}$, na força máxima, sendo este $43 \%$ maior que o deslocamento da viga sem reforço (V50 SR), praticamente na mesma proporção que ampliou a força máxima entre as vigas, em 44\%. Nas vigas V90 o acréscimo no deslocamento foi proporcionalmente menor que nas vigas V50, com incremento de $21 \%$ no deslocamento vertical da viga reforçada V90 CFRP, enquanto que o acréscimo na capacidade de carga foi de $32 \%$.

Os efeitos do aumento do deslocamento vertical em função do aumento da capacidade de carga ocorreram de forma proporcional em todas as vigas, independentemente da presença de carregamento prévio. Este efeito confirma que o carregamento prévio não alterou os resultados referentes a ruptura das vigas.

Ao comparar os deslocamentos verticais das vigas na mesma força $(200 \mathrm{kN})$ pôde-se perceber uma melhoria na rigidez dos elementos reforçados de CFRP, onde todas as vigas com reforço apresentaram deslocamento vertical menores que as vigas sem reforço. 
A presença de carregamento prévio não alterou os deslocamentos verticais verificados na força de $200 \mathrm{kN}$, onde para as vigas V50 os valores são praticamente iguais e nas vigas V90 apenas a com carregamento prévio de $70 \%$ ocorreu pequeno acréscimo.

\subsection{FORÇA X DESLOCAMENTO}

No Gráfico 6.6 são apresentados os diagramas força x deslocamento, onde a inclinação das curvas é determinada pela rigidez da viga, sendo diretamente proporcional ao produto do módulo de elasticidade do material pela inércia equivalente em cada etapa de força.

Neste estudo foram incluídas curvas teóricas, considerando uma rigidez equivalente das vigas conforme prevista na norma ABNT NBR 6118:2014. Nesta formulação a penalização da rigidez é constante e não considera as fissuras de cisalhamento, nem a plastificação dos materiais ocorridos próximas à força máxima.

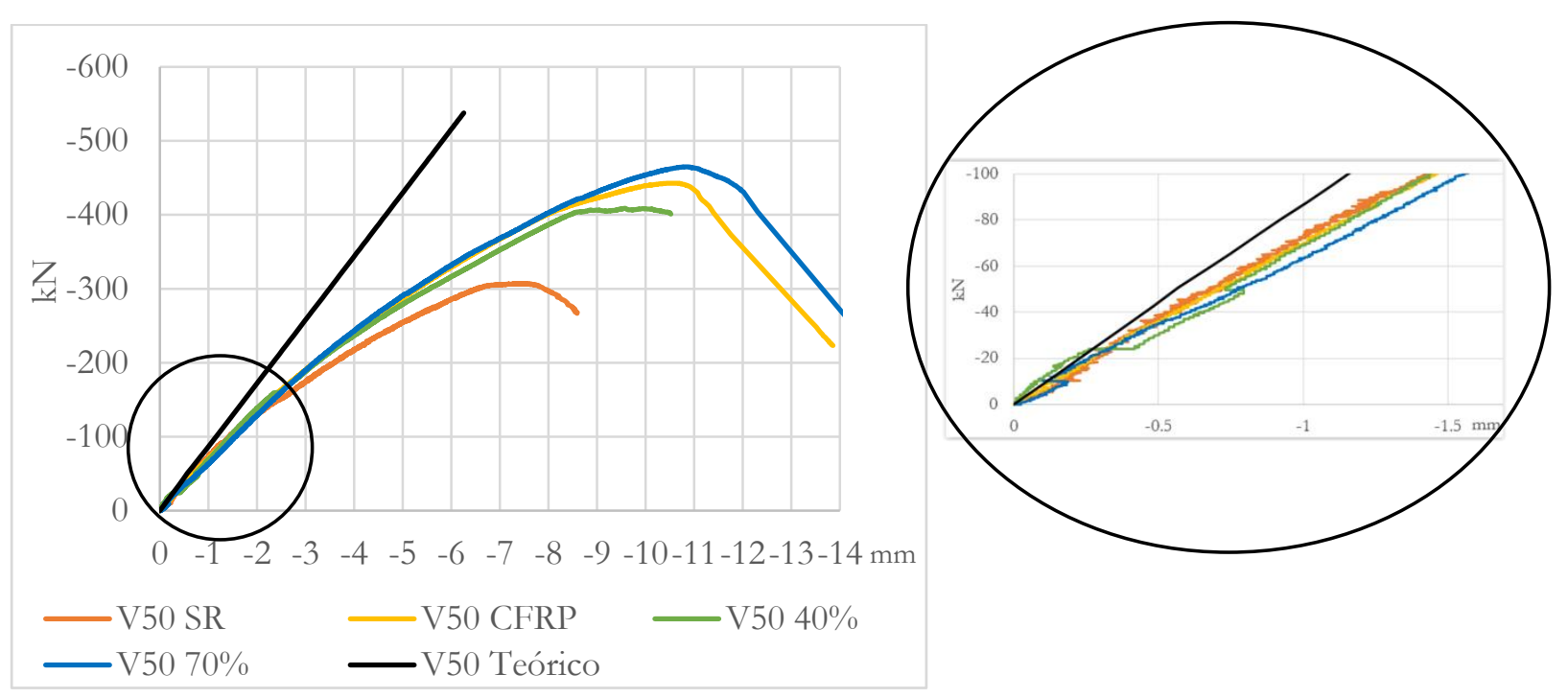

Gráfico 6.6 - Força x Deslocamento das vigas V50

Verificou-se que a viga V50 SR, sem reforço, apresenta menor rigidez que as vigas reforçadas com CFRP. As vigas reforçadas após carregamento prévio V50 40\% e V50 70\% apresentaram rigidezes próximas da viga reforçada íntegra V50 SR, apresentando maior deslocamento vertical para a V50 70\% em consequência da maior força máxima e menor (9,5mm) para a V50 40\% que dentre as reforçadas apresentou menor força máxima.

Os diagramas força x deslocamentos das vigas V90 são apresentados no Gráfico 6.7, juntamente com a curva teórica calculada. 


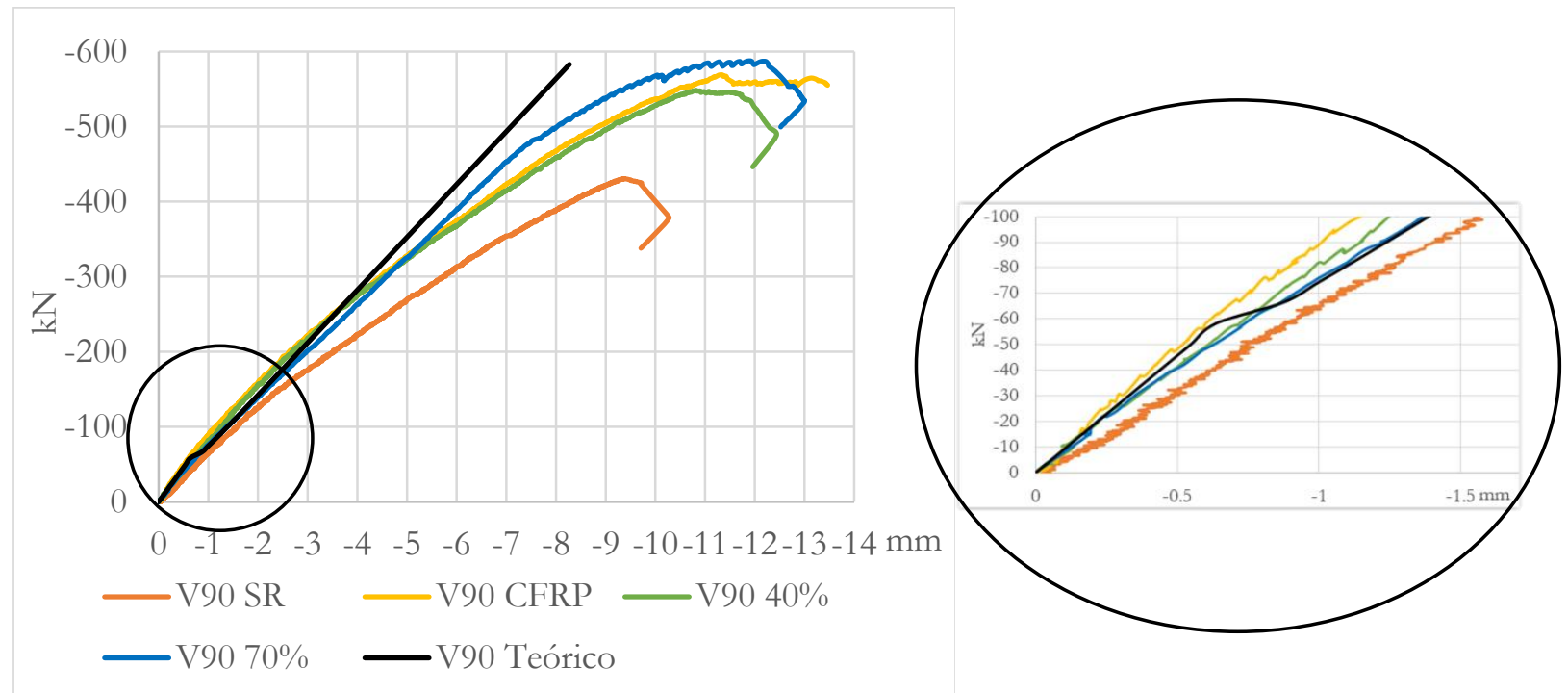

Gráfico 6.7 - Foça x Deslocamento V90

As vigas V90 apresentaram a mesma diferença na rigidez já explicadas nas vigas V50, mas com menor intensidade. Nas vigas reforçadas é possível observar o aumento da rigidez quando comparadas com a viga sem reforço V90 SR, observamos também que as vigas reforçadas após carregamento prévio V90 40\% e V90 70\% apresentam rigidez semelhante à viga reforçada íntegra V90 CFRP.

Todas as vigas com carregamento prévio apresentaram comportamento semelhante as das reforçadas com CFRP íntegras, quanto à inclinação, à força máxima e ao deslocamento máximo, demostrando que o carregamento prévio não interferiu na rigidez das vigas.

\subsection{MOMENTO X CURVATURA}

Buscando maiores informações quanto a rigidez das vigas uma análise da relação momento x curvatura foi realizada. Segundo Buchaim (2001) esse diagrama representa um gradiente de deformação na seção transversal, medindo a variação da rotação por unidade de comprimento em cada momento do carregamento. Segundo o pesquisador, um estudo do gráfico momento x curvatura possibilita uma análise não-linear da estrutura, atendendo as condições de equilíbrio, compatibilidade e as leis constitutivas dos materiais.

Para a determinação do gráfico teórico momento x curvatura das vigas foi utilizado o programa SecTrans ${ }^{\circledR}$, que permite a exportação dos valores das curvaturas em qualquer etapa de carregamento. O dimensionamento deste programa contempla apenas a ruptura à flexão, sendo assim os gráficos teóricos apresentam curvaturas até a força máxima por flexão sem considerar a hipótese de ruptura por cisalhamento. 
A curvatura foi calculada pela diferença de deformação medidas pelos extensômetros posicionados nas armaduras longitudinais, dividida pela distância entre as armaduras, os conforme a Equação 6.1. O extensômetros foram posicionados nas armaduras na mesma seção do ponto de aplicação da carga.

$$
k=\frac{\varepsilon_{s 1}-\varepsilon_{s^{\prime}}}{d-d^{\prime}}
$$

Onde:

$\mathrm{k}=$ Curvatura da viga

$\varepsilon_{\mathrm{s} 1}=$ Deformação da armadura positiva

$\varepsilon_{\mathrm{s}^{\prime}}=$ Deformação da armadura negativa

$\mathrm{d}=$ Altura útil da viga

d' = Cobrimento do concreto

O Gráfico 6.8 apresenta o diagrama momento x curvatura para as vigas com V50. Neste pode-se observar que em todas as vigas V50 os ensaios experimentais apresentaram curvaturas maiores que os valores teóricos. Assim como no gráfico força x deslocamento, a inclinação da curva é função da rigidez das vigas.

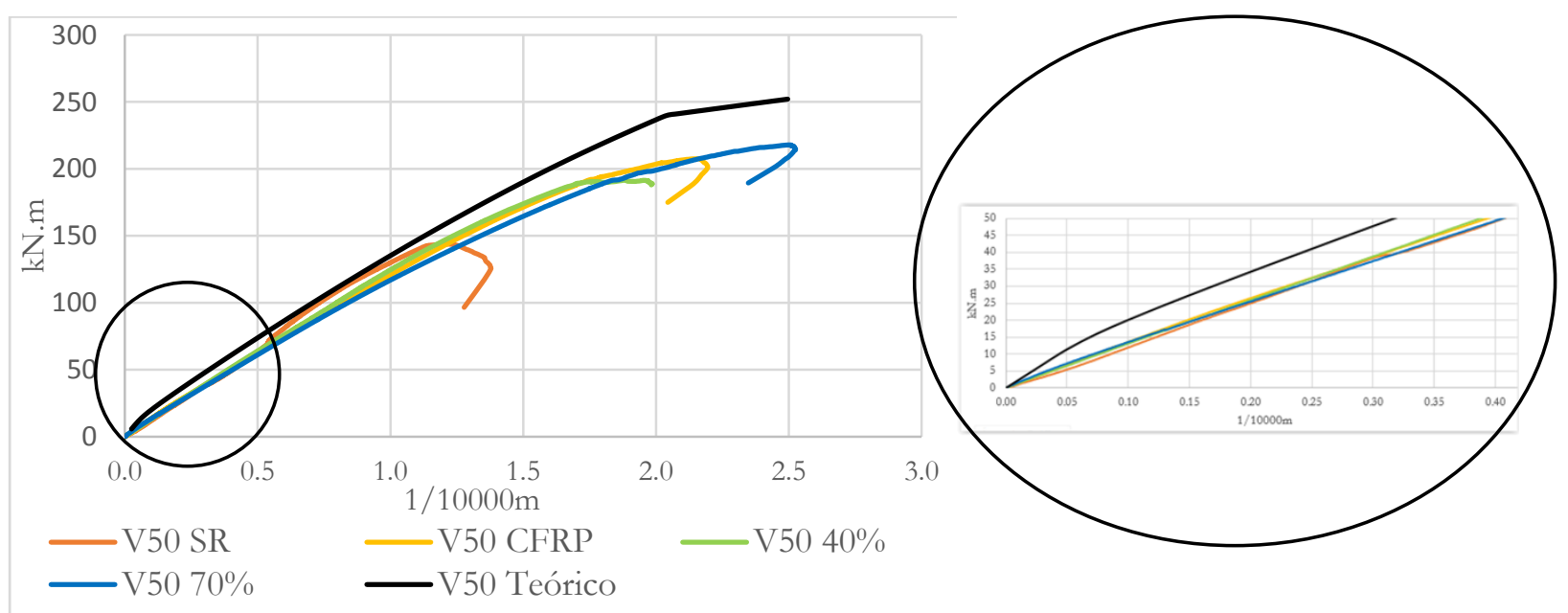

Gráfico 6.8 - Momento x Curvatura V50

Todas as vigas experimentais iniciaram com a mesma rigidez até o momento de $60 \mathrm{kN} . \mathrm{m}$, onde iniciam as fissuras nas vigas. Com o incremento das fissuras ocorreu maior solicitação das armaduras negativas das vigas, e sendo a curvatura calculada pelas deformações nas armaduras ocorre um aumento das curvaturas, com maior incidência na viga V50 SR.

Observou-se que a viga reforçada após carregamento prévio V50 40\% apresentou comportamento praticamente igual à viga V50 CFRP. A viga V50 70\% apresentou gráfico da 
curvatura com inclinação levemente menor. Essa proximidade entre a inclinação das curvaturas mostra que os carregamentos prévios não alteraram as rigidezes das vigas V50.

Nas vigas V90 o diagrama momento x curvatura (Gráfico 6.9) apresentou resultados dispersos, em que a curvatura teórica da V90 representou de forma mais próxima as vigas com carregamento prévio (V90 40\% e V90 70\%).

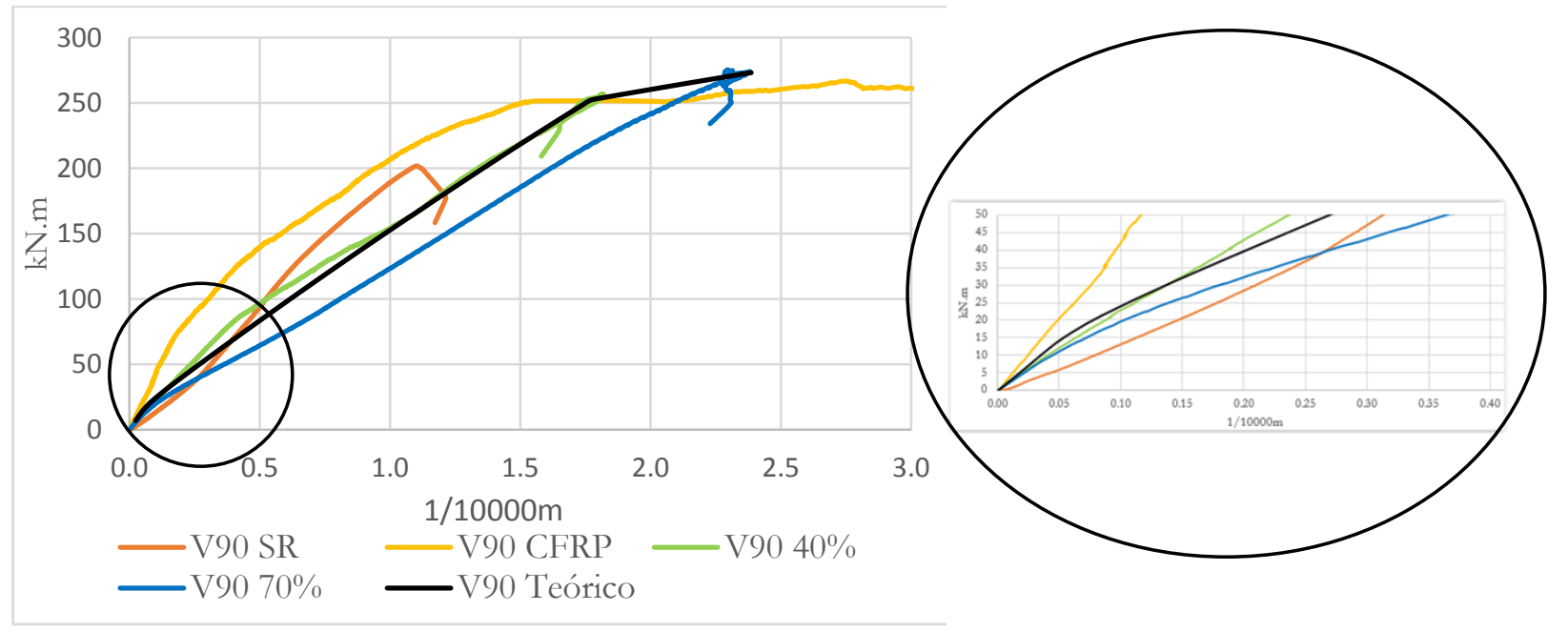

Gráfico 6.9 - Momento x Curvatura V90

Nas vigas íntegras sem (V90 SR) e com reforço (V90 CFRP) observou-se um aumento da rigidez no início do carregamento, fazendo a curvatura distanciar-se da curvatura teórica da V90. Esse aumento foi causado pela baixa deformação na armadura positiva das vigas, que de forma não usual, apresentou pequenas deformações no início do carregamento.

\subsection{DEFORMAÇÕES}

A deformação nas barras de aço e nos laminados de CFRP foram medidas por meio de extensômetros de deformação (Strain Gages), posicionados nas armaduras longitudinais positivas e negativas, no segundo ao quinto estribos e no segundo ao quinto laminados de CFRP.

\subsubsection{Deformações nas armaduras longitudinais}

As deformações ocorridas na força máxima de cada viga são apresentadas na Tabela 6.9, com as deformações das armaduras longitudinais positivas e negativas e com suas devidas variações em relação os valores obtidos nas vigas sem reforço. 
Tabela 6.9 - Deformação nas armaduras positivas e negativas das vigas

\begin{tabular}{c|c|c|c|c|c|c}
\hline \multicolumn{3}{c}{ Força (kN) } & \multicolumn{2}{c}{$\begin{array}{c}\text { Deformação Armadura } \\
\text { Positiva (\%) }\end{array}$} & \multicolumn{2}{c}{$\begin{array}{c}\text { Deformação Armadura } \\
\text { Negativa (\%) }\end{array}$} \\
\hline V50 SR & 307 & & 2,177 & & $-1,429$ & \\
\hline V50 CFRP & 443 & $44 \%$ & 3,061 & $41 \%$ & $-2,361$ & $65 \%$ \\
\hline V50 40\% & 409 & $33 \%$ & 2,824 & $30 \%$ & $-1,895$ & $33 \%$ \\
\hline V50 70\% & 465 & $52 \%$ & 3,331 & $53 \%$ & $-2,918$ & $104 \%$ \\
\hline \hline V90 SR & 430 & & 3,027 & & $-1,400$ & \\
\hline V90 CFRP & 569 & $32 \%$ & 5,384 & $78 \%$ & $-1,465$ & $5 \%$ \\
\hline V90 40\% & 548 & $27 \%$ & 2,634 & $-13 \%$ & $-1,898$ & $36 \%$ \\
\hline V90 70\% & 588 & $37 \%$ & 3,596 & $19 \%$ & $-2,146$ & $53 \%$ \\
\hline
\end{tabular}

As deformações nas armaduras das vigas com sistema de reforço foram em geral maiores que as das vigas sem reforço, ocorrendo escoamento da armadura positiva em todas as vigas.

Observou-se que na comparação entre as vigas sem reforço (V50 SR) com a viga reforçada íntegra (V50 CFRP) houve acréscimo da deformação da armaduras positiva em 43\%, e da armadura negativa em $65 \%$.

As vigas reforçadas após carregamento prévio V50 40\% apresentaram acréscimos de deformação menores que a V50 CFRP, devido ao menor acréscimo na força máxima, sendo em $30 \%$ para a barra comprimida e de 33\% para a barra tracionada. Quando o carregamento prévio foi de $70 \%$ a força máxima aumentou e consequentemente a deformação nas armaduras apresentaram um maior aumento, com 53\% para a armadura positiva e em 104\% na negativa.

É razoável afirmar que com o aumento dos momentos atuantes ocorre uma redução da profundidade da linha neutra e consequentemente redução da área de concreto resistente, assim ocorre maior solicitação das armaduras negativas. Pôde-se observar este efeito nas vigas V50, em que o acréscimo na deformação foi maior nas armaduras negativas que nas positivas.

Nas vigas V90, a relação das deformações com a força não permaneceu proporcional como ocorrido com as vigas V50. Ao analisar a viga V90 CFRP verificou-se que a deformação da barra positiva aumentou em $78 \%$, enquanto que a da armadura tracionada aumentou em apenas $5 \%$, ou seja praticamente todo o acréscimo de força na viga V90 CFRP foi absorvido pela armadura positiva e na parte comprimida do concreto.

$\mathrm{Na}$ viga reforçada após o carregamento prévio ocorreu redução na deformação da barra positiva em 13\% e aumento de 36\% na barra negativa. As vigas reforçadas não deveriam ter redução nas deformações das barras quando comparadas as vigas sem reforço, pois o reforço é ao cisalhamento e este permitiu um aumento na capacidade de carga das vigas. A redução na deformação da armadura positiva demonstra que nesta viga o concreto não apresentou a mesma 
eficiência que as demais, podendo esta redução ter sido ocasionada pelo carregamento prévio. Essa configuração demonstra que a viga V90 40\% apresentou alguma alteração na sua resistência a flexão.

Uma análise das deformações nas armaduras longitudinais objetivou identificar os efeitos do reforço e do carregamento prévio na solicitação das armaduras longitudinais. Para isso foram analisadas as curvas força x deformação na armadura positiva e negativa das vigas. No Gráfico 6.10 são apresentadas as curvas das vigas V50.

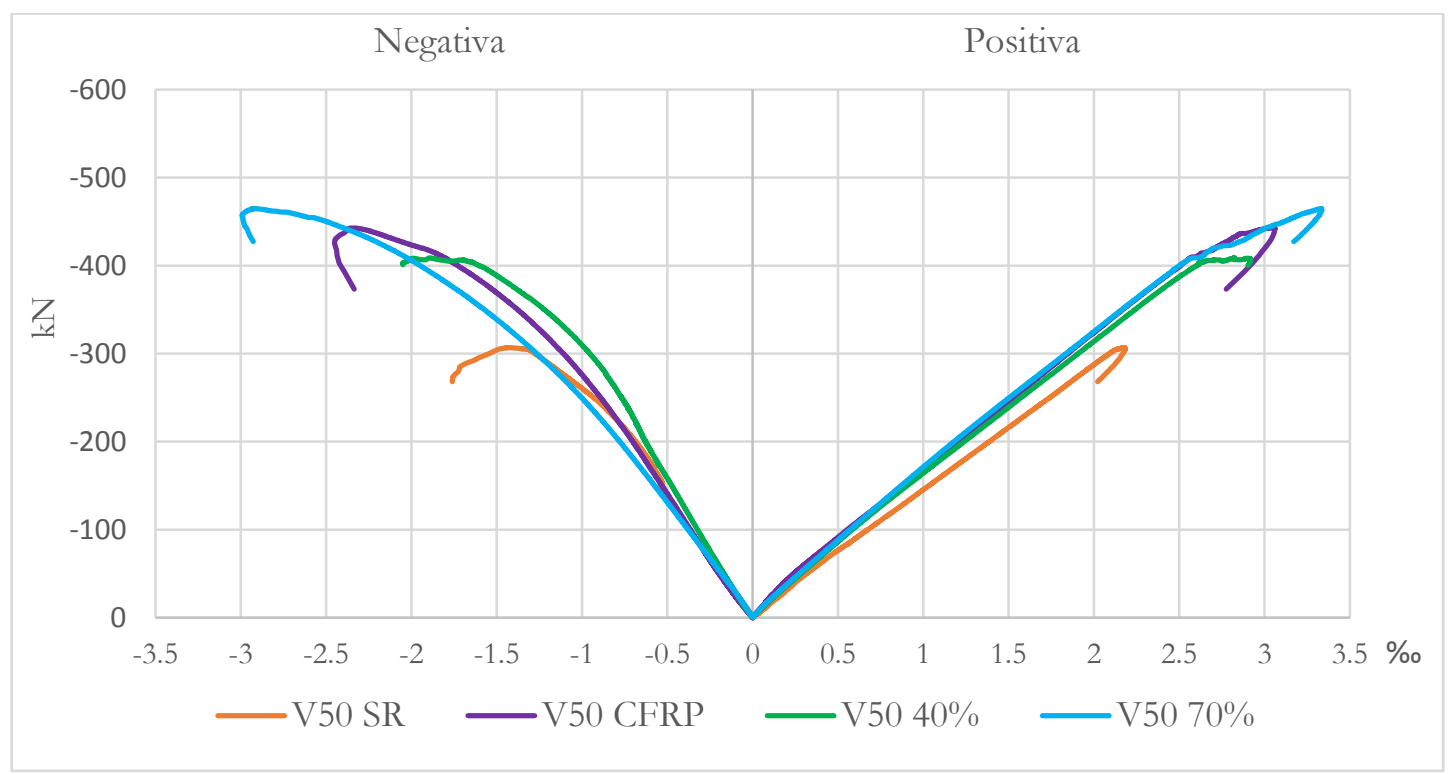

Gráfico 6.10 - Força x Deformação Armadura longitudinal - V50

Nas armaduras positivas verificou-se que a deformação do aço ocorreu de forma linear para todas as vigas, sendo a que a viga sem reforço V50 SR apresentou menor inclinação e as demais vigas com reforço de CFRP apresentaram inclinação praticamente iguais.

Nas armaduras negativas ocorreu maior dispersão nas curvas, ocorrendo alteração na inclinação das curvas à partir do início da fissuração dos concreto, valor próximo a 120 kN. Após o início de fissuração as armaduras negativas passam a ser mais solicitadas, aumentando suas inclinações.

Nenhum efeito do carregamento prévio foi observado nas deformações das armaduras longitudinais nas vigas V50 com reforço. Nas armaduras positivas as curvas são praticamente iguais, enquanto que nas negativas a viga V50 40\% apresentou maiores inclinações das curvas, enquanto que a viga V50 70\% apresentou menores, apesar de carregamento prévio maior.

As curvas força $\mathrm{x}$ deformação na armadura positiva das vigas V90 possuem maiores dispersões de resultado que as vigas V50, e são apresentadas no Gráfico 6.11. 


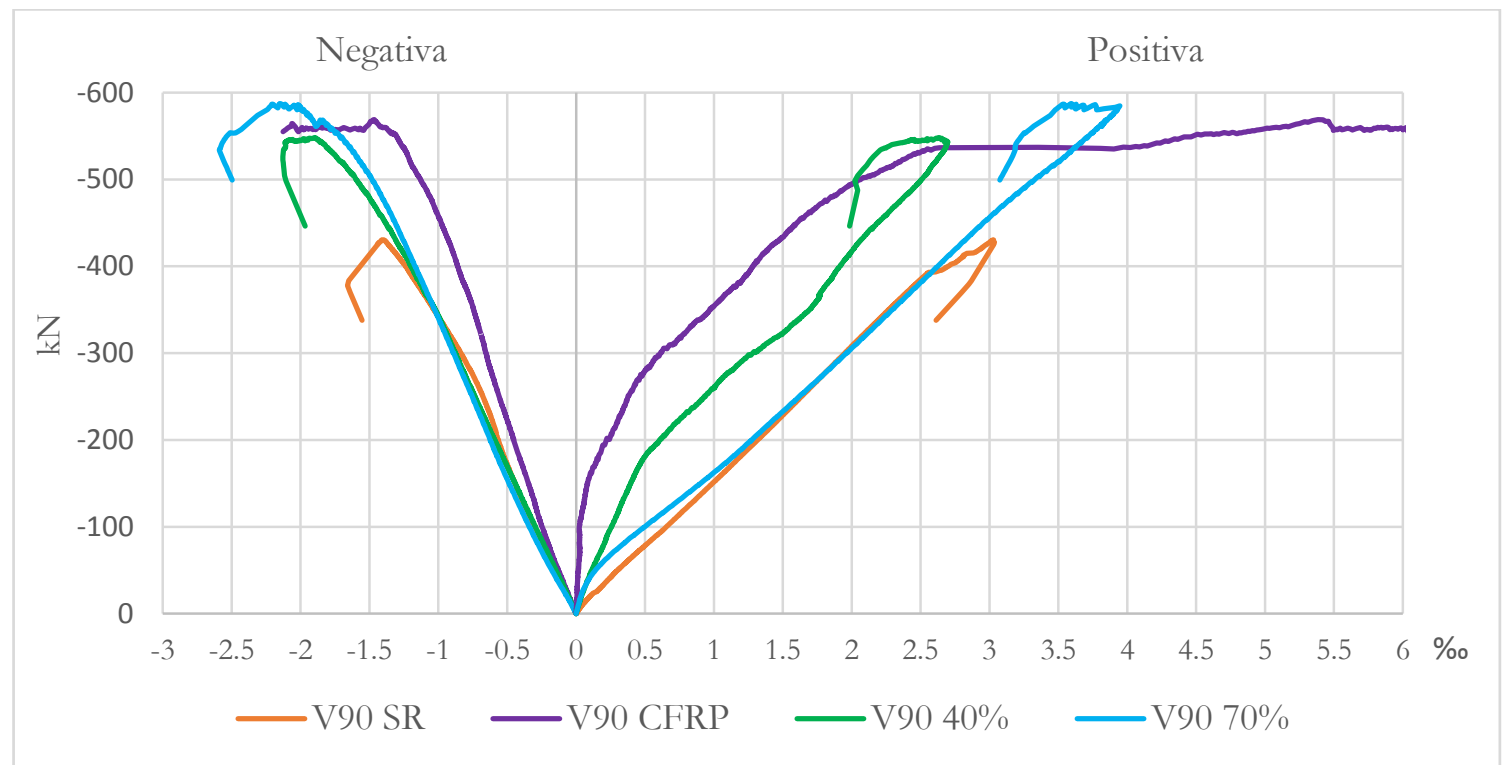

Gráfico 6.11 - Força x Deformação Armadura Positiva - V90

Nas armaduras positivas das vigas V90 ocorreu grande diferença entre os resultados da viga sem reforço V90 SR e os da viga reforçada íntegra V90 CFRP. Nesta ocorreu elevada capacidade de resistência à tração do concreto, pois após o reforço, a armadura positiva apresentou pequenas deformações para forças antes da fissuração, valor próximo a $175 \mathrm{kN}$. Na viga reforçada após carregamento prévio de $40 \%$ o mesmo efeito é observado, mas com menor intensidade.

As armaduras negativas das vigas V90 apresentaram resultados semelhantes aos das vigas V50. Nelas ocorre aumento das inclinações das curvas após o início da fissuração.

Somente nas vigas V50 70\%, V90CFRP e V90 70\% ocorreu escoamento das armaduras positivas antes da ruptura, com deformações acima de 2,81\%, ocorrendo assim deformações nas armaduras longitudinais de maneira análoga ao idealizado teoricamente.

Nas armaduras positivas de todas as vigas reforçadas com CFRP ocorreram reduções das deformações em relação as vigas sem reforço, com pequenas intensidades para as vigas V50 e com maior variação nas vigas V90. Este efeito demonstra uma capacidade do reforço ao cisalhamento reduzir a fissuração do concreto e consequentemente o esforço das armaduras positivas.

\subsubsection{Deformações nas armaduras transversais e laminados de CFRP}

A Figura 6.11 apresenta o posicionamento dos estribos e laminados de CFRP para facilitar a interpretação das análises de resultados das deformações na seção transversal das vigas. 


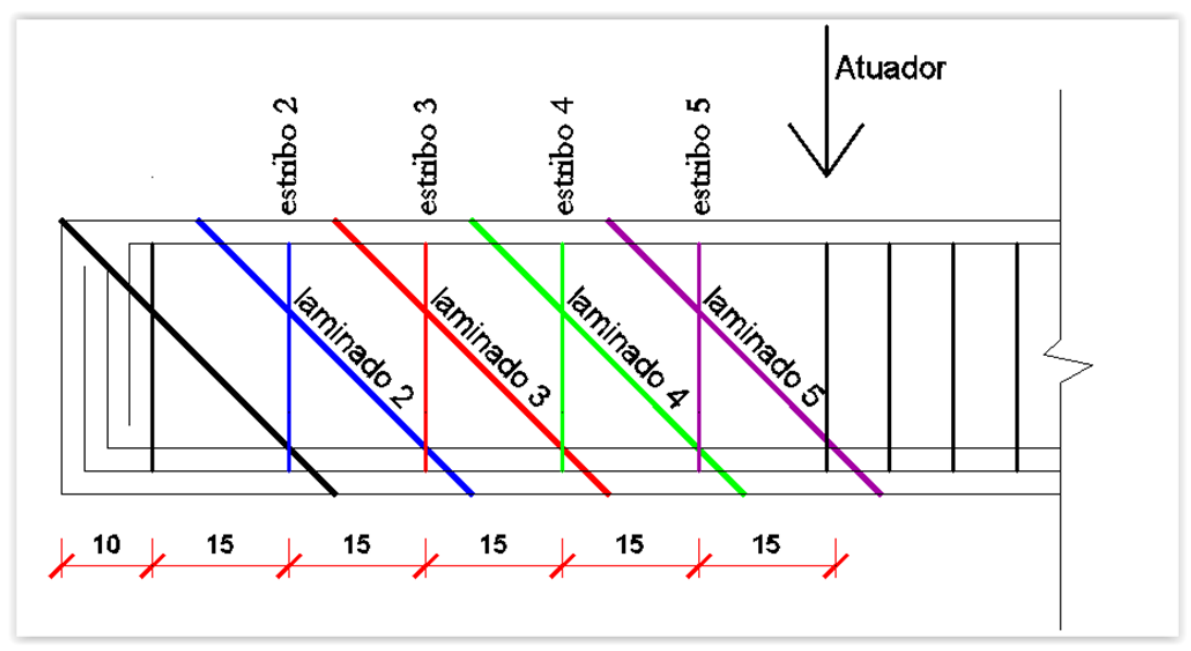

Figura 6.11 - Posicionamento dos estribos e laminados de CFRP

A instrumentação das armaduras transversais foram realizadas conforme o descrito no capítulo materiais e métodos das vigas, onde por meios destas se pretendeu medir as deformações do segundo ao quinto estribo. Infelizmente durante o processo de abertura de ranhuras no concreto para a inserção do reforço de CFRP vários cabos de ligação com o extensômetros foram cortados impossibilitando a leitura de vários estribos. A Tabela 6.10 apresenta a deformação nas armaduras transversais na força máxima das vigas, indicando com " $\mathrm{x}$ " os estribos com erro na captação dos dados.

Tabela 6.10 - Deformação nas armaduras transversais das vigas na força máxima

\begin{tabular}{c|c|c|c|c}
\hline & $\begin{array}{c}\text { Estribo 2 } \\
\mathbf{( \% )}\end{array}$ & $\begin{array}{c}\text { Estribo 3 } \\
\mathbf{( \% )}\end{array}$ & $\begin{array}{c}\text { Estribo 4 } \\
\mathbf{( \% o )}\end{array}$ & $\begin{array}{c}\text { Estribo 5 } \\
\mathbf{( \% o )}\end{array}$ \\
\hline V50 & 5,067 & 2,899 & 16,105 & 1,341 \\
\hline V50 CFRP & $\mathrm{x}$ & 4,588 & $\mathrm{x}$ & 2,367 \\
\hline V50 40\% & $\mathrm{x}$ & $\mathrm{x}$ & $\mathrm{x}$ & $\mathrm{x}$ \\
\hline V50 70\% & $\mathrm{x}$ & $\mathrm{x}$ & $\mathrm{x}$ & 2,437 \\
\hline \hline V90 & 2,313 & 10,791 & 14,769 & 2,088 \\
\hline V90 CFRP & $\mathrm{x}$ & 5,400 & $\mathrm{x}$ & $\mathrm{x}$ \\
\hline V90 40\% & $\mathrm{x}$ & $\mathrm{x}$ & $\mathrm{x}$ & 2,765 \\
\hline V90 70\% & $\mathrm{x}$ & 3,621 & $\mathrm{x}$ & 1,869 \\
\hline
\end{tabular}

A curva força x deformação nos estribos da viga V50 SR é apresentada no Gráfico 6.12. Nesta se observou que no início das curvas os estribos praticamente não apresentaram deformações e só após o início das fissuras eles começam efetivamente a resistir aos esforços. Podese observar ainda que os estribos iniciaram suas deformações em forças diferentes, pois as fissuras iniciam ao longo da seção em forças diferentes.

$\mathrm{Na}$ viga V50 SR, o estribo 5 apresentou a menor deformação, seguido pelo estribo 3 e tendo o estribo 4 o mais solicitado, com deformação de 1,6105\% indicando seu escoamento. 


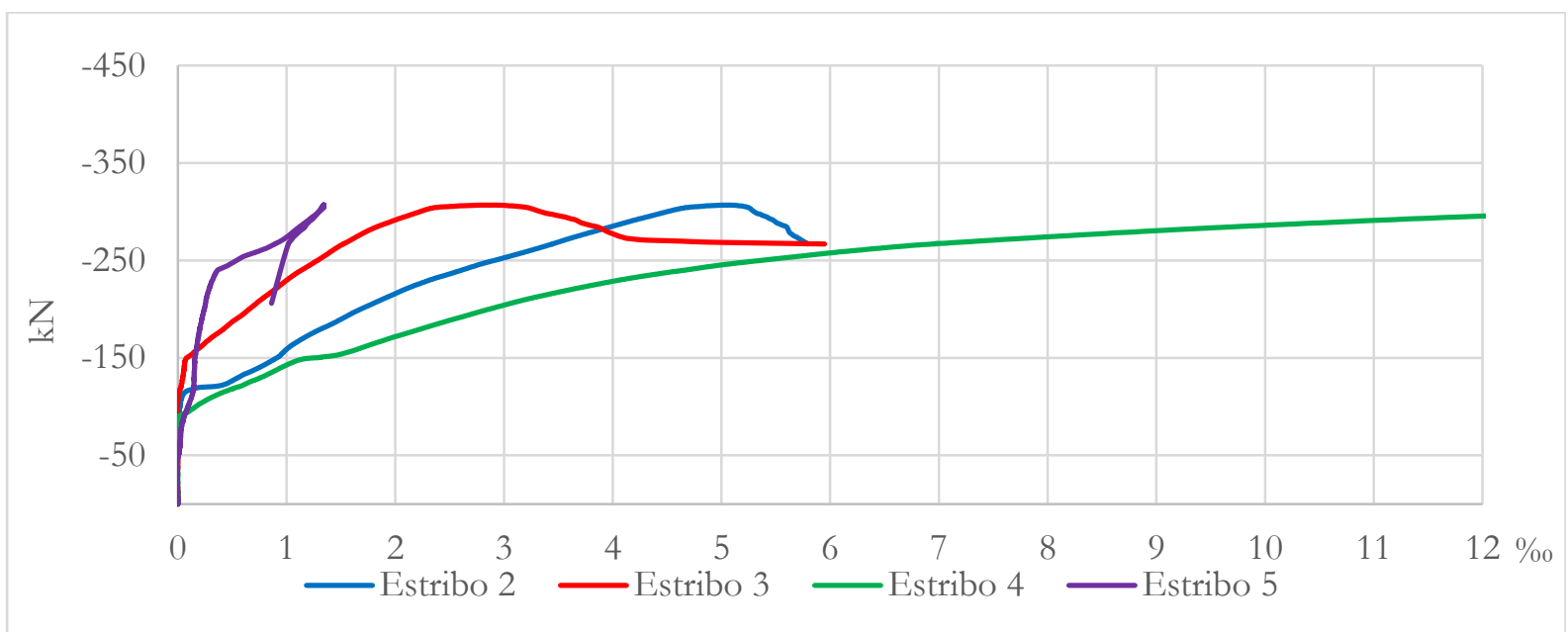

Gráfico 6.12 - Força x Deformação na armadura transversal - V50 SR

O Gráfico 6.13 apresenta as curvas força x deformação dos estribos da viga V50 CFRP. Nesta viga somente foram possíveis de se analisar as deformações dos estribos 3 e 5 .

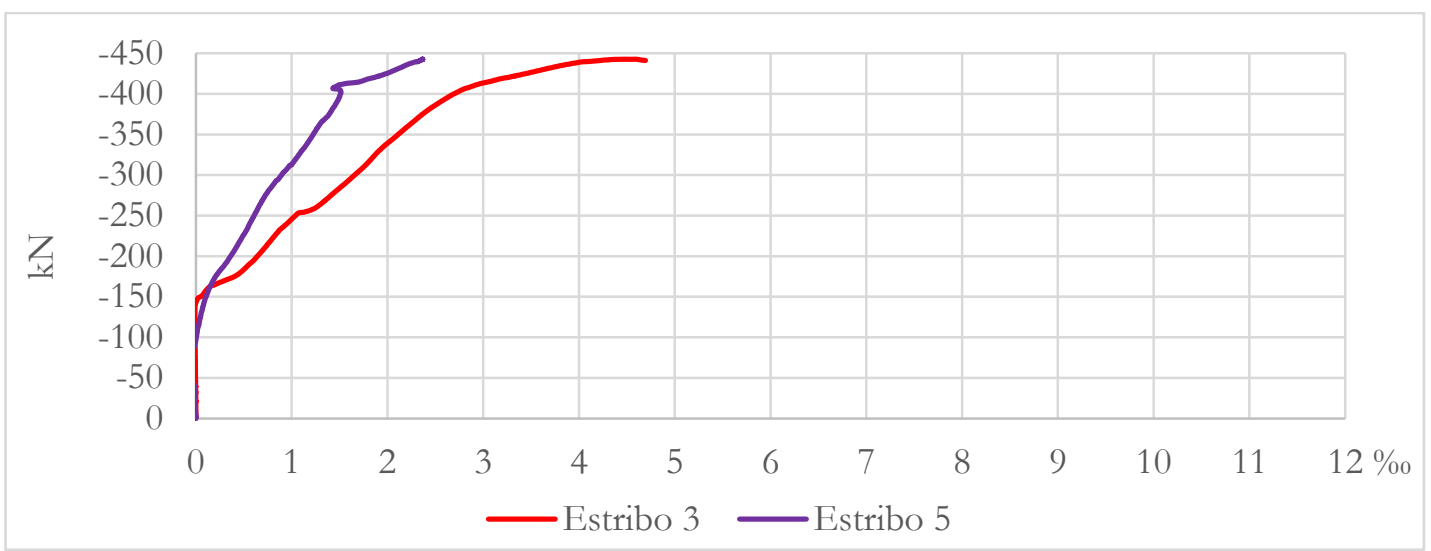

Gráfico 6.13 - Força x Deformação na armadura transversal - V50 CFRP

Os estribos desta viga apresentaram maiores deformações que os mesmos da viga V50 SR, com 2,367\% no estribo 5 e com 4,588\% no estribo 3, essa maior deformação indica que os estribos foram mais solicitados, resistindo a maiores esforços de cisalhamento da viga.

Ao compararmos as deformações nos estribos da viga V50 CFRP com a mesma força máxima da viga V50 SR $(307 \mathrm{kN})$ se observou uma redução das deformações. No estribo 5 reduzindo de 1,341\%o para $0,966 \%$ e no estribo 3 de 2,899\%o para 1,733\%o. Essa redução permitiu identificar a capacidade do reforço de absorver parte da força cortante da viga, aliviando assim as tensões nos estribos.

$\mathrm{Na}$ viga reforçada após carregamento prévio V50 40\% nenhum dos extensômetros dos estribos apresentou leitura de dados, devendo a análise do cisalhamento ser realiza apenas pelo reforço de CFRP. 
A viga reforçada após carregamento prévio V50 70\% somente o estribo 5 apresentou leitura. O Gráfico 6.14 apresenta a comparação entre as deformações nos estribos 5 das vigas V50 SR, V50 CFRP e V50 70\%.

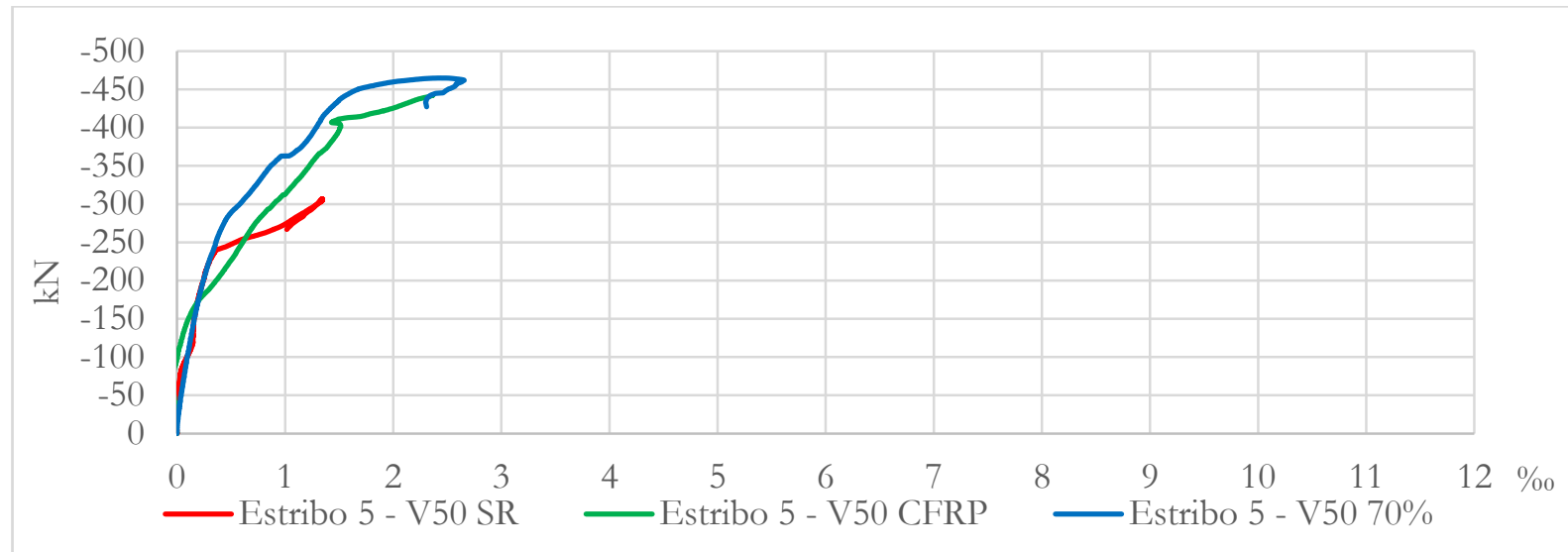

Gráfico 6.14 - Força x Deformação na armadura transversal - V50 estribo 5

Neste gráfico se observou que o estribo da viga após carregamento prévio de $70 \%$ inicia as deformações juntamente com o início do carregamento, diferenciando-se das vigas íntegras (V50 SR e V50 CFRP). Nessas vigas, por serem íntegras, as deformações nos estribos iniciaram efetivamente após a abertura das primeiras fissuras, que ocorreram com valores próximos a $50 \mathrm{kN}$ e $100 \mathrm{kN}$ respectivamente.

Verificou-se neste estribo que as deformações após carregamento prévio de 70\% não apresentaram grandes diferenças das deformações na mesma posição da viga íntegra V50 CFRP após a força de $150 \mathrm{kN}$. Este efeito demonstra que o reforço tem capacidade de absorver a força cortante de forma semelhante, independentemente da ocorrência de carregamento prévio.

O Gráfico 6.15 apresenta as curvas força x deformação das armaduras transversais da viga V90 SR, permitindo comparar a variação ocorrida nos estribos ao utilizar concreto com maior resistência.

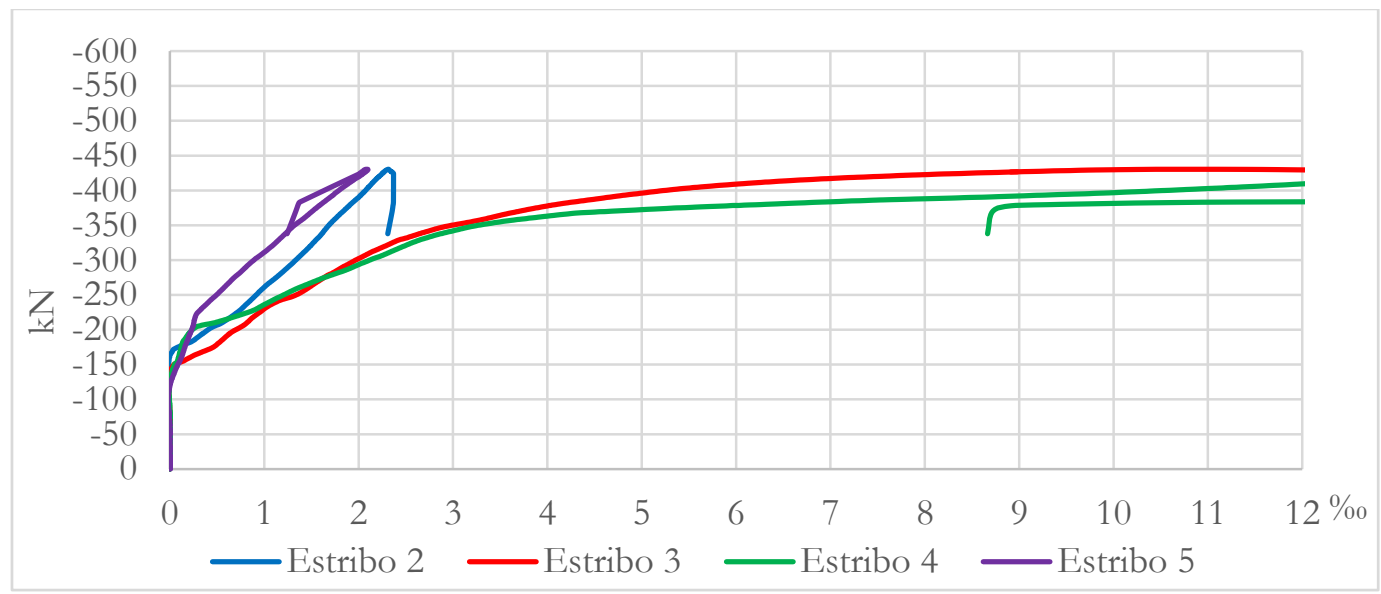

Gráfico 6.15 - Força x Deformação na armadura transversal - V90 SR 
$\mathrm{Na}$ viga sem reforço com concreto mais resistente V90 SR, é possível observar que as deformações nos estribos são praticamente nulas até o início das fissuras, quando os estribos passam a ser realmente solicitados, igualmente ao ocorrido nos estribos da viga V50 SR, porém com forças de início de fissuração maiores. Os estribos 3 e 4 da viga V90 SR apresentaram maiores deformações, obtendo escoamento próximo à força de $350 \mathrm{kN}$.

Na viga V90 CFRP somente foi possível medir a deformação no estribo 3, que apresentou deformação na força máxima de 5,40\%o, valor este bem inferior a 10,791\%o medido no mesmo estribo da viga sem reforço V90 SR. Essa redução da deformação do estribo indica que ocorre uma transferência da força cortante resistida inicialmente somente pelo estribo para os reforços CFRP, mesmo com maior força máxima.

$\mathrm{Na}$ viga V90 com carregamento prévio de 40\% somente as deformações no estribo 5 puderam ser medidas. Igualmente observados nas demais vigas reforçadas, quando comparadas suas deformações, com as das vigas sem reforço, ocorreram menos deformações.

Os estribos 5 e 3 da viga após carregamento prévio V90 70\% iniciaram as deformações juntamente com o início do carregamento e apresentaram deformações na força máxima de $1,869 \%$ e $3,627 \%$ respectivamente, valores inferiores aos da viga íntegra sem reforço V90 SR, mesmo com força máxima maior.

Realizando uma comparação entre as deformações no estribo 3 das vigas V90 SR, V90 CFRP e V90 70\%. As mesmas foram comparadas no Gráfico 6.16, nesta se observou a redução dos esforços nos estribos para as vigas reforçadas, onde, nas vigas com CFRP, ocorreram menores deformações, mesmo com o aumento da capacidade de carga da viga.

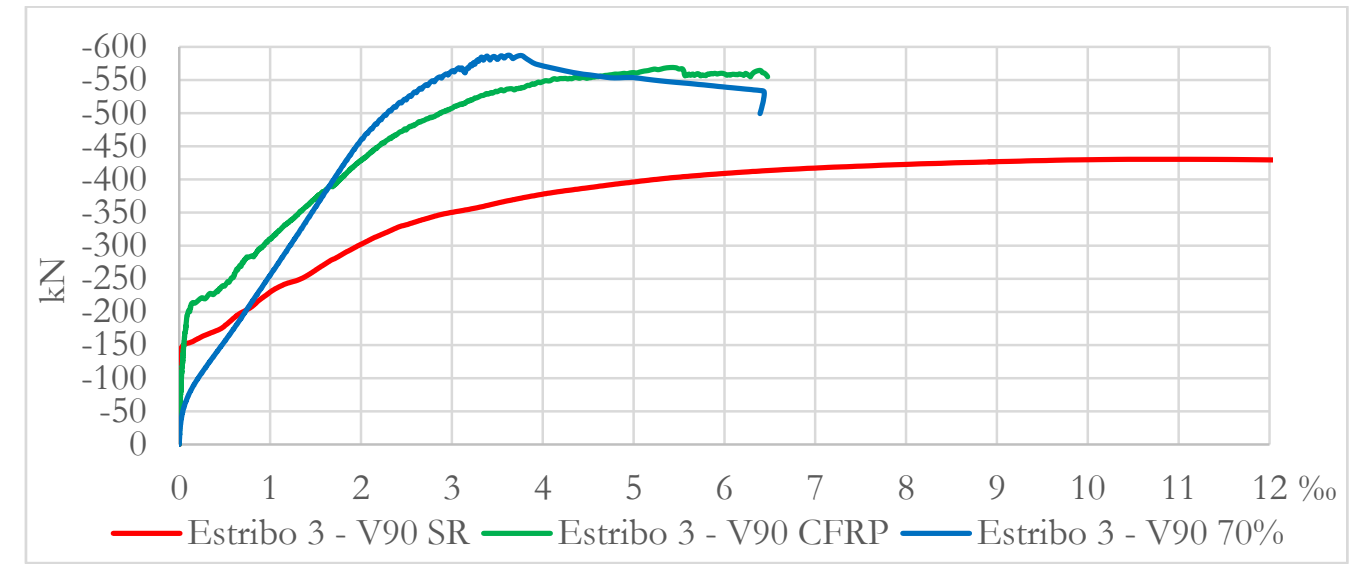

Gráfico 6.16 - Força x Deformação na armadura transversal - V90 estribo 3

Ao realizar uma comparação entre as deformações ocorridas em uma mesma força, em qualquer dos estribos de todas as vigas foi possível observar uma redução das deformações dos 
estribos quando a viga é reforçada com CFRP, confirmando a capacidade do reforço ao cisalhamento de reduzir as tensões nos estribos.

Quando comparados os mesmos estribos, entre vigas reforçadas com e sem carregamento prévio, as curvas força x deformação apresentam comportamento similar. Ocorrendo a principal diferença no início do carregamento, em que as com carregamento prévio apresentam deformações antes do início das fissuras do concreto, diferentemente das vigas íntegras.

\subsubsection{Reforço de CFRP}

Os laminados de CFRP foram introduzidos nas vigas como reforço ao cisalhamento, sendo posicionados conforme a Figura 6.11, já apresentada, com espaçamento igual aos estribos mas com inclinação de 45 graus. Os laminados foram posicionados unicamente para ampliar a resistência ao cisalhamento, absorvendo parte da força cortante que seria resistido pelos estribos e consequentemente aumentando a capacidade de carga das vigas, não sendo realizado aplicação de reforço à flexão nesta pesquisa.

A Tabela 6.11 apresenta a deformação dos Laminados de CFRP na força máxima das vigas. As vigas V50 SR e V90 SR não são apresentados, por não possuírem reforço.

Tabela 6.11 - Deformação no Laminados de CFRP

\begin{tabular}{|c|c|c|c|c|}
\hline & $\begin{array}{c}\begin{array}{c}\text { Laminado } 5 \\
(\% 0)\end{array} \\
\end{array}$ & $\begin{array}{c}\text { Laminado } 4 \\
(\% 0)\end{array}$ & $\begin{array}{c}\text { Laminado } 3 \\
(\%)\end{array}$ & $\begin{array}{c}\text { Laminado } 2 \\
(\% 0)\end{array}$ \\
\hline V50 CFRP & 6,991 & 4,939 & $\mathrm{x}$ & 3,526 \\
\hline V50 40\% & 5,765 & 5,300 & 4,796 & 2,869 \\
\hline V50 70\% & 5,453 & 5,343 & 5,647 & 4,630 \\
\hline V90 CFRP & 4,510 & 5,692 & 4,530 & 5,730 \\
\hline V90 40\% & 5,241 & 4,808 & 4,232 & 4,157 \\
\hline V90 70\% & 4,353 & 5,693 & 4,894 & 1,1575 \\
\hline
\end{tabular}

Observou-se que em todos os laminados de CFRP ocorreram deformações, indicando a capacidade de absorver esforços nas posições selecionadas. Os dados do laminado 3 da viga V50 CFRP não foram captados devido a problemas no cabo da mesa de aquisição de dados.

Nas vigas V50 ocorreu uma tendência de aumento da deformação dos laminados com a proximidade do local de aplicação das forças, sendo os laminados 5 os mais solicitados e os laminados 2 os menos solicitados em todas as vigas V50.

Nas vigas V90 ocorreu uma menor dispersão entre as deformações dos laminados de CFRP independentemente da posição do laminado. As vigas com concreto mais resistente apresentaram deformações na mesma ordem de grandeza dos laminados mais solicitados das vigas V50. Apenas o laminado 2 da viga V90 70\% apresentou valor discrepante dos demais. 
O Gráfico 6.17 apresenta as curvas força x deformação dos laminados da viga íntegra V50 CFRP. Nesta foi identificada a presença de pequenas deformações antes do início de fissuração do concreto, indicando que, diferentemente do ocorrido nos estribos, os laminados de CFRP resistem aos esforços desde o início do carregamento e não somente após a ocorrências das fissuras.

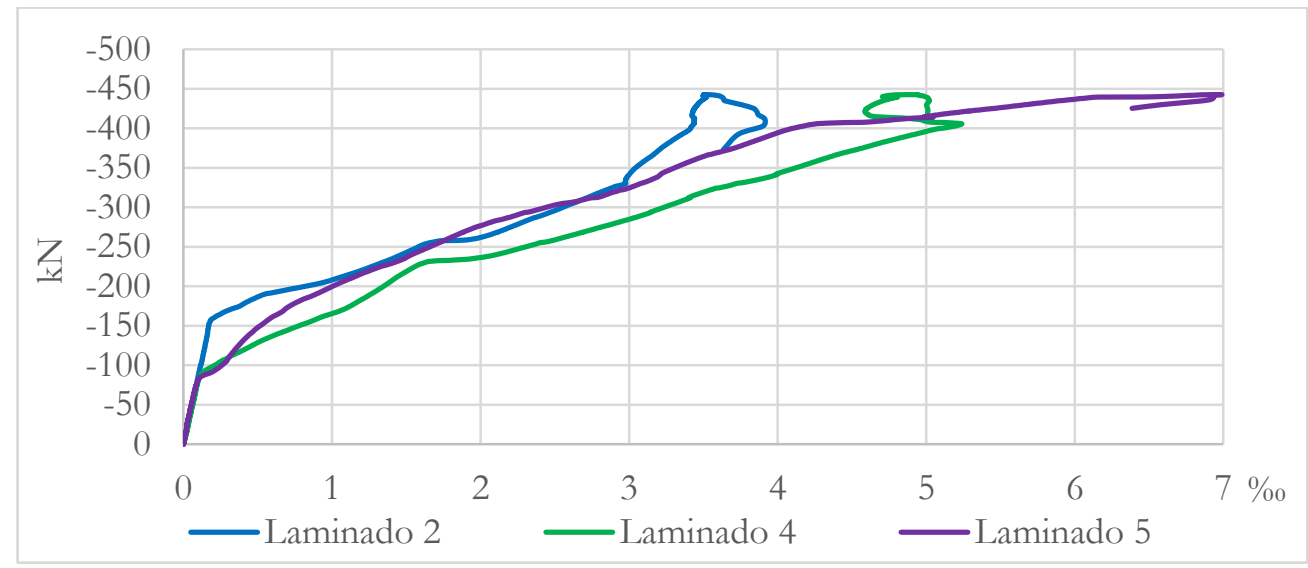

Gráfico 6.17 - Força x Deformação nos Laminados - V50 CFRP

$\mathrm{Na}$ viga V50 CFRP, o laminado 2 apresentou a menor deformação, o laminado 4 apresentou após a força de $400 \mathrm{kN}$, redução na deformação mesmo com o acréscimo de força, indicando fissuração na viga; que a partir desta força passou a solicitar o laminado 5 com maior intensidade. Este laminado apresentou a maior das deformações na força máxima, com 6,991\%o.

$\mathrm{Na}$ viga V50 40\%, os laminados apresentaram a mesma configuração ocorrida na viga V90 CFRP. Com o laminado 2 apresentando a menor deformação e o laminado 4 a maior. Indicando que o carregamento prévio também não influenciou na deformação dos laminados.

Já na Viga V50 70\% todos os laminados apresentaram deformações finais próximas, entre $4,510 \%$ e e 5,730\% , demostrando que as tensões na viga estavam distribuídas mais uniformemente. Apenas o laminado 5 apresentou acréscimo de deformação após a força última,, indicando um possível local de ruptura da viga (Gráfico 6.18).

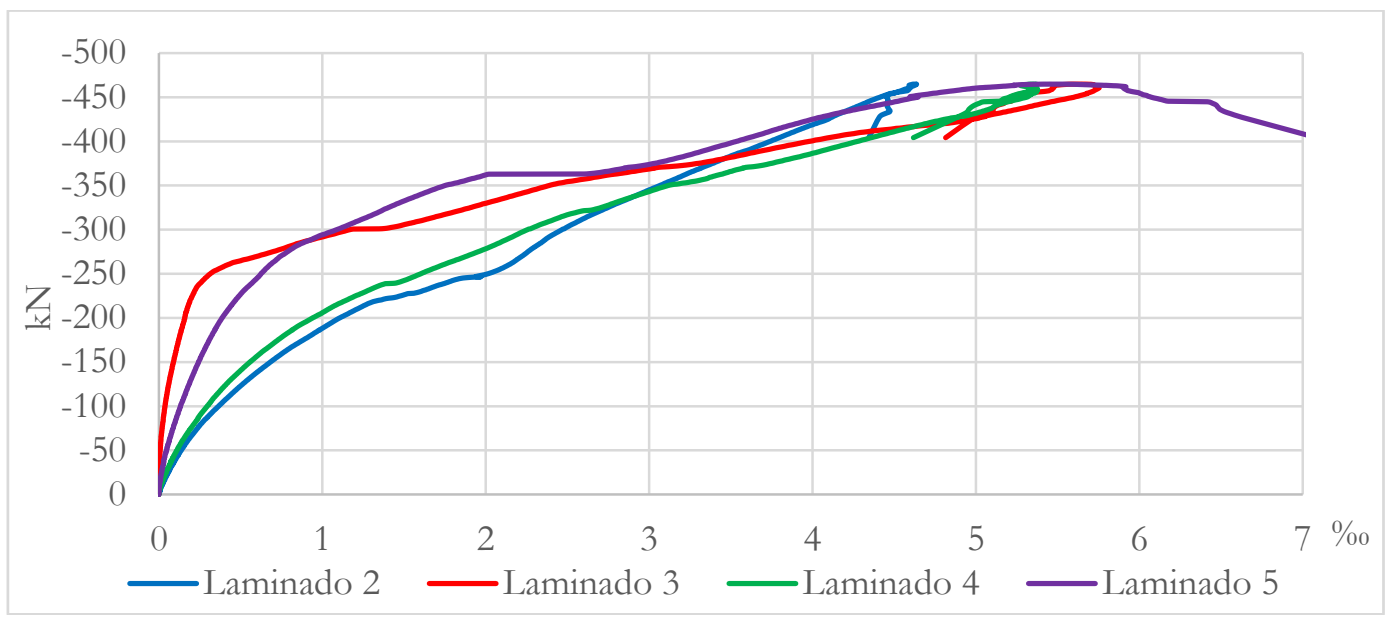

Gráfico 6.18 - Força x Deformação nos Laminados - V50 70\% 
Nas vigas reforçadas após carregamento prévio de V50 40\% e V50 70\% os laminados apresentaram maiores deformações no início do carregamento, tendo as deformações finais na mesma magnitude das deformações da viga íntegra V50 CFRP. Essa configuração indica que as fissuras iniciais das vigas apresentam uma maior transferência de força para o reforço inicialmente, mas que não reduzem a força máxima e a capacidade de acréscimo de resistência oriundas do reforço.

A deformação dos laminados da viga V90 CFRP são apresentadas no Gráfico 6.19, com o intuito de comparar com os resultados das vigas de menor resistência com as demais vigas V90 com carregamento prévio.

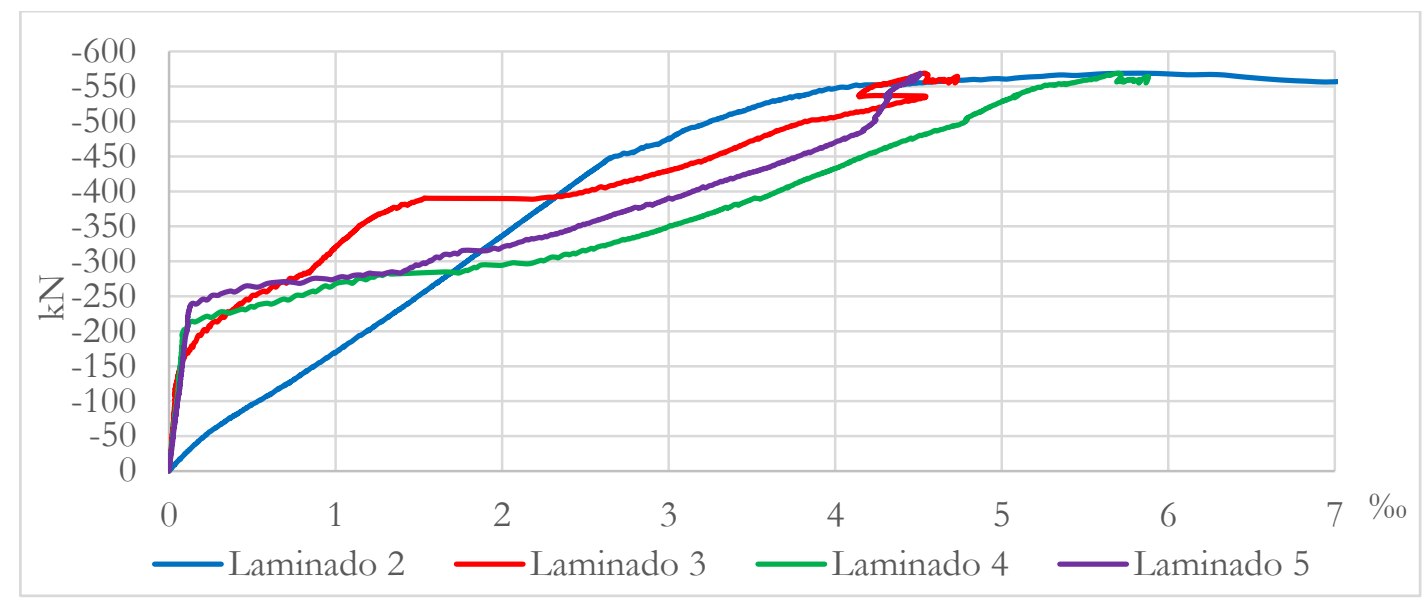

Gráfico 6.19 - Força x Deformação nos Laminados - V90 CFRP

$\mathrm{Na}$ viga V90 CFRP o laminado 2 apresentou curva força $\mathrm{x}$ deformação diferente dos demais reforços, iniciando uma elevada deformação desde o início do carregamento, como se houvesse uma fissura na região deste laminado. Em comparação com a viga V50 CFRP, suas deformações finais dos laminados foram mais homogêneas, e apresentaram a mesma magnitude.

$\mathrm{Na}$ viga reforçada após carregamento prévio V90 40\%, observou-se que os laminados apresentam curvas semelhantes entre si, apresentando menores deformações finais para os laminados 2 e 3 . As deformações na força máxima dos laminados também são semelhantes, entre 4,10\% e 5,20\%o. Após a ruptura, o laminado 3 apresenta acréscimo de deformação, indicando um possível local de fissura de ruptura.

Assim como ocorrido nas vigas com carregamento prévio V90 40\%, as vigas V90 70\% também apresentam curvas força x deslocamento semelhantes entre si, indicando que as vigas que sofreram carregamento prévio apresentam melhor distribuição das tensões de cisalhamento nas regiões reforçadas com CFRP (Gráfico 6.20). 


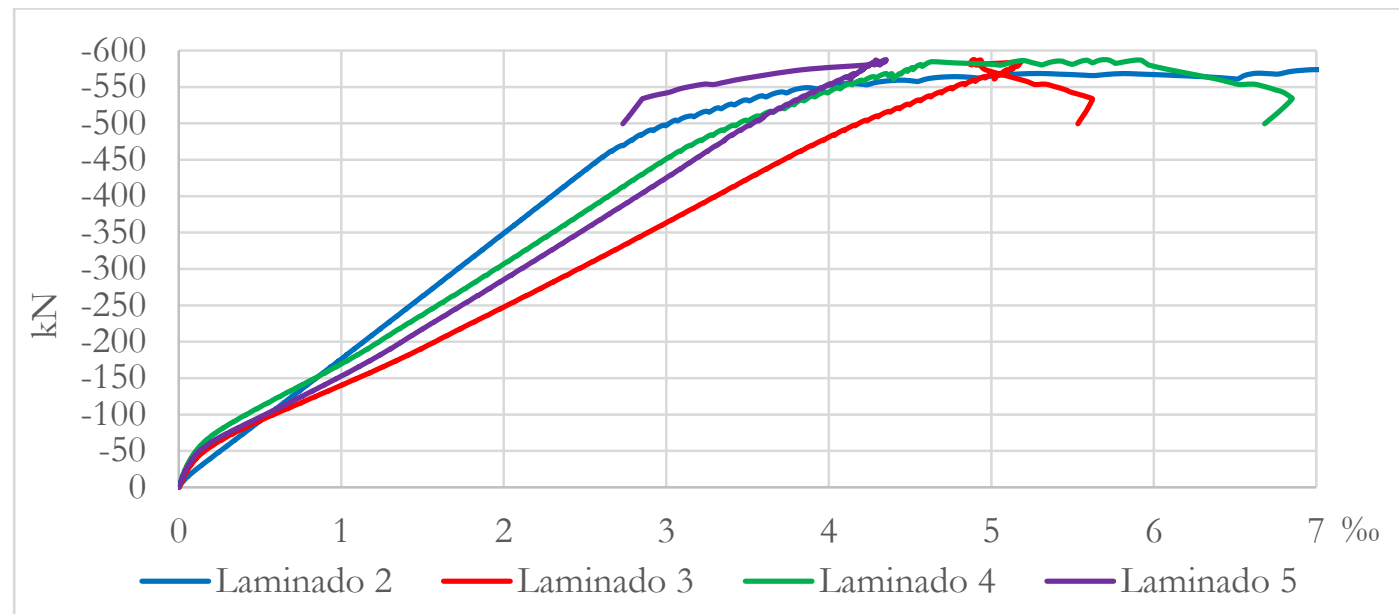

Gráfico 6.20 - Força x Deformação nos Laminados - V90 70\%

A viga V90 70\% teve a maior força máxima, nela ocorreram escoamentos das armaduras longitudinais, apresentando deformações elevadas para os laminados 2 e 4 na força máxima. O escoamento da armadura permitiu que a viga deformasse sem o acréscimo de força, assim influenciando nas deformações dos laminados, sem acréscimo de forças.

A deformação nos laminados de CFRP não permitiram identificar grandes diferenças entre as vigas, ocorrendo para a maioria dos casos uma menor deformação no laminado 2 e uma maior para os laminados 3 ou 4. A deformação dos laminados é função dos esforços absolvidos por eles na viga, sendo assim, a semelhança nos seus resultados indica que as tensões nas vigas não sofreram alterações nas forças após a fissuração do concreto.

\subsection{RESUMO DO CAPÍTULO}

Neste capitulo foram apresentados os resultados dos ensaios experimentais destrutivos para as vigas de concreto armado reforçadas ao cisalhamento com CFRP utilizando a técnica NSM.

Estes resultados foram utilizados para o dimensionamento das vigas, considerando a ruptura por flexão, cisalhamento e cisalhamento com reforço. Os concretos apresentaram resistências superiores ao dimensionado com 52MPa e $90 \mathrm{MPa}$, alterando consequentemente as forças máximas de ruptura das vigas.

As vigas foram ensaiadas com e sem reforços de CFRP, permitindo medir o acréscimo de força devido ao reforço. Para cada classe de viga (V50 e V90) foram reforçadas três vigas, sendo que duas sofreram carregamento prévio antes da Ruptura. Os resultados do efeito do carregamento prévio foram dispersos, onde as vigas com carregamento prévio de $40 \%$ apresentaram redução nas forças de ruptura e as vigas com carregamento prévio de 70\% apresentaram aumento em relação as vigas reforçadas íntegra. 
Todas as vigas apresentaram acréscimo de força devido ao reforço de CFRP, ocorrendo nas vigas V50 reforçadas, ruptura no cisalhamento, com destacamento do cobrimento de concreto com reforço do núcleo da viga, enquanto que as vigas V90 reforçadas apresentaram ruptura por flexão, com esmagamento do concreto comprimido. Em média, as vigas V50 apresentaram acréscimo na capacidade de carga de 43\% para as vigas V50 e de 32,1\% para as vigas V90.

Observou-se também que o sistema de reforço com laminados permitiu uma maior deformação final das vigas de forma proporcional ao acréscimo de carga. Quando comparado o deslocamento em uma mesma carga para todas as vigas, verificou-se que o sistema de reforço reduziu o deslocamento vertical para todas as vigas.

Foram ainda analisados os benefícios dos sistemas de reforço para as armaduras de cisalhamentos e as deformações nos laminados de CFRP em todas as vigas. Verificou-se que para uma mesma força as vigas com reforço de CFRP apresentaram redução nas tensões dos estribos.

$\mathrm{Na}$ análise da deformação dos laminados observou-se que o carregamento prévio alterou deformações no início do carregamento, mas que não alteram a força máxima e a deformação final dos laminados de CFRP. 


\section{APRESENTAÇÃO E ANÁLISE DE RESULTADOS DAS VIGAS - ENSAIOS NÃO DESTRUTIVOS}

Nos ensaios piloto desta pesquisa utilizando prismas de concreto, o estudo da variação da frequência natural para a observação de dano e reforço com ensaios não destrutivos não obteve grande êxito, sendo assim, buscou-se outros métodos de ensaios não destrutivos, com ênfase na análise de resultados utilizando acelerômetros piezoelétricos.

Para a análise de dano e reforço usando características dinâmicas foram selecionados sete formas de comparação entre os resultados, sendo elas: Variação das frequências naturais, Average Normalised Power Spectrum Density (ANPSD), Modos de vibração, modal assurance criterion (MAC), coordinate modal assurance criterion (COMAC), Diferença de Curvatura Modal (DCM) e Índice de dano (ID). Isso permitiu ainda observar a importância de cada método e a coerências entre seus resultados.

As vigas foram ensaiadas em cinco configurações, sendo elas: Íntegra, com Dano, com Ranhuras, Reforçada, após Ruptura. Apenas as vigas com carregamento prévio (V50 40\%, V50 70\%, V90 40\% e V90 70\%) apresentam todas as configurações de dano, enquanto que as vigas sem reforço (V50 SR e V90 SR) apresentam apenas as configurações Íntegra e após Ruptura.

Devido a uma demasiada quantidade de gráficos gerados na análise dos métodos de identificação de dado, em cada critério de avaliação somente foram apresentados alguns desses gráficos, servido como referências para as análises dos resultados. Todos os gráficos dos métodos de avaliação de dano que não são apresentados durante a análise de resultados, serão apresentados nos Apêndices.

\subsection{VARIAÇÃO DAS FREQUÊNCIAS NATURAIS E ANSPD}

O estudo da variação das frequências naturais permite identificar alterações no comportamento das estruturas, onde a alteração da rigidez influenciará nas frequências naturais. Alguns efeitos externos podem influenciar na frequência natural dos elementos, como a alteração da massa, condições de apoio, temperatura ambiente e até pequenos danos oriundos do transporte das vigas. Estes efeitos externos foram desconsiderados nas análises a seguir.

Em qualquer ensaio com o uso de acelerômetros, a retirada e recolocação na mesma posição pode gerar alguma variação nas frequências naturais e nos modos de vibração, mesmo com um rígido controle deste posicionamento. Neste estudo as vigas foram movimentadas em cada etapa de configuração de dano e os efeitos dessas movimentações nas variações das frequências 
naturais e dos modos de vibração foram desconsiderados, uma vez que as vigas, ao serem retiradas e recolocadas nos apoios, ocorreram pequenas mudanças de posição.

As frequências naturais foram coletadas em todas as etapas de danificação das vigas, permitido assim realizar uma comparação entre os estados danificados e a configuração íntegra, bem como comparar a similaridade destes danos entre as vigas.

A análise visual dos Average Normalised Power Spectrum Densities (ANPSD) das vigas nas diversas configurações de integridade permitem observar as variações ocorridas no Power Spectrum devido ao incremento de danos nesta viga, assim como a presença de novos picos intermediários e as dificuldades de definição das frequências naturais.

\subsubsection{Vigas V50}

A Tabela 7.1 apresenta as médias das frequências naturais das vigas V50 em todas as configurações, permitindo observar que o desvio padrão foi baixo para as configurações Íntegro, com Ranhura e com Reforço, havendo dispersão entre os resultados apenas após a Ruptura.

Tabela 7.1 - Média das frequências naturais das vigas V50

\begin{tabular}{c|c|c|c|c|c|c|c|c|c|c|c}
\hline F & \multicolumn{2}{c}{ Íntegro } & \multicolumn{3}{c}{ Ranhura } & \multicolumn{3}{c}{ Reforço } & \multicolumn{3}{c}{ Ruptura } \\
\hline & Média & C.V. & Média & $\Delta$ & C.V. & Média & $\Delta$ & C.V. & Média & $\Delta$ & C.V. \\
\hline $\mathbf{1}^{\mathbf{a}}$ & 318,0 & $2,3 \%$ & 302,9 & $-4,7 \%$ & $3,0 \%$ & 294,1 & $-7,5 \%$ & $4,8 \%$ & 277,2 & $-12,8 \%$ & $10,0 \%$ \\
\hline $\mathbf{2}^{\mathbf{a}}$ & 637,1 & $1,3 \%$ & 594,6 & $-6,7 \%$ & $1,7 \%$ & 613,3 & $-3,7 \%$ & $0,8 \%$ & 491,6 & $-22,8 \%$ & $9,1 \%$ \\
\hline $\mathbf{3}^{\mathbf{a}}$ & 1091,5 & $2,4 \%$ & 1009,8 & $-7,5 \%$ & $9,1 \%$ & 1013,7 & $-7,1 \%$ & $3,1 \%$ & 798,1 & $-26,9 \%$ & $21,9 \%$ \\
\hline $\mathbf{4}^{\mathbf{a}}$ & 1625,0 & $0,8 \%$ & 1520,3 & $-6,4 \%$ & $5,3 \%$ & 1520,3 & $-6,4 \%$ & $5,2 \%$ & 1285,3 & $-20,9 \%$ & $8,4 \%$ \\
\hline $\mathbf{5}^{\mathbf{a}}$ & 2174,5 & $0,6 \%$ & 2023,7 & $-6,9 \%$ & $4,9 \%$ & 2053,3 & $-5,6 \%$ & $2,9 \%$ & 1595,0 & $-26,6 \%$ & $10,9 \%$ \\
\hline
\end{tabular}

Observando a média das frequências naturais das vigas V50 após a Ranhura verificou-se uma redução dos valores da primeira a quinta frequências naturais, sendo o mesmo efeito observado nas configurações Reforço e Ruptura.

Após o Reforço, a média das frequências naturais continuaram menores que na configuração íntegra das vigas, mas quando comparadas com a configuração Ranhura houve aumento das médias da segundas, terceiras e quintas frequências, indicando que o reforço pode ser identificado em algumas frequências pelo simples método da variação das frequências naturais.

Após a ruptura, todas as frequências naturais reduziram muito, com maior variação no desvio padrão, principalmente na terceira frequência com coeficiente de variação de $21,9 \%$ e com redução da frequência natural em $26,9 \%$. 
Tendo como um dos objetivos desta pesquisa a identificação do dano e do reforço utilizando ensaios não destrutivos, realizou-se uma comparação da viga em configuração íntegra com as demais configurações de dano utilizando o método da variação das frequências naturais.

$\mathrm{Na}$ Tabela 7.2 são apresentadas as frequências naturais e a variação $(\Delta)$ das vigas V50 40\% e V50 70\% na configuração íntegra e após o carregamento prévio de 40\% e 70\% da força última respectivamente.

Tabela 7.2 - Frequências naturais das vigas V50 40\% e V50 70\% após Dano

\begin{tabular}{c|c|c|c|c|c|c}
\hline Freq. $\mathbf{~ ( H z ) ~}$ & \multicolumn{3}{c}{ V50 40\% } & \multicolumn{3}{c}{ V50 70\% } \\
\hline & Íntegra & Dano & $\Delta$ & Ítegra & Dano & $\Delta$ \\
\hline $\mathbf{1}^{\mathbf{a}}$ & 326,5 & 316,2 & $-3,2 \%$ & 316,2 & 316,2 & $0,0 \%$ \\
\hline $\mathbf{2}^{\mathbf{a}}$ & 642,5 & 607,4 & $-5,5 \%$ & 629,4 & 594,1 & $-5,6 \%$ \\
\hline $\mathbf{3}^{\mathbf{a}}$ & 1094 & 1044 & $-4,6 \%$ & 1060 & 1032 & $-2,6 \%$ \\
\hline $\mathbf{4}^{\mathbf{a}}$ & 1613 & 1591 & $-1,4 \%$ & 1638 & 1513 & $-7,6 \%$ \\
\hline $\mathbf{5}^{\mathbf{a}}$ & 2191 & 2110 & $-3,7 \%$ & 2163 & 2021 & $-6,6 \%$ \\
\hline
\end{tabular}

$\mathrm{Na}$ viga V50 40\% todas as frequências naturais apresentaram redução, permitindo assim identificar a presença de dano por este método, onde as variações não foram constantes, com reduções entre 1,4\% a 5,5\%. Em números absolutos as frequências naturais mais elevadas apresentam maiores diferenças, permitindo com maior facilmente identificar os danos nas vigas.

A viga V50 70\% após o carregamento prévio, também apresentou redução nas frequências naturais, com porcentagens semelhantes ao ocorrido com a viga V50 40\%, sendo que nesta a primeira frequência não teve redução após o dano. Devido a esta comparação entre as vigas com $40 \%$ e $70 \%$ de dano verificou-se que o método de variação de frequências naturais permite identificar a ocorrência de dano na estrutura, mas não permite quantificar o dano com pequenas variações de intensidades.

A Tabela 7.3 apresenta as frequências naturais e a variação $(\Delta)$ das vigas V50 CFRP, V50 40\% e V50 70\% comparando as configurações Íntegra e após terem sido realizadas as Ranhuras. A viga V50 CFRP não tem carregamento prévio, passando diretamente da configuração Íntegra para a configuração com Ranhuras, diferentemente das demais vigas comparadas nesta tabela.

Tabela 7.3 - Frequências naturais das vigas V50 CFRP, V50 40\% e V50 70\% após Ranhuras

\begin{tabular}{c|c|c|c|c|c|c|c|c|c}
\hline Freq. (Hz) & \multicolumn{3}{c}{ V50 CFRP } & \multicolumn{3}{c}{ V50 40\% } & \multicolumn{3}{c}{ V50 70\% } \\
\hline & Íntegra & Ranhura & $\Delta$ & Íntegro & Ranhura & $\Delta$ & Íntegra & Ranhura & $\Delta$ \\
\hline $\mathbf{1}^{\mathbf{a}}$ & 308,8 & 305,9 & $-0,9 \%$ & 326,5 & 310,3 & $-5,0 \%$ & 316,2 & 292,6 & $-7,5 \%$ \\
\hline $\mathbf{2}^{\mathbf{a}}$ & 630,9 & 605,9 & $-4,0 \%$ & 642,5 & 588,2 & $-8,5 \%$ & 629,4 & 589,7 & $-6,3 \%$ \\
\hline $\mathbf{3}^{\mathbf{a}}$ & 1124 & 1074 & $-4,4 \%$ & 1094 & 1051 & $-3,9 \%$ & 1060 & 904.4 & $-14,7 \%$ \\
\hline $\mathbf{4}^{\mathbf{a}}$ & 1615 & 1591 & $-1,5 \%$ & 1613 & 1538 & $-4,6 \%$ & 1638 & 1432 & $-12,6 \%$ \\
\hline $\mathbf{5}^{\mathbf{a}}$ & 2166 & 2096 & $-3,2 \%$ & 2191 & 2065 & $-5,8 \%$ & 2163 & 1910 & $-11,7 \%$ \\
\hline
\end{tabular}


Com o incremento das Ranhuras os valores da primeira à quinta frequência natural reduziriam, comportando-se de forma similar à configuração Dano. Na viga V50 CFRP, a variação foi menor que as demais devido esta viga não possuir carregamento prévio, apresentando variações entre 0,9 a 4,4\%, enquanto que nas vigas V50 70\% a redução da frequência foi mais acentuada, com valores de até $14,7 \%$.

Comparando dados entre as Tabela 7.2 e Tabela 7.3 verificou-se que a abertura de Ranhuras penalizou a rigidez das vigas com intensidade próxima ao carregamento prévio de $40 \%$, com reduções das frequências naturais entre $0,9 \%$ e 4,4\%, enquanto que o carregamento prévio obteve reduções entre 1,4\% e 5,5\%. Quando são realizadas Ranhuras nas vigas que já possuem carregamento prévio ocorre um incremento do dano, identificado por uma maior redução das frequências naturais.

A comparação entre configurações Íntegra e após o Reforço com CFRP entre as frequências naturais e a variação $(\Delta)$ das vigas V50 CFRP, V50 40\% e V50 70\% são apresentadas na Tabela 7.4.

Tabela 7.4 - Frequências naturais das vigas V50 CFRP, V50 40\% e V50 70\% após Reforço

\begin{tabular}{c|c|c|c|c|c|c|c|c|c}
\hline $\begin{array}{c}\text { Freq. } \\
\text { (Hz) }\end{array}$ & \multicolumn{3}{c}{ V50 CFRP } & \multicolumn{3}{c}{ V50 40\% } & \multicolumn{3}{c}{ V50 70\% } \\
\hline & Íntegro & Reforço & $\Delta$ & Íntegro & Reforço & $\Delta$ & Íntegro & Reforço & $\Delta$ \\
\hline $\mathbf{1}^{\mathbf{a}}$ & 308,8 & 280,9 & $-9,0 \%$ & 326,5 & 292,6 & $-10,4 \%$ & 316,2 & 308,8 & $-2,3 \%$ \\
\hline $\mathbf{2}^{\mathbf{a}}$ & 630,9 & 616,2 & $-2,3 \%$ & 642,5 & 616,2 & $-4,1 \%$ & 629,4 & 607,4 & $-3,5 \%$ \\
\hline $\mathbf{3}^{\mathbf{a}}$ & 1124 & 1049 & $-6,7 \%$ & 1094 & 988,2 & $-9,7 \%$ & 1060 & 1004 & $-5,3 \%$ \\
\hline $\mathbf{4}^{\mathbf{a}}$ & 1615 & 1579 & $-2,2 \%$ & 1613 & 1551 & $-3,8 \%$ & 1638 & 1431 & $-12,6 \%$ \\
\hline $\mathbf{5}^{\mathbf{a}}$ & 2166 & 2104 & $-2,9 \%$ & 2191 & 2069 & $-5,6 \%$ & 2163 & 1987 & $-8,1 \%$ \\
\hline
\end{tabular}

Os resultados da viga V50 CFRP demonstram que o processo de Reforço das vigas reduz suas frequências naturais, não sendo possível por este método determinar a eficiência ou até a presença do reforço usando o método de variação das frequências naturais diretamente entre a configuração Íntegra e Reforçada.

Observou-se ainda que nas vigas com carregamento prévio V50 40\% e V50 70\% também ocorreram reduções das frequências naturais, mas em alguns casos seus valores aumentaram em relação a configuração Ranhura, aproximando-se da configuração anterior (Dano).

$\mathrm{Na}$ Tabela 7.5 são apresentas as frequências naturais e a variação $(\Delta)$ de todas as vigas V50, comparando os resultados das configurações íntegra e após a Ruptura, sendo que a viga V50 SR não sofreu as etapas de Dano, Ranhura e Reforço, passando diretamente da configuração Íntegra para a configuração após Ruptura. 
Tabela 7.5 - Frequências naturais das vigas V50 após Ruptura

\begin{tabular}{c|c|c|c|c|c|c|c|c|c|c|c|c}
\hline F & \multicolumn{3}{c}{ V50 SR } & \multicolumn{3}{c}{ V50 CFRP } & \multicolumn{3}{c}{ V50 40\% } & \multicolumn{3}{c}{ V50 70\% } \\
\hline & Int. & Rup. & $\Delta$ & Int. & Rup. & $\Delta$ & Int. & Rup. & $\Delta$ & Int. & Rup. & $\Delta$ \\
\hline $\mathbf{1}^{\mathbf{a}}$ & 320,6 & 310,3 & $-3,2 \%$ & 308,8 & 277,9 & $-10,0 \%$ & 326,5 & 277,9 & $-14,9 \%$ & 316,2 & 242,6 & $-23,3 \%$ \\
\hline $\mathbf{2}^{\mathbf{a}}$ & 645,6 & 480,9 & $-25,5 \%$ & 630,9 & 458,8 & $-27,3 \%$ & 642,5 & 557,4 & $-13,2 \%$ & 629,4 & 469,1 & $-25,5 \%$ \\
\hline $\mathbf{3}^{\mathbf{a}}$ & 1088 & 942,6 & $-13,4 \%$ & 1124 & 677,9 & $-39,7 \%$ & 1094 & 952,9 & $-12,9 \%$ & 1060 & 619,1 & $-41,6 \%$ \\
\hline $\mathbf{4}^{\mathbf{a}}$ & 1634 & 1200 & $-26,6 \%$ & 1615 & 1376 & $-14,8 \%$ & 1613 & 1381 & $-14,4 \%$ & 1638 & 1184 & $-27,7 \%$ \\
\hline $\mathbf{5}^{\mathbf{a}}$ & 2178 & 1593 & $-26,9 \%$ & 2166 & 1593 & $-26,5 \%$ & 2191 & 1809 & $-17,4 \%$ & 2163 & 1385 & $-36,0 \%$ \\
\hline
\end{tabular}

A Ruptura reduziu as frequências naturais em todas as vigas, com resultados muito variados, com reduções entre 3,2\% e 39,7\% e em todos os casos maiores que as reduções nas etapas de Dano. A dispersão dos resultados nas vigas após a Ruptura depende principalmente do estado de fissuração final da viga, tendo em algumas destas vigas ocorrido destacamento de concreto, fissuras de destacamento da camada de concreto onde é inserido o CFRP, fissuras de cisalhamento e de flexão.

Observar que o ponto de ruptura é considerado na carga máxima resistida pela viga e que o carregamento foi mantido até que ocorresse uma redução de pelo menos $10 \%$ da carga máxima. A paralisação do ensaio foi realizada de maneira individual, onde em algumas vigas ocorrem rupturas mais bruscas, principalmente quando foi utilizado atuador com controle de força e não de deslocamento.

As vigas V50 apresentaram maiores variações nos gráficos ANSPD, principalmente nas configurações Reforço e Ruptura. Com o intuito de fornecer uma visualização geral do Power Spectrum das vigas V50, são apresentadas os ANPSD (Gráfico 7.1 ao Gráfico 7.5) de todas as configurações da viga V50 40\%. Estes possibilitam a visualização da magnitude das frequências naturais em cada configuração da viga. Os demais gráficos dos ANSPD, nas várias vigas e configurações que não foram demonstrados nesse capitulo, são apresentados no Apêndice C.

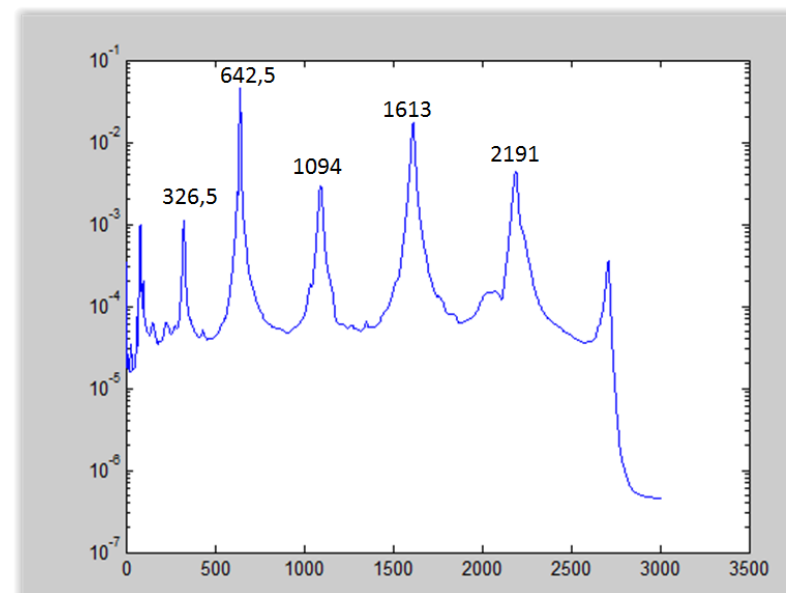

Gráfico 7.1 - ANPSD V50 40\% - Íntegro (Hz) 


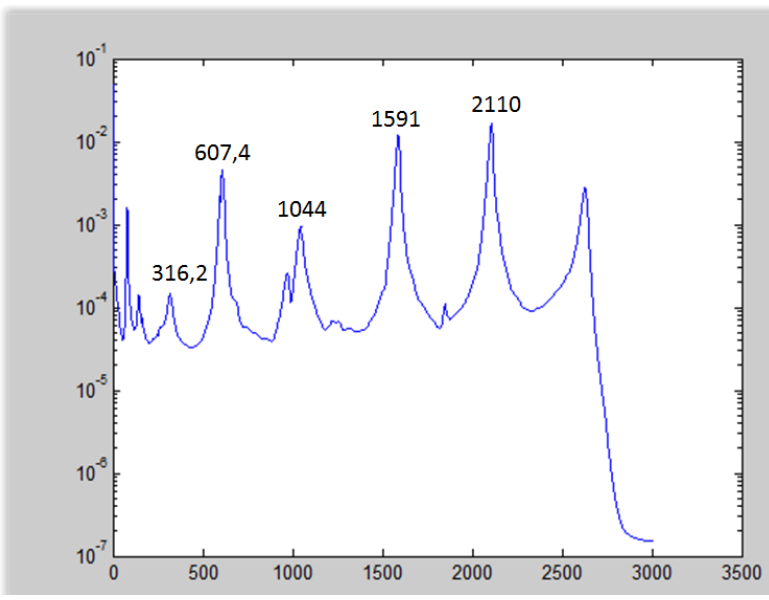

Gráfico 7.2 - ANPSD V50 40\% - Dano (Hz)
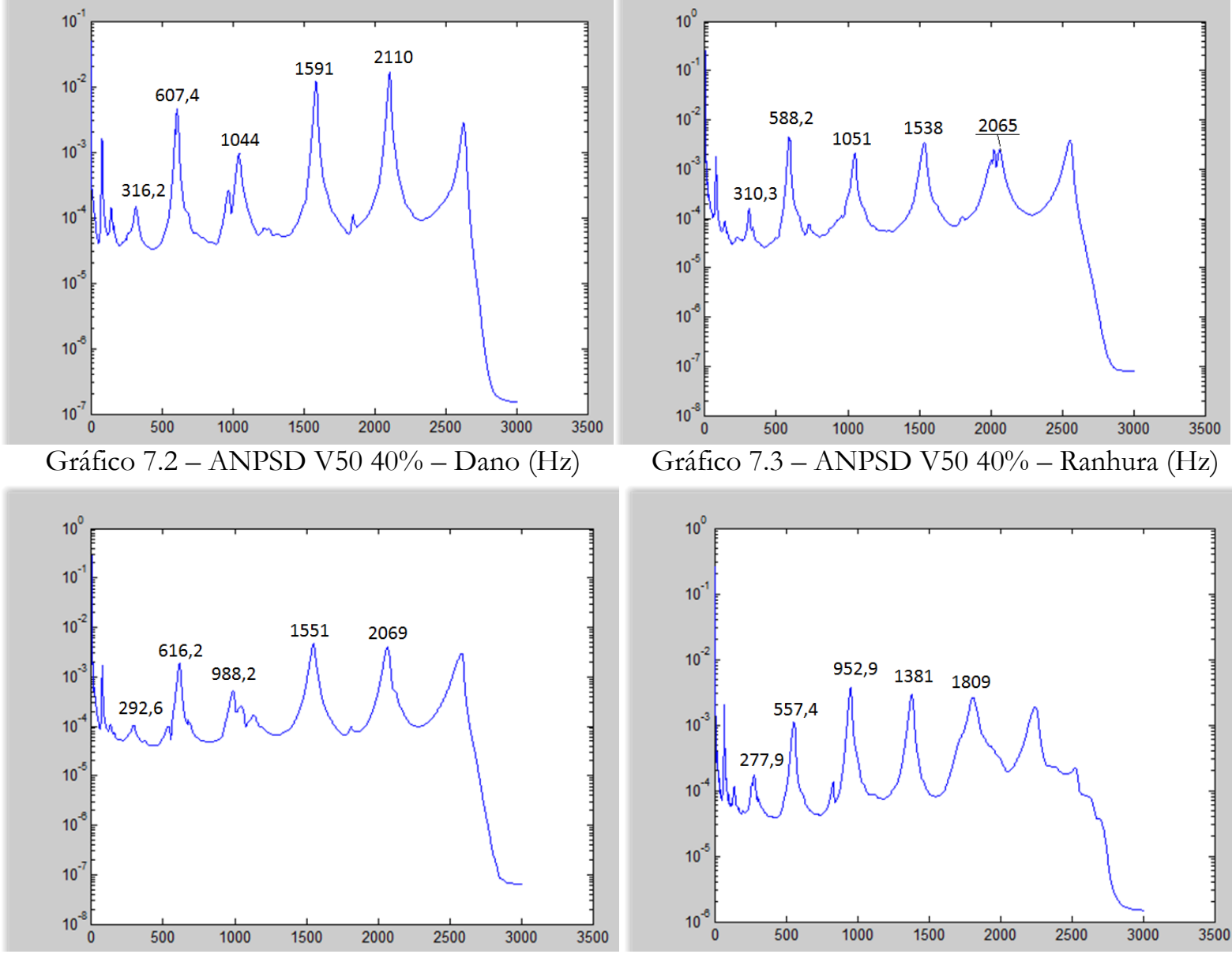

Gráfico 7.3 - ANPSD V50 40\% - Ranhura (Hz)

Gráfico 7.4 - ANPSD V50 40\% - Reforço (Hz)

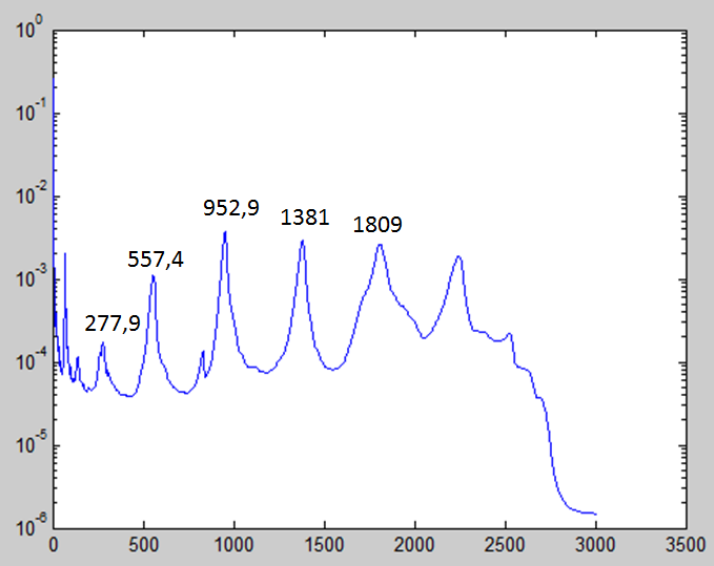

Gráfico 7.5 - ANPSD V50 40\% - Ruptura (Hz)

Nesta viga o gráfico da ANPSD na configuração Íntegra apresenta picos bem definidos para as cinco primeiras frequências naturais flexionais da viga, verificando que com a progressividade do dano além da redução das frequências naturais ocorre redução da magnitude dos picos, principalmente na primeira frequência natural, passando de $10^{-3}$ na configuração Íntegra para $2 \times 10^{-4}$ nas demais configurações danificadas.

Além disso, o início de pequenos picos intermediários que não atrapalharam a definição das frequências naturais foram percebidos. O método permitiu identificar uma redução da rigidez da viga, mesmo com pequeno dano causado pelo carregamento prévio.

No ensaio da viga com Reforço, ocorreu acréscimo nos valores de algumas frequências, neste caso da segunda, quarta e quinta frequência natural. Aumento em apenas algumas das frequências naturais não nos permite afirmar a capacidade de identificar o Reforço pela simples visualização do ANPSD, pois este aumento não ocorreu na mesma frequência em todas as vigas. Observou-se também dificuldade de definição da terceira frequência natural, que apresentou três picos, sendo o primeiro destes o modo de vibração correspondente. 
Nesta viga, após a Ruptura, as frequências naturais não apresentaram dificuldades de identificação, diferentemente do observado nas outras vigas, onde na configuração Ruptura o ANSPD apresentou muitos picos intermediários. As frequências naturais após a Ruptura reduziram significantemente, identificando uma grande redução da rigidez, principalmente a terceira e quarta frequência.

Na viga V50 SR, por exemplo, os gráficos da ANSPD na configuração Ruptura ocorrem picos de frequência que não representam as frequências naturais flexionais, necessitando para a sua identificação a visualização dos modos de vibração (Gráfico 7.6 e Gráfico 7.7).

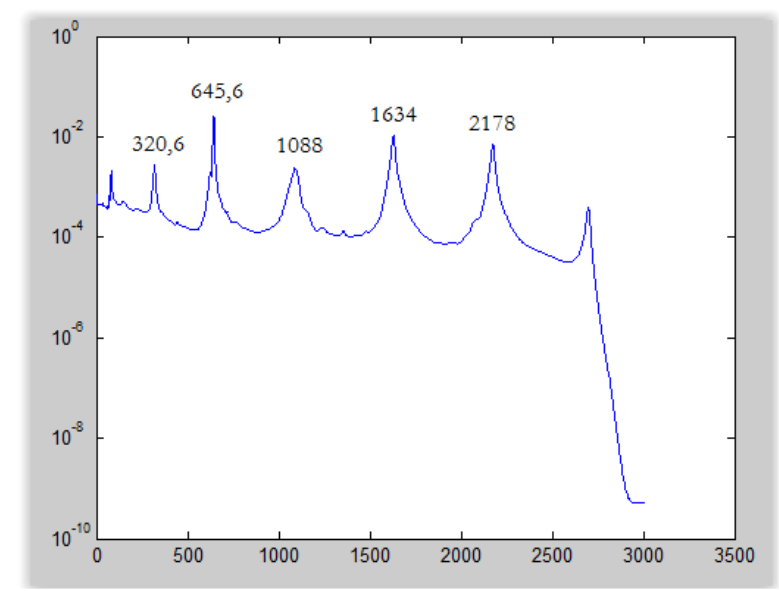

Gráfico 7.6 - ANPSD V50 SR - Íntegro $(\mathrm{Hz})$

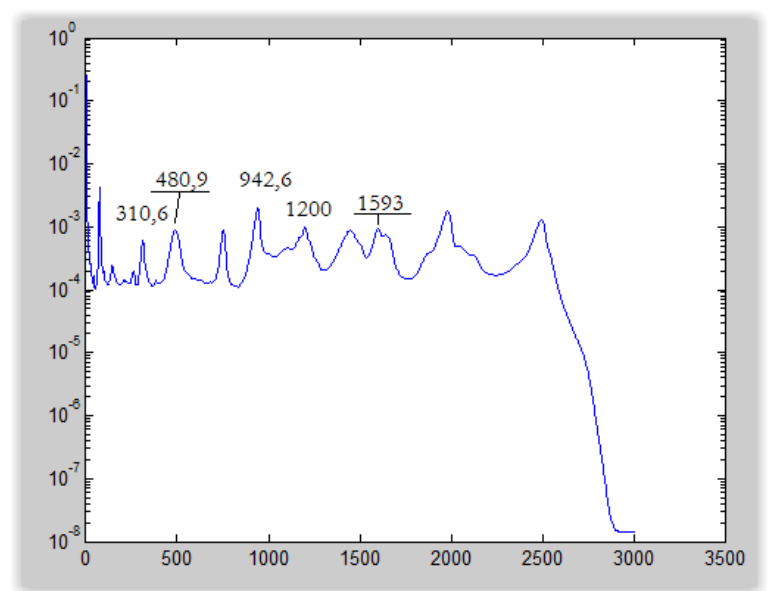

Gráfico 7.7 - ANPSD V50 SR - Ruptura $(\mathrm{Hz})$

$\mathrm{Na}$ viga V50 CFRP os gráficos do ANPSD apresentaram pequenas variações com redução no pico da primeira frequência natural e com dificuldades na identificação da terceira frequência natural, em todas as configurações. Após a ruptura, o ANPSD apresentou picos menores e com vários picos intermediários dificultando a identificação das frequências naturais da viga. Os valores das frequências reduziram significativamente demonstrando que este método permite identificar elevados danos nas estruturas.

De maneira não usual a viga V50 70\% apresentou quatro picos na terceira frequência natural na configuração Íntegra, sendo identificado o segundo destes picos para frequência natural correspondente, as demais frequências foram facilmente identificadas não apresentando interferências. (Gráfico 7.8) 


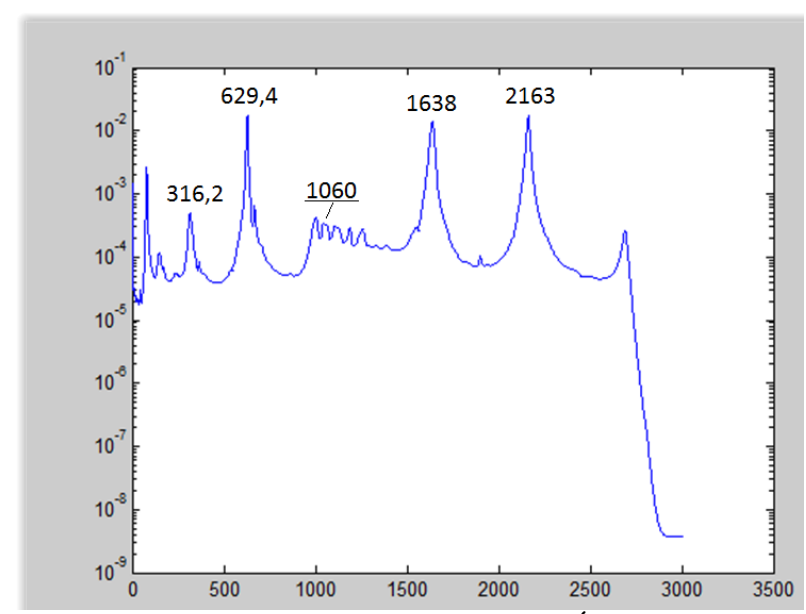

Gráfico 7.8 - ANPSD V50 70\% - Íntegro (Hz)

$\mathrm{Na}$ configuração Dano verificou-se redução das frequências naturais com maior intensidade que na viga V50 40\%, com exceção da primeira frequência onde não houve redução. Além da redução da magnitude dos picos das frequências observou-se novamente o início de pequenos picos intermediários. Novamente o método demostrou capacidade de identificação da presença de dano na viga.

Na viga V50 70\%, após a Ruptura houve extrema dificuldade de definição das frequências naturais, pois o ANPSD apresenta muitos picos intermediários e de baixas magnitudes, as definições da terceira e quarta frequência flexionais foram realizadas em função dos modos de vibração. É importante explicar que existe grande dificuldade de obtenção das frequências naturais e dos modos de vibração em as vigas na configuração Ruptura, uma vez que ocorrem grandes fissuras e destacamento de concreto, como pode ser observado na Figura 7.1.

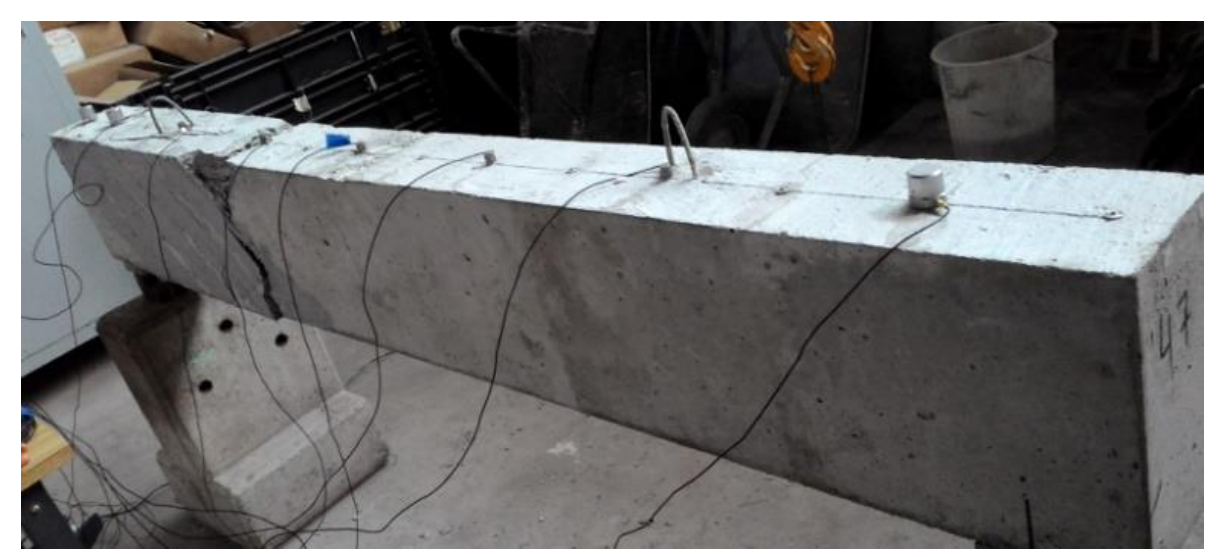

Figura 7.1 - Fissuração da viga V50 70\%

Em todas as configurações da viga foi possível identificar alterações nos ANSPD, com reduções de pico e magnitude das frequências naturais. Este método permitiu identificar alterações na rigidez das vigas em cada etapa de dano e em uma comparação direta identificar o acréscimo deste dano. 
Nas vigas V50 a análise dos ANSPD permitiram identificar a presença do Reforço de CFRP nas vigas reforçadas, mas ocorrendo aumento de rigidez quando comparados com a configuração Ranhura e somente em algumas das frequências naturais. As baixas alterações explicitadas não permitem identificar com clareza a presença do reforço de CFRP por este método de identificação.

\subsubsection{Vigas V90}

Nas vigas V90, as médias e a variação $(\Delta)$ entre as configurações Íntegra, Ranhura, Reforço e Ruptura são apresentadas na Tabela 7.6.

Tabela 7.6 - Média das frequências naturais das vigas V90

\begin{tabular}{c|c|c|c|c|c|c|c|c|c|c|c}
\hline F & \multicolumn{2}{c}{ Íntegra } & \multicolumn{3}{c}{ Ranhura } & \multicolumn{3}{c}{ Reforço } & \multicolumn{3}{c}{ Ruptura } \\
\hline & Média & C.V. & Média & $\Delta$ & C.V. & Média & $\Delta$ & C.V. & Média & $\Delta$ & C.V. \\
\hline $\mathbf{1}^{\mathbf{a}}$ & 337,1 & $3,5 \%$ & 314,2 & $-6,8 \%$ & $3,9 \%$ & 311,8 & $-7,5 \%$ & $2,2 \%$ & 278,5 & $-17,4 \%$ & $6,1 \%$ \\
\hline $\mathbf{2}^{\mathbf{a}}$ & 654,1 & $1,0 \%$ & 626,0 & $-4,3 \%$ & $2,1 \%$ & 631,4 & $-3,5 \%$ & $4,4 \%$ & 560,3 & $-14,3 \%$ & $11,8 \%$ \\
\hline $\mathbf{3}^{\mathbf{a}}$ & 1145 & $5,3 \%$ & 1082 & $-5,5 \%$ & $1,2 \%$ & 1128 & $-1,5 \%$ & $4,2 \%$ & 952 & $-16,9 \%$ & $14,2 \%$ \\
\hline $\mathbf{4}^{\mathbf{a}}$ & 1700 & $0,4 \%$ & 1626 & $-4,3 \%$ & $2,4 \%$ & 1635 & $-3,8 \%$ & $2,9 \%$ & 1405 & $-17,4 \%$ & $12,1 \%$ \\
\hline $\mathbf{5}^{\mathbf{a}}$ & 2251 & $0,9 \%$ & 2168 & $-3,7 \%$ & $2,3 \%$ & 2192 & $-2,6 \%$ & $2,5 \%$ & 1858 & $-17,4 \%$ & $12,3 \%$ \\
\hline
\end{tabular}

As médias das frequências naturais na configuração Íntegra das vigas V90 foram maiores que as das vigas V50 para todos os modos de vibração, demonstrando que o método permite identificar o acréscimo de rigidez proporcionado devido ao aumento da resistência do concreto.

Em todas as etapas de danificação das vigas houve redução das médias das frequências naturais, sendo as variações da primeira a quinta frequência mais homogênea que nas vigas V50. Ocorrendo menores reduções na configuração Ranhura e maiores na configuração Ruptura, com desvio padrão dos resultados, elevado apenas na configuração Ruptura.

Quando comparadas com a configuração Ranhura, o Reforço permitiu um aumento da segunda a quinta frequência natural, mas com valores inferiores a viga Íntegra, efeito semelhante ao observado nas vigas V50.

Observou-se aqui a capacidade de um pequeno acréscimo nas frequências naturais devido ao sistema de reforço, na mesma magnitude da redução causadas pelas ranhuras necessárias para inserir estes reforços, daí a impossibilidade de identificar a ocorrência de reforço por este método.

As frequências naturais e a variação $(\Delta)$ entre as vigas V90 40\% e V90 70\% na configuração íntegra e após o carregamento prévio de 40\% e 70\% são apresentadas na Tabela 7.7. 
Tabela 7.7 - Frequências naturais das vigas V90 40\% e V90 70\% após Dano

\begin{tabular}{c|c|c|c|c|c|c}
\hline Freq. (Hz) & \multicolumn{3}{c}{ V90 40\% } & \multicolumn{3}{c}{ V90 70\% } \\
\hline & Íntegro & Dano & $\Delta$ & Íntegro & Dano & $\Delta$ \\
\hline $\mathbf{1}^{\mathbf{a}}$ & 352,9 & 325,0 & $-7.9 \%$ & 332,4 & 307,4 & $-7,5 \%$ \\
\hline $\mathbf{2}^{\mathbf{a}}$ & 663,2 & 648,5 & $-2.2 \%$ & 651,5 & 611,8 & $-6,1 \%$ \\
\hline $\mathbf{3}^{\mathbf{a}}$ & 1234 & 1100 & $-10,9 \%$ & 1128 & 1076 & $-4,6 \%$ \\
\hline $\mathbf{4}^{\mathbf{a}}$ & 1704 & 1647 & $-3,3 \%$ & 1706 & 1621 & $-5,0 \%$ \\
\hline $\mathbf{5}^{\mathbf{a}}$ & 2263 & 2200 & $-2,8 \%$ & 2263 & 2160 & $-4,6 \%$ \\
\hline
\end{tabular}

Ao comparar as frequências naturais após um carregamento prévio, a Viga V90 40\% apresentou grande variação, principalmente na terceira frequência natural com redução de 10,9\%. A viga V90 70\% apesar do maior carregamento prévio apresentou variações de frequência com menores dispersões. Foi possível observar que não ocorreram grandes distinções entre as variações das vigas com carregamento prévio de $40 \%$ ou $70 \%$, impossibilitando quantificar por este método a diferença dos danos causados pelos diferentes carregamentos prévios.

A Tabela 7.8 apresenta as frequências naturais e a variação $(\Delta)$ das vigas V90 CFRP, V90 40\% e V90 70\% comparando as configurações Íntegra e após terem sido realizadas as Ranhuras.

Tabela 7.8 - Frequências naturais das vigas V90 CFRP, V90 40\% e V90 70\% após Ranhuras

\begin{tabular}{c|c|c|c|c|c|c|c|c|c}
\hline Freq. (Hz) & \multicolumn{3}{c}{ V90 CFRP } & \multicolumn{3}{c}{ V90 40\% } & \multicolumn{3}{c}{ V90 70\% } \\
\hline & Íntegro & Ranhura & $\Delta$ & Íntegro & Ranhura & $\Delta$ & Íntegro & Ranhura & $\Delta$ \\
\hline $\mathbf{1}^{\mathbf{a}}$ & 338,2 & 322,1 & $-4,8 \%$ & 352,9 & 320,6 & $-9,2 \%$ & 332,4 & 300,0 & $-9,7 \%$ \\
\hline $\mathbf{2}^{\mathbf{a}}$ & 654,4 & 641,2 & $-2,0 \%$ & 663,2 & 620,6 & $-6,4 \%$ & 651,5 & 616,2 & $-5,4 \%$ \\
\hline $\mathbf{3}^{\mathbf{a}}$ & 1125 & 1082 & $-3,8 \%$ & 1234 & 1096 & $-11,2 \%$ & 1128 & 1069 & $-5,2 \%$ \\
\hline $\mathbf{4}^{\mathbf{a}}$ & 1693 & 1671 & $-1,3 \%$ & 1704 & 1610 & $-5,5 \%$ & 1706 & 1599 & $-6,3 \%$ \\
\hline $\mathbf{5}^{\mathbf{a}}$ & 2257 & 2222 & $-1,6 \%$ & 2263 & 2159 & $-4,6 \%$ & 2263 & 2125 & $-6,1 \%$ \\
\hline
\end{tabular}

Nas vigas V90 pôde-se identificar que os efeitos das Ranhuras reduziram as frequências naturais para todos os casos, apresentando maior variação na terceira frequência da viga V90 40\%, a mesma em que ocorreu maior redução devido ao Dano. As menores variações de frequência ocorreram na viga V90 CFRP pois a mesma não possui carregamento prévio.

Comparando dados entre a Tabela 7.7 e Tabela 7.8 verificou-se que a redução da rigidez causada pela abertura de Ranhuras nas vigas V90 foram inferiores ao dano causado pelo carregamento prévio, diferentemente do ocorrido nas vigas V50. Permitindo ainda observar uma ampliação na redução da rigidez ao inserir Ranhuras nas vigas que já possuíam carregamento prévio.

A Tabela 7.9 apresenta a comparação entre configurações Íntegra e após o Reforço com CFRP das frequências naturais e da variação $(\Delta)$ das vigas V50 CFRP, V50 40\% e V50 70\%. 
Tabela 7.9 - Frequências naturais das vigas V90 CFRP, V90 40\% e V90 70\% após Reforço

\begin{tabular}{c|c|c|c|c|c|c|c|c|c}
\hline $\begin{array}{c}\text { Freq. } \\
\text { (Hz) }\end{array}$ & \multicolumn{3}{c}{ V90 CFRP } & \multicolumn{3}{c}{ V90 40\% } & \multicolumn{3}{c}{ V90 70\% } \\
\hline & Íntegro & Reforço & $\Delta$ & Íntegro & Reforço & $\Delta$ & Íntegro & Reforço & $\Delta$ \\
\hline $\mathbf{1}^{\mathbf{a}}$ & 338,2 & 305,9 & $-9,6 \%$ & 352,9 & 319,1 & $-9,6 \%$ & 332,4 & 310,3 & $-6,6 \%$ \\
\hline $\mathbf{2}^{\mathbf{a}}$ & 654,4 & 663,2 & $1,3 \%$ & 663,2 & 616,2 & $-7,1 \%$ & 651,5 & 614,7 & $-5,6 \%$ \\
\hline $\mathbf{3}^{\mathbf{a}}$ & 1125 & 1181 & $5,0 \%$ & 1234 & 1091 & $-11,6 \%$ & 1128 & 1113 & $-1,3 \%$ \\
\hline $\mathbf{4}^{\mathbf{a}}$ & 1693 & 1690 & $-0,2 \%$ & 1704 & 1615 & $-5,2 \%$ & 1706 & 1600 & $-6,2 \%$ \\
\hline $\mathbf{5}^{\mathbf{a}}$ & 2257 & 2253 & $-0,2 \%$ & 2263 & 2178 & $-3,8 \%$ & 2263 & 2146 & $-5,2 \%$ \\
\hline
\end{tabular}

A viga V90 CFRP apresenta aumento na segunda e terceira frequência natural, permitindo identificar a melhora devido ao reforço. Esse efeito foi efetivamente identificado apenas nesta viga, o que não nos permite validar a qualidade do método, ainda porque o aumento ocorreu em algumas das frequências naturais.

As vigas com carregamento prévio V90 40\% e V90 70\% apresentaram redução das frequências naturais em todos os modos de vibração, ocorrendo para alguns casos, aumento em relação a configuração Ranhura e assim como nas vigas V50 aproximando seus valores aos das vigas com a configuração Dano.

O aumento das frequências naturais observado apenas em relação a configuração Ranhura cria um problema para a identificação do sistema de reforço em estruturas em real utilização, pois necessita da coleta de dados no meio da aplicação dos sistemas de reforço, quando são realizadas as Ranhuras, além da coleta de dados nos estados inicial e após o reforço da estrutura.

$\mathrm{Na}$ Tabela 7.10 são apresentas as frequências naturais e a variação $(\Delta)$ de todas as vigas V90, comparando os resultados das configurações íntegra e Ruptura.

Tabela 7.10 - Frequências naturais das vigas V90 após Ruptura

\begin{tabular}{c|c|c|c|c|c|c|c|c|c|c|c|c}
\hline F & \multicolumn{3}{c}{ V90 SR } & \multicolumn{3}{c}{ V90 CFRP } & \multicolumn{3}{c}{ V90 40\% } & \multicolumn{3}{c}{ V90 70\% } \\
\hline & Int. & Rup. & $\Delta$ & Int. & Rup. & $\Delta$ & Int. & Rup. & $\Delta$ & Int. & Rup. & $\Delta$ \\
\hline $\mathbf{1}^{\mathbf{a}}$ & 325 & 307,4 & $-5,4 \%$ & 338,2 & 272,1 & $-19,5 \%$ & 352,9 & 272,1 & $-22,9 \%$ & 332,4 & 291,2 & $-12,4 \%$ \\
\hline $\mathbf{2}^{\mathbf{a}}$ & 647 & 494,1 & $-23,6 \%$ & 654,4 & 583,8 & $-10,8 \%$ & 663,2 & 544,1 & $-18,0 \%$ & 651,5 & 552,9 & $-15,1 \%$ \\
\hline $\mathbf{3}^{\mathbf{a}}$ & 1094 & 929,4 & $-15,0 \%$ & 1125 & 958,8 & $-14,8 \%$ & 1234 & 964,7 & $-21,8 \%$ & 1128 & 933,2 & $-17,3 \%$ \\
\hline $\mathbf{4}^{\mathbf{a}}$ & 1697 & 1307 & $-23,0 \%$ & 1693 & 1406 & $-17,0 \%$ & 1704 & 1365 & $-19,9 \%$ & 1706 & 1444 & $-15,4 \%$ \\
\hline $\mathbf{5}^{\mathbf{a}}$ & 2221 & 1900 & $-14,5 \%$ & 2257 & 1859 & $-17,6 \%$ & 2263 & 1835 & $-18,9 \%$ & 2263 & 1882 & $-16,8 \%$ \\
\hline
\end{tabular}

Após a Ruptura, as frequências naturais de todas as vigas reduziram muito, com variação de até $23,6 \%$, tendo a viga V90 SR maior dispersão de resultados que as vigas reforçadas com CFRP. Este efeito de dispersão dos resultados pode ter ocorrido pelo diferente atuador de força utilizado no ensaio de ruptura das vigas V90 SR, onde nas vigas V90 com reforço foi necessário a troca do atuador de força com capacidade maior que $500 \mathrm{kN}$ e com controle de força. 
No capítulo fissuras e forma de ruptura observou-se uma alteração na forma de ruptura ao acrescentar os sistemas de reforço de CFRP nas vigas com C90, passando do cisalhamento pelo destacamento de concerto envolto pelos laminados para uma ruptura por flexão ocorrendo esmagamento do concreto comprimido. Desta forma as fissuras ocorridas nas vigas V90 com reforço são diferentes das identificadas nas vigas V50 com reforço influenciando de maneira diferente a rigidez das vigas.

Como na viga V90 SR ocorreu ruptura por cisalhamento, nela observou-se no ANSPD grande redução, com vários picos intermediários, igualmente ocorrido na viga V50 SR.

Já nas vigas reforçadas com CFRP os ANSPD apresentaram uma configuração mais nítida, mesmo na configuração ruptura. Para ilustra os ANSPD das vigas V90 são apresentados do Gráfico 7.9 ao Gráfico 7.13 referentes a viga V90 40\%.

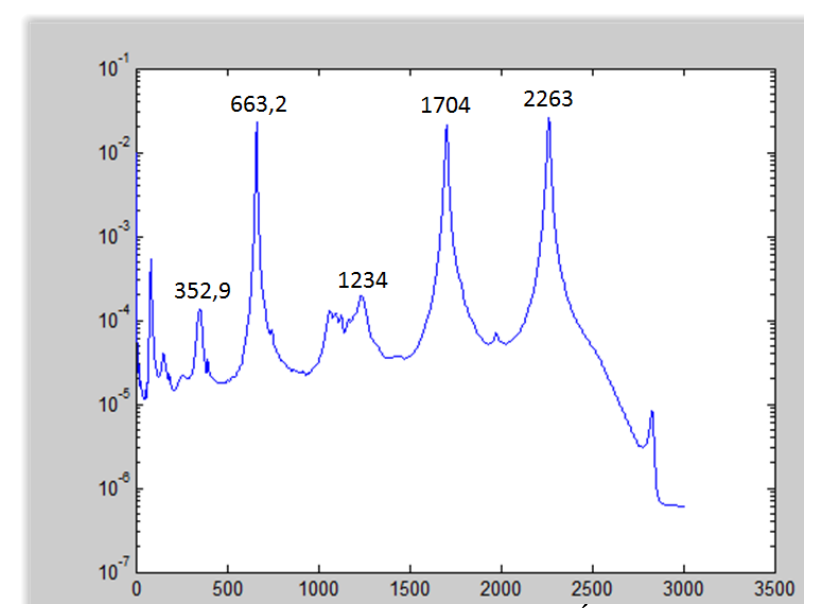

Gráfico 7.9 - ANPSD V90 40\% - Íntegro (Hz)

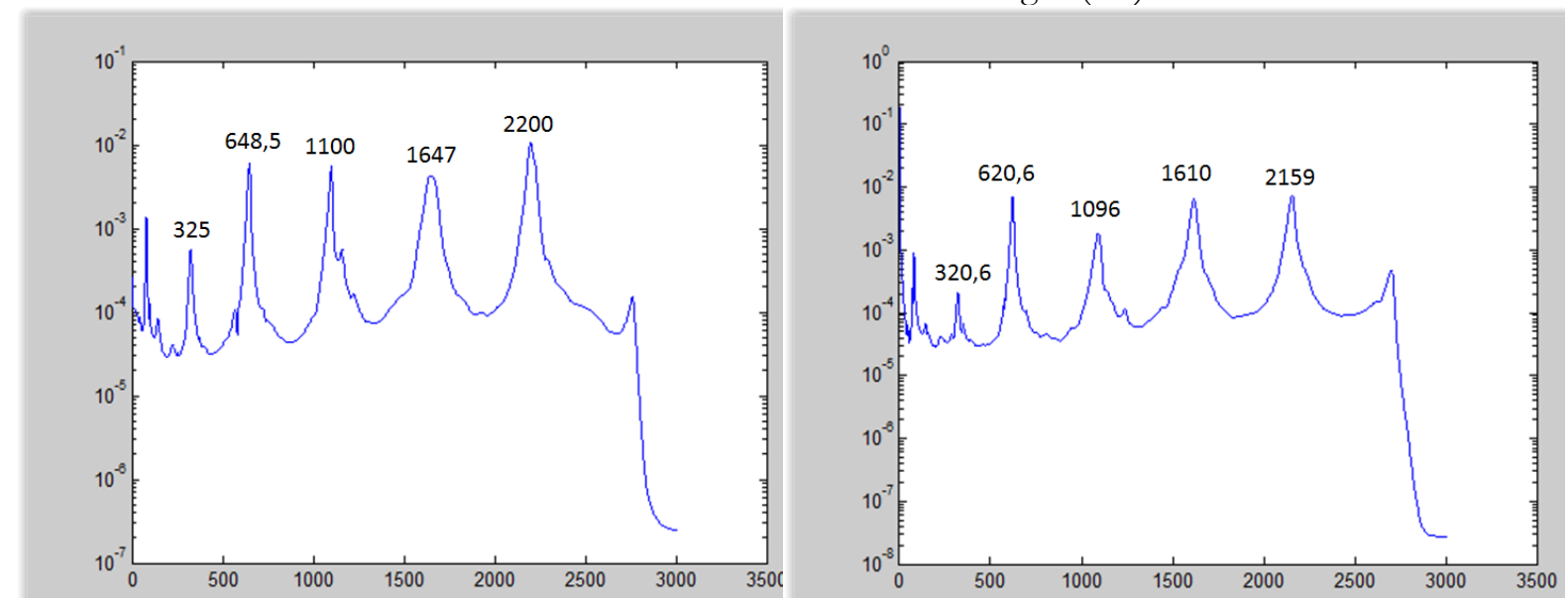

Gráfico 7.10 - ANPSD V90 40\% - Dano (Hz) Gráfico 7.11 - ANPSD V90 40\% - Ranhura (Hz) 


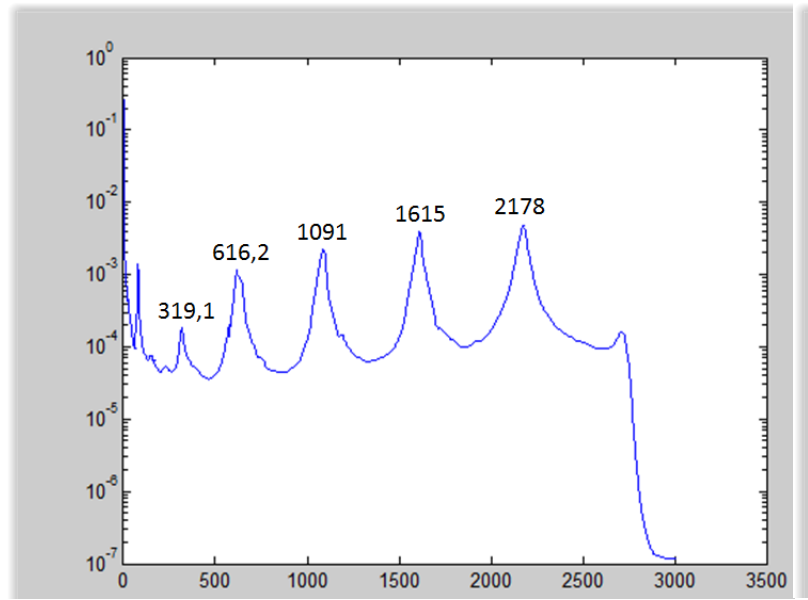

Gráfico 7.12 - ANPSD V90 40\% - Reforço (Hz)

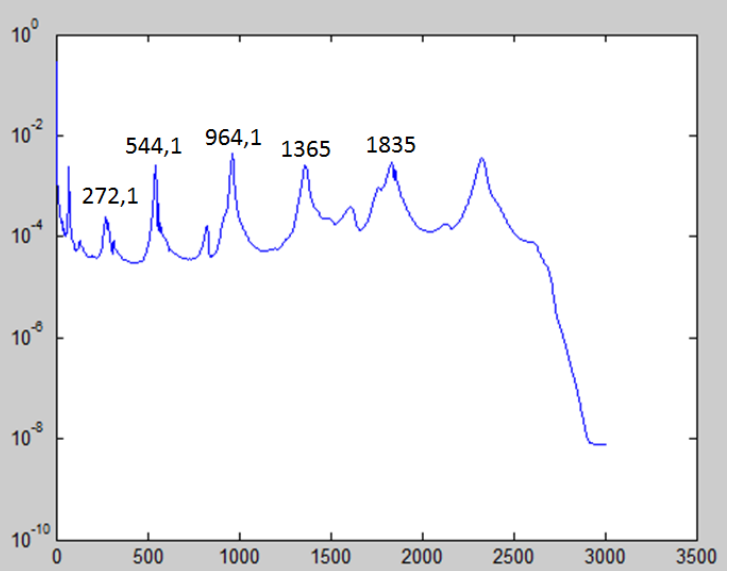

Gráfico 7.13 - ANPSD V90 40\% - Ruptura (Hz)

A configuração Íntegra da viga V90 40\% apresentou na terceira frequência natural vários picos, indefinindo visualmente qual seria o pico para frequência natural correspondente, necessitando para sua confirmação a verificação pelo modo de vibração da viga. O problema apresentado assemelhou-se ao da viga V50 70\% onde o terceiro modo de vibração mesmo na configuração Íntegra, apresenta vários picos.

$\mathrm{Na}$ configuração Dano não foram observadas as reduções usuais na magnitude dos picos das frequências, somente a redução das frequências naturais. Sendo assim, nesta viga o carregamento prévio de $40 \%$ não pode ser identificado pelo método.

Nesta viga, após a Ruptura, as frequências naturais não apresentaram dificuldades de identificação, onde o ANSP apresentou fácil identificação, surgindo alguns picos intermediários, mas com preponderância dos picos das frequências naturais flexionais.

Nas vigas V90 CFRP os gráficos do ANSPD apresentaram o mesmo comportamento dos gráficos das vigas V90 40\%, ocorrendo redução da magnitude das frequências naturais após as ranhuras e com acréscimo de algumas das frequências naturais ao serem realizados sistemas de reforço. $\mathrm{Na}$ ruptura os gráficos apresentaram facilidade de identificação, com picos de frequência nítidos.

Nas vigas V90 70\% foi facilmente identificado o aumento das frequências naturais após o Reforço, onde as três primeiras frequências naturais apresentam maiores valores que na configuração Dano. O mesmo incremento das frequências naturais em relação a configuração Dano foi observada na viga V50 70\%, indicando uma melhoria de eficiência dos sistemas de reforço de CFRP quando a estrutura apresenta maiores fissurações. 
Assim como o ocorrido nas vigas V90 CFRP e V90 40\% o ANPSD apresentou bom comportamento na configuração Ruptura, sem picos intermediários, com fácil identificação das frequências naturais.

Os gráficos ANSPD das vigas V90 apresentaram o mesmo desempenho das vigas V50 nas etapas Íntegra, Dano, Ranhura e Reforço, com alterações parecidas. Na configuração Ruptura as vigas V50 apresentaram ANSPD com maiores interferências, com vários picos intermediários e com dificuldades de identificação das frequências naturais, enquanto que nas vigas V90 seu comportamento foi mais homogêneo. Este efeito ocorreu pela mudança na forma de ruptura das vigas, sendo as V90 por flexão e as V50 por cisalhamento.

É importante lembrar que a identificação do dano somente pela alteração das frequências naturais se mostrou insuficiente no estudo piloto com prismas, principalmente na detecção de aumento da rigidez devido a inserção de reforços de CFRP. A alteração da técnica de ensaio para análise modal permitiu visualizar os gráficos ANSPD juntamente com a análise das alterações das frequências naturais, o que proporcionou melhor identificação da presença de dano, observando além da redução das frequências naturais, a magnitude destas interferências como picos intermediários e duplos picos.

\subsection{MODO DE VIBRAÇÃO}

Como os demais métodos de identificação de dano utilizam os modos de vibração das vigas na sua formulação, todos os modos de vibração são apresentados. Na análise destes foram destacadas as principais variações ocorridas em relação ao modo de vibração da configuração Íntegra, separadamente para os quatro primeiros modos flexionais.

\subsubsection{V50 SR}

Para os modos de vibração foram realizadas análises visuais das variações desses modos devido a ocorrência de dano na viga. O Gráfico 7.14 apresenta do primeiro ao quarto modo de vibração da viga V50 SR nas configurações Íntegra e Ruptura. 

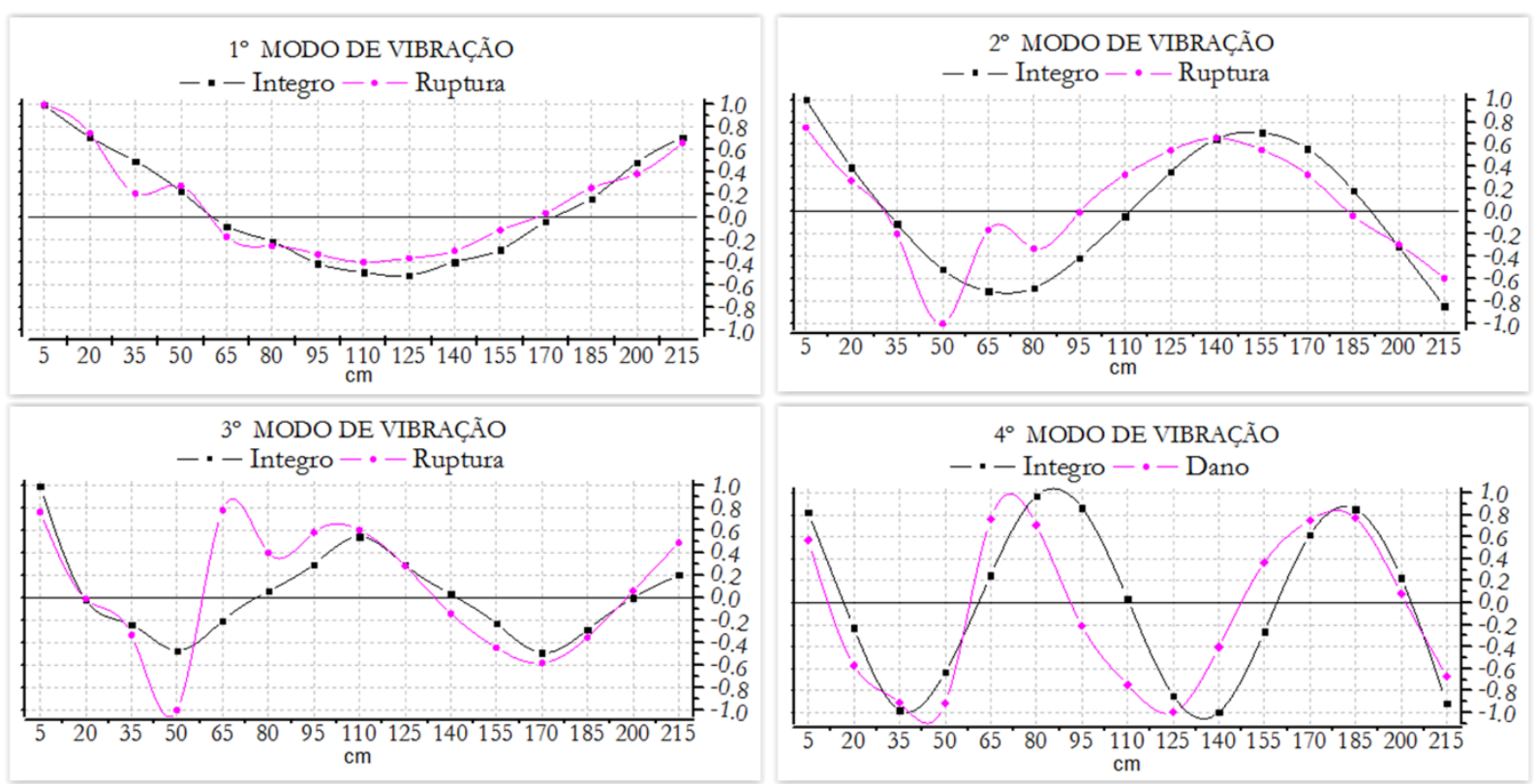

Gráfico 7.14 - Modos de vibração - V50 SR

A análise visual foi individualizada para cada modo de vibração, permitindo assim identificar quais modos sofreram maior influência com a Ruptura da viga:

$\checkmark 1^{\circ}$ Modo-Pequenas variações nas posições $35 \mathrm{~cm}$ e $65 \mathrm{~cm}$;

$\checkmark \quad 2^{\circ}$ Modo - Grandes variações nas posições $50 \mathrm{~cm}$ e $65 \mathrm{~cm}$ e mudança de inflexão da posição $155 \mathrm{~cm}$ para $140 \mathrm{~cm}$;

$\checkmark \quad 3^{\circ}$ Modo - Grandes variações nas posições $50 \mathrm{~cm}$ e $65 \mathrm{~cm}$;

$\checkmark \quad 4^{\circ}$ Modo - Mudança de inflexão da posição $90 \mathrm{~cm}$ para $70 \mathrm{~cm}$ e da posição $130 \mathrm{~cm}$ para a120cm.

$\mathrm{Na}$ análise visual dos modos de vibração foi possível localizar as regiões com maiores variações entre os modos de vibração, identificando na viga V50 SR o local de maior dano entre as posições 35 e $65 \mathrm{~cm}$.

\subsubsection{V50 CFRP}

Os modos de vibração da viga V50 CFRP são apresentadas no Gráfico 7.15, do primeiro ao quarto modos de vibração, nas configurações Íntegra, Ranhura, Reforço e Ruptura, sem a configuração Dano, pois esta viga não houve carregamento prévio. 


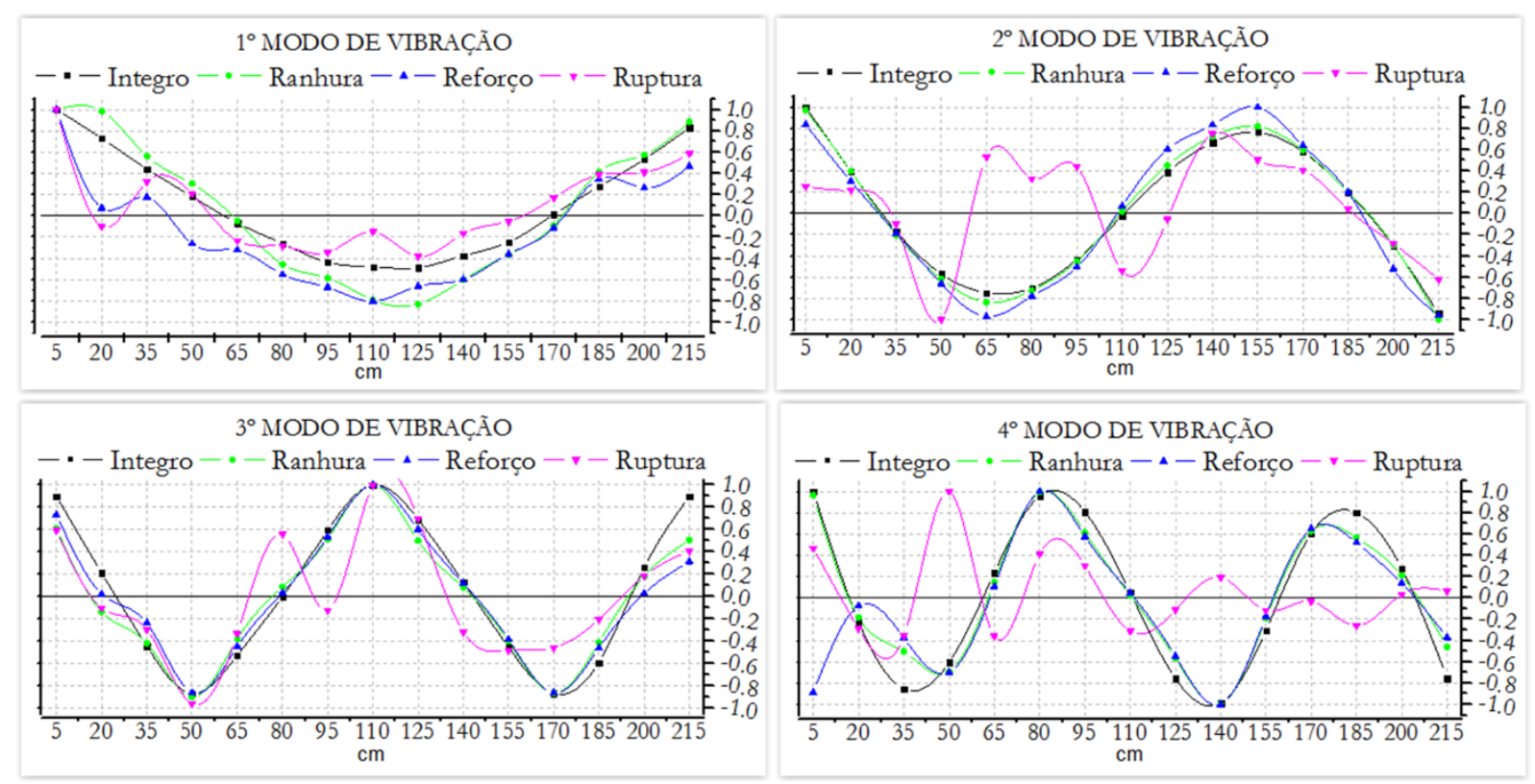

Gráfico 7.15 - Modos de vibração - V50 CFRP

Analisando visualmente cada um dos modos de vibração pode-se identificar que:

$\checkmark \quad 1^{\mathrm{o}}$ Modo - Nas configurações Reforço e Ruptura ocorrem variações nas posições $20 \mathrm{~cm}, 110$ e 200cm; na Ranhura observou-se uma variação na posição $20 \mathrm{~cm}$.

$\checkmark \quad 2^{\circ}$ Modo - A configuração Reforço apresenta ampliação nos pontos de inflexão nas posições $65 \mathrm{~cm}$ e $155 \mathrm{~cm}$; A configuração Ruptura apresenta grande variação entre as posições $65 \mathrm{~cm}$ e $95 \mathrm{~cm}$.

$\checkmark \quad 3^{\circ}$ Modo - Todas as configurações de dano apresentaram variações nas posições $20 \mathrm{~cm}$ e $215 \mathrm{~cm}$, devendo este dano ter ocorrido devido a abertura de ranhuras na viga; $\mathrm{Na}$ configuração Ruptura ocorre grande variações nas posições $80 \mathrm{~cm}, 95 \mathrm{~cm}$ e $170 \mathrm{~cm}$.

$\checkmark \quad 4^{\circ}$ Modo - Com o Reforço ocorreu uma inversão de valores na posição $5 \mathrm{~cm}$ e consequentemente alterações nas posições $35 \mathrm{~cm}$ e $50 \mathrm{~cm}$. O modo após a Ruptura apresentou grande diferença das demais, com inversão de sentido em várias posições.

A avaliação visual dos modos de vibração não permitiram identificar diferenças conclusivas nas configurações Ranhura e Reforço devido a viga não possuir carregamento prévio e consequentemente o dano inserido ocorre apenas pela abertura de Ranhuras na viga. Quando avaliada a configuração Ruptura é possível visualizar o local danificado, principalmente quando observados os segundos e terceiros modos de vibração.

A posição do Reforço entre o início da viga até a posição $90 \mathrm{~cm}$ implica em maiores alterações no segundo modo de vibração, pois neste modo a região com dano e reforçada situa-se onde ocorrem as maiores amplitudes deste modo.

\subsubsection{V50 $40 \%$}


Os quatro modos de vibração da viga V50 40\% são apresentados no Gráfico 7.16, tendo como diferença a presença da configuração Dano devido o carregamento prévio ocorrido.
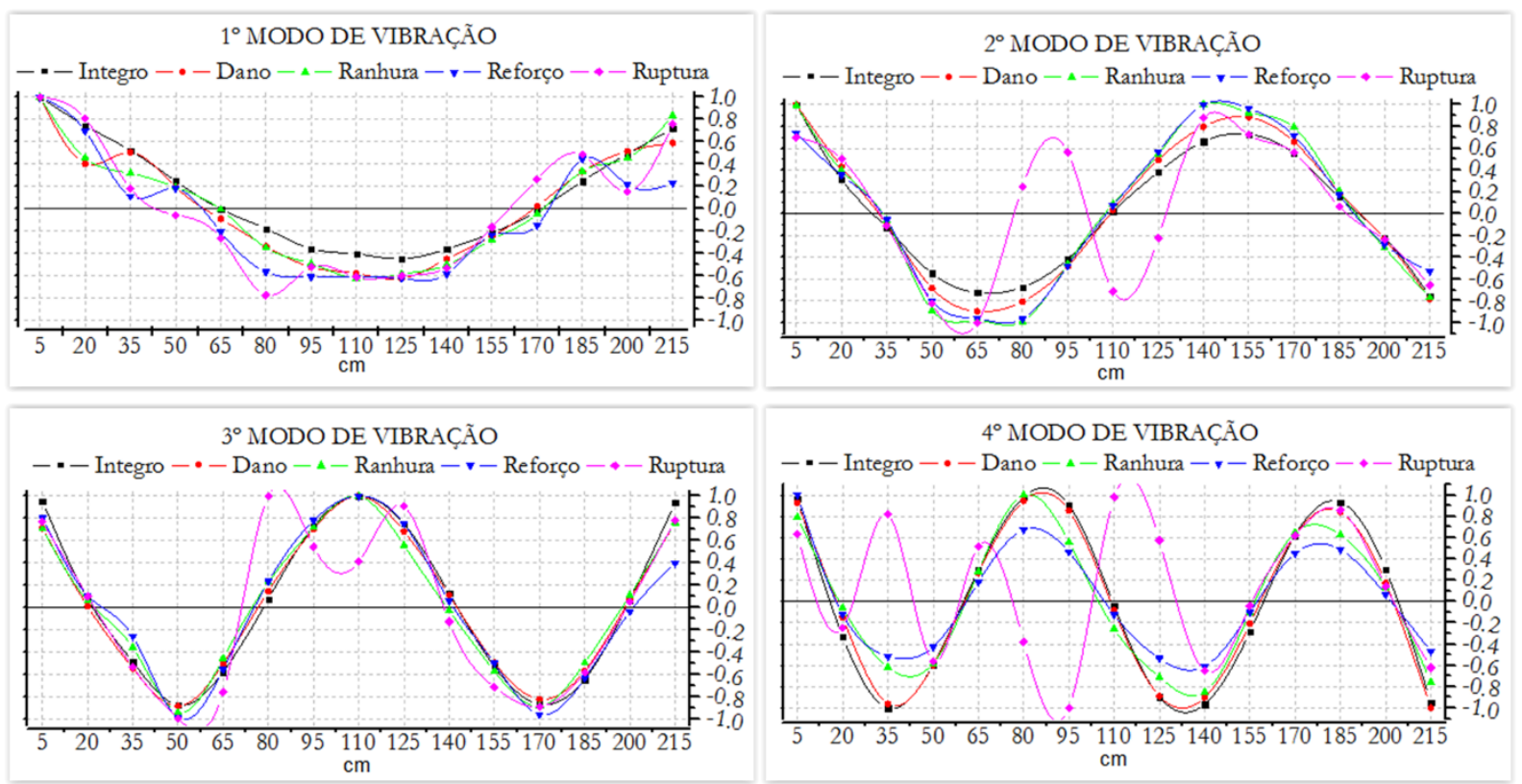

Gráfico 7.16 - Modos de vibração - V50 40\%

Analisando visualmente cada modo de vibração pode-se identificar que:

$\checkmark \quad 1^{\circ}$ Modo - Nas configurações Dano e Ranhura ocorre alteração na posição $20 \mathrm{~cm}$, próximo ao apoio; A configuração Reforço apresentou vários pontos de grande variação, principalmente nas posições $35 \mathrm{~cm}, 80 \mathrm{~cm}, 95 \mathrm{~cm}, 170 \mathrm{~cm}, 200 \mathrm{~cm}$ e $215 \mathrm{~cm} ; \mathrm{Na}$ Ruptura ocorrem grandes variações nas posições $80 \mathrm{~cm}$ e entre $170 \mathrm{~cm}$ e $200 \mathrm{~cm}$.

$\checkmark \quad 2^{\circ}$ Modo - Na análise visual a configuração dano não apresentou alterações em relação à Íntegra; Nas configurações Ranhuras e Reforço ocorreram descontinuidades das curvas nas posições $65 \mathrm{~cm}$ e $110 \mathrm{~cm}$; A configuração Ruptura apresentou grandes variações entre as posições $65 \mathrm{~cm}$ e $140 \mathrm{~cm}$;

$\checkmark \quad 3^{\circ}$ Modo - Apresentou pequenas variações para todas as configurações de dano, onde apenas na Ruptura são observadas grandes variações entre as posições $65 \mathrm{~cm}$ e $110 \mathrm{~cm}$.

$\checkmark \quad 4^{\circ}$ Modo - O carregamento prévio não alterou também este modo, permanecendo o modo de vibração da configuração Dano muito próximo ao da Íntegra; As configurações Ranhura e Reforço apresentaram suavização das ondulações dos modos; Após a Ruptura ocorreram grandes variações entre as posições $20 \mathrm{~cm}$ e $155 \mathrm{~cm}$.

A avaliação visual dos modos de vibração não permitiram identificar grandes alterações causadas pela ocorrência de carregamento prévio nesta viga, verificando pequenas variações nas configurações Ranhura e Reforço, sendo observadas grandes alterações somente após a Ruptura. 


\subsubsection{V50 70\%}

Os modos de vibração da viga V50 70\% são apresentados no Gráfico 7.17, nas configurações Íntegra, Dano, Ranhura, Reforço e Ruptura, para as quatro primeiras frequências naturais.

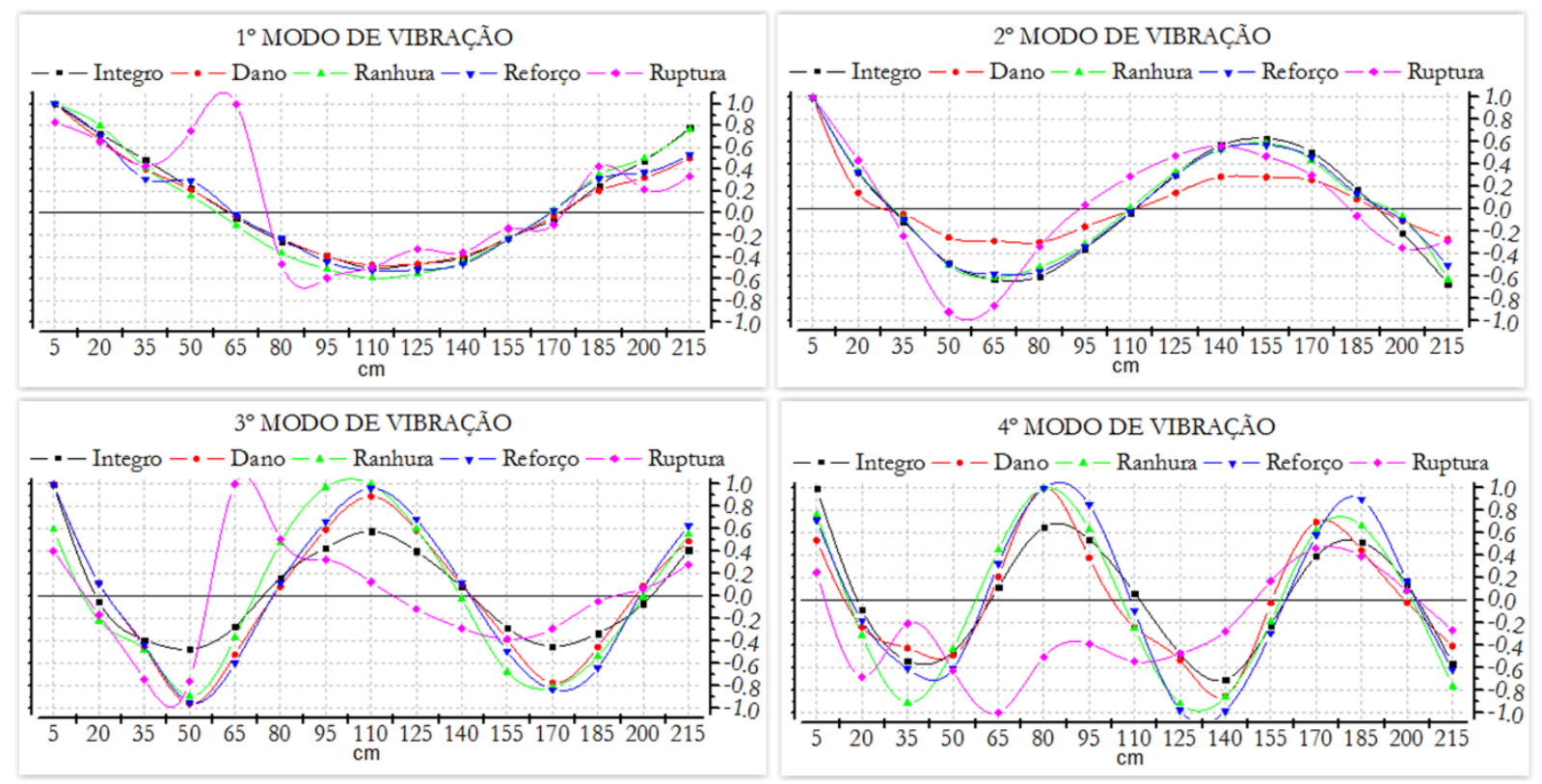

Gráfico 7.17 - Modos de vibração - V50 70\%

Analisando visualmente cada modo de vibração pode-se identificar que:

$\checkmark \quad 1^{\circ}$ Modo - Na configuração Dano e Reforço ocorrem pequenas variações nas posições $20 \mathrm{~cm}, 200 \mathrm{~cm}$ e $215 \mathrm{~cm}$; Na Ruptura ocorrem grandes variações nas posições $200 \mathrm{~cm}$, $215 \mathrm{~cm}$ e entre $50 \mathrm{~cm}$ e $95 \mathrm{~cm}$.

$\checkmark \quad 2^{\circ}$ Modo $-\mathrm{Na}$ análise visual a configuração dano apresentou grandes alterações em relação à Íntegra, onde os modos tem menor amplitude e descontinuidades; Com o acréscimo das Ranhuras e dos Reforço não ocorreram grandes alterações. A configuração Ruptura apresenta grande variações entre as posições $50 \mathrm{~cm}$ e $110 \mathrm{~cm}$ e à $215 \mathrm{~cm}$;

$\checkmark \quad 3^{\circ}$ Modo - As configurações Dano e Reforço apresentaram pequenas variações em relação a Íntegra, com maiores amplitudes; Na configuração Ranhura acorrem alterações na posição 35 e mudança na posição do ponto de inflexão de $110 \mathrm{~cm}$ para $100 \mathrm{~cm}$; Na Ruptura são observadas grandes variações em praticamente toda a viga, com alteração completa deste modo.

$\checkmark \quad 4^{\circ}$ Modo-O Dano nitidamente alterou também este modo de vibração, com variações nas posições $5 \mathrm{~cm}, 80 \mathrm{~cm} 125 \mathrm{~cm}, 140 \mathrm{~cm}$ e $185 \mathrm{~cm}$; As configurações Ranhura e Reforço 
apresentaram aumento na amplitude das ondulações dos modos; Na Ruptura apresentou grandes variações em todo o comprimento da viga.

A avaliação visual dos modos de vibração nesta viga permitiu observar variações devido a presença de carregamento prévio, diferentemente do ocorrido na viga V50 40\%, devido a maior intensidade do dano, que causou maiores reduções locais de rigidez. O método não permitiu identificar grandes alterações causadas pela ocorrência do Reforço, sendo realmente observadas grandes alterações somente após a Ruptura.

\subsubsection{V90 SR}

O Gráfico 7.18 apresenta os modos de vibração da viga V90 SR apenas com as configurações Íntegras e Ruptura.
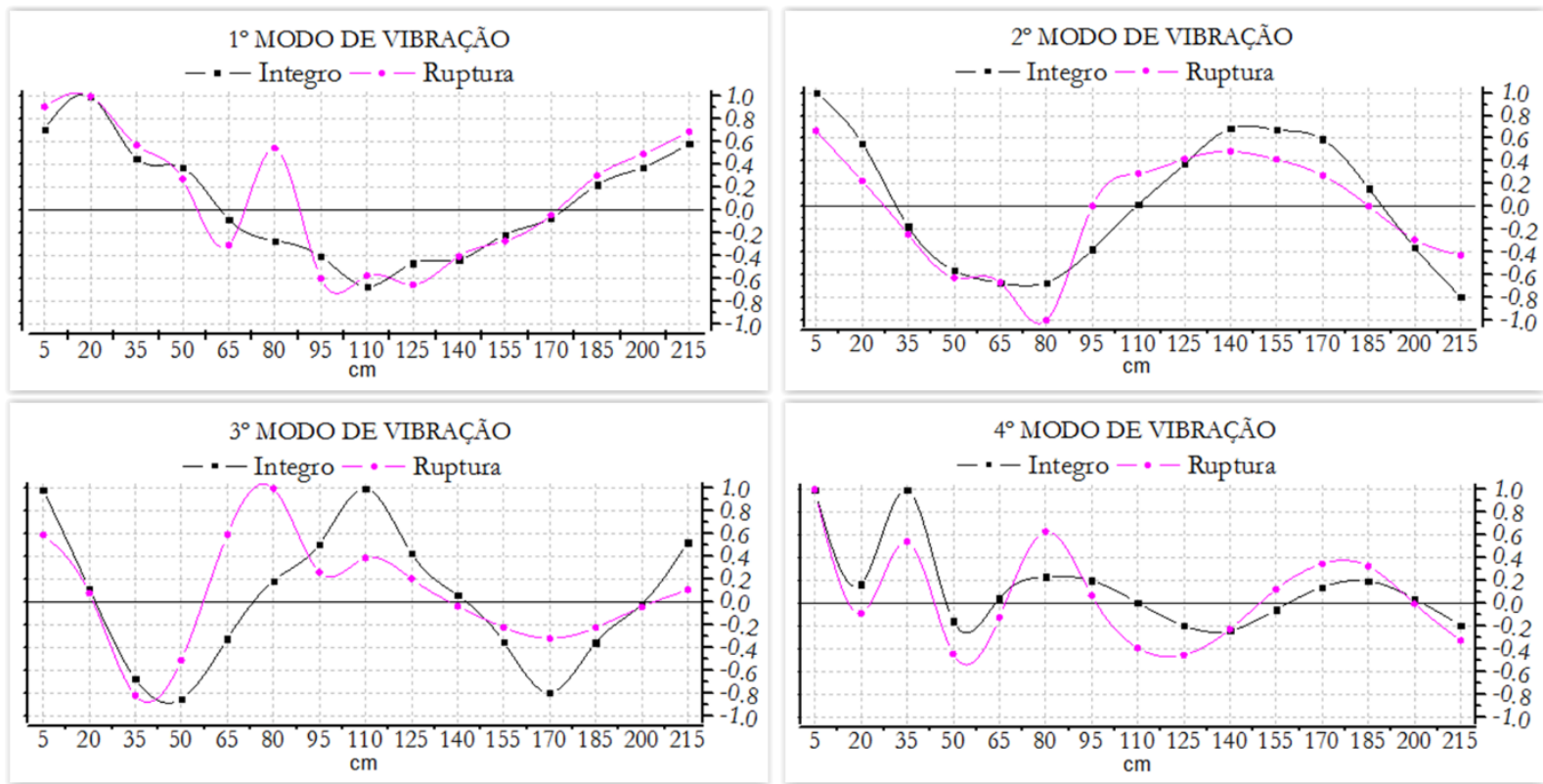

Gráfico 7.18 - Modos de vibração - V90 SR

A viga V90 SR apresentou os piores modos de vibração entre as vigas estudadas, com comportamento da viga na configuração Íntegra similar as vigas com danos. Esse comportamento comprometeu a análise dos métodos de identificação de dano, pois em todos eles ocorre uma comparação entre as configurações íntegra e Ruptura.

Em uma análise visual dos modos de vibração da viga na configuração Íntegra podemos observar:

$\checkmark \quad 1^{\circ}$ Modo - Descontinuidade da parábola nas posições $20 \mathrm{~cm}, 50 \mathrm{~cm}$ e $110 \mathrm{~cm}$;

$\checkmark \quad 2^{\circ}$ Modo-Suavização dos pontos de inflexão nas posições $65 \mathrm{~cm}$ e $155 \mathrm{~cm}$;

$\checkmark \quad 3^{\circ}$ Modo - Ampliação dos pontos de inflexão entre as posições $50 \mathrm{~cm}$ e $80 \mathrm{~cm}$;

$\checkmark \quad 4^{\circ}$ Modo - Inversão de sinal na posição $35 \mathrm{~cm}$. 
Na comparação entre os modos de vibração Íntegra com a de Ruptura observou-se que:

$\checkmark \quad 1^{\circ}$ Modo - As descontinuidades da parábola nas posições $20 \mathrm{~cm}$ e $50 \mathrm{~cm}$ permanecem e ocorre uma grande variação do modo na posição $80 \mathrm{~cm}$, indicando o local de dano;

$\checkmark \quad 2^{\circ}$ Modo - Ocorre uma maior suavização dos pontos de inflexão e grande variação dos modos nas posições $80 \mathrm{~cm}$ e $95 \mathrm{~cm}$;

$\checkmark \quad 3^{\circ}$ Modo - Ocorre uma maior suavização dos pontos de inflexão e grande variação dos modos nas posições $80 \mathrm{~cm}$ e $95 \mathrm{~cm}$;

$\checkmark \quad 4^{\circ}$ Modo-Ocorre a mesma inversão de sinal na posição $35 \mathrm{~cm}$, indicando um possível dano nesta posição mesmo na configuração Íntegra ocorre ampliação dos pontos de inflexão.

Importante destacar que, mesmo com um comportamento não usual dos modos de vibração da viga na configuração Íntegra, obteve-se boa comparação visual entre eles após a Ruptura, indicando que os modos de vibração desta viga possuem realmente esse comportamento diferenciado.

\subsubsection{V90 CFRP}

Os modos de vibração da viga V90 CFRP são apresentadas no Gráfico 7.19, do primeiro ao quarto modo de vibração, sem a configuração Dano, pois esta viga não houve carregamento prévio, sendo apresentadas as demais configurações: Íntegra, Ranhura, Reforço e Ruptura.

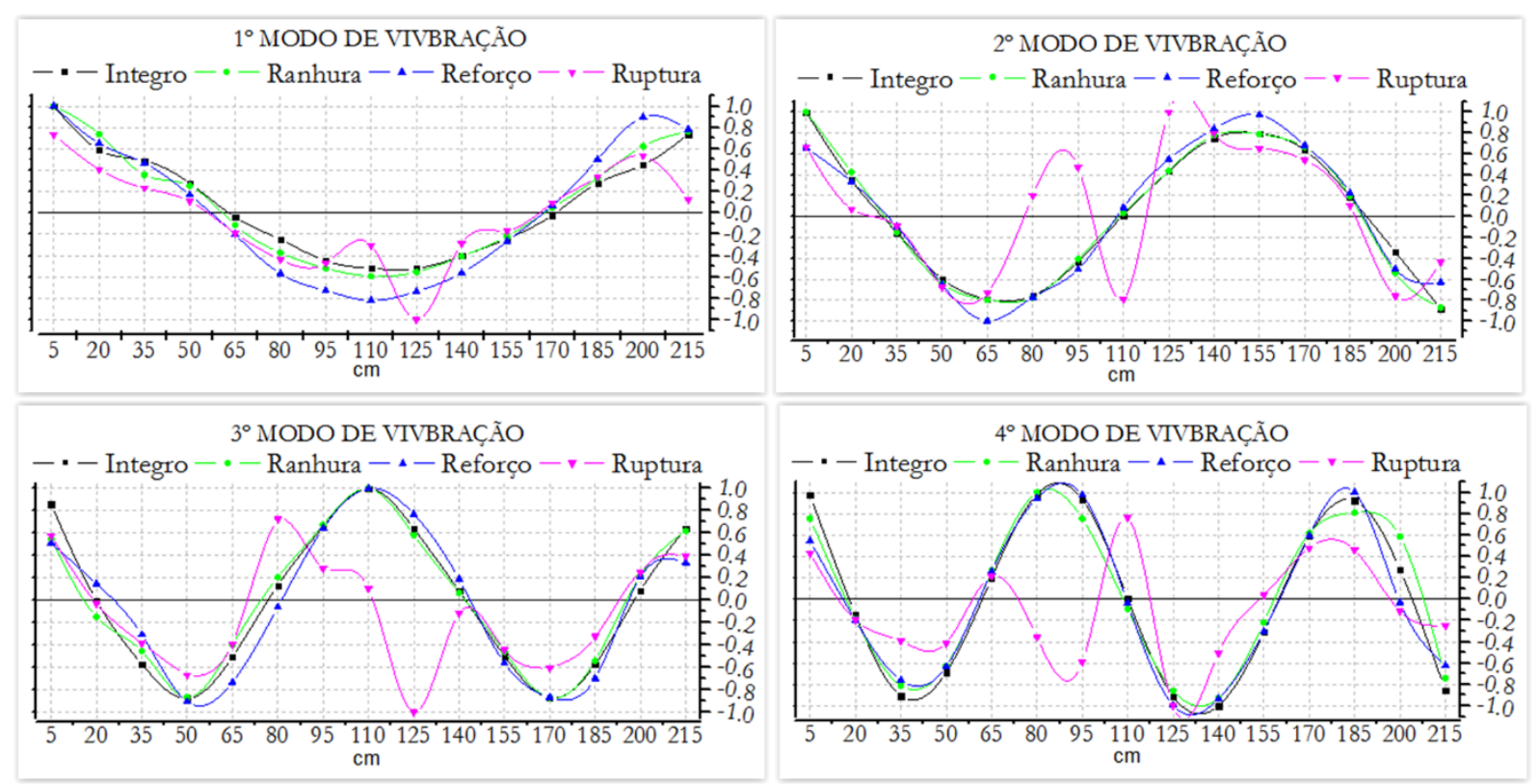

Gráfico 7.19 - Modos de vibração - V90 CFRP

A análise visual de cada modo de vibração permitiu observar onde ocorreram as maiores variações para identificar e localizar o dano: 
$\checkmark \quad 1^{\circ}$ Modo - Nas configurações Ranhura, observou-se pequenas variações nas posições $20 \mathrm{~cm}, 35 \mathrm{~cm}$ e $200 \mathrm{~cm}$; Após o Reforço, identificou-se grande alteração na posição 200cm; Com a Ruptura ocorreram variações nas posições $110,125 \mathrm{~cm} .140 \mathrm{~cm}$ e $215 \mathrm{~cm}$.

$\checkmark \quad 2^{\circ}$ Modo - A configuração Reforço apresenta ampliação nos pontos de inflexão nas posições $65 \mathrm{~cm}$ e $155 \mathrm{~cm}$. A configuração Ruptura apresenta grande variação entre as posições $80 \mathrm{~cm}$ e $125 \mathrm{~cm}$.

$\checkmark \quad 3^{\circ}$ Modo - Na Ranhura, observou-se pequenas variações nas posições $20 \mathrm{~cm}$ e $35 \mathrm{~cm}$; Com o Reforço ocorrem variações nas posições $20 \mathrm{~cm}, 35 \mathrm{~cm}$ e $215 \mathrm{~cm}$; Após a Ruptura ocorreram grandes variações entre as posições $95 \mathrm{~cm}$ e $125 \mathrm{~cm}$.

$\checkmark \quad 4^{\circ}$ Modo - Com as Ranhuras, houve redução apenas na posição $185 \mathrm{~cm}$; Tendo também a configuração Reforço apenas um ponto $(200 \mathrm{~cm})$ com alterações neste modo de vibração; Após a Ruptura, o modo de vibração apresentou grandes variações, principalmente entre as posições $35 \mathrm{~cm}$ e $110 \mathrm{~cm}$.

A avaliação dos modos de vibração desta viga permitiu observar algumas alterações na configuração Ranhura que não apareceram após a inserção dos Reforços. A melhora oriunda dos Reforços foi de difícil observação. Quando avaliada a configuração Ruptura foi possível visualizar o local danificado facilmente, onde todos os modos identificaram, com grandes alterações, dano entre as posições $80 \mathrm{~cm}$ e $110 \mathrm{~cm}$.

\subsubsection{V90 $40 \%$}

A análise visual dos modos de vibração permitiu comparar a forma de vibrar da viga V50 $40 \%$ em todas as suas etapas. Estes são apresentados no Gráfico 7.20.

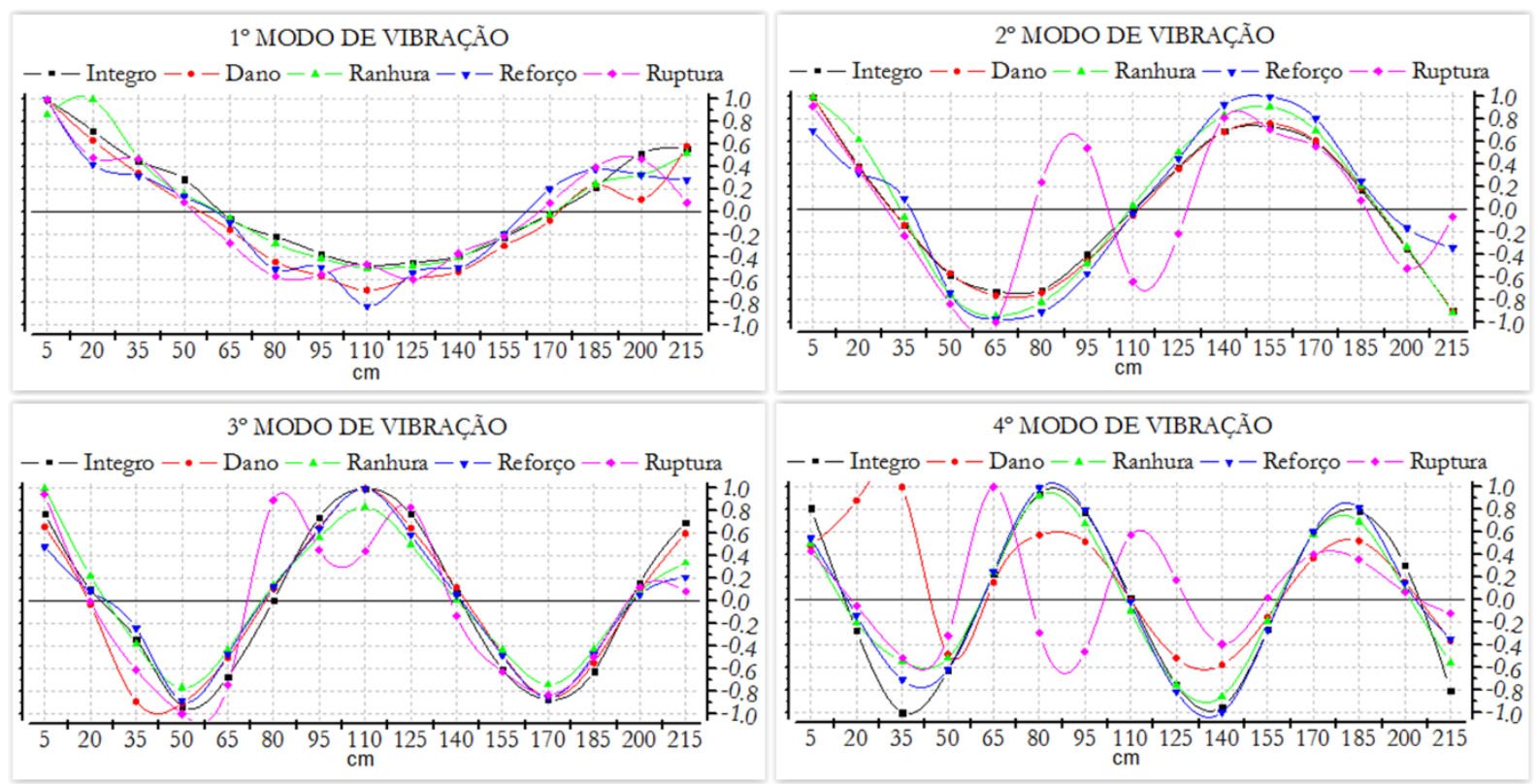

Gráfico 7.20 - Modos de vibração - V90 40\% 
Nesta análise visual foi possível identificar que:

$\checkmark \quad 1^{\circ}$ Modo - Na configuração Dano ocorrem alterações apenas na posição $200 \mathrm{~cm}$; Com as Ranhuras ocorrem variações nas posições $20 \mathrm{~cm}$ e $200 \mathrm{~cm}$; O Reforço apresentou diversas posições com alterações, assim como na configuração Ruptura.

$\checkmark \quad 2^{\circ}$ Modo - Estes modos apresentaram melhor comportamento que o primeiro, com a configuração Dano sem variação; nas configurações Ranhuras e Reforço ocorreram descontinuidades dos modos nas posições $65 \mathrm{~cm}$ e $155 \mathrm{~cm}$, sendo que no Reforço também são observadas variações nas posições $35 \mathrm{~cm}$ e $215 \mathrm{~cm}$; A configuração Ruptura apresentou grandes variações entre as posições $80 \mathrm{~cm}$ e $140 \mathrm{~cm}$ e na posição $215 \mathrm{~cm}$;

$\checkmark \quad 3^{\circ}$ Modo - Todas as configurações apresentaram comportamento parecidos, com maiores alterações apenas na posição $20 \mathrm{~cm}$ para a configuração Dano e entre as posições $80 \mathrm{~cm}$ e $110 \mathrm{~cm}$ na Ruptura.

$\checkmark \quad 4^{\circ}$ Modo - A configuração Dano apresentou grande variações nas posições $20 \mathrm{~cm}$ e $35 \mathrm{~cm}$, ocorrendo inversão de sinal; A configuração Ranhura e Reforço não tiveram grandes diferenças visuais; Após a Ruptura, apresentou grandes variações em toda a viga, com maior intensidade entre as posições $65 \mathrm{~cm}$ e $95 \mathrm{~cm}$.

Nesta avaliação visual observou-se maiores alterações no primeiro modo de vibração, onde os modos de todas as configurações sofreram alterações em posições diferentes, principalmente após o reforço. O segundo e terceiro modo de vibração não apresentaram grandes diferenças das demais vigas, tendo maiores variações apenas na configuração Ruptura, já no quarto modo de vibração da configuração Dano, nitidamente foi possível perceber grandes variações.

\subsubsection{V90 $70 \%$}

Os modos de vibração da viga V90 70\% são apresentadas no Gráfico 7.21, nas configurações Íntegra, Dano, Ranhura, Reforço e Ruptura, para as quatro primeiras frequências naturais. 


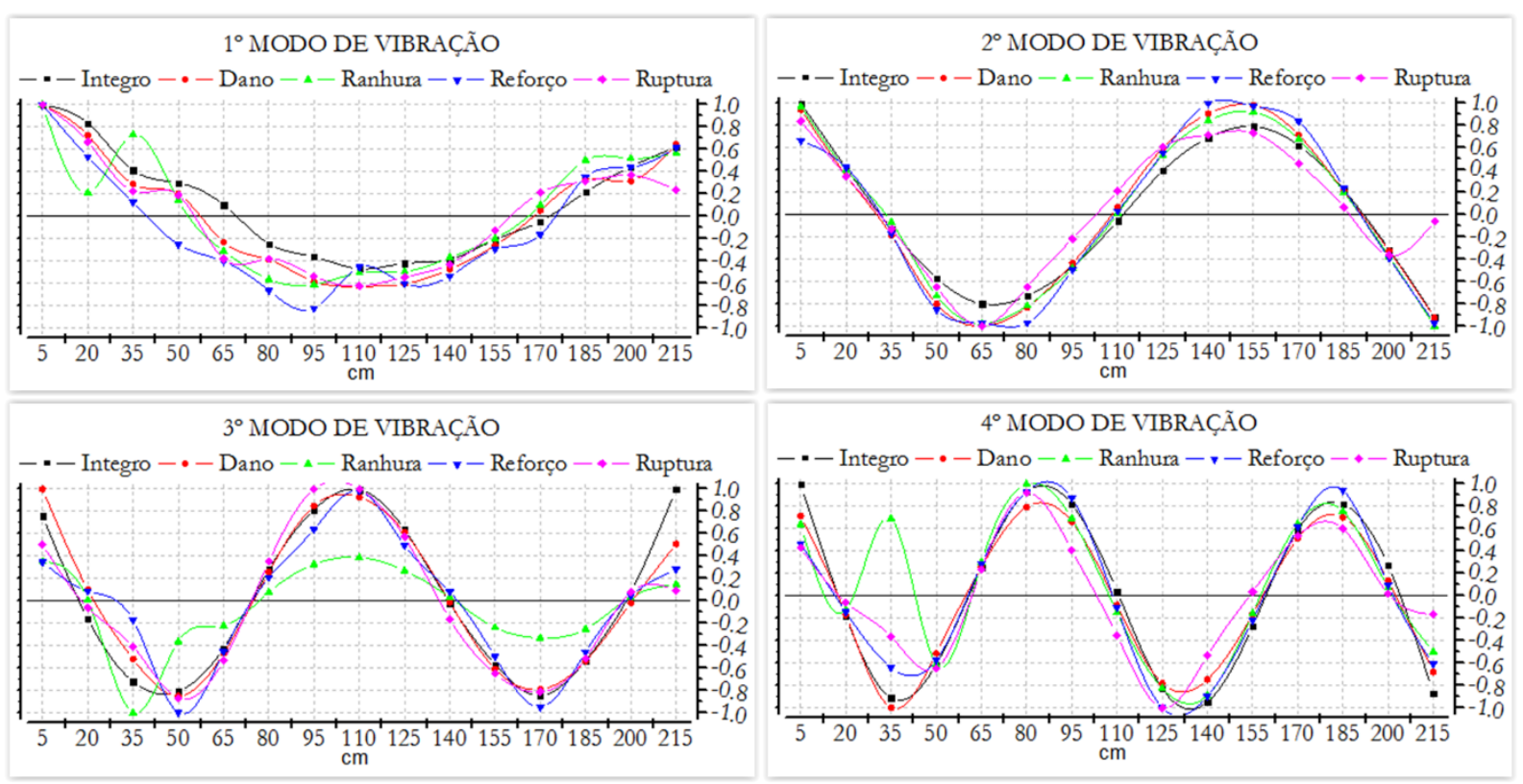

Gráfico 7.21 - Modos de vibração - V90 70\%

Analisando visualmente cada modo de vibração pode-se identificar que:

$\checkmark \quad 1^{\circ}$ Modo - Apresentaram grandes variações entre todas as configurações, tendo nas configurações Dano e Ruptura modos com maior amplitude; Na Ranhura ocorreram grandes variações nas posições $20 \mathrm{~cm}, 35 \mathrm{~cm}$ e $185 \mathrm{~cm}$; No Reforço ocorreu maior amplitude entre as posições $20 \mathrm{~cm}$ e $95 \mathrm{~cm}$, além de pequenas variações nas posições $125 \mathrm{~cm}$ e $185 \mathrm{~cm}$.

$\checkmark \quad 2^{\circ}$ Modo - Apresentou boa comparação visual, ocorrendo descontinuidades dos modos nas configurações Dano e Reforço nas posições $65 \mathrm{~cm}$ e 155cm; Após a Ruptura apresenta grande variação apenas na posição $215 \mathrm{~cm}$.

$\checkmark \quad 3^{\circ}$ Modo - Apresentaram má relação visual dos modos de vibração de todas as configurações entre as posições $5 \mathrm{~cm}$ e $35 \mathrm{~cm}$; Na configuração Ranhura ocorreu redução da amplitude dos resultados.

$\checkmark \quad 4^{\circ}$ Modo-Todas as configurações apresentaram boa comparação visual, com destaque apenas para o ponto $35 \mathrm{~cm}$ que apresentou grandes variações, principalmente na configuração Ranhura.

$\mathrm{Na}$ avaliação visual foi possível observar uma boa relação entre as configurações da viga do segundo ao quarto modo de vibração, ocorrendo uma maior variação na posição $35 \mathrm{~cm}$. $O$ primeiro modo de vibração apresentou grande variação ente as configurações, onde mesmo a Íntegra não apresenta bom comportamento usual. 


\subsection{MAC E COMAC}

O modal assurance criterion (MAC) foi utilizado para avaliar em que modos de vibração sofrem maiores alterações com a presença do dano e do reforço. O MAC foi utilizado ainda como critério para desconsiderar alguns modos de vibração nos demais métodos de avaliação de dano. Para isso foi realizado um estudo da quantidade de modos de vibração.

O coordinate modal assurance criterion (COMAC) faz uma relação entre os vetores dos modos de vibração para cada grau de liberdade, comparando neste trabalho as configurações danificadas com a íntegra. Ele permite identificar a localização do dano ao longo do comprimento da viga mas sem observar qual modo de vibração influenciou nesta identificação. Permite ainda quantificar o dano, onde valores próximos de 1 representam pequenas variações no modo de vibração e valores próximos a 0 grandes variações.

\subsubsection{Estudo da quantidade de modo de vibração}

Durante a análise dos resultados observou-se que em algumas vigas a definição das frequências naturais para a obtenção dos modos de vibração não ocorreriam facilmente quando as vigas apresentavam dano, principalmente nas frequências naturais mais elevadas, sendo assim os modos de vibração nessas frequências apresentaram maiores diferenças que as demais em relação a viga íntegra.

Podemos imaginar que essa maior diferença nos modos de vibração facilite a identificação das regiões danificadas da viga, mas infelizmente ocorre o contrário, pois os métodos apresentados para a identificação do dano apresentam em sua formulação somatórios de variações medidas nas diversas frequências naturais da viga, assim quando ocorre uma variação elevada em uma única frequência, esta pode interferir na análise dos resultados.

Com o objetivo de identificar quantos modos de vibração devem ser consideradas nos métodos de identificação de dano, foi realizado um estudo paramétrico com os resultados da viga V50 40\%, variando de 3 a 5 modos de vibração. Neste estudo verificou-se que o método MAC apresenta a relação entre os modos de vibração separadamente, indicando assim a quantidade máxima de modo de vibração a serem consideradas em cada viga.

Em seguida foram realizadas análises com o método COMAC, variando a utilização de 3 a 5 modos de vibração da mesma viga, para verificar a eficácia do estudo.

É importante destacar que as comparações são realizadas apenas na mesma viga em diferentes configurações de dano, não sendo realizada comparações com vigas de referência, pois 
cada viga apresenta frequências naturais, modos de vibração, massa, amortecimento e rigidez diferentes.

O estudo da quantidade de modos de vibração a serem considerados nos métodos de identificação de dano foi realizado na viga V50 40\%, por esta apresentar todas as configurações da viga: Íntegra, Dando, Ranhura, Reforço e Ruptura.

O método MAC nesta pesquisa será utilizado para correlacionar os vetores modais da configuração íntegra com as danificadas, seus resultados são apresentados em forma de matriz. Nessas matrizes a diagonal representa a relações entre os vetores modais do mesmo modo de vibração, que devem ser próximos a 1 , enquanto que os demais termos da matriz devem ser próximos de 0 , pois comparam vetores modais de graus distintos.

A seguir são apresentadas as comparações via MAC (Gráfico 7.22) e COMAC (Gráfico 7.23) utilizando de $3^{\circ}$ a $5^{\circ}$ modos de deformação na configuração Dano.

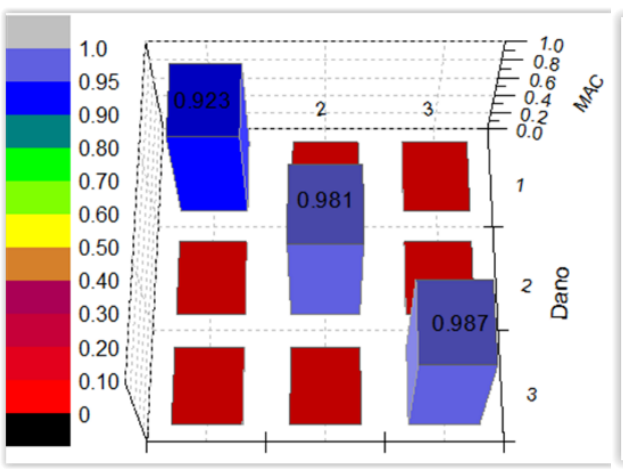

$3^{\circ}$ Modo de vibração

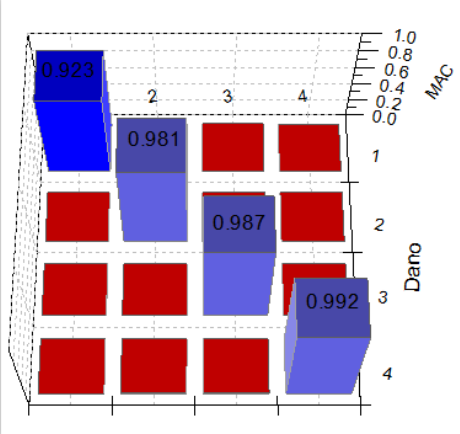

$4^{\mathrm{o}}$ Modo de vibração

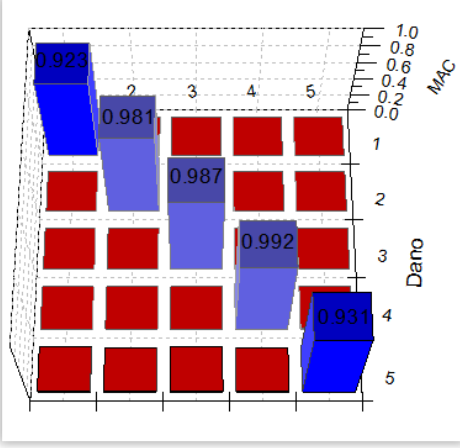

$5^{\circ}$ Modo de vibração

Gráfico 7.22 - Estudo do MAC usando entre 3 e 5 modos de vibração - Dano

Os gráficos de MAC para a configuração Dano obtiveram resultados semelhantes independentemente da quantidade de modo de vibração estudados, onde o primeiro modo apresentou menor coeficiente $(0,923)$, com as demais diagonais próximas a 1 e os demais valores do gráfico próximos a 0 . Quando observado, o quinto modo de vibração apresentou coeficiente 0,932, valor com boa relação entre as configurações Dano e Íntegra, sendo ainda maior que o do primeiro modo. 


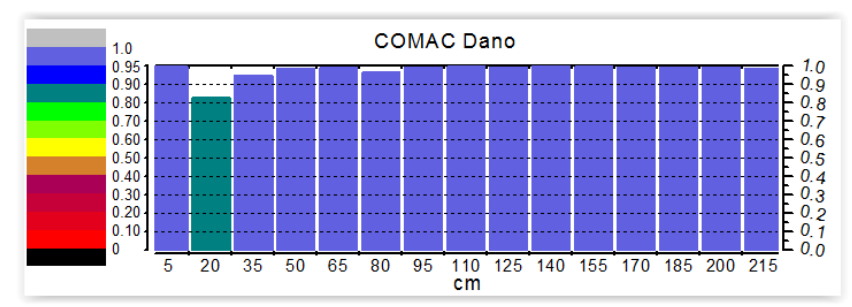

$3^{\circ}$ Modo de vibração

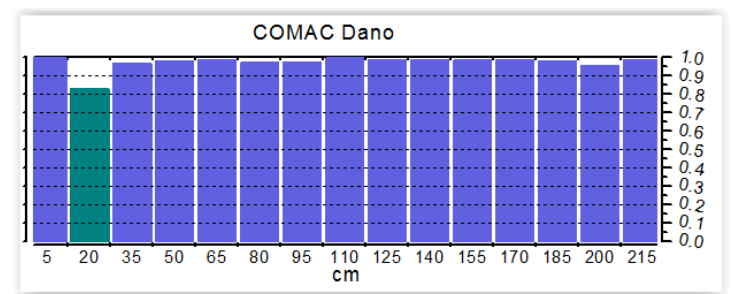

$4^{\circ}$ Modo de vibração

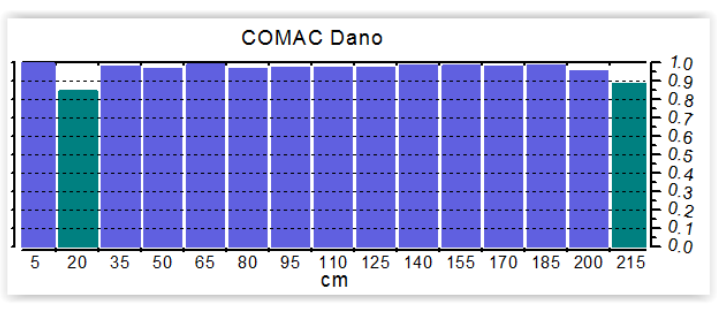

$5^{\circ}$ Modo de vibração

Gráfico 7.23 - Estudo do COMAC usando entre $3^{\circ}$ e $5^{\circ}$ modos de vibração - Dano

$\mathrm{Na}$ configuração Dano, os coeficientes com $3^{\circ}$ modo de vibração praticamente não apresentam alterações, ocorrendo variação apernas na posição $20 \mathrm{~cm}$ com coeficiente de 0,83 , com os demais valores acima de 0,95 . Quando aumentamos para 4 modos de vibração observou-se o mesmo dano na posição 20, com coeficiente 0,832 e considerando os cinco modos de vibração, verificou-se a permanência do dano na posição $20 \mathrm{~cm}$, com coeficiente 0,85 .

É possível observar ainda que ocorre uma falsa identificação de um pequeno dano na posição $215 \mathrm{~cm}$ com coeficiente 0,886 , sendo que esta posição situa-se após o apoio e que o carregamento prévio foi aplicado a 85cm, não devendo ocorrer esta indicação.

Fazendo uma comparação na configuração Ranhura, o Gráfico 7.24 apresenta o MAC, e Gráfico 7.25 apresenta os resultados do COMAC para a viga V50 40\%.

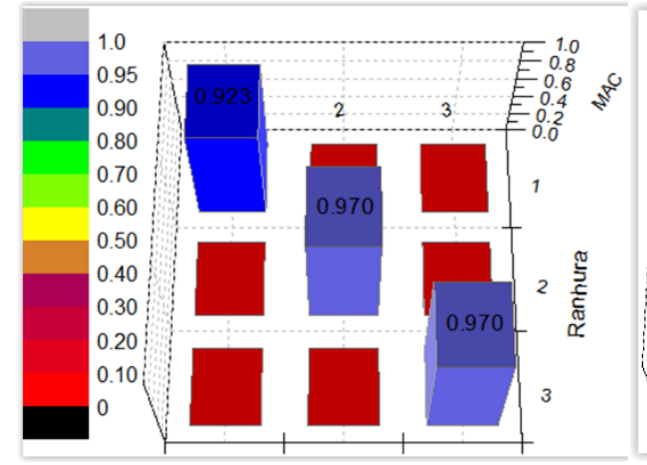

$3^{\circ}$ Modo de vibração

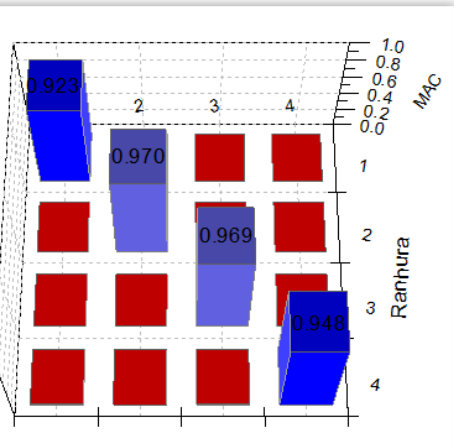

$4^{\circ}$ Modo de vibração

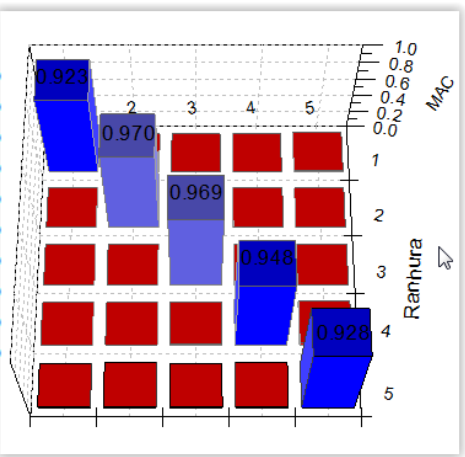

$5^{\circ}$ Modo de vibração

Gráfico 7.24 - Estudo do MAC usando entre $3^{\circ}$ e $5^{\circ}$ modos de vibração -Ranhura

Após acrescentadas Ranhuras nas vigas observamos que os coeficientes MAC praticamente não sofreram alterações, apresentando para o primeiro modo de vibração coeficiente 0,924 e quando observado, o quinto modo de vibração com 0,929 , permanecendo as diagonais próximas a 1. 


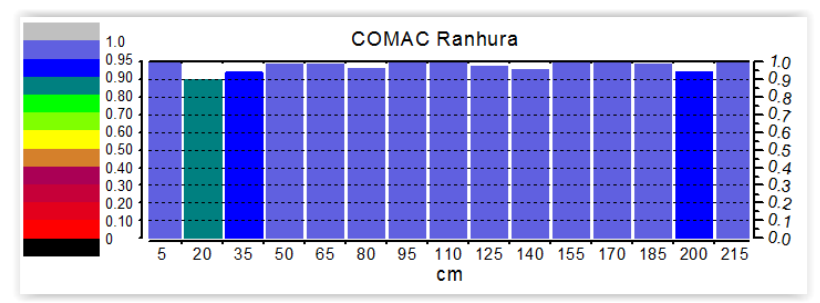

$3^{\circ}$ Modo de vibração

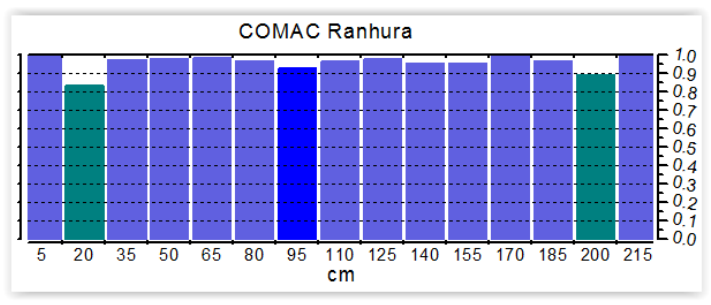

$4^{\circ}$ Modo de vibração

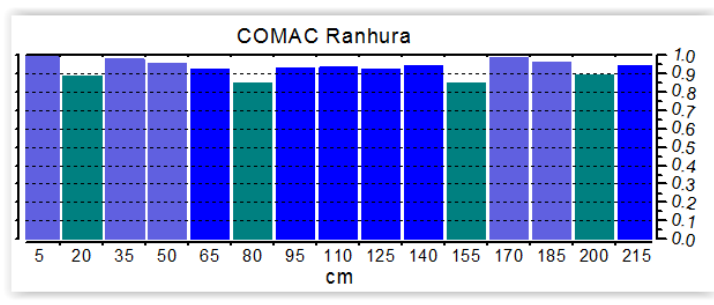

$5^{\circ}$ Modo de vibração

Gráfico 7.25 - Estudo do COMAC usando entre $3^{\circ}$ e $5^{\circ}$ modos de vibração - Ranhura

Nas vigas com Ranhuras o COMAC identificou um aumento de dano em diversas posições da viga, considerando $3^{\circ}, 4^{\circ}$ ou $5^{\circ}$ modos de vibração. Como as ranhuras ocorreram entre as posições 0 e $90 \mathrm{~cm}$ das vigas, somente nesta região deveriam ocorrer redução dos coeficientes COMAC. Quando considerou-se o $5^{\circ}$ modo de vibração, as posições $155 \mathrm{~cm}$ e $200 \mathrm{~cm}$ apresentaram coeficiente de 0,847 e 0,895 respectivamente, identificando novamente a um pequeno dano inexistente nessas posições da viga.

Os resultados nas configurações Dano e Ranhura para esta viga permitem utilizar até o quinto modo de vibração, pois estes valores representam o quão semelhante os modos de vibração nestas configurações foram em relação ao estado íntegro. Ocorrendo pequenas alterações ao se utilizar os valores do $5^{\circ}$ modo de vibração.

Ao inserir reforços de CFRP buscou-se uma melhoria dos coeficientes MAC e COMAC em relação aos valores obtidos na configuração Dano e Ranhura. Essa melhora indica que o modo de vibração da viga Reforçada assemelha-se mais com a configuração Íntegra. O Gráfico 7.26 apresenta os valores de MAC e o Gráfico 7.27 apresenta os valores de COMAC para a configuração Reforço. 


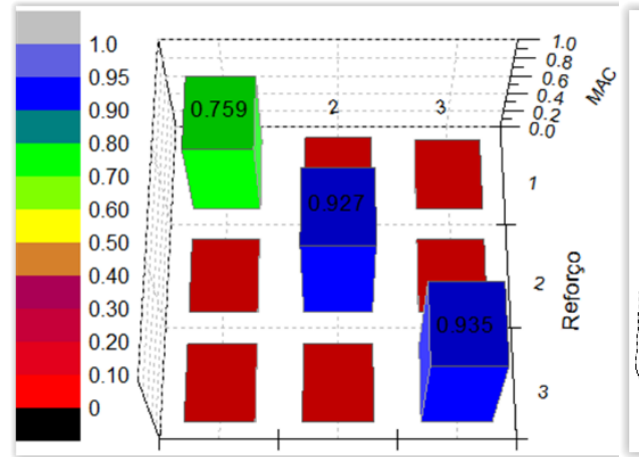

$3^{\circ}$ Modo de vibração

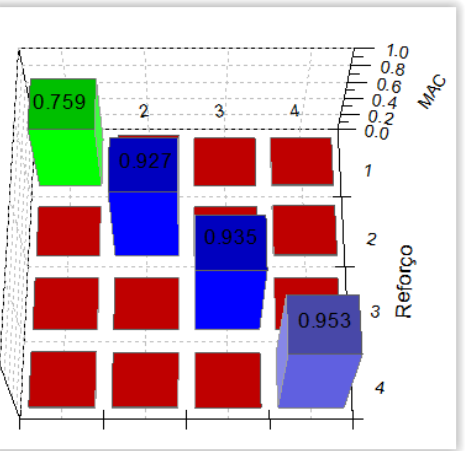

$4^{\circ}$ Modo de vibração

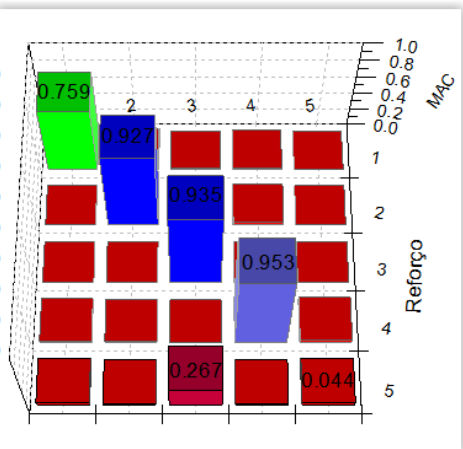

$5^{\circ}$ Modo de vibração

Gráfico 7.26 - Estudo do MAC usando entre $3^{\circ}$ e $5^{\circ}$ modo de vibração - Reforço

$\mathrm{Na}$ configuração Reforço da viga o coeficiente MAC do primeiro modo reduziu para 0,76 , e quando observado, o quinto modo de vibração foi de 0,045 . Este coeficiente identifica que praticamente não existe relação entre os quintos modos de vibração na configuração Íntegra com a Reforçada.

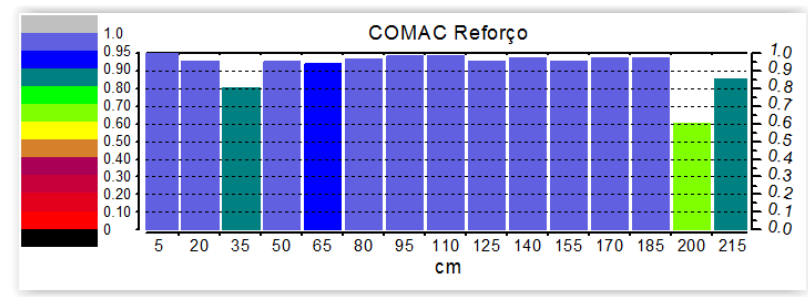

$3^{\circ}$ Modo de vibração

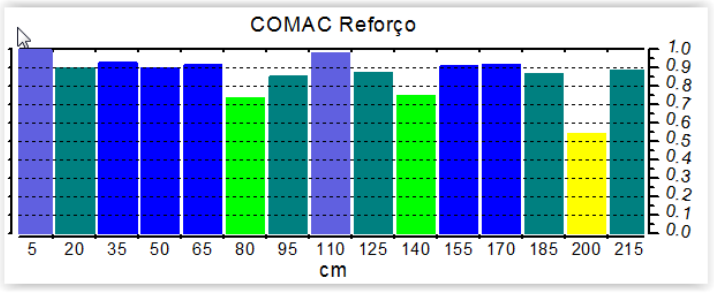

$4^{\circ}$ Modo de vibração

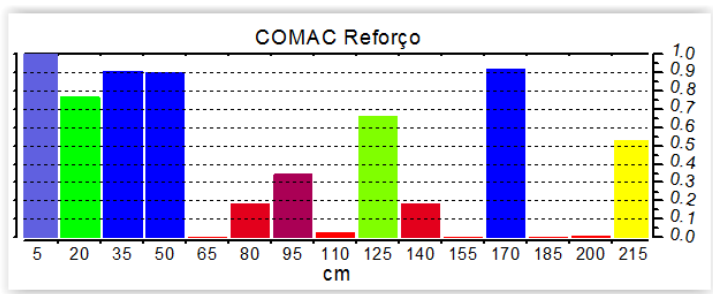

$5^{\circ}$ Modo de vibração

Gráfico 7.27 - Estudo do COMAC usando entre $3^{\circ}$ e $5^{\circ}$ modos de vibração - Reforço

Após o acréscimo do reforço, quando utilizado os $5^{\circ}$ modos de vibração o COMAC apresentou índices de dano completamente incoerentes com a configuração da viga, apresentando coeficientes próximos a 0 em diversas posições, fato que somente deveria ocorrer após a ruptura da viga. O método MAC desta viga destaca a má relação no quinto modo de vibração entre as configurações Íntegra e Reforço, não devendo a mesma ser utilizada nos demais métodos.

Essa falta de relação entre os modos de vibração observada no MAC pode causar interpretações incorretas de dano ao longo da viga ao estudar os métodos de detecção de dano COMAC, DCM e ID.

Foi observado também a capacidade de identificação dos métodos quando a viga possuía dano elevado, como a quantidade de modos de deformação utilizados nessa análise podem 
influencia-las. Os valores de MAC são apresentados no Gráfico 7.28 e os valores de COMAC no Gráfico 7.29 na configuração Ruptura. Após a Ruptura.

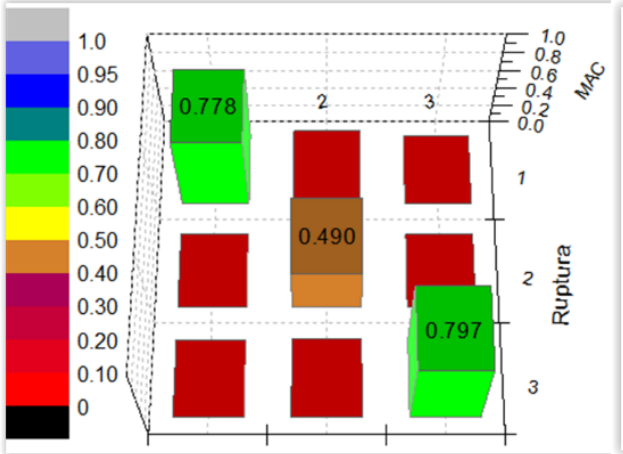

(a) $3^{\circ}$ Modo de vibração

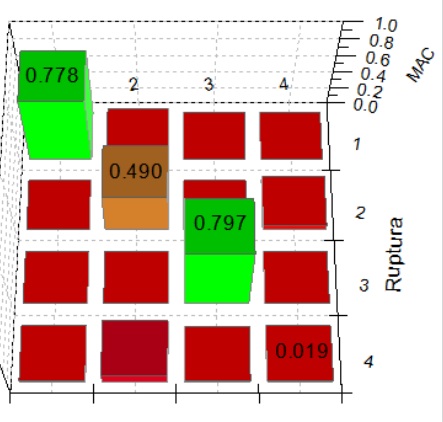

(b) $4^{\circ}$ Modo de vibração

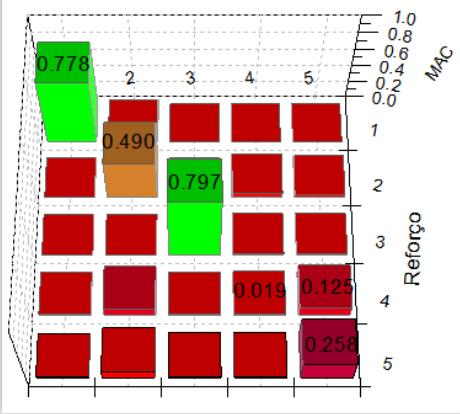

(c) $5^{\circ}$ Modo de vibração

Gráfico 7.28 - Estudo do MAC usando entre $3^{\circ}$ e $5^{\circ}$ modo de vibração - Ruptura

$\mathrm{Na}$ configuração Ruptura é compreensivo que os coeficientes no MAC apresentem maiores discrepâncias, com valores inferiores aos apresentados nas demais configurações das vigas, pois o dano é elevado, tendo em muitas das vigas ocorrido destacamento de camadas de concreto e grandes fissuras. Nesta configuração os três primeiros modos de vibração apresentaram coeficientes baixos, indicando elevada variação na rigidez da viga, mas o quarto e quinto modo de vibração apresentaram valores muito baixos, com MAC de 0,019 para o quarto modo de vibração.

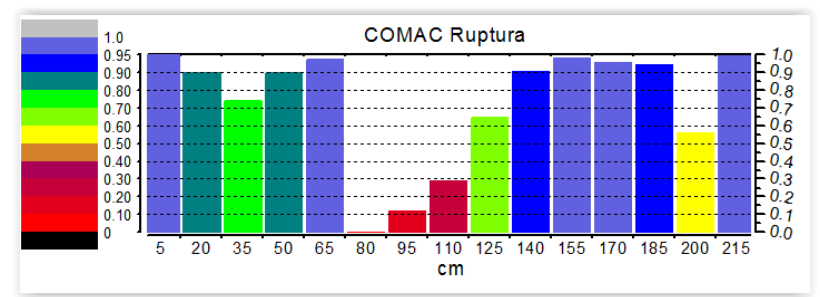

$3^{\circ}$ Modo de vibração

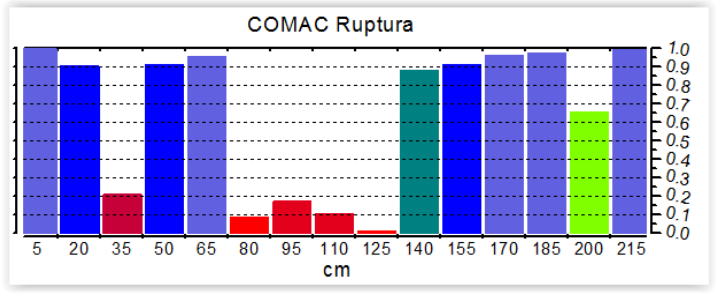

$4^{\circ}$ Modo de vibração

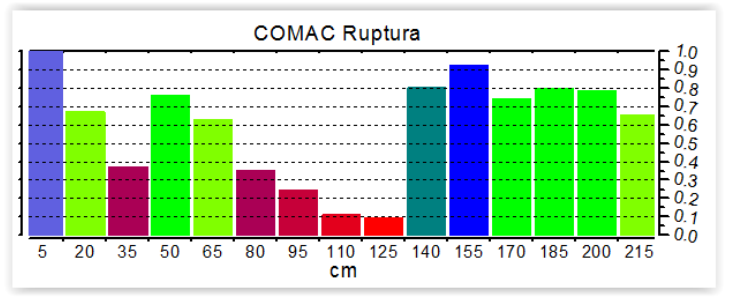

$5^{\circ}$ Modo de vibração

Gráfico 7.29 - Estudo do COMAC usando entre $3^{\circ}$ e $5^{\circ}$ modos de vibração - Ruptura

$\mathrm{Na}$ configuração Ruptura com $3^{\circ}$ modos de vibração, na posição $80 \mathrm{~cm}$ ocorre um coeficiente próximo a 0 , indicando a ruptura da viga, com grandes fissurações nas posições entre $95 \mathrm{~cm}$ e $125 \mathrm{~cm}$. Após o acréscimo do quarto modo de vibração, o COMAC apresentou coeficientes parecidos, com identificação da ruptura nas posições $80 \mathrm{~cm}$ à $125 \mathrm{~cm}$ e quando utilizado os $5^{\circ}$ modos e vibração aparecem vários pontos com baixos coeficientes COMAC entre a posição $170 \mathrm{~cm}$ e $215 \mathrm{~cm}$. 
Sabendo-se que nesta viga a Ruptura ocorreu com maior fissura na posição $80 \mathrm{~cm}$ é possível perceber os problemas causados pela consideração do modo de vibração quando os coeficientes MAC são baixíssimos, como ocorrido para esta viga nas configurações Reforço e Ruptura quando considerado o quinto modo de vibração.

Como conclusão deste estudo, temos que quando a viga apresenta pequeno dano, como nas configurações Dano e Ranhura, a redução dos coeficientes MAC e COMAC também são pequenas, dificultando a identificação do dano. Quando ocorreu a Ruptura e consequentemente um grande dano, os dois métodos apresentaram uma boa capacidade de identificação, assim, a configuração de Ruptura das vigas foi fundamental para identificar a eficácia dos métodos apresentados, definindo assim o que cada método permite identificar.

Dentre as quantidades de modo de vibração estudados observou-se uma maior incidência de falsos danos ao utilizar $5^{\circ}$ modos, principalmente na região com menor fissuração da viga. Este efeito foi aqui demostrado na viga V50 40\%, mas também foi identificado em outras vigas.

Dadas estas conclusões, nesta pesquisa utilizou-se, sempre que possível, quatro modos de vibração para os métodos de identificação de dano. Minimizando possíveis erros ocasionados pelo quinto modo e, quando verificado pelo MAC baixíssimos coeficientes foram utilizados apenas três ou dois modos de vibração. Além do COMAC como método de identificação de dano este critério de limite de modo de vibração será utilizado nos DCM e ID.

\subsubsection{Vigas V50}

Os coeficientes MAC e COMAC destas vigas são apresentados no Apêndice D, devido a grande quantidade de gráficos gerados nesses métodos de avaliação de dano. Sendo aqui descritas apenas as principais observações e análises identificadas em cada viga.

Na viga V50 SR, somente foi avaliada a configuração Ruptura, por esta não apresentar as demais. Nesta o MAC apresentou boa capacidade de identificação do dano, com coeficientes baixos em todos os modos, tendo como pior relação o terceiro modo de vibração com coeficiente 0,597. Essa variação indica grande alteração dos modos de vibração flexionais.

Nesta viga o método COMAC apresentou baixos coeficientes nas posições $65 \mathrm{~cm}, 95 \mathrm{~cm}$, $110 \mathrm{~cm}$ e $155 \mathrm{~cm}$, com coeficientes menores que 0,20 , indicando ruptura ou elevada fissuração nestes locais. Identificando corretamente o local de ruptura da viga, mas apresentando dano elevado em posições incorretas.

Na viga V50 CFRP na configuração Ranhura, os coeficientes MAC apresentaram relação muito próximas a 1 para todos os modos de vibração, tendo como menor valor o terceiro modo, 
com 0,936 . Essa proximidade da unidade indica a presença de baixo dano na viga, causada apenas pela abertura das ranhuras. Quando inserido o Reforço, os coeficientes MAC reduziram consideravelmente no primeiro e quarto modo de vibração, identificando erroneamente a presença de dano na viga.

$\mathrm{Na}$ configuração Ruptura dessa viga, o método MAC apresentou baixas relações no segundo modo de vibração com coeficiente 0,197 , identificando grande presença de dano. O quarto modo de vibração apresentou coeficiente 0,096 demostrando praticamente nenhuma relação entre as configurações Íntegra e Ruptura. Assim, para os demais métodos de identificação de dano utilizados COMAC, DCM e ID, na configuração Ruptura desta viga somente serão considerados os três primeiros modos de vibração.

O Gráfico 7.30 apresenta os coeficientes COMAC para a viga V50 CFRP comparando as configurações de Ranhura, Reforço e Ruptura com a Íntegra.
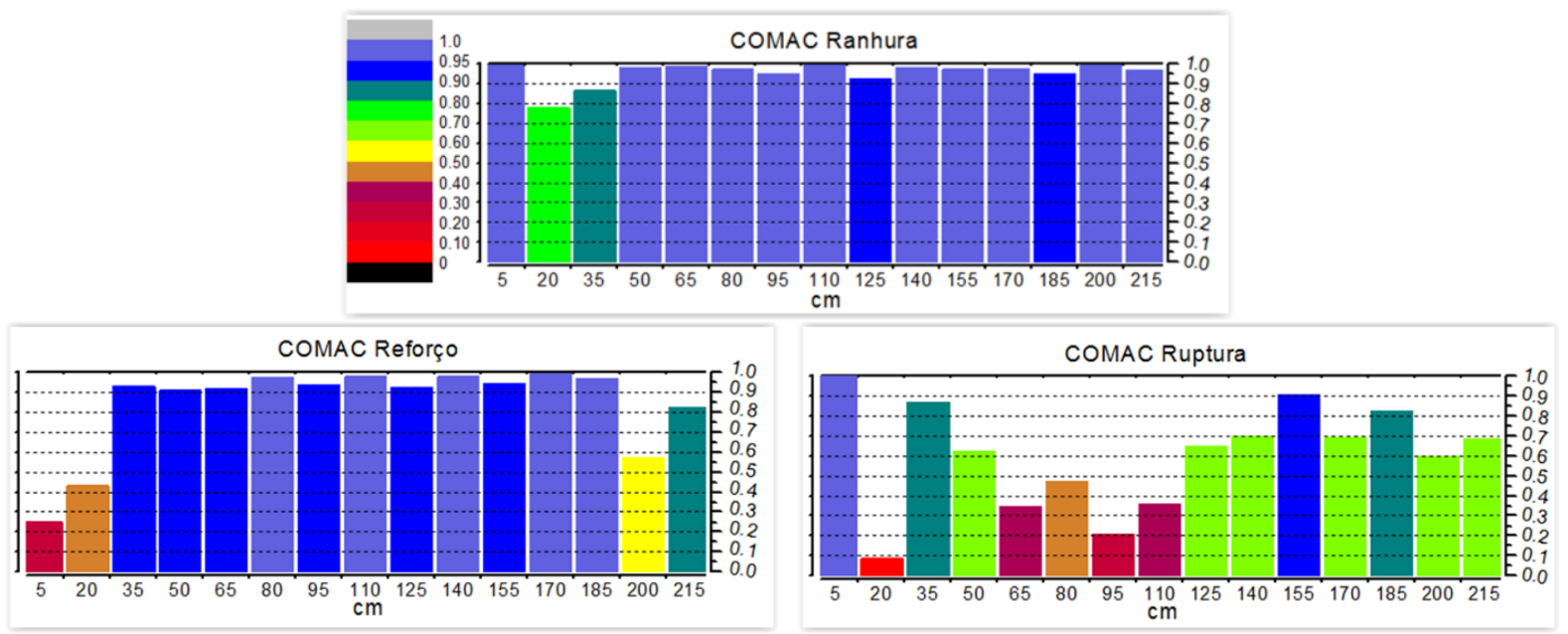

Gráfico 7.30 - COMAC V50 CFRP

$\mathrm{Na}$ viga V50 CFRP com Ranhura, o método COMAC identificou pequeno dano na posição $20 \mathrm{~cm}$ e $35 \mathrm{~cm}$, com os demais coeficientes acima de 0,9 . As pequenas variações do COMAC representam um pequeno dano na viga, assim como identificado no MAC.

Quando reforçada, a viga apresentou baixos coeficientes COMAC nas posições $5 \mathrm{~cm}$, $20 \mathrm{~cm}$ e $200 \mathrm{~cm}$, confirmando a identificação incorreta explicada no método MAC. Ocorreu na posição $5 \mathrm{~cm}$ uma inversão de sinal no modo de vibração.

Em muitas vigas foram identificadas grandes alterações nas posições $20 \mathrm{~cm}$ e $200 \mathrm{~cm}$. Essas posições sofrem maiores influencias dos apoios, regiões onde ocorrem maiores perturbações nos modos de vibração. Em muitos desses resultados, a ocorrência de baixos coeficientes nessas posições são falsas indicações de dano. 
Após a Ruptura, o método COMAC identificou dano generalizado em praticamente toda viga, sendo que a parte esquerda, entre as posições $110 \mathrm{~cm}$ e $215 \mathrm{~cm}$ deveriam apresentar altos coeficientes, pois nesta região não ocorreram grandes fissuras. Foram identificados maiores danos nas posições $20 \mathrm{~cm}$ e $110 \mathrm{~cm}$, de forma errônea, pois a ruptura desta viga ocorreu na posição $80 \mathrm{~cm}$, com grandes fissurações ente $35 \mathrm{~cm}$ e $65 \mathrm{~cm}$.

Para a viga V50 40\% os gráficos de MAC e COMAC já foram devidamente explicados no estudo da quantidade de modos de vibração. Ocorrendo pequenas indicações de dano nas configurações Dano e Ranhura, com maior concentração na posição $20 \mathrm{~cm}$.

$\mathrm{Na}$ mesma viga, na configuração Reforço ocorreram maiores alterações, com COMAC inferiores a 0,75 nas posições $80 \mathrm{~cm}$ e $140 \mathrm{~cm}$, além de coeficientes 0,54 na posição $200 \mathrm{~cm}$. Ao contrário do esperado, a inserção do Reforço reduziu os coeficientes COMAC indicando um acréscimo de fissuração na viga. Os coeficientes MAC apresentaram um coeficiente de 0,759 para o primeiro modo de vibração, valor baixo para uma viga com reforço. Essa mudança no modo de vibração influenciou todos os métodos de detecção de dano.

Na Ruptura, a identificação do dano ocorreu de forma mais adequada que na configuração Reforço, apresentando coeficientes abaixo de 0,10 na posição $80 \mathrm{~cm}$, local onde realmente ocorreu a maior fissura da viga V50 40\%, além de COMAC baixos nas posições $95 \mathrm{~cm}$ e $110 \mathrm{~cm}$ indicando grandes fissuras no local e pequenas variações nas posições $20 \mathrm{~cm}$ e $200 \mathrm{~cm}$ próximos aos apoios onde também houve fissuras. O método COMAC permitiu localizar e quantificar corretamente o dano ocorrido nas configurações Dano e Ruptura, mas não apresentou bons resultados para a viga Reforçada.

$\mathrm{Na}$ viga V50 com maior carregamento prévio, a V50 70\%, na configuração Dano apresentou coeficientes muito baixos, indicando a fissuração da viga entre a posição $50 \mathrm{~cm}$ e $80 \mathrm{~cm}$, além de baixos índices entre as posições $125 \mathrm{~cm}$ e $215 \mathrm{~cm}$ que não deveriam existir. A magnitude do dano identificado pelo método COMAC indica fissuras moderadas, condizentes com o carregamento prévio. Os coeficientes MAC indicaram a mesma presença de dano, ocorrendo maior alteração no $4^{\circ}$ modo de vibração, com MAC de 0,821 .

Após a Ranhura o método COMAC apresentou resultados não usuais, indicando a presença de melhoria dos modos de vibração, com aumento dos coeficientes COMAC em relação a configuração Dano. O mesmo efeito foi identificado no método MAC. O comportamento usual dos coeficientes COMAC nas configurações Ranhura demostram que os valores apresentados na configuração Dano não são adequados, pois ao acrescentar ranhuras na viga danificada seus 
coeficientes deveriam piorar, ou apresentar coeficientes de mesma magnitude, já que o dano permaneceu na viga.

Observou-se na viga V50 70\%, que com o acréscimo do reforço, os coeficientes COMAC reduzem um pouco mais, não permitido identificar por este método as melhorias na rigidez da viga decorrentes do Reforço. Com coeficientes MAC menores no $1^{\circ}$ e $2^{\circ}$ modos e reduzindo no $3^{\circ} \mathrm{e}$ $4^{\circ}$ modos.

$\mathrm{Na}$ ruptura esta viga apresentou os piores coeficientes MAC, sendo desconsiderados os valores dos $3^{\circ}$ e $4^{\circ}$ modos de vibração para os demais métodos de identificação de dano. O método COMAC permitiu identificar na configuração Ruptura a posição onde ocorreu ruptura na viga, com COMAC de 0,27 na posição $65 \mathrm{~cm}$, local onde realmente ocorreram as maiores fissuras da viga V50 70\%. Neste gráfico observamos ainda baixos índices entre a posição $185 \mathrm{~cm}$ e $200 \mathrm{~cm}$ indicando incorretamente um elevado nível de fissuração nesta região.

\subsubsection{Vigas V90}

$\mathrm{Na}$ viga V90 SR, os coeficientes MAC do segundo ao quarto modo de vibração apresentaram baixos valores, identificando em todos as frequências naturais o dano causado pela ruptura e teve como pior relação o terceiro modo de vibração, com coeficientes MAC de 0,459. Ao comparar os coeficientes MAC das vigas V50 SR e V90 SR observou-se valores semelhantes e ocorrendo nas duas vigas após a ruptura uma maior penalização no terceiro modo de vibração.

O método COMAC apresenta coeficientes ao longo da viga V90 SR, identificando os locais em que os modos de deformação das vigas sofreram maiores alterações. O Gráfico 7.31 apresenta seus coeficientes para a viga V90 SR, comparando a configurações Ruptura com a Íntegra.

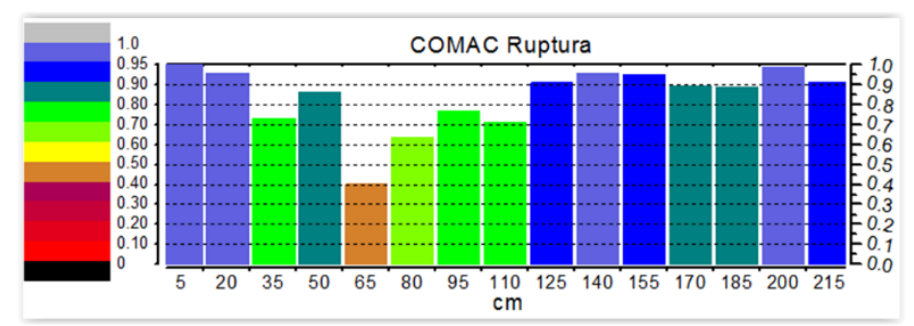

Gráfico 7.31 - COMAC V90 SR

O método COMAC identificou bem as fissurações ocorridas nesta viga, indicando maior alterações na posição $65 \mathrm{~cm}$, onde ocorre realmente na viga, as maiores fissuras e com coeficientes COMAC de menor intensidade nas posições vizinhas. Indicando ainda baixas variações entre as posições $125 \mathrm{~cm}$ e $215 \mathrm{~cm}$ onde ocorreram apenas pequenas fissuras de flexão. 
Os coeficientes MAC da viga V90 CFRP apresentaram relação muito próximas a 1 para todos os modos de vibração Igualmente ao ocorrido na viga V50 SR na configuração Ranhura e Reforço. Essa proximidade da unidade indica a presença de pequenos danos na viga, causada apenas pela abertura das ranhuras, já que estas vigas não sofreram carregamento prévio. No método COMAC a viga apresentou poucas variações apenas nas posições $20 \mathrm{~cm}$ e $200 \mathrm{~cm}$, influenciadas pela proximidade dos apoios.

O método MAC na configuração Ruptura apresentou baixas relações no segundo, terceiro e quarto modos de vibração, identificando elevados índices de dano ou uma péssima relação entre os modos. Novamente o quarto modo de vibração apresentou coeficiente muito baixo, demostrando praticamente nenhuma relação entre as configurações Íntegra e Ruptura, sendo desconsiderado para os demais métodos de identificação de dano. O método COMAC apresentou baixos coeficientes entre as posições $80 \mathrm{~cm}$ e $125 \mathrm{~cm}$, indicando corretamente o local de ruptura da estrutura.

O Gráfico 7.32 apresenta os coeficientes MAC da viga V90 40\% comparando as configurações Dano, Ranhura, Reforço e Ruptura com a Configuração Íntegra.

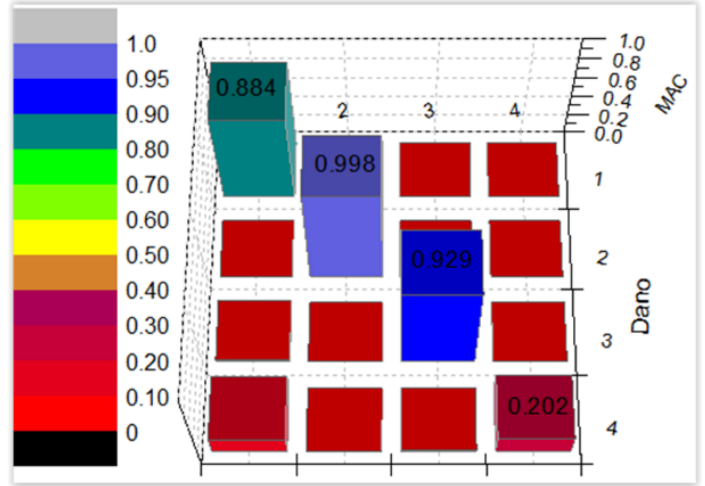

(a) Dano

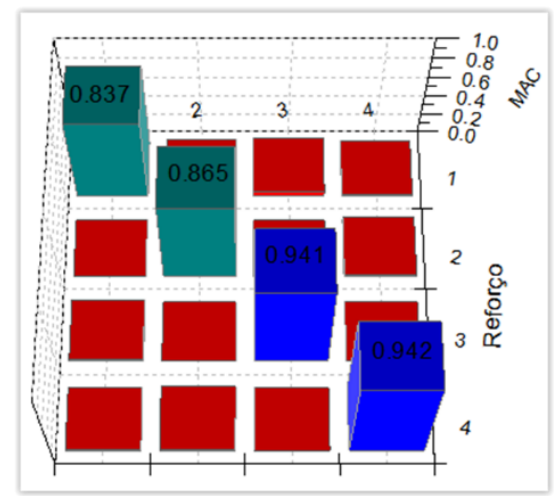

(c) Reforço

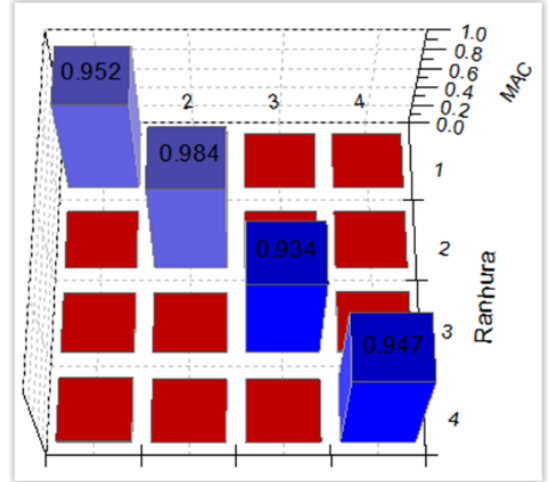

(b) Ranhura

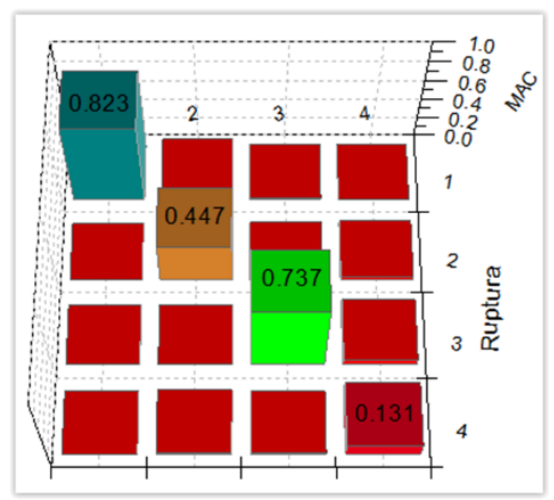

(d) Ruptura

Gráfico 7.32 - MAC V90 40\% 
$\mathrm{Na}$ viga V90 40 \%, após o carregamento prévio foi possível identificar o dano, onde houve maiores alterações no primeiro e quarto modos de vibração, com coeficientes MAC de 0,884 e 0,202 respectivamente. Devido ao baixo coeficiente do quarto modo de vibração, este foi desconsiderado nos demais métodos de identificação de dano. O método COMAC identificou fissuração apenas na posição $35 \mathrm{~cm}$.

Com as Ranhuras, os valores dos coeficientes MAC da viga V90 40\% retornaram ao usual, identificando pequenas reduções oriundas do carregamento prévio e das ranhuras. A melhora dos coeficientes MAC com o acréscimo de ranhuras mostram problemas nos ensaios na configuração Dano. Esse mesmo efeito foi identificado na viga V50 70\%. Já o método COMAC indicou erroneamente dano moderado em quase toda a viga.

Na configuração Reforço ocorrem acréscimos dos coeficientes COMAC, indicando uma melhora na rigidez da viga, permitindo por este método identificar a presença do reforço na viga V90 40\%. Diferentemente do indicado no MAC, que apresentou reduções dos coeficientes no $1^{\circ}$ e $2^{\circ}$ modos.

Na configuração Ruptura o método MAC permitiu identificar grandes variações para todos os modos de vibração, apresentando baixo coeficiente, 0,447 , para o segundo modo. O quarto modo de vibração foi novamente desconsiderado para as análises dos demais métodos de identificação de dano, por apresentar baixíssimo coeficiente MAC $(0,131)$. No COMAC a identificação do dano ocorreu corretamente.

$\mathrm{Na}$ viga V90 70\% O método MAC não permitiu identificar alterações nos modos de vibração, com todos os coeficientes próximos a 1. Já no método COMAC foram identificadas pequenas variações nas posições $20 \mathrm{~cm}, 35 \mathrm{~cm}, 65 \mathrm{~cm}$ e $215 \mathrm{~cm}$, indicando corretamente a presença de pequena fissuração nestas regiões.

Ao acrescentar Ranhuras percebeu-se grande variação dos coeficientes MAC. Principalmente no $1^{\circ}$ e $4^{\circ}$ modos de vibração. No COMAC ocorre a indicação de grande variação nas posições $20 \mathrm{~cm}$ e $35 \mathrm{~cm}$, indicando grande dano na região, causado pela abertura das ranhuras.

Com o Reforço, a viga V90 70\% apresentou pequena melhora nos coeficientes MAC, principalmente no $4^{\circ}$ modo de vibração. Esta melhora foi confirmada no método COMAC, onde continua o dano nas posições $20 \mathrm{~cm}$ e $35 \mathrm{~cm}$, mas com menor intensidade, indicando claramente a capacidade de identificação do reforço pelo método, nesta viga.

Os valores de MAC e COMAC na Ruptura desta viga divergem de todas as demais, com coeficientes elevados em todas as frequências naturais, indicando a presença de poucas fissuras 
como se a viga não estivesse rompida. Nesta viga ocorreu baixa fissuração, com ruptura na flexão e sem destacamento do cobrimento do concreto na região reforçada.

\subsection{DCM E ID}

No método de Diferença de Curvatura Modal (DCM) ocorre uma ampliação das descontinuidades do modo de vibração causadas por danificações localizadas, pois as curvaturas modais são derivadas dos modos de vibração. Desta forma, a diferença entre as curvaturas da configuração Íntegra e danificadas permitem uma melhor localização da região danificada da estrutura. O método permite além de identificar, quantificar o dano ao longo do comprimento da viga.

Para as vigas estudadas observou-se que o método quantifica a variação das curvaturas, podendo comparar seus valores ao longo do comprimento ou com as demais vigas. Neste estudo variações até 4 DCM foram consideradas com baixa intensidade, indicando pequenas ou sem fissuração; Com valores de DCM entre 5 e 7 considerou-se que ocorreram fissuras na viga; valores entre 8 e 10 indicaram elevada fissuração e quando os valores de DCM foram maiores que 10 considerou-se que ocorreu ruptura naquela posição da viga.

Já o método do Índice de Dano (ID), permite identificar ao longo da viga locais onde ocorreram variações na energia de deformação maiores que a média, considerando que a rigidez é reduzida devido uma fissura, este local apresentará uma maior redução na energia de deformação. Devido aos seus índices serem medidos utilizando a média e o desvio padrão, percebeu-se que este método não permite identificar a magnitude do dano, somente a posição.

Para a análise destes métodos são apresentados todos os gráficos de DCM e ID em todas as configurações das vigas. Estes foram analisados na capacidade de identificação da magnitude e local do dano e quando necessário, comparados com os demais métodos utilizados na detecção do dano.

\subsubsection{V50 SR}

Nos Gráfico 7.33 e Gráfico 7.34 são apresentadas as Diferenças de Curvatura Modal e Índice de Dano para a viga V50 SR, comparando a configuração Ruptura com a Íntegra ao longo do comprimento da viga. 


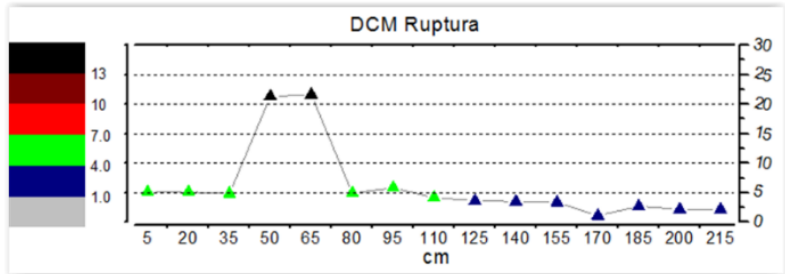

Gráfico 7.33 - DCM V50 SR

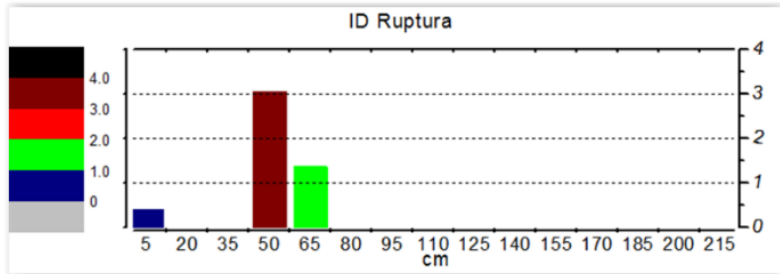

Gráfico 7.34 - ID V50 SR

O método identificou variações da curvatura, com DCM próximo a 5 nas posições $5 \mathrm{~cm}$ a $35 \mathrm{~cm}$ e $80 \mathrm{~cm}$ a $110 \mathrm{~cm}$, indicando local com fissuras e DCM com valores próximos a 22 nas posições $50 \mathrm{~cm}$ e $65 \mathrm{~cm}$, indicando o local com grandes fissuras ou ruptura da viga. A região entre a posição $125 \mathrm{~cm}$ e $215 \mathrm{~cm}$ apresentaram DCM abaixo de 4 , indicando local de baixa fissuração.

O Índice de Dano (ID) identificou elevado valor elevado na posição $50 \mathrm{~cm}$, identificando maiores variações de energia de deformação neste local, um índice médio $(1,3)$ na posição $65 \mathrm{~cm}$ identificou a presença de grandes variações de energia de deformação. A viga não apresentou ID na parte menos solicitada da viga, entre as posições $110 \mathrm{~cm}$ e $215 \mathrm{~cm}$.

Para a viga 50 SR, a DCM e o ID identificaram de maneira correta o dano ocorrido, pois o carregamento foi posicionado a $85 \mathrm{~cm}$, não ocorrendo fissurações no lado menos solicitado da viga $(110 \mathrm{~cm}$ a $220 \mathrm{~cm})$ e com as fissuras de ruptura ocorrendo nas posições entre a posição $35 \mathrm{~cm}$ e $80 \mathrm{~cm}$, conforme verifica-se na Figura 7.2.

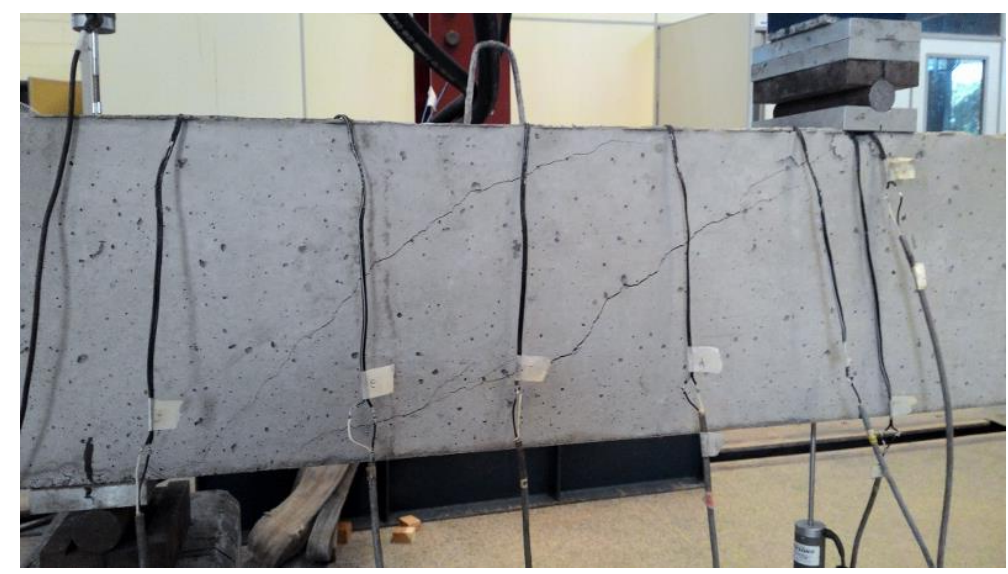

Figura 7.2 - Fissuração da viga V50 SR

\subsubsection{V50 CFRP}

São apresentadas as Diferenças de Curvatura Modal, comparando as configurações Ranhura, Reforço e Ruptura com a configuração Íntegra ao longo do comprimento da viga no Gráfico 7.35 . 

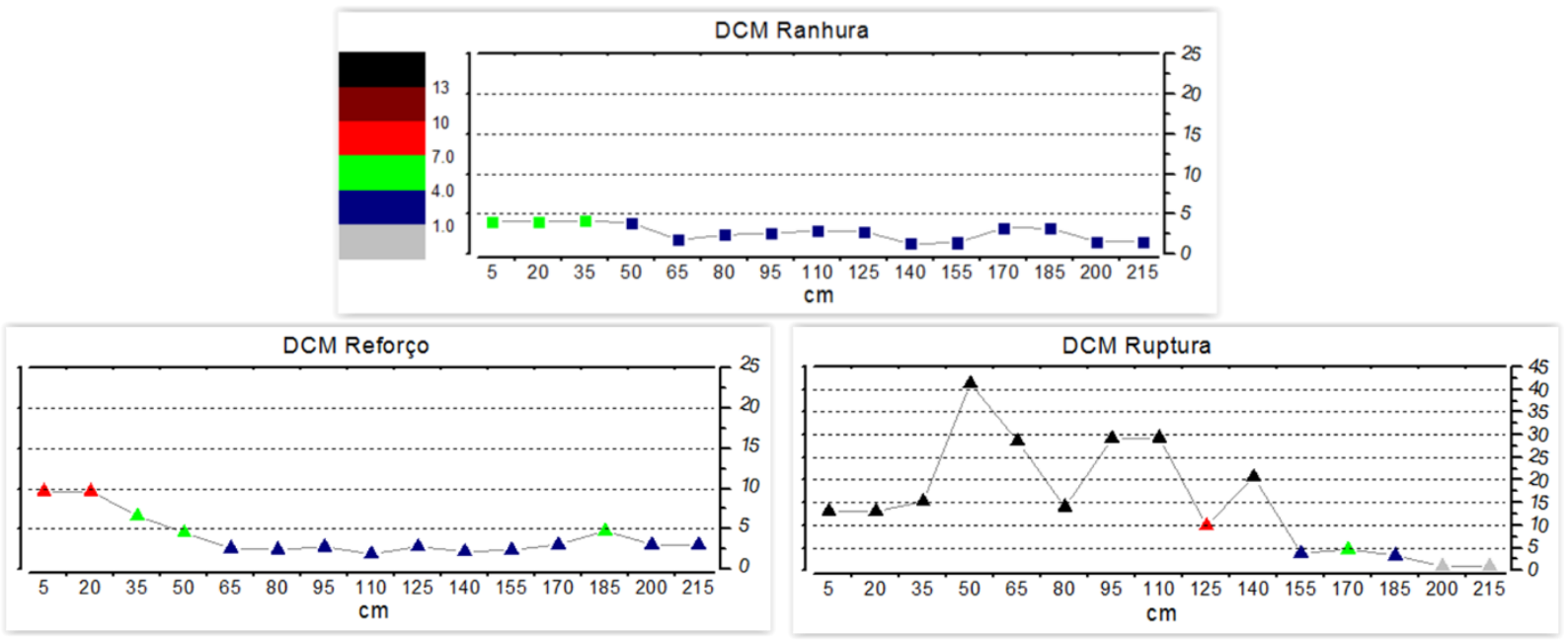

Gráfico 7.35 - DCM V50 CFRP

Ao acrescentar Ranhuras na viga, a DCM identifica fissuração com valores próximos a 5 entre as posições $5 \mathrm{~cm}$ e $50 \mathrm{~cm}$, sendo que as Ranhuras foram inseridas entre as posições $0 \mathrm{~cm}$ e $90 \mathrm{~cm}$. O dano oriundo da Ranhuras é pequeno, igualmente ao identificado pelo método.

Com o Reforço, o método DCM apresenta coeficientes próximos a 10 nas posições $5 \mathrm{~cm}$ e $20 \mathrm{~cm}$, indicando uma fissuração no início da viga. Está hipótese seria plausível caso a viga tivesse sofrido carregamento prévio e consequentemente sofrido fissuras no local de apoio, fato que não ocorreu. Sendo esta identificação de dano falsa, verificada principalmente no quarto modo de vibração onde houve inversão de sinal nesta posição. As demais posições apresentam baixas diferenças de curvatura, com valores próximos aos ocorridos na configuração Ranhura.

A DCM na Ruptura apresenta grandes coeficientes entre as posições $35 \mathrm{~cm}$ e $140 \mathrm{~cm}$, com maior intensidade em $50 \mathrm{~cm}$, diferentemente ao ocorrido na realidade, onde a ruptura ocorre na posição $80 \mathrm{~cm}$, com fissurações entre a posição $20 \mathrm{~cm}$ e $65 \mathrm{~cm}$ e praticamente não ocorre fissuração na região entre as posições $110 \mathrm{~cm}$ a $215 \mathrm{~cm}$.

Os Índices de Dano da viga V50 CFRP são apresentados no Gráfico 7.36, na comparação entre as configurações Ranhura, Reforço e Ruptura com a configuração Íntegra. 


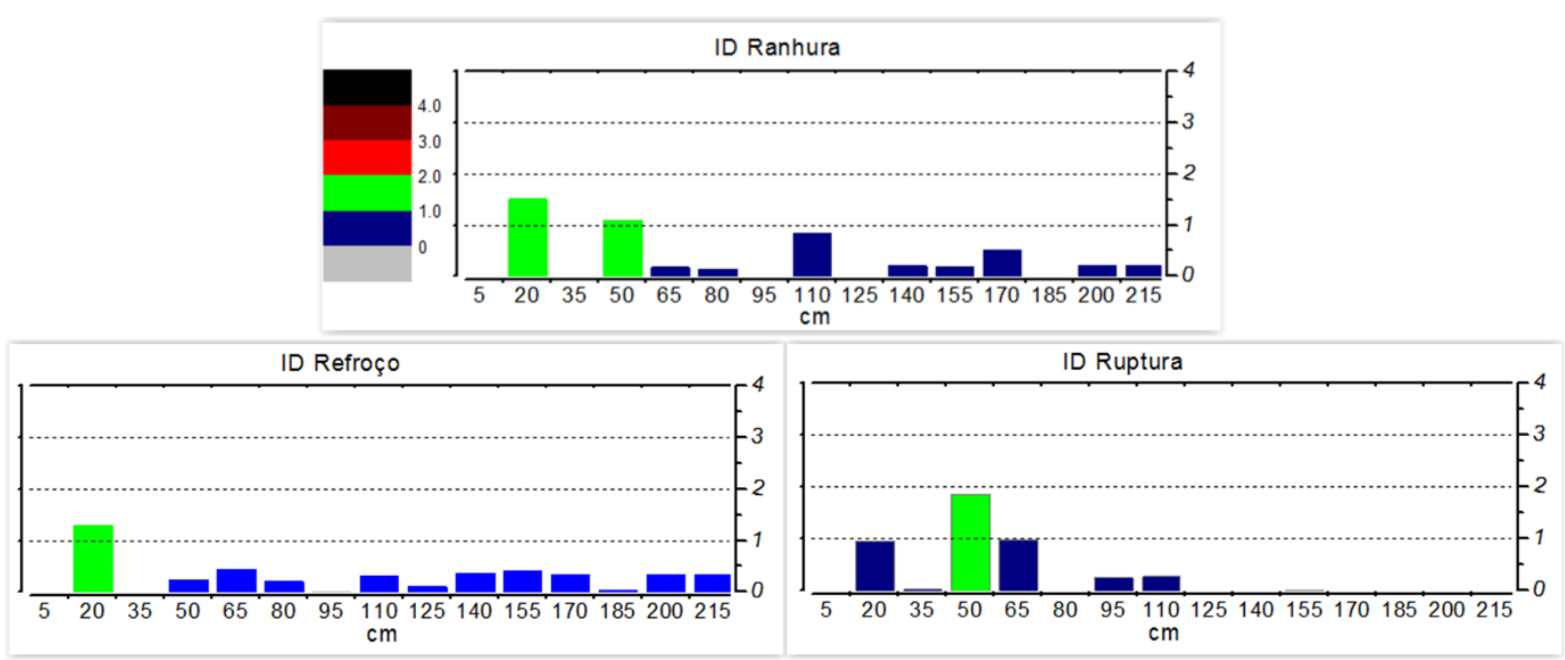

Gráfico 7.36 - ID V50 CFRP

O Índice de Dano permitiu observar as pequenas variações ocorridas na configuração Ranhura, mesmo sendo baixas as variações ocasionadas pelas ranhuras foram identificadas. Observou-se pequenos índices ao longo de quase toda a viga, com maior destaque para as posições $20 \mathrm{~cm}$ e $50 \mathrm{~cm}$.

Com o reforço, o dano causado pelas ranhuras é minimizado, apresentando menores variações de energia de deformação, reduzindo assim o Índice de Dano principalmente nas posições $50 \mathrm{~cm}$ e $110 \mathrm{~cm}$. O maior índice permaneceu na posição $20 \mathrm{~cm}$, mas com baixos ID.

Objetivando a identificação do reforço em estruturas pelos métodos propostos, observou-se que este método apresentou uma pequena redução dos Índices de dano após o reforço, mas com valores insuficientes para que se possa validar a presença de reforço apenas por este método.

Após a ruptura o método apresentou ID de 1,9, com maiores variações de energia de deformação na posição $50 \mathrm{~cm}$, com índice baixo nas posições $20 \mathrm{~cm}$ e $65 \mathrm{~cm}$ e praticamente sem ID no lado direito da viga, na região entre as posições $110 \mathrm{~cm}$ a $215 \mathrm{~cm}$.

Este método para esta viga foi o melhor em identificar a posição de ruptura da viga, sem a identificação de falsos danos como ocorrido no COMAC e DCM. Mesmo assim não apresentou a posição correta do dano na Ruptura, que ocorreu adjacente ao pondo de aplicação da força na posição $80 \mathrm{~cm}$, como pode ser observado na Figura 7.3. 


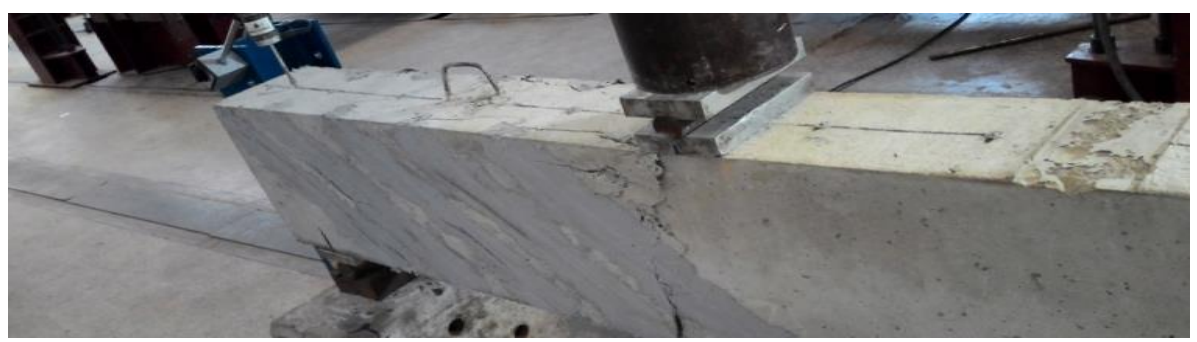

Figura 7.3 - Fissuração da viga V50 CFRP

\subsubsection{V50 $40 \%$}

No Gráfico 7.37 são apresentadas as DCM para todas as configurações da viga V50 40\%.

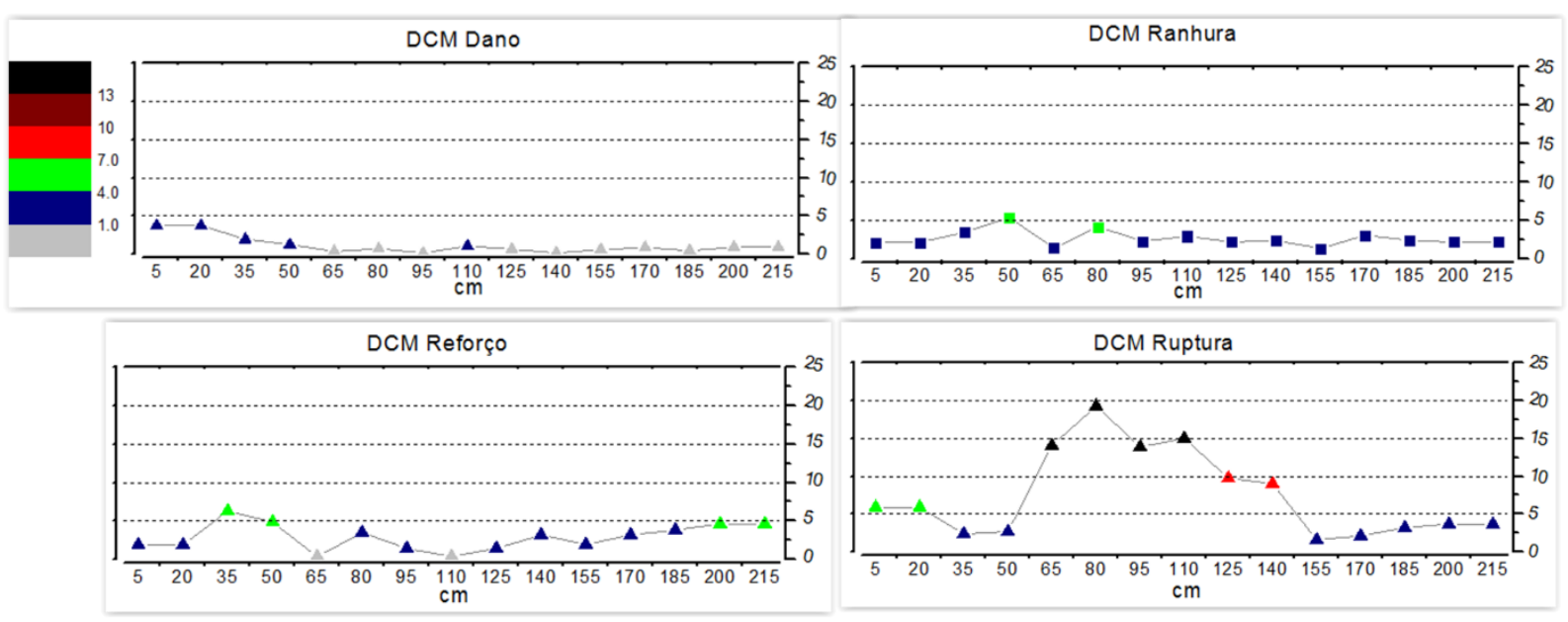

Gráfico 7.37 - DCM V50 40\%

As DCM apresentam pequenos valores nas regiões de $5 \mathrm{~cm}$ a $50 \mathrm{~cm}$, indicando uma pequena alteração da configuração Dano, já com as Ranhuras os coeficientes aumentam para toda a viga, permanecendo em sua maioria abaixo de 4 , com exceção das posições $50 \mathrm{~cm}$ e $80 \mathrm{~cm}$, com valores próximos a 5, indicando um acréscimo na redução da rigidez da viga, mas ainda com pequena intensidade. Nas duas configurações o método DCM permitiu identificar corretamente o comportamento da viga.

A configuração Reforço também apresenta baixas DCM e com coeficientes próximos a 5 nas posições $35 \mathrm{~cm}, 50 \mathrm{~cm}, 200 \mathrm{~cm}$ e $215 \mathrm{~cm}$. Neste método não ocorre a falsa identificação de dano citadas no MAC e COMAC, permanecendo a viga com pequenas alterações em relação a configuração Íntegra.

$\mathrm{Na}$ Ruptura a DCM identifica grande variação na curvatura da viga entre as posições $65 \mathrm{~cm}$ e $140 \mathrm{~cm}$, com pico de 20 DCM na posição $80 \mathrm{~cm}$. O resultado deste método indica corretamente fissuração grande no lado onde ocorre a ruina da viga, mas indica também erroneamente grades fissuras entre as posições $110 \mathrm{~cm}$ e $140 \mathrm{~cm}$. 
O Índices de Dano também são apresentados para todas as configurações da viga V50 40\% no Gráfico 7.38, na comparação entre as configurações Dano, Ranhura, Reforço e Ruptura com a configuração Íntegra.

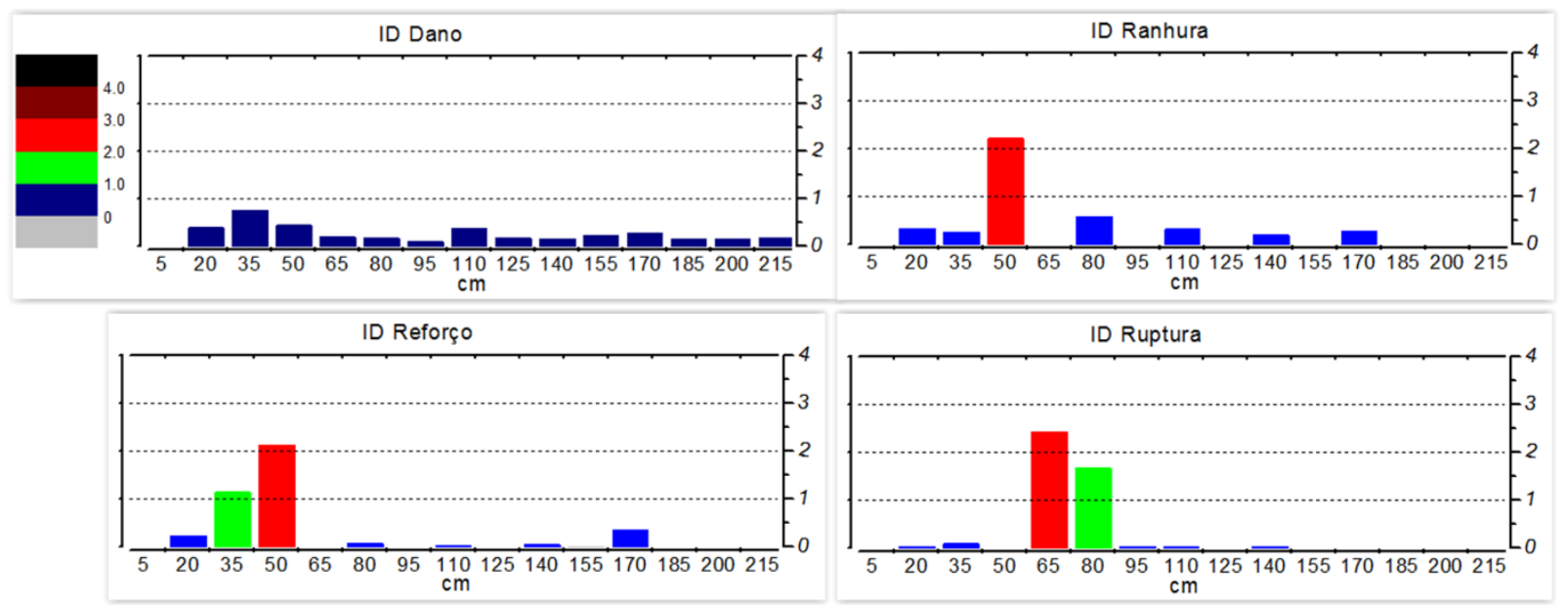

Gráfico 7.38 - ID V50 40\%

Na configuração Dano praticamente toda a viga apresentou baixíssimos ID, indicando pequenas variações de energia na viga toda, sem um ponto especifico de dano, onde apenas a posição $5 \mathrm{~cm}$ apresentou valores menores que a média.

Com o acréscimo das Ranhuras o ID identificou na posição $50 \mathrm{~cm}$ uma maior diferença com índice de 2,2, bem superior às demais posições. Após o Reforço, o ID foram destacados nas mesmas posições, com valores menores. Novamente o método permite identificar pequenas alterações entre as configurações Ranhura e Reforço, com reduções dos índices em quase toda a viga.

Na configuração Ruptura o método identificou maior variação da energia de deformação na posição $65 \mathrm{~cm}$, com valor elevado também na posição $80 \mathrm{~cm}$ e praticamente sem ID no lado direito da viga, na região entre as posições $110 \mathrm{~cm}$ a $215 \mathrm{~cm}$. O método permitiu Identificar a posição de ruptura da viga, sem a identificação de falsos danos como os demais métodos aqui apresentados.

\subsection{4. $\quad \mathrm{V} 5070 \%$}

No Gráfico 7.39 são apresentadas as DCM para todas as configurações da viga V50 70\%. 

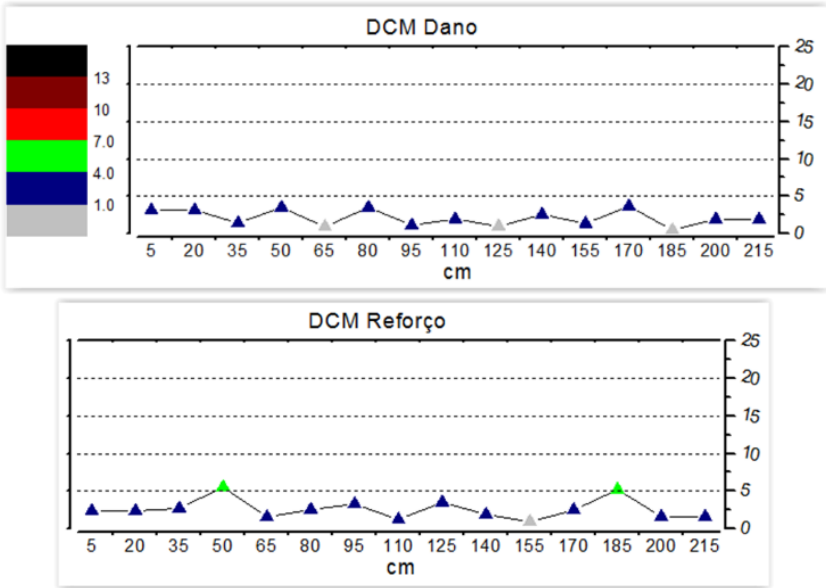

Gráfico 7.39 - DCM V50 70\%
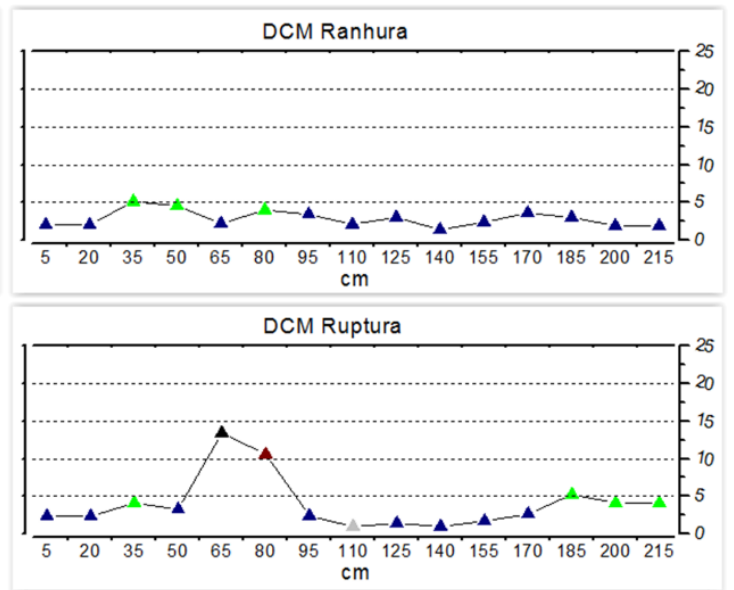

$\mathrm{cm}$

As DCM apresentam pequenos valores na configuração Dano ao longo de toda viga, não identificando o local onde ocorreu o carregamento prévio. Ao inserir as Ranhuras, alguns coeficientes aumentam na região entre as posições $35 \mathrm{~cm}$ e $80 \mathrm{~cm}$, indicando uma maior redução da rigidez da viga, mas ainda com pequena intensidade, podendo ser considerado como pequeno dano na região.

A configuração Reforço também apresenta baixas DCM e com coeficientes próximos a 5 nas posições $50 \mathrm{~cm}$ e $185 \mathrm{~cm}$. A configuração Reforço apresentou variações na curvatura menor que a configuração Ranhura, permitindo perceber por este método melhorias na rigidez da viga, mas com baixa precisão e em pequenas quantidades.

Elevadas variações DCM são identificadas apenas na configuração Ruptura, identificando as posições $65 \mathrm{~cm}$ e $80 \mathrm{~cm}$ com maiores variações das curvaturas, com o valor máximo de 14 DCM na posição $65 \mathrm{~cm}$. O resultado deste método indica corretamente o local de ruptura da viga e com coeficientes indicando pequenas fissuras nas regiões menos solicitadas da viga.

O Índices de Dano foi utilizado para analisar a diferença de energia de deformação para todas as configurações da viga V50 70\%, estes são apresentado no Gráfico 7.40.
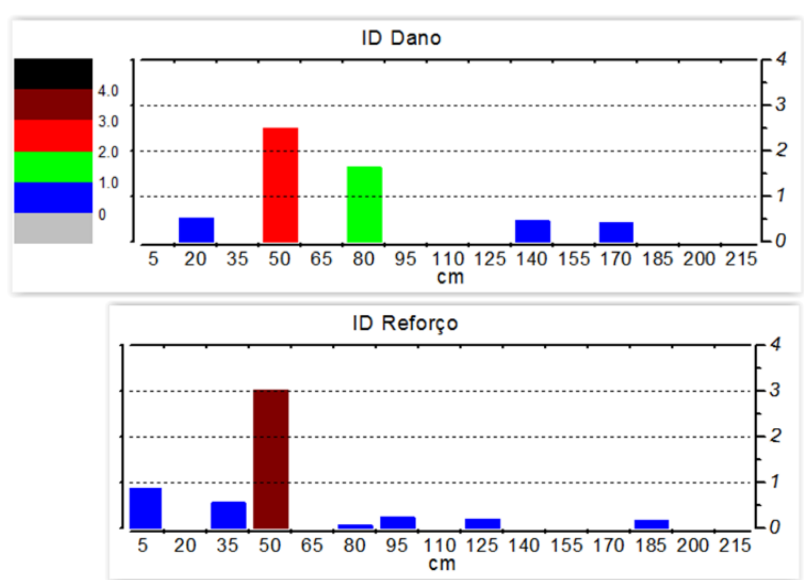

Gráfico 7.40 - ID V50 70\%
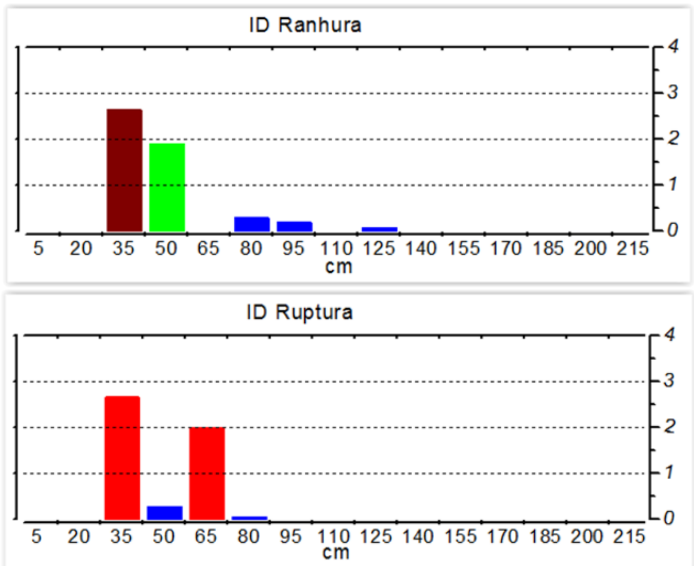

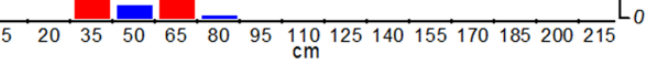


Com o incremento do Dano observou-se locais com elevada variação da energia de deformação desde o carregamento prévio, indicando a presença de fissuras na viga nesta configuração. O ID indica que nas posições $50 \mathrm{~cm}$ e $80 \mathrm{~cm}$ ocorreram as maiores fissuras após o carregamento prévio.

$\mathrm{Na}$ configuração Ranhura o ID identificou nas posições $35 \mathrm{~cm}$ uma maior variação de energia, alterando a posição indicada anteriormente na configuração Dano, indicando que o dano causado pelas ranhuras também foram captados pelo método e tem magnitude considerável.

Com o Reforço, o ID apresentou novamente maior valor para a posição $50 \mathrm{~cm}$, reduzindo índice da posição $35 \mathrm{~cm}$ anteriormente identificado na configuração Ranhura. Este efeito confirma a capacidade de identificação do reforço pelo método, devendo para isso realizar ensaios nas configurações iniciais do elemento, com as Ranhuras e com os Reforços.

$\mathrm{Na}$ configuração Ruptura o método identificou maior variação da energia de deformação nas posições $35 \mathrm{~cm}$ e $65 \mathrm{~cm}$, com ID de 2,5 e 2,0 respectivamente e praticamente sem ID no lado direito da viga, na região entre as posições $95 \mathrm{~cm}$ a $215 \mathrm{~cm}$. O método permitiu Identificar a posição de ruptura da viga, sem a identificação de falsos danos observados no método COMAC.

\subsubsection{V90 SR}

A DCM e ID na configuração Ruptura são apresentados no Gráfico 7.41 e Gráfico 7.42 respectivamente, comparando a configuração Ruptura com a Íntegra da viga V90 SR.

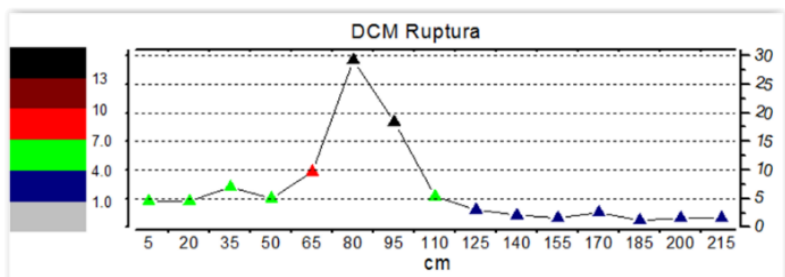

Gráfico 7.41 - DCM V90 SR

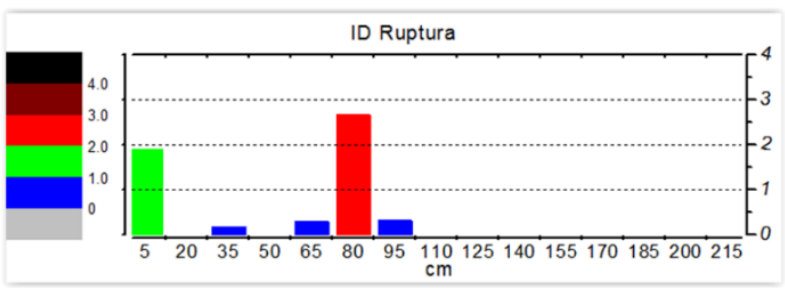

Gráfico 7.42 - ID V90 SR

O método permitiu identificar elevadas variações nas curvaturas modais entre as posições $65 \mathrm{~cm}$ e $95 \mathrm{~cm}$, indicando local de grande fissuração. Identificou ainda DCM com menores intensidades entre as posições $5 \mathrm{~cm}$ e $50 \mathrm{~cm}$, indicando local de algumas fissuras.

Assim como ocorrido na viga V50 SR, a DCM identificou de maneira correta o dano ocorrido, pois com o carregamento na posição $85 \mathrm{~cm}$, as fissuras de ruptura ocorreram nas posições entre a posição $35 \mathrm{~cm}$ e $85 \mathrm{~cm}$ e sem ocorrer grandes fissuras no lado menos solicitado da viga.

O ID identificou na posição $80 \mathrm{~cm}$ maiores variações de energia de deformação com Índice de 2,8, com a presença de ID elevado também na posição $5 \mathrm{~cm}$. Ocorrendo a identificação 
correta da posição de ruptura da viga, mas uma falsa indicação de dano na posição $5 \mathrm{~cm}$, local onde não houve grande fissuração.

\subsubsection{V90 CFRP}

São apresentadas as DCM comparando as configurações Ranhura, Reforço e Ruptura com a configuração Íntegra ao longo do comprimento da viga no Gráfico 7.43.
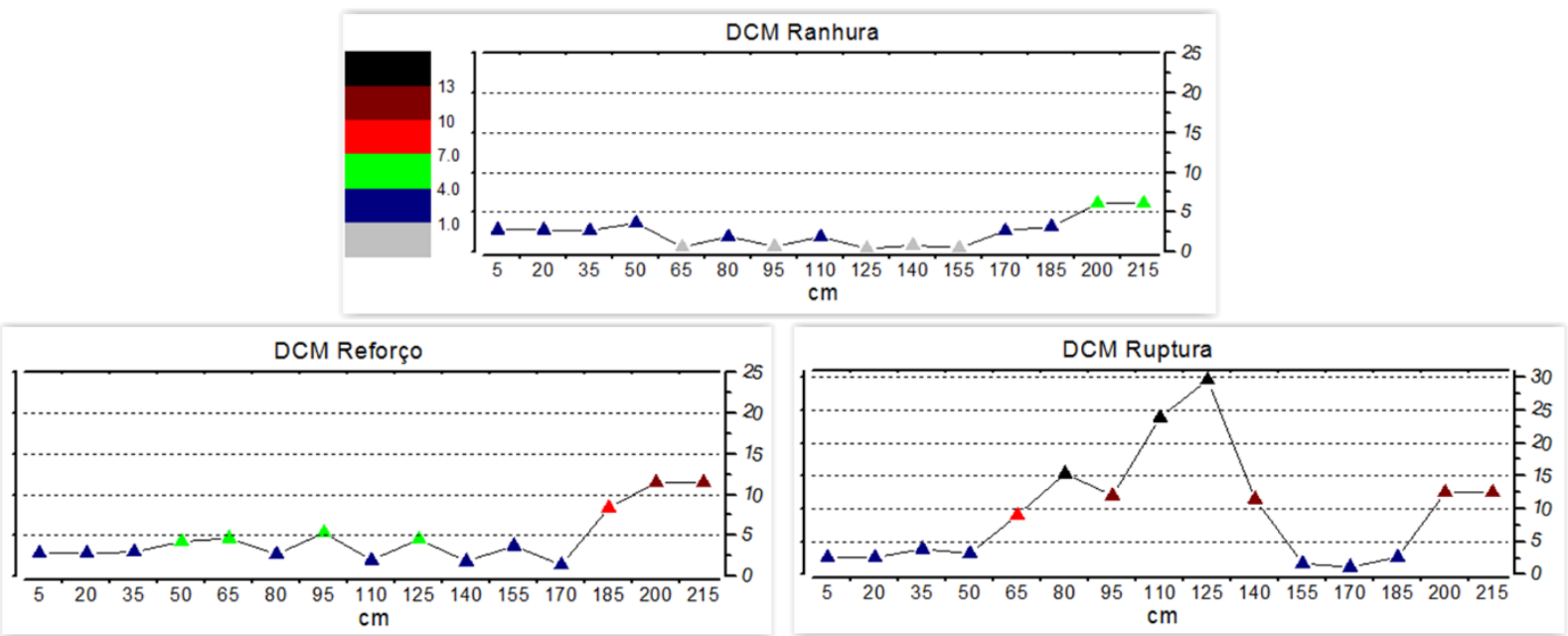

Gráfico 7.43 - DCM V90 CFRP

O método DCM identificou baixas variações de curvatura em toda a viga após as Ranhuras, com maiores coeficientes com valores próximos a 6 para as posições 200 e 215, onde não ocorrem as ranhuras. Indicando falso dano na região próxima ao apoio.

Com o Reforço as diferenças de curvatura, aumentaram para toda a viga de forma proporcional, apresentando erroneamente um dano elevado com DCM próximos a 12 nas posições $200 \mathrm{~cm}$ e $215 \mathrm{~cm}$. Assim como ocorrido na viga V50 CFRP, este método não permitiu observar a presença do Reforço.

A DCM na Ruptura apresentou grandes coeficientes entre as posições $80 \mathrm{~cm}$ e $125 \mathrm{~cm}$, igualmente ao indicado no método COMAC, indicando corretamente a posição da Ruptura da viga. Continuando com a indicação errônea de grandes fissuras nas posições $200 \mathrm{~cm}$ e $215 \mathrm{~cm}$.

O Gráfico 7.44 apresenta os ID da viga V90 CFRP relacionando as configurações Ranhura, Reforço e Ruptura com a configuração Íntegra. 

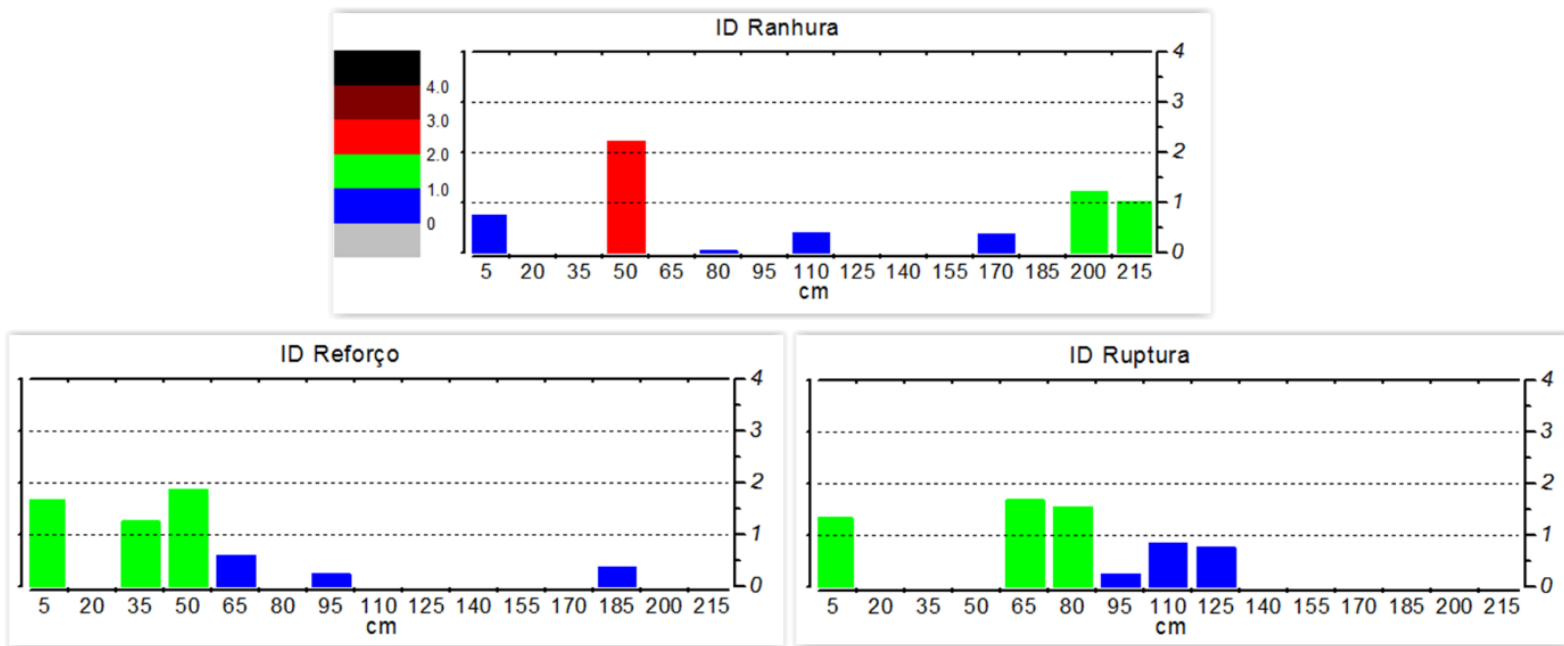

Gráfico 7.44 - ID V90 CFRP

O Índice de Dano permitiu identificar as pequenas variações de energia ocorridos com as Ranhuras, indicando uma maior variação na posição $50 \mathrm{~cm}$, mas com aparecimento de falsos danos nas posições $200 \mathrm{~cm}$ e $215 \mathrm{~cm}$. Com o Reforço, o dano causado pelas Ranhuras é minimizado, apresentando menores variações de energia, reduzindo assim o Índice de Dano na posição $50 \mathrm{~cm}$.

Após a Ruptura o método apresentou ID entre as posições $65 \mathrm{~cm}$ e $125 \mathrm{~cm}$, identificando corretamente o local de ruptura da viga. Este método não identificou erroneamente dano nas posições $200 \mathrm{~cm}$ e $215 \mathrm{~cm}$, diferentemente do ocorrido na DCM, sendo para esta viga o melhor método de localização dos locais danificados.

Com a ruptura da viga ocorrendo via flexão, por esmagamento do concreto, houve uma diferenciação na posição da região mais danificada das vigas V90 em relação as vigas V50 com Reforço, sendo agora as fissuras de flexão mais preponderantes.

\subsubsection{V90 $40 \%$}

No Gráfico 7.45 são apresentadas as DCM para todas as configurações da viga V90 40\%.
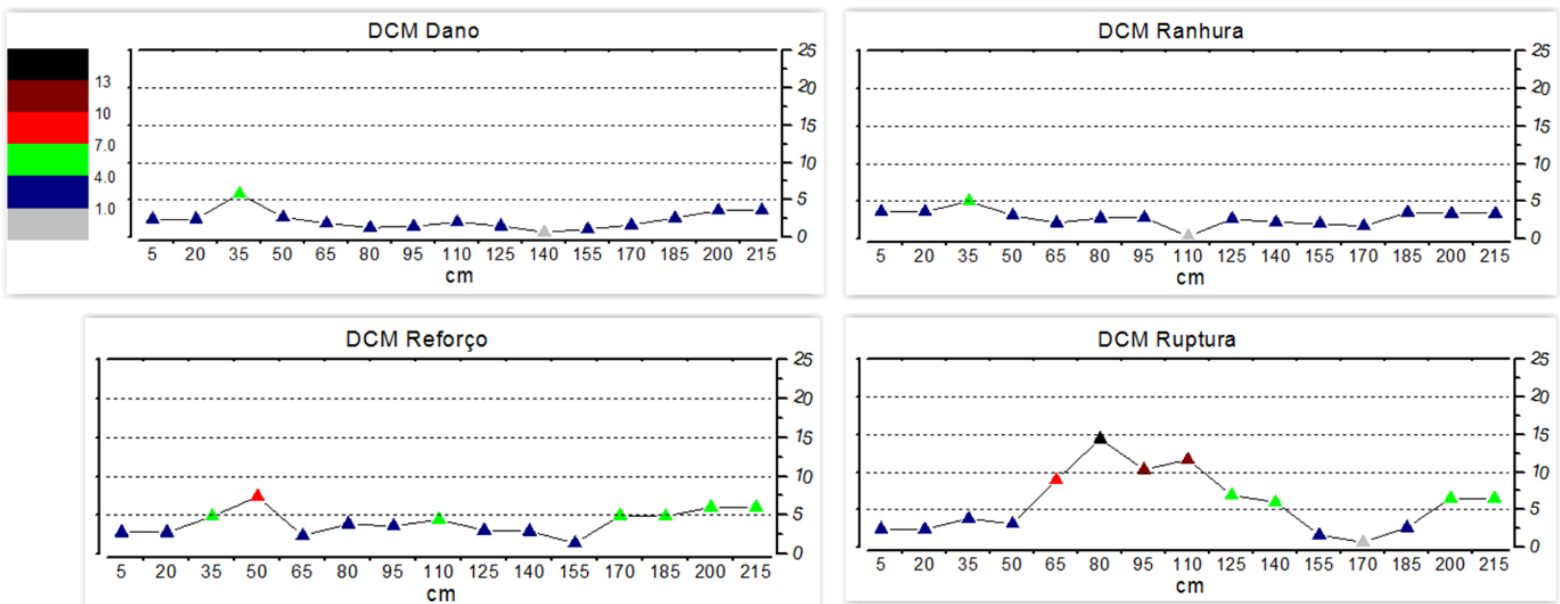

Gráfico 7.45 - DCM V90 40\% 
Após o carregamento prévio foram verificadas pequenas variações na curvatura modal, com destaque apenas para a posição $35 \mathrm{~cm}$ com coeficiente DCM acima de 5. Quando comparados com o método COMAC, observa-se uma melhor capacidade de identificação do local do dano e uma menor interferência dos apoios na indicação e falsos danos.

Com a abertura de Ranhuras, os valores de DCM praticamente não sofreram alterações, indicando que o dano permanece na posição $35 \mathrm{~cm}$, e com baixas DCM em toda a viga. O método não permitiu identificar a presença das ranhuras, mas não apresentou a falsa identificação de dano ocorrida no método COMAC na região pouco solicitada.

Na configuração Reforço foram observados aumento na diferença de curvatura modal, com maior destaque para a posição $50 \mathrm{~cm}$ e entre as posições $170 \mathrm{~cm}$ e $215 \mathrm{~cm}$. Apesar de a maioria das DCM apresentarem baixos índices, os valores apresentados na configuração Reforço não condizem com a realidade, pois a aplicação de sistemas de reforço de CFRP deveriam reduzir os valores.

$\mathrm{Na}$ Ruptura, a DCM identifica grande variação na curvatura da viga entre as posições $65 \mathrm{~cm}$ e $110 \mathrm{~cm}$, com pico de 15 DCM na posição $80 \mathrm{~cm}$, indicando corretamente grande fissuração no local onde ocorre a ruina da viga.

A DCM novamente apresentou bons resultados na identificação da localização e magnitude do dano nas comparações com as configurações Dano, Ranhura e Ruptura, mas apresentou de forma incorreta os seus valores para a viga Reforçada.

O ID é apresentado para todas as configurações da viga V90 40\% no Gráfico 7.46, na comparação entre as configurações Dano, Ranhura, Reforço e Ruptura com a configuração Íntegra.
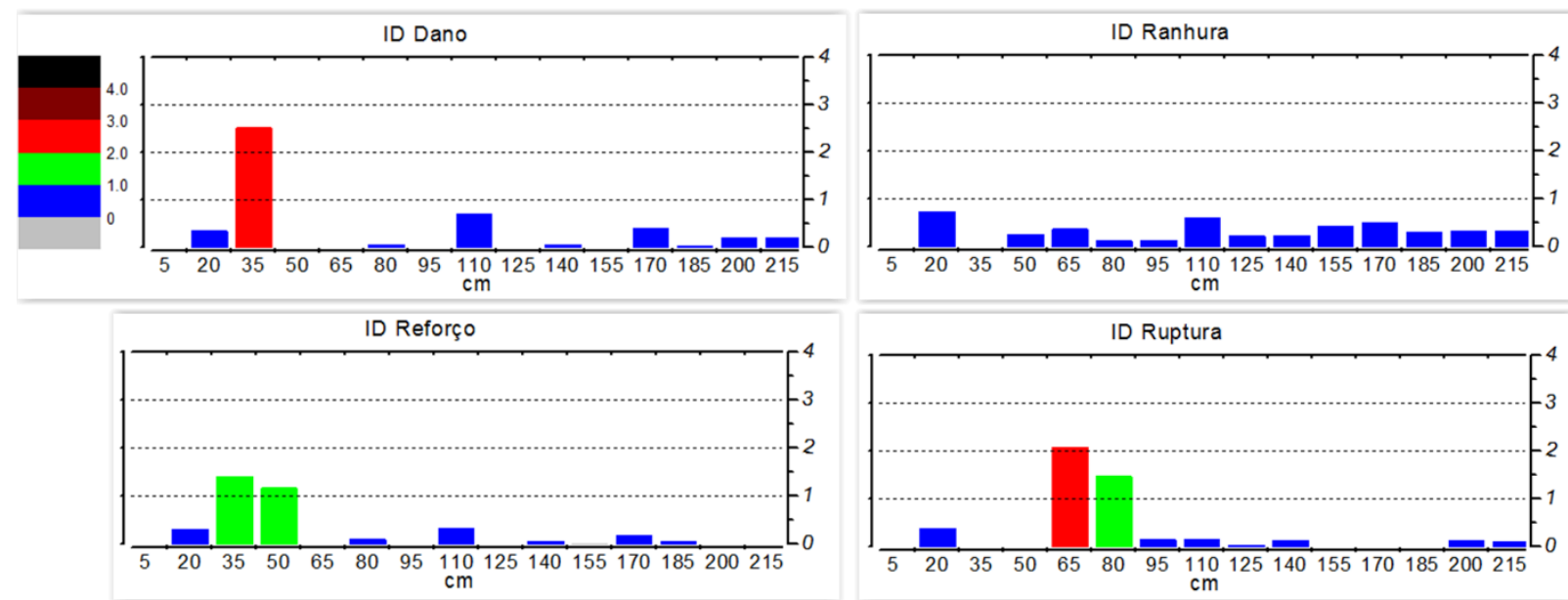

Gráfico 7.46 - ID V90 40\% 
O ID indica uma variação da energia de deformação maior na posição $35 \mathrm{~cm}$, igualmente ao indicado nos métodos COMAC e DCM, permitindo assim identificar que nesta posição ocorreu a maior fissura da viga após o carregamento prévio.

Com o acréscimo das Ranhuras, o ID apresentou baixos valores ao longo de praticamente toda a viga, indicando que as variações de energias foram uniformizadas pelo dano causado na inserção das ranhuras, mas sem identificar a presença das Ranhuras. Os resultados do método COMAC também não foram satisfatórios.

Após o Reforço, os ID apresentam destaque nas posições $35 \mathrm{~cm}$ e $50 \mathrm{~cm}$. O reforço reestabeleceu os vazios das ranhuras, permitindo novamente identificar a real posição do dano inserido no carregamento prévio. Comparando o ID da configuração Reforço com a configuração Dano é possível perceber essa melhora.

Na configuração Ruptura, o método identificou maior variação da energia de deformação nas posições $65 \mathrm{~cm}$ e $80 \mathrm{~cm}$ e praticamente não apresentou ID no lado direito da viga, na região entre as posições $95 \mathrm{~cm}$ a $215 \mathrm{~cm}$, permitindo assim a identificação da posição de ruptura, em $80 \mathrm{~cm}$.

\subsubsection{V90 70\%}

No Gráfico 7.47 são apresentadas as DCM para todas as configurações da viga V90 70\%.
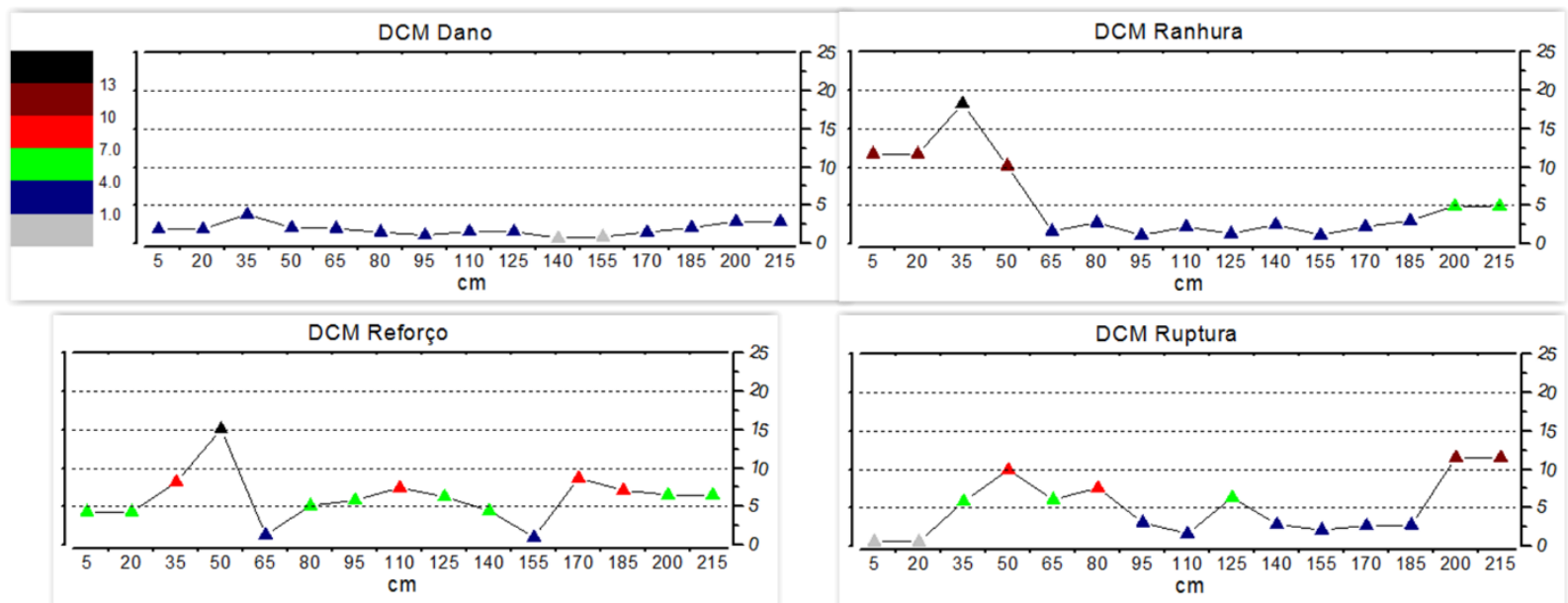

Gráfico 7.47 - DCM V90 70\%

Assim como ocorrido na viga V50 70\% as DCM apresentaram pequenos valores em toda a viga na configuração Dano, não identificando o local onde ocorreram as fissuras oriundas do carregamento prévio.

Com o incremento das Ranhuras é possível identificar elevadas DCM entre as posições $5 \mathrm{~cm}$ e $50 \mathrm{~cm}$, indicando uma região com grandes alterações na rigidez da viga, tendo o mesmo efeito verificado nos métodos MAC e COMAC. 
Na configuração Reforço ocorre uma redução dos valores de DCM entre as posições $5 \mathrm{~cm}$ e $50 \mathrm{~cm}$, indicando uma recuperação dessa região danificada. O DCM no reforço indica ainda a presença de dano entre as posições $80 \mathrm{~cm}$ e $185 \mathrm{~cm}$ não identificadas nas etapas Dano e Ranhura, nem observadas no método COMAC, sugerindo uma falsa identificação do dano pois ao acrescentar Reforço a DCM deveria reduzir.

A DCM na configuração Ruptura também identificou falsos danos na posição $200 \mathrm{~cm}$ e $215 \mathrm{~cm}$, tendo ocorrido nessas posições os maiores índices. Valores de DCM elevado também são observados nas posições $50 \mathrm{~cm}$ e $80 \mathrm{~cm}$, região próxima ao ponto de aplicação da força, onde realmente ocorreu a ruptura desta viga $(80 \mathrm{~cm})$.

O ID também foi utilizado para analisar a diferença de energia de deformação entre a configuração Íntegra e as demais da viga V90 70\%. (Gráfico 7.48)

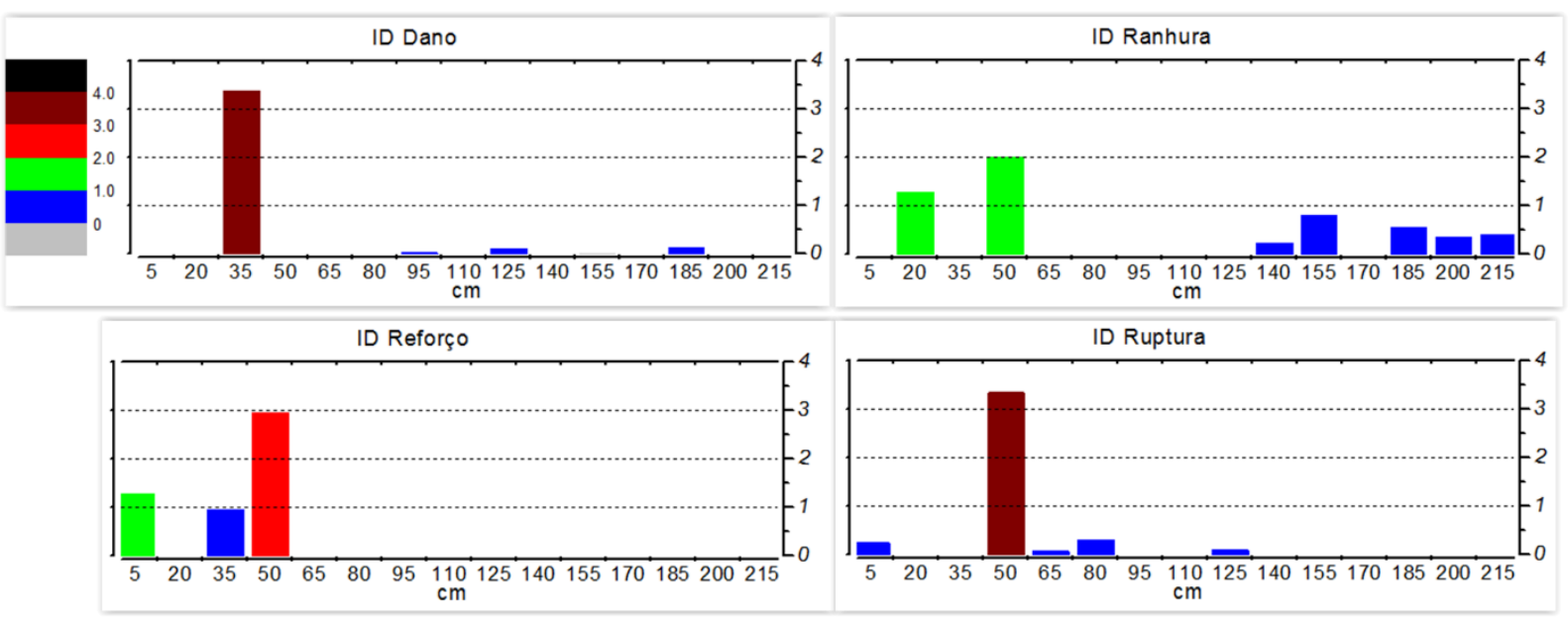

Gráfico 7.48 - ID V90 70\%

O Índice de Dano permitiu identificar uma maior diferença na energia de deformação na posição $35 \mathrm{~cm}$, informando que o carregamento prévio ocasionou fissuras neste local. Um elevado dano também foi identificado nesta posição pelos métodos COMAC e em várias configurações da DCM.

Observou-se que, para este método a ocorrência da abertura de fissuras causa uma uniformização dos resultados, deixando de ocorrer a localização da fissura com maior intensidade em uma posição, para ter em várias. Com o acréscimo das Ranhuras a variação da energia de deformação foi alterada para as posições $20 \mathrm{~cm}$ e $50 \mathrm{~cm}$.

Após o Reforço, o ID reaparece na posição $35 \mathrm{~cm}$, indicando novamente que as variações de energia causadas pela Ranhura foram minimizadas com a inserção do Reforço de CFRP, permitindo assim observar novamente o dano gerado no carregamento prévio. Aparece também um dano acentuado na posição $50 \mathrm{~cm}$. 
Na configuração Ruptura, o método identificou maior variação da energia de deformação na posição $50 \mathrm{~cm}$, sem praticamente ID no lado direito da viga, na região entre as posições $95 \mathrm{~cm}$ a $215 \mathrm{~cm}$. Não identificando corretamente a posição da ruptura da viga.

Nenhum dos métodos utilizados na Ruptura permitiu identificar corretamente e sem a presença de falsos danos, o local de ruptura da viga. Nas demais configurações os métodos apresentaram bom desempenho, identificando a presença do dano causado pelo carregamento prévio, o aumento deste dano ao serem realizadas as Ranhuras e a recuperação da rigidez ao serem inseridos Reforços.

\subsection{RESUMO DO CAPÍTULO}

Neste capitulo foram apresentados os resultados dos ensaios experimentais não destrutivo para oito (8) vigas de concreto armado reforçadas ao cisalhamento com CFRP utilizando a técnica NSM.

Nos ensaios não destrutivos foram obtidas as frequências naturais e modos de vibração das vigas utilizando quinze acelerômetros piezoelétricos ao longo do comprimento das vigas. Sendo os dados captados em duas etapas, com oito (8) acelerômetros em cada, com uma posição repetida utilizada como referencias entre as etapas.

Para a análise das curvaturas modais foi necessário o desenvolvimento de um programa, desenvolvido no Matlab® utilizando métodos de identificação modal estocástica Neste programa permitiu unir as duas series de ensaios com acelerômetros, permitindo ainda obter a média normalizada dos auto-espectros e os modos de vibração.

Para a análise dos resultados foram selecionados sete métodos objetivando a identificação do dano e dos reforços de CFRP, sendo eles: Variação das frequências naturais, análise visual dos gráficos ANPSD, Modos de vibração, MAC, COMAC, DCM e ID.

Para todos os métodos foram apresentados resultados em forma de gráficos e analisados na sua capacidade de identificação das configurações das vigas, sendo elas: Íntegra, Dano, Ranhura, Reforço e Ruptura. Alguns métodos permitiram identificar quais frequências naturais sofreram maiores alterações (Variação das frequências naturais e MAC), enquanto outros permitiram identificar a localização dessas alterações (COMAC, DCM e ID).

Nenhum dos métodos apresentou resultados perfeitos, com as corretas identificações de dano e reforço, tendo os métodos DCM e ID apresentado os melhores resultados. Observou-se que algumas vezes os métodos apresentaram falsos danos, sendo necessário para uma melhor compreensão dos dados uma análise conjunta de todos os métodos apresentados. 
Com a intenção de tabular os efeitos identificados pelos métodos, é apresentada a Tabela 7.11 considerando a eficácia de cada método em identificar os efeitos do Dano, Ranhura, Reforço e Ruptura em cada viga.

Tabela 7.11 - Resumo da identificação de Dano, Ranhura, Reforço e Ruptura

\begin{tabular}{|c|c|c|c|c|c|c|c|c|c|c|c|c|}
\hline \multirow[t]{2}{*}{ Método } & \multirow{2}{*}{$\frac{\text { V50 SR }}{\text { Rup }}$} & \multicolumn{3}{|c|}{ V50 CFRP } & \multicolumn{4}{|c|}{ V50 40\% } & \multicolumn{4}{|c|}{ V50 70\% } \\
\hline & & Ran & Ref & Rup & Dan & Ran & Ref & Rup & Dan & Ran & Ref & Rup \\
\hline ANSPD & & & $\mathrm{N}$ & & & & $\mathrm{N}$ & & & & $\mathrm{N}$ & \\
\hline MAC & & & $\mathrm{F}$ & & $\mathrm{N}$ & & $\mathrm{N}$ & & & $\mathrm{N}$ & & \\
\hline COMAC & & & $\mathrm{F}$ & F & & $\mathrm{N}$ & $\mathrm{N}$ & & & $\mathrm{N}$ & $\mathrm{N}$ & $\mathrm{F}$ \\
\hline DCM & & & $\mathrm{F}$ & F & & & & $\mathrm{F}$ & & & & \\
\hline ID & & & & & $\mathrm{N}$ & & & & & & & \\
\hline \multirow[t]{2}{*}{ Método } & V90 SR & \multicolumn{3}{|c|}{ V90 CFRP } & \multicolumn{4}{|c|}{ V90 40\% } & \multicolumn{4}{|c|}{ V90 70\% } \\
\hline & Rup & Ran & Ref & Rup & Dan & Ran & Ref & Rup & Dan & Ran & Ref & Rup \\
\hline ANSPD & & & & & & & $\mathrm{N}$ & & & & $\mathrm{N}$ & \\
\hline MAC & & & $\mathrm{N}$ & & & $\mathrm{N}$ & & & $\mathrm{N}$ & & $\mathrm{N}$ & $\mathrm{N}$ \\
\hline COMAC & & $\mathrm{N}$ & & & $\mathrm{F}$ & $\mathrm{F}$ & & & & & & $\mathrm{N}$ \\
\hline DCM & & F & $\mathrm{F}$ & & & $\mathrm{N}$ & $\mathrm{N}$ & & $\mathrm{N}$ & F & $\mathrm{F}$ & $\mathrm{F}$ \\
\hline ID & $\mathrm{F}$ & $\mathrm{F}$ & & & & $\mathrm{N}$ & & & & $\mathrm{F}$ & & $\mathrm{F}$ \\
\hline
\end{tabular}

Onde:

$\mathrm{N}$ - Sem alterações relevantes, não permitindo a identificação correta das alterações de cada configuração indicada da viga;

F - Identificação de Falso Dano em posições incorretas da viga;

$\square$ - Identificação correta das alterações pelo método, mas com baixa precisão;

F- Identificação das alterações pelo método com baixa precisão, mas apresentando

Falso Dano em posições incorretas da viga;

- Identificação correta das alterações pelo método. 


\section{CONSIDERAÇÕES FINAIS}

Pesquisar em estruturas de concreto permitiu a compreensão de uma área de conhecimento da engenharia civil, principalmente, na utilização de técnicas de reforço utilizando materiais de elevado desempenho, como o CFRP.

O estudo sobre sistema de reforço ao cisalhamento com CFRP foi o principal tema desta tese, permitindo compreender as principais técnicas de reforço. Observando nas revisões bibliográficas que as técnicas usuais de reforço, com colagem de mantas ou laminados na face do concreto (EBR) não utilizavam toda a sua capacidade, optou-se por investigar uma técnica mais elaborada, sendo utilizada a técnica NSM, que se baseia na inserção de laminados de CFRP em ranhuras no concreto de recobrimento das faces laterais da viga.

$\mathrm{Na}$ investigação dos benefícios dessa técnica de reforço buscou-se identificar a sua eficiência em concretos de classe usual e de elevado desempenho. Além disso foi avaliado a eficiência do reforço em estruturas com carregamento prévio.

Com o intuito de identificar a eficiência do reforço ao cisalhamento, ensaios não destrutivos com análise modal foram realizados. Nestes ensaios buscaram-se métodos para identificar os danos oriundos do carregamento prévio, ranhura e ruptura em estruturas civis. A localização do dano por análise modal permite realizar reforço apenas nos locais específicos, de maneira menos onerosa.

Foram realizados ainda ensaios para a identificação modal nas vigas reforçadas, com o intuito de investigar por ensaios não destrutivos a presença do reforço e confirmar sua eficácia sem a necessidade de provas de força.

Testes iniciais foram realizados com prismas de concreto permitindo obter acréscimos significativos na capacidade de carga devido ao sistema de reforço, mas não obtendo bons resultados na análise modal. Nos ensaios principais com vigas, diferentes métodos de identificação de dano por análise modal estocástica foram utilizados. 


\subsection{CONCLUSÕES}

O estudo do sistema de reforço com CFRP confirmou sua eficiência em ampliar a capacidade de carga de elementos estruturais. Nos primeiros ensaios experimentais no estudo piloto, ocorreu aumento na capacidade de carga em 20,8\% para os prismas P40 e de 47,5\% para os prismas P60. Quando os prismas possuíam carregamento prévio o acréscimo na capacidade de carga não sofreu grandes alterações, em que alguns exemplares apresentaram aumento da carga máxima e outros redução.

Após a aplicação do sistema de reforço, a forma de ruptura dos prismas permaneceu ocorrendo por cisalhamento, mudando apenas a inclinação da fissura principal. A disposição do sistema de reforço, que não atuou em toda a extensão do prisma e as pequenas dimensões dos prismas não permitiram que o reforço utilizasse todo seu desempenho.

$\mathrm{Na}$ análise modal dos prismas observou-se que o método utilizado analisando apenas a variação das frequências naturais identificou de forma simplificada a presença de dano, mas não apresentou bons resultados para a configuração Reforço. O processo de abertura de ranhuras, necessário para a realização do reforço, reduziu muito as frequências naturais dos prismas, inviabilizando a análise modal na identificação do reforço.

Concluiu-se que as pequenas dimensões nos prismas influenciaram nos resultados experimentais destrutivos e não destrutivos. Devido a isso, os ensaios foram aprimorados, realizando vigas com dimensões reais e métodos de identificação de dano na análise modal.

$\mathrm{Na}$ análise estática das vigas, observou-se que a técnica de reforço com laminados CFRP inseridos na camada de cobrimento do concreto, o NSM, foi promissora no acréscimo de força de todas as vigas. A ruptura das vigas sem reforço ocorreu por cisalhamento, com fissuras entre o ponto de aplicação da força e o apoio. A presença do reforço alterou a ruptura, utilizando nas vigas V50 toda a capacidade do reforço, com destacamento do laminado e cobrimento de concreto.

Nas vigas com concreto de elevada resistência (V90) também verificou-se que o reforço aumento na capacidade de carga, ampliada em 32\%. Nessas vigas a ruptura ocorreu por esmagamento do concreto via flexão, não sendo utilizada toda a capacidade do reforço. Algumas dessas vigas apresentaram fissuras de destacamento do laminado, indicando uma proximidade de ruina por este efeito.

Concluiu-se que nas vigas com concreto de alto desempenho a capacidade de reforço dos laminados foi eficiente, apesar do reforço não ter sido utilizado em toda sua capacidade, ele permitiu alterar a forma de ruptura e cumprir a sua função de reforço ao cisalhamento. 
Os valores teóricos obtidos no dimensionamento de vigas com reforço apresentaram boa relação com os resultados experimentais. Esse dimensionamento foi efetuado conforme as formulações desenvolvidas por Dias (2008) devido à ausência de normas Brasileiras. Recomendase o uso deste método de cálculo de sistemas de reforços ao cisalhamento com a técnica NSM, bem como utilizar suas considerações na elaboração de uma norma Brasileira.

Quanto a presença de carregamento prévio, observou-se que as forças máximas e a forma de ruptura não apresentaram alteração, independentemente da classe de concreto analisada. Esta verificação permite concluir que vigas danificadas podem ser reforçadas ao cisalhamento com a mesma eficiência de vigas íntegras.

Alterações no comportamento das vigas com carregamento prévio foram observados apenas no início dos carregamentos, onde estribos e laminados apresentaram maiores deformações quando comparados com as vigas integras. Nas forças próximas à máxima, as deformações dos tem valores semelhantes.

Outro benefício confirmado do uso de reforço ao cisalhamento, foi a redução das deformações nos estribos. Essa redução possibilita a reabilitação de estruturas com problemas estruturais de cisalhamento, aliviando as tensões nas armaduras transversais e no concreto.

No estudo com análise modal observou-se que os métodos variação das frequências naturais, modos de vibração e MAC permitiram identificar em que frequências ocorreram as maiores alterações, enquanto que o COMAC, DCM e ID permitiram identificar a localização dessas alterações.

No estudo foi possível identificar com análise modal estocástica a presença e local do dano nas vigas, principalmente quando ocorrido um grande dano, como após a ruptura. Quando o dano foi pequeno, a maioria dos métodos identificou com baixa precisão a sua ocorrência, devendo serem utilizados com cautela.

Nenhum dos métodos apresentou resultados perfeitos, com as corretas identificações de dano e reforço, tendo os métodos DCM e ID apresentado os melhores resultados. Observou-se que algumas vezes os métodos apresentaram falsos danos, sendo necessário para uma melhor compreensão dos dados uma análise conjunta de todos os métodos apresentados.

O método Índice de Dano apresentou os melhores resultados quanto a identificação da posição do dano, permitindo observar alterações mesmo com pequenos danos. Enquanto que o método DCM foi o melhor em observar a magnitude do dano. Os métodos não permitiram a 
identificação dos reforços de maneira conclusiva, indicando melhoras em relação a configuração com ranhura, mas não em relação a viga íntegra.

Concluiu-se que o uso de análise modal para identificação de dano em estruturas de concreto é eficiente, mesmo quando este dano ocorre principalmente no cisalhamento, que os métodos utilizados não permitiram identificar com precisão adequada a presença do reforço.

Os ensaios destrutivos da viga permitiram observar acréscimos de rigidez quando inseridos os sistemas de reforço, identificados de forma imprecisa na análise modal. O aumento da rigidez estática deverá ser observado em estruturas sob carregamento de uso, por exemplo em pontes. No laboratório não foi possível realizar ensaios com as vigas sob carregamento, pois o atuador alteraria os modos de vibração.

\subsection{SUGESTÕES PARA TRABALHOS FUTUROS}

Com o objetivo de incrementar o nível de conhecimento do comportamento estrutural de vigas de concreto armado reforçadas ao cisalhamento com laminados de CFRP inseridos, são aqui sugeridas orientações para trabalhos futuros.

Avaliar a eficiência da técnica NSM de reforço em vigas com variações de: seção transversal da viga, taxa de reforço, posição e inclinação do reforço.

Realizar ensaios experimentais com vigas com danos maiores, ou até mesmo após a ruptura, verificando assim a eficiência do reforço na recuperação de estruturas colapsadas.

Realizar ensaios experimentais com carregamento cíclico, verificando a diferença no comportamento de uma viga de concreto armado reforçada ao cisalhamento com a técnica NSM.

Fazer simulação computacional, com programa de elementos finitos, para simular o comportamento de vigas de concreto armado reforçadas ao cisalhamento com a técnica NSM. Identificando os parâmetros adequados para simular a técnica e extrapolar seus resultados, como a distância, quantidade e orientação dos de laminados de CFRP.

Utilizar outros métodos de identificação de dano com análise modal, objetivando observar a presença do reforço ao cisalhamento. Verificar a eficiência dos métodos MAC, COMAC, DCM e ID com métodos de análise modal clássica.

Considerando que nas vigas foram analisadas as alterações nas frequências flexionais. Estudar os métodos de identificação de dano utilizados em vigas reforçadas à flexão. Ou ainda verificar a eficiência dos métodos considerando as alterações das frequências torcionais. 


\section{REFERÊNCIAS BIBLIOGRÁFICAS}

ABNT - ASSOCIAÇÃO BRASILEIRA DE NORMAS TÉCNICAS. NBR 5739: Concreto Ensaios de compressão de corpos-de-prova cilíndricos. Rio de Janeiro, 2007.

ABNT - ASSOCIAÇÃO BRASILEIRA DE NORMAS TÉCNICAS. NBR 6118: Projeto de estruturas de concreto - Procedimento. Rio de Janeiro, 2007.

ABNT - ASSOCIAÇÃO BRASILEIRA DE NORMAS TÉCNICAS. NBR 6118: Projeto de estruturas de concreto - Procedimento. Rio de Janeiro, 2014.

ABNT - ASSOCIAÇÃO BRASILEIRA DE NORMAS TÉCNICAS. NBR 6692: Materiais metálicos - Ensaio de tração à temperatura ambiente. Rio de Janeiro, 2015.

ABNT - ASSOCIAÇÃO BRASILEIRA DE NORMAS TÉCNICAS. NBR 7222: Argamassa e concreto - Determinação da resistência à tração por compressão diametral de corpos de prova cilíndricos. Rio de Janeiro, 2011.

ABNT - ASSOCIAÇÃO BRASILEIRA DE NORMAS TÉCNICAS. NBR NM 67: Concreto Determinação da consistência pelo abatimento do tronco de cone. Rio de Janeiro, 1998.

ACMANT - AMERICAN COMPOSITES MANUFACTURERS ASSOCIATION. Disponível em: < http://www.mdacomposites.org/mda/psgbridge_rebar_intro3.html>. Acesso em: 20 de março de 2013.

ACI 440.1R-15. Guide For The Design And Construction Of Structural Concrete

Reinforced With Fiber-Reinforced Polymer (Frp) Bars. Committee 440, American Concrete Institute, Farmington Hills, MI. 2015.

ACI 440.2R-08. Guide for the Design and Construction of Structural Concrete Reinforced with FRP Bars. Committee 440, American Concrete Institute, Farmington Hills, MI. 2008.

ALLEMANG, R. J.; BROWN, D. L. A Correlation Coefficient for Modal Vector Analysis, IMAC I, Orlando, USA. 1982.

ALMEIDA, S. F. Análise dinâmica experimental da rigidez de elementos de concreto submetidos à danificação progressiva até a ruptura. Dissertação (Mestrado) - Escola de Engenharia de São Carlos, Universidade de São Paulo, São Carlos. 2005.

ALMEIDA, S. F. Análise experimental estática e dinâmica da rigidez de ligações viga pilar de concreto pré-moldado. Tese de Doutorado - Escola de Engenharia de São Carlos, Universidade de São Paulo, São Carlos. 2010.

AMANCIO, D. T. Avaliação da integridade estrutural de elementos de concreto armado a partir das propriedades modais obtidas por técnicas de excitações aleatórias e transientes 163 p. Dissertação (Mestrado) - Escola de Engenharia de São Carlos, USP, São Carlos, 2016.

ARQUEZ A. P. Aplicação de laminado de polímero reforçado com fibras de carbono (PRFC) inserido em substrato de microconcreto com fibras de aço para reforço à flexão 
de vigas de concreto armado. Dissertação (Mestrado) - Escola de Engenharia de São Carlos, Universidade de São Paulo, São Carlos. 2010.

ATCP - Engenharia Física. Disponível em <http://www.atcp.com.br/pt/produtos/ > . Acesso em: 10 de fevereiro de 2014.

ASTM C 215. Standard Test Method for Fundamental Transverse, Longitudinal, and Torsional Resonant Frequencies of Concrete Specimens. ASTM International. 2008.

ASTM Standard E1876-09. Standard test method for dynamic Young's modulus, shear modulus, and Poisson's ratio by impulse excitation of vibration. ASTM International, West Conshohocken, PA. 2003.

ASTM Standard D3039M-00. Standard Test Method for Tensile Properties of Polymer Matrix Composite Materials. ASTM International. 2000.

BEBER, A. J.; CAMPOS F. A.; CAMPAGNOLO, J. L. Reforço de estruturas e concreto armado com tecidos pré-impregnados de fibras de carbono. Revista Téchne, São Paulo, n. 45 , p. 52-55, mar - abr. 2000.

BEBER A. J. Comportamento estrutural de vigas de concreto armado reforçadas com compósitos de fibra de carbono. Tese de Doutorado. Porto Alegre. 2013.

BONALDO, E. Composite materials and discrete steel fibres for the strengthening of thin concrete structures. PhD Thesis, University of Minho, Guimarães, Portugal. 2008.

BUCHAIM, R. A influência da não-linearidade física do concreto armado na rigidez à flexão e na capacidade de rotação plástica. Tese de Doutorado. - Escola Politécnica de São Paulo, São Paulo -SP. 2001.

Canadian Standards Association. CAN/CSA-S806. Design and Construction of Building Structures with Fibre-reinforced Polymers. Ottawa, Ontario, Canada. 2012.

CARRILLO, O. J. B.; LAIER, J. E. Detecção de dano a partir da resposta dinâmica da estrutura: estudo analítico com aplicação a estruturas do tipo viga. Cadernos de Engenharia de Estruturas, São Carlos, v. 8, n. 35, p. 29-45. 2006

CEB - COMITÉ EURO - INTERNATIONAL DU BÉTON, CEB -FIP. Model Code for Concrete Structures. MC 90, 437p. 1993.

fib - Bulletin 14. Externally bonded FRP reinforcement for RC structures. Technical report by Task Group 9.3 FRP (Fiber Reinforced Polymer) reinforcement for concrete structures, Féderation Internationale du Béton, 130p, July 2001.

fib - Bulletin 40. FRP reinforcement for in structures. Technical report by Task Group 9.3 FRP (Fiber Reinforced Polymer) reinforcement for concrete structures, Féderation Internationale du Béton, 147p, 2015.

CORREIA, J. R. Utilização de materiais FRP na reabilitação e reforço de estruturas. Instituto Superior Técnico / ICIST, Universidade Técnica de Lisboa. 2012. 
DALFRÉ. G. e BARROS, J. Reforço à flexão de faixas de lajes contínuas de BA utilizando laminados de carbono aplicados segundo a técnica NSM. $54^{\circ}$ Congresso Brasileiro do Concreto. Instituto Brasileiro do Concreto. Maceió - AL. 2012.

DE LORENZIS, L.; NANNI, A. Shear Strngthening of Reinforced Concrete Beams with Near-Surface Mounted Fiber-Reinforced Polymer Rods. ACI Structural Journal, vol. 98, n¹, January-February, pp. 60-68. 2001.

DE LORENZIS, L.; TENG, J.G. Near-surface mounted FRP reinforcement: an emerging technique for strengthening structures. Composites Part B, vol. 38, pp. 119-143. 2006.

DIANA, T. DIANA Finite Element Analysis. User's manual release 9.4.4. Delft, Netherland, 2012.

DIAS, S. J. E. Investigação experimental e analítica no reforço ao corte de vigas de betão armado com a técnica da inserção de laminados de CFRP. Tese de Doutorado.

Universidade do Minho - Portugal. 2008.

DIOGENES, H. J. F. Análise numérica e experimental de ligações por aderência açoconcreto aplicada em estruturas mistas. Tese de Doutorado. - Escola de Engenharia de São Carlos, São Carlos-SP. 2013.

DIOGENES, H. J. F.; COSSOLINO, L. C.; PEREIRA, A. H. A.; EL DEBS, M. K.; EL DEBS, A. L. H. C. Determinação do módulo de elasticidade do concreto a partir da resposta acústica. Revista IBRACON de Estrutura e Materiais. Volume 4 n 5. Páginas 792-813. São Paulo. Dezembro. 2011.

DOS SANTOS, A. M.; CABRAL, L. M. C.; MONTEIRO, E. B.; HELENE, P. R. DO L. Análise do módulo de elasticidade estático e dinâmico para diferentes dosagens de concreto. Revista IBRACON de estruturas e materiais. 2013.

FARRAR, C.R.; WORDEN, K. Structural health monitoring - A machine learning perspective. Chichester, Reino Unido: John Wiley \& Sons, Ltd, 2013.

FELBER, A. Development of a Hybrid Bridge Evaluation System. Ph.D. Thesis, University of British Columbia. Canada.1993.

FONSECA, T. C. C. S. Reforço e incremento da rigidez à flexão de ligações viga-pilar de estruturas de concreto pré-moldado com polímero reforçado com fibra de carbono (PRFC). Dissertação (Mestrado) - Escola de Engenharia de São Carlos, Universidade de São Paulo, São Carlos. 2007.

FORTES; A. S., BARROS J. A. O. de; PADARATZ, I. J. Estudo comparativo de três técnicas de reforço à flexão com CFRP. $45^{\circ}$ Congresso Brasileiro do Concreto. Instituto Brasileiro do Concreto. Vitória - ES. 2003.

GAMINO, A. L. Modelagem física e computacional de estruturas de concreto reforçadas com CFRP. Tese (Doutorado) Universidade de São Paulo, São Paulo. 2007. 
GARCEZI, M. R.; SILVA FILHO, G. L. C. P.; MEIER, URS. Reforço de vigas de concreto armado com laminados de PRFC protendidos. Parte 1: análise sob ação de carregamento estático. Revista IBRACON de Estrutura e Materiais. Volume 5 nº 3. São Paulo. Junho. 2012. GÓMEZ, I. D. (2015) Análise modal operacional: método de identificação baseado em transmissibilidade. Tese (Doutorado) - Escola de Engenharia de São Carlos, Universidade de São Paulo, São Carlos. 2015.

JAYAPRAKASH, J.; SAMAD; A. A. A.; ABBASOVISH, A. A.; ALI, A. A. Shear capacity of precracked and non-precracked reinforced concrete shear beams with externally bonded bi-directional CFRP strips. Construction and Building Materials 22. p. 1148-1165. 2008.

JULIANI, T.M. Detecção de danos em modelos de pontes em escala reduzida pela identificação modal estocástica. 189 p. Dissertação (Mestrado) - Escola de Engenharia de São Carlos, USP, São Carlos, 2014.

JUVANDES, L. Matérias compósitos reforçados com fibras, FRP. Apostila, Universidade do Porto, Portugal. 2002.

KHALIFA, A. Shear performance of reinforced concrete beams strengthened with advanced composites. PhD Thesis, Structural Engineering Department, Alexandria University, Egypt. 1999.

KHALIFA, A.; DE LORENZIS, L.; NANNI A. FRP Composites for Shear Strengtheneing of RC Beams. 3rd Inter. Conf. on Advanced Composite Materials in Bridges and Structures, Ottawa,Canada, J. Humar and A.G. Razaqpur, Editors, 15-18, pp. 137-144. 2000.

LIEVEN, N.; EWINS, D. J. Spatial Correlation of Mode Shapes - The Coordinate Modal Assurance Criterion (COMAC), IMAC VI, Kissimmee, USA.1988.

MENON, N. V.; PADARATZ, I. J. Desempenho de duas técnicas de reforço ao cisalhamento em vigas de concreto armado através de inserção de laminados de CFRP. Revista Tecnológica, v. 17, p. 19-28, 2008.

NEPOMUCENO, M. C. S. Ensaios não destrutivos em betão. Provas de Aptidão Pedagógica e Capacidade Científica. Universidade da Beira Interior, Portugal. 1999.

PANDEY, A.K.; BISWAS, M. Damage detection in structures using changes in flexibility. Journal of Sound and Vibration. v.169, p.3-17. 1994.

RADI, J. N. Simulação numérica do comportamento pósfissuração de vigas de concreto armado pelo método dos elementos finitos. Dissertação de Mestrado. Faculdade de Engenharia Civil da Universidade Federal de Uberlândia. 2007.

RODRIGUES, J. Identificação Modal Estocástica: Métodos de análise e aplicações em estruturas de engenharia civil. Tese de Doutorado. Universidade do Porto - Portugal. 2004. SALAWU, O. S.; WILLIAMS, C. Review of full-scale dynamic testing of bridge structures. School of Civil and Structural Engineering, University of Plymouth, Palace Court, Palace Street, Plymouth, PLI 2DE, UK. 1993. 
SIKA. Sika ${ }^{\circledR}$ CarboDur ${ }^{\circledR}$ Lâminas de fibra de carbono para reforço estrutural. Ficha de produto 2009 .

SIKA. Sikadur ${ }^{\circledR} 30$ Adesivo para colagem estrutural. Ficha de produto .2010.

STUBBS, N.; KIM, J.-T.; FARRAR, C.R. Field verification of a nondestructive damage localization and severity estimation algorithm. In: INTERNATIONAL MODAL

ANALYSIS CONFERENCE (IMAC), 13º, Nashville, Estados Unidos. p. 1520-1529. 1995. 


\section{APÊNDICE A - MEMORIA DE CÁLCULO}

\section{MEMÓRIA DE CÁLCULO DAS VIGAS V50}

$\checkmark$ Dimensionamento à flexão

Determinação da linha neutra pelo programa Sec'Trans ${ }^{\circledR}$

$$
x=13,75 \mathrm{~cm}
$$

Momento máximo admissível na flexão pelo programa Sec'Trans ${ }^{\circledR}$

$$
M_{\text {máx }}=25208 \mathrm{kN} . \mathrm{cm}
$$

Força máxima admissível na flexão pela Eq. 5.1

$$
F_{\text {máx }}=\frac{25208 \mathrm{kN} \cdot \mathrm{cm} \cdot 200 \mathrm{~cm}}{75 \mathrm{~cm} \cdot 125 \mathrm{~cm}} \quad=537,8 \mathrm{kN}
$$

Dimensionamento ao cisalhamento

Força cortante resistente de cálculo, relativa à ruína das diagonais comprimidas de concreto

$$
V_{R D 2}=0,27.0,792 \cdot 5,2 \frac{\mathrm{kN}}{\mathrm{cm}^{2}} \cdot 16 \mathrm{~cm} \cdot 27 \mathrm{~cm} \quad=480,4 \mathrm{kN}
$$

Parcela de força cortante resistida pela armadura transversal

$$
V_{S W}=0,9 \cdot \frac{0,62 \mathrm{~cm}^{2}}{0,15 \mathrm{~cm}} \cdot 27 \mathrm{~cm} \cdot 59 \frac{\mathrm{kN}}{\mathrm{cm}^{2}} \quad=59,3 \mathrm{kN}
$$

Parcela de força cortante resistida pelo concreto transversal

$$
V_{c}=0,6 \cdot 0,418 \frac{\mathrm{kN}}{\mathrm{cm}^{2}} \cdot 16 \mathrm{~cm} \cdot 27 \mathrm{~cm} \quad=108,3 \mathrm{kN}
$$

Força cortante resistente de cálculo, relativa à ruína por tração diagonal

$$
V_{R D 3}=108,3 k N+59,3 k N \quad=167,6 \mathrm{kN}
$$

$\mathrm{V}_{\mathrm{SD}}$ é o menor valor entre $\mathrm{V}_{\mathrm{RD} 2}$ e $\mathrm{V}_{\mathrm{RD} 3}$ 


$$
V_{S D} \leq\left\{\begin{array}{c}
480,4 k N \\
167,6 k N
\end{array}\right\}
$$

Força máxima admissível para ruptura ao cisalhamento

$$
F_{\text {Wmáx }}=\frac{167,6 \mathrm{kN} \cdot 200 \mathrm{~cm}}{125 \mathrm{~cm}} \quad=268,1 \mathrm{kN}
$$

Dimensionamento ao cisalhamento com reforço de CFRP

Taxa de reforço de CFRP.

$$
\rho_{f}=\left(\frac{2.0,0014 m}{0,16 m}\right) \cdot\left(\frac{0,02 m}{0,15 m}\right) \quad=0,233 \%
$$

Taxa de armadura transversal

$$
\rho_{s}=\left(\frac{0,62 \mathrm{~cm}^{2}}{15 \mathrm{~cm} \cdot 16 \mathrm{~cm}}\right)
$$

Deformação especifica do reforço

$$
\varepsilon_{f, e}=0,1685 .\left(\frac{0,00233.165 G P a+0,00258210 G P a}{(52 M P a)^{2 / 3}}\right)^{-1,117} \cdot 10^{-3} \quad=0,0035
$$

Parcela da força cortante resistente, relativa à ruína por tração diagonal

$$
V_{f d}=0,3 m \cdot \frac{0,000056 \mathrm{~mm}^{2}}{0,15 \mathrm{~m}} \cdot 0,0035 \cdot 165 \cdot 10^{6} \frac{\mathrm{kN}}{\mathrm{m}^{2}} \cdot(\cot 45+\cot 45) \cdot \operatorname{sen} 45 \quad=90,8 \mathrm{kN}
$$

Obtendo assim a força cortante resistente de cálculo Reforçada, relativa à ruína por tração diagonal pela soma das resistências do concreto, aço e reforço.

$$
V_{R d}=108,3 k N+59,3 k N+90,8 k N \quad=258,4 \mathrm{kN}
$$

$V_{S D R}$ é o menor valor entre $V_{R D 2}$ e $V_{R d}$

$$
V_{S D R} \leq\left\{\begin{array}{l}
480,4 k N \\
258,4 k N
\end{array}\right\} \quad=258,4 \mathrm{kN}
$$

Força admissível com reforço para ruptura ao cisalhamento 


$$
F_{W R}=\frac{258,4 k N \cdot 200 \mathrm{~cm}}{125 \mathrm{~cm}} \quad=413,5 \mathrm{kN}
$$

\section{MEMÓRIA DE CÁLCULO DAS VIGAS V90}

\section{$\underline{\text { Dimensionamento à flexão }}$}

Determinação da linha neutra pelo programa SecTrans ${ }^{\circledR}$

$$
x=11,19 \mathrm{~cm}
$$

Momento máximo admissível na flexão pelo programa SecTrans ${ }^{\circledR}$

$$
M_{\text {máx }}=2731 \% N . c m
$$

Força máxima admissível na flexão

$$
F_{\text {máx }}=\frac{27319 \mathrm{kN} \cdot \mathrm{cm} \cdot 200 \mathrm{~cm}}{75 \mathrm{~cm} \cdot 125 \mathrm{~cm}} \quad=582,8 \mathrm{kN}
$$

Dimensionamento ao cisalhamento

Força cortante resistente de cálculo, relativa à ruína das diagonais comprimidas de concreto

$$
V_{R D 2}=0,27 \cdot 0,64 \cdot 9 \frac{\mathrm{kN}}{\mathrm{cm}^{2}} \cdot 16 \mathrm{~cm} \cdot 27 \mathrm{~cm} \quad=671,8 \mathrm{kN}
$$

Parcela de força cortante resistida pela armadura transversal

$$
V_{S W}=0,9 \cdot \frac{1,01 \mathrm{~cm}^{2}}{0,15 \mathrm{~cm}} \cdot 27 \mathrm{~cm} \cdot 59 \frac{\mathrm{kN}}{\mathrm{cm}^{2}} \quad=96,5 \mathrm{kN}
$$

Parcela de força cortante resistida pelo concreto transversal

$$
V_{c}=0,6 \cdot 0,508 \frac{\mathrm{kN}}{\mathrm{cm}^{2}} \cdot 16 \mathrm{~cm} \cdot 27 \mathrm{~cm} \quad=131,7 \mathrm{kN}
$$

Força cortante resistente de cálculo, relativa à ruína por tração diagonal

$$
V_{R D 3}=131,7 k N+96,5 k N \quad=228,3 \mathrm{kN}
$$

$\mathrm{V}_{\mathrm{SD}}$ é o menor valor entre $\mathrm{V}_{\mathrm{RD} 2}$ e $\mathrm{V}_{\mathrm{RD} 3}$ 


$$
V_{S D} \leq\left\{\begin{array}{l}
671,8 k N \\
228,3 k N
\end{array}\right\}
$$

Força máxima admissível para ruptura ao cisalhamento

$$
F_{\text {Wmáx }}=\frac{228,3 \mathrm{kN} \cdot 200 \mathrm{~cm}}{125 \mathrm{~cm}} \quad=365,2 \mathrm{kN}
$$

Dimensionamento ao cisalhamento com reforço de CFRP

Taxa de reforço de CFRP.

$$
\rho_{f}=\left(\frac{2 \cdot 0,0014 m}{0,16 m}\right) \cdot\left(\frac{0,02 m}{0,15 m}\right) \quad=0,233 \%
$$

Taxa de armadura transversal

$$
\rho_{s}=\left(\frac{0,62 \mathrm{~cm}^{2}}{15 \mathrm{~cm} \cdot 16 \mathrm{~cm}}\right)
$$

Deformação especifica do reforço

$$
\varepsilon_{f, e}=0,1685 .\left(\frac{0,00233 \cdot 165 G P a+0,00421 \cdot 210 G P a}{(90 M P a)^{2 / 3}}\right)^{-1,117} \cdot 10^{-3} \quad=0,368 \%
$$

Parcela da força cortante resistente do reforço, relativa à ruína por tração diagonal

$$
V_{f d}=0,3 m \cdot \frac{0,000056 \mathrm{~mm}^{2}}{0,15 \mathrm{~m}} \cdot 0,00368165 \cdot 10^{6} \frac{\mathrm{kN}}{\mathrm{m}^{2}} \cdot(\cot 45+\cot 45) \cdot \operatorname{sen} 45 \quad=96,3 \mathrm{kN}
$$

Obtendo assim a força cortante resistente de cálculo Reforçada, relativa à ruína por tração diagonal pela soma das resistências do concreto, aço e reforço

$$
V_{R d}=131,7 k N+96,5 k N+96,3 k N \quad=324,5 \mathrm{kN}
$$

$V_{S D R}$ é o menor valor entre $V_{R D 2}$ e $V_{R d}$

$$
V_{S D R} \leq\left\{\begin{array}{l}
671,8 k N \\
324,5 k N
\end{array}\right\}
$$

Força admissível com reforço para ruptura ao cisalhamento

$$
F_{W R}=\frac{324,5 \mathrm{kN} \cdot 200 \mathrm{~cm}}{125 \mathrm{~cm}} \quad=519,3 \mathrm{kN}
$$




\section{APÊNDICE B - DEFORMAÇÃO DOS LAMINADOS}

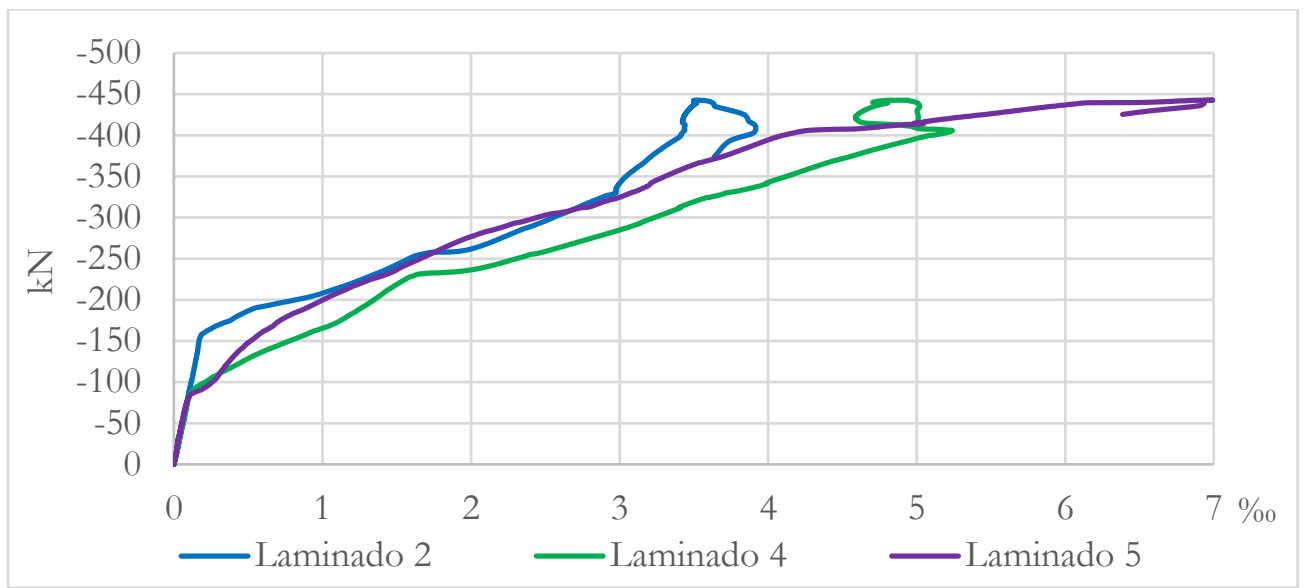

Gráfico 0.1 - Força x Deformação nos Laminados - V50 CFRP

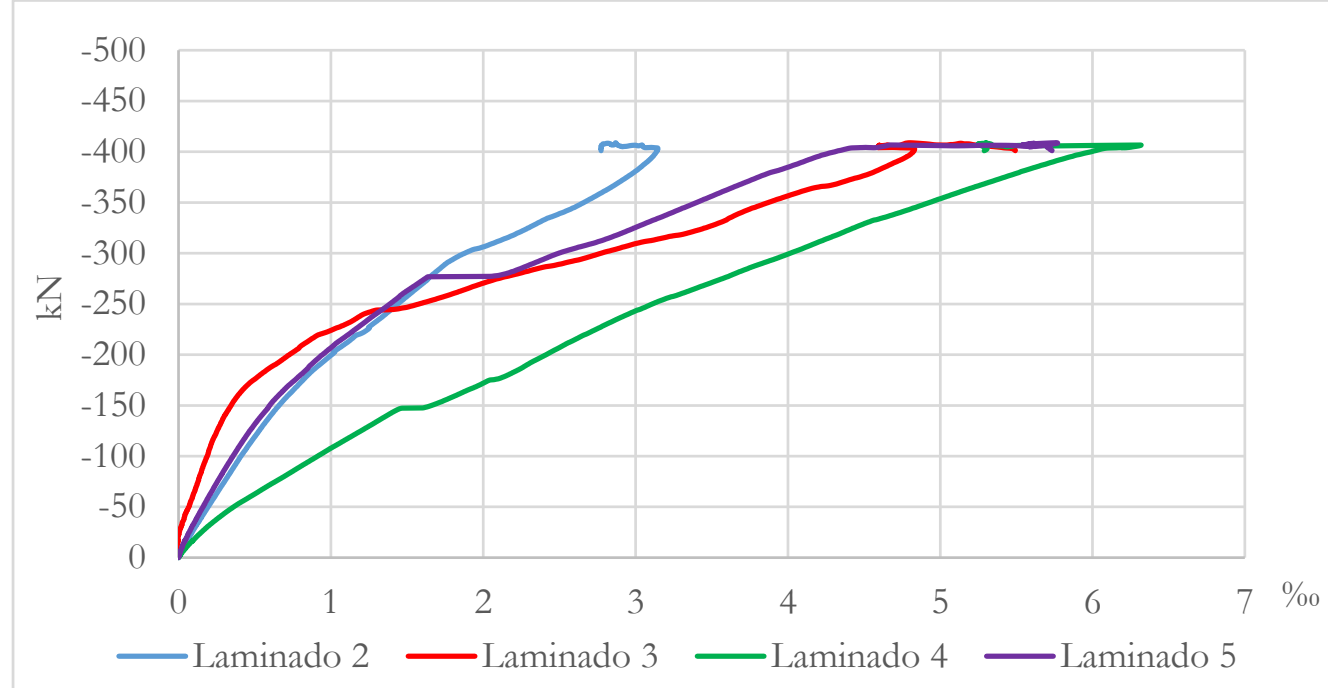

Gráfico 0.2 - Força x Deformação nos Laminados - V50 40\%

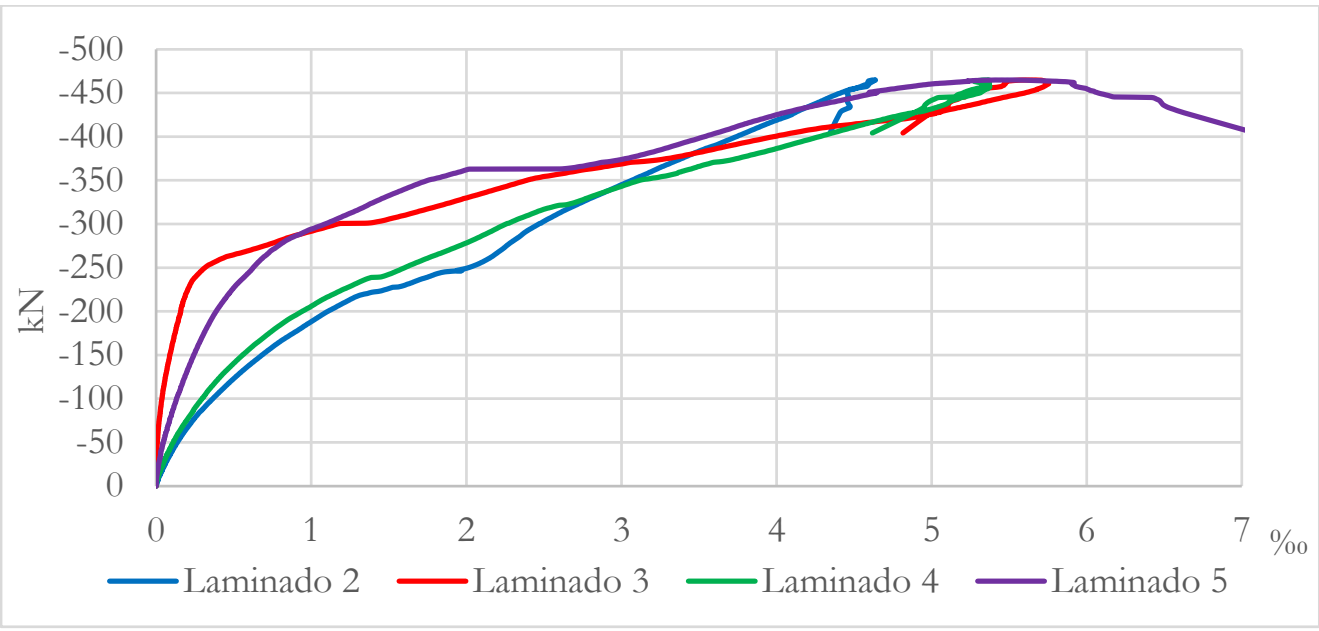


Gráfico 0.3 - Força x Deformação nos Laminados - V50 70\%

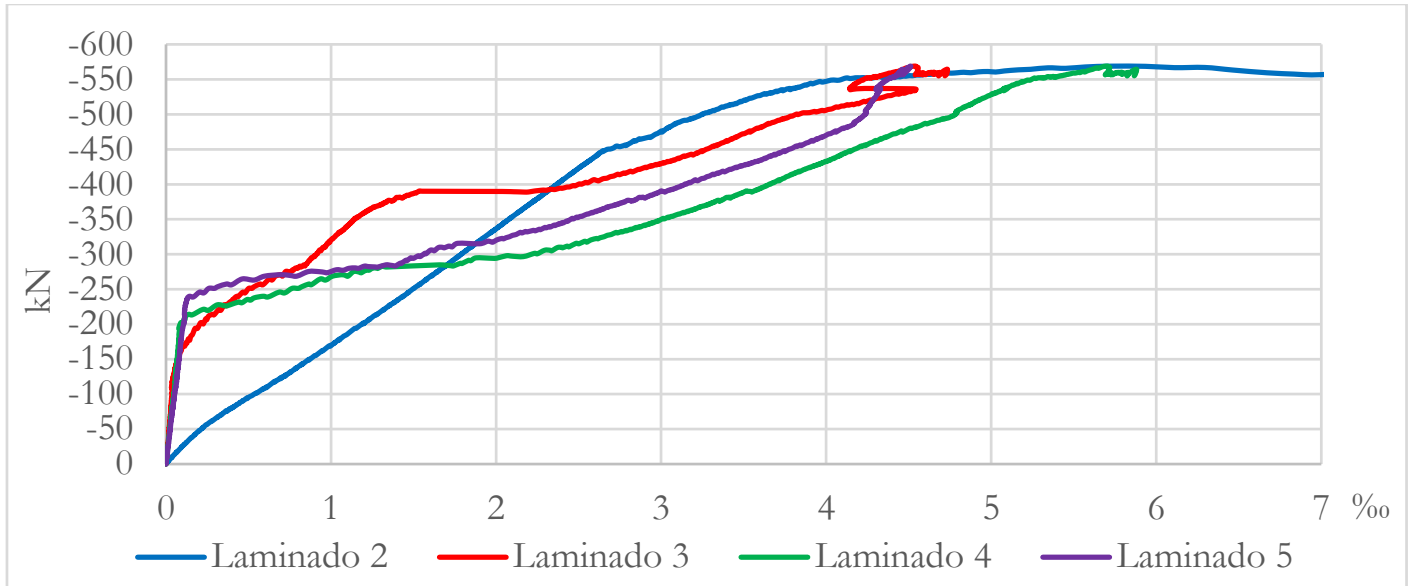

Gráfico 0.4 - Força x Deformação nos Laminados - V90 CFRP

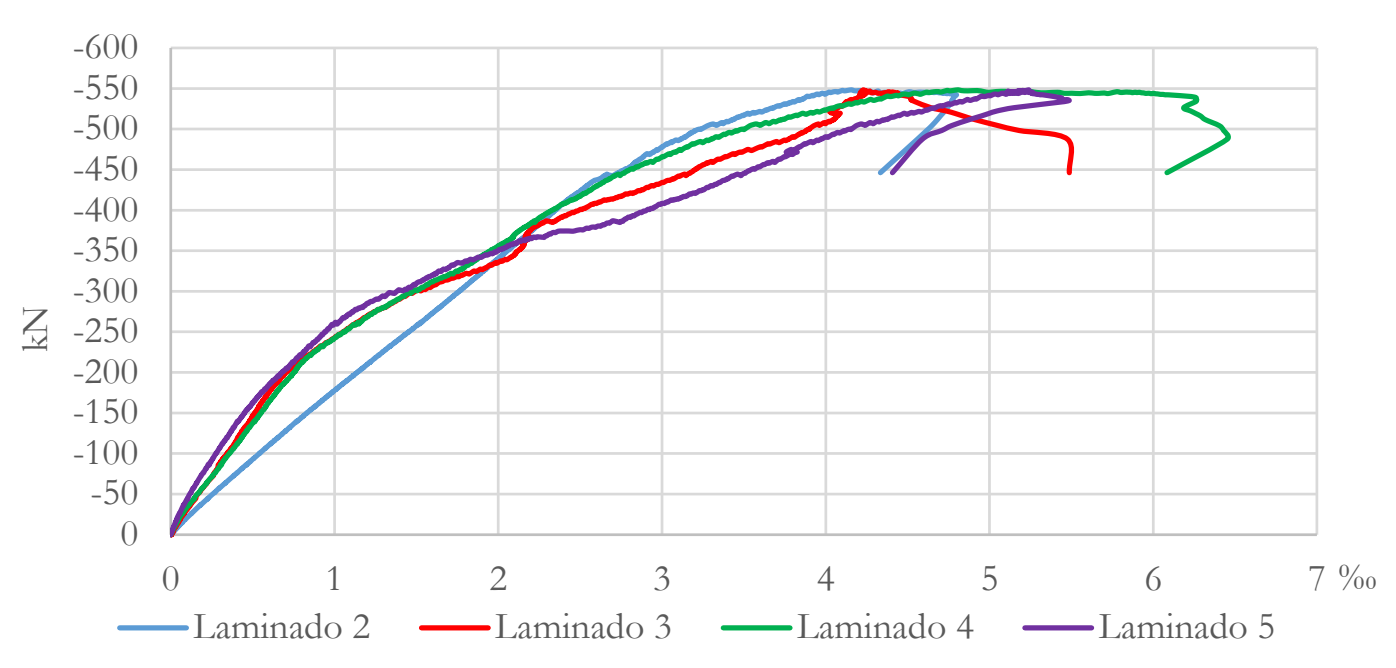

Gráfico 0.5 - Força x Deformação nos Laminados - V90 CFRP

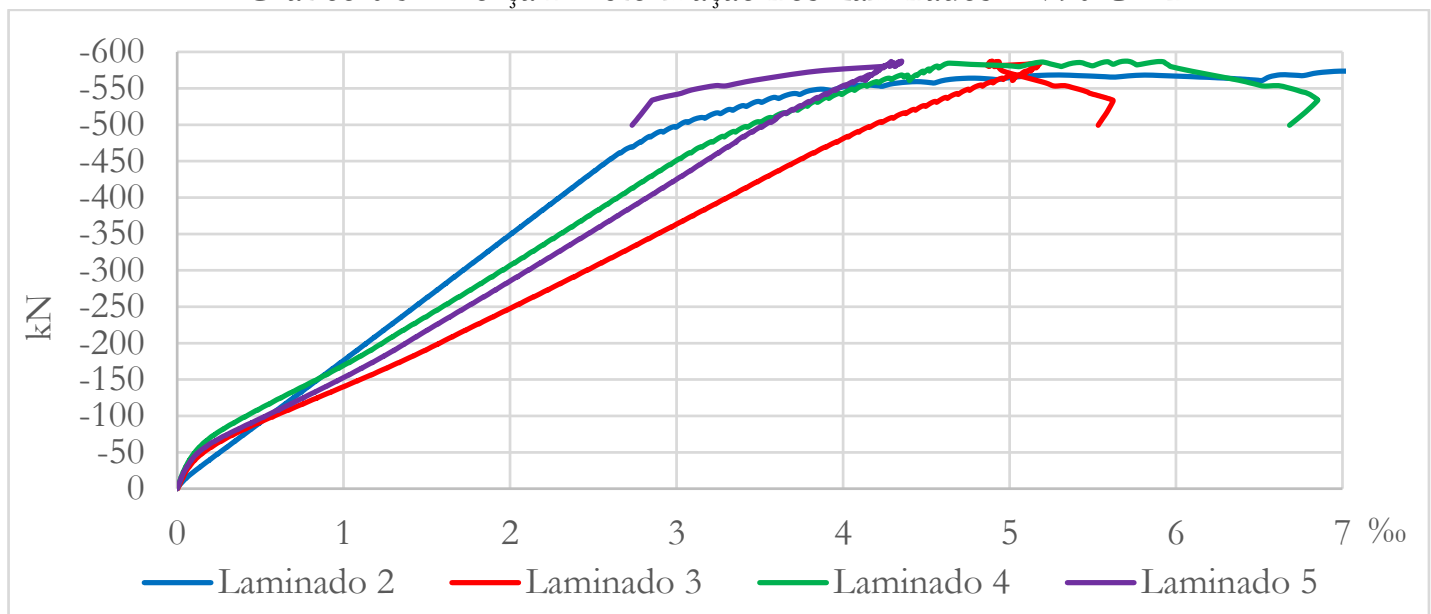

Gráfico 0.6 - Força x Deformação nos Laminados - V90 70\% 


\section{APÊNDICE C - ANSPD}

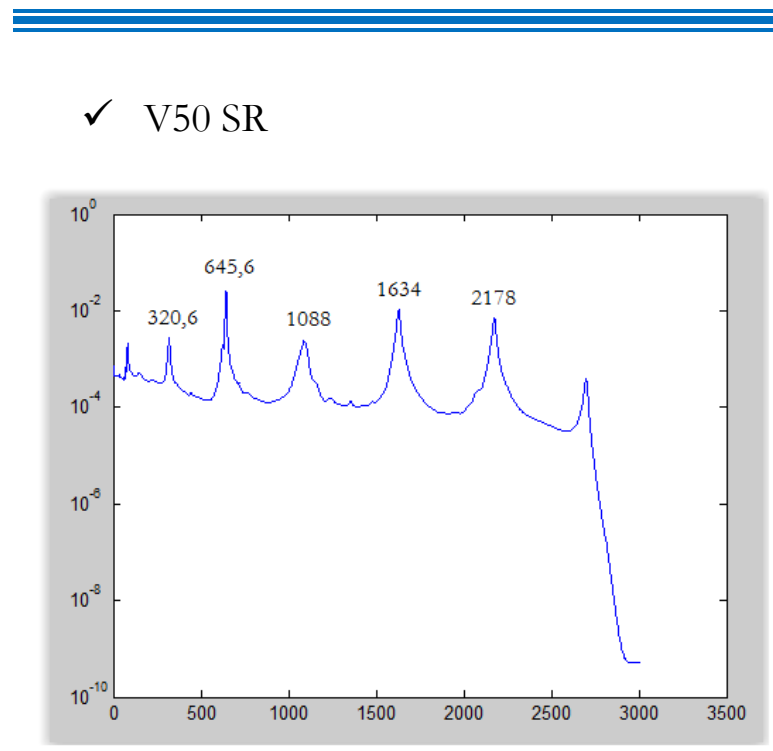

Gráfico 0.1 - ANPSD V50 SR - Íntegro $(\mathrm{Hz})$

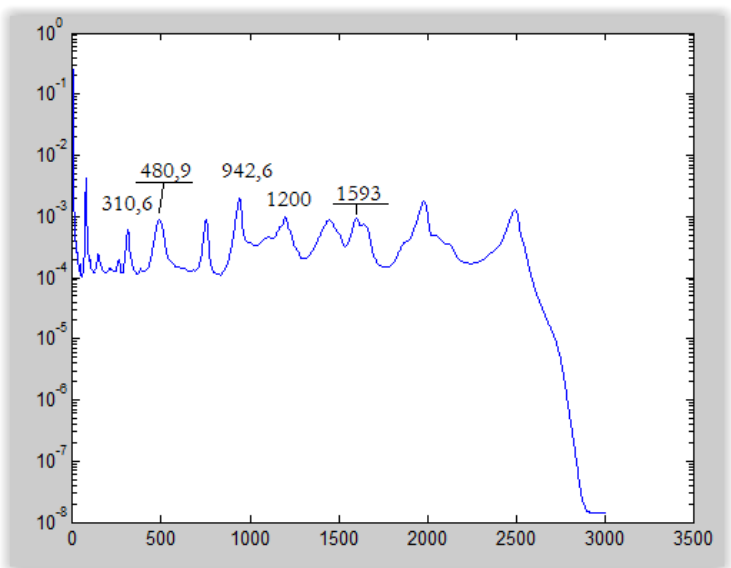

Gráfico 0.2 - ANPSD V50 SR - Ruptura $(\mathrm{Hz})$

$\checkmark$ V50 CFRP

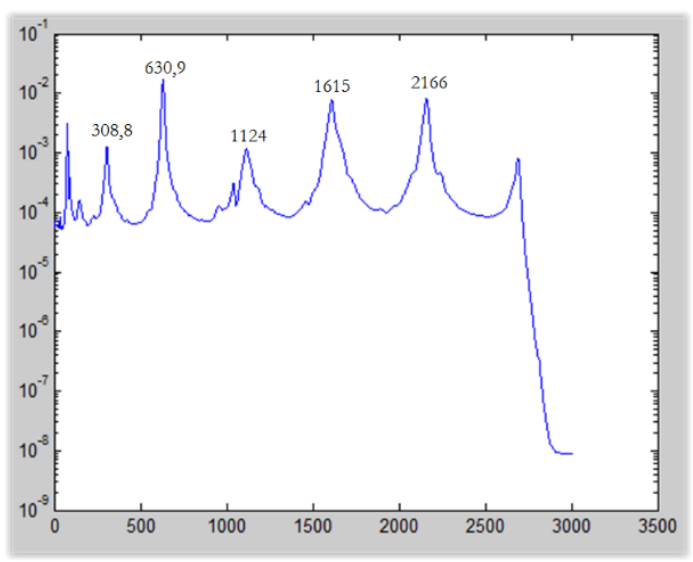

Gráfico 0.3 - ANPSD V50 CFRP - Íntegro

$(\mathrm{Hz})$

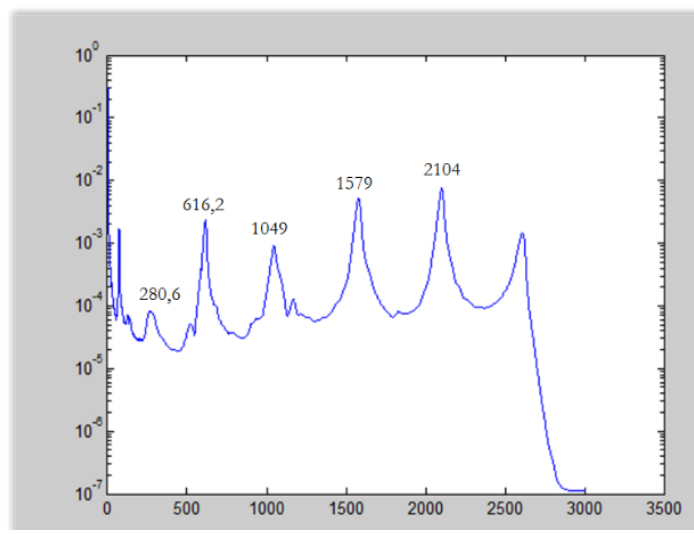

Gráfico 0.5 - ANPSD V50 CFRP - Reforço

$(\mathrm{Hz})$

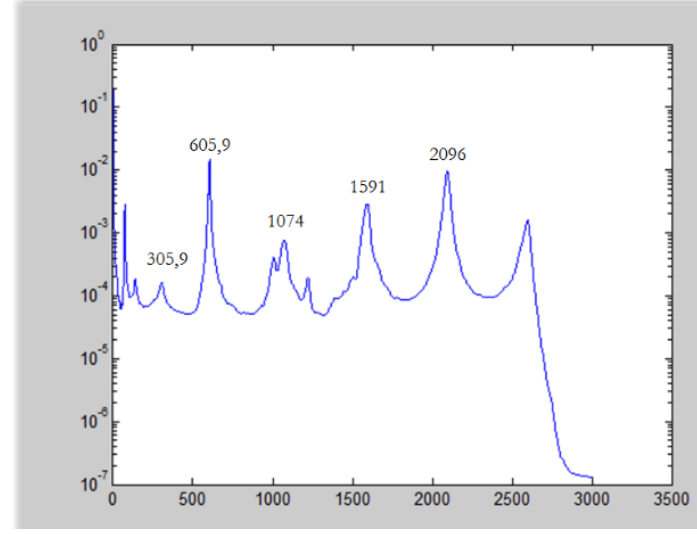

Gráfico 0.4 - ANPSD V50 CFRP - Ranhura

$(\mathrm{Hz})$

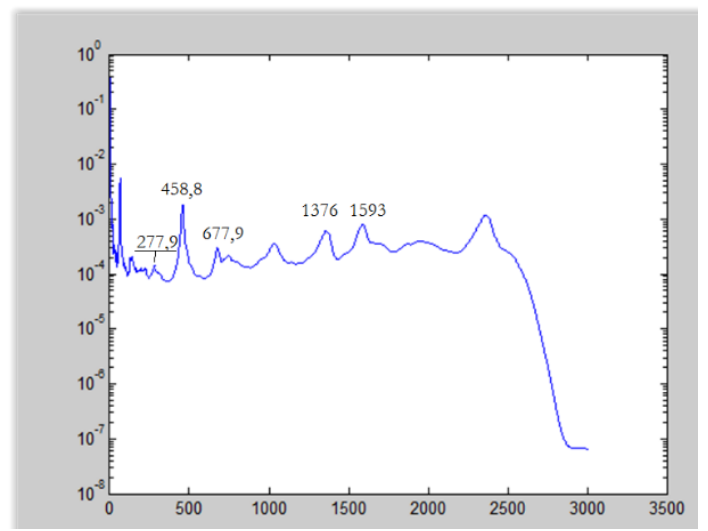

Gráfico 0.6 - ANPSD V50 CFRP - Ruptura

(Hz) 
V50 40\%

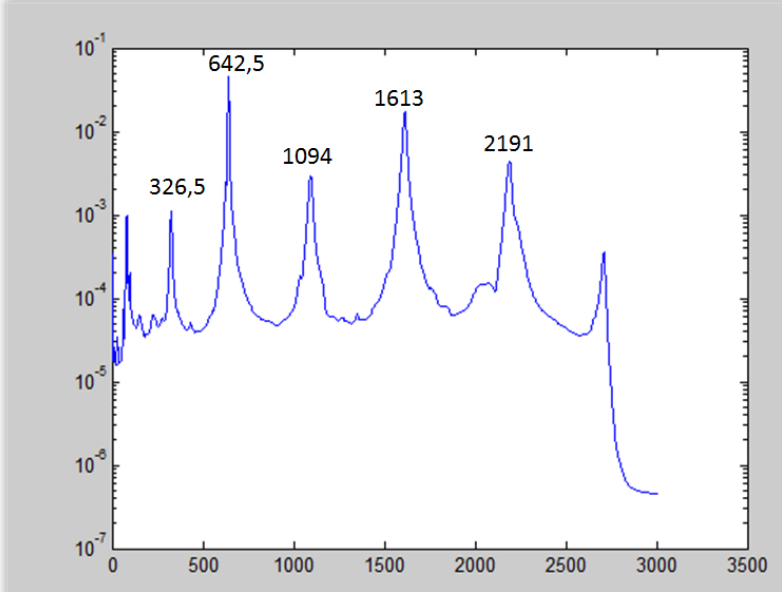

Gráfico 0.7 - ANPSD V50 40\% - Íntegro (Hz)

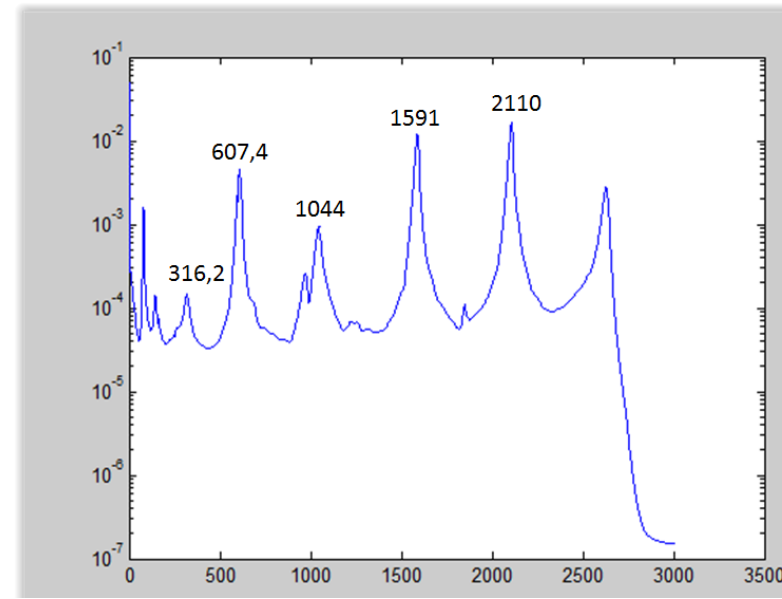

Gráfico 0.8 - ANPSD V50 40\% - Dano (Hz)

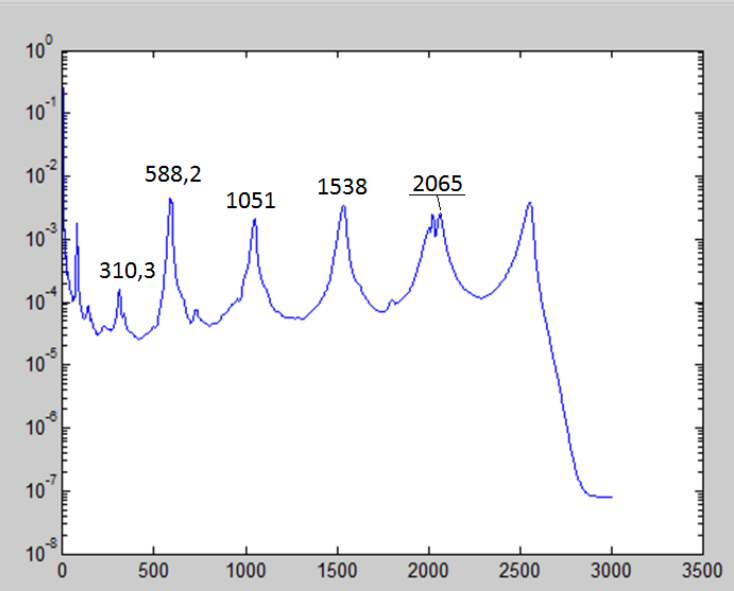

Gráfico 0.9 - ANPSD V50 40\% - Ranhura (Hz)
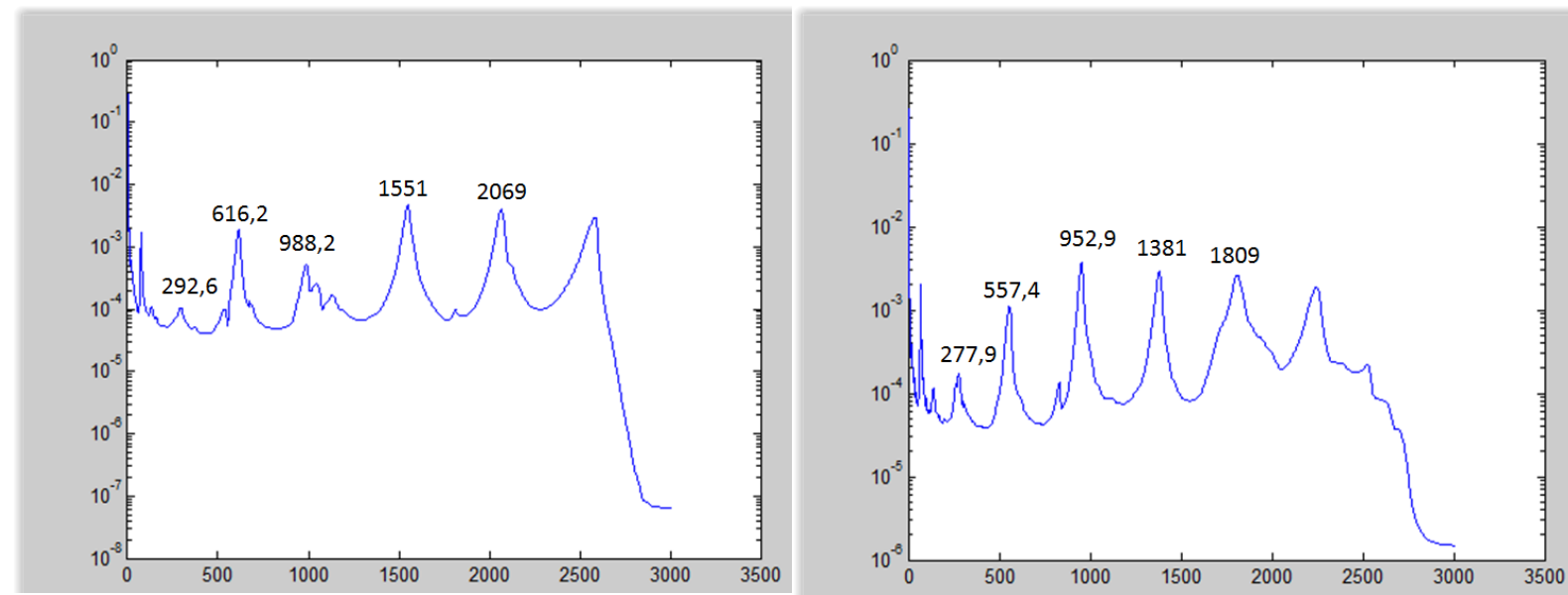

Gráfico 0.10 - ANPSD V50 40\% - Reforço (Hz)

Gráfico 0.11 - ANPSD V50 40\% - Ruptura (Hz) 
$\checkmark$ V50 70\%

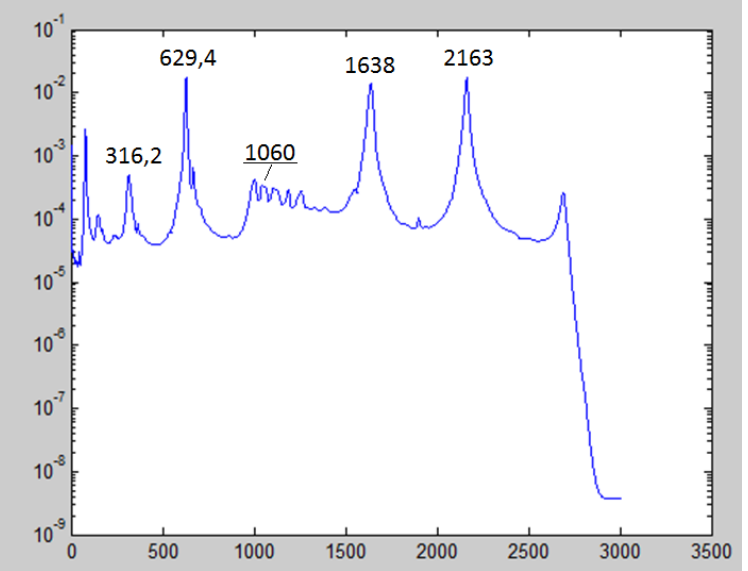

Gráfico 0.12 - ANPSD V50 70\% - Íntegro (Hz)

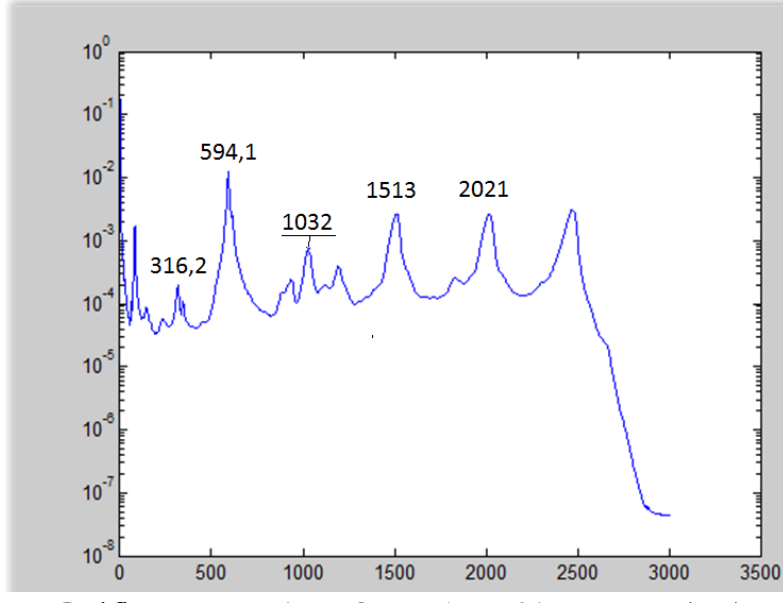

Gráfico 0.13 - ANPSD V50 70\% - Dano (Hz)

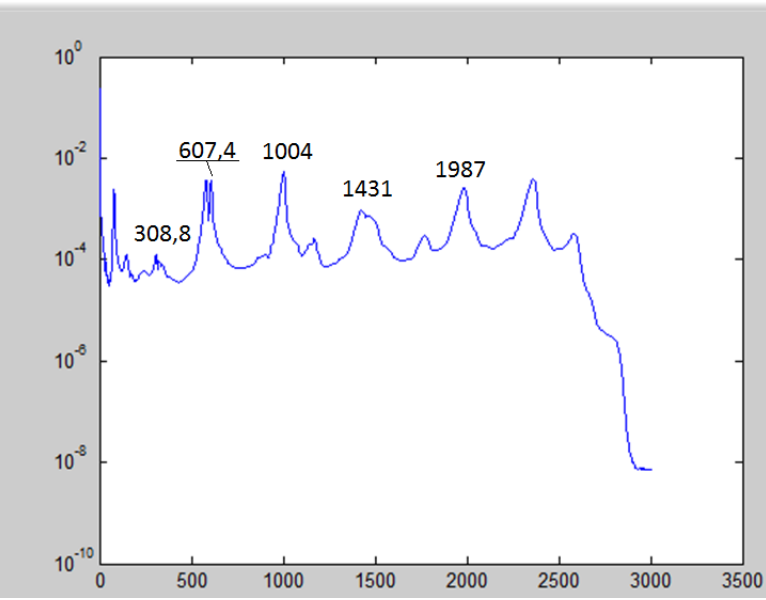

Gráfico 0.15 - ANPSD V50 70\% - Reforço (Hz)

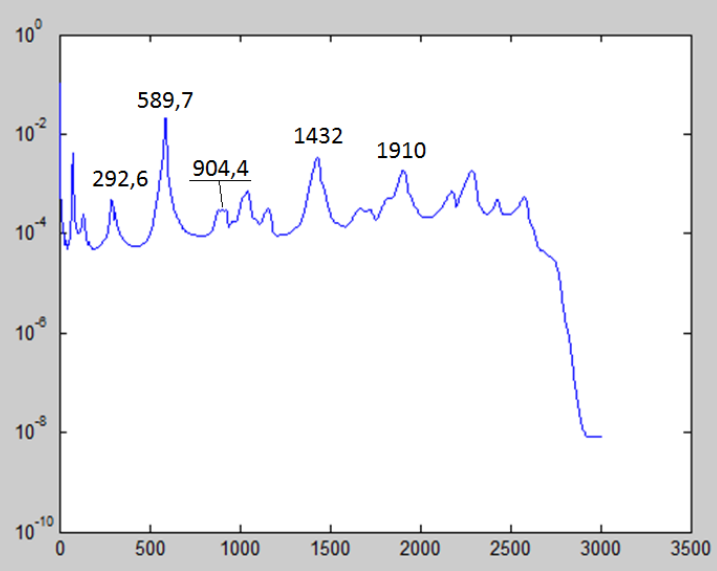

Gráfico 0.14 - ANPSD V50 70\% - Ranhura (Hz)

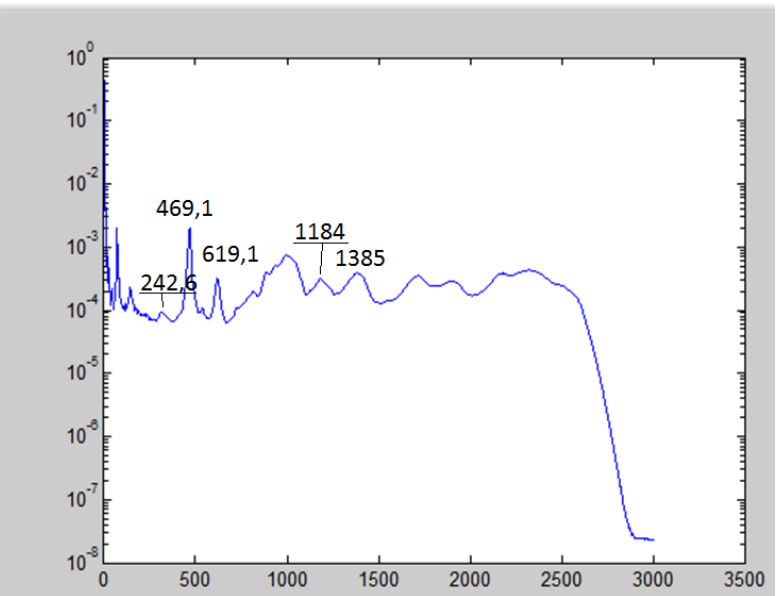

Gráfico 0.16 - ANPSD V50 70\% - Ruptura (Hz) 
V90 SR

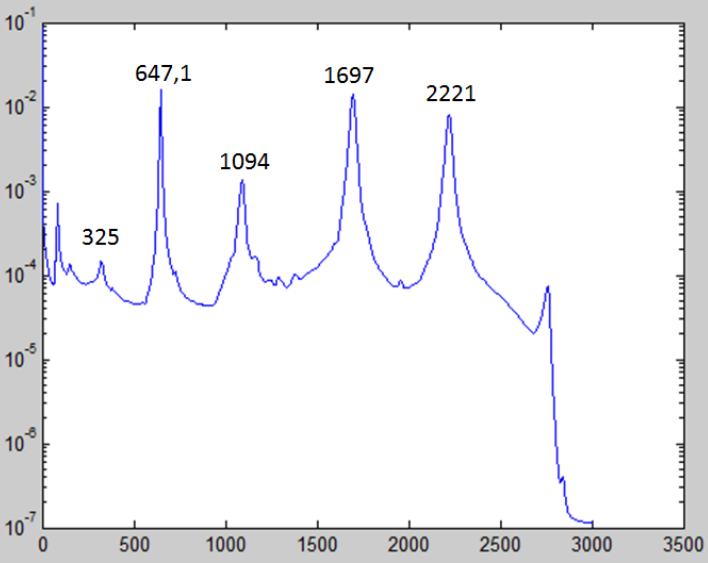

Gráfico 0.17 - ANPSD V90 SR - Íntegro (Hz)

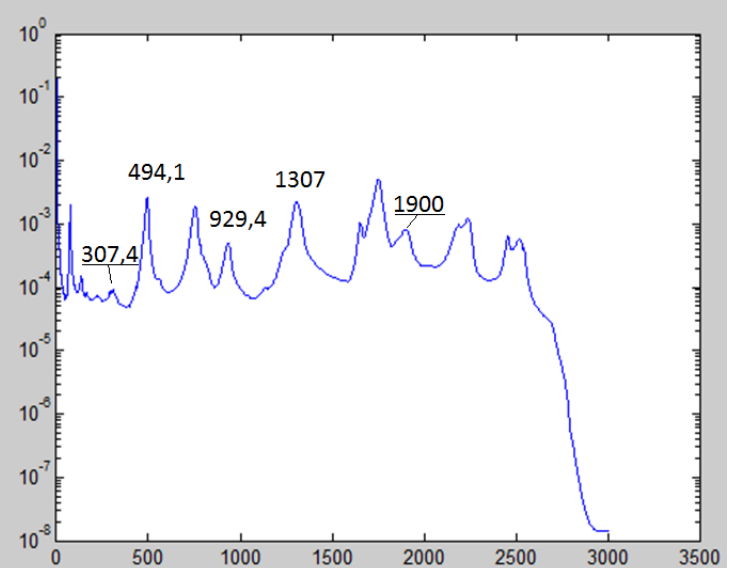

Gráfico 0.18 - ANPSD V90 SR - Ruptura $(\mathrm{Hz})$

$\checkmark$ V90 CFRP

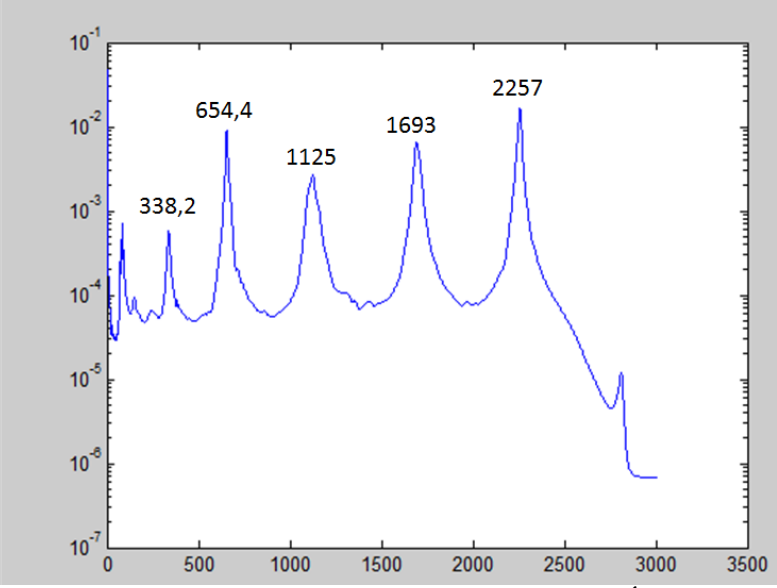

Gráfico 0.19 - ANPSD V90 CFRP - Íntegro

$(\mathrm{Hz})$

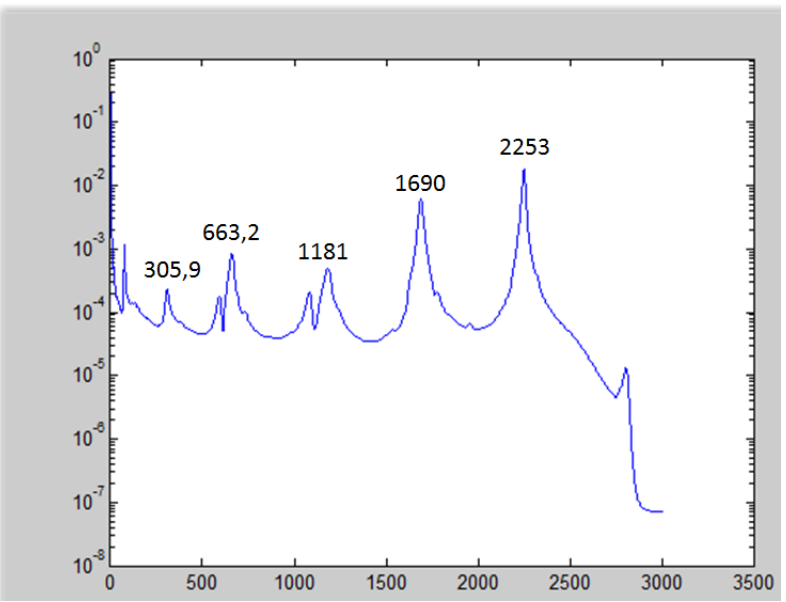

Gráfico 0.21 - ANPSD V90 CFRP - Reforço

$(\mathrm{Hz})$

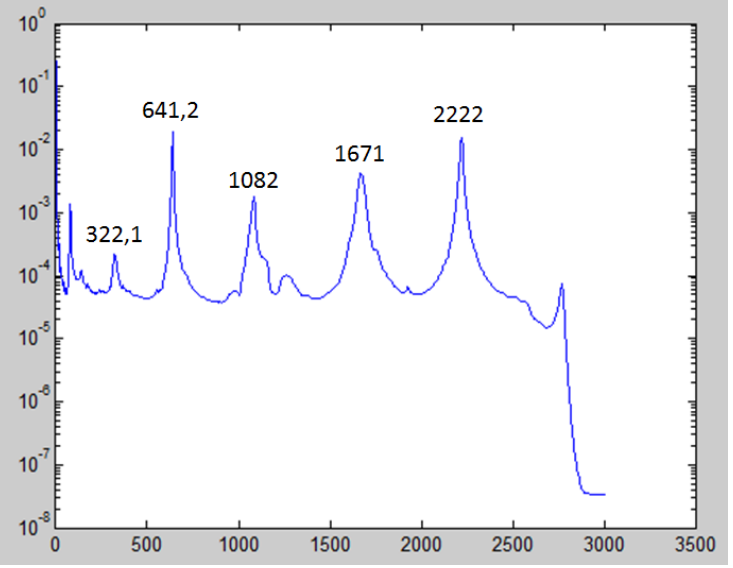

Gráfico 0.20 - ANPSD V90 CFRP - Ranhura (Hz)

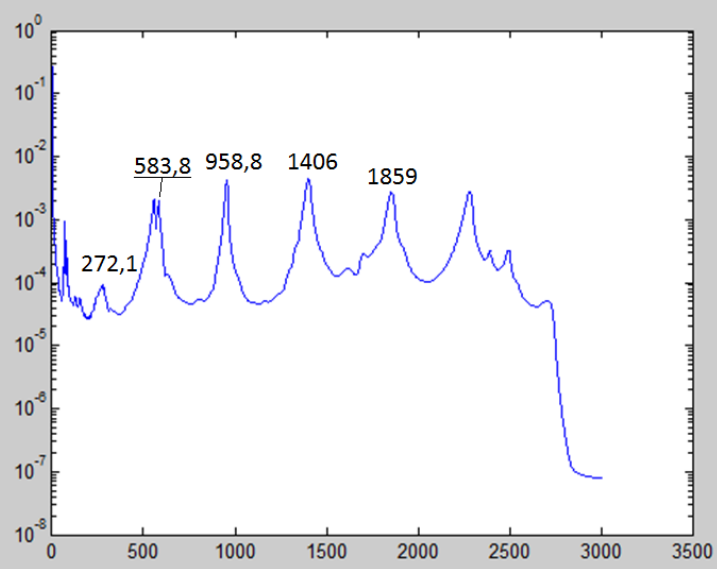

Gráfico 0.22 - ANPSD V90 CFRP - Ruptura $(\mathrm{Hz})$ 
$\checkmark \mathrm{V} 9040 \%$

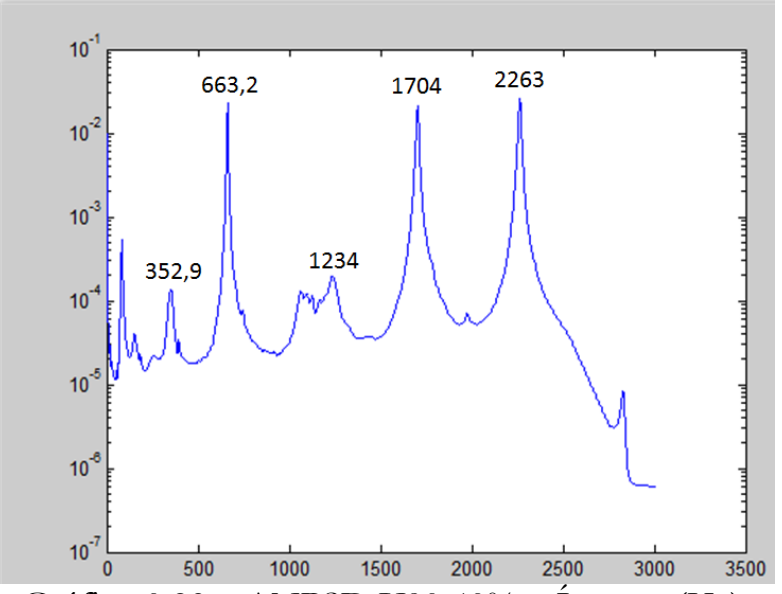

Gráfico 0.23 - ANPSD V90 40\% - Íntegro (Hz)
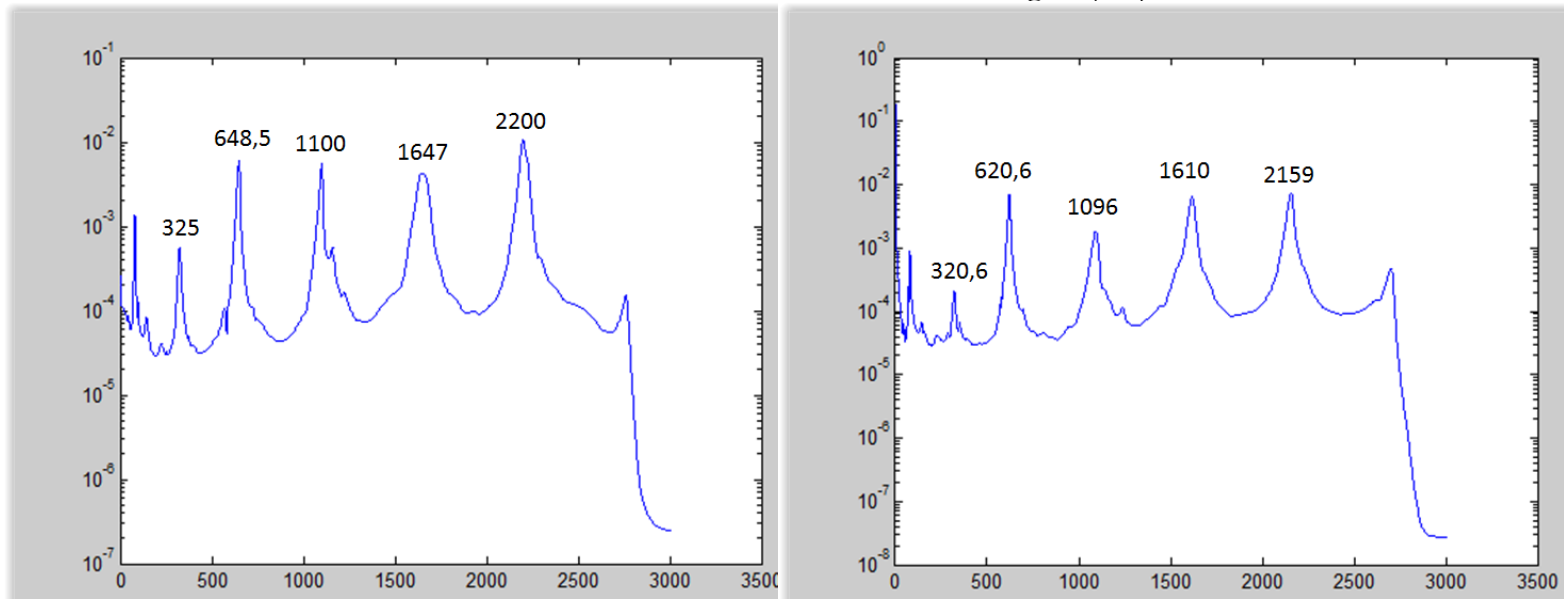

Gráfico 0.24 - ANPSD V90 40\% - Dano (Hz)

Gráfico 0.25 - ANPSD V90 40\% - Ranhura (Hz)
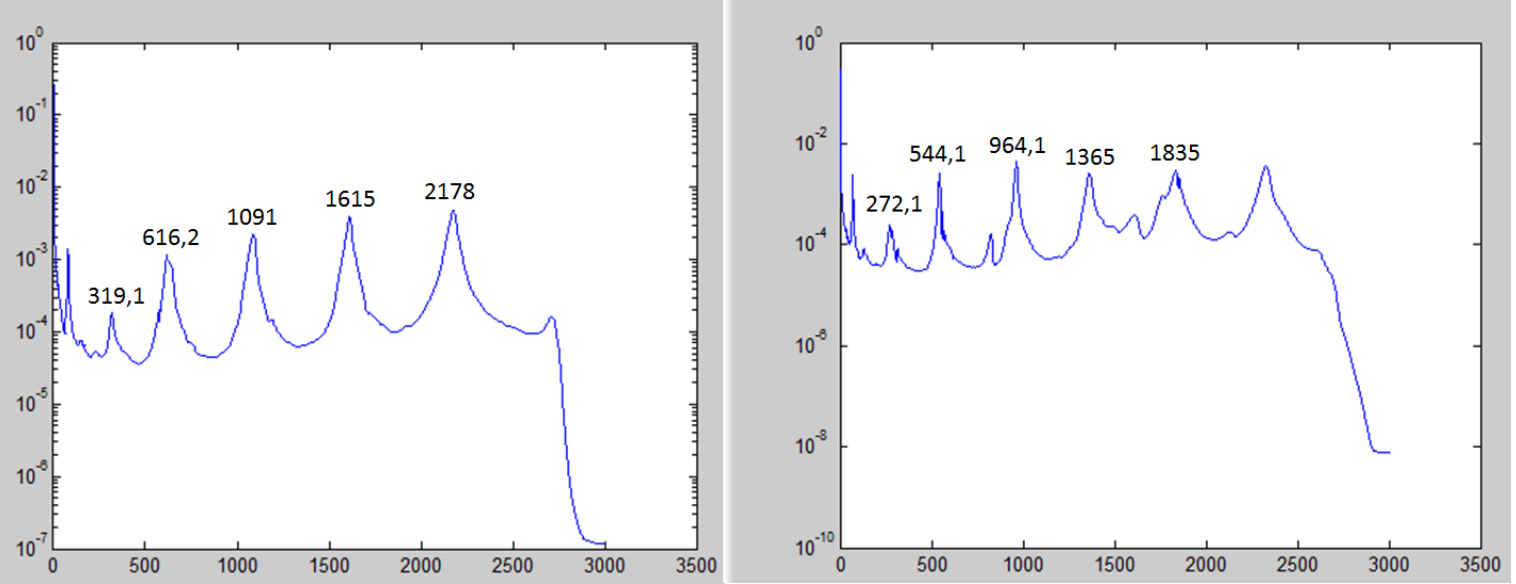

Gráfico 0.26 - ANPSD V90 40\% - Reforço (Hz)

Gráfico 0.27 - ANPSD V90 40\% - Ruptura (Hz) 
$\checkmark$ V90 70\%

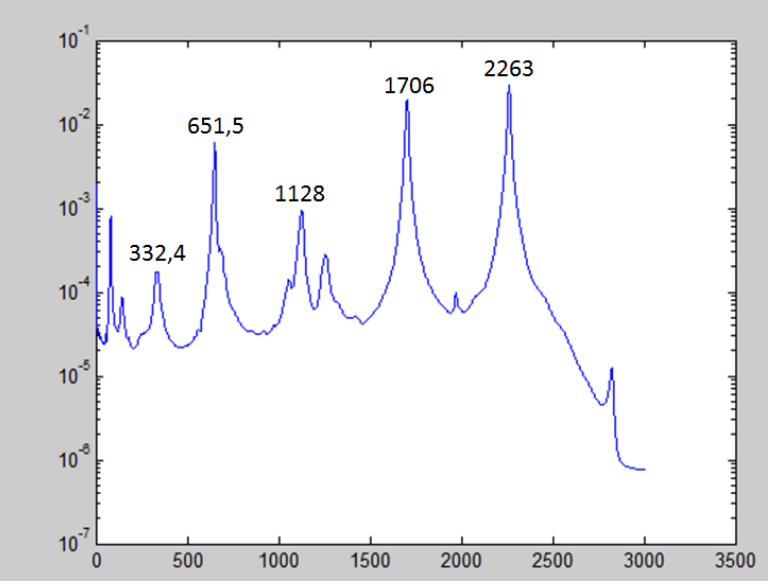

Gráfico 0.28 - ANPSD V50 70\% - Íntegro (Hz)

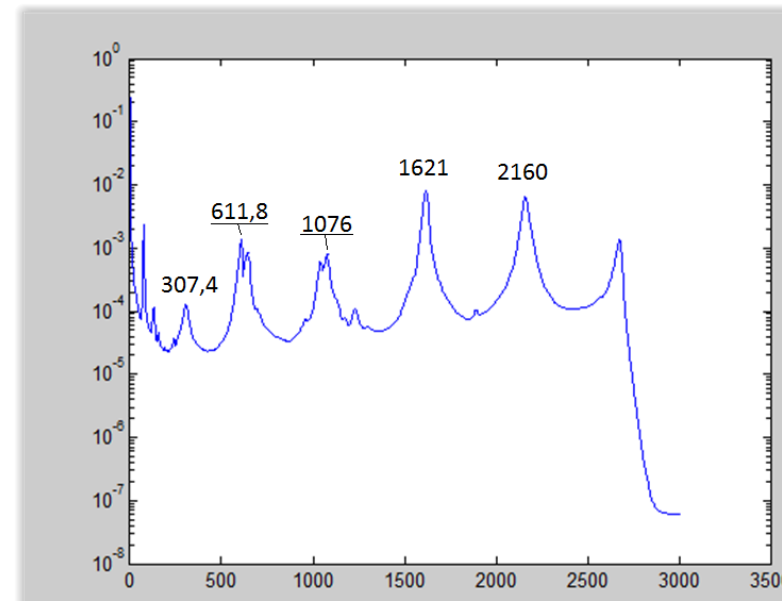

Gráfico 0.29 - ANPSD V90 70\% - Dano $(\mathrm{Hz})$

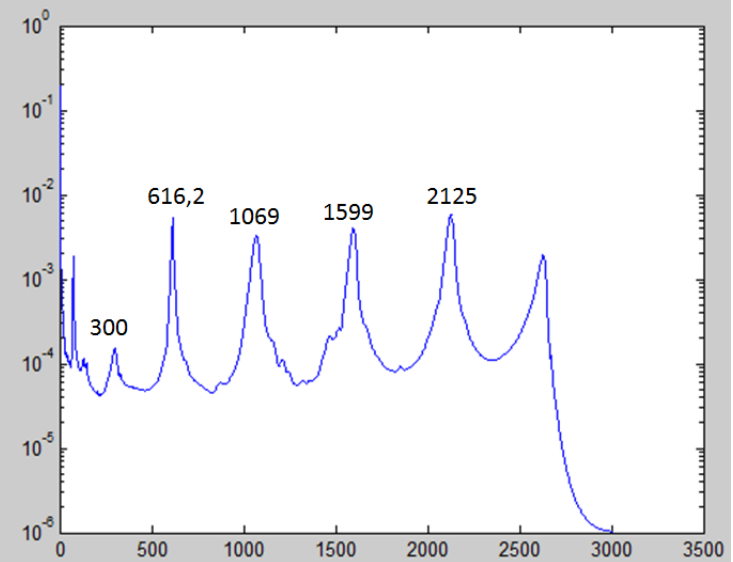

Gráfico 0.30 - ANPSD V90 70\% - Ranhura (Hz)
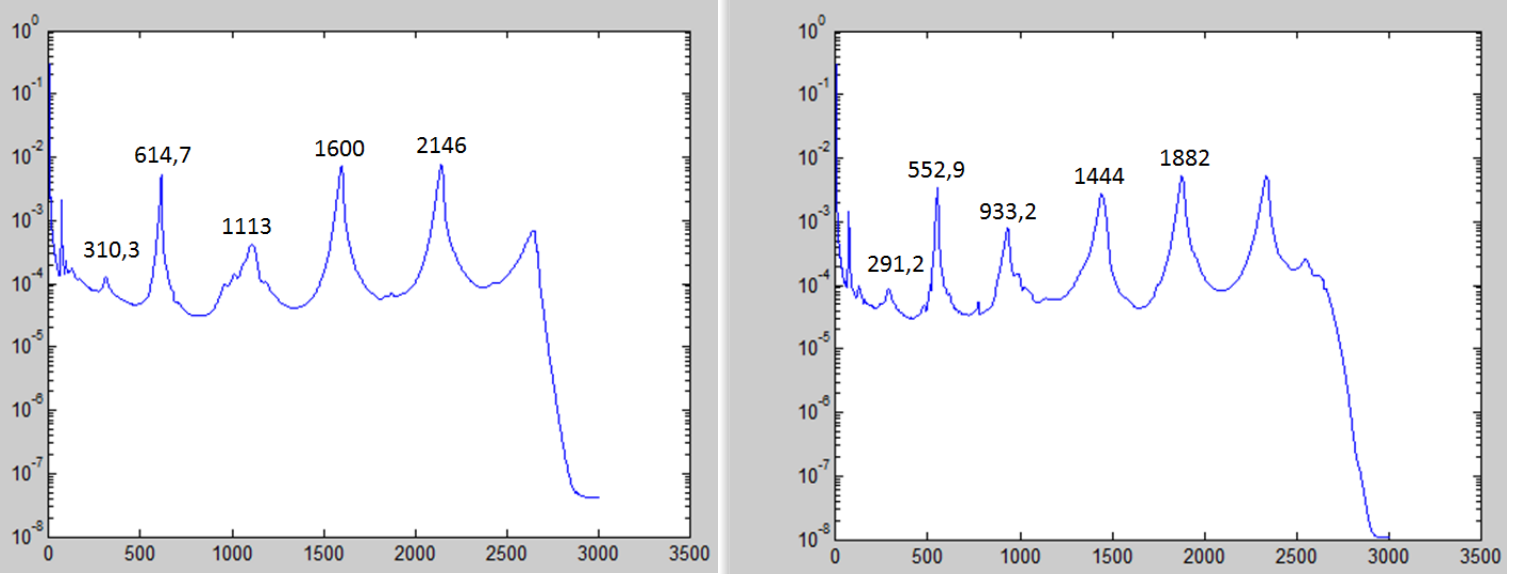

Gráfico 0.31 - ANPSD V90 70\% - Reforço (Hz)

Gráfico 0.32 - ANPSD V90 70\% - Ruptura (Hz) 


\section{APÊNDICE D - MAC E COMAC}

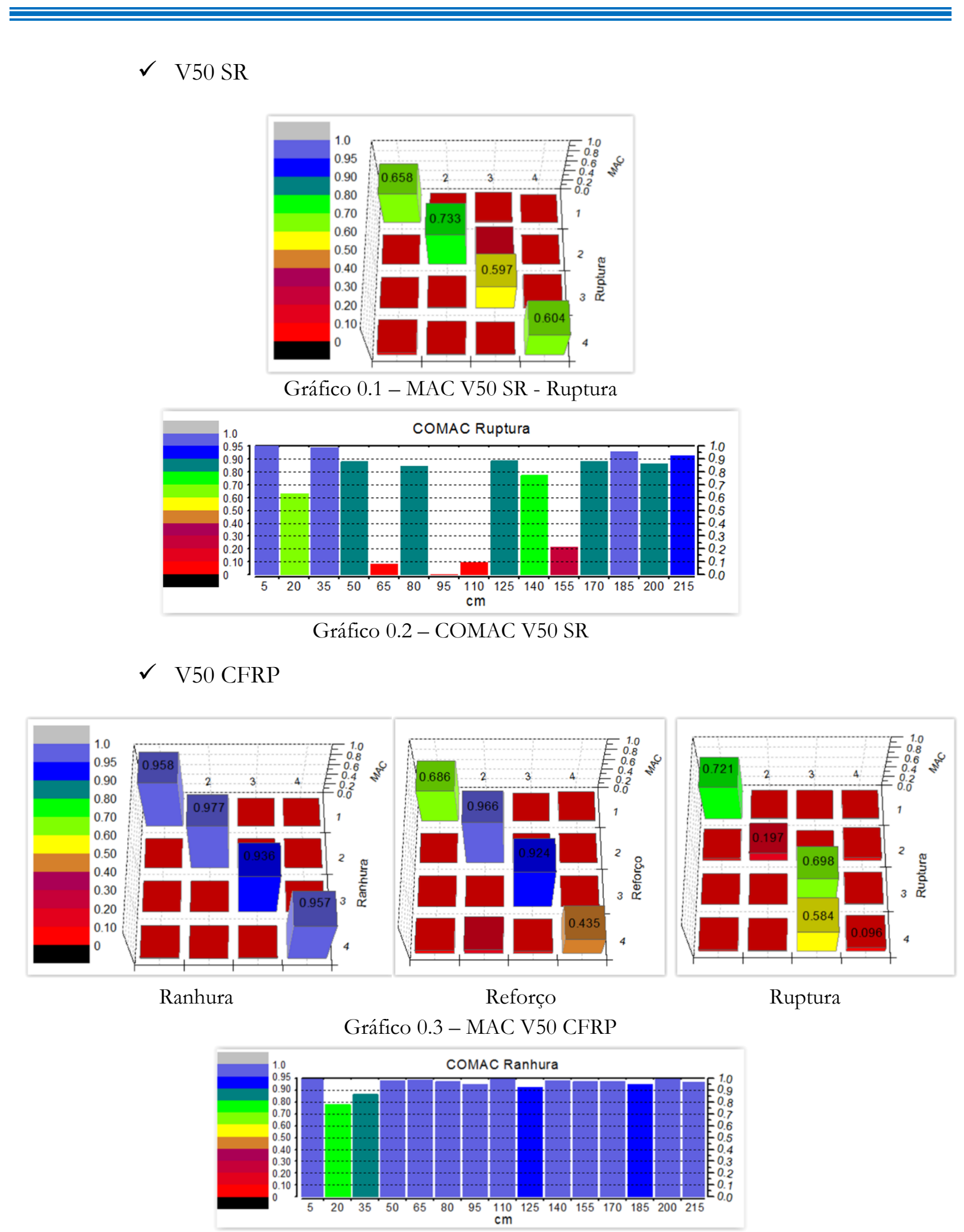



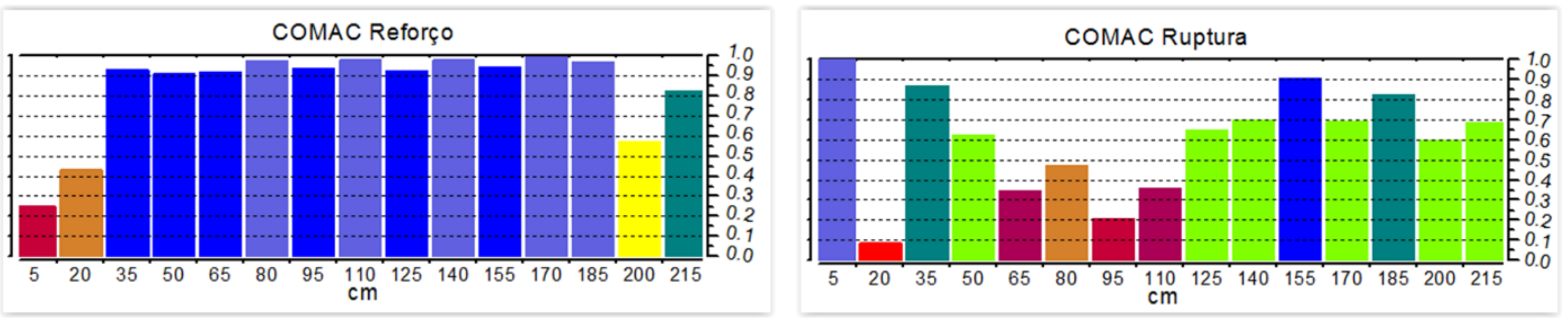

Gráfico 0.4 - COMAC V50 CFRP

$\checkmark$ V50 40\%

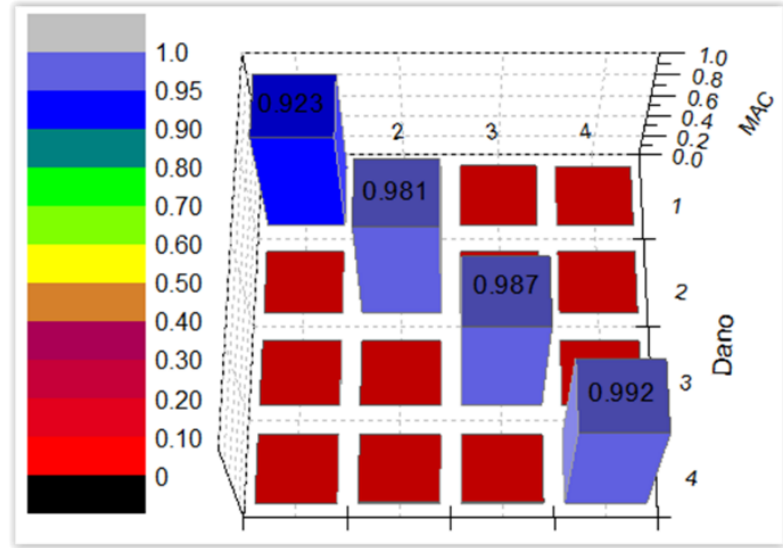

Dano

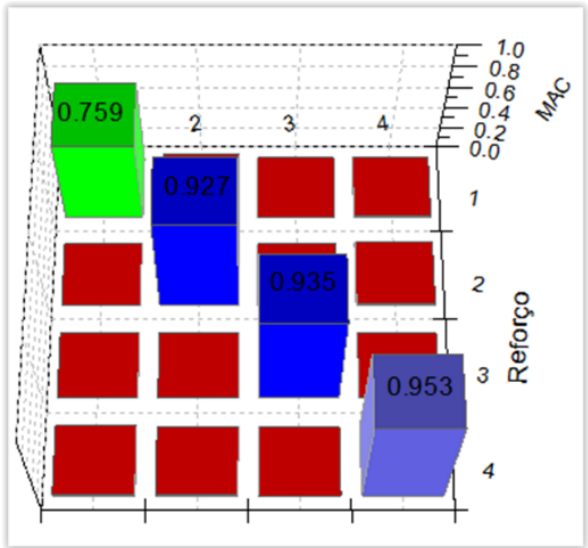

Reforço

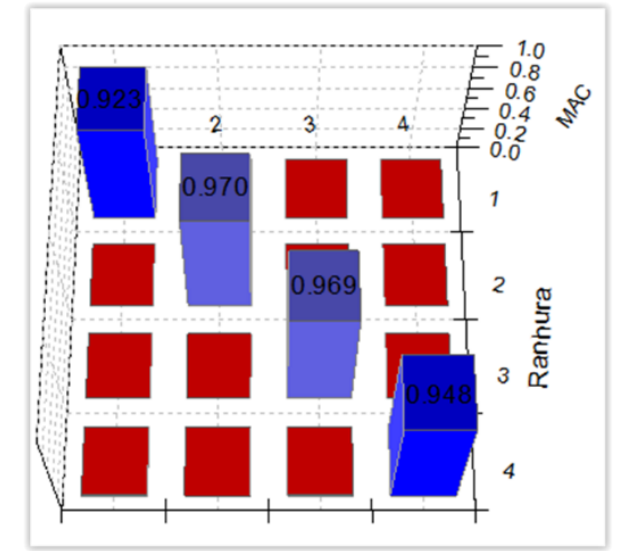

Ranhura

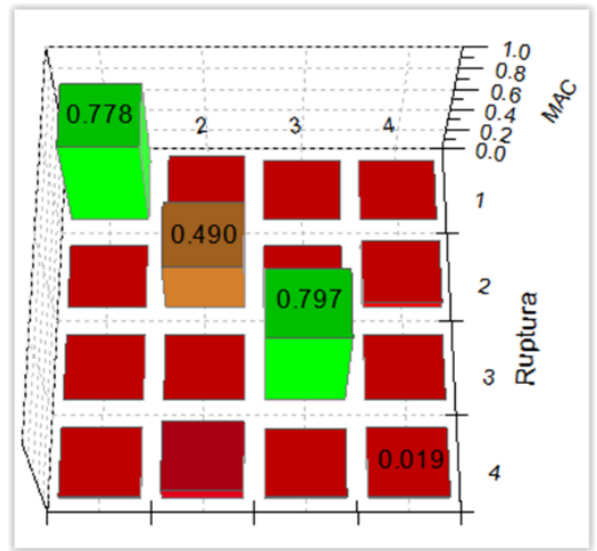

Ruptura

Gráfico 0.5 - MAC V50 40\%
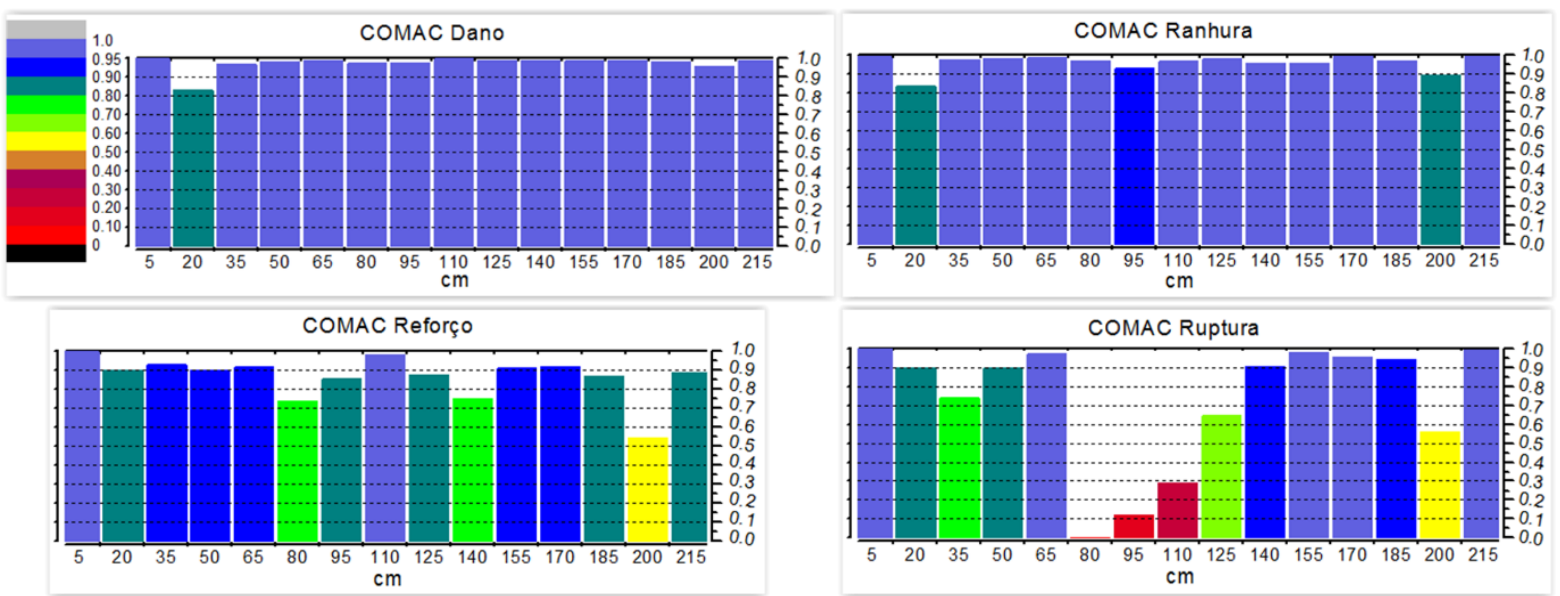

Gráfico 0.6 - COMAC V50 40\% 
V50 70\%

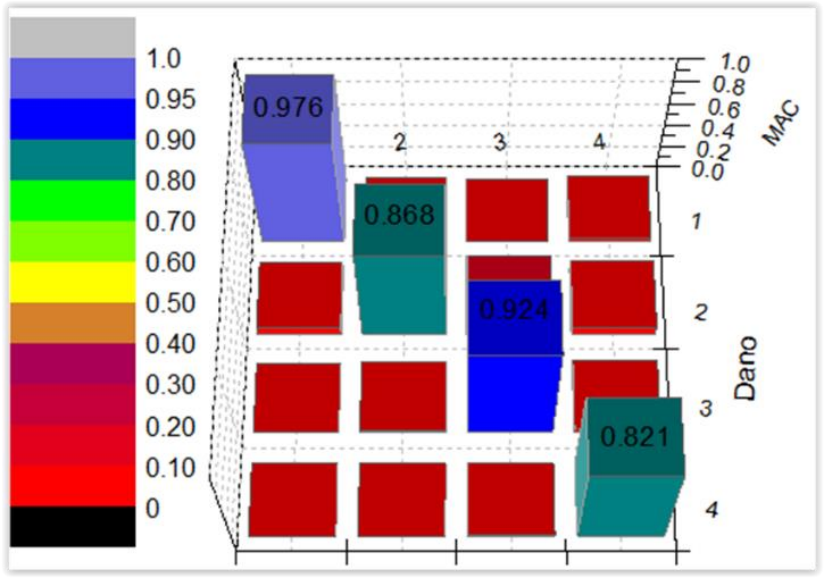

Dano

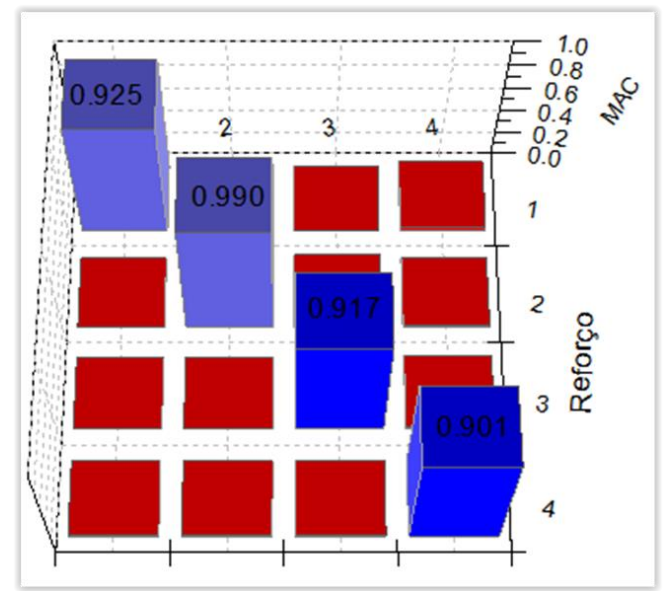

Reforço

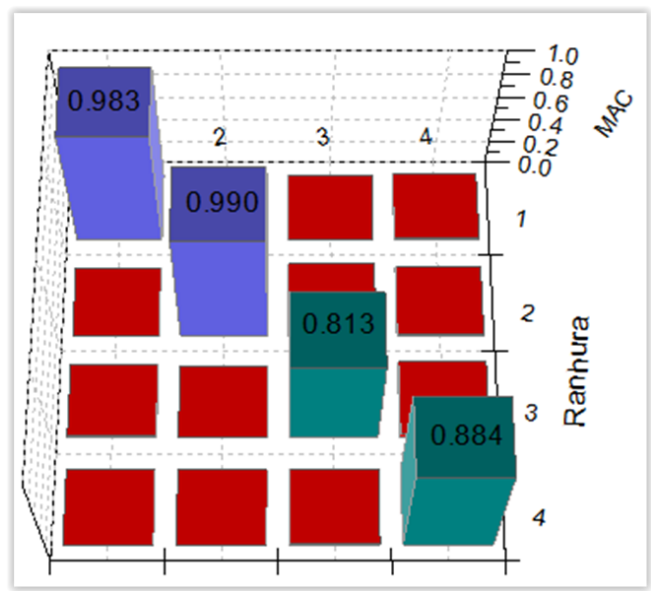

Ranhura

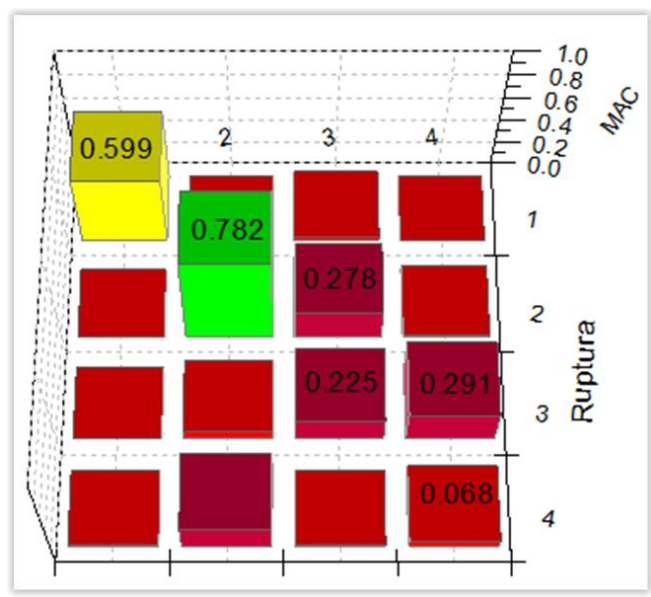

Ruptura

Gráfico 0.7 - MAC V50 70\%
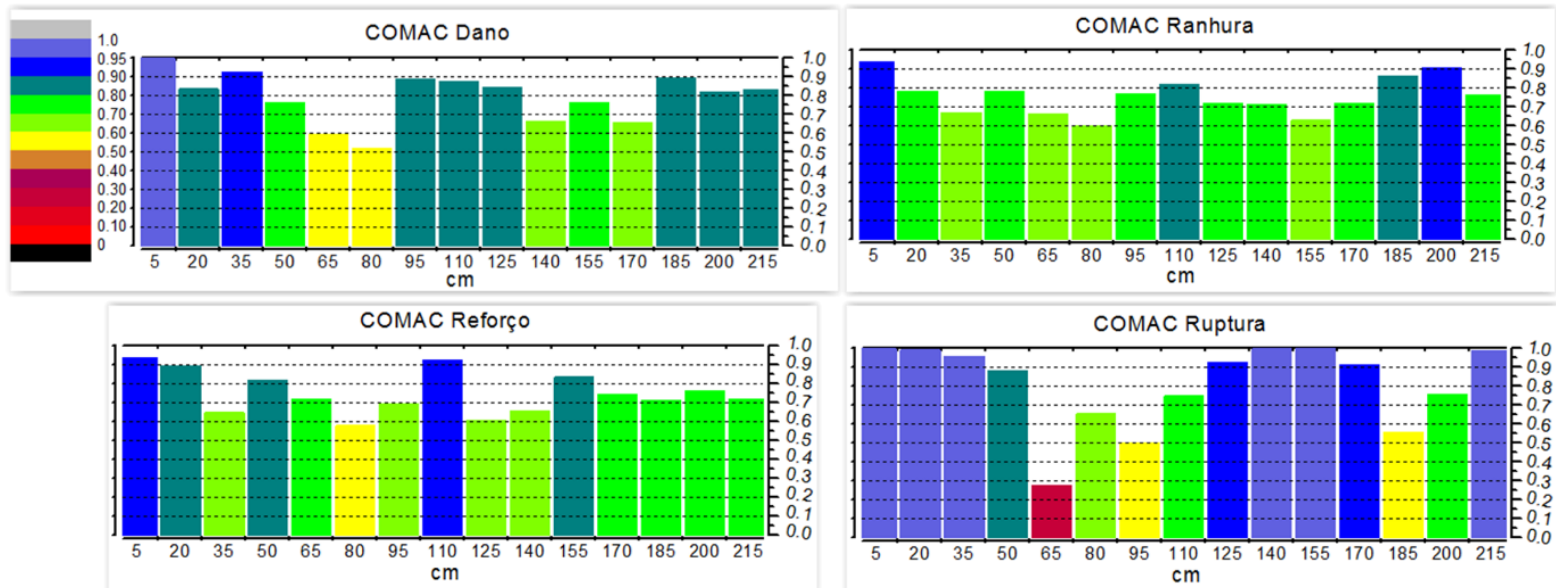

COMAC Ruptura

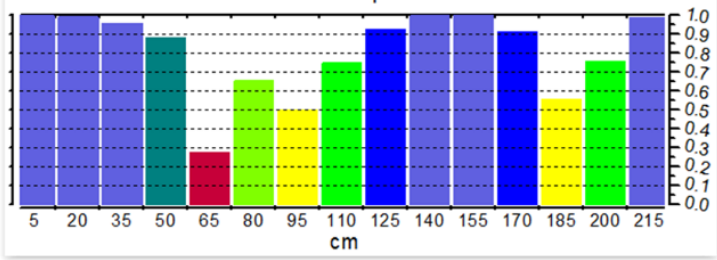

Gráfico 0.8 - COMAC V50 70\% 
$\checkmark$ V90 SR

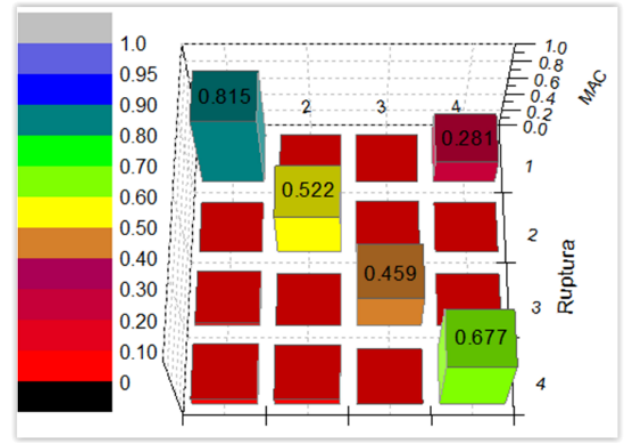

Gráfico 0.9 - MAC V90 SR - Ruptura

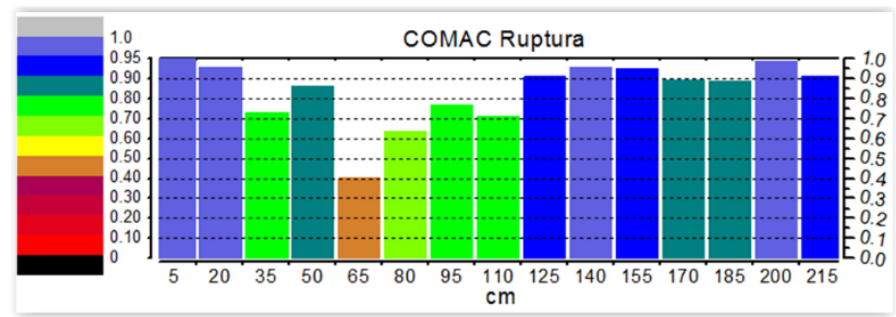

Gráfico 0.10 - COMAC V90 SR

$\checkmark$ V90 CFRP

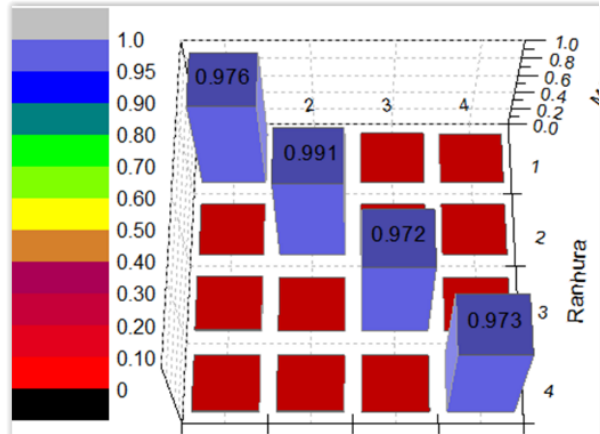

Ranhura

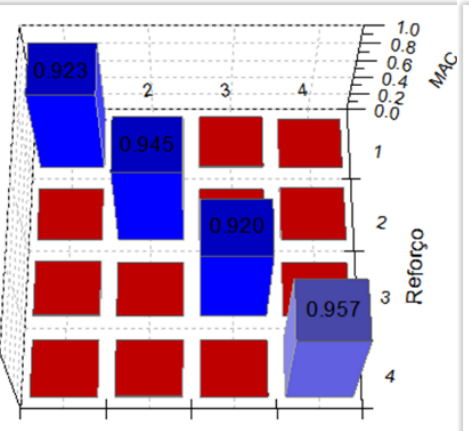

Reforço

Gráfico 0.11 - MAC V90 CFRP

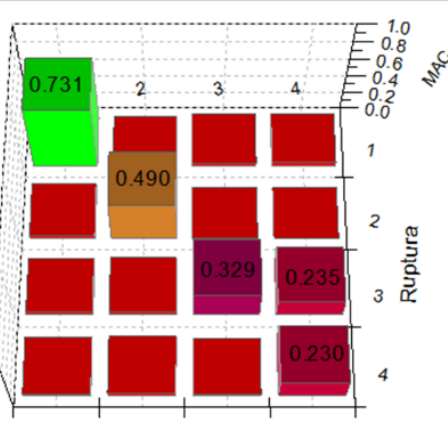

Ruptura
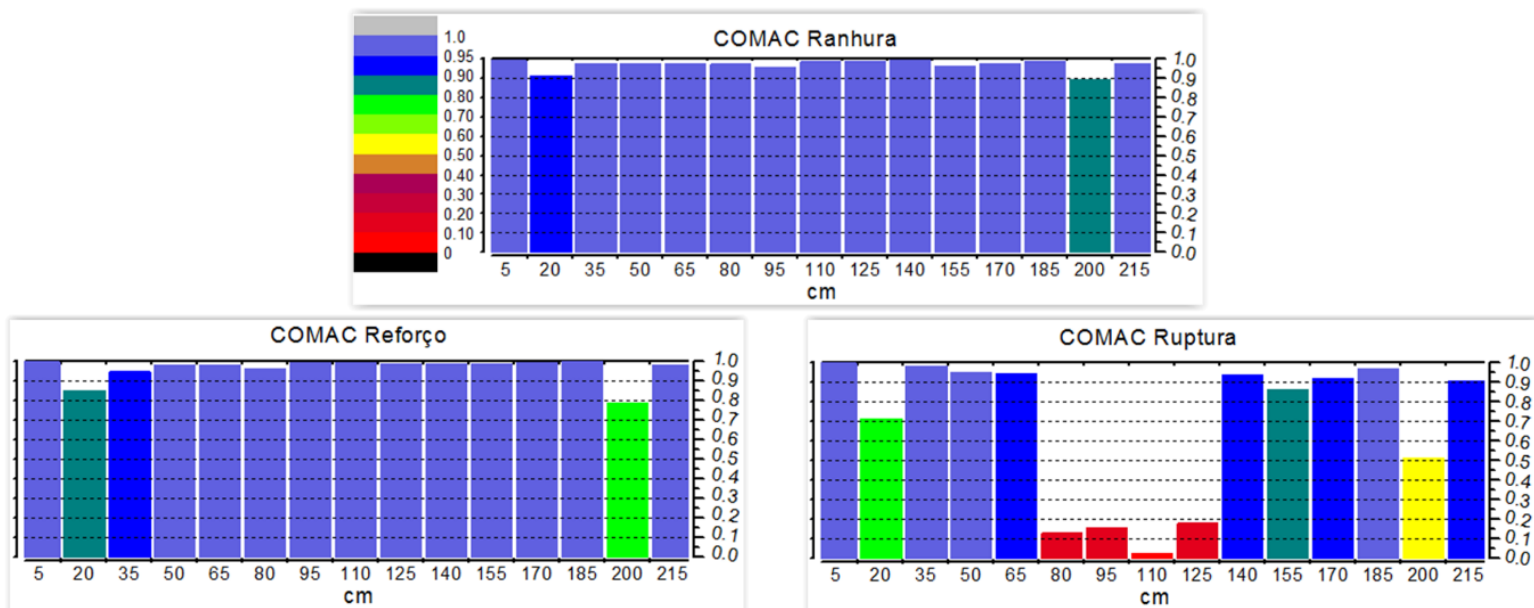

Gráfico 0.12 - COMAC V90 CFRP 
V90 40\%

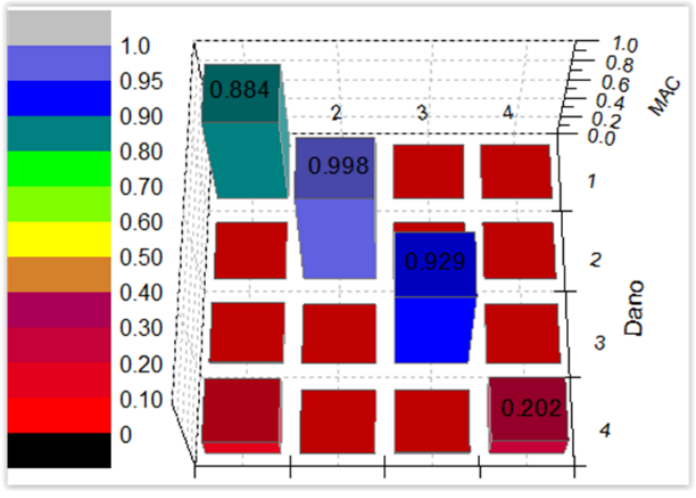

Dano

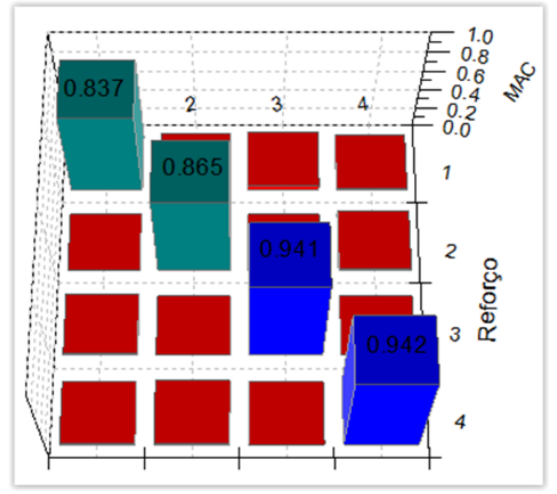

Reforço

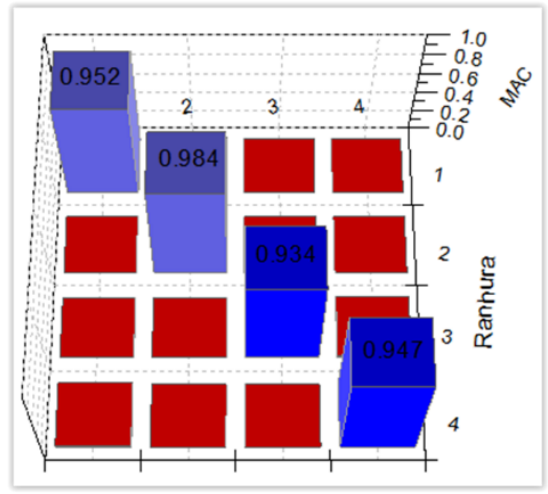

Ranhura

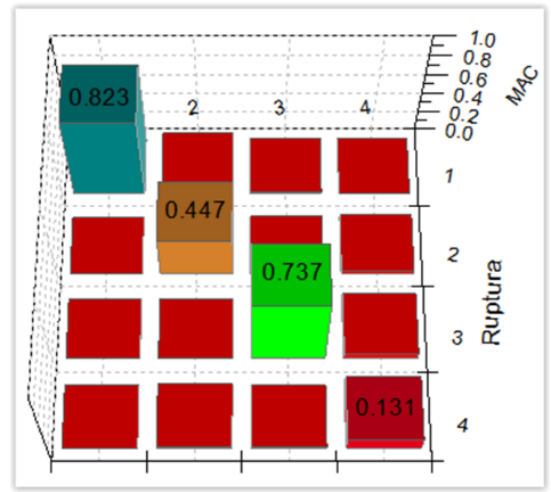

Ruptura

Gráfico 0.13 - MAC V90 40\%
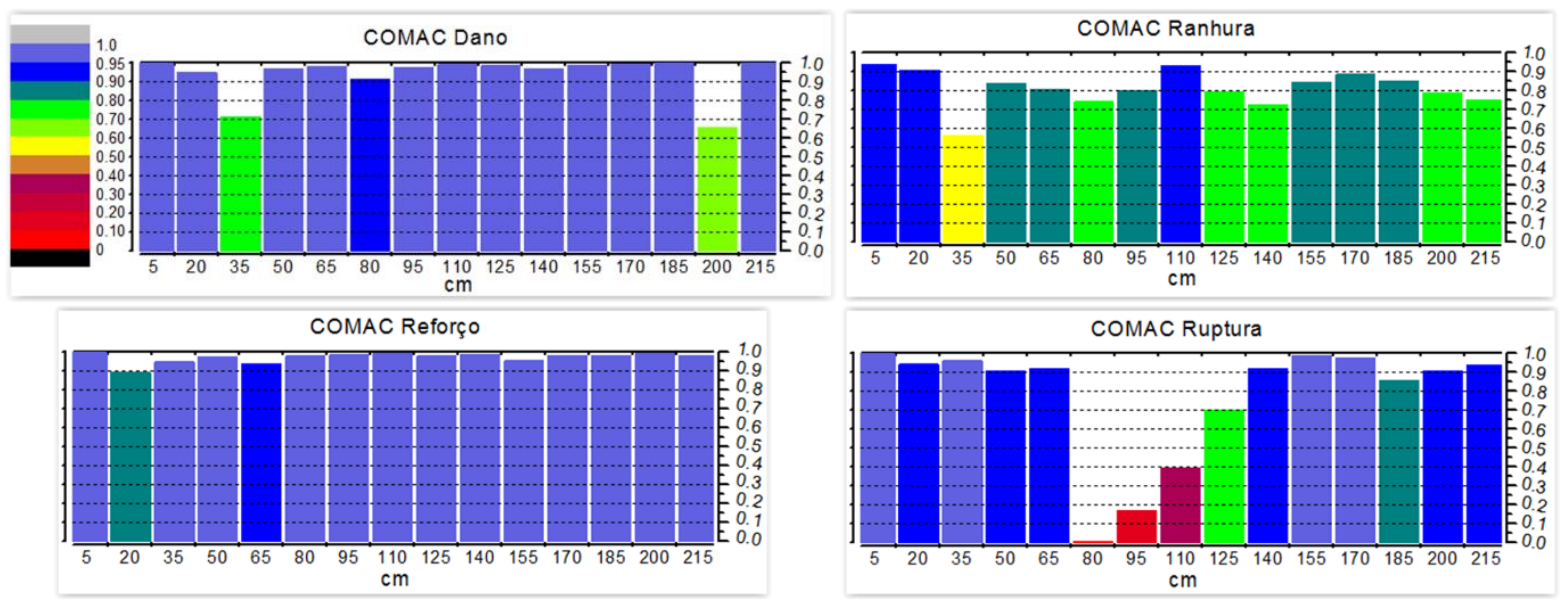

Gráfico 0.14 - COMAC V90 40\% 
$\checkmark$ V90 70\%
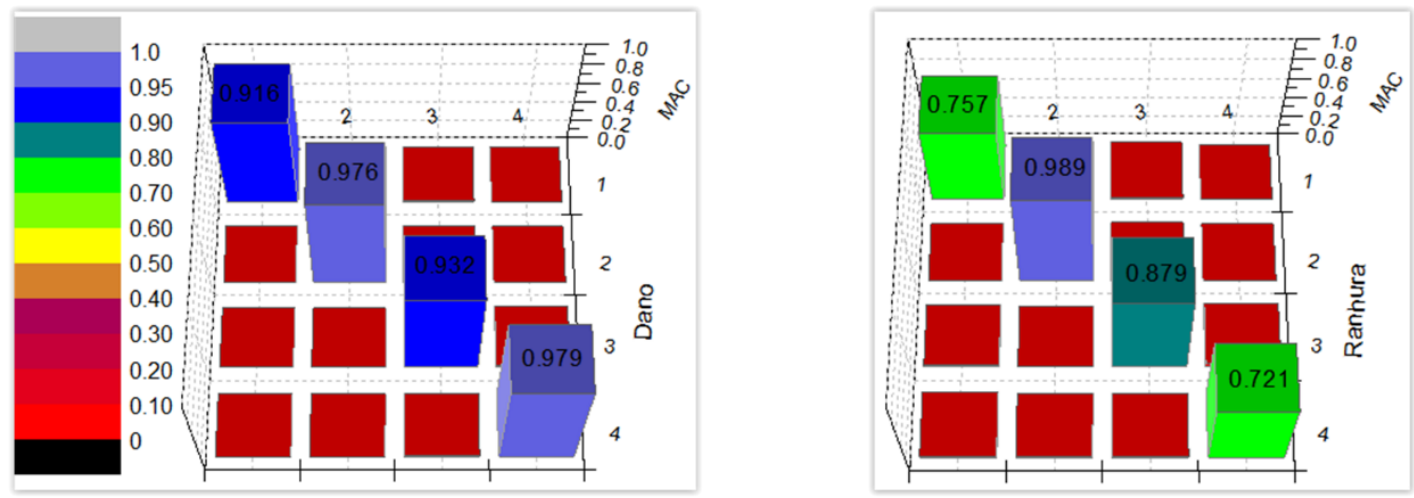

Dano

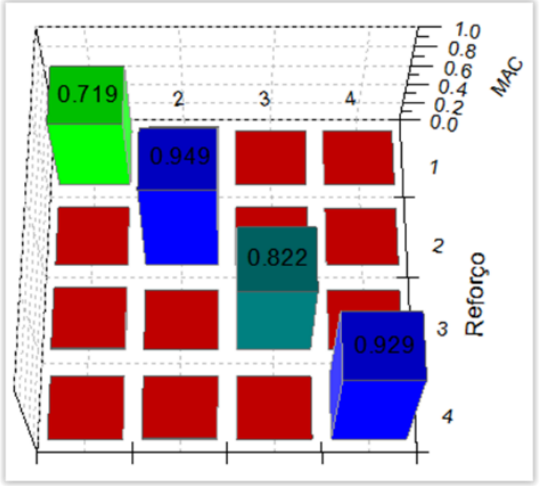

Reforço

Ranhura

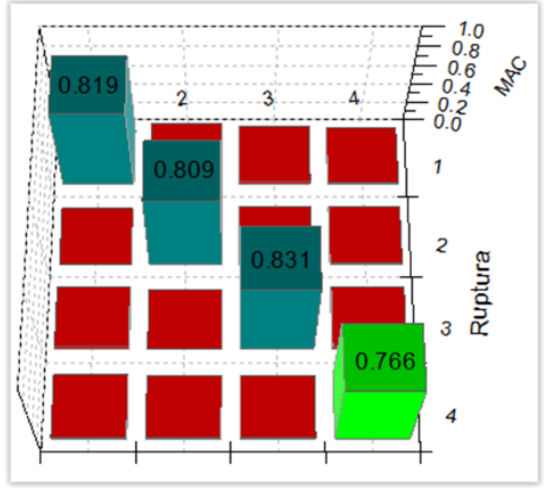

Ruptura

Gráfico 0.15 - MAC V90 70\%
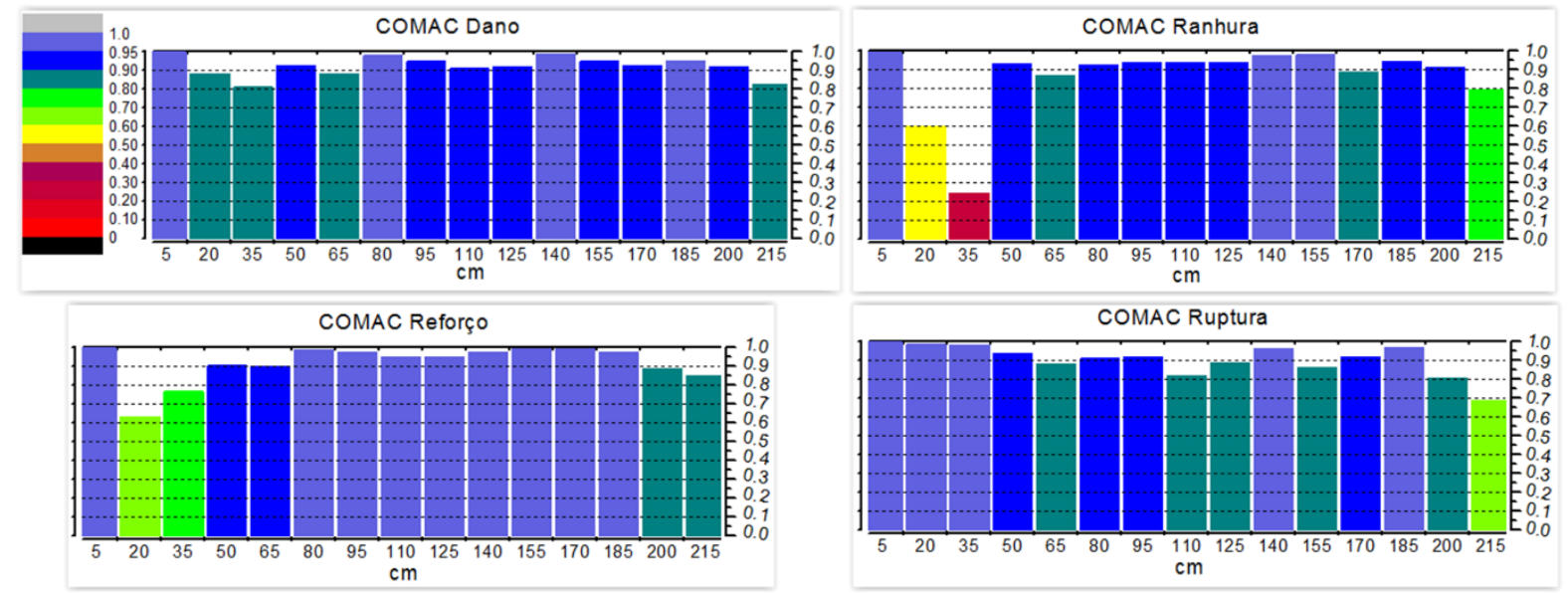

Gráfico 0.16 - COMAC V90 70\% 


\section{ANEXO I - CARBODUR S214}
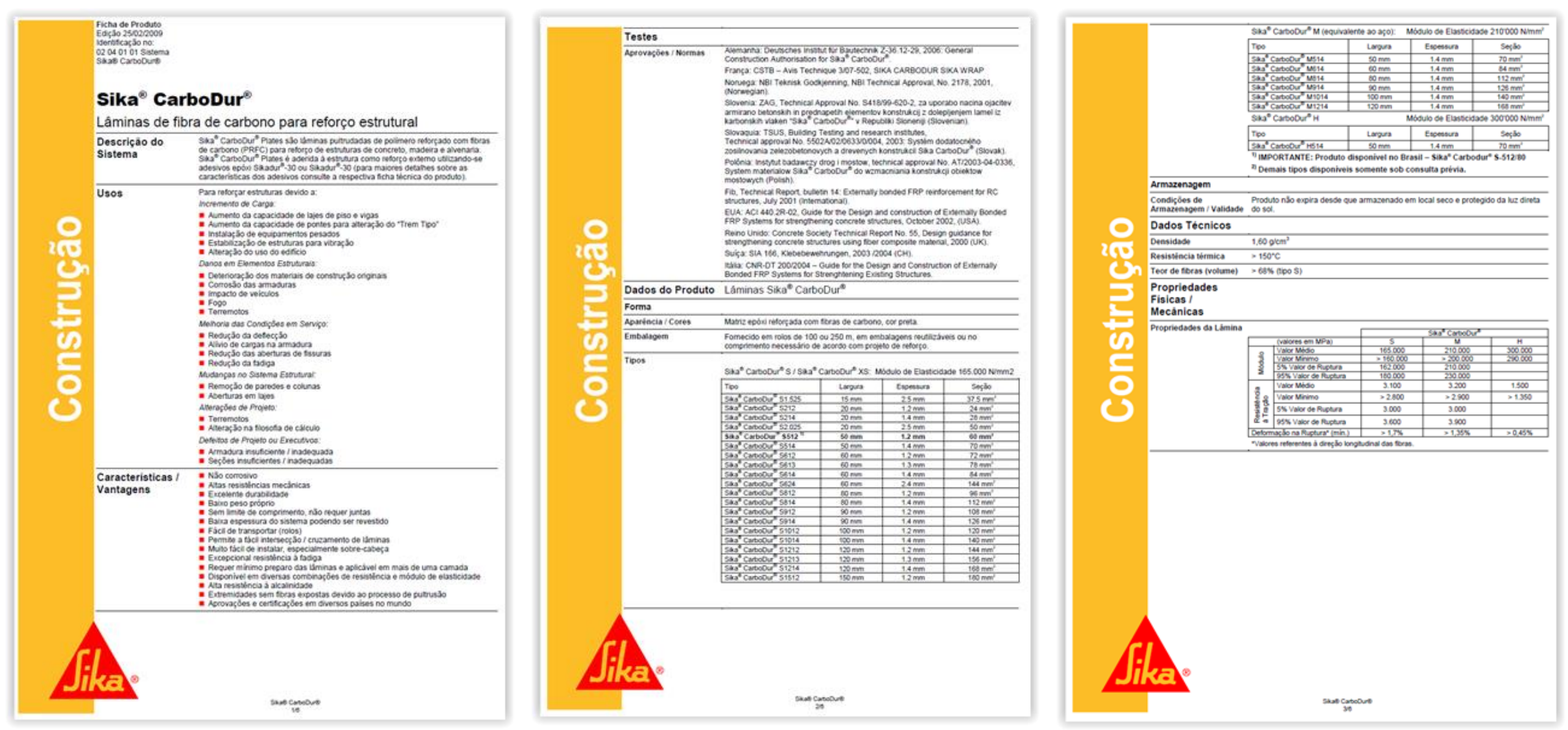

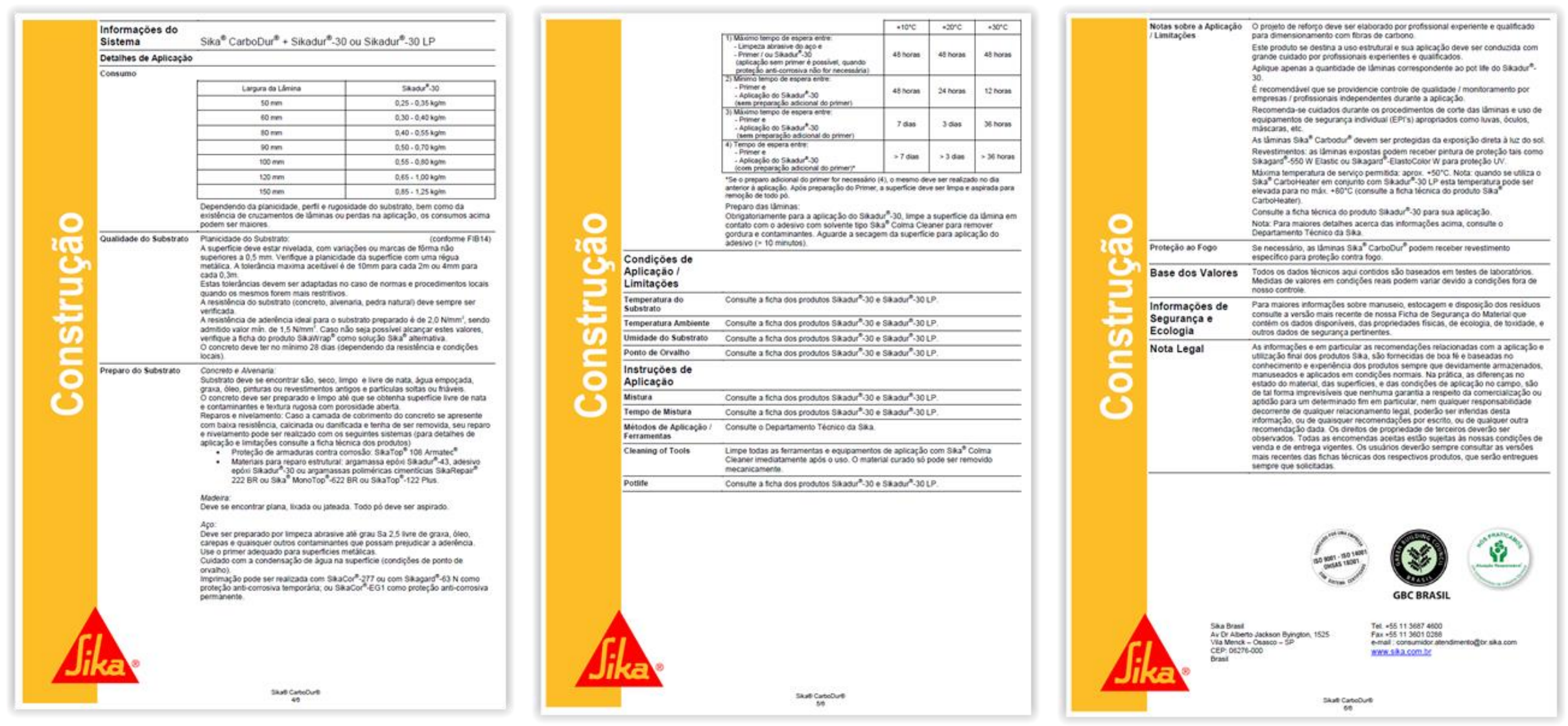
ANEXO II - SIKADUR 30

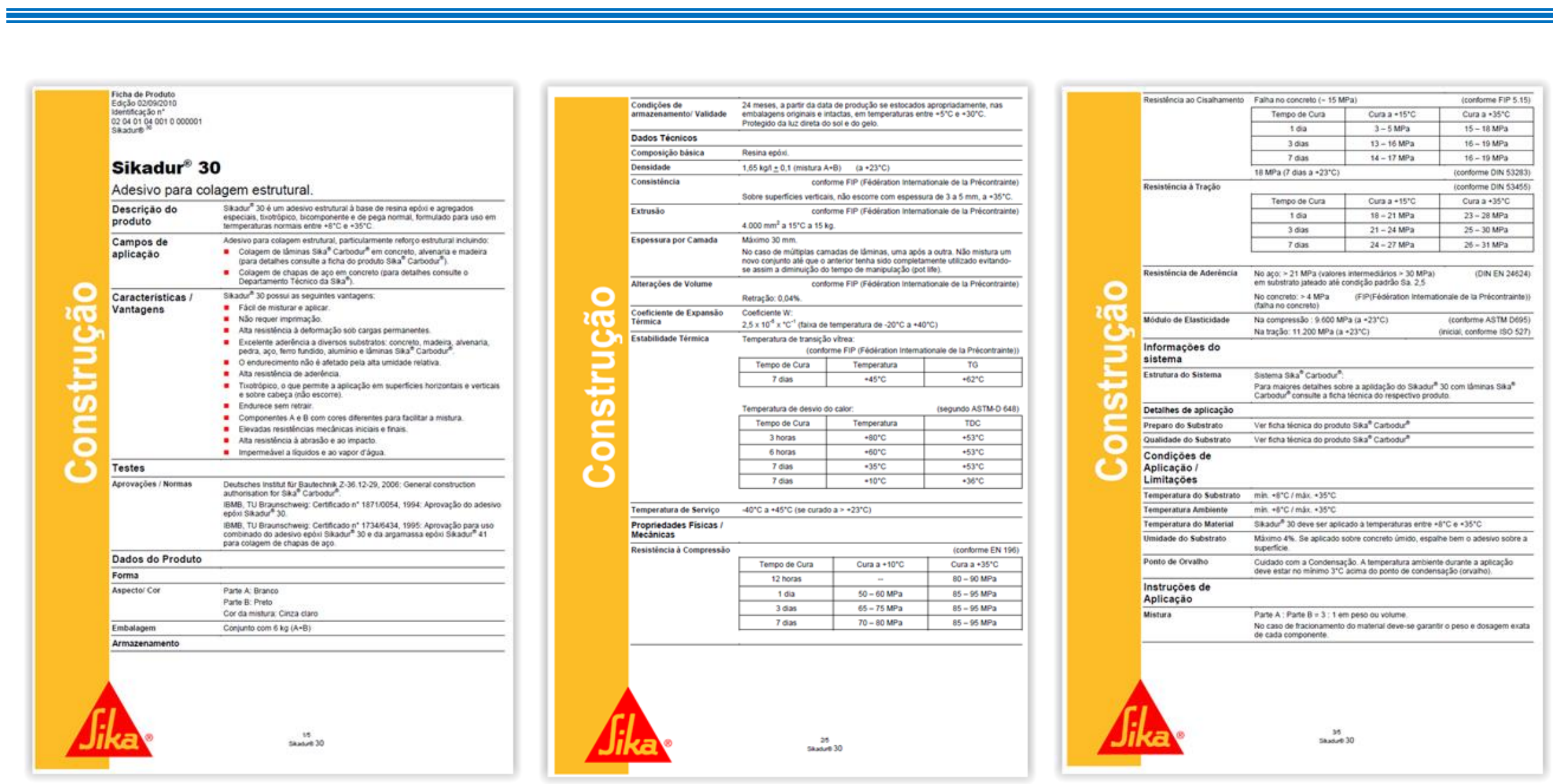



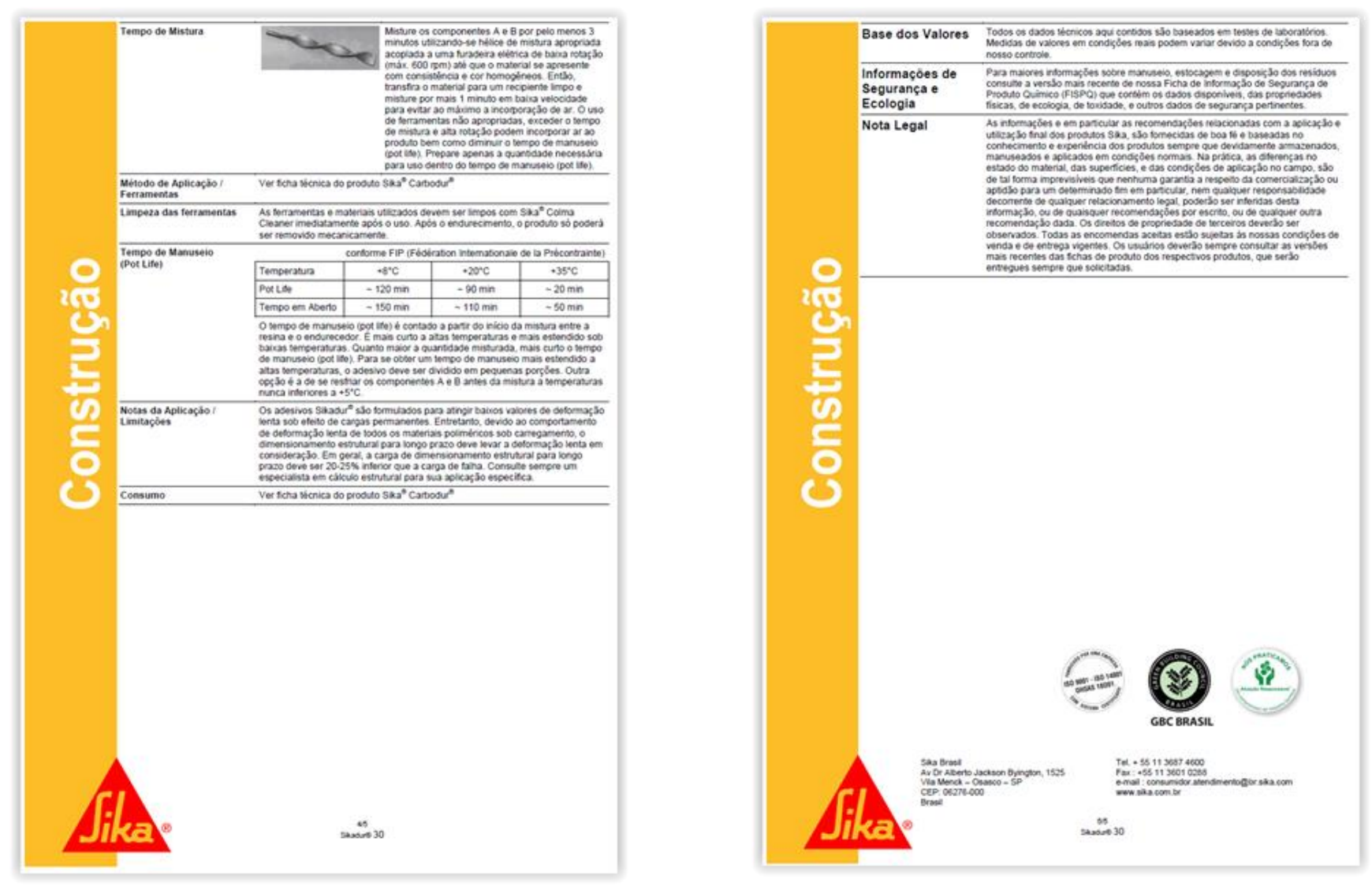